PRIMARY PRODUCTION OF PARTICULATE PROTEIN AMINO ACIDS: ALGAL PROTEIN METABOLISM AND ITS RELATIONSHIP TO THE COMPOSITION OF PARTICULATE ORGANIC MATTER

by

STEVEN ERIC LOHRENZ

B.A., University of Oregon, Eugene (1978)

SUBMITTED IN PARTIAL FULFILLMENT

OF THE REQUIREMENTS FOR THE DEGREE OF

DOCTOR OF PHILOSOPHY

AT THE

MASSACHUSETTS INSTITUTE OF TECHNOLOGY

AND

WOODS HOLE OCEANOGRAPHIC INSTITUTION

APRIL, 1985

(C) Steven Eric Lohrenz

The author hereby grants to M.I.T. and W.H.O.I. permission to reproduce and distribute coples of this, thesis document in whole or in part.

Signature of Author,. . . . . . . . .

Kgebechistetts Institute of Jechnology/Woodsnde

Oceanographic Institution. Apr11 1985

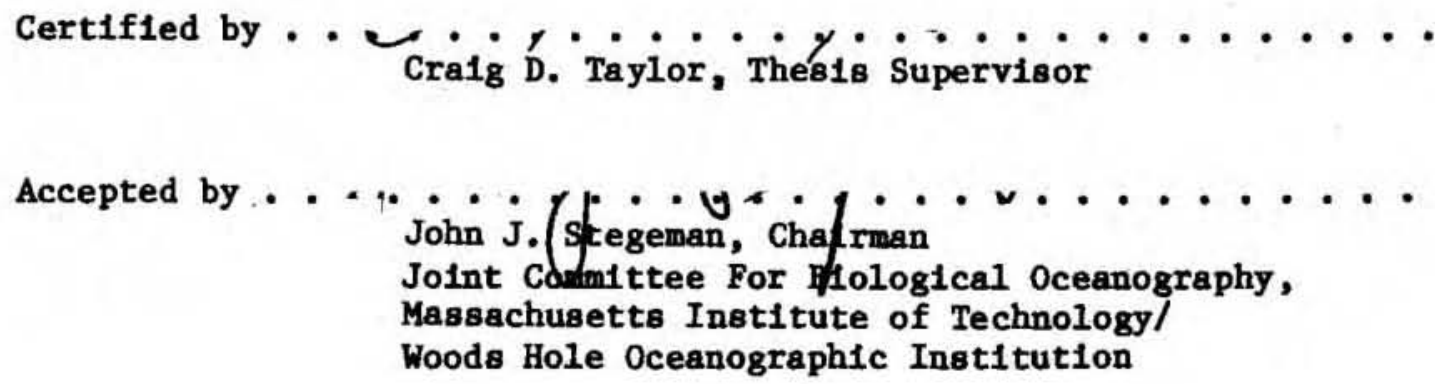


$-2-$

To my family, and George the dog 
"If someone tells me that in making these conclusions I have gone beyond the facts I reply: 'This is true, that I have freely put myself among ideas which cannot be rigorously proved. That is my way of looking at things. Every time a chemlst concerns himself with these mysterlous phenomena and every time he has the luck to make an Important step forward he will be led instinctively to attribute their prime cause to a class of reactions in harmony with the general results of his own researches. That is the loglcal course of the human mind, in all controversial matters."

Louis Pasteur, 1857 


\title{
$-4-$ \\ PRIMARY PRODUCTION OF PARTICUIATE PROTEIN AMINO ACIDS: ALGAL PROTEIN METABOLISM AND ITS RELATIONSHIP TO THE COMPOSITION OF PARTICULATE ORGANIC MATTER
}

by

STEVEN ERIC LOHRENZ

Submitted to the Department of Blology on April 29, 1985

in partial fulfillment of the requirements for the Degree of Doctor of Philosophy

\begin{abstract}
The biochemical and physlological bases underlying primary production of particulate protein amino acids were investigated in an effort to understand the relationship between algal prote1n metabolism and particulate organic matter composition.

In order to examine blochemical processes associated with conversion of inorganic carbon and nitrogen into protein, the effects of $\mathrm{NH}_{4}$ limitation on free amino acid and protein composition and incorporation of inorganic ${ }^{14} \mathrm{C}$ were stiudied in the marine chlorophyte, Nannochloris sp. (clone GSB Nanno). Free amino acid metabolism was sensitive to changes in steady state $\mathrm{NH}_{4}-11 \mathrm{mited}$ growth rates. Reduced carbon and nitrogen flux into protein resulting from nitrogen limitation of growth was associated with reductions in proportions of cellular carbon and nitrogen in the intracellular free amino acid (IFAA) pool. Growth rate-dependent changes in IFAA pool composition reflected changes in rate limiting steps which were intermediate between assimilation of inorganic nitrogen and the incorporation of nitrogen into macromolecules. The proportion of cellular carbon in both protein and pools of free amino acids decreased with decreasing growth rate. Distributions of incorporated inorganic ${ }^{1 / 4} \mathrm{C}$ among free amino acids and protein provided qualitative descriptions of growth related compositional variations. Saturation rates of (IFAA) carbon with dissolved inorganic ${ }^{14} \mathrm{C}$ did not significantly change as growth rates decreased. In contrast, saturation rates of free glutamate, glycine + alanine, and valine did decrease with growth rate. At low growth rate, specific activities of the newly assimilated glutamate, valine, and glycine + alanine in protein were higher than specific actilvities of their corresponding free amino acid pools. This was $11 \mathrm{kely}$ a consequence of metabolic segregation and more rapid saturation of protein precursor pools.

Enrichment of $\mathrm{NH}_{4}-11$ raited steady state cultures of Nannochlor $1 \mathrm{~s}$ sp. with $\mathrm{NH}_{4}$ led to a dramatic time dependent increase in free glutamine concentrations accompanied by differential increases in other free amino acids. Patterns off lsotope incorporation into the free amino acids reflected real changes in concentrations. Increases were assoclated with the diversion of photosynthetically fixed carbon from 1ipophilic material towards amino acid biosynthesis, and signalled the onset of increased protein synthesis. Prelfiminary investigations of two other marine phytoplankton species, Dunalie1la tertiolecta (clone Dun) and Thalassiosira weissflogi1. (clone Actin), suggested that the nature and timing of the biochemical. response to $\mathrm{NH}_{4}$ enrichment is different among different species.
\end{abstract}




\section{ABSTRACT (continued)}

At high 11ght intensity, increased $\mathrm{NH}_{4}$ 11mitation of Nannochloris sp. was assoclated with decreases in cellular protein, protein to carbon ratios, and protein to chlorophy11 a ratios. At low light intensities, cellular protein and protein to carbon ratios did not decrease with increasing NHt limitation. Chlorophyll a to protein ratios were generally higher at low light intensity and decreased with increasing NHt limitation, suggesting that nitrogen limitation suppressed low 11ght enhancement of chlorophyll a production. Observed incorporation rates of inorganic ${ }^{14} \mathrm{C}$ exceeded predicted rates for glycine and alanine in protein under combined conditions of light and nitrogen limitation, an indication that protein turnover in excess of net synthesis was important under these conditions.

The characteristics of protein composition and incorporation of inorganic ${ }^{14} \mathrm{C}$ were examined in steady state $\mathrm{NH}_{4}-11$ mited cultures of three other species of marine phytoplankton. The species studied Included Chaetoceros simplex (clone BBSM), Chattonella luteus (clone 0 listh), and Chroomonas salina (clone $3 \mathrm{C}$ ). Saturation of protein precursors was different for different specles and for different protein amino acids. Nannochloris sp. displayed the most rapid and complete equilibration, while C. simplex exhibited relatively slow or incomplete saturation and high sensitivity to nitrogen depletion. Intermediate patterns were observed for the other specles. For all species examined, protein glycine and alanine demonstrated relatively rapid and complete equilibration of precursor pools, and were least sensitive to nitrogen depletion.

With the knowledge that these selected amino aclds consistently demonstrated relatively rapid and complete equilibration of precursor pools with ${ }^{14} \mathrm{C}$-inorganic carbon in several taxonomically distinct marine algae, primary production of particulate protein amino acids and its relationship to the composition of particulate organic matter was Investigated in the epilimnion of a semi-enclosed marine basin, Salt Pond, MA. Studles were conducted previous to and throughout a major bloom of 011sthodiscus magnus. Before the bloom, the ratio of particulate protein amino acid (PPAA) production to particulate organic carbon (POC) production was not significantly different from the relative proportions of PPAA and POC in the particulate organic matter. Comparisons between estimated production and observed concentration changes indicated residence times of POC and PPAA were similar ( $10-20$ days). Thus with respect to POC and PPAA, particulate organic matter composition reflected the composition of organic matter belng produced by photoautotrophs. During the bloom decline, the PPAA/POC production ratio, a reflection of the activities of the metabolically active algal population, was significantly less than the PPAA/POC ratio of the particulate organic matter. This discrepancy can be attributed either to increased turnover of protein assoclated with the low inorganic nitrogen concentrations and in situ light intensities, or selective removal of PPAA carbon by secondary transformational processes.

Thesis Supervisor: C. D. Taylor

Title: Associate Sclentist

Woods Hole Oceanographic Institution 


\section{ACKNOWLEDGEMENTS}

Because of a number of special people, I w11l fondly remember the years I've spent in Woodis Hole. One of the people I was introduced to when I first came to Woods Hole was Russell L. Cuhel. He was integral in both my acclimation to this unique research environment, and in my choice of thesis research. I was then, and still am inspired by his dedication to excellence in both work and play.

My closest advisor and counselor throughout my thesis research was Craig D. Taylor. Craig's ability to laugh at inevitable mishaps helped me to place them in their: proper perspective. An essential part of research is getting back up on one's feet after a fall. Craig made this part much easier. In addition, his insight helped me to make the most of my research efforts and explore aspects I would otherwise not have considered.

Another member of my thesis committee was Cindy Lee, whose advice helped considerably throughout my research. Her support was a lifesaver during troublesome times. Sallie $W$. Chisholm provided me the opportunity to explore some algal physlology during my stint at MIT. It was a refreshing change from cl.asses, and the experlence I galned helped me when I began working in Woods Hole. Both she and Graham Walker were my MIT "connections". Despl.te the obstacle of distance separating WHOI and MIT, their input as thesi.s committee members was integral in the evolution of my thesis. Joel Goldman contributed much information and many 1deas which influenced my thesis research. He provided me the opportunfty to conduct some experiments in his lab, and later supplied valuble equipment. The help of his lab members Mark Dennett and Carol Riley is also appreciated. John Waterbury formally Joined my thesis committee late in the game, but he was always a member in spirit. He generously provided advice, equipment, supplies, and taught me alot about growing "little beasties"'. I am also grateful to Freddy Valois and Stan Watson.

One of the things I was most impressed by when I first came to Woods Hole was the cooperative spirit of the people who work here. This is exemplified by Holger Jannasch and the members of his lab, Carl Wirsen and Steve Molyneaux. Their help, both in terms of counsel and allowing me access to their lab, was very important. Others who generously provided assistance, information, and equipment were John Molongoski, Brian Howes, Dale Goehringer, Doug Nelson, Steve Boyd, Frank Carey, John Dacey, John Stegeman, Nancy Marcus, Don Anderson, Pat Glibert, Linda Graham, Dlana Franks, Bonnie Woodward, and Debble Wiebe. 


\section{ACKNOWLEDGEMENTS (continued)}

Jane Peterson and Peggy Dimmock defended me against mechanlcal conspiracies. They were delightful and tolerant teachers, and friends. I am also grateful to the people who made being a student much easier: A. L. Peirson, III (Jake), Abble Jackson, Dixie Berthel, and Connie Brackett.

Friendships come in many different shapes and sizes. I was lucky enough to have a few which I hope made me a better person, and definitely made my time in Woods Hole something to be cherished. Anne McElroy was and is a friend and scientific colleague. As co-classmates, we were both sympathetic and enthusiatic research partners. My sole, single, and only officemate was Melissa Lakich. She was tolerant of my constant requests for reviews and she frequently entertained me with welcome distractions. My gifted summer student, Mlchael Knapp, was an excellent and devoted associate in fleld endeavours. Maura Connor discussed the thesis with me at length throughout the writing stages, and her continued support and help is greatly appreclated. My housemates, Dave Kulls and Sher1 Schmaltz, were extremely tolerant of my bizarre schedule and were all round good people to live with. My famlly was and is a constant source of love and support. thanks.

There are many others whom I have not mentioned. To all of you,

Financial support for this research was provided by the Coastal Research Center (25/67.10) through a grant from the Andrew W. Mellon Foundation, by the National Science Foundation (OCE-82-15854), and by the Education Department. 


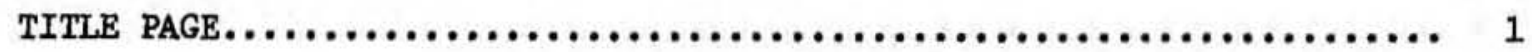

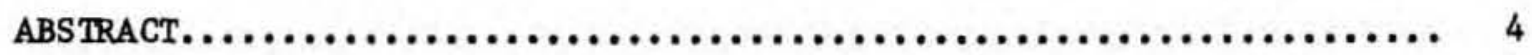

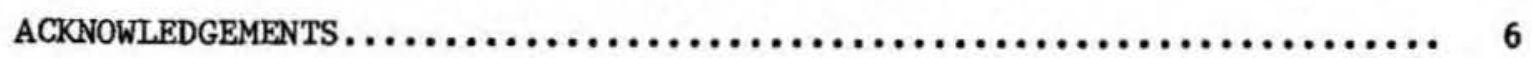

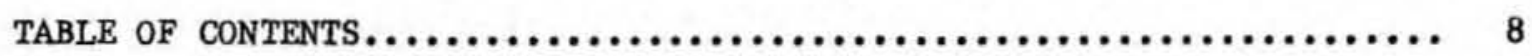

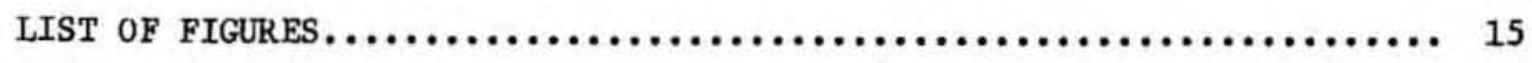

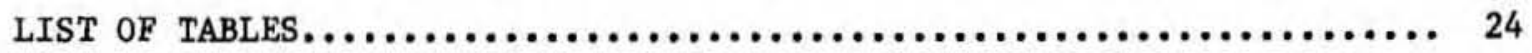

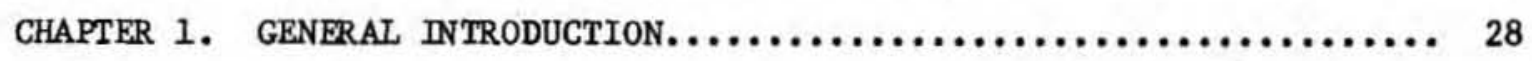

THE COMPOSITIONAL DYNAMICS OF ORGANIC MATTER IN AQUATIC

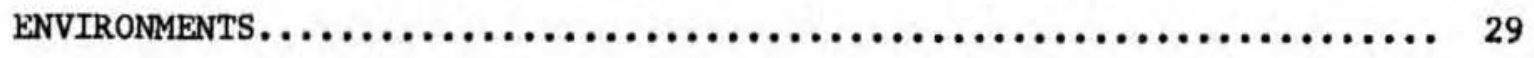

BACKGROUND :

The Marine Food Chain and the Composition

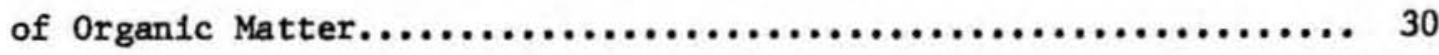

Biochemical Cycles and the Distribution

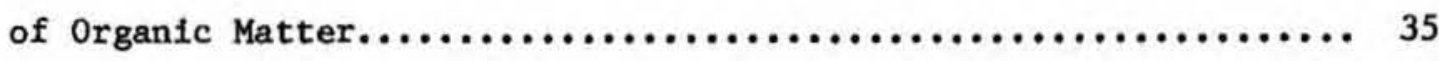

The Chemical Composition of Natural

Populations......................................... 39

Isotope Tracing of Microbial Activities.................. 42

CHAPTER 2. METHODS AND MATERIALS $\ldots \ldots \ldots \ldots \ldots \ldots \ldots \ldots \ldots \ldots \ldots \ldots \ldots \ldots, 47$

CULTURE METHODS...................................... 48

Media Composition................................... 48

Growth Conditions................................ 48 
TABLE OF CONTENTS (continued)

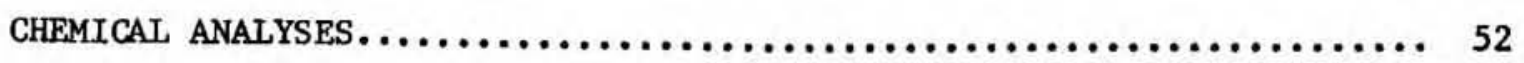

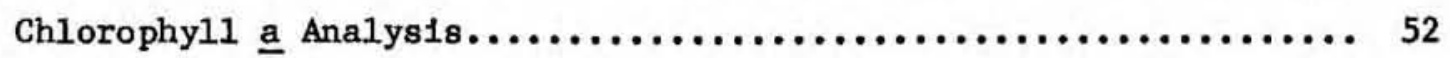

Blemental Carbon and Nitrogen Analyses.................. 53

Nutrient Analyses.................................. 53

Dissolved Inorganic and Organic Carbon Analyses............. 53

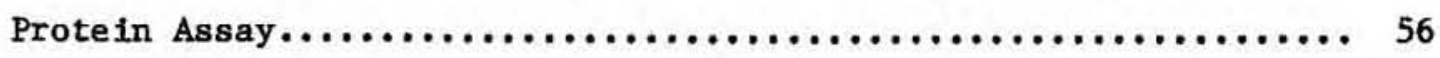

LABORATORY INCUBATION PROCEDURES $\ldots \ldots \ldots \ldots \ldots \ldots \ldots \ldots \ldots \ldots \ldots \ldots \ldots \ldots \ldots$

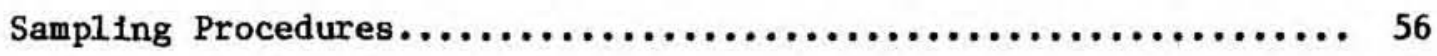

Radioassay Procedures.............................. 57

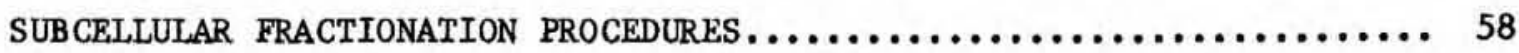

Modification of Existing Procedures.................... 58

Comparison of Subcellular Fractionation Procedures........... 60

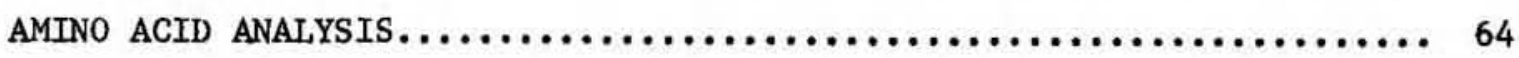

Amino Acid Derivatization Procedure..................... 64

Column Packing Procedure............................ 71

Separation and Collection........................... 72

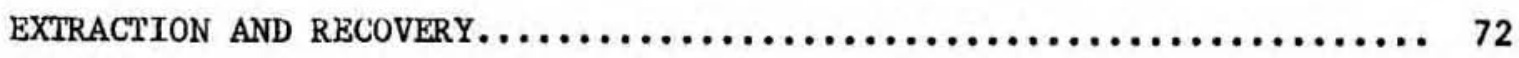

Free Amino Acid Extraction and Recovery $\ldots \ldots \ldots \ldots \ldots \ldots \ldots \ldots \ldots$

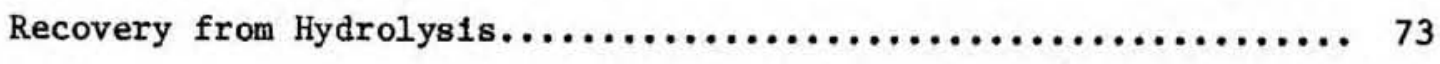

Recovery of Protein............................... 79

Recovery of Other Subcellular Fractions $\ldots \ldots \ldots \ldots \ldots \ldots \ldots \ldots \ldots \ldots . \quad 82$

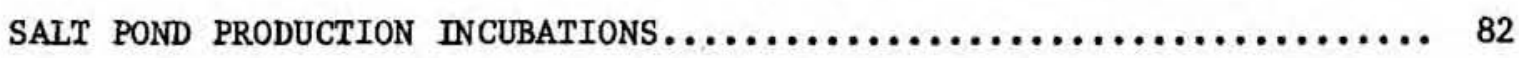

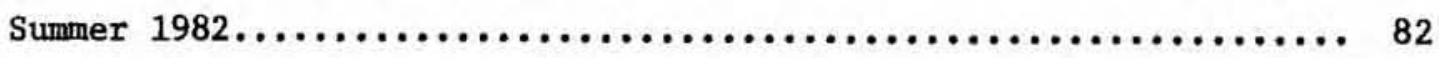

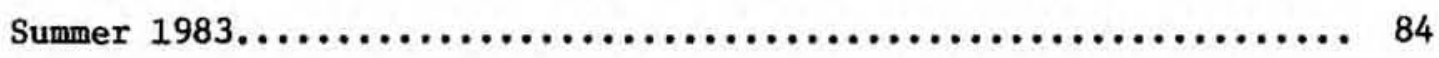

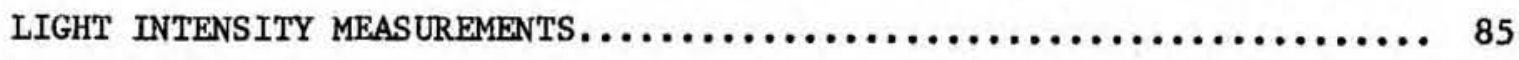


TABLE OF CONTENTS (continued)

CHAPTER 3. RELATIONSHIPS BETWEEN FREE AMINO ACID AND PROTEIN COMPOSITION AND INCORPORATION OF INORGANIC ${ }^{14} \mathrm{C}$ IN NH $4_{4}^{+}$-LIMITED STEADY STATE CULTURES OF MARINE PHYTOPLANKTON

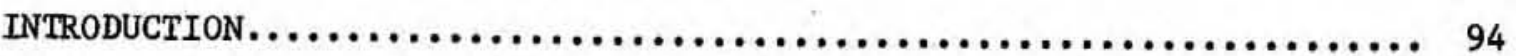

Relationships Between Cellular Chemical Composition and Nitrogen Limited Growth Rate................................ 94

Relationships of the Distribution of Assimilated Inorganic ${ }^{14} \mathrm{C}$ to Cellular Chemical Composition......................... 96

Effects of Nitrogen 11mitation on Patterns of Inorganic ${ }^{14} \mathrm{C}$

Incorporation Into Cell Mater1al........................ 98

I. DYNAMICS OF FREE AMINO ACID AND PROTEIN COMPOSITION AND INCORPORATION OF INORGANIC ${ }^{14} \mathrm{C}$ IN $\mathrm{NH}_{4}^{+}$-LIMITED STEADY STATE CULTURES OF THE

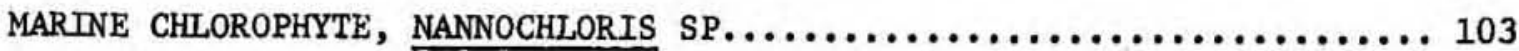

METHODS................................................ 103

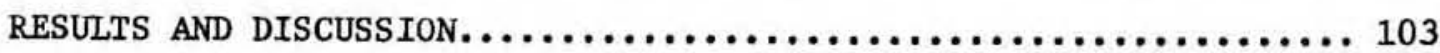

Cellular Chemical Composition as a Function of Relative Growth Rate.......................................... 103

N1trogen Specif1c Turnover of N1trogen Transport Mediators... 111 Saturation with Inorganic ${ }^{14} \mathrm{C}$ : Relative Specific Activities of Intracellular Free Amino Ac1ds.

Relationships Between Free and Proteln Amino Acid Saturation

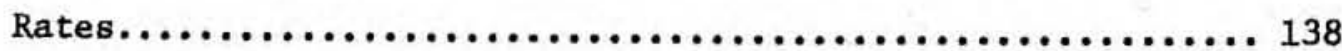


TABLE OF CONTENTS (continued)

Time Course Distributiton of ${ }^{14} \mathrm{C}$-label Among Cellular Materials and its Relationship to Cellular Chemical Composition....... 158 Comparisons Between the Composition of Free Amino Acids and the

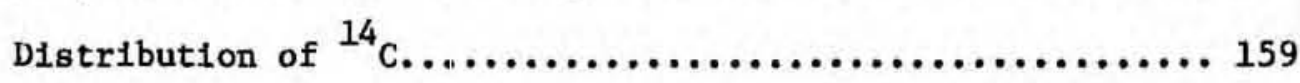
Time Course Distribut:Lons of ${ }^{14} \mathrm{C}$ Among Subcellular Fractions as a Function of Relative Growth Rate................. 171 II. EFFECTS OF $\mathrm{NH}_{4}^{+}$ENRICHMENT ON AMINO ACID AND TOTAL CARBON METABOLISM IN AN $\mathrm{NH}_{4}^{+}$-LIMITED STEADY STATE CULTURE OF

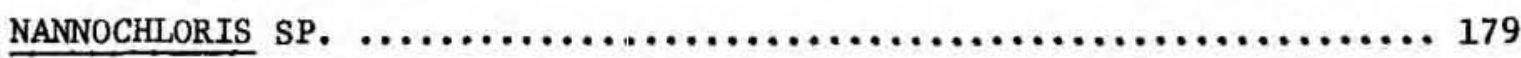

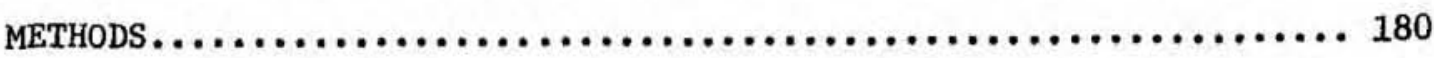

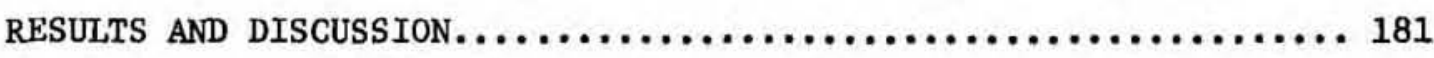

Increases in Intracellular Free Amino Actds in Response to Nitrogen Enrichment............................. 181 Saturation of Free Amino Ac1ds with ${ }^{14} \mathrm{C}$ in Control and Enriched Cultures............................... 198 Effects of $\mathrm{NH}_{4}^{+}$Enrichment on the T1me Course Distributions

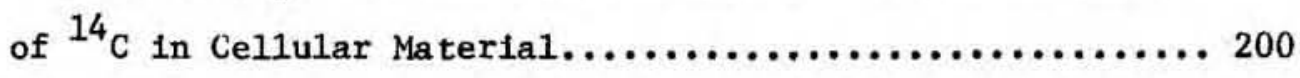

III. PRELIMINARY OBSERVATIONS OF $\mathrm{NH}_{4}^{+}$ENRICHMENT EFFECTS ON CARBON

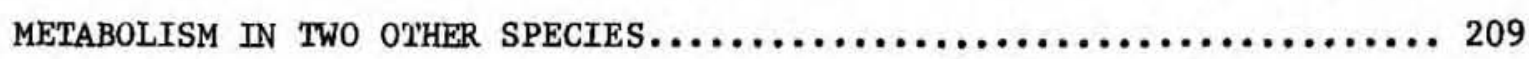

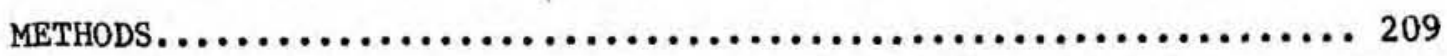

Response of Intracellular Free Amino Ac1ds of Dunaliella tertiolecta to Nutrient Enrichment................... 209 Effects of $\mathrm{NH}_{4}^{+}$Enrichment on TIme Course Distributions of ${ }^{14} \mathrm{C}$ in Cellular Material.............................. 210

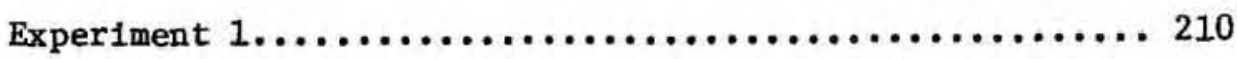


TABLE OF CONTENTS (continued)

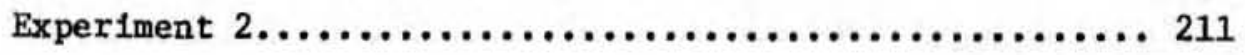

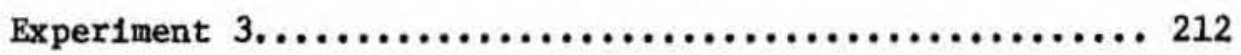

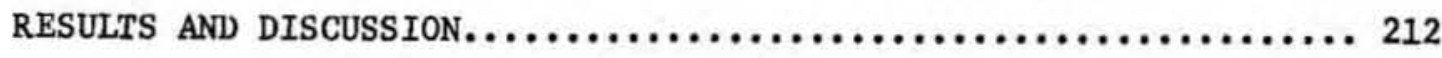

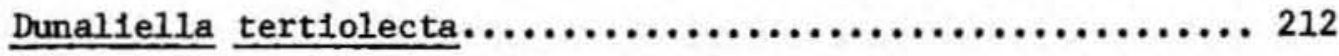

Thalass1osira welssflogi1 ....................... 215

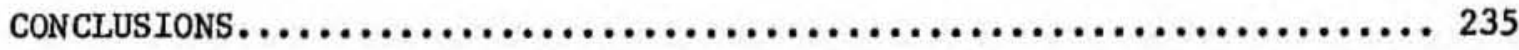

CHAPTER 4. RELATIONSHIPS BETWEEN NET SYNTHESIS RATES OF PROTEIN AMINO ACIDS AND INCORPORATION OF INORGANIC ${ }^{14} \mathrm{C}$ IN MARINE PHYTOPLANKTON.... 238

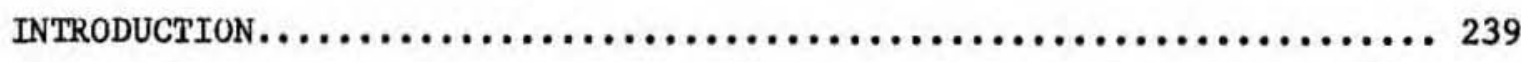

BACKGROUND:

Tracing Production of Particulate Protein Amino Ac1ds.......... 240

Radioisotoplc Tracing of Microblal Activities............... 242

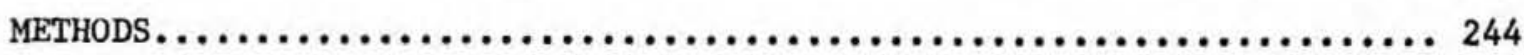

Comparison of Protein Assay Methodologies.................. 244

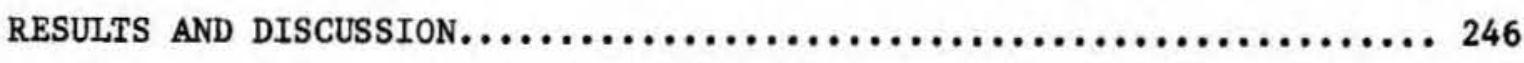

Effects of Growth Conditions on Chemical Composition of

Nannochloris sp..................................... 246

Interspecies Comparisons of Chemical Compostion ............. 249

K1net1cs of Isotope Incorporation: Agreement Between Predicted and

Observed Carbon Incorporation Rates..................... 256

High Light Adapted Steady State Cultures of Nannochloris sp.:

Isotope Kinetics at High and Low Relative Growth Rates...... 258 
TABLE OF CONTENTS (continued)

POC and PPAA............................... 258

Carbon Incorporation Into Individual

Protein Amino Acids........................... 260

Elucidation of Nitrogen Depletion Effects Using Valine

as a Model Protein Am1no Ac1d.................... 296

Comparisons of Carbon Incorporation and Net Protein Synthesis

Rates in Nannochloris sp. During Growth under Combined

Conditions NH4t-1imitation and Low Light............... 302

POC Predicted versus Observed Production.......... 302

Total PPAA Carbon Predicted versus Observed

Production............................... 302

Individual Protein Amino Acid Observed versus

Predicted Carbon Incorporation............... 302

Protein Turnover........................ 318

Comparisons of Observed and Predicted Carbon Incorporation in

other Species of Marine Algae....................... 324

Observed and Predicted Carbon Incorporation Into

Particulate Organic Carbon...................... 324

PPAA Observed versus Predicted Carbon Incorporation..... 324

Observed versus Predicted Carbon Incorporation into

Individual Protein Amino Acids................. 325

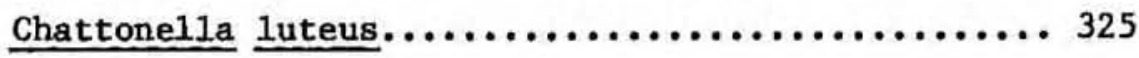

Chroomonas salina...................... 337

Chaetoceros simplex..................................

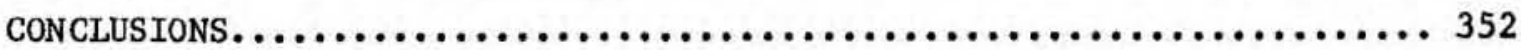


TABLE OF CONTENTS (continued)

CHAPTER 5. PRIMARY PRODUCTION OF PARTICULATE ORGANIC CARBON AND PARTICULATE PROTEIN AMINO ACIDS IN SALT POND, MA: THE RELATIONSHIP TO THE COMPOSITION OF PARTICUIATE ORGANIC MATTER.

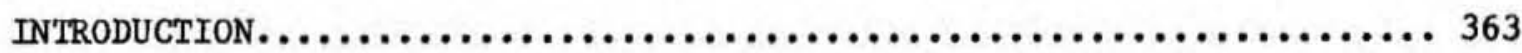

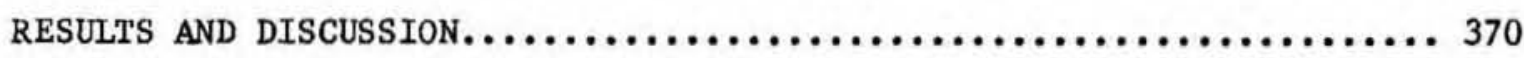

Compositional Dynamics of Particulate Organic Matter in a Well Mixed

Euphot1c System................................... 370

Incubation Procedures................................ 378

Primary Production of Particulate Organic Carbon.............. 380

Integrated POC Production Est1mates..................... 381

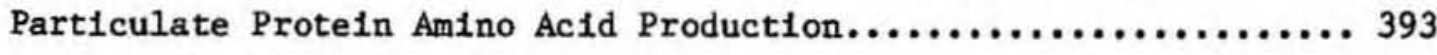

Relationship Between Production and Concentration............. 404

Prebloom Comparisons of POC and PPAA Dynamics.............. 405

POC and PPAA Dynamics During Bloom................... 419

Production Characteristics and Population Metabolism....... 421

Net Removal of PPAA Relative to POC During the Bloom....... 427

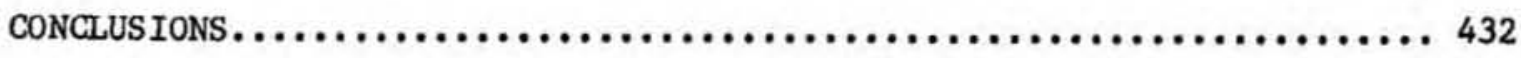

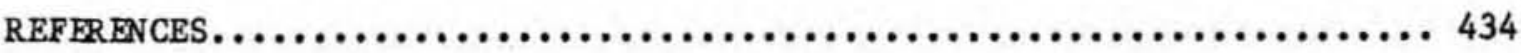

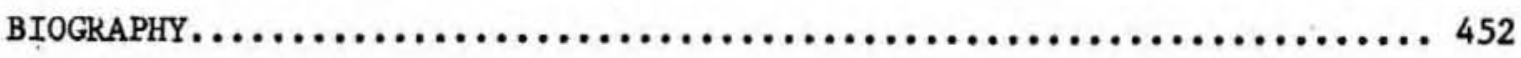


Figure 2-1. Schematic of continuous culture system............ 54

Figure 2-2. Representat1ve chromatogram showing elution pattern of dansylated amino acids separation by reverse phase high pressure 11quid chromatography................. 74

Figure 2-3. Schematic of incubation system used in Salt Pond 1982

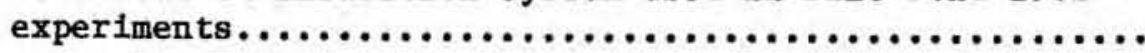

Figure 2-4. Schematic of single chamber SID (sampler incubation device).

F1gure 2-5. Schematic of dual chamber hydraulically operated SID.... 90

Figure 3-1. Proportions of intracellular free amino acid carbon assoclated with individual amino acids of $\mathrm{NH}_{4}-1$ imited steady state cultures of Nannochloris sp. at high and low relative growth rates........................ 108

Figure 3-2. Time course of the relative specific activity of intracellular free amino acld carbon in batch and $\mathrm{NH}_{4}-1$ imited steady state cultures of Nannochloris sp.

Figure 3-3. Time course of the relative specific activity of intracellular free glutamate at high and low relative growth rates in $\mathrm{NH}_{4}-11 \mathrm{mited}$ steady state cultures

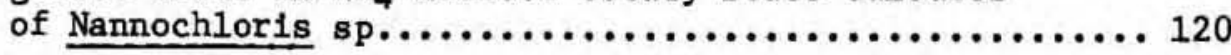

Figure 3-4. Extended time course of the relative specific activity of intracellular free glutamate in batch and NH41imited steady state cultures of Nannochloris sp.

Figure 3-5. Time course of the relative specific activity of intracellular free glutamine in batch and $\mathrm{NH}_{4}-$ 11mited steady state cultures of Nannochloris sp....... 124

Figure 3-6. Time course of the relative specific activity of intracellular free glycine + alanine in batch and $\mathrm{NH}_{4}$-1imlted steady state cultures of Nannochlor1s sp............................ 126

Figure 3-7. Time course of the relative specific activity of intracellular free aspartate in batch and $\mathrm{NH}_{4}-$ limited steady state cultures of Nannochloris

Figure 3-8. Time course of the relative specific activity of Intracellular free valine in batch and $\mathrm{NH}_{4}^{-}$ limited steady state cultures of Nannochloris 130 
F1gure 3-9. Time course of the relative specific activity of Intracellular free proline in batch and $\mathrm{NH}_{4}-$ 11mited steady state cultures of Nannochlor1s sp........ 134

F1gure 3-10. Simplifled diagram showing the major pathways associated with the blosynthesis of glycine, serine, glutamine, glutamate, alanine and aspartate......... 136

Figure 3-11. Time course of the relative specific activity of intracellular free glutamate and nascent protein glutamate in batch and $\mathrm{NH}_{4}-1$ imited steady state

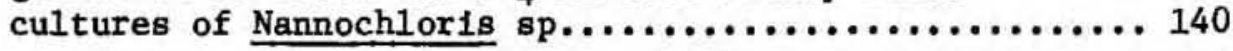

Figure 3-12. T1me course of the relative specific activity of intracellular free glutamate and nascent protein glutamate in an $\mathrm{NH}_{4}-11 \mathrm{mited}$ steady state culture of Nannochloris sp. at low relative growth rate....... 142

F1gure 3-13. Time course of relative specific activity of nascent protein glutamate at $\mathrm{hlgh}$ and low relative growth rate in NHt-1imited steady state cultures of Nannochlor1s sp.............................. 146

Figure 3-14. T1me course of the relative specific activity of intracellular free valine and nascent protein valine in an NHt-11mited steady state culture of Nannochloris sp. at high relative growth rate........ 148

Figure 3-15. T1me course of the relative specific activity of intracellular free aspartate and nascent protein aspartate in an $\mathrm{NH}_{4}-11 \mathrm{mi}$ ted steady state cultures of Nannochlor1s sp. at high relative growth rate....... 150

F1gure 3-16. Time course of the relative spec1fic activity of intracellular free valine and nascent proteln valine in an $\mathrm{NH}_{4}-11 \mathrm{mited}$ steady state culture of Nannochloris 8 . at low relative growth rate......... 152

Figure 3-17. Time course of the relative specific activity of nascent protein proline + arginine in NHt-11mited steady state cultures of Nannochlor $18 \mathrm{sp}$. at high and

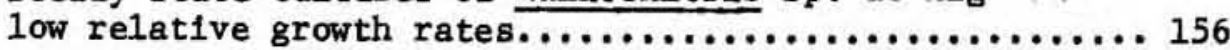

F1gure 3-18. Tfme course of distribution of incorporated inorganic ${ }^{14} \mathrm{C}$ relative to equilibrium distribution among subcellular fractions in a batch culture of Nannochloris 
Figure 3-19. T1me course of the distribution of incorporated inorganic ${ }^{14} \mathrm{C}$ in alcohol soluble material from batch cultures of Nannochloris sp ..................

F1gure 3-20. Time course of the distribution of incorporated inorganic ${ }^{14} \mathrm{C}$ in intracellular free amino ac1ds in $\mathrm{NH}_{4}-11$ mited steady state cultures of Nannochloris sp. at high and low relative growth rates.. 164

Figure 3-21. Proportions of intracellular free amino acid carbon and $C$ associated 1 ith individual amino acids of NHt-11mited steady state cultures of Nannochloris sp. at high and low relative growth rates............. 172

Figure 3-22. T1me course of the distribution of incorporated inorganic ${ }^{14} \mathrm{C}$ among subcellular fractions in $\mathrm{NH}_{4}-11 \mathrm{~m} 1$ ted steady state cultures of Nannochloris 8 . at high and low relative growth rates.. 174

Figure 3-23. Distribution of total cellular carbon and total ${ }^{14} \mathrm{C}$ uptake among intracellular free amino acids and protein in $\mathrm{NH}_{4}-11 \mathrm{mited}$ steady state cultures of Nannochloris sp. at high and low relative growth rates.. 176

Figure 3-24. Increase in intracellular free glutamine concentrations in response to $\mathrm{NH}_{4} \mathrm{Cl}$ enrichment (200 micromolar) of an NHt-11mited steady state culture of

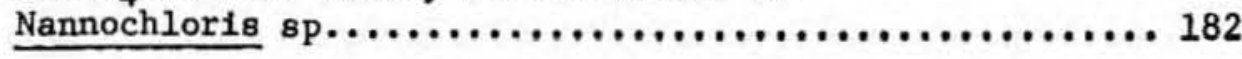

F1gure 3-25. Increase in intracellular free glutamate concentrations in response to $\mathrm{NH}_{4} \mathrm{Cl}$ enrichment (200 micromolar) of an $\mathrm{NH}_{4}-11 \mathrm{mited}$ steady state culture of Nannochlor1s sp..............................

F1gure 3-26. Increase in intracellular free proline concentrations in response to $\mathrm{NH}_{4} \mathrm{Cl}$ enrichment (200 micromolar) of an $\mathrm{NH}_{4}-1 \mathrm{mit}$ ted steady state culture of

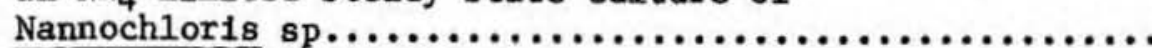

F1gure 3-27. Increase in intracellular free aspartate concentrations In response to $\mathrm{NH}_{4} \mathrm{Cl}$ enrichment (200 micromolar) of an $\mathrm{NH}_{4}-11 \mathrm{mit}$ ted steady state culture of Nannochloris sp...............................

Figure 3-28. Increase in intracellular free alanine concentrations In response to $\mathrm{NH}_{4} \mathrm{Cl}$ enrichment (200 micromolar) of an $\mathrm{NH}_{4}-1 \mathrm{mit}$ ted steady state culture of Nannochloris sp............................... 
F1gure 3-29. T1me course of the relative specific activity of total intracellular free amino acid carbon in control and enriched NHF-1imited steady state cultures of Nannochloris sp.

Figure 3-30. T1me course of total inorganic ${ }^{14} \mathrm{C}$ uptake by control and enriched $\mathrm{NH}_{4}$-1imlted steady state cultures of Nannochloryls sp...............................

F1gure 3-31. Time course of the incorporation of inorganic ${ }^{14} \mathrm{C}$ into subcel.lular fractions in control and enriched NHt-limited steady state cultures of

Nannochlor $1 \mathrm{~s}$ sp. growing at $24^{\circ} \mathrm{C} \ldots \ldots \ldots \ldots \ldots \ldots \ldots \ldots$

F1gure 3-32. Time course of the incorporation of inorganic ${ }^{14} \mathrm{C}$ into subcellular fractions in control and enriched $\mathrm{NH}_{4}$-1Imited steady state cultures of Dunallella tertlolecta growing at $24^{\circ} \mathrm{C} . \ldots \ldots \ldots \ldots \ldots$

Figure 3-33. Time course of the incorporation of inorganic ${ }^{14} \mathrm{C}$ into subcellular fractions in control and enriched NHt-1imited steady state cultures of Dunaliella tertiolecta growing at $16^{\circ} \mathrm{C} . \ldots \ldots \ldots \ldots \ldots$

Figure 3-34. Time course of total inorganic ${ }^{14} \mathrm{C}$ uptake by control and enriched NHt-limited steady state cultures of Dunallella tertiolecta growing at $16^{\circ} \mathrm{C} . .$.

F1gure 3-35. Time course of the distribution of incorporated inorganic ${ }^{14} \mathrm{C}$ among subcellular fractions in control and enriched $\mathrm{NH}_{4}$-1imited steady state cultures of Dunallella tertiolecta growing at $12^{\circ} \mathrm{C} . .$.

F1gure 3-36. Time course of total inorgan1c ${ }^{14} \mathrm{C}$ uptake by control and enriched $\mathrm{NH}_{4}$-limtted steady state cultures of Dunallella tertiolecta growing at $12^{\circ} \mathrm{C} . \ldots \ldots \ldots \ldots \ldots$

Figure 3-37. Time course of total inorganic ${ }^{14} \mathrm{C}$ uptake by control and enriched $\mathrm{NH}_{4}$-limited steady state cultures of Thalass1osira we1ssflog11 growing at $16^{\circ} \mathrm{C} \ldots \ldots \ldots \ldots \ldots$

Figure 3-38. Time course of total inorganic ${ }^{14} \mathrm{C}$ uptake by control and enriched $\mathrm{NH}_{4}$-limited steady state cultures of Thalassiosira welssflogil growing at $12^{\circ} \mathrm{C}$.

Figure 3-39. Time course of the distribution of incorporated inorganic ${ }^{14} \mathrm{C}$ among subcellular fractions in control and enriched $\mathrm{NH}_{4}-11 \mathrm{mited}$ steady state cultures of Thalassiosica weissflogil growing at $16^{\circ} \mathrm{C} . \ldots \ldots \ldots \ldots$ 
Figure 3-40. Time course of the distribution of incorporated

inorganic ${ }^{14} \mathrm{C}$ among subcellular fractions in control and enriched $\mathrm{NH}_{4}^{+}-11 \mathrm{mi}$ ted steady state cultures of Thalassiosira weissflogil growing at $12^{\circ} \mathrm{C}$.

Figure 4-1. Comparisons of observed total ${ }^{14} \mathrm{C}$ uptake rates with theoretical particulate organic carbon production rates of high light $\mathrm{NH}_{4}$-limited steady state cultures of

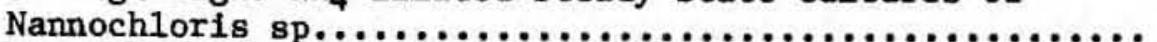

Figure 4-2. Comparisons of observed particulate protein amino acid 1sotope incorporation rates with theoretical rates in high 11ght $\mathrm{NH}_{4}$-limited steady state cultures of Nannochlor1s sp...............................

Figure 4-3. Observed and predicted 1.5 hour time courses of 1sotope incorporation into particulate protein amino acids where flow was interrupted during the incubation of high 11 ght $\mathrm{NH}_{4}$-limited steady state cultures of Nannochloris sp.............................

Figure 4-4. Observed and predicted 1.0 hour time courses of 1sotope incorporation into particulate protein amino acids where flow was not interrupted during the incubation of a high 11ght $\mathrm{NH}_{4}$-11mited steady state culture of

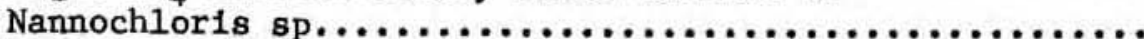

Figure 4-5. Observed and predicted 3.0 hour time courses of 1sotope incorporation into particulate protein amino acids where flow was interrupted during the incubation of high light $\mathrm{NH}_{4}-1$ imited steady state cultures of

Nannochloris sp...............................

Figure 4-6. Observed and predicted 6.0 hour time courses of 1sotope incorporation into particulate protein amino acids where flow was not interrupted during the incubation of a high light $\mathrm{NH}_{4}$-11mited steady state culture of Nannochloris sp..............................

Figure 4-7. Observed and predicted 66 hour time courses of 1sotope incorporation into particulate protein amino acids where flow was not interrupted during the incubation of a high light $\mathrm{NH}_{4}$-11mited steady state culture of Nannochloris sp.

Figure 4-8. Theoretical and observed 1sotopic carbon incorporation rates into alanine, glycine, glutamate, and aspartate in protein of high 11 ght $\mathrm{NH}_{4}^{+}-1$ imited steady state cultures of Nannochloris sp.................... 276 
Figure 4-9. Simplifled diagram showing major pathways associated with the blosynthesis of glycine, serine, glutamine,

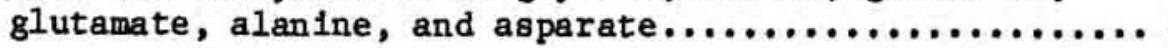

Figure 4-10. Observed and predicted time courses of 1sotope Incorporation into glycine, alanine, glutamate, and aspartate in protein of h1gh 11ght NH4-11mited steady state cultures of Nannochlor1s

F1gure 4-11. Diagram showing proposed routes for intrachloroplast production and utilization of phosphoenol pyruvate and

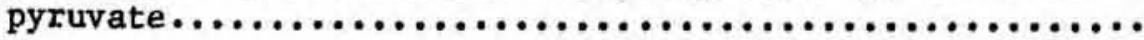

F1gure 4-12. Pathways associated with the b1osynthesis of tryptophan, tyrosine, and phenylalanine.

Figure 4-13. Observed and predicted time courses of 1sotope incorporation into phenyalanine in protein of high light NHt-11mited steady state cultures of Nannochloris sp.

F1gure 4-14. Pathways associated with the biosynthesis of methionine, threonine, isoleucine, 1ysine, valine, and leucine..... 290

Figure 4-15. Theoretical and observed rates of 1sotopic carbon incorporation into 1soleucine + leucine, proline + arginine, valine, phenyalanine, lysine, and threonine in protein of high light NHt-limitied steady state

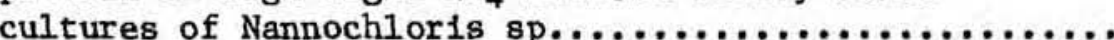

Figure 4-16. Observed and predicted time courses of isotope incorporation into threonine, valine, isoleucine + leucine, and 1ysine in protein of high 1ight NHt-1imited steady state cultures of Nannochloris $\mathrm{sp}$. 294

Figure 4-17. Comparisons of observed isotopic carbon incorporation into valine in protein with that predicted on the assumption that all carbon flux through the free intracellular valine pool was assoclated with synthesis of protein valine.

F1gure 4-18. Observed total ${ }^{14} \mathrm{C}$ uptake rates and theoret1cal particulate organic carbon production rates of low 11ght NHt-limited steady state cultures of

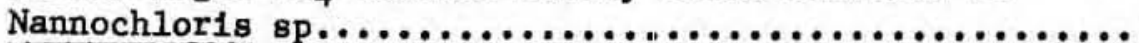

Figure 4-19. Theoretical and observed rates of 1sotopic carbon incorporation into particulate protein amino acids in low light NHt-limited steady state cultures of Nannochloris sp. 
Figure 4-20. Observed and preticted time courses of isotope incorporation into particulate protein amino acids of low light NHt--1imited steady state cultures of Nannochloris sp.............................. 308

F1gure 4-21. Theoretical and observed rates of 1sotopic carbon incorporation into alanine, glycine, glutamate, and aspartate in protein of low 11ght $\mathrm{NH}_{4}-11 \mathrm{mited}$ steady

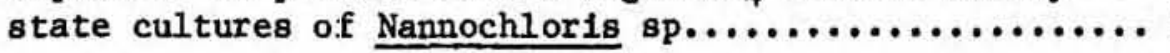

Figure 4-22. Observed and predicted time courses of isotope incorporation into glycine, alanine, glutamate, and aspartate in protein of low light $\mathrm{NH}_{4}$-1imited steady state cultures of Nannochloris sp.............

Figure 4-23. Theoretical and observed rates of 1sotopic carbon incorporation into isoleucine + leucine, proline, phenylalanine, lysine, and threonine in proteln of low light $\mathrm{NH}_{4}$-limited steady state cultures of Nannochloris sp.

Figure 4-24. Observed and predicted time courses of isotope incorporation in to threonine, isoleucine + leucine, phenylalanine, and lysine in protein of low light NHt-limited steady state cultures of Nannochloris sp..............................

F1gure 4-25. Observed total ${ }^{14} \mathrm{C}$ uptake and theoretical particulate organic carbon production rates of high light NHf-limited steady state cultures of four specles of marine phytoplankton...........................

Figure 4-26. Theoretical and observed rates of 1sotopic carbon incorporation into particulate protein amino acids of high light $\mathrm{NH}_{4}-1$ imited steady state cultures of four species of marine phytoplankton................

Figure 4-27. Observed and predicted time courses of 1sotope incorporation into particulate protein amino aclds of high light $\mathrm{NH}_{4}-11 \mathrm{mited}$ steady state cultures of Chattonella 1uteus, Chroomonas salina, and Chaetoceros

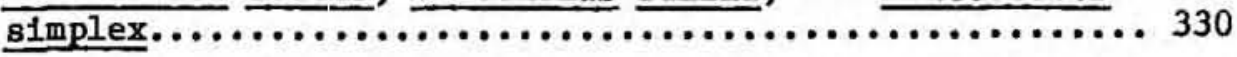

F1gure 4-28. Theoretical and observed rates of isotopic carbon incorporation into alanine, glycine, glutamate, aspartate, and serine in protein of high light NH4-11mited steady state cultures of Chattonella 1uteus, Chroomonas salina, and Chaetoceros s1mplex..... 332

F1gure 4-29. Observed and predicted time courses of 1sotope incorporation into glycine, alanine, glutamate, and aspartate in protein of a high 11ght NHt-11mited steady state culture of Chattonella 1uteus ........... 334 
Figure 4-30. Theoret1cal and observed rates of isotoplc carbon incorporation into isoleucine + leucine, valine + arginine, proline, phenyalanine, lysine, and threonine In protein of high 11ght $\mathrm{NH}_{4}$-limited steady state cultures of Chattonella luteus, Chroomonas salina, and Chaetoceros simplex.

Figure 4-31. Observed and predicted time courses of 1sotope incorporation into threonine, valine + arginine, isoleucine + leucine, lysine, phenyalanine, and proline in protein of high light NHF-11mited steady state cultures of Chattonella luteus ..................

F1gure 4-32. Observed and predicted time courses of 1sotope incorporation into glycine, alanine, glutamate, and aspartate in protein of h1gh 11ght $\mathrm{NH}_{4}-11 \mathrm{mited}$ steady state cultures of Chroomonas salina.................. 344

Figure 4-33. Observed and predicted time courses of 1sotope incorporation into threonine, valine + arginine, Isoleucine + leucine, lysine, phenyalanine, and proline in proteln of high light $\mathrm{NH}_{4}$-limited steady state cultures of Chroomonas sallna...

Figure 4-34. Observed and predicted time courses of 1sotope Incorporation into glycine, alanine, glutamate, and aspartate in protein of high light $\mathrm{NH}_{4}-1$ imited steady state cultures of Chaetoceros simplex............... 348

Figure 4-35. Observed and predicted time courses of isotope incorporation into threonine, valine + arginine, isoleucine + leucine, lysine, phenyalanine, and proline in protein of high light $\mathrm{NH}_{4}-1$ imited steady state cultures of Chaetoceros simplex.................. 350

Figure 5-1. Processes involved in production and removal of organic

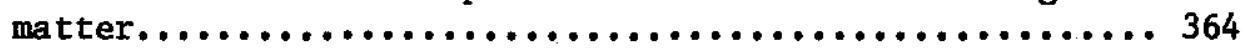

Figure 5-2. Simplifled diagram 11lustrating the influence of primary inputs and net removal of organic matter on particulate organic matter composition.................... 368

Figure 5-3. Depth profiles of chlorophyll a on days during which incubations were conducted in Salt Pond............. 372

Figure 5-4. Depth profiles of specific gravity during study period in Salt Pond................................ 374

Figure 5-5. Representative Incubation (5 Aug 83) showing particulate organic carbon production in conjunction with surface light regime............................... 382 
F1gure 5-6. Particulate organic carbon production during sampling period shown in relationship to dynamics of chlorophy11 a and particulate organic carbon.................... 384

Figure 5-7. Diel 11ght regime from 1982 during the same time of year as the period of study in Salt Pond............. 386

Figure 5-8. Time course of carbon fixation by surface sample from Salt Pond incubated during midday under natural sunlight attenuated to different intensities.......... 394

Figure 5-9. Proportion of surface 11ght reaching 1 meter during study period in Salt Pond......................... 396

Figure 5-10. Particulate organic carbon, chlorophyll a, and particulate protein amino acid concentrations in the Salt Pond mixed layer during the study period.................... 406

Figure 5-11. Comparison of observed concentrations of particulate organic carbon and particulate proteln amino acids to the projected concentrations based on mean production rates....................... 408

Figure 5-12. Comparison of production and concentration ratios of particulate protein amino acids and protein glycine relative to particulate organic carbon..............4 410

Figure 5-13. Orthophosphate, ammonium, nitrate, and nitrite concentrations at the one meter sampling depth in relationship to particulate organic carbon and chlorophyll a concentrations during the perlod of study in Salt Pond.................................. 422

F1gure 5-14. Particulate organic carbon to chlorophyll a ratios during the study period in Salt Pond.

F1gure 5-15. Proportions of total ${ }^{14} \mathrm{C}$ incorporation associated with subcellular fractions of natural phytoplankton populations during the study period in Salt Pond. 
Table 2-1. Mineral concentrations in artificlal seawater..........

Table 2-2. Concentrations of nutrients and trace elements in standard culture media....................... 50

Table 2-3. Specles 11st of marine algae obtained from the culture collection of marine phytoplankton.......... 51

Table 2-4. Outline of fractionation procedures............... 62

Table 2-5. Comparison of results obta1ned using different fractionation procedures....................... 63

Table 2-6. Response factors for integrated absorbance by dansylated amino acids at $254 \mathrm{~nm} . \ldots \ldots \ldots \ldots \ldots \ldots \ldots \ldots . \ldots 66$

Table 2-7. Analytical variations (95\% confidence intervals) for individual amino acids resulting from the combination of errors assoclated with injection, storage, variation in derivatization efficiency, and peak integration.............................

Table 2-8. Comparison of derfvatization incubation periods of one and four hours at $37^{\circ} \mathrm{C} \ldots \ldots \ldots \ldots \ldots \ldots \ldots \ldots \ldots \ldots$

Table 2-9. Correlations between response factors and molar ratio of amino groups/dansy1 chloride (range $0.001-0.12$ ) in the derivatization mixture.

Table 2-10. Dependence of response factor on time of storage at $-6^{\circ} \mathrm{C}$

Table 2-11. Proportion of labeled free amino acids recovered in subcellular fractions............................

Table 2-12. Free amino acid recovery in aqueous alcohol fraction....

Table 2-13. Recovery of amino acids from hydrolysis............. 78

Table 2-14. Comparison of different methodologies for measurement of protein in Nannochloris sp...................... 80

Table 2-15. Recovery of protein amino ac1ds after storage in

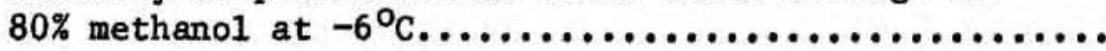

Table 2-16. Stability of subcellular fractions with storage at $-20^{\circ} \mathrm{C}$ relative to storage in 11 quid $\mathrm{N}_{2} \ldots \ldots \ldots \ldots \ldots$ 
Table 3-1. Proportions of total cellular carbon and nitrogen in free amino acids of Nannochloris sp. as a function of relative growth rate......................... 105

Table 3-2. Proportions of total cellular carbon and nitrogen in protein of Nannochloris sp. as a function of relative

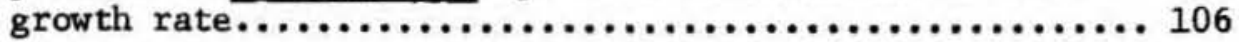

Table 3-3. Proportions of the intracellular free amino ac1d carbon pool associated with individual amino acids as a function of relative growth rate of

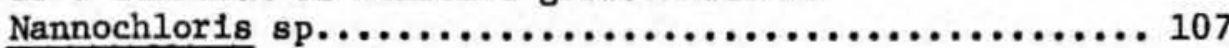

Table 3-4. Nitrogen specific turnover rates of nitrogen transport mediators in relationship to relative growth rate of Nannochloris sp............................... 113

Table 3-5. Relative specific activities of nascent protein amino acids in Nannochloris sp............................. 154

Table 3-6. Distributions of total cellular carbon and total ${ }^{14} \mathrm{C}$ uptake among the intracellular free amino acld pool of Nannochloris sp. at high relative growth rate......... 166

Table 3-7. Distributions of total cellular carbon and total ${ }^{14} \mathrm{C}$ uptake among free amino acids in Nannochloris sp. at low relative growth rate........ 167

Table 3-8. Proportions of intracellular free amino acid carbon and ${ }^{14} \mathrm{C}$ associated with individual amino acids of Nannochloris sp. at high relative growth rate........ 169

Table 3-9. Proportions of intracellular free amino acid carbon and ${ }^{14} \mathrm{C}$ assoclated with individual amino actds of Nannochloris sp. at low relative growth rate.

Table 3-10. Proportions of the intracellular free amino acid carbon pool associated with individual amino ac1ds in control and NHt enriched cultures of Nannochlor1s sp.............................. 190

Table 3-11. Comparisons of intracellular free amino acid concentrations in control and $\mathrm{NH}_{4}^{t}$ enriched cultures of Nannochloris sp...................... 191

Table 3-12. Relative specific activities of intracellular free amino acids in control and enriched cultures of Nannochloris sp.................................. 199 
Table 3-13. Distributions of total ${ }^{14} \mathrm{C}$ uptake among intracellular free amino acids in control and enriched cultures of Nannochloris sp.............. 206

Table 3-14. Distributions of ${ }^{14} \mathrm{C}$ uptake within the intracellular free amino aclds of control and enriched cultures of Nannochloris sp.

Table 3-15. Intracellular free amino acld concentrations in control and enriched cultures of $\underline{\mathrm{D}}$. tertiolecta........... 213

Table 4-1. Bulk chemical composition parameters for high 11ght batch cultures of Nannochlor1s sp..................... 245

Table 4-2. Bulk chemical composition parameters for high light NH4-11mited steady state growth of Nannochlor1s sp. 247

Table 4-3. Bulk chemical composition parameters for low 11ght batch and $\mathrm{NH}_{4}-1$ imlted steady state growth of Nannochlor1s sp................................ 248

Table 4-4. Bulk chemical composition parameters for high light $\mathrm{NH}_{4}$-IImited steady state cultures of selected marine algae.................................. 251

Table 4-5. Bulk chemical composition parameters for high 11ght batch and $\mathrm{NH}_{4}-11 \mathrm{~m}$ ted steady state cultures of Chat tonella luteus. .........................0.0.0...

Table 4-6. Cellular chemical composition parameters of high 11ght batch and NHt-1imited steady state cultures of Nannochloris

Table 4-7. Cellular chemical composition parameters of $10 \mathrm{w}$ light batch and NHA-limited steady state cultures of Nannochloris sp...........................

Table 4-8. Cellular chemical composition parameters of NHt-11mited steady state cultures of selected marine algae........................................

Table 4-9. Turnover rate constants for 11ght and NHt-limited steady state cultures of Nannochloris sp............ 322

Table 4-10. Intracellular free amino acid carbon concentrations in high light $\mathrm{NH}_{4}$-limited steady state cultures of Nannochlor1s

Table 4-11. Relative abundance of glycine and alanine in protein of different algal sources........................ 357 
Table 4-12. Relative abundance of glycine and alanine in protein.... 358

Table 4-13. Comparison of observed, predicted and extrapolated protein carbon incorporation rates................. 359

Table 5-1. Dissolved organic carbon concentrations from ground water, rain water, and Salt Pond surface water........ 376

Table 5-2. Comparison of inorganic ${ }^{14} \mathrm{C}$ fixation as determined by acidification/sparging and filtration............... 388

Table 5-3. Coefficlents of variation for replicate production estimates...................................... 389

Table 5-4. Particulate organic carbon production rates for consecutive Incubations in Salt Pond, summer 1983.............. 390

Table 5-5. Product-moment correlation coefficients.............. 391

Table 5-6. S1mulated in s1tu production rates for Salt Pond, 1982.. 398

Table 5-7. Light extinction in the mixed layer of Salt Pond,

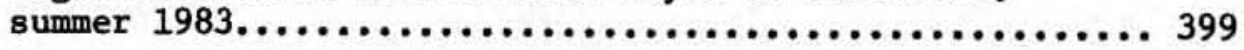

Table 5-8. Surface Incident and atmosphere corrected solar radiation: 10 Aug - 1 Sept 83 , Salt Pond................... 400

Table 5-9. Particulate protein amino ac1d production rates.......4 401

Table 5-10. Proportion of glycine and alanine carbon in protein recovered from hydrolysis.......................4 403

Table 5-11. Production and net removal of POC and PPAA......... 412

Table 5-12. Changes in dissolved 1norgan1c and organ1c carbon, dissolved organic nitrogen, and $\mathrm{NH}_{4}$ concentrations below three meters in Salt Pond, summer 1983.......... 414

Table 5-13. Dark uptake rates of inorganic ${ }^{14} \mathrm{C}$ : Salt Pond, summer

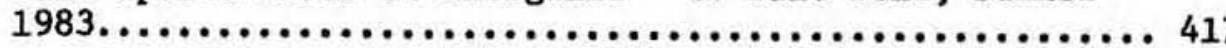

Table 5-14. Comparisons of morning and midday production and composition ratios, Salt Pond, 1 Sept 83 . 
$-28-$

CHAFIER 1. GENERAL INTRODUCTION 
THE COMPOSITIONAL DYNAMICS OF ORGANIC MATTER IN AQUATIC ENVIRONMENTS

Planktonlc photoautotrophs account for the greatest proportion of primary productivity in the world's oceans (e.g. Whittle, 1977; Woodwe11 et al., 1978; Peterson, 1980; Ne1nhaus, 1981). Through their ab1lity to synthesize organic matter from primary substrates using the sun's energy, phytoplankton provide the source of energy and bullding blocks for growth of virtually all other marine organisms. Yet phytoplankton carbon 1s a 8mall proportion of the ocean's total particulate carbon (Cauwet, 1981; Ne1nhaus, 1981). Even if only the euphotic layer particulate organic matter is considered, phytoplankton carbon may often account for less than half the particulate carbon, especially in olfgotrophic systems (e.g Hobson, 1971; Hobson et a1., 1973; Beers et a1., 1975; Eppley et a1., 1977; Wangersky, 1977; Whittle, 1977; Sharp et al., 1980).

The processes whereby phytoplankton derived primary organic matter 18 converted, elther directly or indirectly, into other organisms of the marine food chain and into non-living reservolrs of organic matter have been the subjects of study since the very earliest stages of oceanographic research. Despite the intensity and duration of these investigations, and largely as a result of methodological limitations, researchers have only just begun to unravel the complexities of organic matter transformations and the roles of blological processes which mediate them.

The remainder of this introduction reviews the major processes which Influence the composition of organic matter in the oceans as they are current1y understood, and specifically considers the relative importance of primary Inputs by phytoplankton in influencing the particulate organic matter composition in surface waters of the oceans. Evidence is cited 
suggesting that processes other than primary production of organic matter may significantly influence particulate organic matter composition, and lead to ambiguities in attempts to use chemical and blochemical measurements as assays of phytoplankton physlological state and blosynthet1c activity.

\section{BACKGROUND}

The Marine Food Chain and the Composition of Organic Matter

The composition of particulate organic matter is a function of the Interactive roles of microblal autotroph1c and heterotrophic processes which are the basis for the marine food web. Recent investigations have begun to recognize the importance of the behaviour of Individual organisms and Individual organic compounds in controlling this level of marine trophodynamics. The classical view of the marine food chain is that phytoplankton pass through herbivores on to primary carnivores, and it is through this stepwise transfer of organic matter that production of commercially Important species is realized (e.g. Issaccs, 1969;

Antkouchine and Sternberg, 1973; Steele, 1974). This paradigm has since been re-examined and the importance of non-phytoplanktonic microorganisms in food web processes is now being evaluated (Pomeroy, 1974; Sleburth et al., 1977, 1978; Landry, 1977; Jo1r1s, 1977; Porter et a1., 1979; Sorok1n, 1981; W1ll1ams, 1981; Azam et al., 1983). One of the major problems plaguing the classic paradigm is that it falls to account for the fate of the large portion of primary organic matter which passes directly to the dissolved organic pool (Williams, 1981). In the rest of this section, I discuss how production and utilization of dissolved organic matter can Influence particulate organic matter composition. 
The highest concentration of dissolved organic carbon in the oceans Is in the euphotic zone (e.g. Menzel and Ryther, 1970; Handa, 1970; Degens, 1970; Gagosian and Lee, 1981) where the vast majortty of primary production occurs. Dissolved organic matter may be produced by a varlety of mechanisms Including phytoplankton excretion (e.g. Fogg, 1962, 1977; Hellebust, 1965; Sharp, 1977; Mague et al., 1980), cell autolytic processes (e.g. Golterman, 1964; Bell and Mitche11, 1972; Dawson and Duursma, 1981), release of soluble material during ingestion (e.g. Whittle, 1977), and zooplankton excretion (Webb and Johannes, 1967). Williams (1981) cited evidence that as much as $50 \%$ of primary production may pass through the dissolved organic pool. Poulet and Martin-Jezequel (1983) and Hammer and Brockman (1983) observed highest release of dissolved free amino acids in algal cultures nearing statlonary phase. This would suggest that higher proportions of primary organic matter may be transferred to the dissolved organic matter in algal populations which are stressed (e.g. the latter portion of a bloom).

A number of studies have observed significant increases in dissolved organic compounds associated with blooms. These include amino acids (Jeffries, 1969; Ittekkot, 1982), fatty acids (Jeffr1es, 1970; Kattner et al., 1983), and carbohydrates (Handa, 1970; Ittekkot et al., 1981, 1982). Stress related compensations in algal metabolism result in significant changes in biosynthetic patterns (e.g. Syrett, 1953; Thomas and Krauss, 1955; Fogg, 1956,1959; Handa, 1969; Caperon and Meyer, 1972; Myklestad and Haug, 1972; Thomas and Dodson, 1972; Rhee, 1973, 1978; Morris et al., 1974; Conover, 1975; Harrison et a1., 1976; Myklestad, 1977; Edge and Ricketts, 1977; Laws and Wong, 1978; Goldman and Peavey, 1979; Goldman, 1980; Laws and Bannister, 1980; Hitchcock, 1981; Shifrin 
and Ch1sholm, 1981; Konopoka and Schnur, 1981). However, the effect of such changes in algal blosynthet1c patterns on particulate organic matter composition could be obscured by production and utilization of dissolved organtc mater1al.

Investigations of the relative contribution of spec1fic organic compounds to particulate organlc matter indicate selective depth-dependent $10 \mathrm{ss}$ of biogenic materials such as amino ac1ds (Degens, 1970; Slezen and Mague, 1978; Lee and Cronin, 1982,1984; Lee et al., 1983), 11p1d (Wakeham et al., 1980; Gagos1an et al., 1982; Lee et al., 1983), and carbohydrates (Handa, 1970). Lee and Cronin (1982) constructed a model based on the composition of sediment trap material showing $80 \%$ of the particulate amino acids produced during photosynthesis are decomposed or released in the upper $14 \mathrm{~m}$ in a Peru upwelling area. Relative depth dependent variations among particulate amino ac1ds are different for different amino acids, suggesting different production mechanlsms and susceptibility to heterotrophic activity (Siezen and Mague, 1978; Lee and Cron1n, 1982, 1984).

Bacterlal growth can be supported by both dissolved and particulate organic material. An operational distinction of particulate material is any substance retalned on an $0.45 \mathrm{~m} 1 \mathrm{cron}$ f1lter. Th1s $1 \mathrm{~s}$ an adequate definition for the purposes of this discussion, as it 1s 1ikely that larger material is an obligatory intermediate in the conversion of primary substrates to upper trophic levels. On the other hand, dissolved organic matter accounts for by far the largest proportion of organic material in the marine environment (Ne1nhaus, 1981; Cauwet, 1981). It has been suggested that bacterlal utilization of dissolved organic material and subsequent grazing of the bacterla by microzooplankton may 
provide a route for the dissolved organic reservolr to re-enter the particulate organic phase, and hence the food web (e.g. Beers and Stewart, 1969 in Landry, 1977; Sorok1n, 1981; W11liams, 1981; Azam et al., 1983). Such a mechan1sm for production of particulate organic material could potentially influence particulate organic matter composition independently of primary production.

There is substantial evidence suggesting that bacterfa may indeed efficiently assimilate specific dissolved organic substrates including glucose, (Andrews and W1ll1ams, 1971; Derenbach and W1ll1ams, 1974), amino acids (Hobbie et al., 1968; Andrews and Williams, 1971; Crawford et al., 1974; Willlams et al., 1976; Dawson and Gocke, 1978; Holl1baugh et al., 1980; W1ll1ams, 1981; Hagström et a1., 1984), and protein (Hollibaugh and Azam, 1983). Direct utilization by bacterla of dissolved organ1c matter released by phytoplankton has been demonstrated using selective filtration of natural samples incubated with ${ }^{14} \mathrm{C}-\mathrm{HCO}_{3}$ (Azam and Holm-Hansen, 1973; Derenbach and W1ll1ams, 1974; Larsson and Hagström, 1979; Cole et al., 1982). Although the selective filtration methods used in these studies result in ambigulties in production and ut1lization rates (see critique in Smith and Horner, 1981), bacterial incorporation of label was conslstently observed. A varlety of attempts have been made to distinguish the production and heterotrophic utilization of photosynthesized dissolved organic matter including kinetic analyses of 1sotope distribution between dissolved and part1culate phases (Wiebe and Smith, 1977; Bell, 1980, 1983; Bell and Sakshaug, 1980; L1, 1983) and use of antibiot1cs (e.g. Jensen, 1984). Bell and Mitchell (1972) have shown that microbial association with algal cultures seems to be greatest as the algal culture nears 
senescence, and it is at this time that, through cell autolysis, the largest amounts of dissolved organic matter are released. Other evidence for close coupling between production and utillzation 1s the diel periodicity in concentrations of some dissolved substrates. D1el variations have been observed in the concentrations of amino acids (Mopper and L1ndroth, 1982) and other compounds (e.g. S1eburth et al., 1977). Consistent with this was the observations by Hammer and Brockman (1983) of a rhythmic release of dissolved free amino acids in partially synchronized outdoor cultures of Thalassiosira rotula. Harvey (1983) also observed rapid fluctuations in dissolved carbohydrates in the New York B1ght and attributed it to rapid cycles of production and utilization. Ittekkot (1982) noted that changes in dissolved carbohydrates and amino acids during a spring plankton bloom in the northern North Sea were dissimilar when both were analyzed in the same samples, demonstrating the unique behaviour of different types of organic material. Mopper and Lindroth (1982) suggested on the basis of their studies of diel variations in dissolved free amino acids in the Baltic Sea that the differential behaviour of individual amino acids provided Insights as to the production and utilization processes which dominated during different periods in a diel cycle.

Because processes controlling the composition and distribution of bulk organic matter in seawater involve differentlal rates of production and consumption of individual organic compounds, understanding these processes and their influence on particulate organic matter composition w111 require rate measurements of individual classes of organic material. The relatively low concentrations of 1dentified blogenic compounds shows that organlc carbon 18 being removed at a rate comparable 
to production (Gagosian and Lee, 1981). Although determinations of concentrations of compounds by themselves cannot provide estimates of rates of production or utilization, the rapid depth- and time-dependent fluctuations of these blogenic compounds is consistent with an interactive role of autotrophic and heterotrophic processes in Influencing the composition and cycling of dissolved and particulate organic material in the ocean.

\section{Blochemical Cycles and the Distribution of Organic Matter}

Menzel and Ryther (1970) noted that 1t is "increasingly obvious that blochemical cycling of organic matter is not closely coupled with that of plants and animals which produce and 1mmediately consume organic matter In the famillar food cycle of the sea". Recycling of organic matter relles on the role of non-phytoplanktonic organisms to transform the primary organic matter back to substrates ut1lizable by phytoplankton. Heterotrophic organisms may significantly influence part1culate organic composition simply by the presence of their biomass. Perhaps an even greater impact on composition may be through their activities as catalysts of organic matter transformations independent of algal metabol1sm.

The recycling of a variety of materials in euphotic systems has been investigated. Estimates of losses of organic material from the euphotic layer Indicate that in oligotrophic systems, as 11ttle as 1- $10 \%$ of the primary production escapes Into the deep ocean (B1shop, 1977, 1978; Whittle, 1977; Parsons et al., 1977; Harr1son, 1980). Rap1d cycles of nutrient utilization and remineralization have been demonstrated (e.g. Glibert et al., 1982; Caperon et al., 1979; Harrison et al., 1978; 
Harr1son, 1980; Garside and Glibert, 1984; Gars1de, 1984). Eppley and Peterson (1979) argue that $80 \%$ of nitrogen used by open ocean phytoplankton 1o recycled. W11l1ams (1981), c1ting ev1dence from varlous worka, suggested that zooplankton metabollsm cannot account for the majority of nitrogen regeneration and bacteria may not be primarily responsible for remineralization since they tend to assimilate organic substrates w1th high efflclency. Although others have shown that bacterla are capable of remineralizing nutrients from decomposing algae, turnover of particulate matter in seawater is apparently more rapld than possible from microbial activity alone (Harrison, 1980).

These observations have st1mulated 1nterest in the role of m1crozooplankton in remineralization of organic matter. Johannes (1965) demonstrated that remineralization is enhanced by the presence of both bacterla and protozoa, compared to just bacterla alone. Evidence as to the importance of these microorgan1sms in organic matter cycling 18 stead11y accumulating (e.g. Johannes, 1965; Stout, 1980; Sorok1n 1981; Willams, 1981; Banse, 1982; Azam et al., 1983; Azam and Ammerman, 1984).

The inclusion of bacteria and microzooplankton in chemical analyses of particulate organic material could bias the results since their composition may be significantly different from phytoplankton (e.g . Beers, 1966; Banse, 1974, 1977). Frequent efforts have been made to estimate the proportion of particulate carbon associated with phytoplankton and other 1lving and nonliving reservolrs using microscopically and electronically derived particulate volumes to estimate carbon content (Strathman, 1967; Ze1tzchel, 1970; Hobson et al., 1971; Hobson et al., 1973; Beers et al., 1975; Wh1ttle, 1977; Eppley et 
al., 1977; Sharp et a1., 1980; Sorok1n, 1981; Hendrikson et al., 1982;

Holligan et al., 1984). Some of these studies have been criticized since they are based on carbon to volume ratios which are clearly subject to variations as a result of differences in species and physiological state (Chan, 1978, 1980), and preservation methods can destroy or morphologically alter organisms (e.g. Paer1, 1984). Nevertheless, these studies indicate almost exclusively that phytoplankton do not account for the majority of particulate organic material, and heterotrophic biomass may be comparable to phytoplankton (e.g. Sorokin, 1981; Caron, pers. comm.). Frequently, the detrital material (generally including some bacteria) accounts for the majority of particulate carbon (e.g. Zeitzschel, 1970; Beers et al., 1975).

The importance of detrital material as a reservolr of particulate organic material and a potential food source (e.g. Alldrege, 1979; Wangersky, 1977) has provoked interest in 1ts chemical composition and mechanisms of formation. Suggested modes of formation include aggregation of colloldal materlal assoclated with collapse of bubbles (e.g. Baylor and Sutcliffe, 1963; Johnson, 1976), bacterial clumping (e.g. Pearl, 1974; Sorokin, 1981), and adsorption of dissolved organic matter onto collo1dal material (e.g. Wangersky, 1977; Cauwet, 1978, Gagosian and Lee, 1981). Histochemical analyses of aggregates has shown that they may contain protein and carbohydrate (Nemoto and Ishikawa, 1969; and Gordon, 1970; In Parsons et al., 1977). Fallon and Brock (1979) observed that the composition of particles during the latter portion of a bloom Indicated partially autolyzed or decomposed algal cells may also be an important nonliving source of particles. 
There have been a varlety of attempts to chemically distinguish living particulate carbon from non-living detrital carbon. Frequently, the concentration of total particulate carbon is regressed against chlorophyll concentrations in fleld samples from a particular water mass over some period of time. The assumptions are that chlorophy11 not associated with living plant material is rapldly degraded, so that the intercept of such a regression provides an average value for nonphytoplanktonic carbon in the particulate material, and the slope is an average value of the carbon to chlorophyll rat1o of the phytoplankton population (Banse, 1977). Packard and Dortch (1975) used a similar approach comparing regressions of proteln-N against chlorophyll in oceanic and upwelling communit1es. They estimated that anywhere from $35 \%$ (upwelling) to $80 \%$ (oceanic) of the particulate proteln-N may be nonphytoplanktonic. Barlow (1982b) c1ting evidence that chlorophyll may be associated with nonliving particulate matter, questioned its value as a tracer of living plant materlal. He used glucan, a labile reserve polysaccharide in diatoms, in place of chlorophyll to estimate detrital (including bacteria) content of protein, ATP, and total carbohydrate. The validity of such exptrapolations is dependent on the constancy of the relative blochemical composition of living organic matter (e.g. Steele and Balrd, 1962; Donaghay et al., 1978; Kar1, 1980; Goldman, 1980), and Independence of the behaviour of different organic reservolrs over time (Banse 1977). Desplte the limitations, the results consistently indicate a substantial amount of carbon and biogenic compounds such as protein and carbohydrate may not be assoclated with phytoplankton. 
Wangersky (1977) suggested that only during a bloom are phytoplankton a major portion of particulate material, and that yearly cycles of particulate organic carbon and productivity are not necessarily correlated in time. Microautoradiographic techniques have shown that even if phytoplankton biomass dominates the particulate organic material, proportions of production associated with different species may not be representative of their biomass (eg. Watt, 1971; Maguire and Ne111, 1971; Gutel'makher, 1973; Davenport and Maguire, 1984). The presence of significant amounts of particulate organic matter not directly assoclated with the active phytoplankton population raises doubts as to whether primary production is the dominant factor influencing the composition of particulate organic matter. The possiblity that other processes may be more important in controlling particulate organic matter composition makes it less feasible to use the chemical and blochemical composition of particulate organic matter as an Index of phytoplankton physiological state.

\section{The Chemical Composition of Natural Populations}

Phytoplankton possess the capacity for physiological interaction with their environment, which can lead to changes in their metabolism and resulting biochemical composition. Consequently, it seems reasonable to expect phytoplankton generated variations in the composition of particulate organic material. But to what extent can we attribute the composition of particulate organic material to the activities of phytoplankton? Various investigators have suggested the use of chemical ratios as an indication of a natural phytoplankton population's physiological state. The $C: N$ ratio has been one of the most commonly 
referred to in the 11terature largely because it is a straightforward measurement and, in the laboratory, demonstrates a reasonably uniform correlation with relative growth rate for a variety of species (Donaghay et al., 1978; Goldman et al., 1979; Goldman, 1980). However, 1ts value as a precise indicator of the physlological state of natural populations has been criticized on the basis that it is sensitive only at low relative growth rates (Donaghay et al., 1978), and 1s subject to interference by nonphytoplankton material (Banse, 1974, 1977; Goldman, 1980). Similar criticlsms can be raised against carbon to phosphorus rat10s, and carbon to chlorophy11 ratios as indices of relative growth rate (c.f. Goldman, 1980).

Another chemical ratio which has been suggested as a useful relative Indicator of population physiological state is the protein/carbohydrate ratio (Myklestad and Haug, 1972; Haug et al., 1973; Barlow, 1982a,b; . Barlow and Henry, 1982; Konopka, 1982). As is the case for other rat1os, 1t is subject to interference by nonphytoplankton material. Moreover, results of 1 ts application to mixed natural populations may often be ambiguous since different species have different protein content even if they are growing under similar conditions (Chan, 1978,1980). Konopka (1982) compared several biochemical indices in a relatively pure natural population of Osc1llatoria rubescens including protein to chlorophyll, carbohydrate to protein, and RNA to protein rat1os. Despite the relative uniformity of the natural community, results led to conflicting conclusions illustrating the difficulties in interpreting blochemical measurements. A fundamental criticism of such biochemical approaches is their use of colorimetric assays on natural mixtures of particulate organic material. Such assays provide an adequate relative index when 
used with pure cultures in controlled laboratory situations, but are less meaningful when applied to complex organic matrices which make up particulate organic matter in natural systems (Cauwet, 1981).

An additional problem which is independent of the interference of nonphotosynthetically derived material is that diel variations in blosynthetic patterns can substantially influence the results of chemical and blochemlcal assays. Goldman (1980) noted that average carbon to nitrogen and carbon to chlorophyll a ratios for cultures grown in light/dark cycles were lower than values for cultures grown in constant light regimes. The discrepancy was most pronounced at relative growth rates of approximately $0.7 u_{\max }$ and below, and would consequently affect interpretations of the relationship between these ratios and relative growth rate. H1tchcock (1980) Investigated time-dependent variations in blochemical parameters throughout a 11ght/dark cycle. He observed significant increases during the photoperiod in cellular chlorophyll a and carbohydrate of Skeletonema costatum, particularly at higher temperatures and lower 11ght intensities. Cellular protein seemed to be the least variable of these parameters. Hitchcock noted that the protein/carbohydrate ratio showed a diel range comparable to that in a culture progressing from a nutrient sufficient to defficient state and cautioned the use of this ratio as an indication of nutrient status of natural populations. Van Liere et al. (1979) also observed higher ratios of carbohydrate production during the photoperiod in continuous cultures of Osc1llatoria agardhif grown on a 11ght/dark cycle. Other biopolymers were produced at a relatively constant rate throughout the light and dark period, presumably with dark synthesis occurring at the expense of carbohydrate. This general pattern of storage product accumulation 
during the photoperiod has been observed by other 1nvestigators in laboratory situations (Darley et al., 1976; also Tamiya (1957) and Kanazawa (1964) In Morris, 1981). Desp1te the well recognized dependence of biosynthet1c processes on the diel cycle, it has rarely been considered in field 1nvestigations which used chemical and biochemical ratios in efforts to physiologically characterize phytoplankton populations.

In light of the variety of criticisms which have been raised, it is apparent that conclusions about the activities of microorganisms based solely on determinations of the concentrations of chemical substances are often amb1guous and provide 11ttle Information about the organisms' respective roles in organic matter cycling. A more direct approach to estimating microblal activity and biochemical composition involves the use of 1sotoplc tracers. Although such an approach is subject to significant methodological constraints which will be discussed, it provides the most definitive means of probing the composition of living mlcrobial blomass and tracing production of specific organic materials.

\section{Isotope Tracing of Microblal Activitiea}

Isotopic methods avold problems of detrital interference by directly tracing microblal metabolism. However, they are subject to other potentlal artifacts. I will 11mit this discussion to the use of $\mathrm{C}$ and $\mathrm{N}$ 1sotopes as tracers for the sake of brevity. Probably the most commonly used 1sotope is ${ }^{14} \mathrm{C}-\mathrm{HCO}_{3}$ after the method of Steeman-Ne1lsen (1952). However, the history of this technique has been one of controversy since 1ts inception (Yentsch and Menzel, 1974; Iean and Burnison, 1979; Peterson, 1980; Dring and Jewson, 1982). Some of the problems are 
assoclated with sample manipulation and include effects of containment, potential contamination and the use of endpoint incubations which must assume 11near uptake (e.g. Carpenter and Lfvely, 1980; Fitzwater et al., 1982; Ge1skes et al., 1979; Goldman et al., 1981a; Venr1ck et al., 1977; Ferguson et a1., 1984; Ferguson and Sunda, 1984). Other problems are associated with the lack of a clear understanding of the integrated effects of blological processes of carbon fixation, resplration and photorespiration, and their relationship to the net production of part1culate carbon (e.g. Harris et al., 1979; Peterson, 1980; L1 and Goldman, 1981; Dring and Jewson, 1982).

The introduction of the ${ }^{15} \mathrm{~N}$ method (Neess et al., 1962; Dugdale and Goering, 1967) provided another tool for tracing the utilization of a primary substrate by phytoplankton. In addition to problems associated with sample manipulation mentioned for ${ }^{14} \mathrm{C}-\mathrm{HCO}_{3}$, there are other potential artifacts unique to this method. The relatively low concentration of 1norganic nitrogen in seawater increases the chance for perturbing the system by the addition of tracer and can result in artificlally enhanced uptake rates (Dugdale and Goering, 1967; Fisher et al., 1981; McCarthy and Goldman, 1979; Gl1bert and Goldman, 1981; Goldman et al., 1981a,b). Conversely, if ambient nitrogen levels are low, depletion of substrate could lead to underestimates of uptake if endpoint Incubations are extended over too long a period (e.g. Goldman et al., 1981a). Freezing of samples can alter amblent concentrations, particularly at low levels (Carpenter and McCarthy, 1975). Other potential artifacts include dilution of added tracer by remineralization (Harrison et al., 1978; Caperon et al., 1979; Glibert et al., 1982) and uptake of organic nitrogen sources not traced (e.g. Remsen, 1971; 
McCarthy, 1972; Schell, 1974; Wheeler et al., 1974; Wheeler and Stephens, 1977) both leading to underestimates of uptake.

Despite their 11mitations, the combined use of ${ }^{14} \mathrm{C}$-inorganic carbon and ${ }^{15} \mathrm{~N}$-1norgan1c nitrogen permitted comparisons of phytoplankton uptake ratios of carbon and nitrogen (1.e. ${ }^{14} \mathrm{C}-\mathrm{HCO}_{3}$ and ${ }^{15} \mathrm{~N}$ ) with the carbon to nitrogen ratio in particulate matter (Slawyk et al., 1977; Co11os and Slawyk, 1979; Eppley et al., 1977; Caperon et al., 1979; Sharp et al., 1980; Slawyk et al., 1980; Harrison et al., 1983). These Investigations provided a comparison of measured activities of primary producers and the composition of particulate organic matter. The results of these investigations have frequently demonstrated a positive correlation between $C: N$ uptake ratios and the $C: N$ ratio in the particulate material, but quantitative agreement was generally poor and uptake rat10s varied over a much larger range than particulate ratios. In addition to potential interference by detritus and non-algal biomass, some of the discrepancies may have been due to the fact that nitrogen and carbon uptake are not necessarily coupled (Bassham and Kirk, 1964; Collos and Slawyk, 1979; Goldman et al., 1981a). Consequently, the C:N uptake ratios may not have been a reflection of the relative composition or blosynthes1s of particulate carbon and nitrogen.

The ubiquitous nature of carbon in living blomass, and the specificity of the association of inorganic carbon fixation with photosynthet1c organisms provide a basis for using inorganic ${ }^{14} \mathrm{C}$ to trace the blochemical composition and metabolism of phytoplankton populations. Through precise rate measurements of primary production of chemically distinct biogenic materials, it is possible to determine the extent to wh1ch changes in particulate organlc matter composition are 
attributable to phytoplankton production as opposed to transformations mediated by other blological processes. Information about rates of primary production of specific types of organic material will help to define the role of phytoplankton in blochemical cycling of organic matter, as well as provide a direct assessment of growth-related phytoplankton activity.

Amino acids are the bullding blocks of protein and several 1nvestigators have pointed out the ut1lity of proteln as a model blopolymer reflecting growth (Cuhel, 1981; Cuhel et al., 1981a,b,c, 1982a,b,1983; Bates, 1981; L1 and Harr18on, 1982). Amino ac1ds and protein are nutritionally important to heterotrophs, and make up a substantial proportion of primary production.

Th1s thesis describes a series of studies conducted in order to evaluate the use of 1norganic ${ }^{14} \mathrm{C}$ as a probe of composition and rates of biosynthesis of free amino acids and protein in marine phytoplankton. The investigative approach consisted of three main parts. Initially, the growth rate-related steady state composition of free amino acid and protein and their kinetics of ${ }^{14} \mathrm{C}$ incorporation were determined in $\mathrm{NH}_{4}^{+}$-limited cultures of the marine chlorophyte, Nannochlor $1 \mathrm{~s}$ sp. In addition, the dynamics of free amino acid composition and 1sotope incorporation associated with $\mathrm{NH}_{4}^{+}$enrichment were examined. The results provided a basis for relating the distribution of incorporated Inorganic ${ }^{14} \mathrm{C}$ to cellular chemical composition and metabolism. Differences between species in their responses to enrichment were also evaluated. 
Secondly, 1sotope incorporation rates were compared to net synthesis rates of protein amino acids in $\mathrm{NH}_{4}^{+}-11$ mited steady state cultures of Nannochloris sp. at high and low light intensities. Intercomparisons were also made among the incorporation characteristics in $\mathrm{NH}_{4}^{+}-$ 11mited steady state cultures of three other marine phytoplankton species. The results revealed that 1sotope incorporation into the protein amino ac1ds glycine and alanine were generally in good agreement with net synthesis rates. This observation provided a foundation for estimating net protein synthesis rates in natural populations.

Finally, with the ald of an extensive framework of laboratory results, I examined the relationship of primary production of particulate organic carbon and particulate protein amino acids to observed concentration changes and relative abundances of particulate organic carbon and protein amino acids in a well mixed euphotic system. The studies were conducted over a wide range of environmental conditions and population physiological states. The objectives were to assess the degree to which phytoplankton metabolism is reflected by particulate organic matter composition, and determine the relative importance of primary inputs and secondary transformations in influencing the particulate protein amino acid content of particulate organic matter. This 1nvestigation provided an unprecedented opportunity to explore the relationship between phytoplankton as a primary source of particulate amino ac1ds, and the behaviour of this 1mportant class of organic compounds in the marine environment. 
CHAPTER 2. METHODS AND MATERIALS 
CULTURE METHODS

Media Composition

Cultures were maintalned in an artificlal seawater medium (Guillard, 1975; Guillard and Ryther, 1962; Goldman and McCarthy, 1978). The mineral composition of the mixture 18 given in Table 2-1. The amounts shown were dissolved in defonized water (Barnstead Nannopure water purification system). Hefore use, the solution was filtered through $47 \mathrm{~mm}$ Whatman GF/F filters and autoclaved in teflon containers. The artificial seawater was subsequently enriched with nutrients, individually sterilized in teflon contalners (w1th the exception of the vitamin mixture which was filter sterilized and stored in screw cap pyrex test tubes). Media concentrations and working stock concentrations of nutrlents are given in Table 2-2. Formation of a reddish precipitate was frequently observed after nutrient enrlchment. Guillard (1975) noted that a reddish precipitate containing phosphorus appeared after autoclaving the artificial seawater media together with the nutrients and trace elements. The reddish color suggests that Iron hydroxides may also have been present. This could be removed by sterile filtration through a $0.22 \mu$ Millipore membrane filter.

\section{Growth Conditions}

Axenic stock cultureis were obtained from R. R. L. Guillard, currently associated with the Culture Collection of Marine Phytoplankton (CCMP) at Bigelow Laboratories in Maine, USA. A 11st of species used in this thesis is given in Table 2-3. 
Table 2-1. Mineral concentrations in artificial seawater.

\begin{tabular}{ll}
\hline Nutrient & $\begin{array}{c}\text { Concentration } \\
(\mathrm{mM})\end{array}$ \\
\hline $\mathrm{NaCl}$ & 400 \\
$\mathrm{MgSO}_{4}($ anhydr. $)$ & 20 \\
$\mathrm{MgCl}_{2} \cdot 6 \mathrm{H}_{2} \mathrm{O}$ & 20 \\
$\mathrm{CaCl}_{2}($ anhydr. $)$ & 10 \\
$\mathrm{KCl}^{\mathrm{KBr}}$ & 10 \\
$\mathrm{H}_{3} \mathrm{BO}_{4}$ & $.80^{\mathrm{a}}$ \\
\hline
\end{tabular}

aprepared as a stock solution of $1.6 \mathrm{M}$ and diluted $0.5 \mathrm{ml}$ per 11 ter. brepared as a stock solution of $0.4 \mathrm{M}$ and diluted $0.5 \mathrm{ml}$ per 11 ter. 
Table 2-2. Concentrations of nutrients and trace elements in standard culture medla.

\begin{tabular}{|c|c|c|c|}
\hline Nutrient & \multicolumn{2}{|c|}{$\begin{array}{l}\text { Media Concentration } \\
(\mu \mathrm{M}) \quad(\mathrm{mg} / 1)\end{array}$} & $\begin{array}{l}\text { Working Stock } \\
\text { Concentration (mM) }\end{array}$ \\
\hline $\begin{array}{l}\mathrm{NaH}_{2} \mathrm{PO}_{4} \cdot \mathrm{H}_{2} \mathrm{O} \\
\mathrm{Na}_{2} \mathrm{~S}_{3} \cdot \mathrm{H}_{2} \mathrm{O} \\
\mathrm{Fe} \mathrm{Sequestrene} \\
\mathrm{CuSo} 45 \mathrm{H}_{2} \mathrm{O} \\
\mathrm{ZnSO}_{4}: 7 \mathrm{H}_{2} \mathrm{O} \\
\mathrm{CoCl}_{2}: 6 \mathrm{H}_{2} \mathrm{O} \\
\mathrm{MnCl}_{2} \cdot 4 \mathrm{H}_{2} \mathrm{O} \\
\mathrm{Na}_{2} \mathrm{MoO}_{4} \cdot \mathrm{H}_{2} \mathrm{O} \\
\mathrm{NH}_{4} \mathrm{Cl}\end{array}$ & $\begin{array}{l}40 \\
106 \\
11.7 \\
0.04 \\
0.08 \\
0.5 \\
0.9 \\
0.03 \\
500^{b}\end{array}$ & $\begin{array}{l}5.5 \\
30 \\
5 \\
0.01 \\
0.022 \\
0.01 \\
0.18 \\
0.006 \\
26.5\end{array}$ & $\begin{array}{l}40 \\
106 \\
11.7 \\
0.04^{a} \\
0.08^{a} \\
0.5^{a} \\
0.9^{a} \\
0.03^{a} \\
500\end{array}$ \\
\hline $\begin{array}{l}\text { V1tamins: } \\
\text { Thiamin-HC1 } \\
\text { B1otin } \\
\mathrm{B}_{12}\end{array}$ & $\begin{array}{c}0.3 \\
2.0 \times 10^{-3} \\
3.7 \times 10^{-4}\end{array}$ & $\begin{array}{l}0.1 \\
0.5 \mu \mathrm{g} / 1 \\
0.5 \mu \mathrm{g} / 1\end{array}$ & $\begin{array}{c}0.3 \\
2.0 \times 10^{-3} \\
3.7 \times 10^{-4}\end{array}$ \\
\hline
\end{tabular}

aprepared as Individual primary stocks; working stock consisted of a mixture of each metal solution diluted 1000 times plus Fe sequestrene. This mixture was autoclaved in teflon, followed by sterile filtration through a $0.22 \mu$ Millipore membrane filter.

${ }^{b}$ For continuous culture experiments, $\mathrm{NH}_{4} \mathrm{Cl}$ was added to $125 \mu \mathrm{M}$.

cPrepared as a primary stock at a concentration of $0.1 \mathrm{mg} / \mathrm{ml}$.

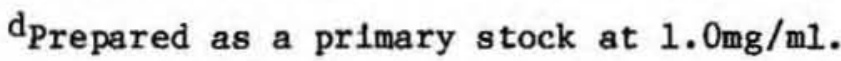


Table 2-3. Species 1ist of marine algae obtained from the culture collection of marine phytoplankton.

\begin{tabular}{|c|c|c|c|c|}
\hline Clone & Species & Isolator & Location & Date \\
\hline Dum & Dunalle1la tertiolecta & & & \\
\hline Actin & Thalassiosira wiessflogi1 & Guillard & $\begin{array}{l}\text { Gardiner's Island } \\
\text { Pond, N. Y. }\end{array}$ & \\
\hline $\begin{array}{l}\text { GSB } \\
\text { Nanno }\end{array}$ & Nannochloris sp. & & $\begin{array}{c}\text { Great South Bay, } \\
\text { N. Y. }\end{array}$ & \\
\hline \multicolumn{2}{|c|}{$\begin{array}{l}\text { 01isth } \frac{\text { Chattone1la }}{\text { (preus }} \\
\text { Loeviousiy 011sthodiscus) } \\
\text { Loeblich and Fine, } \\
\text { also Gibbs et al. }\end{array}$} & Conover & $\begin{array}{c}\text { Long Island Sound, } \\
\text { USA }\end{array}$ & \\
\hline & $\frac{\text { Chroomonas }}{\text { (W1slouch) }} \frac{\text { salina }}{\text { Butcher }}$ & Guillard & (Tank) M11ford, CT & 1956 \\
\hline BBsm & Chaetoceros simplex & Guillard & $32^{\circ} 10^{\prime} \mathrm{N} 64^{\circ} 30^{\prime} \mathrm{W}$ & 14 Apr 60 \\
\hline
\end{tabular}


Cultures were maintained at $20^{\circ} \mathrm{C}$ in a $12: 12$ 11ght:dark cycle regime In $15 \times 150 \mathrm{~mm}$ borosilicate tubes capped with white polypropylene caps. Prior to inoculation tubes were extracted w1th $1.5 \mathrm{~N} \mathrm{HCl}$ overnight, rinsed and subsequently autoclaved with approximately $10 \mathrm{mls}$ delonized water. The water was poured off and medla was added aseptically.

Flasks used for continuous culture experiments (F1g. 2-1) were constructed by Anderson Glass. The 0.511 ter jacketed flasks were similar to those used by Goldman and McCarthy (1978). Temperature was maintained within $1^{\circ} \mathrm{C}$ of $21^{\circ} \mathrm{C}$ by a Haake D2 heating-circulation water bath cooled with tap water. Cultures were 1lluminated using three parallel Vita-Lite fluorescent bulbs which provided an average quantum density of approximately $176 \pm 70$ ( $95 \%$ confidence interval) $\mu \mathrm{E} / \mathrm{m}^{2} / \mathrm{s}$ (range $90-200 \mu \mathrm{E} / \mathrm{m}^{2} / \mathrm{s}$ from top to bottom of culture vessel). L1ght intensities were determined in flasks containing delonized water using a Blospherics submersible $4 \mathrm{pl}$ probe. Cultures were mixed by a combination of aeration (Second Nature Whisper 600 aquarium type air pump) and magnet1c stirring (F1sher Cat. No. 14-511-IV2 magnet1c stirrer). Alr was pumped through a combined mixture of sterile glass wool and cotton, followed by sparging through sterile distilled water, and finally passed through an additional sterile cotton filter before being blown into the culture. Media was dispensed to the cultures via Harvard Apparatus Peristalic Pumps. Tubing was sillcon and glass.

\section{CHEMICAL ANALYSES}

\section{Chlorophy11 a analyses}

Chlorophyll concentrations were determined by the fluorometric method of Yentsch and Menzel (1963), as described by Sm1th et al. (1981). 
Samples were filtered on a Millipore type HA (nominal $0.45 u m$ pore size) and the filter dissolved in $90 \%$ aqueous acetone. Samples were incubated for 10 minutes and fluorescence read on a Turner designs Model 10-005R fluorometer equipped with filters for chlorophy11 a fluorescence. Readings were corrected for phaeoplgment fluorescence by subtracting readings for acidifled samples (two drops of $0.75 \mathrm{~N} \mathrm{HCl}$ ) from those for unacidified samples.

\section{Elemental Carbon and N1trogen Analyses}

Samples were filtered on combusted $\left(500^{\circ} \mathrm{C}\right.$ overnight) Whatman $\mathrm{GF} / \mathrm{F}$ $25 \mathrm{~mm}$ glass fiber filters using a M1lipore filtration apparatus, and filters were dried in an oven at $55^{\circ} \mathrm{C}$. Dried filters were stored dessicated until they were analysed for elemental carbon and nitrogen using a Perkin-E1mer 240 elemental analyzer. Philip Klarner and Bonnie Woodward performed the analyses.

\section{Nutrient Analyses}

Samples for nutrient analysis were f1ltered through combusted Whatman $\mathrm{GF} / \mathrm{F}$ filters and stored frozen at $-20^{\circ} \mathrm{C}$ unt 11 they were analyzed. Nutrients (ammonium, nitrate, nitrite, silicate, and orthophosphate) were analyzed using a Technlcon autoanalyzer. All nutrient analyses were made by Zophia Mlodzinksa.

\section{Dissolved Inorganic and Organic Carbon Analyses}

Dissolved inorganic carbon analyses were performed by adding $3 \mathrm{ml}$ samples, previously filtered through combusted Whatman GF/F filters, into $15 \mathrm{ml}$ serum bottles stoppered with butyl rubber. Samples were acidified 
Figure 2-1. Schematic of continuous culture system. Abbreviations: CF, cotton filter; GW, glass woo1; AP, air pump; OR, overflow reservo1r; $C B$, c1rculating bath flow; SS, sterile syringe; LLV, Luer-lok valve; S, magnetic stirrer; MR, media reservolr; PP, peristaltic pump. 


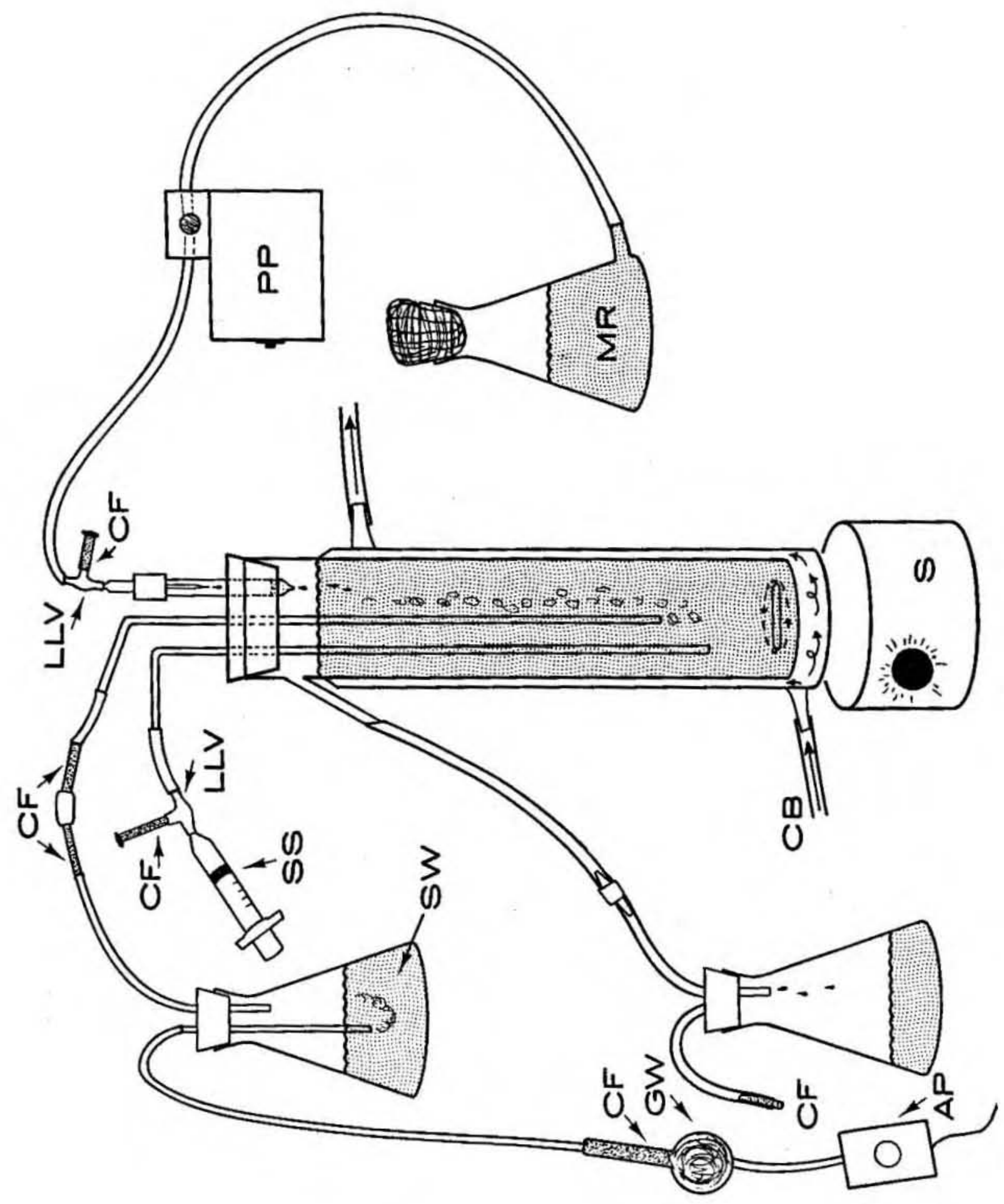


with $0.15 \mathrm{mls} 18 \mathrm{~N} \mathrm{H}_{2} \mathrm{SO}_{4}$ and stirred for a minimum of 3 hours. Gaseous $\mathrm{CO}_{2}$ was then analyzed by infrared spectroscopy and corrected for air blank. D1ssolved organic carbon was determined by the method of Menze1 and Vaccaro (1964). Analyses were made by Brian Howes and Dale Goehringer .

\section{Proteln Assay}

Bulk proteln analyses were made using the method of Bradford (1976). The method use Coomassie Brilliant Blue dye binding reagent which is commercially avallable from Blo-Rad. Standard curves were determined using egg ovalbumin (S1gma) which has a response factor representative of average proteins. Extraction for this assay involved grinding the filtered sample in $0.5 \mathrm{~N} \mathrm{NaOH}$ and subsequently extracting two times for 10 minutes at $80^{\circ} \mathrm{C}$, centrifuging at $4000 \mathrm{~g}$ for 20 minutes and combining the supernates (Rausch, 1981). The assay solution consisted of $0.5 \mathrm{ml}$ sample in $0.5 \mathrm{~N} \mathrm{NaOH}, 0.5 \mathrm{ml} 0.5 \mathrm{M} \mathrm{H}_{3} \mathrm{PO}_{4}$, and $0.25 \mathrm{ml}$ concentrated Blo-Rad reagent solution of Coomassie Brilliant Blue. The solution was allowed to incubate for 10 minutes and absorbance was read at $595 \mathrm{~nm}$. I have found that the response factor for this assay is highly sensitive to the $\mathrm{pH}$ of the solution. The solution composition described here gives adequate sensitivity in the $2-25 \mu \mathrm{g} / \mathrm{ml}$ sensitivity range (in the extracted solution).

\section{LABORATORY INCUBATION PROCEDURES}

\section{Sampling Procedure}

For culture experiments, steady state was defined as the time when chlorophyll a concentration and cell density remained constant for at 
least 2 generations. For the lowest growth rate under low 11ght conditions, steady state was maintained only 1.1 generations. Immediately preceding 1sotope incubations, samples were removed for particulate elemental carbon and nitrogen analyses. F1ltrates were collected and stored refrigerated for subsequent analysis of dissolved Inorganic carbon. Cells were counted on a Spencer Bright-11ne hemocytometer. In addition, chlorophyll a concentration and $\mathrm{pH}$ were determined. For these analyses, no more than $15 \%$ of the culture volume was removed from the full steady state chemostat, and the isotope Incubation was begun within 20 minutes of 1nftial sampling. Immediately before introducing the radiolabel ( $c^{14}$-inorganic carbon, New England Nuclear), aeration was stopped.

Time series sampling during the incubations included filtration of particulates on combusted Whatman GF/F glass fiber filters. For radiolabeled samples, filters were cut to a diameter of $13 \mathrm{~mm}$ using a template (Cuhel et al., 1981a) and housed in Millipore sx00 13 syringe f11ter holders. A Gast Manufacturing Corp. Serles \#1077 vacuum pump was used. Filtration pressures did not exceed $150 \mathrm{~mm} \mathrm{Hg}$. Filtered samples for amino acid analyses were placed in acld washed $20 \mathrm{ml}$ glass scintillation vials contalning $1.5 \mathrm{ml} 80 \%$ methanol and stored at $-6^{\circ} \mathrm{C}$ unt1l analysis.

\section{$\underline{\text { Radioassay Procedures }}$}

For estimates of total particulate ${ }^{14} \mathrm{C}$ f1xation, filters were placed in the bottom of a $20 \mathrm{ml}$ scintillation vial, covered with $0.1 \mathrm{ml} 1 \mathrm{~N}$ $\mathrm{HCl}$, and drled under a gentle air flow at $55^{\circ} \mathrm{C}$. The drled filters were molstened with a drop of deionized water, and $10 \mathrm{ml}$ scintillation fluor 
was added. Aquasol was used for all high 11ght intensity experiments with Nannochloris sp., and Salt Pond experiments prior to 13 August 83 . Scintiverse II (FIsher) was used for all other experiments. Comparisons between Aquasol and Scintiverse II indicated their quench characteristics were quite similar for the materials being counted (data not shown). Total acid non-volatile ${ }^{14} \mathrm{C}$ was assayed by a method similar to that described by Schindler and Holmgren (1971) and L1 and Goldman (1981). One $\mathrm{ml}$ of the culture was acidifled to a concentration of $0.32 \mathrm{~N} \mathrm{H}_{2} \mathrm{SO}_{4}$ (pH 1.2) in a $7 \mathrm{ml}$ scintillation vial, sparged with air for 15 minutes, and $6 \mathrm{ml}$ Scintiverse II added. Counts per minute were measured with a Beckman IS-100C 11quid scintillation counter. Measured counts were quench corrected by the channels ratio method (Kobayashi and Maudsiey, 1974).

\section{SUBCELLULAR FRACTIONATION FROCEDURES}

\section{Modification of Existing Procedures}

Subcellular fractionation procedures involve sequential solvent extraction of cellular inaterial into fractions whose chemical characteristics are operationally defined by the solvent characteristics. The procedure described here involves several modifications of procedures previously described by Roberts et al. (1963), Morris et al. (1974), Ll et al. (1980), Larsen et al. (1981),

Cuhel et al. (1981b), and Hitchcock (1981).

Initially, samples containing glass fiber filters were transferred to Bellco 12ml glass tissue homogenizers. Homogentzer tubes were cut down to a $10 \mathrm{ml}$ volume using a glass saw so that they would fit in the HS-4 rotor. The contents were ground in approximately $0.1 \mathrm{ml} 80 \%$ aqueous 
methanol, which had previously been f1ltered through a combusted Whatman $\mathrm{GF} / \mathrm{F}$ filter. In cases where the sample had been stored in $80 \%$ aqueous methanol in scintillation vials, the excess 11quid was subsequently transferred to the grinder, along with an $80 \%$ aqueous methanol rinse of the scintillation vial. The resulting homogenous suspension was vortexed, and subsequently centrifuged at $4000 \mathrm{~g}$ for 20 minutes in a Sorvall RC2B refrigerated centrifuged with an HS-4 swinging bucket rotor. Temperature was maintalined at $15^{\circ} \mathrm{C}$. The supernatant was removed, and temporarily held aside in a small test tube, while the pellet was subsequently resuspended and extracted in $1.5 \mathrm{ml} 80 \%$ aqueous ethanol at $60^{\circ} \mathrm{C}$ for 20 minutes. This mixture was again centrifuged, and the supernates combined. The pellet was extracted two additional times with a 1:1 mixture of $80 \%$ aqueous ethanol and diethyl ether at $60^{\circ} \mathrm{C}$ for 20 minutes and 10 minutes respectively, again combining the supernates. The combined supernate included intracellular free amino acids, other low molecular weight metabolites, and 11pophilic polymers. The lipophilic material was separated by concentrating the combined supernatant to $3 \mathrm{ml}$ at $60^{\circ} \mathrm{C}$ under air, adding $1 \mathrm{ml}$ defonized water, and extracting this solution two t:lmes with $5 \mathrm{ml}$ diethyl ether. For scintillation counting of the aqueous alcohol soluble and the Iipophilic fractions, the entire fraction or an allquot was transferred to either a $20 \mathrm{ml}$ or a $7 \mathrm{ml}$ scintillation vial, evaporated to near dryness, and scintillation fluor added in a ratio of less than 1:6 sample to fluor volume. In the case of the aqueous alcohol fraction, $0.1 \mathrm{ml} 1 \mathrm{~N} \mathrm{HCl}$ was added before evaporative drying to insure complete removal of inorganic ${ }^{14} \mathrm{C}$. 
The remaining pellet was then subjected elther to hydrolysis for high pressure 11quid chromatographic separation, quantitation, and collection of protein amino acids (see Amino Acid Analyisis), or was further fractionated into hot $\left(95^{\circ} \mathrm{C}\right)$ trichloroacetic acid soluble (largely carbohydrate and nucleic acld material) and fnsoluble material (largely residual protein) (e.g. Roberts et a1., 1963; Cuhel et a1., 1981b; Morr1s et al., 1974; Konopka and Schnur, 1980, 1981). For the latter procedure, the pellet was resuspended in $1.5 \mathrm{ml}$ trichloroacetic acld and extracted two times for 20 minutes and 10 minutes respectively at $95^{\circ} \mathrm{C}$. The acid supernatants were combined and $1 \mathrm{ml}$ mixed with $0.75 \mathrm{ml} \mathrm{Tr} 1 \mathrm{~s}-$ hydroxyethanolamine ( $\mathrm{pH} 13)$ and transferred t:o a $10 \mathrm{ml}$ Nalgene filmware scintillation envelope. Scintillation fluor (6 ml) was added to form a gel. Alternatively, the ent1re ac1d fract1on (approximately 3ml) was added to a $20 \mathrm{ml}$ glass scintillation vial and $17 \mathrm{ml}$ scintillation fluor added. The remaining pellet was transferred with sequential rinses of $0.75 \mathrm{ml} 0.1 \mathrm{~N} \mathrm{NaOH}, 1.0 \mathrm{ml}$ delonized water, and $0.75 \mathrm{ml} 1 \mathrm{M} T \mathrm{Tr}$ is $(\mathrm{pH} 7)$ Into elther a $10 \mathrm{ml}$ filmware bag or a $20 \mathrm{ml}$ glass scintillation vial and combined with 6-10 ml scintillation fluor.

\section{Comparison of Subcellular Fractionation Procedures}

The prolific use of subcellular fractionation procedures over the past 2 decades has resulted in the development of a variety of techniques. The lack of clear chemical definitions for the operationally defined fractions has limited the extent to which results using different procedures can be directly compared. Hitchcock (1981) compared the ability of different fractionation procedures to recover standards representative of the operationally defined fractions. He found 
substantial differences between the different methods. He also compared the carbon content of different subcellular fractions as determined by chemical analysis with that derived from ${ }^{14} \mathrm{C}$ in subcellular fractions of Gonyaulax tamarensis labelled for 6 hours. He found good agreement between the amount of 1ipid carbon derived from chemical composition and 1ipophilic ${ }^{14} \mathrm{C}$. In contrast, hot trichloroacetic acid extractable ${ }^{14} \mathrm{C}$ underestimated that determined from chemical analyses, while the residual ${ }^{14} \mathrm{C}$ in the pellet was higher than the estimate of protein carbon.

In view of these observations, I felt it was important to compare my fractionation method with two procedures described in the 11terature. One of these methods, that of $L 1$ et al. (1980), was also described in the Hitchcock study so that intercomparison of results was possible. The method of Cuhel et al. (1981b) is very similar to the fractionation procedure described by Roberts et al. (1963). Flow diagrams outlining the procedures are shown in Table 2-4. Material for fractionation was an axenic batch culture of Nannochloris sp. which was grown in the presence of inorganic ${ }^{14} \mathrm{C}$ for 4 generations to ensure approximate equilibrium label distribution. Amounts of carbon, as calculated from the levels of ${ }^{14} \mathrm{C}$ label associated with comparable fractions for each method are shown in Table 2-5. All three procedures gave very similar results for the cold acid/aqueous alcohol, and lipophilic fractions, and agreement between the Cuhel et al. and my method were quite simlar for all fractions. However, the if et al. procedure, which uses filtration rather than centrifugation to separate soluble and insoluble material, tended to give lower proportions of label in the hot trichloroacetic acid fraction, and higher estimates in the residue fraction. 
Table 2-4. Outline of fractlonation procedures.

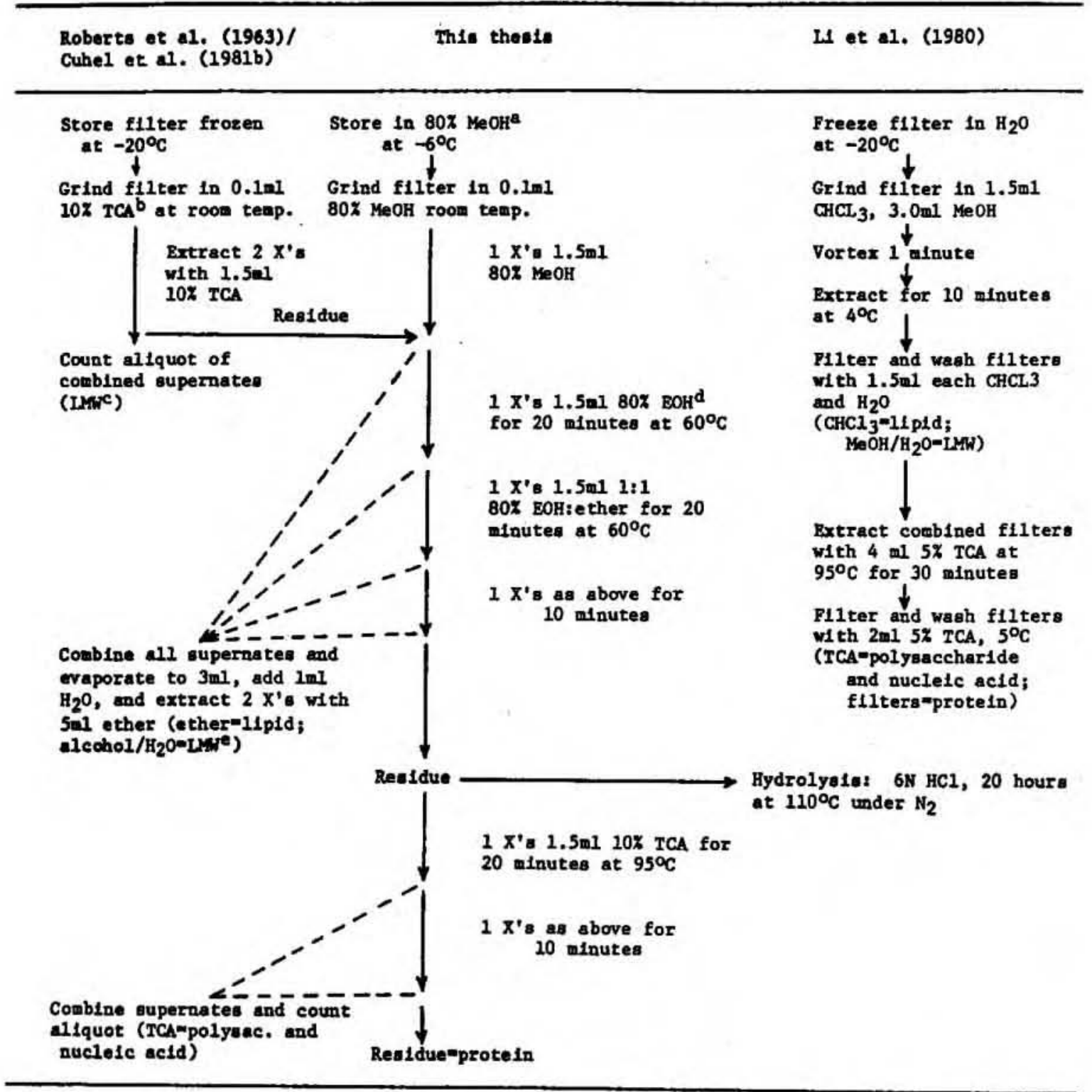

aethanol

btrichloroscetic acid

c1ow molecular welght metabolltes

dethanol

eFor the Roberts et al. method, this fraction containa alcohol soluble protein. 
Table 2-5. Comparilson of results using different fractionation procedures.

\begin{tabular}{|c|c|c|c|}
\hline $\begin{array}{l}\text { Method: } \\
\text { Fraction }\end{array}$ & L1 et al. & $\begin{array}{l}\text { Roberts et al.l } \\
\text { Cuhel et al. } \\
\qquad(\mu \mathrm{gC} / 1)\end{array}$ & My method \\
\hline $\begin{array}{l}\text { Alcohol or } \\
\text { Cold Acld } \\
\text { Soluble }\end{array}$ & $1500(104)^{a}$ & $1710(156)$ & $2010(381)$ \\
\hline L1 pophylic & $3650(322)$ & $3580(50)$ & $3610(248)$ \\
\hline $\begin{array}{l}\text { Hot Acid } \\
\text { Soluble }\end{array}$ & $1050(24)$ & $1380(547)$ & 1840 (149) \\
\hline Resldue & $5960(248)$ & $4010(348)$ & 3990 (199) \\
\hline $\begin{array}{l}\text { Sum of } \\
\text { Fractions }\end{array}$ & 12060 (419) & $10680(668)$ & $11450(518)$ \\
\hline $\begin{array}{l}\text { Actual } \\
\text { Total }\end{array}$ & $12376(414)$ & & \\
\hline
\end{tabular}

arrors in parentheses represent $95 \%$ confldence 1imits $(n=3)$. 
The residue is considered to be largely protein. More efficient recovery of protein by the method of If et al. 1s unlikely since comparisons of different proteln assay methodologies indicated relatively complete recovery of protein in the hot trichloroacetic acid insoluble fraction (see Recovery of Protein by Extraction). Rather, it seems the L1 et al. method results in a less complete separation of hot ac1d soluble and insoluble fractions. It may be that the resuspension associated with vortexing used in my method and that of Cuhel et al. leads to more effective solubilisation than the flltration procedure used by til et al.

\section{AMINO ACID ANALYSIS}

\section{Amino Acid Derivatization Procedure}

Free or hydrolyzed amino ac1ds were derivatized with dansyl chloride (5-(dimethylamino)-1-naphthalene-sulfony1 chloride) In a procedure which was a modification of a number of published literature methods (Wiedmier et al., 1982; DeJong et al., 1982; Tapuhi et al., 1981; Parris and Gallelli, 1984; MacNlcoll, 1978; Bayer et al., 1976). Dansyl chlorlde (S1gma) was dissolved in acetonitrile (Spectra UV Grade, Fisher) to a concentration of $6 \mathrm{mg} / \mathrm{ml}$. Th1s solution was stored dessicated under argon or nitrogen at $-20^{\circ} \mathrm{C}$. Extracted amino acld samples were dried under air at $60^{\circ} \mathrm{C}$ and ressuspended in equal volumes of $0.5 \mathrm{M} \mathrm{NaHCO}_{3}(\mathrm{pH}$ 8.5), $\mathrm{KMnO}_{4}$ distilled $\mathrm{H}_{2} \mathrm{O}$, and the dansyl chloride solution. It was found that this suspension could be effectively mixed by brief sonication. The reaction mixture was incubated in darkness for 1 hour at $37^{\circ} \mathrm{C}$. The reaction was terminated by addition of $\mathrm{KMnO}_{4}$ distilled $\mathrm{H}_{2} \mathrm{O}$ and $0.1 \mathrm{M} \mathrm{H}_{3} \mathrm{PO}_{4}$ (HPLC: Grade, Fisher) in final volume proportions of $7.5: 3: 2\left(\mathrm{H}_{2} \mathrm{O}\right.$ : reaction mixture: $\left.\mathrm{H}_{3} \mathrm{PO}_{4}\right)$. 
Potential sources of error in determining amino acid concentrations Included injection error, storage losses, varlations in derivatization efficiency, error in peak integration, and error in preparation of standards. Mean response factors (Integrated peak area/nanomoles injected) are shown along with $95 \%$ confidence intervals in Table 2-6. The $95 \%$ confidence intervals include all previously mentioned sources of error. This error was propagated in all subsequent calculations. Analytical varlations resulting from errors other than that associated with preparation of standards are shown in Table 2-7. These errors were smaller than those in Table 2--6, indicating that the standard preparation error was significant.

Various conditions which night affect the efficiency of derivatization were evaluated. No significant increases in response factors were observed if the derivatization mixture was incubated 4 hours versus 1 hour (Table 2-8). Correlations between response factors and the reaction mixture molar ratio of amino groups/dansyl chloride (range 0.001-0.12) were examined. Correlation coefficients are given in Table 2-9, and were not significant at the 0.05 probability level except in the case of serine and threonine. This indicates that adequate derivatization can generally be achieved provided dansyl chloride is present in a 10-fold molar excess relative to amino nitrogen (c.f. Bayer et al., 1976). The dependence of response factors on time of storage at $-6^{\circ} \mathrm{C}$ is shown in Table 2-10. There did not appear to be any consistent decreases up to 90 days after derivatization. Samples in this study were analyzed within 2 weeks of derivatization. DeJong et al. (1981) noted that Dns-tyrosine was relatively unstable. However, it was not included in my analyses. 
Table 2-6. Response factors for integrated absorbance by dansylated amino acids at $254 \mathrm{~nm}$.

\begin{tabular}{|c|c|c|c|c|}
\hline $\begin{array}{l}\text { Amino } \\
\text { Acld }\end{array}$ & $\begin{array}{l}\text { Response factor } \\
\qquad(V \text { sec }\end{array}$ & $\begin{array}{l}95 \% \text { Conf. Int.a } \\
\left.\text { nmole }{ }^{-1}\right)\end{array}$ & $\mathrm{n}$ & $\%$ \\
\hline $\begin{array}{l}\text { asp } \\
\text { glu }\end{array}$ & $\begin{array}{l}0.588 \\
0.570\end{array}$ & $\begin{array}{l}0.111 \\
0.113\end{array}$ & $\begin{array}{l}8 \\
9\end{array}$ & $\begin{array}{l}18.9 \\
19.8\end{array}$ \\
\hline $\begin{array}{l}\text { gln } \\
\text { ser }\end{array}$ & $\begin{array}{l}0.474 \\
0.715\end{array}$ & $\begin{array}{l}0.170 \\
0.170\end{array}$ & $\begin{array}{l}8 \\
8\end{array}$ & $\begin{array}{l}35.9 \\
23.8\end{array}$ \\
\hline $\begin{array}{l}\text { thr } \\
\text { gly }\end{array}$ & $\begin{array}{l}0.572 \\
0.748\end{array}$ & $\begin{array}{l}0.074 \\
0.149\end{array}$ & $\begin{array}{l}6 \\
7\end{array}$ & $\begin{array}{l}12.9 \\
19.9\end{array}$ \\
\hline $\begin{array}{l}\text { ala } \\
\text { Baba }\end{array}$ & $\begin{array}{l}0.658 \\
0.365\end{array}$ & $\begin{array}{l}0.121 \\
0.176\end{array}$ & $\begin{array}{l}6 \\
1\end{array}$ & $\begin{array}{l}18.4 \\
48.2\end{array}$ \\
\hline $\begin{array}{l}\text { Gaba } \\
\text { arg }\end{array}$ & $\begin{array}{l}0.614 \\
0.585\end{array}$ & $\begin{array}{l}0.236 \\
0.232\end{array}$ & $\begin{array}{l}5 \\
5\end{array}$ & $\begin{array}{l}38.4 \\
39.6\end{array}$ \\
\hline $\begin{array}{l}\text { pro } \\
\text { val }\end{array}$ & $\begin{array}{l}0.615 \\
0.554\end{array}$ & $\begin{array}{l}0.202 \\
0.145\end{array}$ & $\begin{array}{l}4 \\
6\end{array}$ & $\begin{array}{l}32.8 \\
26.2\end{array}$ \\
\hline $\begin{array}{l}\text { 1le } \\
\text { leu }\end{array}$ & $\begin{array}{l}0.361 \\
0.602\end{array}$ & $\begin{array}{l}0.171 \\
0.120\end{array}$ & $\begin{array}{l}4 \\
4\end{array}$ & $\begin{array}{l}47.3 \\
19.9\end{array}$ \\
\hline $\begin{array}{l}\text { trp } \\
\text { phe }\end{array}$ & $\begin{array}{l}0.451 \\
0.621\end{array}$ & $\begin{array}{l}0.280 \\
0.241\end{array}$ & $\begin{array}{l}3 \\
3\end{array}$ & $\begin{array}{l}62.1 \\
38.8\end{array}$ \\
\hline $\begin{array}{l}\text { iys } \\
\text { his }\end{array}$ & $\begin{array}{l}0.945 \\
1.09\end{array}$ & $\begin{array}{l}0.436 \\
0.264\end{array}$ & $\begin{array}{l}3 \\
3\end{array}$ & $\begin{array}{l}46.1 \\
24.2\end{array}$ \\
\hline orn & 0.884 & 0.318 & 3 & 36.0 \\
\hline
\end{tabular}

a Error due to injection error, storage 1osses, variation in derivatization efficlency, peak integration error, and standard preparation error. 
Table 2-7. Analytical variations (95\% confidence intervals) for individual amino acids resulting from the combination of errors assoclated with injection, storage, variation in derivatization efficlency, and peak integration.

\begin{tabular}{lll}
\hline $\begin{array}{l}\text { Amlno } \\
\text { Ac1d }\end{array}$ & \%a & n \\
\hline asp & 5.2 & 36 \\
glu & 6.2 & 36 \\
gln & 5.7 & 32 \\
ser & 5.0 & 31 \\
thr & 5.5 & 23 \\
gly & 8.1 & 30 \\
ala & 8.4 & 20 \\
gaba & 7.4 & 24 \\
arg & 8.7 & 20 \\
pro & 7.0 & 16 \\
val & 10.2 & 26 \\
1le & 10.5 & 18 \\
leu & 4.4 & 18 \\
trp & 14.2 & 13 \\
phe & 7.5 & 14 \\
lys & 9.7 & 13 \\
h1s & 5.1 & 13 \\
orn & 8.8 & 13 \\
\hline
\end{tabular}

a95\% confidence interval expressed as percentage of the response factor. 
Table 2-8. Comparison of derivatization incubation periods of one and four hours at $37^{\circ} \mathrm{C}$.

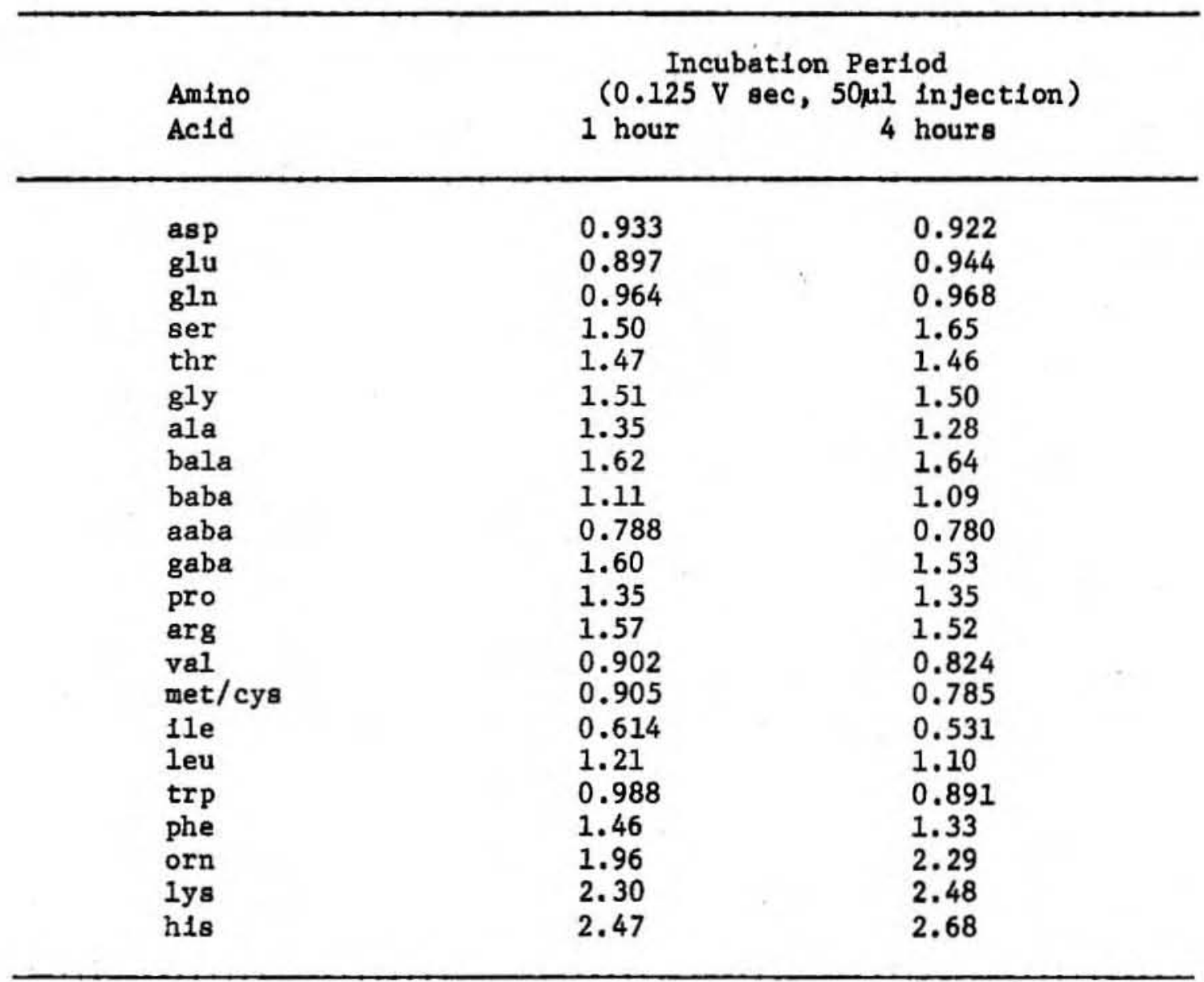


Table 2-9. Correlations between response factors and molar ratio of amino groups/dansyl chloride (range 0.001-0.12)

in the derfvatization mixture.

\begin{tabular}{lll}
\hline $\begin{array}{l}\text { Amino } \\
\text { Ac1d }\end{array}$ & $\begin{array}{c}\text { Correlation } \\
\text { Coefficient }\end{array}$ & $\mathrm{n}$ \\
\hline asp & 0.0493 & 10 \\
glu & -0.580 & $11^{\mathrm{a}}$ \\
gln & -0.546 & $11^{\mathrm{a}}$ \\
ser & -0.726 & $11^{\mathrm{b}}$ \\
thr & -0.856 & $10^{\mathrm{c}}$ \\
gly & 0.175 & 10 \\
ala & -0.162 & 8 \\
arg & -0.696 & $8^{\mathrm{a}}$ \\
pro & -0.328 & 8 \\
va1 & -0.212 & 10 \\
ile & -0.150 & 10 \\
leu & -0.172 & 10 \\
trp & 0.016 & 9 \\
phe & 0.185 & 9 \\
lys & -0.147 & 9 \\
his & -0.463 & 9 \\
orn & -0.360 & 9 \\
\hline
\end{tabular}

${ }^{a}$ Significant at $\mathrm{P}=0.10$ level.

${ }^{b}$ Significant at $P=0.02$ level.

${ }^{\mathrm{c}}$ Significant at $\mathrm{P}=0.01$ level. 
Table 2-10. Dependence of response factor ${ }^{a}$ on time of storage at $-6^{\circ} \mathrm{C}$.

\begin{tabular}{lccccccc}
\hline $\begin{array}{l}\text { Date of derivatization: } \\
\text { Days of storage: }\end{array}$ & 14 Aug 83 & 15 Mar 83 & 14 Feb 83 \\
Amino Ac1d & 0 & 87 & 0 & 81 & 0 & 95 \\
& & & & & & \\
\hline & & & & & & & \\
asp & 3.49 & 3.15 & 4.80 & 6.31 & 4.98 & 5.30 \\
glu & 5.53 & 5.03 & 4.10 & 7.32 & 3.60 & 3.60 \\
gln & 3.55 & 3.71 & 3.23 & 3.72 & 3.59 & 2.65 \\
ser & 4.96 & 5.22 & 8.29 & 6.70 & 6.00 & 6.80 \\
thr & 4.54 & 5.11 & 4.98 & 4.49 & 4.77 & 4.58 \\
gly & 6.26 & 5.42 & 5.62 & 4.92 & 5.70 & 6.30 \\
ala & n.d. & n.d. & 5.60 & 4.9 & 4.94 & 5.40 \\
pro & 3.56 & 3.73 & 6.37 & n.d. & 4.80 & 5.70 \\
arg & 6.87 & 4.80 & 6.15 & 5.40 & 6.00 & 4.80 \\
val & 5.34 & 4.28 & 3.99 & 5.50 & 3.37 & 3.53 \\
1le & 4.52 & 2.95 & 2.50 & 3.10 & 1.94 & 1.80 \\
leu & 5.84 & 5.03 & 4.98 & 6.63 & 3.92 & 3.86 \\
trp & 5.63 & 3.47 & 3.32 & 4.23 & 2.86 & 2.66 \\
phe & 4.91 & 4.84 & 5.89 & 8.50 & 4.43 & 4.98 \\
orn & 9.33 & 6.84 & 7.90 & 9.00 & 5.89 & 6.06 \\
lys & 8.80 & 6.01 & 9.50 & 10.0 & 6.51 & 6.62 \\
his & 9.26 & 8.11 & 9.50 & 8.56 & 8.00 & 8.37 \\
\hline
\end{tabular}

${ }^{a}$ Values represent mean of 2 or more injections. 
Column Packing Procedure

The dansylated amino acids were separated by high pressure 11quid chromatography. All columns were slurry-packed. The dimensions of the column were: Inner diameter $4.1 \mathrm{~mm}$, outer diameter $1 / 4 \mathrm{inch}$, length $25 \mathrm{~cm}$ with an additional $5 \mathrm{~cm}$ guard column (Alltech Associates). The packing procedure involved connecting an SSI slurry reservolr to a well cleaned analytical column containing a $2 \mu \mathrm{m}$ frit at the bottom and plumbed so that waste solvent would drain into a beaker. The column was initially filled with dibromomethane, and an amount of packing material adequate to fill the column with a slight excess was suspended in a 1:1 mixture of methylene chloride and dibromonethane and gently layered onto the dibromomethane. Finally, the slurry was layered with acetonttrile or acetone until the reservoir was filled. At this point an air driven fluid pump (Haskel Engineering and Supply Co.) well primed with the mobile phase solvent was connected to the reservolr. Back pressure was increased to approximately $8000-10,000$ psi and rapidly released onto the reservolr/analytical column system. Once a volume adequate to flush the system several times had passed through, pressure was reduced. The analytical column was disconnected from the reservoir and excess packing materlal was carefully smoothed off the top and a frit and endcap firmly screwed on. The column was rinsed well with the mobile phase carrier (acetonitrile) before analyses were made. Packing materlal used was always 5 micron octyldecasilane (ODS), however, two different brands were used: Spherisorb S5-ODS and Nucleosil $5 \mathrm{C}_{18}$ both available from Al1tech Associates. 


\section{Separation and Collection}

Separation was accomplished using a gradient system driven by a Waters Associates 6000A pump assisted by an M-45 pump. Both were Interfaced with a Waters Assoclates M660 Solvent Programmer. A Waters Assoclates UK6 injector was used w1th a $1 \mathrm{ml}$ sample loop. Detect1on was by ultraviolet absorbtion at $254 \mathrm{~nm}$ on a Waters Associates Model 440 absorbance detector. Integration of curve signals was accomplished by either an Hewlett Packard 3390A integrator or an SP4270 Spectrophysics integrator. A Linsels chart recorder was also used. The gradient conditions for Spherisorb were $12-55 \%$ acetonitrile in $0.03 \mathrm{M}$ phosphate buffer ( $\mathrm{pH}$ 6.25) over a convex gradient (curve 7, Waters M660 Solvent Programmer) of 75 minutes duration. For Nucleos1l packing material, comparable separation could be achleved with a convex gradient (curve 7) of $15-55 \%$ acetonitrile in $0.03 \mathrm{M}$ phosphate buffer ( $\mathrm{pH} 6.25$ ) over 40 minutes. A representative elution scheme is shown in F1g. 2-2.

Fractions for isotope quantitation were collected directly from the detector outflow. Scintillation fluor was added directly to the fractions, and fraction volume generally did not exceed $35 \%$ of fluor volume. Quench corrections were made by the channels ratio method.

\section{EXIRACTION AND RECOVERY}

\section{Free Amino Acid Extraction and Recovery}

Recovery of free amino acids in the aqueous alcohol fraction was determined by two different techniques. In the first procedure, aliquots of an 1sotopically labeled mixture of amino acids were added to a combusted Whatman GF/F glass f1ber f1lter (cut to a diameter of $13 \mathrm{~mm}$ and 
combusted overnight at $500^{\circ} \mathrm{C}$ ). The filters were subsequently extracted and the proportion of label assoclated with each solvent fraction was quantifled by liquid scintillation counting. The results are shown in Table 2-11 and indicate that the free amino acids will be relatively completely extracted into the aqueous alcohol fraction, provided they are released from cell material during grinding.

Recovery of individual free amino acids was also determined by adding an aliquot of a standard mixture (prepared from amino acids purchased from Sigma) to a combusted Whatman GF/F glass fiber filter and extracting. Recoveries for the individual amino acids, shown in Table 2-12, were uniformly high.

\section{Recovery from Hydrolysis}

Conditions for hydrolysis of protein into individual protein amino acid residues ( $6 \mathrm{~N} \mathrm{HCl}, 20$ hours at $110^{\circ} \mathrm{C}$ under $\mathrm{N}_{2}$ ) results in 10 ss of amide nitrogen from aparagine and glutamine, and nearly complete destruction of tryptophan (DeJong et al., 1981). The effects of such treatment on the individual amino acids was investigated by adding allquots of a standard mixture of free amino acids to a combusted Whatman $\mathrm{GF} / \mathrm{F}$ filter (13mm) in a $10 \mathrm{ml}$ ampule and hydrolyzing under conditions as described above. Recoverles of Individual amino acids are given in Table 2-13. In addition to the losses referred to above, my results indicate substantial loss of serine and threonine, and some loss of methionine + cysteine, phenylalanine and isoleucine. Possibly, the presence of low levels of residual oxygen led to oxidative destruction of these amino acids during hydrolysis. 
Figure 2-2. Representative chromatogram showing elution pattern of dansylated amino acids separated by reverse phase high pressure liquid chromatography. Column contained Spherisorb S5-0DS 5 micron octyldecasilane. Mobile phase consisted of a 75 minute exponential gradient of $15-55 \%$ acetonitrile in $0.03 \mathrm{M} \mathrm{NaH}_{2} \mathrm{PO}_{4}$ (pH 6.25$)$. 


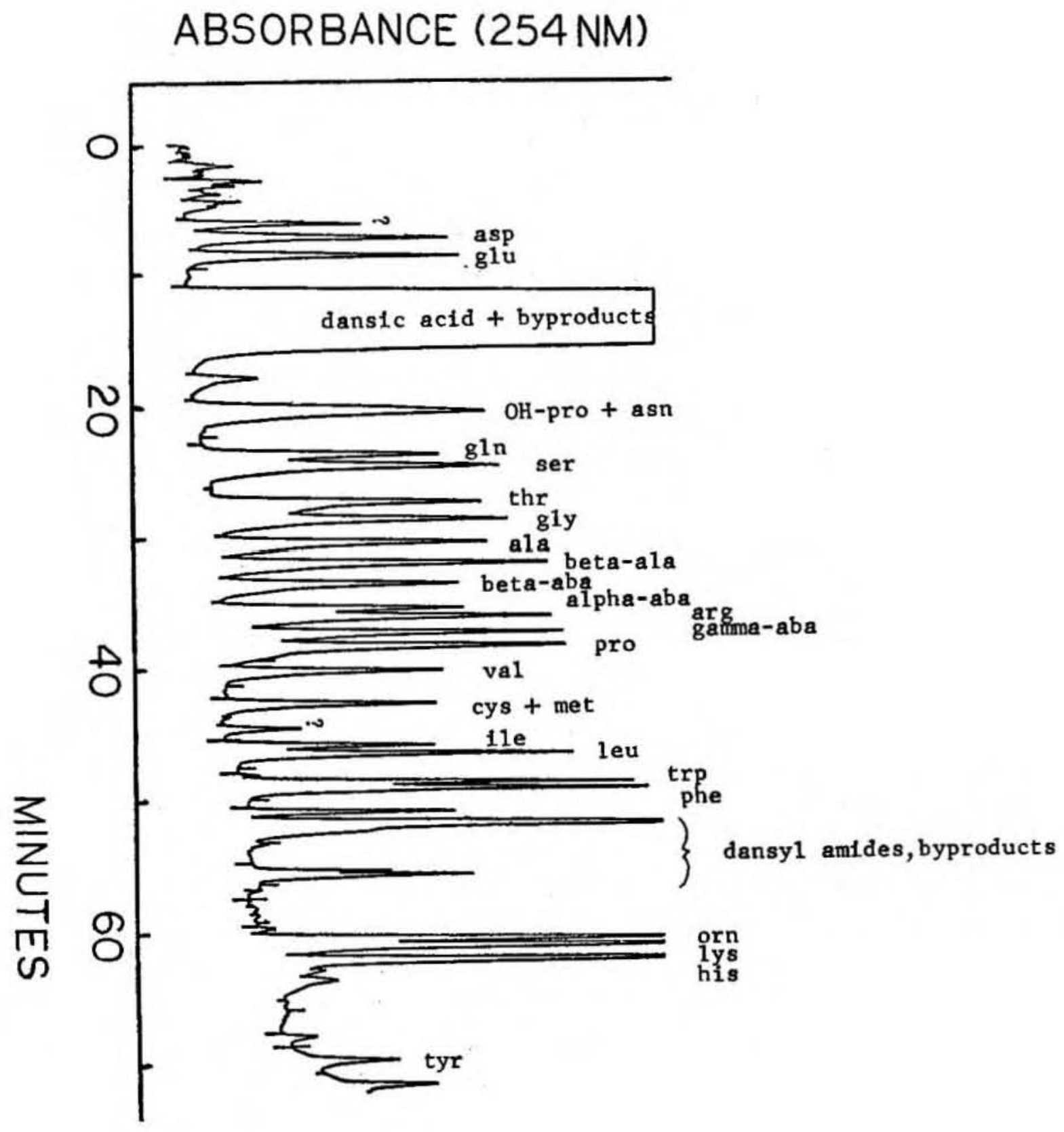


Table 2-11. Proportion of labeled free amino acids recovered in subcellular fractions.

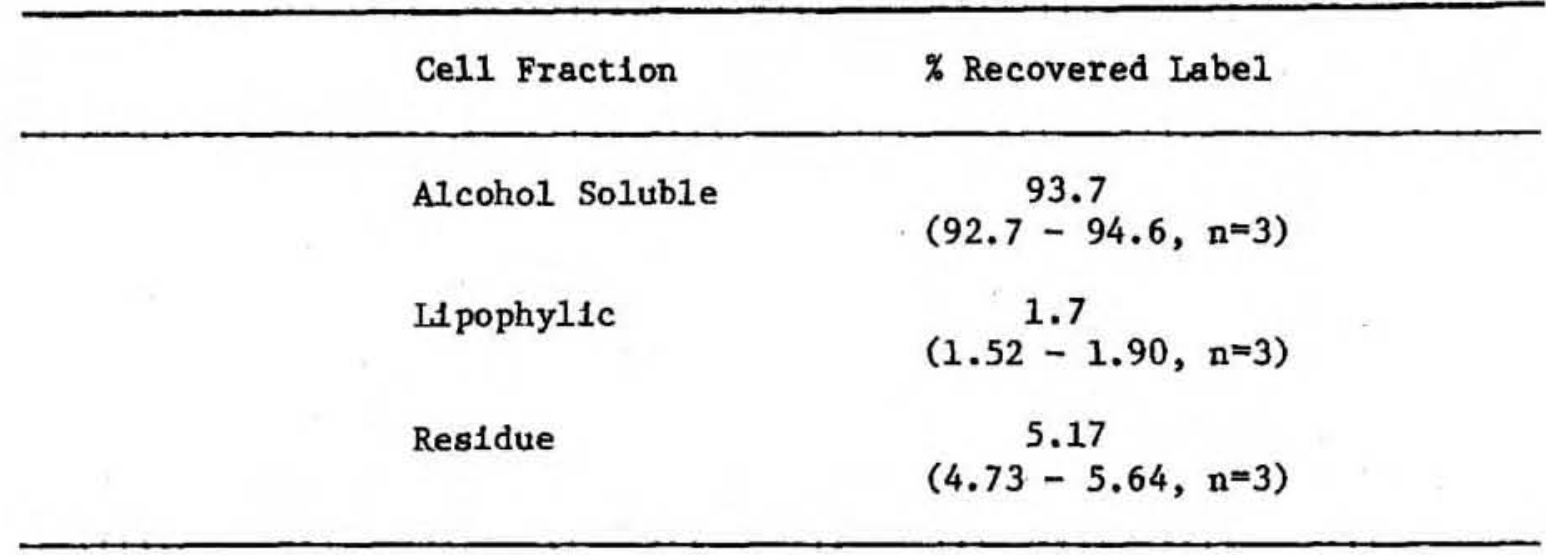


Table 2-12. Free amino acld recovery in the aqueous alcohol fraction.

\begin{tabular}{ll}
\hline Amino Ac1d & \% a \\
\cline { 2 - 2 } asp & n.d. \\
glu & 103.0 \\
gln & 93.9 \\
ser & 110.0 \\
thr & 98.4 \\
gly & 104.0 \\
ala & 108.3 \\
baba & 83.9 \\
aaba & n.d. \\
gaba & 110.1 \\
pro & 110.0 \\
arg & 101.6 \\
val & 103.5 \\
met/cys & $\mathrm{n} . \mathrm{d}$. \\
1le & 118.4 \\
leu & 86.8 \\
trp & 114.1 \\
phe & 107.0 \\
orn & 100.7 \\
1ys & 101.6 \\
h1s & 103.1 \\
& \\
\hline
\end{tabular}

${ }^{a}$ Values represent the mean of three replicates. 
Table 2-13. Recovery of amino ac1ds from hydrolysis.

\begin{tabular}{ll}
\hline Amino acid & \% a \\
\hline asp & 87.6 \\
glu & 158.5 \\
gln & 10.1 \\
ser & 5.0 \\
thr & 25.7 \\
gly & 92.6 \\
ala & 91.8 \\
baba & 81.6 \\
aaba & 88.9 \\
gaba & 89.4 \\
pro & 84.6 \\
arg & 69.2 \\
val & 102.0 \\
met/cys & 58.2 \\
11e & 74.1 \\
leu & 94.6 \\
trp & - \\
phe & 73.2 \\
orn & 103.5 \\
lys & 99.2 \\
his & 95.7 \\
& \\
\hline
\end{tabular}

${ }^{a}$ Values represent the mean of three replicates. 
No attempt was made to correct for these losses. Losses were assumed to be internally consistent among different experiments. In the next section, recoveries of hydrolyzed protein are compared to those of other assay and extraction procedures.

\section{Recovery of Protein}

Recoverles of protein using different assay and extraction procedures are shown in Table 2-14, expressed as a percent of total particulate carbon. For the purposes of this comparison, it was assumed that protein was $53 \%$ carbon by weight based on the average amino acid residue composition (Jukes et al., 197.5; Dolittle, 1981). Differences between recoverles of protein assayed by the Bradford method before and after extraction of free amino acids were slight. Direct chemical analysis of hydrolyzed protein amino acids ylelded a slightly lower recovery, probably due to destruction of some proteln amino acids (see previous section). Recovery of $c^{14}-1 a b e l$ in the hot trichloroacetic acid Insoluble fraction of equilibrium labeled cells gave the highest recovery as might be expected since nonprotein carbon may be included in this material.

Overall, there was good agreement between the different procedures. There was apparently 1ittle loss of protein during extraction of free amino acids and 11pophilic material, and most of the carbon in the hot trichloroacetic acid insoluble: material was in protein. Recovery of hydrolyzed protein was good despite specific losses.

In general, the recoveries of individual protein amino acids did not decline over an approximately 22 month storage period in $80 \%$ methanol at $-6^{\circ} \mathrm{C}$ (Table 2-15). In fact, in some cases recoveries increased, 
Table 2-14. Comparison of different methodologles for measurement of protein in Nannochlor is $\mathrm{sp}$.

\begin{tabular}{|c|c|}
\hline Method & $\begin{array}{l}\% \text { Carbon in } \\
\text { Prote1n }\end{array}$ \\
\hline $\begin{array}{l}\text { Bradford Assay } \\
\text { (B1o-Rad Coomassie Blue): } \\
\text { be:fore extraction }{ }^{a} \\
\text { after extraction }\end{array}$ & $\begin{array}{l}21.4 \\
22.5\end{array}$ \\
\hline $\begin{array}{l}\text { Sum of hydrolyzed } \\
\text { protein amino acids }\end{array}$ & 18.9 \\
\hline $\begin{array}{l}\text { Equilibiclum }{ }^{14} \mathrm{C} \\
\text { residual carbon }\end{array}$ & 24.2 \\
\hline
\end{tabular}

aprotein extracted from whole cells with $0.5 \mathrm{~N} \mathrm{NaOH}$ ( 2 x 10 minutes @ $80^{\circ} \mathrm{C}$ ) and assayed using Coomassle Blue dye binding reagent.

b protein extracted and assayed as above from cell material previously extracted for alcohol soluble and 11pophylic fractions.

${ }^{\text {c}}$ Sum of hydrolyzed protein amlno ac1ds from cell materlal previously extracted for alcohol soluble and 11pohylic fractions; Individual amino aclds were quantified by dansylation.

$\mathrm{d}_{\text {Residual hot }}$ trichloroacetic acid insoluble ${ }^{14} \mathrm{C}$ from equilibrium labeled cell material. 
Table 2-15. Recovery of protein amino aclds after storage in $80 \%$ methanol at $-6^{\circ} \mathrm{C}$.

\begin{tabular}{|c|c|c|c|c|c|c|c|c|c|c|}
\hline \multirow{3}{*}{$\begin{array}{l}\text { Amino } \\
\text { Acid }\end{array}$} & \multirow[t]{3}{*}{ Days of storage } & \multirow{2}{*}{\multicolumn{2}{|c|}{16}} & \multirow[b]{3}{*}{$\mathrm{n}$} & \multirow{2}{*}{\multicolumn{3}{|c|}{$\left(0.5 \stackrel{84}{v}^{\mathrm{sec}}\right)$}} & \multirow{2}{*}{\multicolumn{3}{|c|}{662}} \\
\hline & & & & & & & & & & \\
\hline & & mean & $\mathrm{SE}^{\mathrm{a}}$ & & mean & SE & $\mathrm{n}$ & mean & SE & $\mathbf{n}$ \\
\hline asp & & 0.98 & 0.01 & 2 & 1.32 & 0.08 & 3 & 1.18 & 0.12 & 3 \\
\hline glu & & 2.04 & 0.11 & 2 & 2.51 & 0.17 & 3 & 2.92 & 0.50 & 3 \\
\hline thr & & 0.47 & 0.06 & 2 & 1.22 & 0.06 & 3 & 1.03 & 0.23 & 3 \\
\hline gly & & 5.74 & 0.01 & 2 & 5.79 & 0.38 & 3 & 5.52 & 0.17 & 3 \\
\hline ala & & 3.89 & 0.20 & 2 & 5.15 & 0.51 & 3 & 4.92 & 0.22 & 3 \\
\hline pro & & 2.15 & 0.01 & 2 & 2.35 & 0.06 & 3 & 2.33 & 0.08 & 3 \\
\hline arg & & 2.18 & 0.06 & 2 & 1.78 & 0.09 & 3 & 2.69 & 0.12 & 3 \\
\hline val & & 3.60 & 0.25 & 2 & 3.64 & 0.12 & 3 & 2.91 & 0.05 & 3 \\
\hline \multicolumn{11}{|l|}{$11 e+$} \\
\hline leu & & 6.61 & 0.31 & 2 & 6.85 & 0.12 & 3 & 5.75 & 0.15 & 3 \\
\hline $1 \mathrm{ys}$ & & 4.54 & 0.30 & 2 & 3.53 & 0.30 & 3 & 4.64 & 0.20 & 3 \\
\hline his & & 0.96 & 0.07 & 2 & 0.65 & 0.03 & 3 & 1.04 & 0.02 & 3 \\
\hline
\end{tabular}

astandard error 
probably reflecting an improvement in analytical technique. Independent observations support the view that the protein fraction is relatively stable during storage (see, for example, next section). These observations suggest that specific 1osses which may have occurred would not significantly affect interpretation of the results.

\section{Recovery of Other Subcellular Fractions}

Table 2-16 shows the results of a comparison of ${ }^{14} \mathrm{C}$ associated with different subcellular fractions as a function of time of storage at $-20^{\circ} \mathrm{C}$. These values are compared to label distributions associated with material which had been stored in 11quid $\mathrm{N}_{2}$. For the latter, there was 11ttle variation with time, and so all values were pooled. The only fraction showing a consistent difference is the 11pophylic fraction, which was low for samples stored at $-20^{\circ} \mathrm{C}$ even after only 13 days storage. Ifpld is known to be susceptible to lipase activity, even at this low temperature (Christie, 1973). It was not feasible to store all samples in 1iquid $\mathrm{N}_{2}$. Therefore, in order to minimize the possibility of enzymatic degradation, samples were inftially fixed by placing in $80 \%$ aqueous methanol in $20 \mathrm{ml}$ glass scintillation vials, and subsequently stored at $-6^{\circ} \mathrm{C}$.

\section{SALT POND FRODUCTION INCUBATIONS}

\section{Summer 1982}

During summer of 1982 two experiments were conducted in which the light intensity dependence of ${ }^{14} \mathrm{C}$ incorporation into subcellular fractions was determined in surface samples from Salt Pond. Samples were obtained from a depth of one meter approximately 25 yards from shore and 
Table 2-16. Stability of subcellular fractions with storage at $-20^{\circ} \mathrm{C}$ relative to storage in 11 quid $\mathrm{N}_{2}{ }^{\mathrm{a}}$.

\begin{tabular}{|c|c|c|c|c|c|}
\hline Fraction & & 13 & $\begin{array}{c}\text { ays Stored } \\
-20^{\circ} \mathrm{C}: \\
120\end{array}$ & 164 & Liquid $\mathrm{N}_{2}$ \\
\hline $\begin{array}{l}\text { Alcohol } \\
\text { Soluble }\end{array}$ & 1980 & $(149)^{b}$ & $2120(99)$ & $2220(130)$ & $1927(118, n=7)$ \\
\hline Lipohylic & 3210 & (149) & $3050(248)$ & $3040(20)$ & $3651(109, n=7)$ \\
\hline $\begin{array}{l}\text { Hot Acld } \\
\text { Soluble }\end{array}$ & 1840 & (149) & 1760 (99) & $2130(230)$ & $1720(549, \mathrm{n}=8)$ \\
\hline Residue & 4380 & (149) & $4910(224)$ & $4360(90)$ & $4269(287, n=8)$ \\
\hline
\end{tabular}

a Fractions stored in 11quid $\mathrm{N}_{2}$ were relatively constant and values given here represent overall mean.

berrors in parentheses represent $95 \%$ confidence intervals. 
Incubated on shore in a series of syringe-1ike cylindrical incubation chambers provided by John Waterbury (F4g. 2-3). The chambers were shaded by neutral density fiberglass screening and cooled by circulating Vineyard Sound seawater (approx. temp $19^{\circ} \mathrm{C}$ ). Gentle rolling of a small teflon ball inside the chambers maintained adequate mixing. In order to assess effects of nitrogen enrichment on primary production and algal metabolic characteristics, $\mathrm{NH}_{4} \mathrm{Cl}$ was added to selected chambers to a concentration of $100 \mu \mathrm{M}$. Sampling methods differed slightly from the laboratory procedures outlined previously. Samples (25ml) were taken in a time course and filtered through uncombusted Whatman GF/F filters which had been cut to $13 \mathrm{~mm}$ dlameter and housed in M1111pore sx00-13 syringe filter holders. Filters were rinsed with $5 \mathrm{ml}$ filtered seawater, heat sealed in Nalgene polypropylene filmware bags, and placed on dry ice unt11 return to the laboratory where they were then stored at $-20^{\circ} \mathrm{C}$ until analysis.

\section{Summer 1983}

During summer of 1983, all fleld production measurments were made in s1tu. Incubations conducted from $20 \mathrm{July} 83$ through 10 Aug 83 were conducted using a spring loaded sampler incubation device (F1g. 2-4). A prototype design is described by Taylor et al. (1983). For incubations conducted from 26 Aug 83 through 3 october 83, a dual chamber hydraulfc sampling and subsampling device was used (FIg. 2-5). All aspects of 1sotope addition and subsample collection were executed in s1tu without vertical movement of the incubation chamber. With the exception of some stainless steel components, metal surfaces of the device were coated with teflon so as to minimize metal contamination. The devices were suspended 
at the one meter depth from a wooden $2 \times 4$ beam mounted on an aluminum rowboat. Mixing during the incubation was accomplished by the natural wave action on the boat, and by periodic manual agitation of the chamber. Time course sampling was accomplished by means of teflon tubing which extended to the surface. Samples were drawn into shaded Luer-1ok plastic syringes and contents were subsequently filtered. The filtration apparatus was shaded from direct sunlight. A vacuum was generated by a Nalgene Mytivac vacuum pump equipped with a pressure gauge. Pressures did not exceed $150 \mathrm{~mm} \mathrm{Hg}$. Sample fixation and storage was as described for the laboratory experiments. Water samples for chlorophyll a particulate elemental carbon and nitrogen, nutrients, and dissolved Inorganic carbon were collected into polypropylene bottles using a peristaltic pump with a silicon tube incremented in $0.5 \mathrm{~m}$ intervals. These were returned to the laboratory and stored at $5^{\circ} \mathrm{C}$ until they were processed (within two hours of collection).

\section{LIGHT INTENSITY}

Surface incldent light intensity during fleld incubations was continuously monitored with a Blospherics $4 \mathrm{pl}$ quantum sensor interfaced with a calibrated chart recorder. Depth profiles of 11ght intensity were determined using a submersible $\mathrm{L1}$-Cor $2 \mathrm{p} 1$ quantum sensor. Intensity was measured at $0.5 \mathrm{~m}$ intervals and extinction was estimated by taking the mean over the mixed layer of $\ln \left(P_{z} / P_{0}\right)$ where $P_{0}$ is surface quantum flux and $P_{z}$, the quantum flux at depth $z$. 
Figure 2-3. Schematic of Incubation system used in Salt Pond 1982 experiments. A. Dlagram of polycarbonate incubation chamber. Abbreviations: SV, sampling valve; FP, f1ll port; TB, teflon ball (for mixing); P, piston. Piston was pushed inward during sampling operation using a screw-crank device. B. Diagram of chambers in plexiglas incubation case. Chambers were attenuated to different light intensity using fiberglas screening. Arrows indicate direction of flow of surface temperature seawater. Abbreviations: L, latch. 


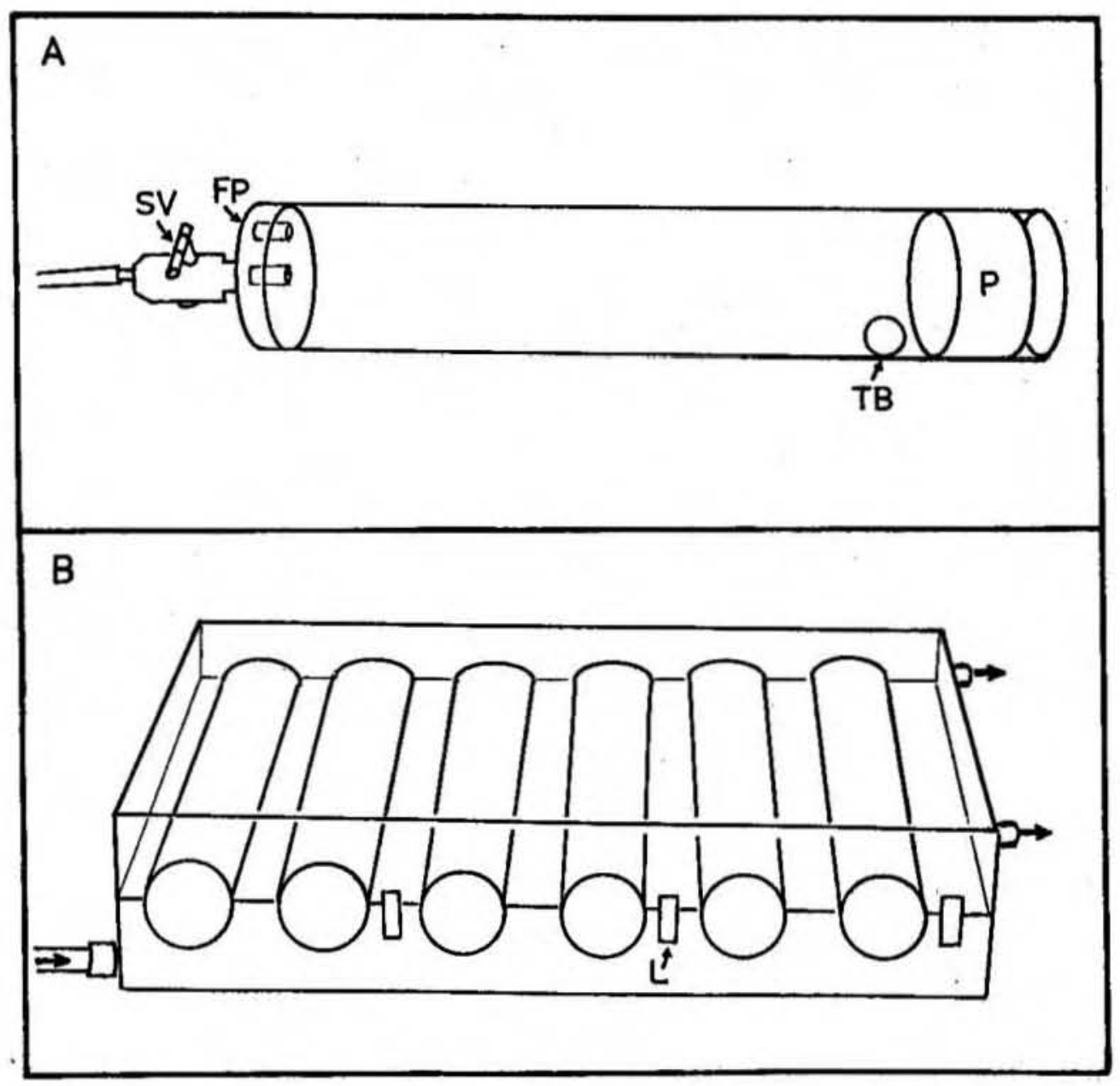


F1gure 2-4. Schematic of single chamber SID (sampler incubation device). Lower sequence shows principle of operation. Abbreviations: P, piston; PS, pressure spring; CV, check valve; 1p, isotope injection port; Sp, spring; cl, spring retainer cl1p; $R$, 1sotope reservolr. 

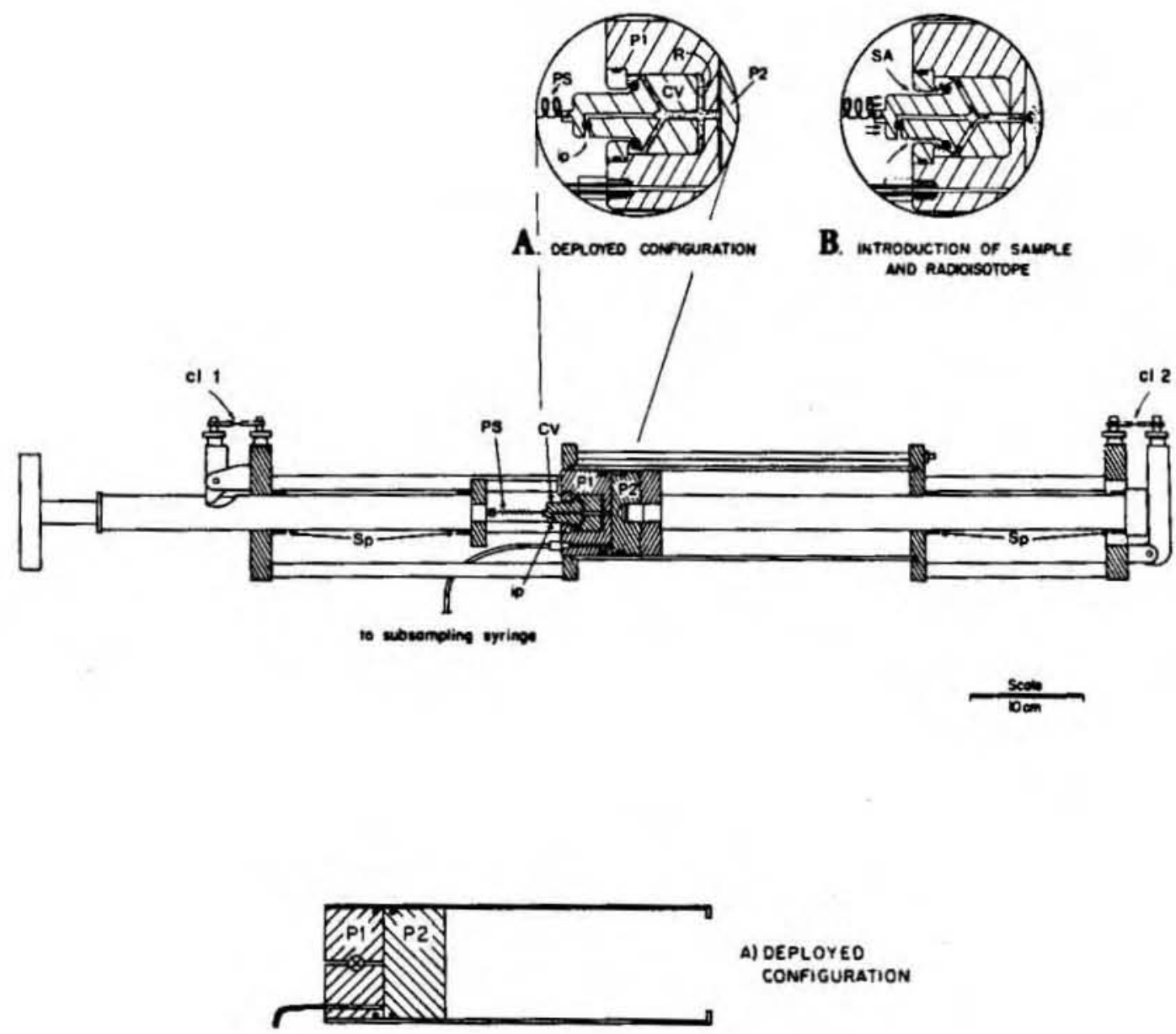

A) DEPLOYEO

CONFIGURATION

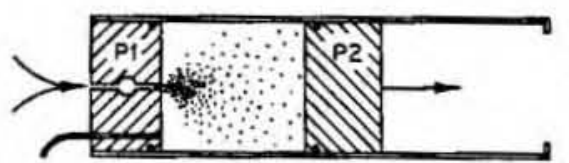

B) INTROOUCTION OF SAMPLE ANO RADIOISOTOPE

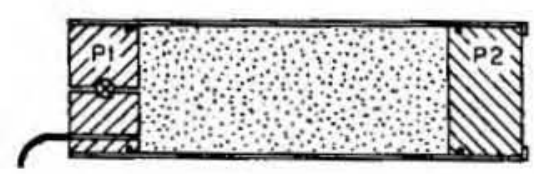

C) CONFIGURATION OURING INCUBATION

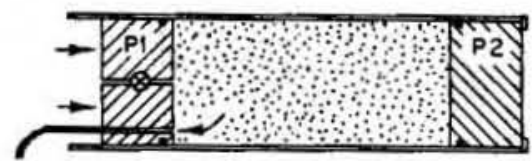

D) FIRST

SUBSAMPLE TAKEN

SUBSAMPLE

TO SYRINGE

(2) CLOSED

O OPEN 
F1gure 2-5. Schematic of dual chamber hydraulically operated SID. Principle of operation is similar to design shown in Fig. 2-4, except that endcap (EC) with check valve (CV) remains stationary throughout sampling and 1ncubation, while piston (P) is moved hydraulically for both Inftial sample Introduction, and subsequent subsampling operation. 0ther symbols: T, teflon sampling tube; SP, spring; IC, incubation chamber; PU, pump (only front pump shown). Pumps were controlled from surface (w1res not shown). 
<smiles>C1=CC2CC[C+]2=C1</smiles> 
-92- 
CHAPTER 3. RELATIONSHIPS BETWEEN FREE AMINO ACID AND PROTEIN COMPOSITION AND INCORPORATION OF INORGANIC ${ }^{14} \mathrm{C}$ IN $\mathrm{NH}_{4}^{+}$-LIMITED STEADY STATE CULTURES OF MARINE PHYTOPLANKTON 


\section{INTRODUCTION}

Relationsh1ps Between Cellular Chem1cal Composition and Nitrogen Limited Growth Rate

The potential importance of nitrogen in limfting phytoplankton growth has long been recognized (e.g. Chu, 1943, in Conover, 1975). The supply of nitrogen is also known to substantially affect plant metabolism and cellular chemical composition. Changes in metabolism assoclated with nitrogen 1imitation affect the relative abundances of carbon associated with free and protein amino acids (Rhee, 1978, 1980; Demanche et al., 1979; Demanche, 1980; Dortch, 1982; Maske, 1982; Wheeler, 1983). Growth rate-dependent changes in the levels of free amino acids reflect changes In rate limfting steps of nitrogen assimilation and incorporation into macromolecules (Wheeler, 1983). Such growth rate-related changes in mechanisms of processing intracellular nitrogen may be responsible for the transient rapid $\mathrm{NH}_{4}^{+}$uptake capabilities of laboratory and natural phytoplankton populations (McCarthy and Goldman, 1979; Glibert and Goldman, 1981; Goldman and Glibert, 1982; Wheeler, 1983).

The first step in assimilation of inorganic nitrogen is the glutamine synthetase/glutamine oxoglutarate glutamate aminotransferase or GS/GOGAT enzyme couple (e.g. Miflin and Lea, 1977; Miflin et al., 1980; Syrett, 1981). A varlety of studies have documented differential increases in intracellular free glutamine and other selected amino acids upon $\mathrm{NH}_{4}^{+}$ enrichment of nitrogen deficient algal cultures (Syrett, 1953; Hattori, 1958 1n Syrett, 1981; R1esner et a1., 1960; Turpin and Harrison, 1978). These responses are analogous to observed patterns of assimilation of Inorganic ${ }^{14} \mathrm{C}$ into intracellular free amino acids in response to $\mathrm{NH}_{4}^{+}$enrichment in algae (e.g. Holm-Hansen et al., 1959; Kanazawa et 
al., 1970, 1972) and hlgher plants (Platt et al. 1977; Paul et al., 1978; Larsen et al., 1981). With the exception of the study by Turpin and Harrison (1978), the pre-enrichment physiological states and growth rates were not precisely defined in the investigations c1ted above. This precludes an evaluation of the relationship between growth rate and the steady state levels of individual free amino acids. In view of the observed responses to enrichment, it is 11kely that growth rate dependent changes in total free amino acid pool size are accompanied by changes in the relative abundances of indjividual free amino actds. Th1s would reflect changes in rate 1imiting steps intermediate between uptake of Inorganic nitrogen, and nitrogen assimilation into macromolecules. Descriptions of such compositional changes may serve as an Index of the n1trogen status of phytoplankton populations.

Goldman (1980) noted that C:N rat1os were uniformly related to relative growth rate for many different algae. However, the presence of other microbes and non-living organic matter leads to an ambiguous relationship between algal prinary production and particulate organic matter composition (e.g. Beers et al., 1975; Banse, 1974, 1977; Wangersky, 1977). The abllity to probe compositional changes in free amino acids and protein using inorganic ${ }^{14} \mathrm{C}$ as a tracer may permit selective characterization of the nitrogen status of natural algal populations, and perhaps, a relative Index of growth rates. Such an approach would be free of problems relating to interference by nonalgal blomass, thereby providing an imblased assay of the metabolism and composition of the active autotrophic population. A prerequisite to relating ${ }^{14} \mathrm{C}$ distributions to relative abundances of carbon in free and 
protein amino aclds will be to characterlze the effects of nitrogen 1imitation on the kinetics of 1sotope incorporation.

Relationships of the D1istribution of Assimilated Inorganic 14C to Cellular Chemical Compoisition

Radiolsotopic carbon can be used to trace varlous levels of algal metabolism. On the basis of kinetic analyses of ${ }^{14} \mathrm{C}$ distributions among specific biological molecules in chlorella, Calvin and co-workers postulated a mechanism ffor the photosynthetic carbon reduction cycle (e.g. Bassham et al., 1954). The rapid saturation characteristics of the photosynthetic carbon reduction cycle intermediates made it possible to equate steady state label distributions to the carbon pool sizes of functioning intermediate reservoirs (Calvin and Massini, 1952). In this manner, 1t was possible to determine their responses to changes in growth conditions. It was later recognized that some molecules from the photosynthetic carbon reduction cycle were used directly in the blosynthesis of Intraceliular free and protein amino aclds (Smith et al., 1961; Bassham and Kirk, 1964; Bassham et a1., 1964). Studies w1th isolated chloroplasts helve since demonstrated the abllity of chloroplasts to synthesize a variety of amino acids (e.g. Kirk and Leech, 1972; Leech and Murphy, 1976; M111s et al., 1980; Schulze-Se1bert et al., 1984). Desplte the close relationship, saturation of intracellular free amino ac1ds with inorganic ${ }^{14} \mathrm{C}$ was generally observed to be slower than that of the photosynthetic carbon reduction cycle intermediates, and may be incomplete even after a few hours of incubation with inorganic ${ }^{14} \mathrm{C}$ (Smith et al., 1961; Bassham and K1rk, 1964; Bassham et al., 1964; Hellebust and B1dwell, 1964; Larsen et al., 1981). Furthermore, 
different amino acids have different isotope incorporation kinetics due to differences in the degree to which their blosynthesis is coupled to the metabolic flux of photosynthetic carbon. As a result of the relatively slow saturation characteristics, the specific activity of the free amino acids may be significantly less than that of the dissolved Inorganic carbon pool during the initial period of an incubation. The relationsh1p between the amount: of label assoclated with the free amino acids and their carbon pool sizes will be time dependent. It is 1ikely that growth rate and physlological state will affect the saturation rates of free amino ac1ds. Because growth rates were not precisely defined in previous investigations, it has not been possible to evaluate the effect of growth rate variations on free amino acid saturation rates. Incorporation of ${ }^{14} \mathrm{C}$ into protein amino acids does not necessarily reflect the incorporation characteristics of the free amino acids. Bassham et al. (1964) found that ${ }^{14} \mathrm{C}$ incorporation into some protein amino acids of Chlorella rapidly became linear, despite the fact that corresponding free amino acid pools had not yet fully equilibrated. The 1nterpretation was that protein amino ac1d precursor pools were metabollcally segregated, and turning over faster than the total intracellular free amino acid pools. The concept of metabolic segregation has been supported by the work of other researchers (Hellebust and B1dwell, 1964; Oaks and B1dwe11, 1970; Wheeler and Stephens, 1977). One explanation for the observed segregation is that the actively turning over pools represented the chloroplast pools, the synthesis of which were closely coupled to the photosynthet1c carbon 
reduction cycle. However, metabolic segregation may not necessarily require physical separation of pools by membranes (Miflin and Lea, 1977). If rapidly saturating pools exist, and serve as the exclusive source of precursors for cellular protein synthesis, then carbon incorporation into protein amino acids should rapidly reflect net blosynthetic rates provided there is little or no turnover of protein in excess of net synthesis. Furthermore, the proportion of total ${ }^{14} \mathrm{C}$ uptake associated with protein would correspond to the proportion of cellular carbon in protein.

Effects of Nitrogen Limitation on Patterns of Inorganic 14C Incorporation Into Cellular Materlal

A number of investigators have described effects of nitrogen IImitation or deficiency on inorganic carbon incorporation into algal cell material (Fogg, 1956; Morris et al., 1974; Konopka and Schnur, 1981). In these studies, the labeled cell materlal was fractionated using sequential solvent extraction techniques. In general, increased nitrogen limitation led to increased proportions of incorporated ${ }^{14} \mathrm{C}$ in storage materials such as carbohydrate or 11pid, and decreased proportions associated with protein. This is consistent with independent observations of biochemical varlations associated with nitrogen starvation (e.g. Syrett, 1953; Thomas and Krauss, 1955; Fogg, 1959; Handa, 1969; Myklestad and Haug, 1972; Conover, 1975; Edge and Ricketts, 1977; Myklestad, 1977; Hitchcock, 1981; Shifrin and Chisholm, 1981) and nitrogen limitation (e.g. Thomas and Dodson, 1972; Caperon and Meyer, 1972; Rhee, 1973, 1978, 1980; Harrison et al., 1976; Laws and Wong, 1978; Goldman and Peavey, 1979; Goldman, 1980; Laws and Bannister, 1980; 
Konopka and Schnur, 1981; Dortch, 1982; Maaske, 1982; Wheeler et al., 1983). An exception was the observations of Morris et al. (1974) that ${ }^{14} \mathrm{C}$ incorporation into hot trichloroacetic acid insoluble material (protein) was enhanced in nitrogen 11mited continuous cultures of Phaeodactylum tricornutum.

Fractions of cellular material derived by solvent extraction techniques are operationally characterized. The lack of precise chemical definitions of the subcellular fractions makes their relationship to cellular metabolism somewhat ambiguous. Comparisons of different fractionation procedures by Hitchcock (1981) demonstrated the potentlal for variations assoclated with the different methodologies. Changes in species composition can also Influence the chemical contents of subcellular fractions even when obtained by 1dentical procedures. H1tchcock (1981) also noted a lack of correlation between the distribution of ${ }^{14} \mathrm{C}$ among subcellular fractions after a 6 hour incubation and the amount of carbon estimated by chemical assays of constituents. Although Konopka and Schnur (1981) did conduct blochemical analyses, the data presented were not adequate to make direct comparisons to inorganic ${ }^{14} \mathrm{C}$ incorporation patterns and the influence of nitrogen status on this relationship. It is obvious that solvent extractions which are not further chemically characterized can at best be classified as operational definitions of a "type" of cell material. I have avolded this problem by isolating, quantifying, and radioassaying individual free and protein amino ac1ds, so that my results can be interpreted on clearly defined chemical and physiological bases. 
Another problem with current fractionation methods is the lack of proper consideration of potential contalnment artifacts and effects of Incubation period on 1sotope distribution. Olive and Morrison (1967) and Olive et al. (1969) employed endpoint incubations from sunrise to sunset, while Hitchcock (1978) Incubated his samples for 24 hours. Morris and Skea (1978), Smith and Morris (1980a,b), Morris et al. (1981), and Priscu and Goldman (1983) sampled in a time course over a 11ght/dark cycle. Because of the problems assoclated with extended containment (Vollenwelder and Nauwerck, 1961; Venrick et al., 1977; Goldman et al., 1981a; Peterson, 1980; Ferguson et al., 1984), the degree to which the behaviour of samples from long term incubations reflects the activity of the natural populations is questionable. This has led to use of shorter Incubation periods.

Barlow (1982), Barlow and Henry (1982), Konopka (1982), and Priscu and Goldman (1983) used endpoint incubations of approximately 4 hours. If and Platt (1982) conducted endpoint incubations of 2 hour duration. Li et al. (1980) compared distribution of ${ }^{14} \mathrm{C}$ among subcellular fractions from 2 and 4 hour Incubations of samples of natural populations of 0scillatoria. They found significant time dependent changes which were influenced by photosynthetic rate.

Although short incubation periods minimize containment artifacts, they are more subject to the effects of 1sotopic disequilibrium. Hitchcock (1981) characterized the time dependence of 1sotopic distribution into different cell fractions of dinoflagellate cultures. H1s results demonstrated an Inftial accumulation of label in the low molecular weight pool, which subsequently diminishes as label is distributed into other cell fractions. He noted that up to four hours 
were required to reach plateaus in distributions. Cuhel and Waterbury (1984) compared equilibrium distributions of isotopes with short term distributions in the cyanobacterfum Synechococcus sp. and found that even after 6 hours, the short term distribution of 1sotopic carbon in the hot TCA insoluble material (protein) underestimated the equilibrium distribution by about $10 \%$.

These studies illustrated the Importance of understanding the dynamics of ${ }^{14} \mathrm{C}$ incorporation in order to relate it to cellular chemical composition. A major objective of this investigation was to characterize the effects of nitrogen limitation the steady state composition of free amino acids and protein, and their kinetics of inorganic ${ }^{14} \mathrm{C}$ incorporation.

As pointed out by Goldman and Glibert (1983), a direct relationship between growth and nitrogen uptake only occurs when a population is in steady state balanced growth. Although steady state continuous cultures are not representative of the natural populations (Jannasch, 1974), they do provide a means for studying characteristics of populations of well defined physiological state where growth rate, dilution rate, and specific nutrient uptake rates $(\mathrm{Vm})$ are equal. Initially, results from $\mathrm{NH}_{4}^{+}-1$ imited steady state populations w111 be considered, where growth rate and nitrogen uptake are coupled and precisely defined. Subsequently, I will describe the metabolic dynamics assoclated with enrichment of $\mathrm{NH}_{4}^{+}-1$ imited cultures with saturating levels of $\mathrm{NH}_{4}^{+}$. 
Specifically, this study addressed the following questions:

1) What is the effect of growth rate on steady state levels of intracellular free amino acids?

2) What is the effect of growth rate on the time course of saturation of free amino acids with inorganic ${ }^{14} \mathrm{C}$ ?

3) What is the relationship between nitrogen turnover of nitrogen transport mediators, and saturation rates with ${ }^{14} \mathrm{C}$ ?

4) What is the relationship between the specific activities of free amino acids and newly assimilated protein? Does segregation of precursor pools result in rapid saturation such that the incorporation of ${ }^{14} \mathrm{C}$ Into proteln reflects actual protein carbon production?

5) To what extent does the distribution of ${ }^{14} \mathrm{C}$ among free amino acids reflect their proportion of total cellular carbon?

5) How is the relationship of ${ }^{14} \mathrm{C}$ distribution among other cellular materlal influenced by growth rate?

Important considerations in the $\mathrm{NH}_{4}^{+}$enrichment studies were:

1) What are the transient responses of both composition and 1sotope distribution to $\mathrm{NH}_{4}^{+}$enrichment of an $\mathrm{NH}_{4}^{+}$11mited steady state culture?

2) To what extent can metabolic responses of $\mathrm{NH}_{4}^{+}$enrichment be generalized among species?

Most of the results involve studies conducted with the marine chlorophyte, Nannochloris sp. (clone GSB Nanno). This spec1es was chosen because it commonly occurs in near shore environments, and is easily cultured. It is a small organism (approximately 2 micron diameter), and 
contains only one chloroplast. Its relative simplic1ty makes it an ideal model organism for these studies. Subsequently, results of preliminary Investigations on several other species will be discussed.

The potential impact of nitrogen supply on algal growth and cellular chemical composition has important implications for the abundance and composition of primary organic matter, and 1ts incorporation into the marine food web. This study provides information about relationships between carbon assimilation pat:terns and changes in cellular chemical composition assoclated with nitrogen 11mitation. The information will provide a foundation for using inorganic ${ }^{14} \mathrm{C}$ to probe chemical composition and quantify blosynthetic rates in natural autotrophic populations. Such an investigative approach will be useful in characterizing the metabolism of primary producers, and defining their role in the flux and compositional dynamics of particulate organic matter.

I. DYNAMICS OF FREE AMINO ACID AND PROTEIN COMPOSITION AND INCORPORATION OF INORGANIC ${ }^{14} \mathrm{C}$ IN $\mathrm{NH}_{4}^{+}$-LIMITED STEADY STATE CULTURES OF THE MARINE CHLOROPHYTE, NANNOCHLORIS SP.

METHODS

All methods used in this section were described in Chapter 2.

\section{RESULTS AND DISCUSSION}

Cellular Chemical Composition as a Function of Relative Growth Rate

The relationship between relative growth rate $\left(\mu / \mu_{\max }\right)$ of $\mathrm{NH}_{4}^{+}$-11mited cultures of Nannochlor1s sp. and distributions of 
cellular carbon and nitrogen among intracellular free amino acids (IFAA) and protein are shown in Tables 3-1 and 3-2 respectively. Relative growth rate is defined as the dilution rate of the chemostat ( $u$, absolute growth rate) normalized to the maximum growth rate $\left(\mu_{\max }=\right.$ batch culture growth rate under the same conditions of 1 ight and temperature (e.g. Goldman, 1980). Percentages of cellular carbon associated with the intracellular free amino acids (IFAA) decreased with relative growth rate as shown in Table 3-1. S1milarly, the percentage of cellular carbon assoclated with protein decreased (Table $3-2$ ). There was a decline in the percentage of cellular nitrogen associated with the free amino acids, but no significant change in the percentage of cellular nitrogen associated with proteln as a function of relative growth rate (Table 3-2) as has been prev1ously reported (Maske, 1982). Maske (1982) observed a decrease of from $8.0-2.5 \%$ of the cellular nitrogen associated with free amino acids in continuous cultures of the diatom, Skeletonema costatum, with increasing $\mathrm{NH}_{4}^{+}$limitation. This was within the range reported in this study (Table 3-1). Maske (1982) also reported a decrease in the proportion of cellular nitrogen assoclated with protein from $82-52 \%$ as growth rate increased, which was slightly higher than the range observed for Nannochloris sp. (Table 3-2). Rhee (1978) found $44 \%$ of the cellular nitrogen was associated with protein in nitrate 1imited continuous cultures of Scenedesmus sp., similar to the value I observed for Nannochloris $8 \mathrm{p}$.

Significant changes in the IFAA pool composition accompanied the growth rate-related decline in pool size (Table 3-3, Figure 3-1). Individual amino acids were identified by comparison of retention times with authentic standards. In general, the separation was adequate 80 as 
Table 3-1. Proportions of Total Cellular Carbon and N1trogen in Free Amino Acids of Nannochloris sp. as a Function of Relative Growth Rate

\begin{tabular}{lll}
\hline $\begin{array}{l}\text { Relative } \\
\text { Growth Rate }\end{array}$ & \% Carbon & \% Nitrogen \\
\hline $1.00(0.037)^{\mathrm{b}}$ & $6.8(1.7)$ & $12.0(3.2)$ \\
$.965(0.098)$ & $5.0(1.5)$ & $8.5(3.3)$ \\
$.933(0.031)$ & $4.5(0.90)$ & $7.0(1.7)$ \\
$.458(0.014)$ & $2.7(0.60)$ & $5.8(1.5)$ \\
$.229(0.016)$ & $0.31(0.07)$ & $1.4(0.34)$ \\
\hline
\end{tabular}

$\mathrm{a}_{\mu / \mu_{\max }}$ where $\mu_{\max }=1.44(0.04) \mathrm{day}^{-1}$.

balues in parentheses represent $95 \%$ confidence intervals. 
Table 3-2. Proportions of Total Cellular Carbon and Nitrogen in Protein of Nannochloris sp. as a Function of Relative Growth Rate

\begin{tabular}{lll}
\hline $\begin{array}{l}\text { Relative } \\
\text { Growth Rate }\end{array}$ & \% Carbon & \% N1trogen \\
\hline $1.00(0.037)^{\mathrm{b}}$ & $22.5(3.7)$ & $59.0(12.5)$ \\
$0.965(0.098)$ & $21.9(3.9)$ & $42.8(9.5)$ \\
$0.933(0.031)$ & $18.9(4.9)$ & $31.2(21.0)$ \\
$0.458(0.014)$ & $16.8(3.0)$ & $36.8(8.4)$ \\
$0.229(0.016)$ & $8.8(2.0)$ & $42.0(7.3)$ \\
\hline
\end{tabular}

$a_{\mu} / \mu_{\max }$ where $\mu_{\max }=1.44(0.04) \mathrm{day}^{-1}$.

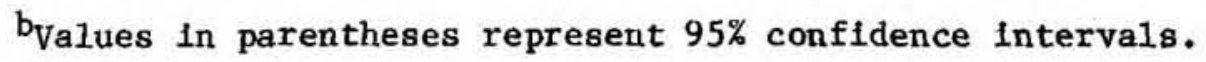


Table 3-3. Proportions of the Intracellular Free Anino Acid Carbon Pool Assoclated with Individual Amlno Acids as a Punction of Relative Growth Rate of Nannochloris sp.

\begin{tabular}{|c|c|c|c|c|c|c|}
\hline \multirow{2}{*}{\multicolumn{2}{|c|}{$\begin{array}{l}\text { Relative }^{\mathrm{a}} \\
\text { Growth Rate: }\end{array}$}} & \multicolumn{5}{|c|}{ X Intracellular Free Amino Ac1d Pool Carbon } \\
\hline & & $1.00^{\mathrm{b}}$ & 0.965 & 0.933 & $0.458^{b}$ & 0.229 \\
\hline \multirow[t]{16}{*}{$\begin{array}{l}\text { AaIno } \\
\text { Acld: }\end{array}$} & ASP & $1.7(0.93)^{c}$ & $1.2(0.64)$ & $1.05(0.25)$ & $2.1(1.8)$ & $1.3(1.6)$ \\
\hline & GLU & $9.2(2.6)$ & $9.1(3.8)$ & $9.2(2.3)$ & $18.7(4.9)$ & $53.4(14.9)$ \\
\hline & GLN & $4.4(1.6)$ & $7.8(3.1)$ & $11.5(3.6)$ & $1.5(0.61)$ & $3.7(1.6)$ \\
\hline & SER & $3.3(1.9)$ & $0.52(0.19)$ & $0.38(0.38)$ & $2.3(1.1)$ & $0.92(0.69)$ \\
\hline & THR & $0.49(0.29)$ & $0.14(0.14)$ & $0.21(0.04)$ & $1.1(1.0)$ & $0.71(0.31)$ \\
\hline & GLY & $0.74(0.20)$ & $0.24(0.12)$ & $0.22(0.08)$ & $0.72(0.44)$ & $0.50(0.22)$ \\
\hline & AIA & $3.0(1.4)$ & $0.43(0.29)$ & $1.06(0.82)$ & $13.7(7.2)$ & $8.3(3.1)$ \\
\hline & PRO & $56.7(22.1)$ & $70.5(30.0)$ & $75.6(16.5)$ & $38.5(14.4)$ & $21.4(8.6)$ \\
\hline & VAL & $1.6(0.42)$ & $0.58(0.84)$ & n.d. & $2.8(1.6)$ & $3.7(1.3)$ \\
\hline & ARG & $7.8(3.6)$ & $6.0(11.0)$ & n.d. & $7.8(3.4)$ & n.d. \\
\hline & BABA & n.d. & $0.72(0.58)$ & $0.77(0.20)$ & $2.0(1.4)$ & $6.0(1.7)$ \\
\hline & IRP & n.d & n.d. & n.d. & $6.6(3.9)$ & n.d. \\
\hline & PHB & n.d. & $0.13(0.06)$ & n.d. & n.d. & n.d. \\
\hline & LYS & n.d. & $0.63(0.34)$ & n.d. & $1.4(0.85)$ & n.d. \\
\hline & HIS & n.d. & $1.4(1.2)$ & n.d. & $0.82(0.26)$ & n.d. \\
\hline & ORN & $2.2(1.8)$ & $0.71(0.32)$ & n.d. & n.d. & n.d. \\
\hline
\end{tabular}


Figure 3-1. Proportions of intracellular free amino acid carbon associated with individual amino acids of $\mathrm{NH}_{4}^{+}-11 \mathrm{mited}$ steady state cultures of $\left.\underline{N a n n o c h l o r i s}_{\text {sp. at high }\left(\mu / \mu_{\max }\right.}=0.933\right)$ and 1 ow $\left(\mu / \mu_{\max }\right.$ $=0.229$ ) relative growth rates. 


\section{HIGH RELATIVE LOW RELATIVE GROWTH RATE | GROWTH RATE}

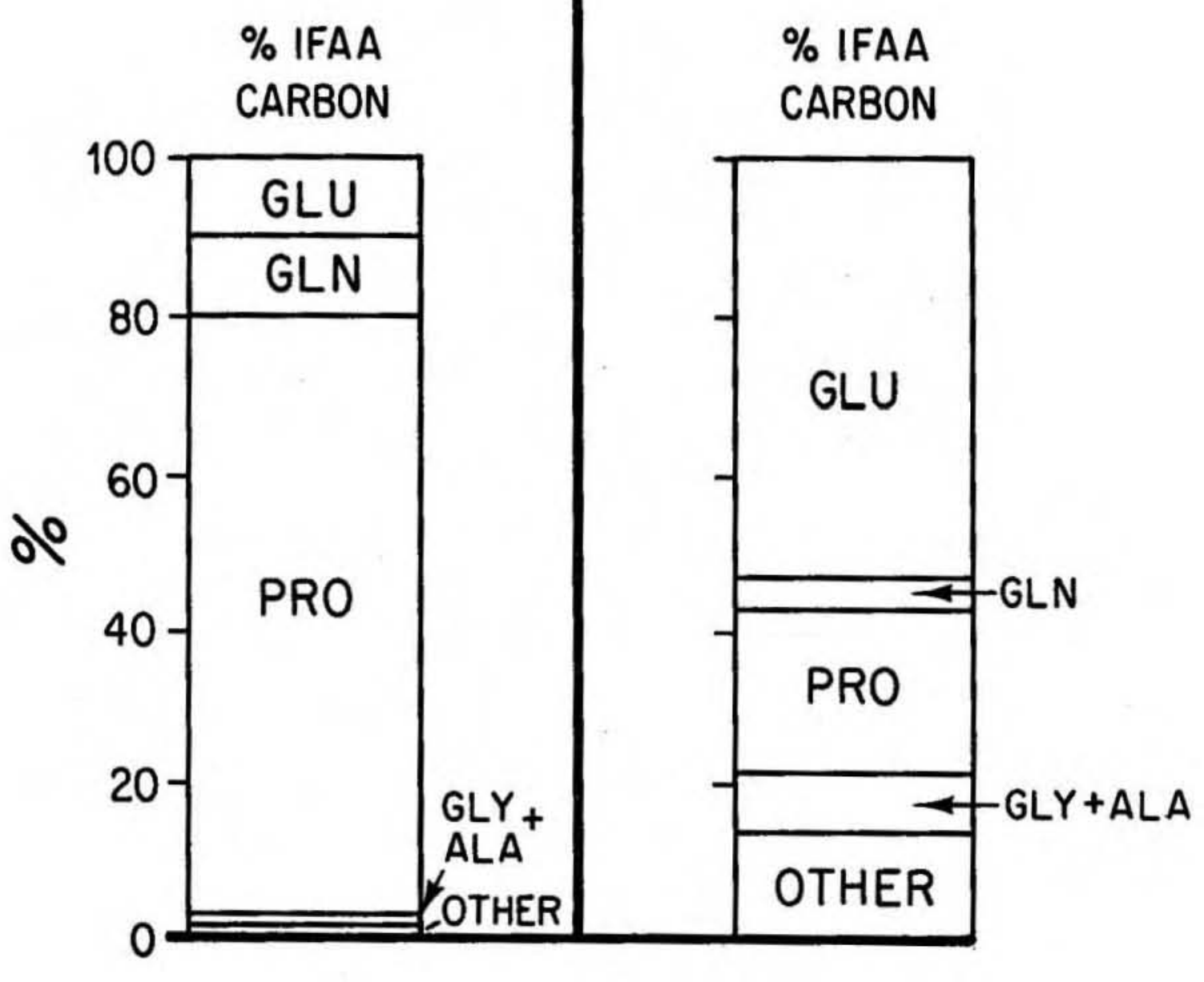


to make identification unambiguous. I was not able to resolve beta-glutamic and glutamic acid, however. Furthermore, proline, gamma-aminobutyric acid, and arginine all eluted closely, making distinctions difficult. In the remainder of the thesis, I designate derivatizable compounds of interest according to the elution characteristics of standards. However, these identifications have not been verified by an alternate separation procedure, or more rigorous procedures such as mass spectrometry.

It has been suggested that the relative proportions of cellular nitrogen associated with free amino acids may be a means of indexing n1trogen status of the phytoplankton population (e.g. Rhee, 1978; Dortch, 1982). My results suggest even more information may be revealed by characterizing the composition of individual intracellular free amino acids. Knowledge about variations in individual free amino acids as a function of nitrogen supply may also help in understanding the relative importance of rate limiting steps in the metabolic flux of nitrogen.

Glutamate and alanine increased in proportion to IFAA pool carbon as relative growth rate decreased (Table $3-3$ ). The proportion associated with proline decreased, and there was some indication of a decrease in glutamine, although proportions were varlable. The decrease in the proportion of proline carbon in IFAA carbon as growth rate decreased suggests 1ts production/utilization ratio decreased more than that of other IFAA's. The accumulation of proline as a free amino acid in a microalga has not been observed to my knowledge. Wheeler and Stephens (1977) noted the presence of a large storage pool of arginine in Platymonas sp. Arginine elutes close to proline, and I recognize the possibility that what I have Identifled as proline is actually arginine. 
On the basis of extensive comparisons of retention times to proline standards, I belleve the compound was proline and shall continue to refer to it as such. In Nannochloris. sp., the proline pool serves as a reserve nitrogen source during nitrogen 1imitation (Table 3-3). Levels of free proline in some higher plants are sensitive to water stress (Stewart et al., 1977). Prollne is a major dissolved free amino acid associated with salt marsh grasses, thought to be an osmoregulator. In view of the range of halotolerance by Nannochlor $1.8 \mathrm{sp}$, which can be inferred from its broad distribution in coastal environments, it's possible that proline serves as an osmoregulator in this organism as well.

The proportion of IFAA carbon associated with other free amino acids increased slightly or remalned constant as relative growth rate decreased, an indication that their utilization was coupled to the decrease in nitrogen supply. The fact that glutamate concentration remained relatively high would suggest that transamination involved with the formation of other amino acids was inhibited. Possibly, reductions in supp1y of carbon skeletons ffor transamination occurred as a result of regulatory effects of nitrogen on the storage of carbon (e.g. Mohamed and Gnaman, 1979; H1pkin and Syrett, 1977).

\section{N1trogen Spec1fic Turnover Rateg of N1trogen Transport Mediators}

Obvious1y, in a nitrogen 1:Lm1ted steady state culture, the ultimate rate limiting step in nitrogen assimilation and growth rate is the supply of nitrogen to the culture. Metabolically, the reaction which limits growth may vary as a result of changes in nitrogen supply. The relative importance of different metabolic steps in limiting the assimilative flux 
of nitrogen was examined by comparing the specific flux of nitrogen through intracellular pools of nftrogen transport intermediates. Rates of nitrogen uptake were estimated based on the dilution rates of the steady state cultures and measured particulate organic nitrogen concentrations according to the equation:

$$
\mathrm{R}_{\mathrm{N}}=\mathrm{DN}_{\mathrm{O}}
$$

where $R_{N}$ is the net nitrogen uptake rate $\left(\mu \mathrm{M} \mathrm{N} 1^{-1} \mathrm{hr}^{-1}\right)$, $D$ is the dilution rate of the continuous culture $\left(\mathrm{hr}^{-1}\right)$, and $\mathrm{N}_{0}$ is the steady state particulate organic nitrogen concentration ( $\mu \mathrm{M} 1^{-1}$ ). Nitrogen specific turnover rates of nitrogen transport mediators were determined by normalizing $\mathrm{R}_{\mathrm{N}}$ to the concentrations of IFAA nitrogen, glutamine amide nitrogen (Initial site of nitrogen assimilation via glutamine synthetase, GS), and glutamate nitrogen (obligatory Intermediary transport pool via glutamine-oxoglutarate glutamate aminotransferase, GOGAT). There were dramatic differences between high and low relative growth rates in turnover rates for glutamine amide nitrogen and glutamate nitrogen (Table 3-4). Glutamine amide nit:rogen had a much higher turnover rate at the low relative growth rate, while in contrast, glutamate nitrogen specific turnover decreased with decreasing relative growth rate. At high relative growth rate, glutamine amide nitrogen, and glutamate nitrogen turn over at approximately the same rate. This indicates that these rates are coupled under conditions of nitrogen saturation. The decline in levels of glutamine relative to glutamate as relative growth rate decreases (Table 3-3) and the high specific turnover of glutamine amide nitrogen at low relative growth rate 
Table 3-4. Nitrogen Specific Turnover Rates of Nitrogen Transport Medlators in Relationship to Growth Rate of Nannochloris sp.

\begin{tabular}{lccc}
\hline $\begin{array}{l}\text { Relative } \\
\text { Growth Rate }\end{array}$ & $\begin{array}{c}\text { N1trogen Specific Turnover Rates }(\mathrm{hr}-1)^{\mathrm{b}} \\
\text { Fitrogen }\end{array}$ \\
$0.933(0.031)^{\mathrm{c}}$ & $0.74(0.17)$ & $7.8(2.6)$ & $9.8(2.8)$ \\
$0.229(0.016)$ & $1.00(0.25)$ & $30.2(14)$ & $2.1(0.66)$ \\
\hline
\end{tabular}

$a_{\mu / \mu_{\max }}$ where $\mu_{\max }=1.44(0.04)$ day $^{-1}$.

b Total nitrogen uptake rate normalized to transport pool nitrogen concentrations.

${ }^{c_{V}}$ alues in parentheses represent $95 \%$ confidence Intervals. 
(Table 3-4) are an indication of a high utlization/production ratio. This would be the case if the glutamine synthetase (GS) reaction becomes increasingly rate Iimiting with decreasing nitrogen supply, and is in agreement with the conclusions of Wheeler (1.983) based on studies assaying the activities of enzymes involved in nitrogen assimilation. GOGAT, which uses glutamine and alpha-ketoglutarate as substrates, is competitively inhibited by glutamate (Miflinı et al., 1980). Thus a decline in the glutamine/glutamate ratio would tend to reduce the rate of nitrogen flux through the GOGAT reaction as we11. The reduced flux of nitrogen ultimately contributed to the decline in proportions of other free amino acids, and the supression of growth.

There were no significant differences in. IFAA nitrogen specific turnover rates at high and low relative growth rates (Table 3-4). Although turnover of glutamine amide nitrogen increased with decreasing relative growth rate, its relative abundance decreased, thereby diminishing its 1mpact on total IFAA nitrogen turnover. In contrast, the turnover rate of glutamate nitrogen decreased and the proportion of IFAA nitrogen in glutamate increased. It is not possible to directly assess the nitrogen turnover rates for proline, glycine + alanine, and aspartate with my data. Apparently the decline in other free amino acids such as proline, which are probably turning over more slowly, compensated for the decreased glutamate nitrogen turnover rate. This resulted in 11 ttle or no change in bulk free amino acid nitrogen turnover rates with growth rate. 
Saturation With Inorganic 14C: Relative Spec1f1c Act1vit1es of

Intracellular Free Amino Actds

Time course descriptions of specific activities of free amino acids were determined by both quantifying the concentration of the individual free amino actds and radioassaying their incorporation of ${ }^{14} \mathrm{C}$. The absolute specific activity of an amino acid is given as:

$$
S A_{A A}=C^{*}(t) / C_{A A}
$$

where $\mathrm{SA}_{\mathrm{A}}$ is the absolute specific activity, $C^{\star}(t)$ is the dpms of ${ }^{14} \mathrm{C}$ In the amino acid pool at time $t$, and $C_{A A}$ is the steady state carbon pool concentration of the amino acid. In order to facilitate comparisons among different experiments, absolute specific activities were normalized to the specific activity of the dissolved inorganic carbon pool:

$$
\mathrm{SA}_{\mathrm{DIC}}=\mathrm{C}_{\text {total }} / \mathrm{C}_{\mathrm{DIC}}
$$

where $C^{*}{ }_{\text {total }}$ equals total ${ }^{14} \mathrm{C}$ dpms in the dissolved inorganic carbon pool, and $C_{D I C}$ is the concentration of dissolved Inorganic carbon (both of which are assumed to remain constant during the incubation). The relative specific activity, $\mathrm{SA}_{\mathrm{AA}} / \mathrm{SA} \mathrm{DIC}$, is equal to one when the specific activities of the free amino acid and dissolved organic carbon pools are equal.

The time dependence of the relative specific activity of IFAA carbon is shown in Figure 3-2. Arrows indicate times when flow was interrupted. There was no apparent effect of variations in relative growth rate on total IFAA carbon saturation rate. Saturation rema1ned 
below 50\% throughout the three hour incubation perfod for both high and low relative growth rates. The turnover rate of intracellular free amino acld nitrogen was also unaffected by changes in relative growth rate (Table 3-4). The constancy of saturation rates over varying conditions of nitrogen limitation means that assimilative flux of carbon and nitrogen through IFAA's is proportional to the total pool levels. That is, given relatively constant turnover rates, pool size provides an index of flux. Turnover rates for IFAA carbon, as derived from the time course variations in relative specific activity, were substantially lower than those for nitrogen (approximately $0.2 \mathrm{hr}^{-1}$ for carbon as opposed to 0.7 - $1.0 \mathrm{hr}^{-1}$ for nitrogen). This reflects the Independence of carbon and nitrogen flux through the IFAA pool, and 1s consistent with the results of Bassham and K1rk (1964), who found that labelling rates of free amino acids with ${ }^{15} \mathrm{~N}$ derived from $\mathrm{NH}_{4}^{+}$were higher than incorporation rates of inorganic ${ }^{14} \mathrm{C}$.

Despite the apparent uniformity in total IFAA carbon saturation rates, saturation characteristics of individual free amino acids were differentially affected by changes in relative growth rate. Comparisons between time course variations in glutamate relative specific activities revealed a higher saturation rate associated with high relative growth rate (Figure 3-3). The extended time course in Figure 3-4 includes results from batch cultures and another chemostat experiment at an Intermedlate relative growth rate. Batch cultures would not be subject to nutrient depletion effects which may result from the interruption of media input in the continuous cultures (indicated by arrows in Figs. 3-3 and 3-4). Flow was not interrupted in the intermediate growth rate continuous culture. It is apparent that the batch and high relative 
growth rate patterns were similar and higher than the intermediate and low relative growth rate patterns. A similar trend was observed in the growth rate dependence of glutamate nitrogen turnover (Table 3-4). Again, the turnover of glutamate nitrogen was considerably higher than that of carbon (c.f. F1g. 3-3 and Table 3-4), an 1llustration of the importance of glutamate as a mediator of intracellular nitrogen transport.

Growth rate dependence of glutamine carbon saturation rates was less clear (F1g. 3-5). Batch culture saturation rates were higher, while no slgnificant differences could be shown for high and low relative steady state growth rates. It may be that saturation of glutamine is highly sensitive to nitrogen depletion as a result of cessation of nutrient supply (time of which 1s indicated by the arrows in Figure 3-4).

In contrast to the relatively slow saturation of glutamate, glutamine, and IFAA carbon with inorganic ${ }^{14} \mathrm{C}$, the specific activities of glycine + alanine (F1gure 3-6) and aspartate (F1gure 3-7) rapidly approached unity at high relative growth rate. This suggests their biosynthesis is closely coupled to the production of photosynthetically derfved carbon skeletons. As in the case of glutamate, saturation of glycine + alanine was slower at low relative growth rate and may have been sensitive to the interruption of media inflow (1ndicated by arrows). Data were insufficient to make any such conclusions for aspartate. Valine saturation characteristics resembled glutamate, displaying a higher saturation. rate at the high relative growth rate (F1gure 3-8). As for glycinetalanine, saturation at the low relative growth rate appeared to be sensitive to the interruption of media inflow. Proline displayed slow saturation kinetics at both high and low 
Figure 3-2. Time course of the relative specific activity of Intracellular free amino acid carbon in batch and $\mathrm{NH}_{4}^{+}-11 \mathrm{mited}$ steady state cultures of Nannochloris sp. Relative specific activity is the specific activity of the amino acid normalized to that of the dissolved Inorganic carbon pool; see text for further discussion. Symbols correspond to different relative growth rates $\left(\mu / \mu_{\max }\right): \operatorname{triangle}, 1.00$ (batch culture); X, .965 (batch culture); square, .933; cross, .229. Errors represent propagated estimates of analytical error based on $95 \%$ confidence intervals. Media inflow was stopped at 0.33 hours for $\mu / \mu_{\max }=0.933$, and at 1.0 hour for $\mu / \mu_{\max }=0.229$ (indicated by arrows). 


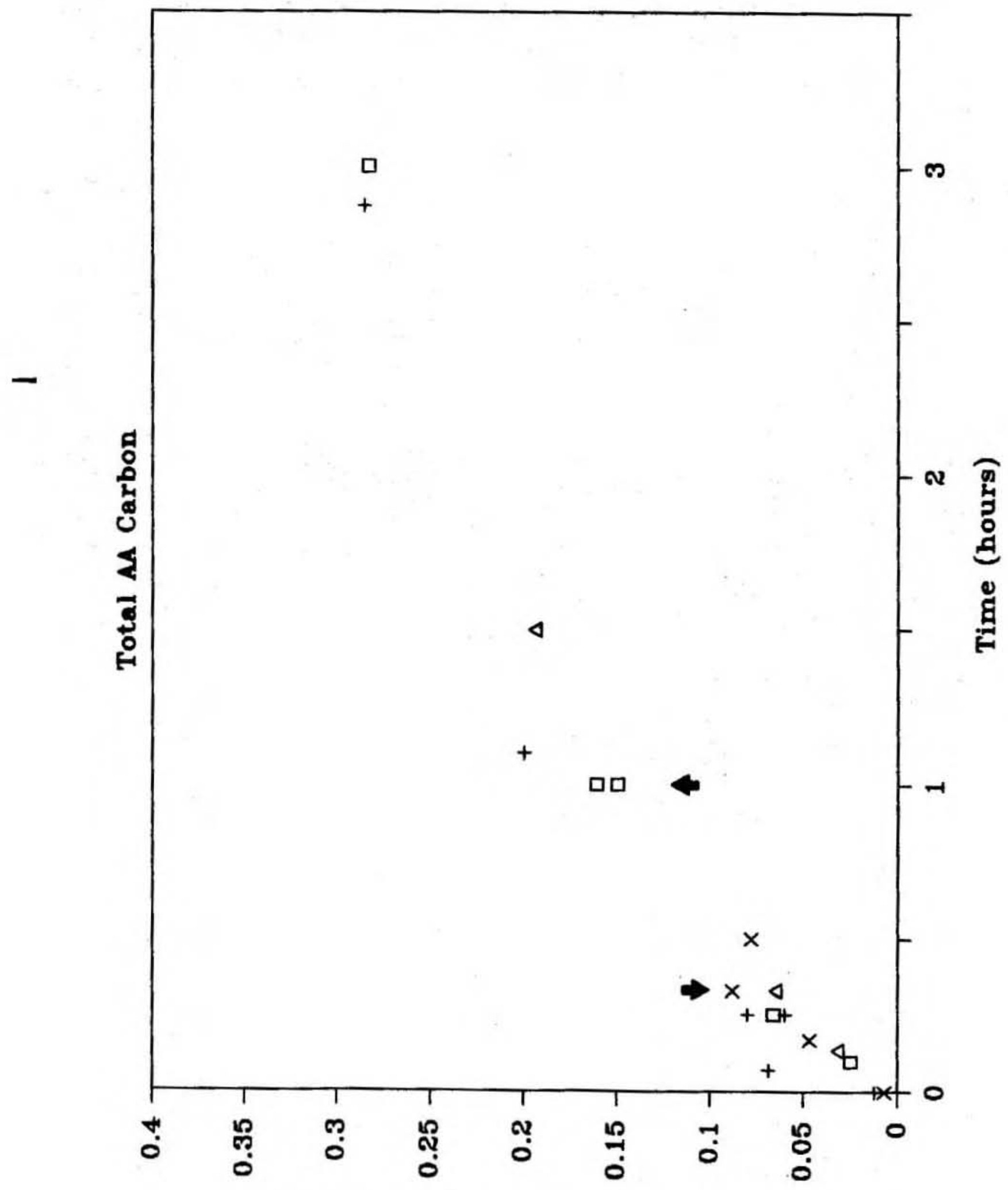

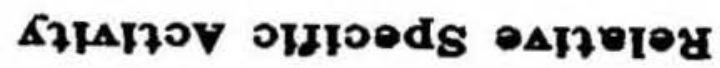


Figure 3-3. Time course of the relative specific activity of intracellular free glutamate at high and low relative growth rate in $\mathrm{NH}_{4}^{+}$-11mited steady state cultures of Nannochloris sp. Relative specific activity is the specific activity of the amino acid normalized to that of the dissolved Inorganic carbon pool; see text for further discussion. Symbols correspond to different relative growth rates $\left(\mu / \mu_{\max }\right):$ square, 0.933 ; cross, 0.229 day $^{-1}$. Errors represent propagated estimates of analytical error based on $95 \%$ confidence intervals. Media inflow was stopped at 0.33 hours for $\mu / \mu_{\max }=0.933$, and at 1.0 hour for $\mu / \mu_{\max }=0.229$ (indicated by arrows). 


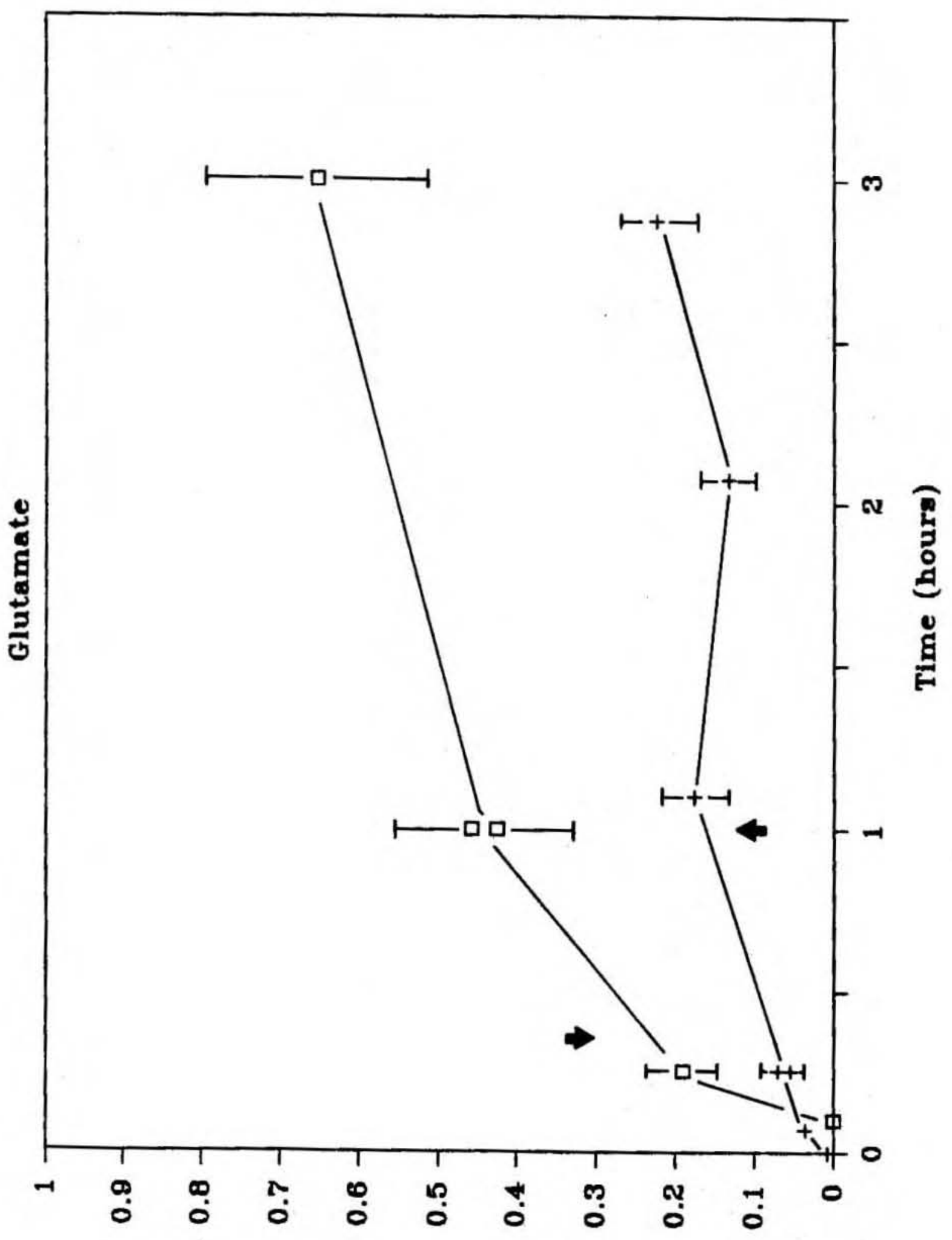

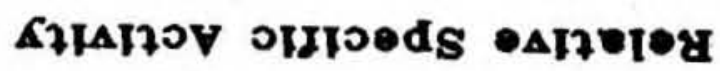


Figure 3-4. Extended time course of the relative specific activity of Intracellular free glutamate in batch and $\mathrm{NH}_{4}^{+}-11$ mited steady state cultures of Nannochloris sp. Relative specific activity is the specific activity of the amino acid normalized to that of the dissolved inorganic carbon pool; see text for further discussion. Symbols correspond to different relative growth rates $\left(\mu / \mu_{\max }\right): \operatorname{trlangle}, 1.00$ (batch culture); $X, 0.965$ (batch culture); square, 0.933; diamonds, 0.458; cross, 0.229. Errors represent propagated estimates of analytical error based on $95 \%$ confidence intervals. Media Inflow was stopped at 0.33 hours for $\mu / \mu_{\max }=0.933$, and at 1.0 hour for $\mu / \mu_{\max }=0.229$ (Indicated by arrows). 


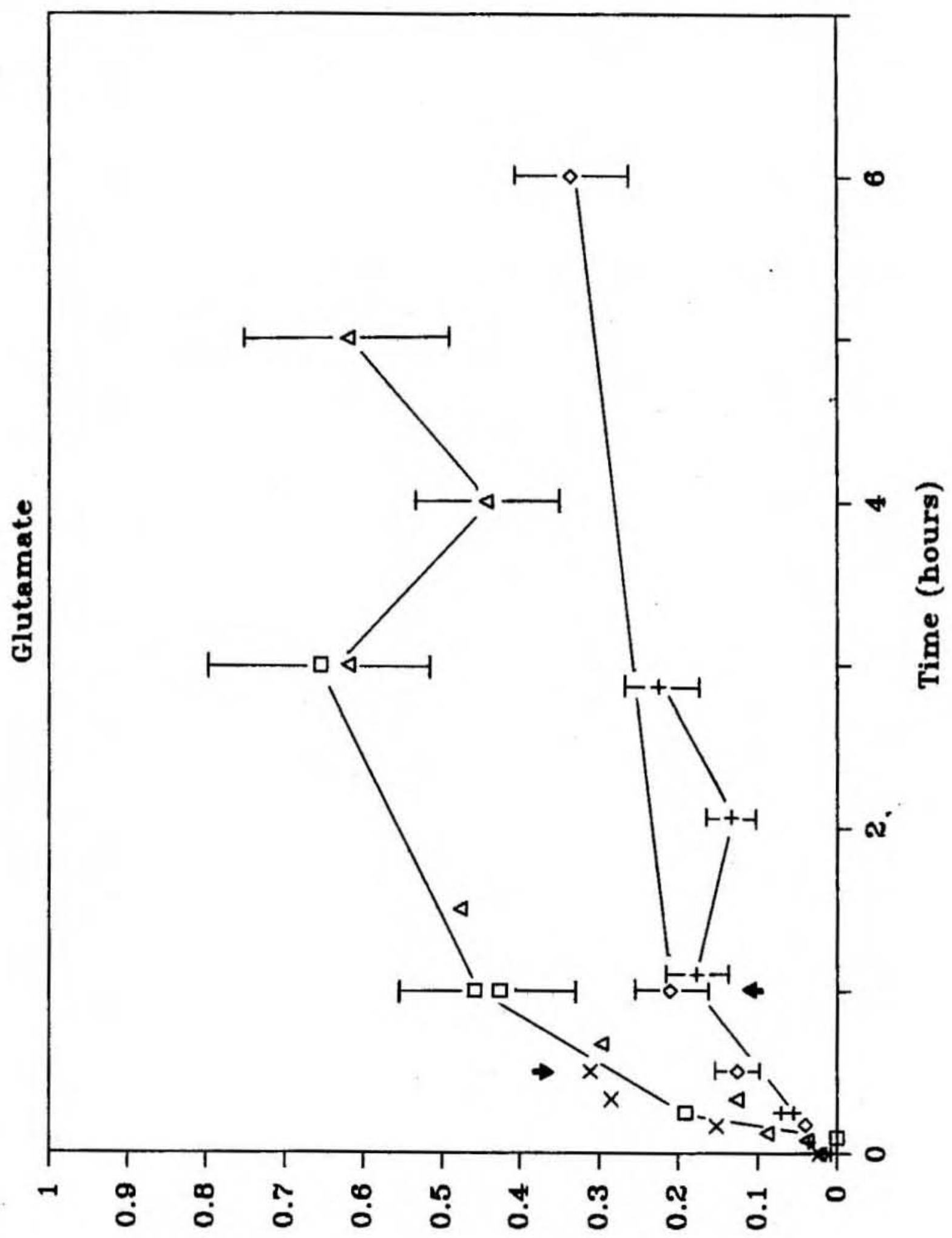

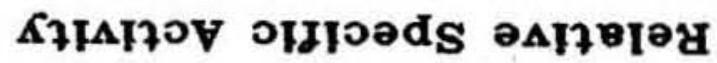


F1gure 3-5. T1me course of the relative specific activity of intracellular free glutamine in batch and $\mathrm{NH}_{4}^{+}-11$ mited steady state cultures of Nannochloris sp. Relative specific activity is the specific activity of the amino acid normalized to that of the dissolved inorganic carbon pool; see text for further discussion. Symbols correspond to different relative growth rates $\left(\mu / \mu_{\max }\right):$ triangle, 1.00 (batch culture); $X, 0.965$ (batch culture); square, 0.933; diamonds, 0.458 ; cross, 0.229. Errors represent propagated estimates of analytical error based on $95 \%$ confidence intervals. Media Inflow was stopped at 0.33 hours for $\mu / \mu_{\max }=0.933$, and at 1.0 hour for $\mu / \mu_{\max }=0.229$ (indicated by arrows). 


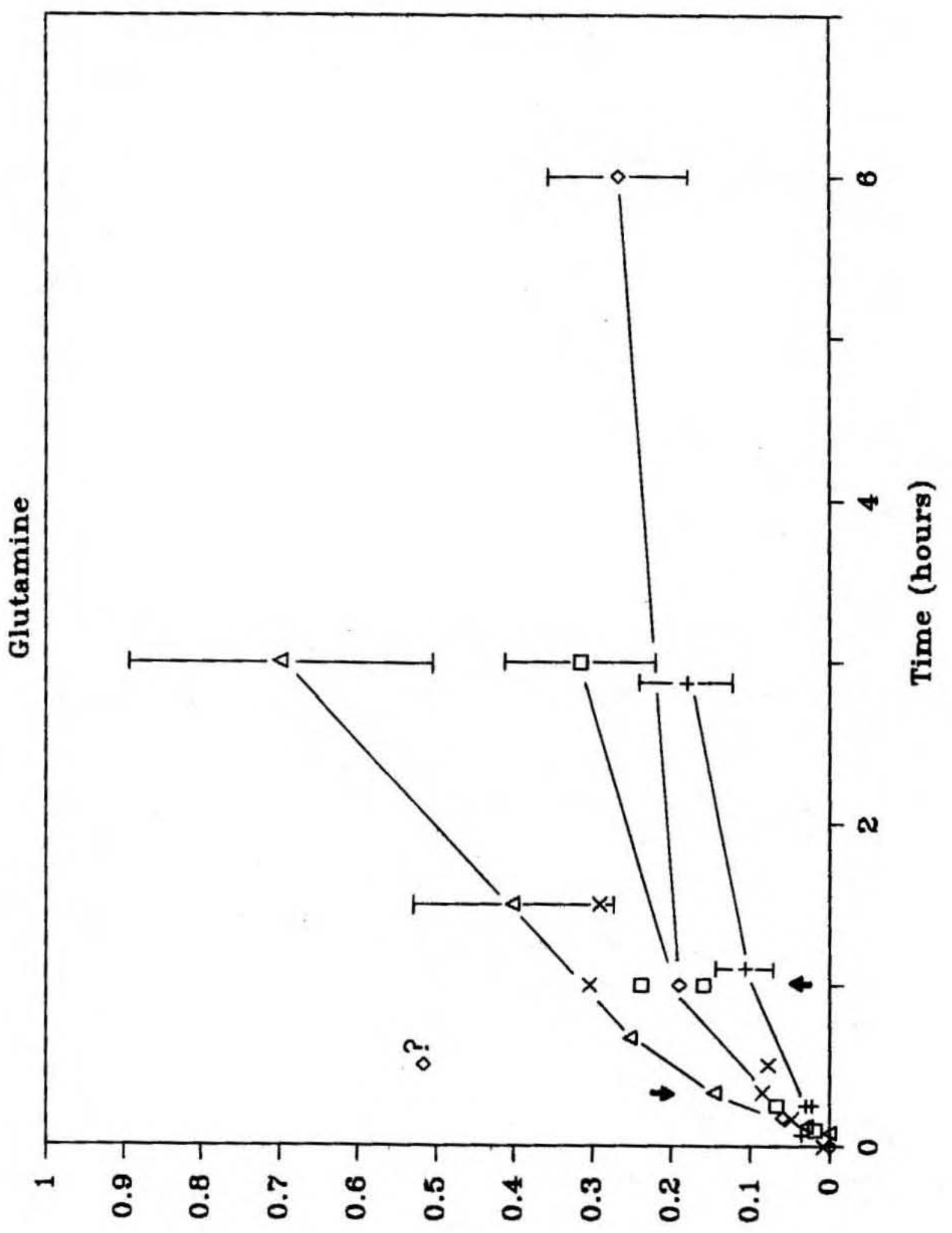


Figure 3-6. Time course of the relative specific activity of intracellular free glycine + alanine in batch and $\mathrm{NH}_{4}^{+}-11$ mited steady state cultures of Nannochloris sp. Relative specific activity is the specific activity of the amino acid normalized to that of the dissolved inorganic carbon pool; see text for further discussion. Symbols correspond to different relative growth rates $\left(\mu / \mu_{\max }\right): x, 0.965$ (batch culture); square, 0.933; cross, 0.229. Errors represent propagated estimates of analytical error based on $95 \%$ confidence intervals. Media inflow was stopped at 0.33 hours for $\mu / \mu_{\max }=0.933$, and at 1.0 hour for $\mu / \mu_{\max }=0.229$ (indicated by arrows). Curves drawn by eye. 


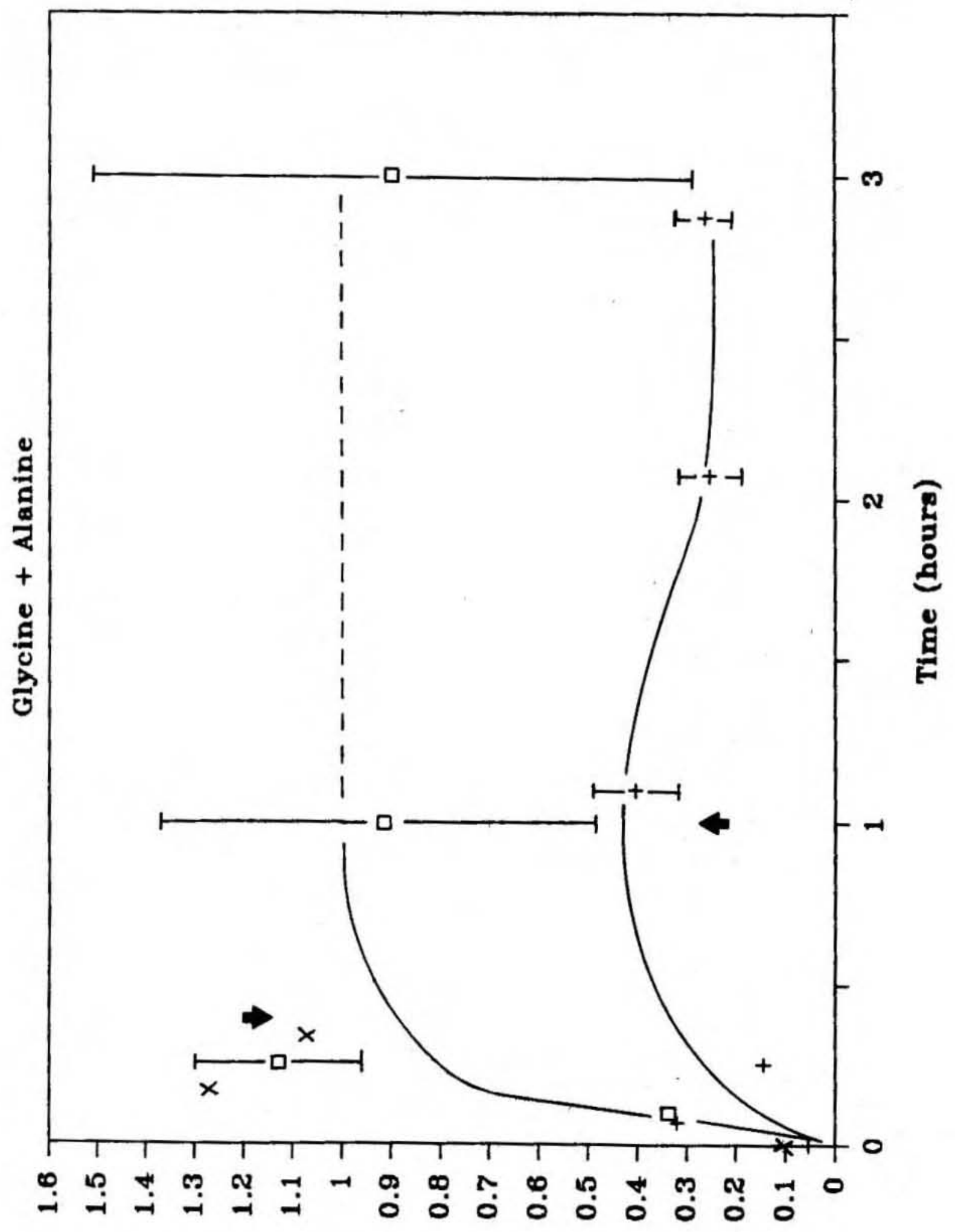


Figure 3-7. Time course of the relative specific activity of Intracellular free aspartate in batch and $\mathrm{NH}_{4}^{+}-11 \mathrm{mited}$ steady state cultures of Nannochloris sp. Relative specific activity is the specific activity of the amino acid normalized to that of the dissolved inorganic carbon pool; see text for further discussion. Symbols correspond to different relative growth rates $\left(\mu / \mu_{\max }\right):$ triangle, 1.00 (batch culture); $X, 0.965$; square, 0.933; dlamonds, 0.458; cross, 0.229. Errors represent propagated estimates of analytical error based on $95 \%$ confidence intervals. Curve drawn by eye. 


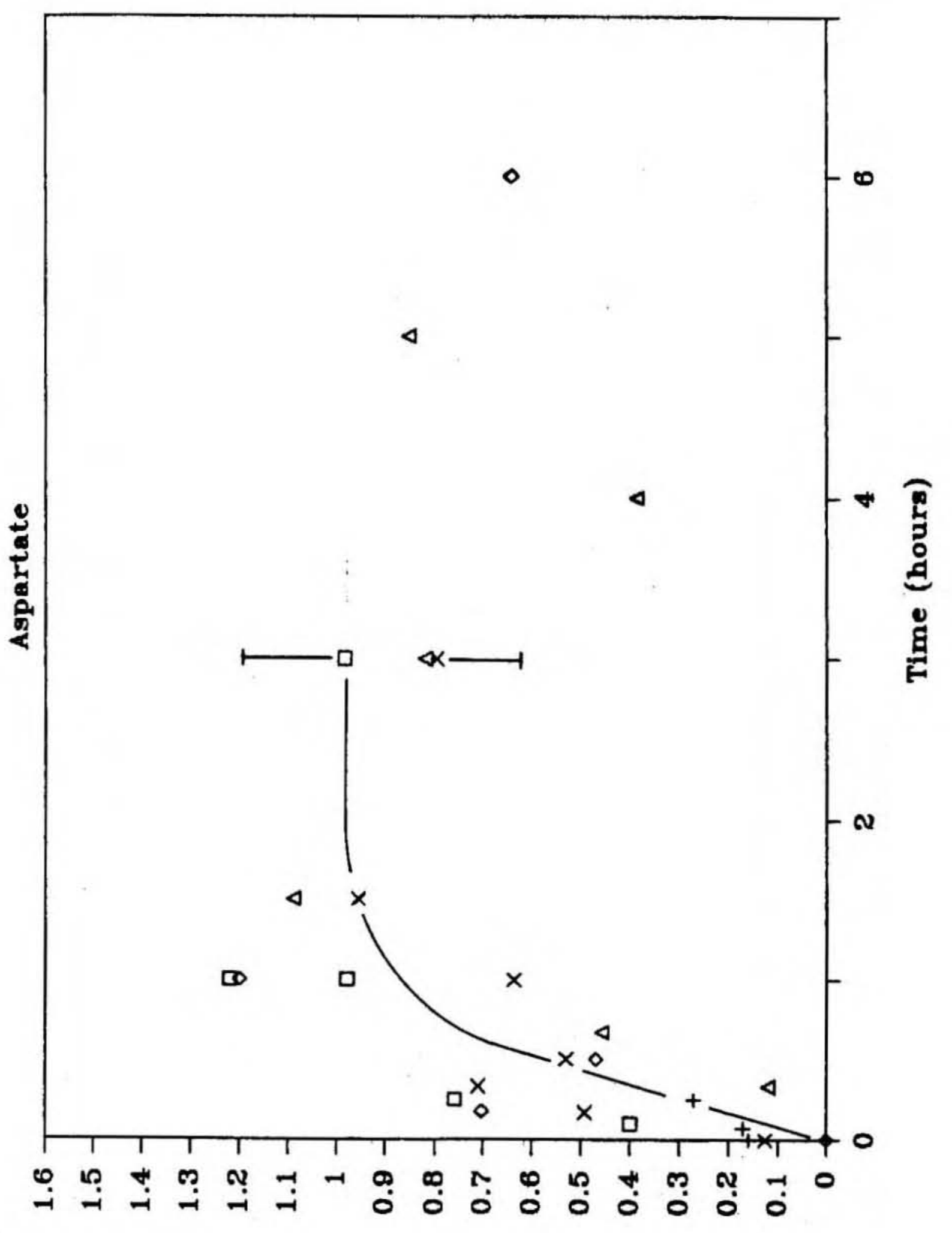


Figure 3-8. Time course of the relative specific activity of intracellular free valine in batch and $\mathrm{NH}_{4}^{+}-11 \mathrm{mited}$ steady $\mathrm{s}$ tate cultures of Nannochloris sp. Relative specific activity is the specific activity of the amino acid normalized to that of the dissolved inorganic carbon pool; see text for further discussion. Symbols correspond to different relative growth rates $\left(\mu / \mu_{\max }\right)$ : triangle, 1.00 (batch culture); $X, 0.965$ (batch culture); square, 0.933; diamonds, 0.458; cross, 0.229. Errors represent propagated estimates of analytical error based on $95 \%$ confidence intervals. Media inflow was stopped at 0.33 hours for $\mu / \mu_{\max }=0.933$, and at 1.0 hour for $\mu / \mu_{\max }=0.229$ (indicated by arrows). Curves drawn by eye. 


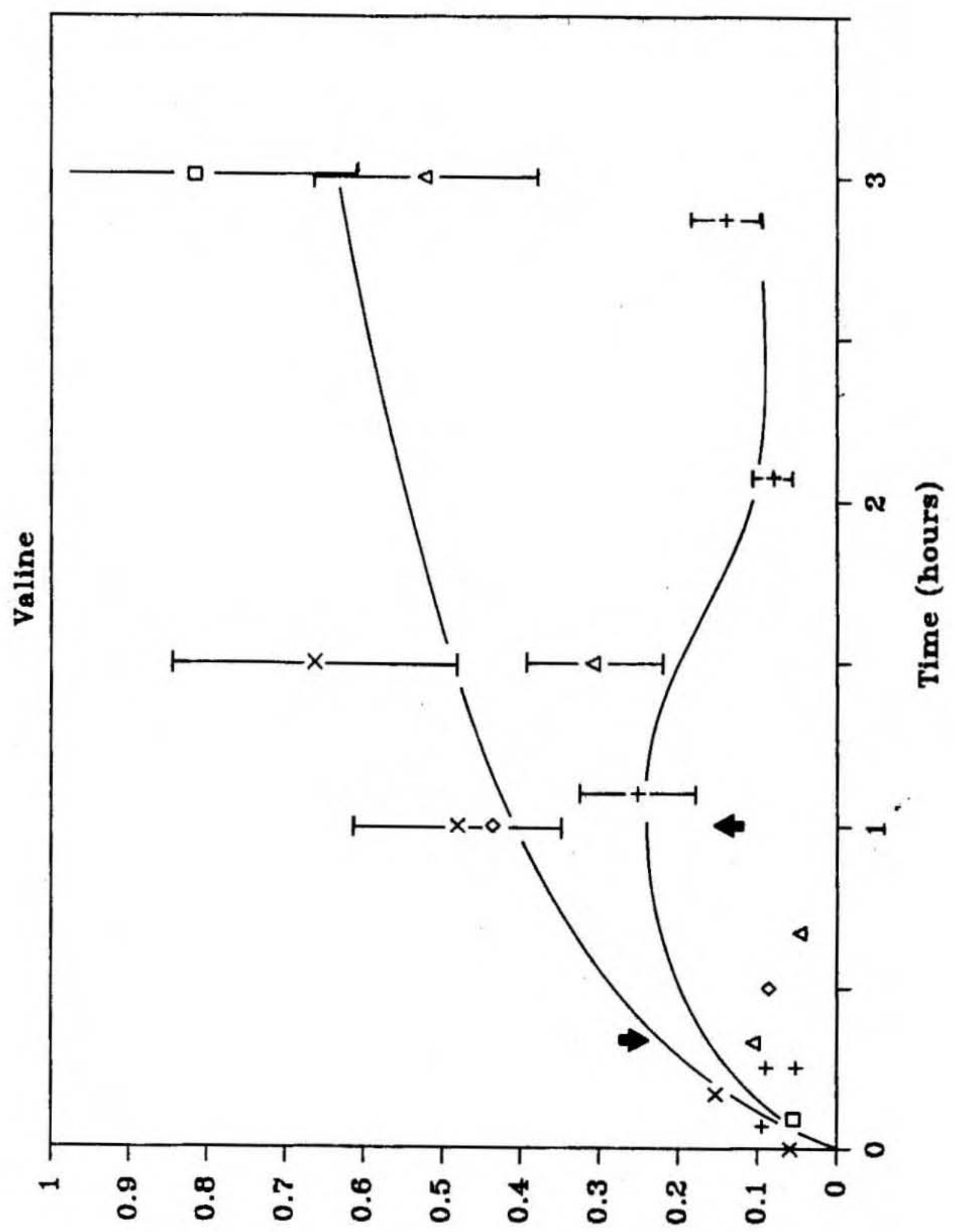

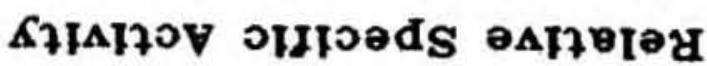


relative growth rates (Figure 3-9), supporting the hypothesis of its function as a reserve nitrogen source or osmoregulator, as opposed to a central biosynthetic intermediate.

A diagram of the blosynthetic pathways of glutamate, glutamine, aspartate, alanine, glycine and serine is shown in Figure 3-10. Glutamate and glutamine are products of the reductive amination of alpha-ketoglutarate, which is a carbon skeleton derived from the tricarboxylic acid cycle. This may explain their relatively slow equilibration rates, which involve saturation of both the large Intracellular free glutamate and glutamine pools, as well as the respiratory intermediate, alpha-ketoglutarate.

The biosynthesis of glycine and serine can be derived from 3-phosphoglycerate produced by the RuDP carboxylase reaction of the Calvin cycle, and consequently would be expected to rapidly saturate. However their formation may also involve reactions of the photorespiratory product glycolate which are catalyzed by enzymes localized in the peroxisomes and mitochondria (Keys et al., 1978 in Miflin et al., 1980). If the latter blosynthetic pathway is important, it may involve saturation of a larger carbon precursor pool. There is evidence from studies with Chlorella to suggest that the glycolate photorespiratory pathway is less favored under conditions where ammonia 1s the sole nitrogen source (Beudeker and Tabita, 1984). Alanine is derived from pyruvate, and aspartate from oxaloacetate. Both pyruvate and oxaloacetate are produced outside the chloroplast by enzymes of the glycolysis cycle. The fact that glycine + alanine and aspartate rapidly saturated at the high relative growth rate would require e1ther that the entire cytosolic pools of their carbon skeletons equilibrated with 
inorganic ${ }^{14} \mathrm{c}$, or that production of their carbon skeletons was 1solated from more slowly turning over pools. Studies with spinach chloroplasts have Indicated that pyruvate and oxaloacetate may be produced within the chloroplast (Schulze-Slebert et al., 1984) wh1ch could explain the rapid saturation of aspartate and alanine at the high relative growth rate.

Proline is derived from glutamate. Its low saturation rate 1s 11kely a consequence of its high intracellular pool concentration and the slow saturation of glutamate. Valine is derived from pyruvate. Its saturation characteristics are discussed further in Chapter 4.

IFAA carbon and nitrogen turnover rates were relatively uniform over a wide range of nitrogen limited growth rates, despite the diverse responses of nitrogen and carbon turnover of individual amino acids to changes in relative growth rate. This is apparently a consequence of adjustments in relative abundances, as well as saturation rates. The fact that total IFAA carbon saturation was unaffected by growth rate can be explained at least partially by the fact that the proportion of the slowly turning over proline declined as growth rate declined. Hence, although the turnover of other amino ac1ds such as glutamate, glycine + alanine, and valine were lower for the low relatlve growth rate, the decline in proline had a buffering effect on the saturation rate of total pool carbon.

Obviously, IFAA carbon metabolism is highly sensitive to growth rate, and responses of individual free amino aclds are diverse. Free amino acids are intermediates in the synthesis of protein. However, protein amino acid precursor pools may be segregated from the bulk intracellular free amino acid pools. In the next section I discuss the extent to which 
Figure 3-9. Time course of the relative specific activity of Intracellular free proline in batch and $\mathrm{NH}_{4}^{+}-1$ imited steady state cultures of Nannochloris sp. Relative specific activity is the specific activity of the amino acid normalized to that of the dissolved Inorganic carbon pool; see text for further discussion. Symbols correspond to different relative growth rates $\left(\mu / \mu_{\max }\right)$ : triangle, 1.00 (batch culture); X, 0.965; square, 0.933; dlamonds, 0.458; cross, 0.229. Errors represent propagated estimates of analytical error based on $95 \%$ confidence intervals. 


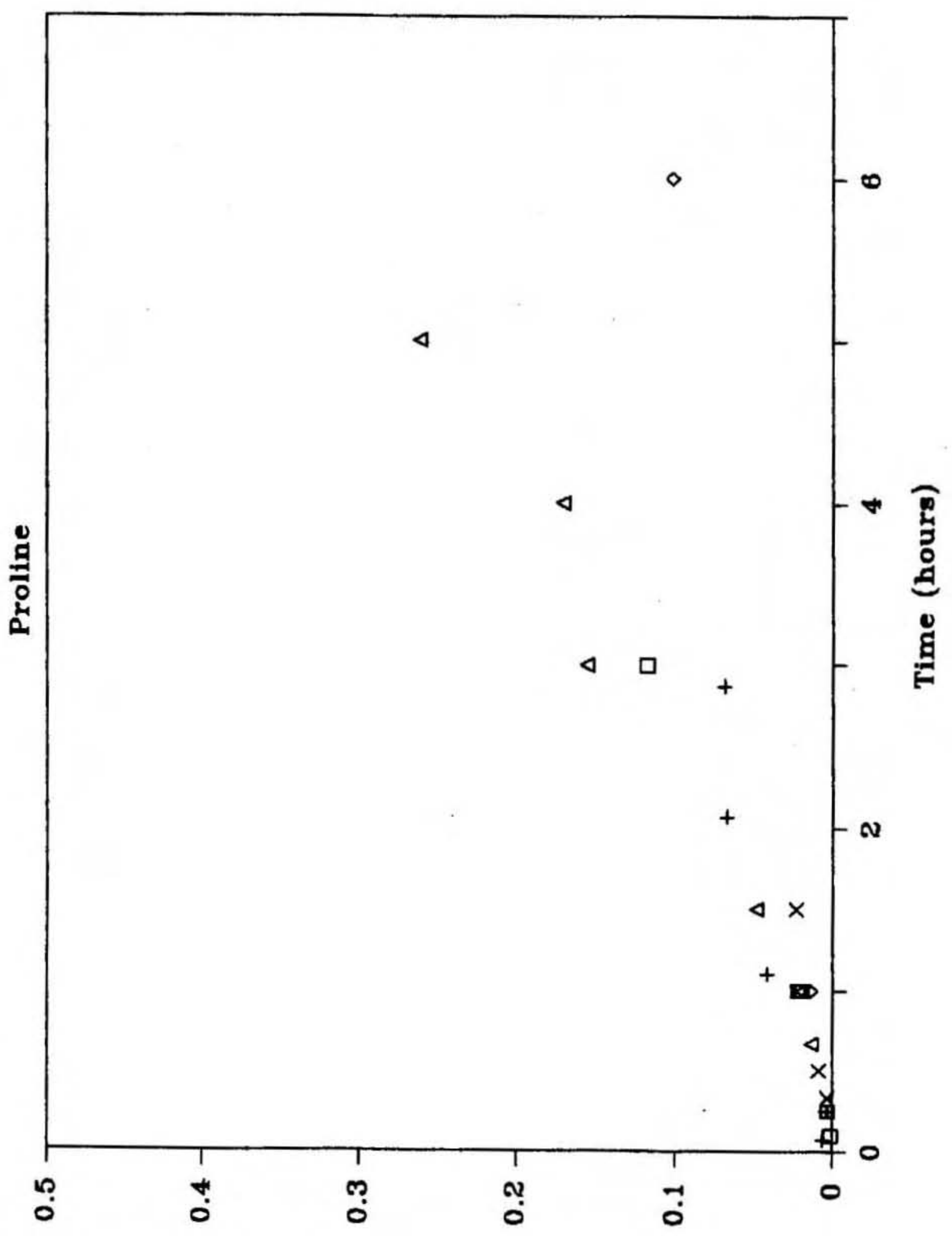

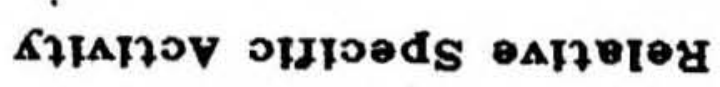


Figure 3-10. Simplified diagram showing the major pathways associated with the biosynthesis of glycine (GLY), serine (SER), glutamine (GLN), glutamate (GLU), alanine (ALA), and aspartate (ASP). After Miflin and Lea (1977) and M1f1in et al. (1980). PGA = phosphoglycerate, PEP = phosphoenolpyruvate, $\mathrm{PYR}=$ pyruvate, $\mathrm{OAA}=$ oxaloacetate, $\mathrm{TCA}=$ tricarboxylic acid cycle, KGA $=$ alpha-ketoglutatarate, RuDP $=$ ribulose-1,5-d1phosphate, FDP = fructose-1,6-d1phosphate; $G 6 P=$ glucose-6-phosphate. Formation of glycine and serine from glycolate may Involve participation of peroxisomes and mitochondria (not indicated, see Keys et al., 1978, in Miflin et al., 1980). The proposed direct formation of phosphoenolpyruvate and pyruvate within the chloroplast (Schulze-Siebert et al., 1984) is also not shown. 


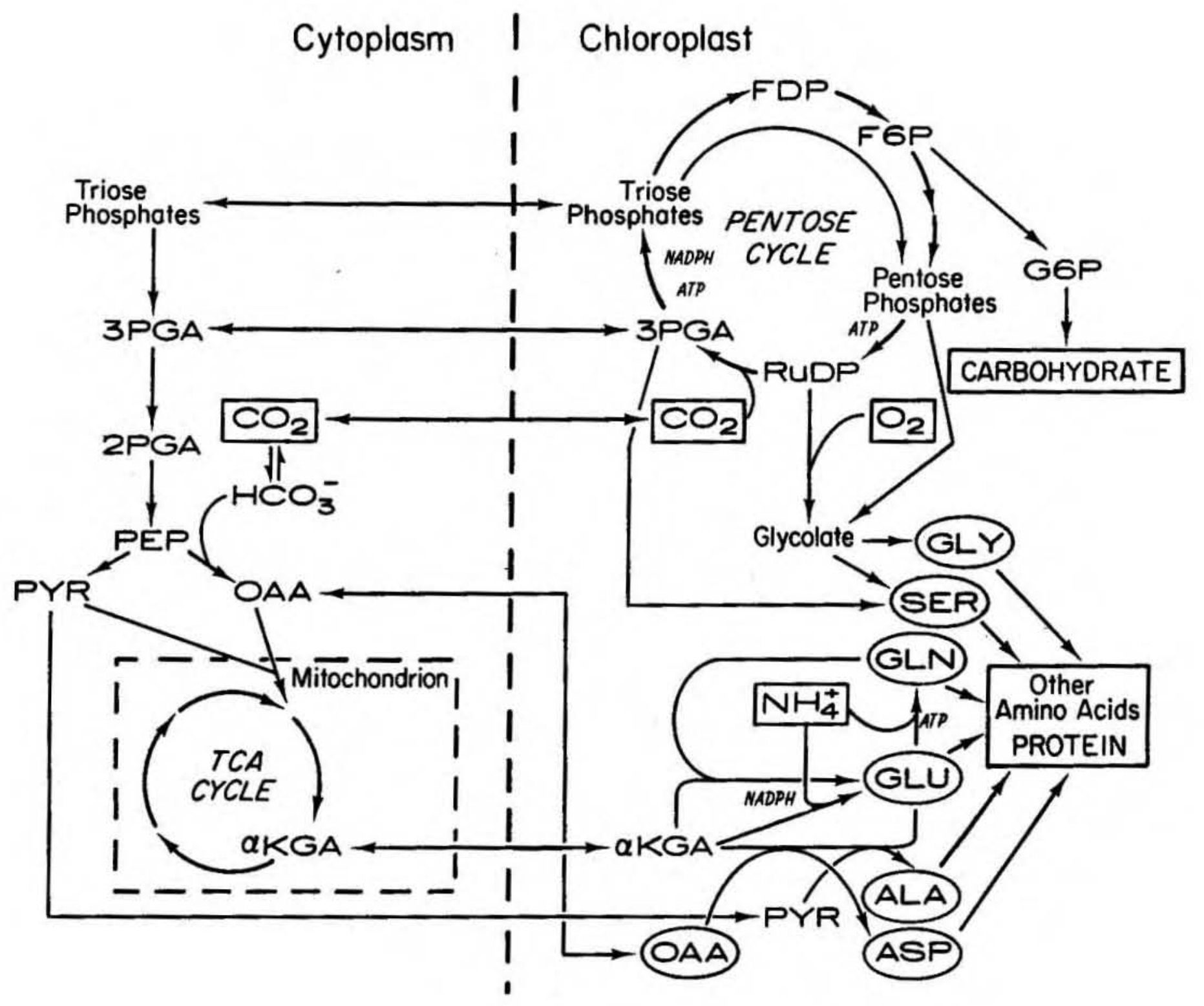


observed saturation characteristics of free amino acids reflect that of newly assimilated protein amino acids. Such information is crucial in attempts to understand the relationship of 1sotopic labeling of protein to actual net protein synthesis, and the path of photosynthetically fixed carbon in the blosynthesis of proteln amino acid precursors.

Relationships Between Free and Protein Amino Acid Saturation Rates The production of nascent protein amino acids in a steady state continuous culture w111 be:

$$
\mathrm{dP} / \mathrm{dt}=\mathrm{DP}
$$

where $D$ is the dilution rate of the chemostat, and $P_{0}$ is the steady state protein amino acid carbon concentration. dP/dt is also equal to the rate of dilution of proteln carbon as a result of media 1nflow. Now let a source of radioactive substrate (e.g. inorganic ${ }^{14} \mathrm{C}$ ) be added at time zero. For short incubation times and low growth rates (Dt less than $0.05)$, the dilution of nascent 1sotoplcally labeled protein can be ignored, and the chemostat can be effectively treated as a batch culture with growth rate D. In the cultures which w11l be considered, flow was interrupted during the Incubation, at which point this assumption becomes even more valid. For further discussion, refer to Chapter 4. Given that the concentration of nascent protein, $P_{n}(t)$, is zero at time zero, then integration of equation 3-4 yields:

$$
P_{n}(t)=P_{0}\left(e^{D t}-1\right)
$$


The specific activity of the nascent protein is:

$$
P^{*}(t) / P_{n}(t)=\left(P *(t) / P_{0}\right)\left(1 /\left(e^{D t}-1\right)\right)
$$

where $\mathrm{P}^{*}(t)$ is the amount of 1sotope incorporated into the protein amino acid at time $t$ (c.f. Wheeler and Stephens, 1977). $p *(t) / P_{0}$ would be the specific activity of the total protein amino acid. As for the intracellular free amino acids, the specific activities were expressed as a relative specific activity, by normalizing to the specific activity of the dissolved inorganic carbon pool, SA DIC (equation 4-3). A value of one indicates complete saturation with inorganic carbon.

Glutamate is one of the most abundant intracellular free amino acids, and is also an important component of protein. It should be noted that protein "glutamate" Includes both glutamate and hydrolyzed glutamine. However, in view of the simflarity in the saturation characteristics of free glutamate and glutamine, and the fact that glutamine is present in lower abundance relative to glutamate in average protein (mole \% is approximately 5.5 for glutamate, and 3.5 for glutamine, Jukes et al., 1975; Dolittle, 1981), I feel it is reasonable to compare specific activitles of proteln glutamate and free glutamate. Comparisons between the relative specific activities of nascent protein glutamate and intracellular free glutamate indicated that they were generally similar at high relative growth rate with the exception of one transient point (F1gure 3-11). This suggests that intracellular pools of glutamate were in equilibrium with the source of precursors to protein biosynthesis. At low relative growth rate, nascent protein glutamate had a higher speciflc activity than the intracellular free amino ac1d pool (Figure 3-12), a 
Figure 3-11. Time course of the relative specific activity of intracellular free glutamate and nascent protein glutamate in batch and $\mathrm{NH}_{4}^{+}$-limited steady state cultures of Nannochloris sp. Relative specific activity is the specific activity of the amino acid normalized to that of the dissolved inorganic carbon pool; see text for further discussion. Symbols for intracellular free amino acids $\left(\mu / \mu_{\max }\right)$ : triangle, 1.00 (batch culture); $X, 0.965$; square, 0.933 . Cross represents relative specific activity of nascent protein glutamate in culture growing at 0.933 . Errors represent propagated estimates of analytical error based on $95 \%$ confidence intervals. 


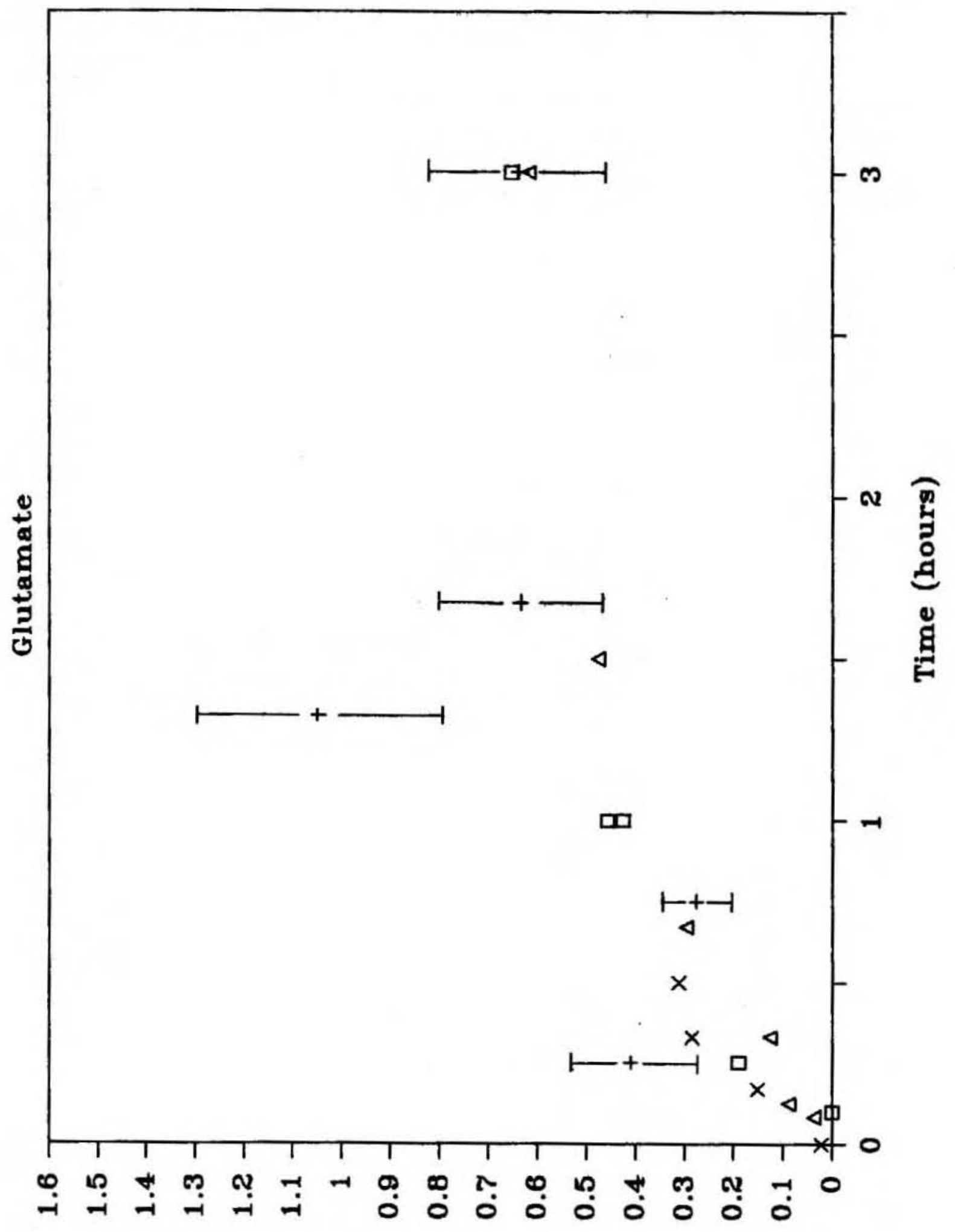

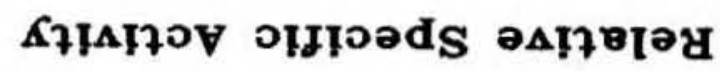


Figure 3-12. Time course of the relative specific activity of intracellular free glutamate and nascent protein glutamate in an $\mathrm{NH}_{4}^{+}-1$ imited steady state culture of Nannochloris sp. at low relative growth rate $\left(\mu / \mu_{\max }=0.229\right)$. Relative specific activity 1 s the specific activity of the amino acid normalized to that of the dissolved inorganic carbon pool; see text for further discussion. Symbols: square, nascent proteln glutamate specific activity; cross, intracellular free glutamate specific activity. Errors represent propagated estimates of analytical error based on $95 \%$ confidence intervals. 


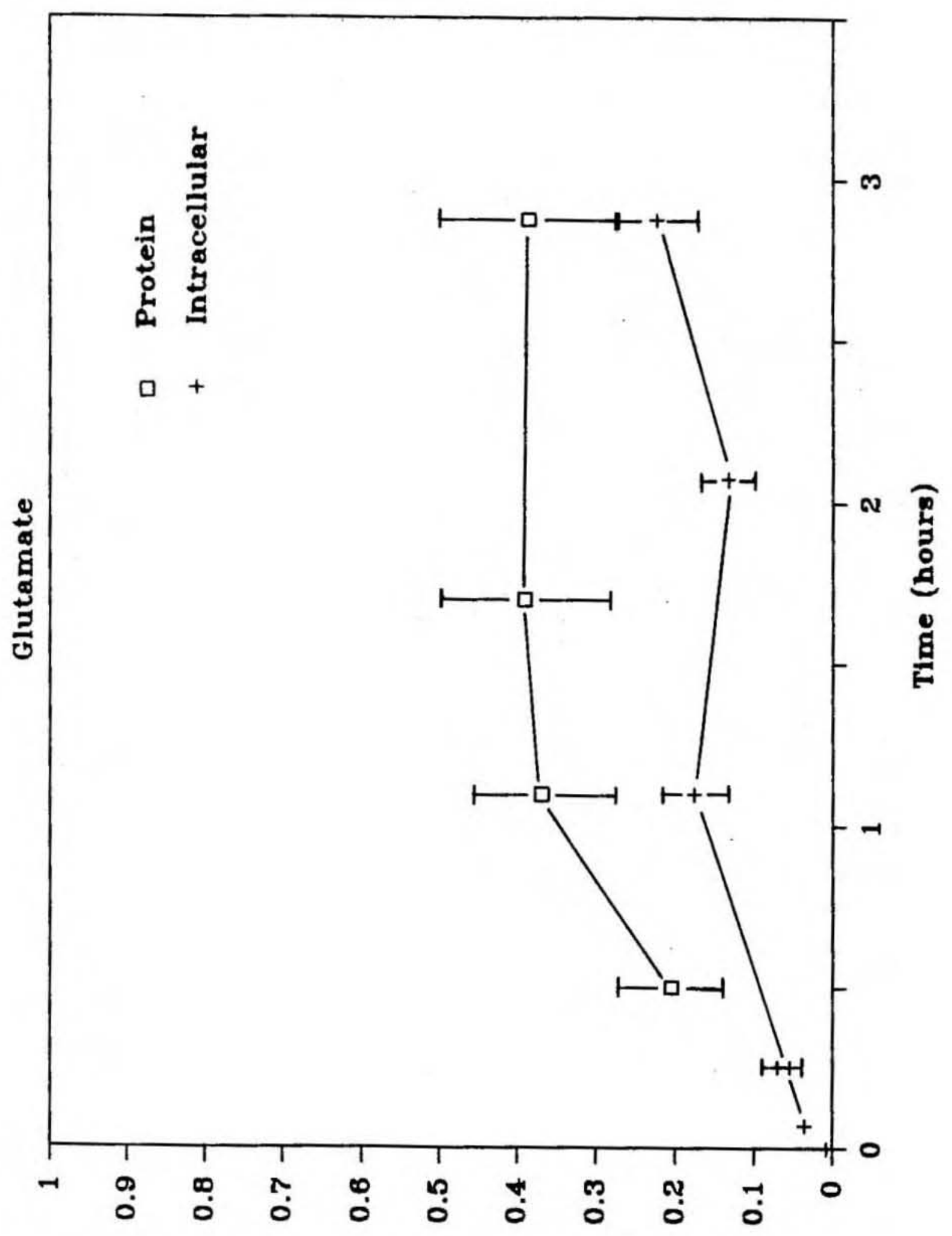

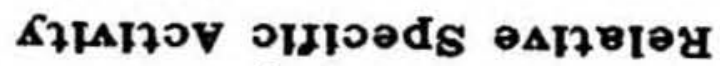


possible Indication that a semi-1solated more rapidly turning over pool was preferentially used as the precursor source for proteln synthesis. Despite this apparent preferential use of photosynthetically derfved amino acid carbon, nascent specific activities of protein glutamate were still higher at high relative growth rate (Figure 3-13).

There was consistent agreement between protein and free amino acid specific activities of valine (Figure 3-14) and aspartate (FIgure 3-15) at high relative growth rates. As for glutamate, nascent protein valine specific activity tended to exceed the free amino acid specific activity at the low relative growth rate (Figure $3-16$ ). There was insufficient data to evaluate this relationship for aspartate at the low relative growth rate. For glycine + alanine, nascent protein amino acids appeared to rapidly saturate (Table 3-5). Again, at the low relative growth rate free amino acid activities were considerably below the specific activities of these nascent protein amino acids (c.f. Figs. 3-6 and 3-5).

Likely explanations for discrepancies between the specific activities of the amino acids in the intracellular pool and the nascent protein include compartmentalization of free amino acid pools. A separate more rapidly saturating pool of free amino acid precursors for protein could result in differences between specific activities of intracellular free and nascent protein amino acids. The existence of multiple metabolic pools has been reported by a number of investigators (Smith et al., 1961; Bassham and KIrk, 1964; Oaks and B1dwell, 1970; Wheeler and Stephens, 1977). I observed significant differences between the free and nascent protein specific activities only under conditions of nitrogen limitation. Th1s would would suggest that as nitrogen limitation 
1ncreased, an increased proportion of protein amino ac1d precursors were drawn from the rapidly saturating pool. Previous studies where compartmentalization has been demonstrated have generally not considered effects of varlations in the physiological state. Unlike glycine and alanine, nascent protein glutamate and valine do not fully equilibrate. Therefore, these protein amino acids cannot be derived exclusively from rapidly saturating precursor pools. The close relationship between free and protein amino acid specific activities of glutamate and valine at high relative growth rate suggests ther is some interequilibration of their different metabolic pools.

Another possible explanation for differences between free and nascent protein amino acid speciflc activities is protein turnover (e.8. Huffaker and Peterson, 1974; Cuhel et al., 1984; Trevawas et al., 1972; B1dwell et al., 196 ; Bates, 1981). Turnover of protein could result in a significantly greater gross rate of protein synthesis than the net rate which was est1mated. If isotopic assimilation reflected this gross rate, which would be the case if resplred protein was not immediately equilibrated with nascent protein, then this could lead to an overestimate of nascent protein specific activity by our methods. Such a discrepancy would be larger under conditions of greater protein turnover, such as might be expected under conditions of nitrogen depletion (e.g. Trevawas et al., 1972). If turnover of protein was the predominant cause of the discrepancy between free and nascent protein specific activities at the low relative growth rate, then there was a fortuitous mixing of the 1sotopic inputs into glycine and alanine precursor pools such that enhancement due to turnover offset the low saturation rate of the intracellular free amino acid pools. However, this seems unlikely. 
Figure 3-13. Time course of relative specific activity of nascent protein glutamate at high and low relative growth rate in $\mathrm{NH}_{4}^{+}$-Iimited steady state cultures of Nannochloris sp. Relative specific activity is the specific activity of the amino acid normalized to that of the dissolved inorganic carbon pool; see text for further discussion. Symbols $\left(\mu / \mu_{\max }\right):$ square, .933; cross, .229. Errors represent propagated estimates of analytical error based on 95\% confidence intervals. 


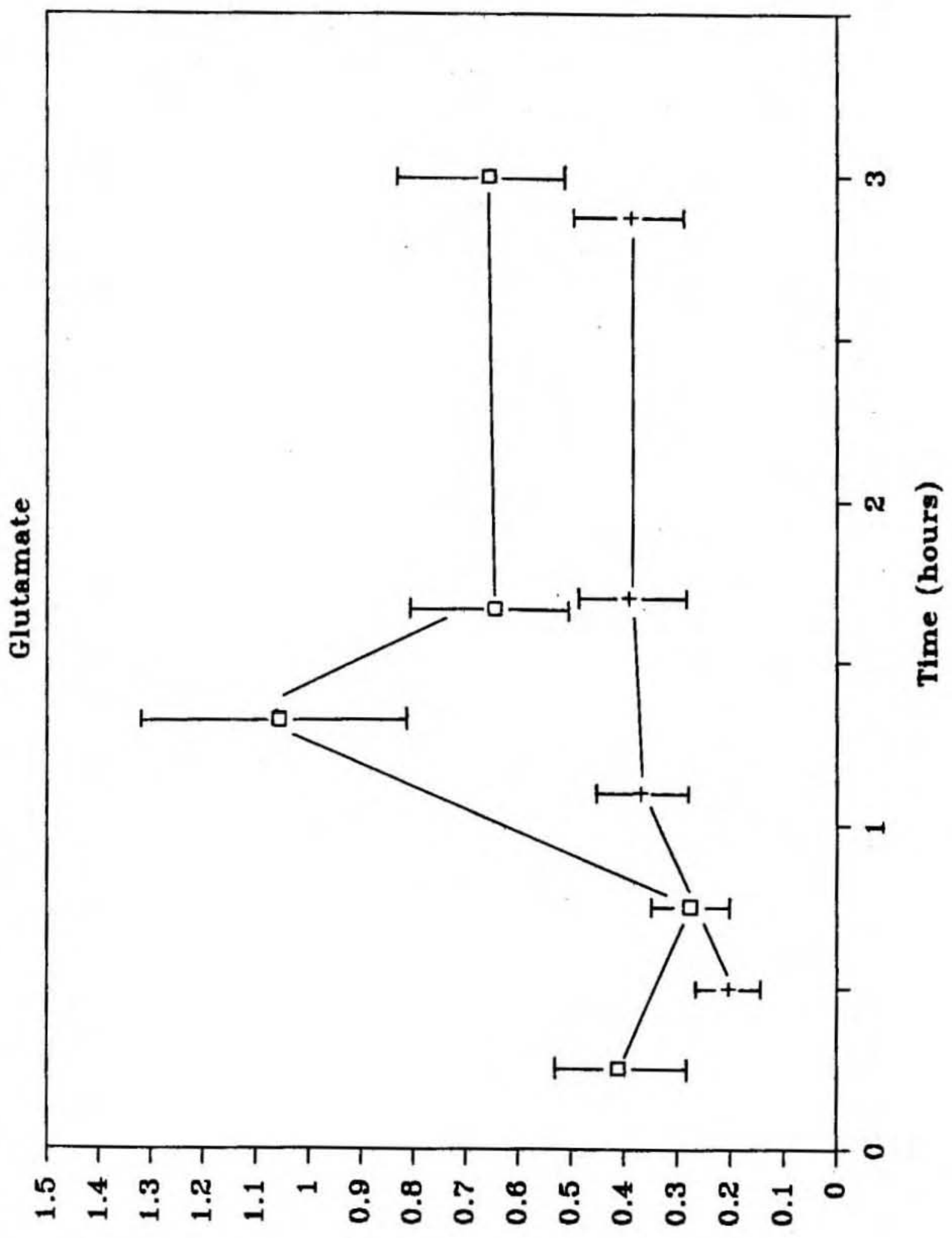

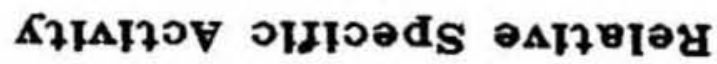


Figure 3-14. Time course of the relative specific activity of intracellular free valine and nascent prote:ln valine in an $\mathrm{NH}_{4}^{+}$-1imited steady state culture of Nannochlor1s sp. at high relative growth rate $\left(\mu / \mu_{\max }=0.933\right)$. Relative specific activity is the specific activity of the amino acid nornalized to that of the dissolved inorganic carbon pool; see text for further discussion. Symbols: square, nascent protein valine specific activity (connected by line); cross, Intracellular free valine specific activity. Errors represent propagated estimates of analyticall error based on 95\% confidence intervals. 


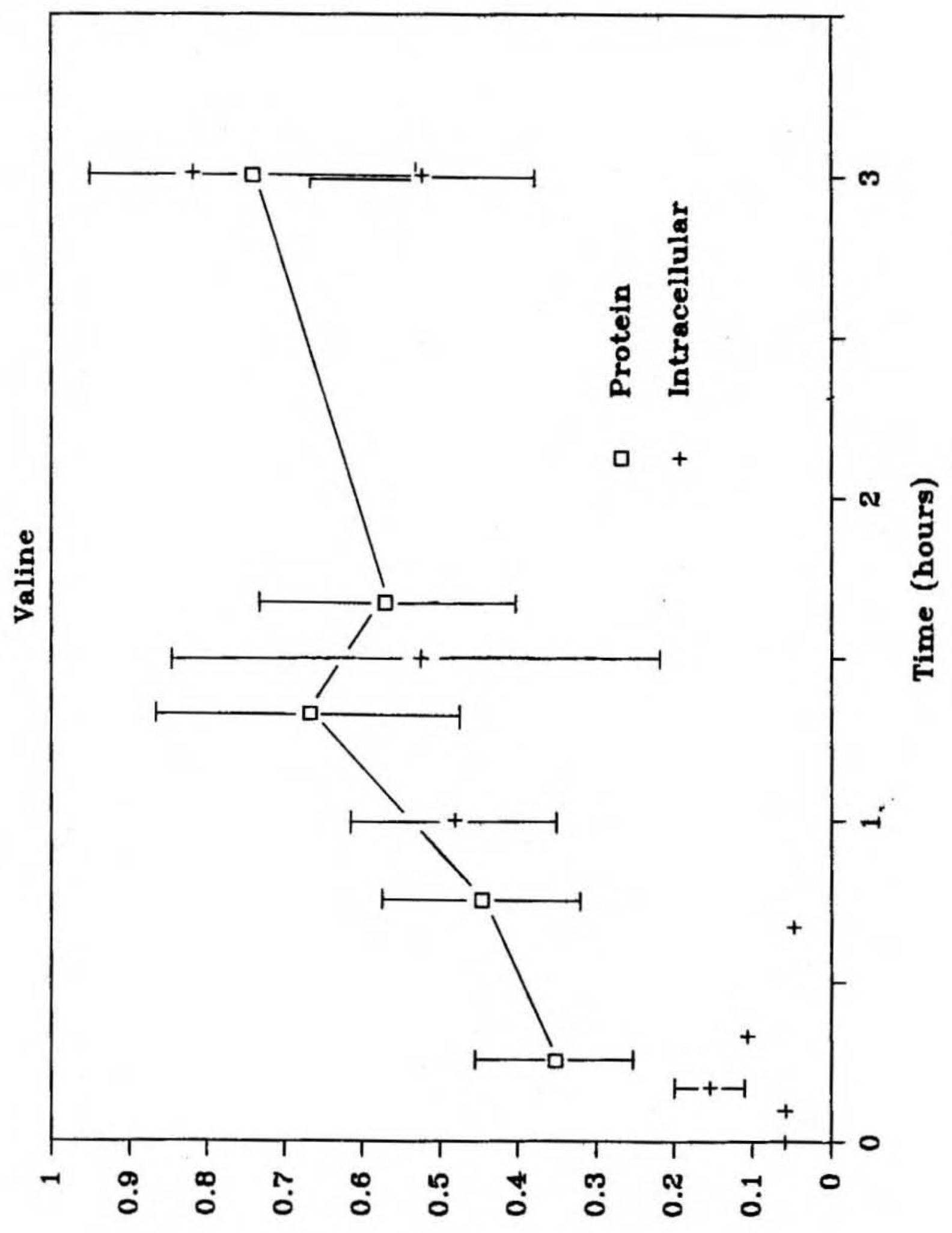

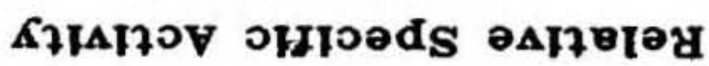


F1gure 3-15. Time course of the relative specific activity of Intracellular free aspartate and nascent protein aspartate in an $\mathrm{NH}_{4}^{+}-11$ mited steady state cultures of Nannochloris sp. at high relative growth rate $\left(\mu / \mu_{\max }=0.933\right)$. Relative specific activity is the specific activity of the amino acid normalized to that of the dissolved Inorganic carbon pool; see text for further discussion. Symbols: square, nascent protein aspartate spec1fic activity; cross, intracellular free aspartate specific activity. Errors represent propagated estimates of analytical error based on $95 \%$ confidence intervals. 


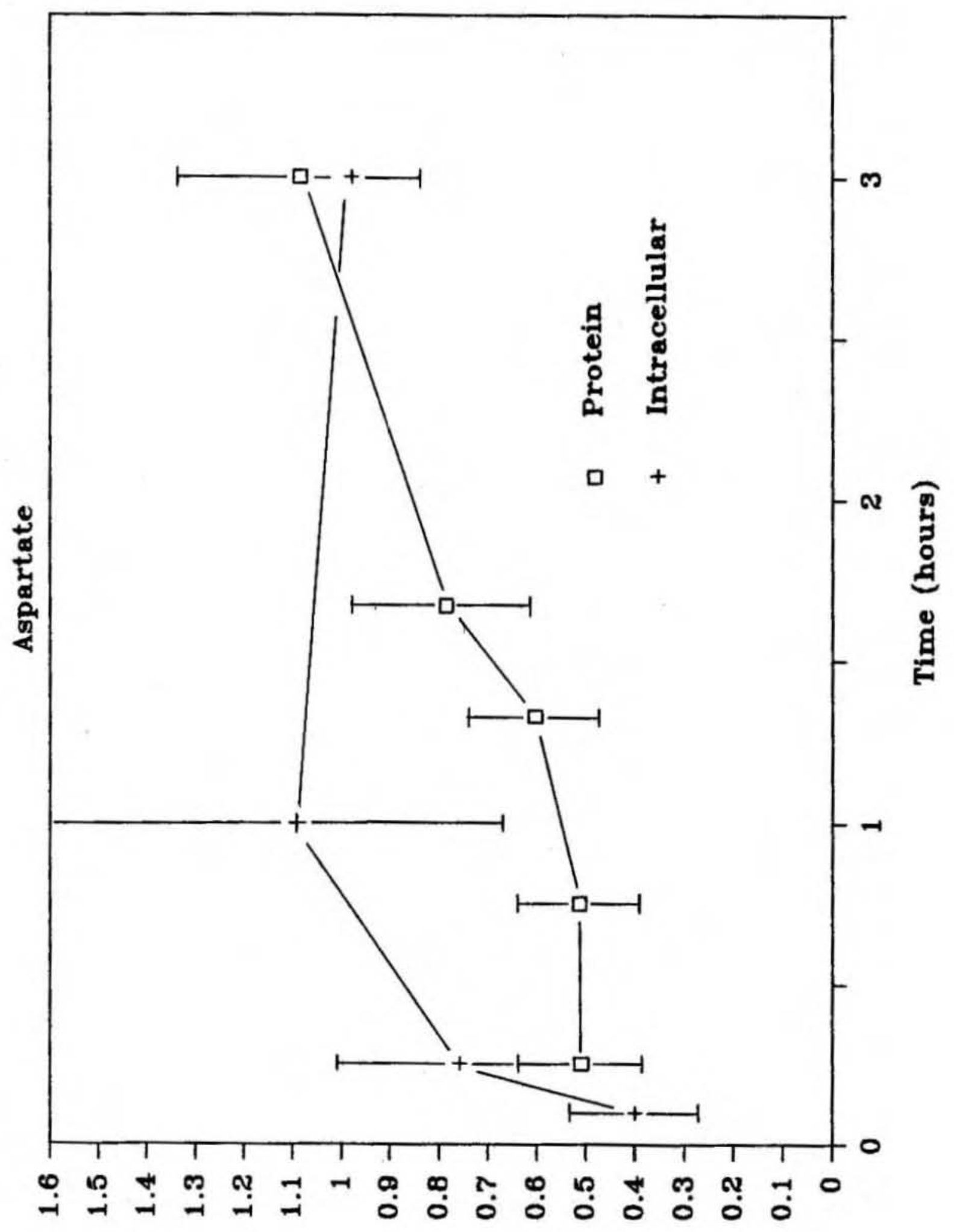

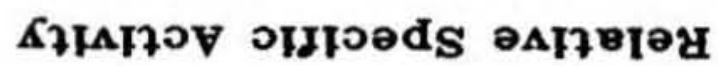


- Figure 3-16. Time course of the relative specific activity of intracellular free valine and nascent protein valine in an $\mathrm{NH}_{4}^{+}$-Iimited steady state culture of Nannochloris $\mathrm{sp}$. at low relative growth rate $\left(\mu / \mu_{\max }=0.229\right)$. Relative specific activity is the specific activity of the amino acid normalized to that of the dissolved inorganic carbon pool; see text for further discussion. Symbols: square, nascent protein valine specific activity; cross, intracellular free valine specific activity. Errors represent propagated estimates of analytical error based on $95 \%$ confidence intervals. 


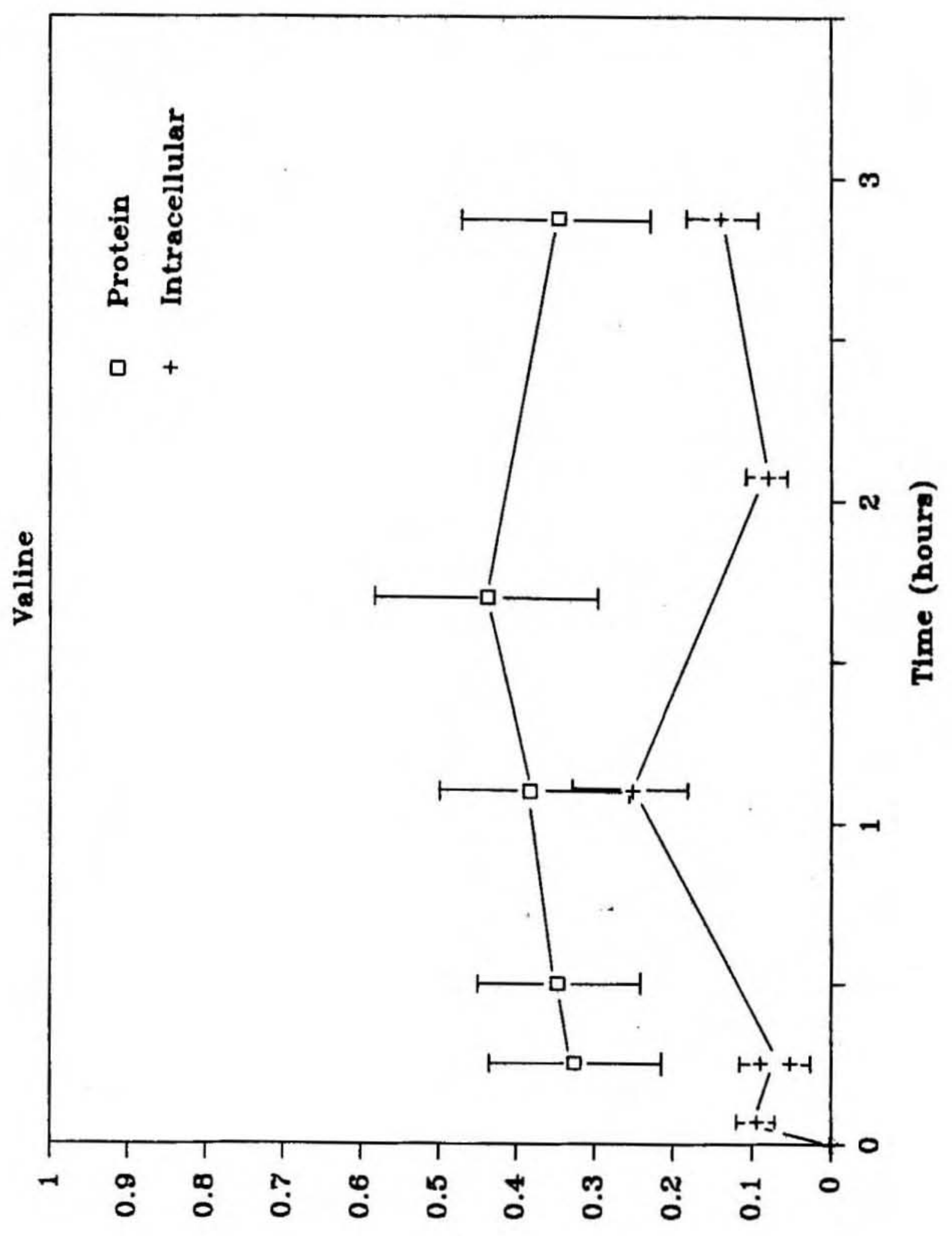

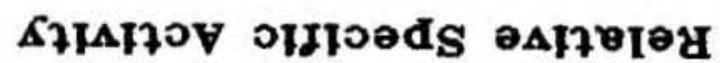


Table 3-5. Relative Specific Activitles of Nascent Proteln Amino Ac1ds In Nannochlor18 8p.

\begin{tabular}{|c|c|c|c|c|c|c|}
\hline \multirow{2}{*}{$\begin{array}{l}\text { Relative } \\
\text { Growth Rate }\end{array}$} & \multirow{2}{*}{$\begin{array}{l}\text { Incubation } \\
\text { Time } \\
\text { (hr) }\end{array}$} & \multirow[b]{2}{*}{$\begin{array}{l}\text { Anino } \\
\text { Acid: }\end{array}$} & \multicolumn{4}{|c|}{ Relative Specific Activities b } \\
\hline & & & GLY & ALA & $\underset{\text { LEU }}{\text { ILE }}+$ & PHE \\
\hline $0.933(0.031)^{c}$ & $\begin{array}{l}0.25 \\
0.75 \\
1.33 \\
1.67 \\
3.0\end{array}$ & & $\begin{array}{l}0.82(0.19)^{d} \\
0.99(0.22) \\
1.05(0.23) \\
1.04(0.23) \\
1.07(0.24)\end{array}$ & $\begin{array}{l}0.94(0.20) \\
0.76(0.16) \\
0.84(0.17) \\
0.99(0.20) \\
1.11(0.23)\end{array}$ & $\begin{array}{l}0.52(0.12) \\
0.57(0.13) \\
0.63(0.14) \\
0.59(0.13) \\
0.63(0.14)\end{array}$ & $\begin{array}{l}1.09(0.45) \\
1.21(0.49) \\
1.44(0.58) \\
1.38(0.55) \\
1.02(0.41)\end{array}$ \\
\hline $0.229(0.016)$ & $\begin{array}{l}0.25 \\
0.50 \\
1.1 \\
1.7 \\
2.87\end{array}$ & & $\begin{array}{l}1.20(0.32) \\
1.26(0.32) \\
1.32(0.33) \\
1.22(0.31) \\
1.05(0.26)\end{array}$ & $\begin{array}{l}1.43(0.39) \\
1.10(0.25) \\
1.05(0.25) \\
1.42(0.34) \\
0.80(0.19)\end{array}$ & $\begin{array}{l}0.32(0.08) \\
0.64(0.16) \\
1.06(0.26) \\
0.89(0.22) \\
0.59(0.14)\end{array}$ & $\begin{array}{l}0.39(0.17) \\
0.68(0.28) \\
1.37(0.57) \\
\text { n.d. e } \\
0.58(0.24)\end{array}$ \\
\hline
\end{tabular}

$\mathrm{a}_{\mu} / \mu_{\max }$ where $\mu_{\max }=1.44(0.04) \mathrm{day}^{-1}$.

belative specifle, activity = dpos/amino acid carbon noraslized to specific activity of the dlssolved Inorganic carbon pool.

'Growth rate errors (1n parentheses) represent $95 \%$ confidence intervals.

dSpeciflc activity errors (In parenthesea) represent propagated estimates of analytical error based on $95 \%$ confidence intervals.

en.d. - no data. 
Analytical methods were not adequate to resolve proline and arginine from hydrolyzed protein, so it 18 not possible to compare nascent protein specific activities directly to intracellular free proline specific activities. However, nascent proteln arginine and proline specific activities were low as were those for free proline (Figure 3-17), which does not support the existence of a segregated proline precursor pool.

The characteristics of nascent protein isoleucine + leucine and phenyalanine were also examined. Differences between high and low relative growth rate were not significant (Table 3-5). Intracellular free amino acid concentrations were close to the limlt of sensitivity for detection, so 1t was not possible to compare free amino acid specific activities with protein.

Thus far, I have discussed the characteristics of saturation of the free and protein amino acids with inorganic carbon. In the case of a few amino acids (glycine, alanine, aspartate, and valine), their saturation rate is rapid enough that their specific activity can be related directly to that of the dissolved inorganic carbon pool. However, this was only the case at the high relative growth rate. Nascent protein glycine and alanine, appear to rapidly equilibrate, irrespective of growth rate. As w1II be demonstrated in Chapter 4, such rapid saturation kinetics make these amino acids ideal model compounds for tracing protein synthesis.

For the remaining amino acids, determining their absolute concentrations based on ${ }^{14} \mathrm{C}$ incorporation is difficult for short incubations. However, it is possible to obtain qualitative descriptions of the free amino acid and proteln composition of the algal biomass by examining the proportions of total ${ }^{14} \mathrm{C}$ uptake associated with these blogenic materials. This information may be useful in providing an Indication of the nitrogen status of an algal population. 
Figure 3-17. Time course of the relative specific activity of nascent protein proline + arginine in $\mathrm{NH}_{4}^{+}-11$ mited steady state cultures of Nannochloris sp. at high and low relative growth rate. Relative specific activity is the specific activity of the amino acid normalized to that of the dissolved inorganic carbon pool; see text for further discussion. Symbols $\left(\mu / \mu_{\max }\right):$ square, 0.933; cross, 0.229. Errors represent propagated estimates of analytical error based on $95 \%$ confidence intervals. 


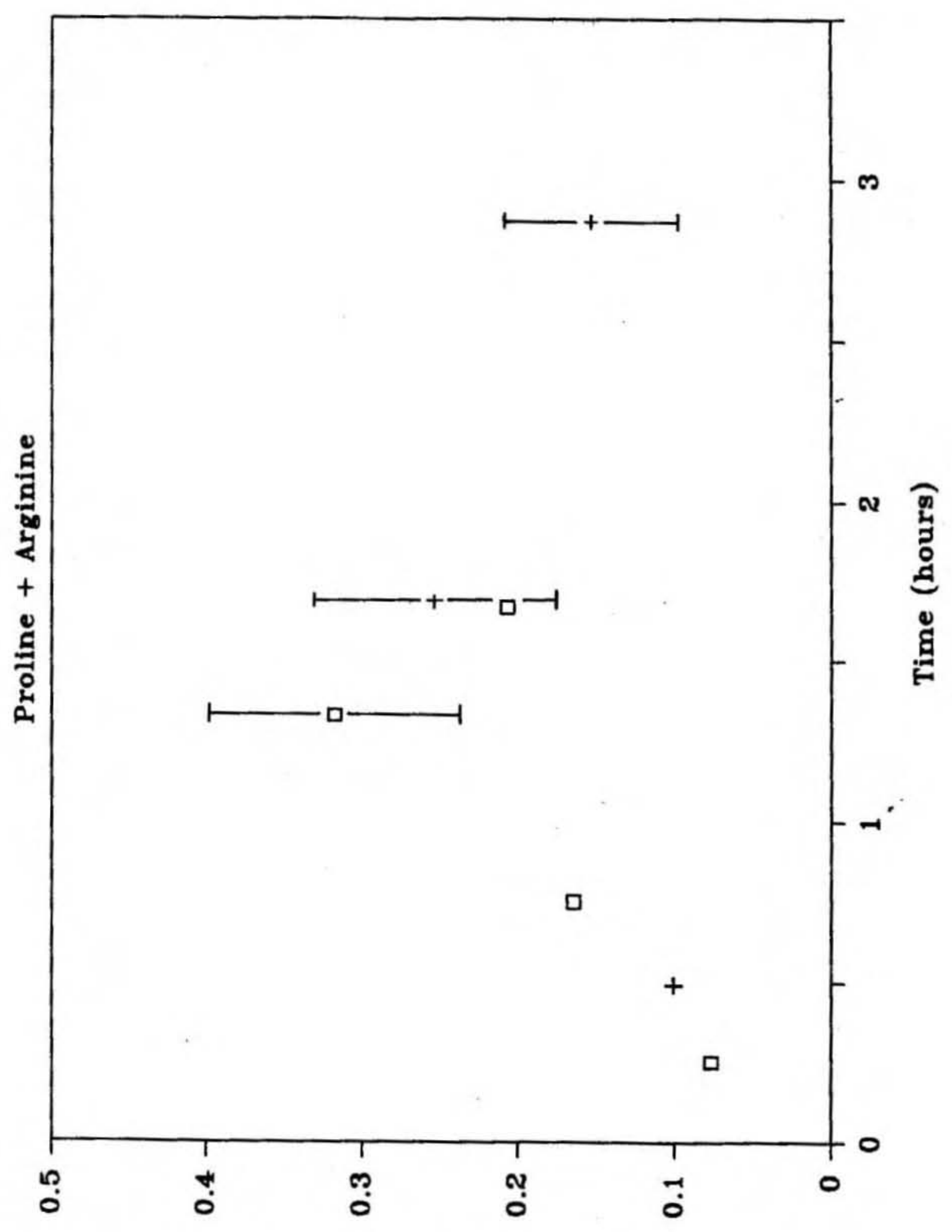


Time Course Distribution of 14C-1abel Among Cellular Materials and Its

\section{Relationship to Cellular Chenical Composition}

In Figure $3-18$, the short term time course distributions of inorganic ${ }^{14} \mathrm{C}$ among different subcellular fractions from a batch culture are compared to equilibrium labeled distributions (1.e. distributions in a culture which had been grown for at least 4 generations in the presence of inorganic ${ }^{14} \mathrm{c}$ ). The operationally defined fractions included alcohol soluble material (intracellular free amino actds and low molecular weight metabolites), ether soluble material (11pophilic material), hot trichloroacetic acid soluble material (carbohydrate and nucleic acids), and an insoluble proteinaceous residue. The dotted line enveloped by the two solid 1ines indicates the mean with $95 \%$ confidence limits for the equilibrium label distribution.

Short term label distributions were initially very different from saturated label distributions. A majority of the label initially accumulates in the alcohol soluble material, and subsequently redistributes. This is an indication that the alcohol soluble material Includes compounds which equilibrate more rapidly than other cell materlal. Discrepancies substantially diminished within the three hour Incubation period, although significant differences persisted for the protein and alcohol soluble fractions. This is consistent with the observations of Cuhel and Waterbury (1984), whose results indicated that short term inorganic ${ }^{14} \mathrm{C}$ distributions underestimated equilibrium distributions in the protein fraction of the cyanobacterium, Synechoccocus sp. even after 6 hours. The equilibrium proportions of label associated with the protein residue agreed well with estimates of 
the proportion of total cellular carbon in protein based on chemical analyses (Table 3-2), suggesting that the equilibrium proportion of ${ }^{14} \mathrm{C}$ in the residue reflected primarily protein carbon.

\section{Comparisons Between the Composition of Free Anino Acids and the}

\section{Distribution of $14 \mathrm{C}$}

In Figure 3-19, the time course distribution of ${ }^{14} \mathrm{C}-1$ abel in the Intracellular free amino acids is compared to other metabolites in the alcohol soluble material. As can be seen, the time dependent variation in distribution is due primarily to the labelling patterns of the intracellular free amino acids. A similar pattern of free amino acid incorporation was observed at both high and low relative growth rates (Figure 3-20).

Although the specific activities of free amino aclds were generally less than that of dissolved Inorganic carbon, their proportion of total ${ }^{14} \mathrm{C}$ uptake exceeded their proportion of total cellular carbon. This is because the free amino acid pools, or portions thereof, saturated more rapidly than other cell material such as protein. The tendency for proportions of total ${ }^{14} \mathrm{C}$ uptake associated with free amino acids to exceed their proportion of total cellular carbon was particularly evident during the initial period of incubation with 1sotope. The proportions of total ${ }^{14} \mathrm{C}$ uptake associated with individual free amino acids are compared to proportions of cellular carbon for the high and low relative growth rates in Tables 3-6 and 3-7 respectively. Because free amino acid carbon was a small proportion of total carbon, the incorporation of ${ }^{14} \mathrm{C}$ into other cell material resulted in a decresse in the proportions of total ${ }^{14} \mathrm{C}$ uptake in free amino acids during the incubation period. 
Figure 3-18. Short term time course of distribution of incorporated inorganic ${ }^{14} \mathrm{C}$ relative to equilibrium label distributions among subcellular fractions in a batch culture of Nannochloris sp. Dotted line indicates mean of equilibrium labeled culture ( 4 generations) w1th 95\% confidence limits designated by solid lines. 


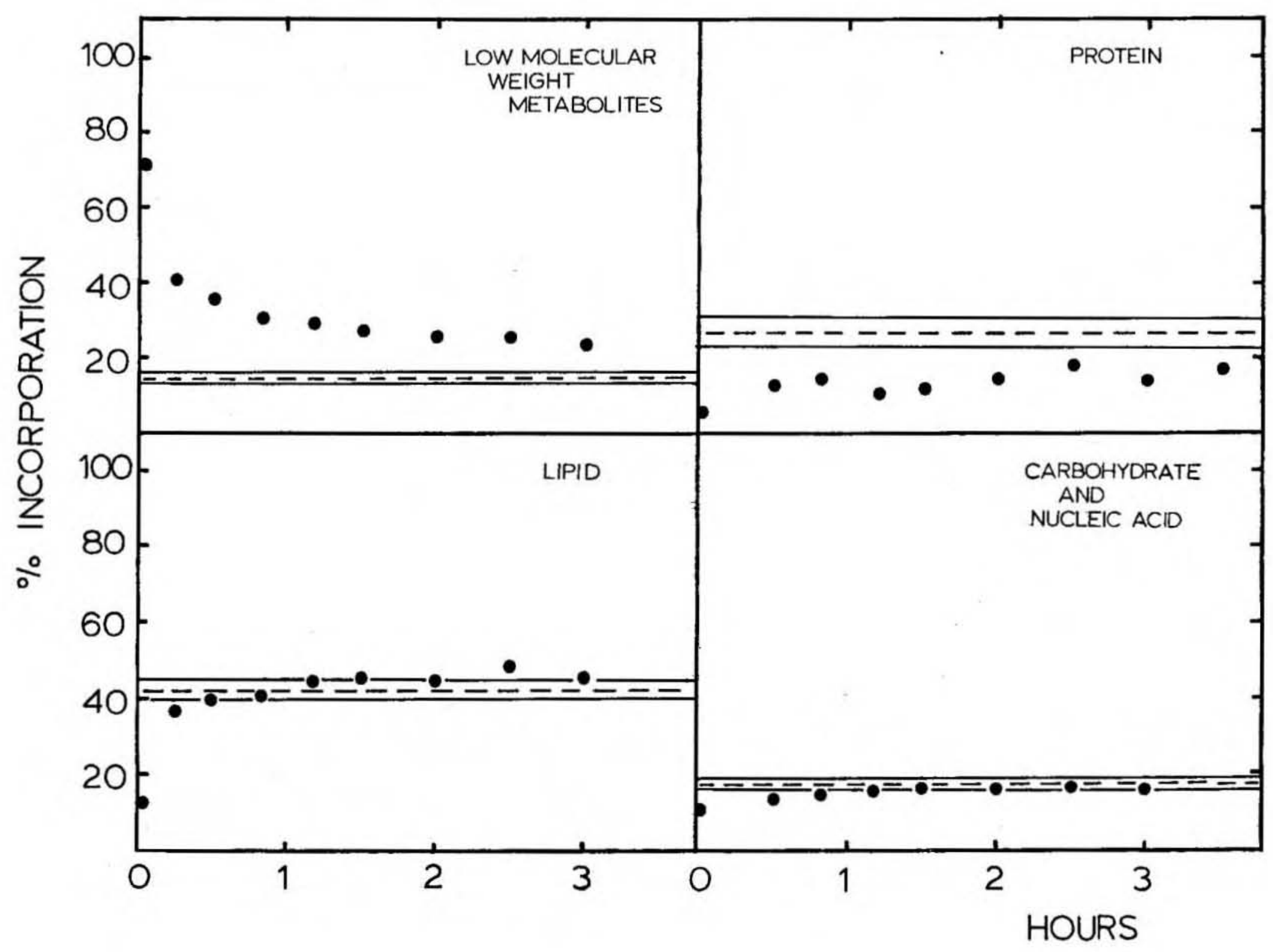


F1gure 3-19. Time course of the distribution of incorporated inorganic

${ }^{14} \mathrm{C}$ in alcohol soluble material from batch cultures of Nannochloris sp. 


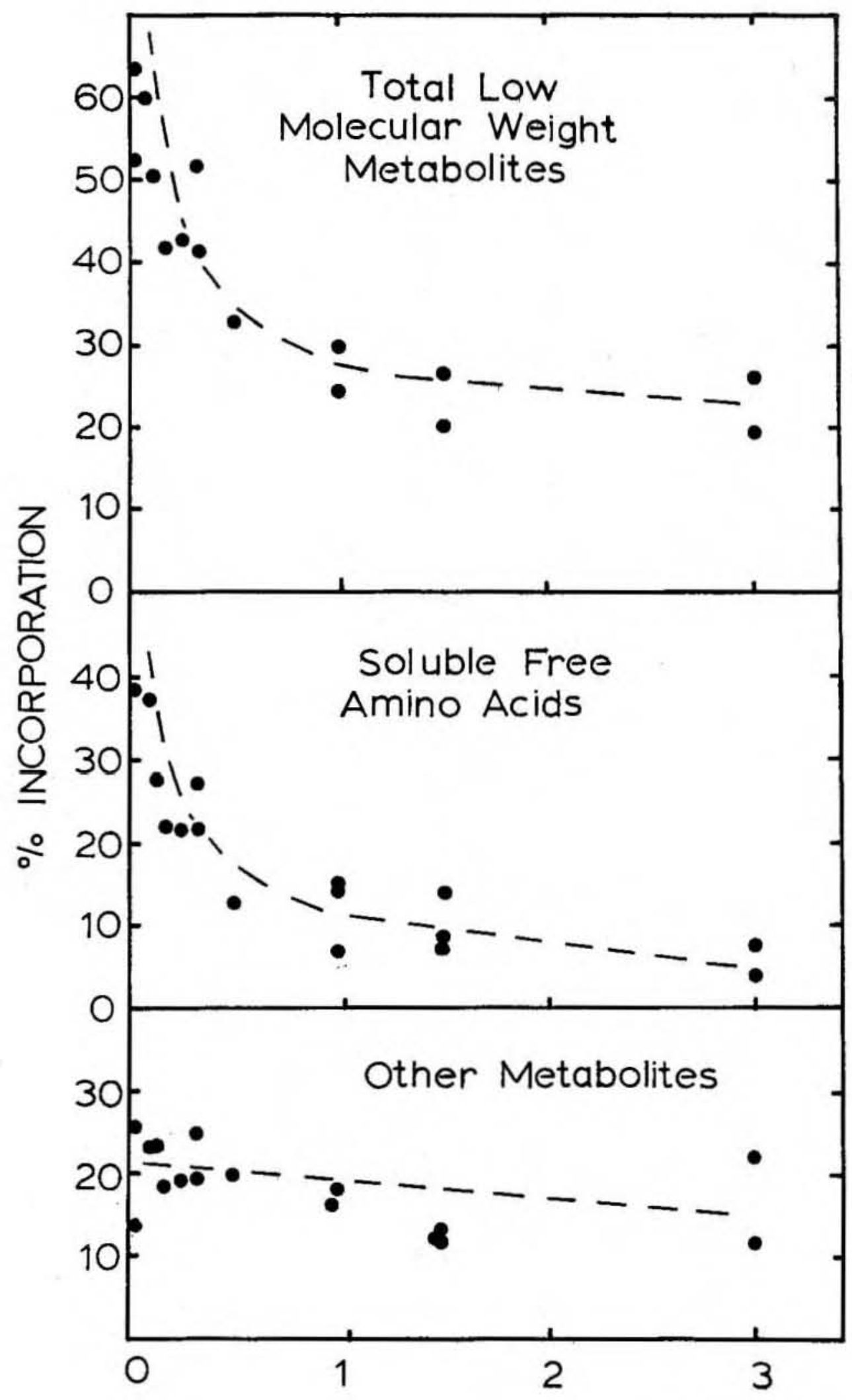

HOURS 
Figure 3-20. Time course of the distribution of incorporated inorgan1c ${ }^{14} \mathrm{C}$ in intracellular free amino acids of $\mathrm{NH}_{4}^{+}-11 \mathrm{mited}$ steady state cultures of Nannochloris 8p. at h1gh and low relative growth rate. Symbols $\left(\mu / \mu_{\max }\right):$ square, 0.933 ; cross, 0.229 . 
-165-

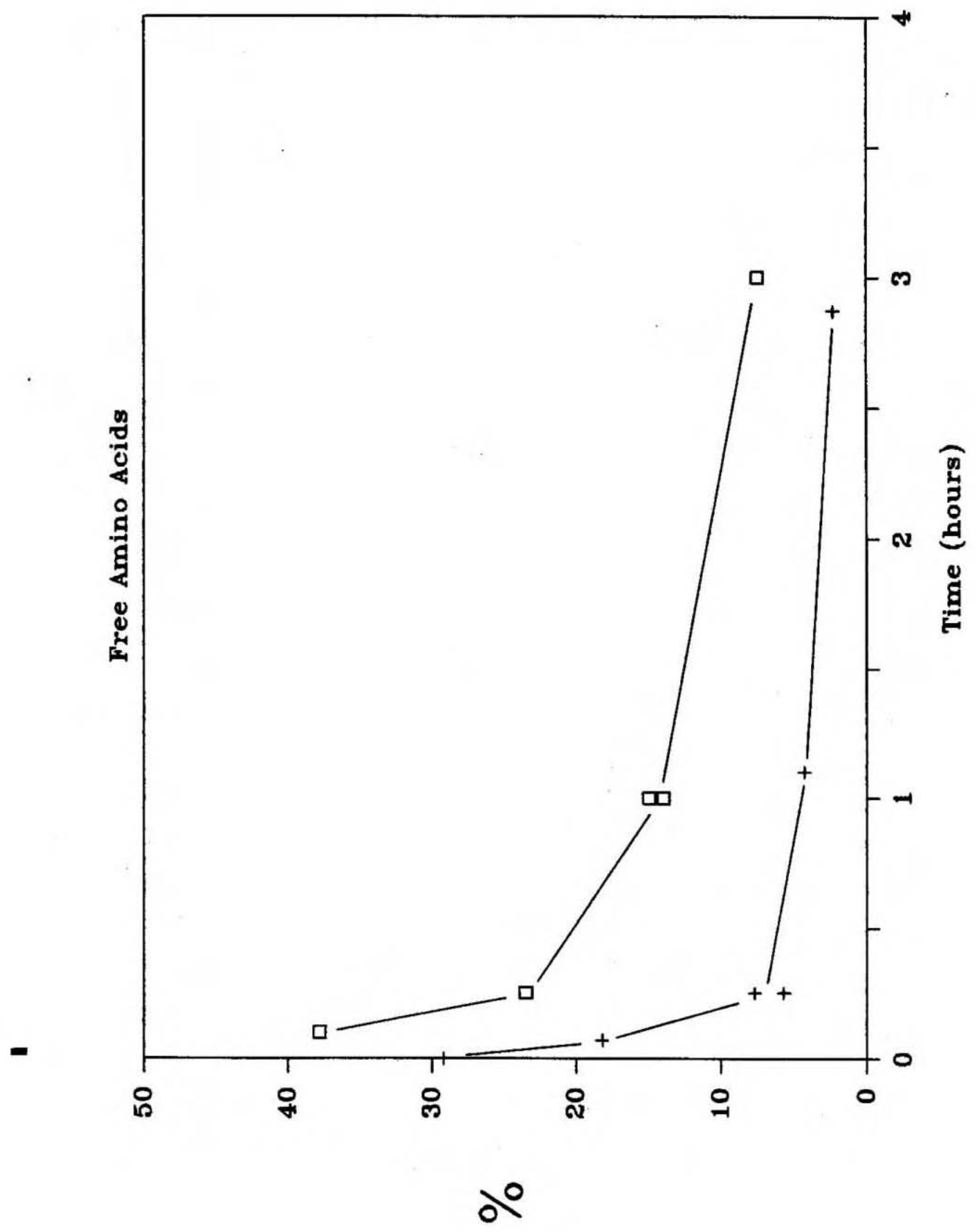


Table 3-6. Distributions of Total Cellular Carbon and Total ${ }^{14} \mathrm{C}$ Uptake Among Free Amino Aclds in Nannochlorls sp. at High Relative Growth Ratea

\begin{tabular}{|c|c|c|c|c|c|c|c|}
\hline \multirow[b]{2}{*}{$\begin{array}{l}\text { Amino } \\
\text { Acld }\end{array}$} & \multirow[b]{2}{*}{ Ce11 $\stackrel{\%}{\text { Carbon }}$} & \multirow[b]{2}{*}{$\begin{array}{l}\text { Incubation } \\
\text { Time (hrs): }\end{array}$} & \multicolumn{5}{|c|}{$\% 14 \mathrm{C}-$-Carbon } \\
\hline & & & 0.1 & 0.25 & 1.0 & 1.0 & 3.0 \\
\hline ASP & $0.047(0.010)^{b}$ & & 4.6 & 2.8 & 1.2 & 1.2 & 0.28 \\
\hline GLU & $0.41(0.085)$ & & 8.3 & 6.1 & 3.8 & 4.2 & 1.6 \\
\hline GLN & $0.51(0.14)$ & & 2.0 & 2.8 & 2.4 & 2.2 & 1.0 \\
\hline THR & $0.009(0.001)$ & & 0.89 & 0.65 & 0.56 & 0.28 & 0.10 \\
\hline SER & $0.017(0.017)$ & & 2.5 & 1.3 & 1.0 & n.d.c & n.d. \\
\hline \multicolumn{8}{|l|}{ GLY + } \\
\hline ALA & $0.057(0.036)$ & & 6.8 & 3.0 & 0.94 & 1.0 & 0.29 \\
\hline PRO & $3.4(0.58)$ & & 1.1 & 0.85 & 1.6 & 1.4 & 1.8 \\
\hline VAL & $0.074(0.023)$ & & 1.7 & 0.80 & 0.23 & 0.67 & 0.21 \\
\hline Total & $4.5(0.9)$ & & 27.9 & 18.3 & 11.7 & 11.0 & 5.3 \\
\hline
\end{tabular}

$a_{\mu / \mu_{\max }}=0.933$.

bValues in parentheses represent $95 \%$ confidence intervals.

$c_{\text {n.d. }}=$ no data. 
Table 3-7. Distributions of Cellular Carbon and Total ${ }^{14} \mathrm{C}$ Uptake Among Free Amino Aclds in Nannochloris sp. at Low Relative Growth Ratea

\begin{tabular}{|c|c|c|c|c|c|c|c|c|c|}
\hline \multirow[b]{2}{*}{$\begin{array}{l}\text { Amino } \\
\text { Acid }\end{array}$} & \multirow[b]{2}{*}{ Ce11 $\stackrel{\%}{\text { Carbon }}$} & \multirow[b]{2}{*}{$\begin{array}{l}\text { Incubation } \\
\text { Time (hrs): }\end{array}$} & \multicolumn{7}{|c|}{$\%$ 14C-Carbon } \\
\hline & & & 0.0 & 0.07 & 0.25 & 0.25 & 1.1 & 2.07 & 2.87 \\
\hline ASP & \multicolumn{2}{|l|}{$0.004(0.005)^{b}$} & 3.1 & 1.0 & 0.40 & 0.48 & 0.28 & 0.29 & 0.008 \\
\hline GLU & \multicolumn{2}{|l|}{$0.16(0.05)$} & 10.2 & 6.3 & 3.0 & 3.0 & 2.8 & 0.69 & 0.64 \\
\hline GLN & \multicolumn{2}{|l|}{$0.01(0.005)$} & $N D^{C}$ & 0.26 & 0.08 & 0.11 & 0.14 & n.d.d & 0.03 \\
\hline SER & \multicolumn{2}{|l|}{$0.003(0.003)$} & $\mathrm{ND}$ & 1.1 & 0.30 & 0.37 & 0.17 & n.d & n.d. \\
\hline THR & \multicolumn{2}{|l|}{$0.002(0.001)$} & ND & n.d. & 0.17 & 0.10 & 0.13 & 0.03 & n.d. \\
\hline GLY + & \multirow{2}{*}{\multicolumn{2}{|c|}{$0.03(0.01)$}} & & & & & & & \\
\hline ALA & & & 14.2 & 4.6 & 1.5 & 1.6 & 0.54 & 0.27 & 0.19 \\
\hline PRO & \multicolumn{2}{|l|}{$0.06(0.03)$} & ND & 0.38 & 0.08 & 0.07 & 0.27 & 0.18 & 0.09 \\
\hline VAL & \multicolumn{2}{|l|}{$0.01(0.004)$} & ND & 0.76 & 0.22 & 0.26 & 0.09 & 0.04 & 0.05 \\
\hline Total & \multicolumn{2}{|l|}{$0.31(0.07)$} & 27.5 & 14.4 & 5.8 & 6.0 & 4.4 & 1.5 & 1.0 \\
\hline
\end{tabular}

$\mathrm{a}_{\mu / \mu_{\max }}=0.229$.

bValues in parentheses represent $95 \%$ confidence intervals.

$\mathrm{C}_{\mathrm{ND}}=$ not detectable.

$d_{\text {n.d. }}=$ no data. 
Their proportion of total ${ }^{14} \mathrm{C}$ uptake approached the corresponding proportions of cellular carbon. An exception to this at the high relative growth rate was proline. Its proportion of ${ }^{14} \mathrm{C}$ uptake underestimated its proportion of cellular carbon and gradually increased rather than decreased. This is consistent with its slow saturation rate and large relative abundance of the intracellular proline pool at high relative growth rate (Table 3-3; F1gure 3-1).

Examination of the ${ }^{14} \mathrm{C}$ distributions within the free amino acid pool revealed that most of the label was initially associated with glutamate, glycine + alanine, and aspartate (Tables 3-8 and 3-9). Other free amino acids which subsequently accounted for substant1al proportions of label included glutamine, serine, proline and valine. Pathways for the biosynthesis of glutamate, glutamine, aspartate, alanine, glycine and serine are shown in $\mathrm{Fig}$. 3-10. The initial accumulation of label in these amino acids is an indication of the close relationship between the photosynthetic carbon reduction cycle, and the production of carbon skeletons for amino acid blosynthesis (e.g. Miflin and Lea, 1976). In Figure 3-21, distributions of ${ }^{14} \mathrm{C}$ are compared to distributions of cellular carbon within the intracellular free amino acid pool. Although there were quantitative differences, particularly in the case of proline, the label distribution did provide a qualitative description of the growth rate dependence of free amino acid composition. Qualitative changes in the amounts of label assoclated with glutamate and glutamine tended to reflect their relative abundance. Even, in the case of proline, although the proportion of ${ }^{14} \mathrm{C}$ consistently underestimated its proportion of carbon, qualitative relationships between high and low relative growth rates reflected the trends in actual abundance. Thus the 
Table 3-8. Proportions of Intracellular Free Amlno Acld Carbon and

${ }^{14} \mathrm{C}$ Associated With Individual Amino Aclds of Nannochloris sp. at High Relative Growth Rate ${ }^{a}$

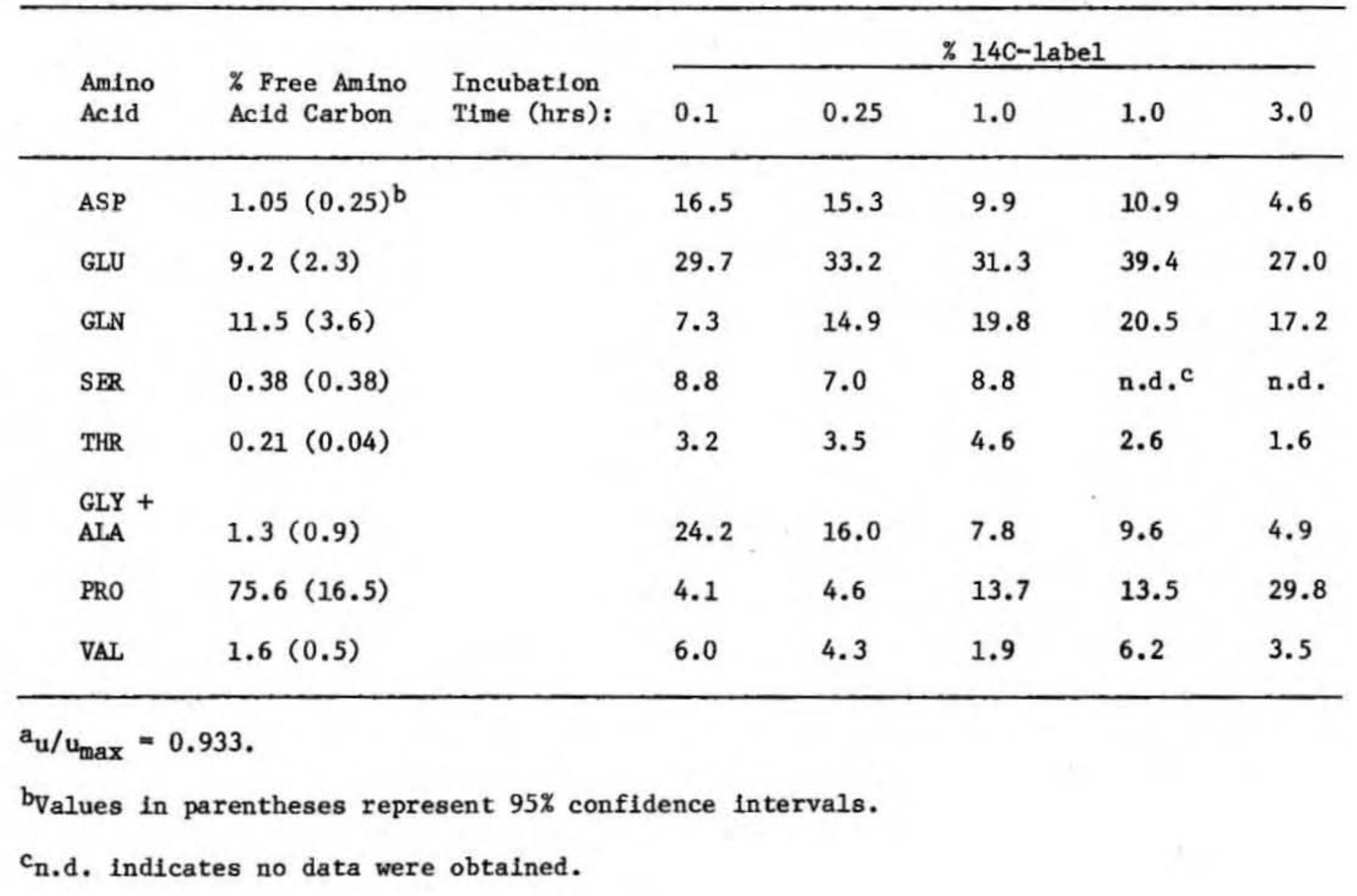


Table 3-9. Proportions of Intracellular Free Amino Ac1d Carbon and

${ }^{14} \mathrm{C}$ Associated with Individual Amino Acids of Nannochloris sp. at Low Relative Growth Ratea

\begin{tabular}{|c|c|c|c|c|c|c|c|c|}
\hline \multirow[b]{2}{*}{$\begin{array}{l}\text { Amino } \\
\text { Acld }\end{array}$} & \multirow[b]{2}{*}{$\begin{array}{l}\text { \% Free Amino } \\
\text { Acid Carbon }\end{array}$} & \multirow[b]{2}{*}{$\begin{array}{l}\text { Incubation } \\
\text { Time (hrs): }\end{array}$} & \multicolumn{6}{|c|}{$\%$ 14C-1abe1 } \\
\hline & & & 0.0 & 0.07 & 0.25 & 0.25 & 1.1 & 2.87 \\
\hline ASP & $1.3(1.6)^{b}$ & & 10.4 & 5.6 & 6.5 & 7.7 & 6.0 & 7.2 \\
\hline GLU & $53.4(14.9)$ & & 34.3 & 34.3 & 50.0 & 47.4 & 61.1 & 59.4 \\
\hline GLN & $3.7(1.6)$ & & $\mathrm{ND}^{\mathrm{C}}$ & 1.5 & 1.4 & 1.2 & 3.0 & 2.8 \\
\hline SER & $0.92(0.69)$ & & n.d. & 5.9 & 5.0 & 5.9 & 3.8 & n.d.d \\
\hline THR & $0.71(0.31)$ & & $\mathrm{ND}$ & n.d. & 2.9 & 1.6 & 2.8 & n.d. \\
\hline $\begin{array}{l}\text { GLY + } \\
\text { ALA }\end{array}$ & $8.8(3.1)$ & & 48.0 & 25.3 & 25.2 & 25.6 & 11.6 & 17.6 \\
\hline PRO & $21.4(8.6)$ & & n.d. & 2.1 & 1.4 & 1.2 & 5.8 & 8.3 \\
\hline VAL & $3.7(1.3)$ & & n.d. & 4.1 & 3.5 & 4.2 & 2.0 & 4.4 \\
\hline
\end{tabular}

$a_{u} / u_{\max }=0.229$.

bValues in parentheses represent $95 \%$ confidence intervals.

$\mathrm{c}_{\mathrm{ND}}=$ not detectable.

$d_{n \cdot d .}=$ no data . 
metabolism of inorganic ${ }^{14} \mathrm{C}$ is a useful probe of this sensitive level of cellular chemical composition, which is a reflection of population nitrogen status.

\section{Time Course Distributions of 14C Among Subcellular Fractions as a}

\section{Function of Relative Growth Rate}

It is clear from the previous discussion that the extent to which the distribution of ${ }^{14} \mathrm{C}$ reflects amino acid composition is time dependent, and influenced by growth rate. In this section, I discuss the time course distribution of ${ }^{14} \mathrm{C}$ among other cell materials as $1 \mathrm{t}$ is influenced by relative growth rate. In Figure 3-22, the time course label distributions for high $\left(u / u_{\max }=0.933\right)$ and 1 low $\left(u / u_{\max }=\right.$ 0.229) relative growth rates are compared. At low relative growth rate, a higher proportion of label is associated with the ether soluble nonpolar materlal, a substantial proportion of which probably consists of 1ipid. Futhermore, a consistently lower proportion of label was associated with the protein residue at low relative growth rate. This is In agreement with the trend in the proportion of total particulate carbon associated with protein based on chemical analyses (Table 3-2). Initially, a slightly higher proportion of label is associated with the hot trichloroacetic acid soluble material at the low relative growth rate, but this subsequently decreased. Finally, the proportion of label assoclated with the alcohol soluble low molecular weight material is consistently lower at low relative growth rate than at high relative growth rate. This is due to the labelling characteristics of the intracellular free amino acids (Figure 3-20). 
Figure 3-21. Proportions of intracellular free amino ac1d carbon and ${ }^{14} \mathrm{C}$ associated with individual amino ac1ds of $\mathrm{NH}_{4}^{+}-1$ imited steady state cultures of Nannochloris $\mathrm{sp}$. at high $\left(\mathrm{u} / \mathrm{u}_{\max }=0.933\right)$ and low $\left(\mu / \mu_{\max }=0.229\right)$ relative growth rates. 


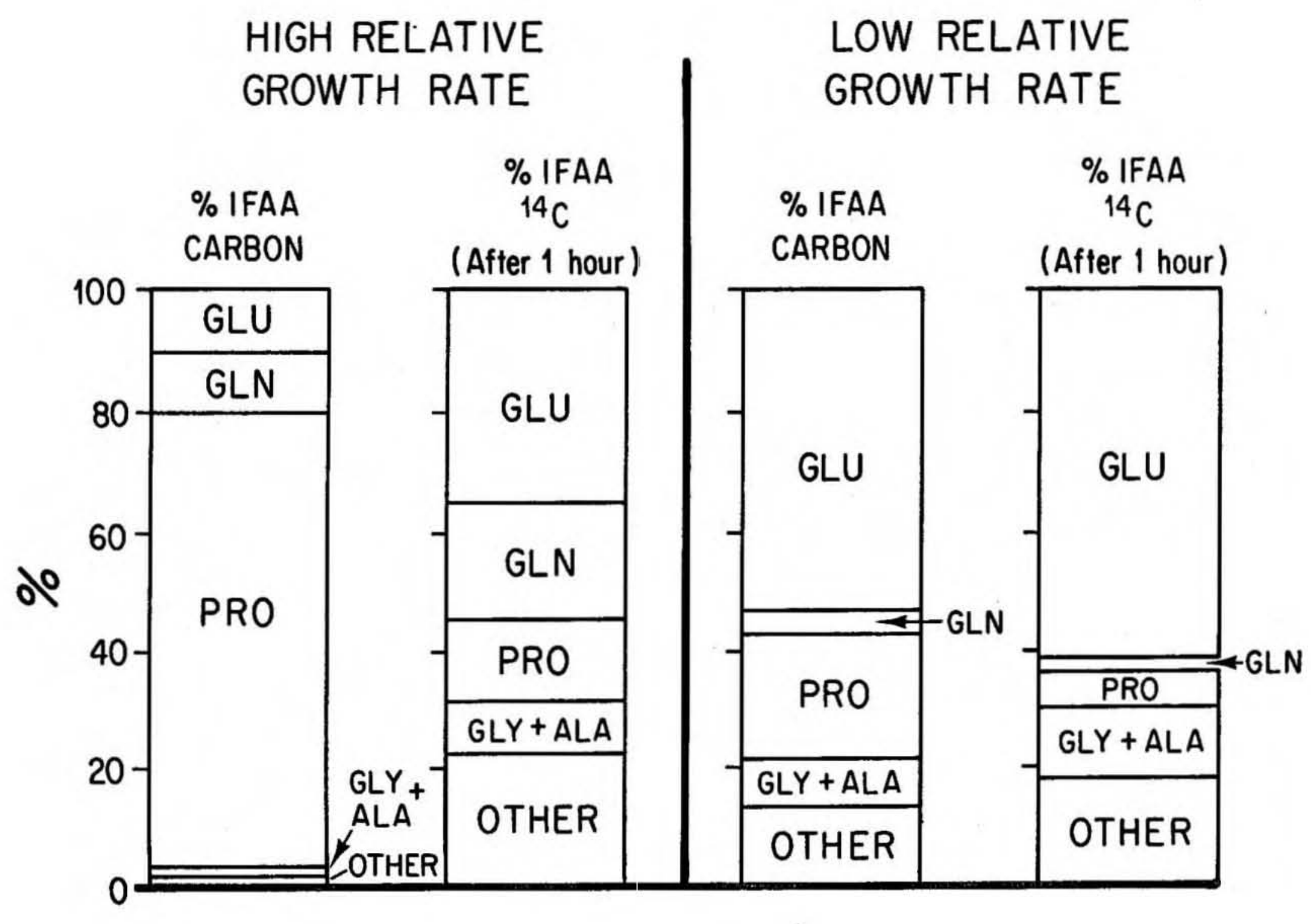


Figure 3-22. Time course of the distribution of incorporated inorganic ${ }^{14} \mathrm{C}$ among subcellular fractions in $\mathrm{NR}_{4}^{+}-11$ mited steady state cultures of Nannochloris sp. at high and low relative growth rate. Symbols $\left(\mu / \mu_{\max }\right):$ square, 0.933 ; cross, 0.229 . 

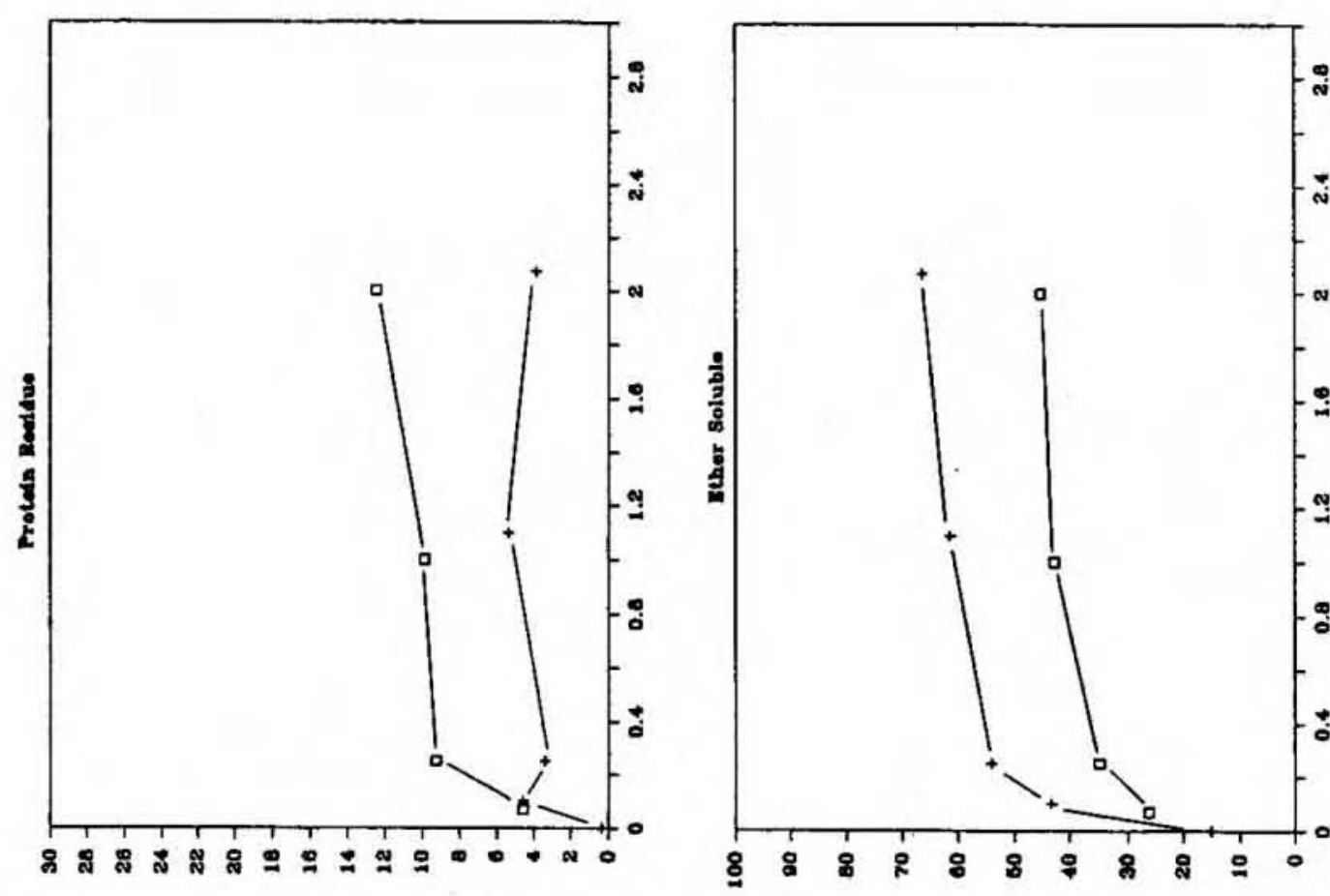

弯
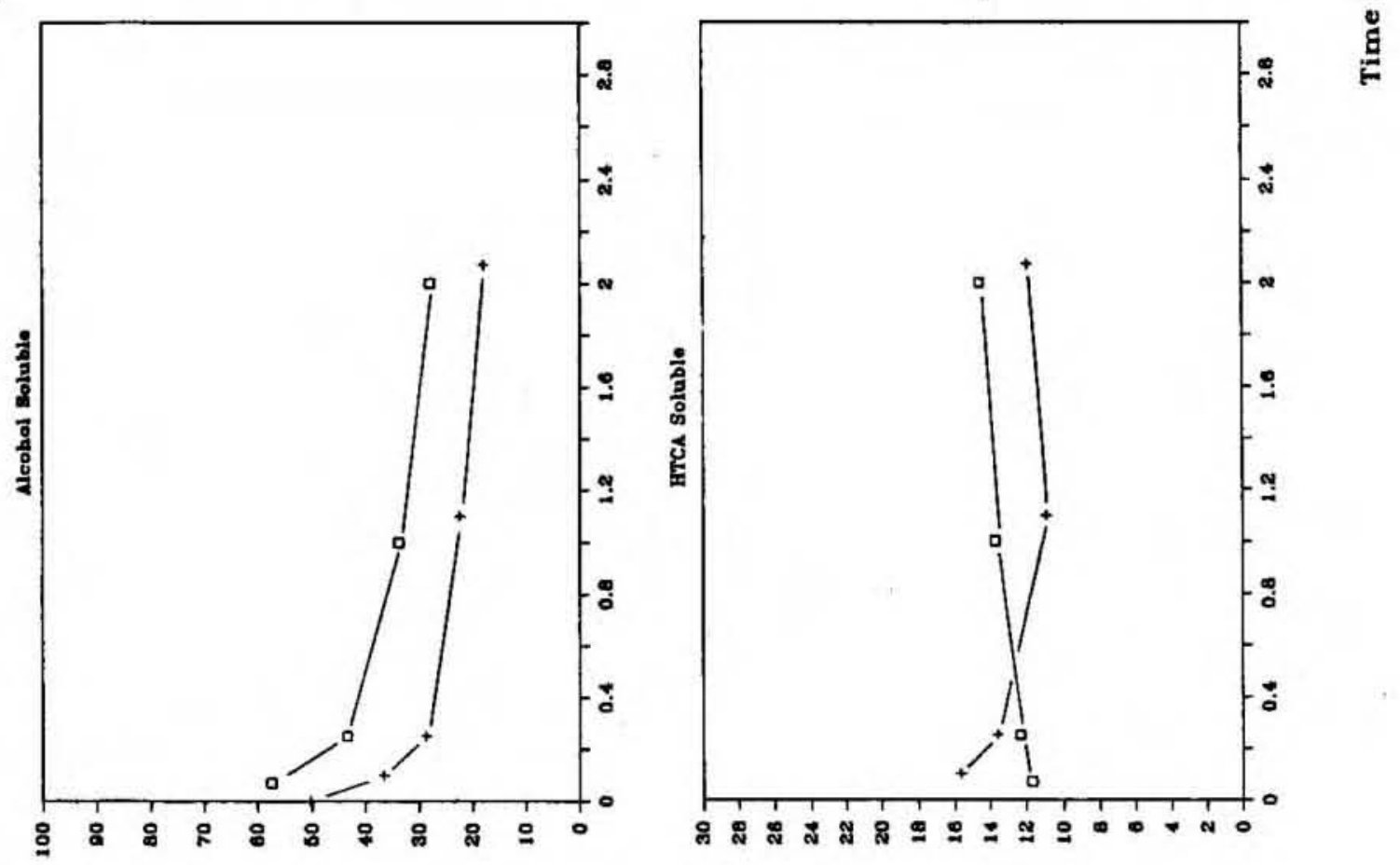

dீ 
F1gure 3-23. Distribution of total cellular carbon and total ${ }^{14} \mathrm{C}$ uptake among intracellular free amino acids and protein in $\mathrm{NH}_{4}^{+}-1$ imlted steady state cultures of Nannochloris sp. at high $\left(\mu / \mu_{\max }=0.933\right)$ and low $\left(\mu / \mu_{\max }=0.229\right)$ relat1ve growth rates. 


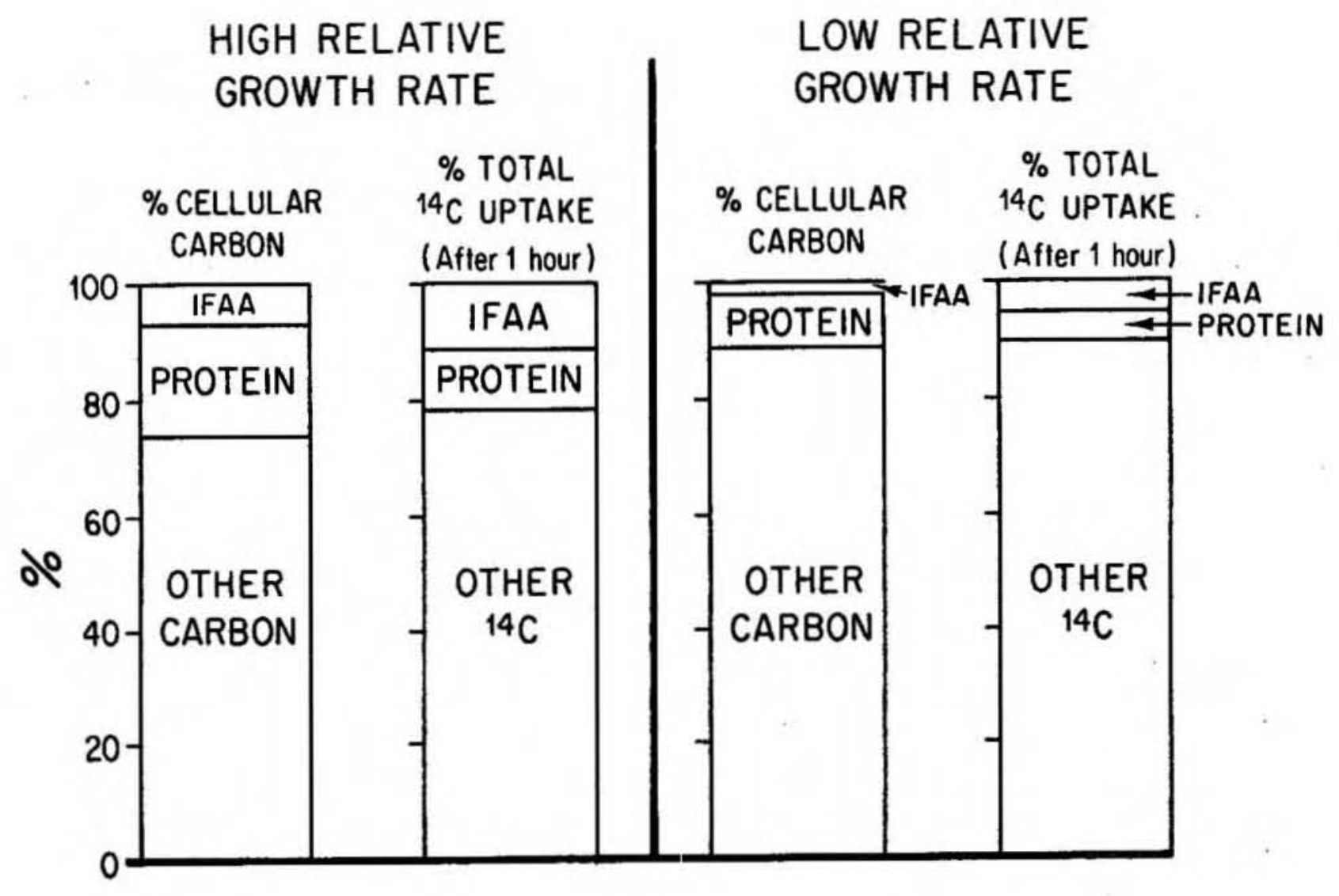


The growth rate dependent differences in the distribution of ${ }^{14} \mathrm{C}$ among free amino acids and protein reflected actual trends in chemical composition (Table 3-1 and 3-2; FIg. 3-23). These data demonstrate the utility of using the dynamics of ${ }^{14} \mathrm{C}$ metabolism to probe actual compositional variations related to physiological state.

A higher proportion of label assoclated with ether soluble material at low relative growth rate was was an indication of greater emphasis on energy storage rather than growth related metabolism. This is consistent w1th the large number of investigations which have reported increased $C: N$ rat1os (e.g. Conover, 1975; Goldman and Peavey, 1979; Goldman et al., 1979; Goldman, 1980), and Increased abundance of storage materials relative to nitrogen contalning blogenic materlal, and increased carbohydrate to proteln ratios (e.g. Fogg, 1959; Handa, 1969; Myklestad and Haug, 1972; Edge and Rlcketts, 1977; Myklestad, 1977; Rhee, 1978, 1980; Morris, 1981). In addition, my results are consistent with studies involving regulatory characteristics of enzymes controlling tradeoffs between energy storage and production of precursors for growth and protein synthesis (e.g. Hipkin and Syrett, 1977; Mohamed and Gnaman, 1979). Fogg (1956) similarly reported enhanced incorporation of ${ }^{14} \mathrm{C}$-label into nonpolar cellular material in nitrogen starved cultures. Konopka and Schnur (1981) reported enhanced assimilation of ${ }^{14} \mathrm{C}$ into hot trichloroacetic acid extractable material (polysaccharide and nucleic acid) In nitrogen limited cultures of the cyanobacterium, Merismopedia tenuissima. In contrast, Morris et a1. (1974) presented evidence for enhanced protein incorporation in nitrogen 1imited cultures of Phaeodactylum tricornutum, which he attributed to conservation of proteln synthesis as a result of nitrogen limitation. Konopka and Schnur 
(1981) suggested that the results of Morris et al. may have been due to the fact that nitrate $11 \mathrm{mited}$ cultures were resuspended in fresh medium before incubating with inorganic ${ }^{14} \mathrm{C}$. This would have been equivalent to enriching the cultures with inorganic nitrogen. In the following sections, I examine the metabolic responses of an $\mathrm{NH}_{4}^{+}-11$ mited culture to enrichment with $\mathrm{NH}_{4}^{+}$.

\section{EFFECTS OF NH4+ ENRICHMENT ON AMINO ACID AND TOTAL CARBON} METABOLISM IN AN NH4+-LTMITED STEADY STATE CULTURE OF NANDOCHLORIS SP.

In the preceding section, I presented results of experiments examining the relationship of amino acid and protein composition to incorporation of inorganic ${ }^{14} \mathrm{C}$ in steady state $\mathrm{NH}_{4}^{+}-11$ mited cultures. Because of the dynamic physicochemical environment in which they exist, natural phytoplankton populations are unlikely to be in a state of balanced growth. In this section, I discuss the relationship between free amino acid composition and incorporation of inorganic ${ }^{14} \mathrm{C}$ by $\mathrm{NH}_{4}^{+}$-1imited cultures exposed to a saturating enrlchment of $\mathrm{NH}_{4}^{+}$. The results illustrate the utility of using ${ }^{14} \mathrm{C}$ for tracing cellular composition and metabolism in non-steady state conditions. As w111 be demonstrated, intracellular free amino ac1d metabolism is more sensitive to increases in nitrogen supply than total ${ }^{14} \mathrm{C}$ uptake, supporting the view that probing responses at this level of metabolism may be useful in diagnosing the nitrogen status of phytoplankton populations. 


\section{METHODS}

Nannochloris sp. was grown in continuous culture at a relative growth rate of $.216(.028)$ day $^{-1}$. The temperature was $24^{\circ} \mathrm{C}$. $\mathrm{NH}_{4} \mathrm{Cl}$ concentration in the media was 250 micromolar and all other nutrients were present at " $h / 2$ " concentrations (w1thout s1licate and nitrate, Guillard, 1975) in an artificlal seawater base as described in chapter 2. The culture vessel was a liter Erlenmeyer flask, equipped with a butyl rubber stopper through which glass tubing was run for air sparging, sampling, media addition and effluent removal. Media was delivered through a latex rubber tube using a Harvard peristaltic pump. Efforts were made to maintain axenic conditions, however, they were not checked other than by microscopic Inspection (1000X, ofl immersion). Other culturing conditions were as described in chapter 2.

After the culture cell counts had stabilized for 2 consecutive days (approximate cell density of $10^{7}$ per $\mathrm{ml}$ ), two $100 \mathrm{ml}$ aliquots were removed and placed in $250 \mathrm{ml}$ Erlenmeyer flasks under the same conditions of 11 ght and temperature. Inorganic ${ }^{14} \mathrm{C}$ was added to both flasks and subsequently, to one of the flasks, $\mathrm{NH}_{4} \mathrm{Cl}$ was added to a concentration of 200 micromolar. Samples were filtered onto Whatman GF/F filters, fumed with $6 \mathrm{~N} \mathrm{HCl}$ for 10 minutes, sealed in Nalgene filmware polypropylene envelopes, and stored at $-20^{\circ} \mathrm{C}$ until analysis. $2 \mathrm{ml}$ samples were also collected for determination of actd non-volatile ${ }^{14} \mathrm{C}$. These samples were acidified in a $20 \mathrm{ml}$ glass scintillation vial to a concentration of $0.316 \mathrm{~N} \mathrm{H}_{2} \mathrm{SO}_{4}$, and left in a fume hood overnight. Subsequently, $15 \mathrm{ml}$ Aquasol was added, and they were radioassayed as described previously. 
Samples were fractionated according to the procedure described previous1y, within one week of the harvest. Radioactivity in the ether, hot trichloroacetic acid, and protein residue fractions was assayed as described in the general methods. The alcohol extract was stored at $-20^{\circ} \mathrm{C}$ unt11 amino ac1ds were quantified and radioassayed as previously described.

All other methods are described in chapter 2.

\section{RESULTS AND DISCUSSION}

\section{Increases in Intrace1lular Free Amino Ac1ds In Response to N1trogen}

\section{Enrichment}

Increases in concentrations of selected free amino acids occurred as a result of the saturating (200 mlcromolar) $\mathrm{NH}_{4}^{+}$enrichment. The most dramatic increase occurred in glutamine concentrations (Figure 3-24). Glutamine increased to approximately $70 \%$ of the low molecular welght amino acid carbon after 1.0 hour of enrichment and remained at this level through 1.5 hours (Table 3-10). Glutamate continuously increased after an initial lag (Figure 3-25), although 1ts proportion of low molecular weight amino acid carbon declined after enrichment from $36 \%$ to roughly 6-9\% (Table 3-10). Proline showed a shorter lag before increasing in concentration (F1gure 3-26), and its proportion of free amino acid carbon declined as did that of glutamate (Table 3-10). Aspartate displayed an initial time dependent 1ncrease in concentration, and subsequently stabilized (Figure 3-27). Its proportion of the total intracellular free amino acid carbon remained relatively constant throughout 1.5 hours (Table 3-10). Other intracellular am1no acids which Increased in concentration over controls included glycine, alanine, and 
Figure 3-24. Increase in intracellular free glutamine concentrations in response to $\mathrm{NH}_{4} \mathrm{Cl}$ enrichment (200 micromolar) of an $\mathrm{NH}_{4}^{+}-11 \mathrm{mited}$ steady state culture of Nannochloris sp. Dotted line represents mean of glutamine concentration in control culture. Solld Iines indicate 95\% confidence limits. Errors represent propagated estimates of analytical error based on $95 \%$ confidence intervals. 


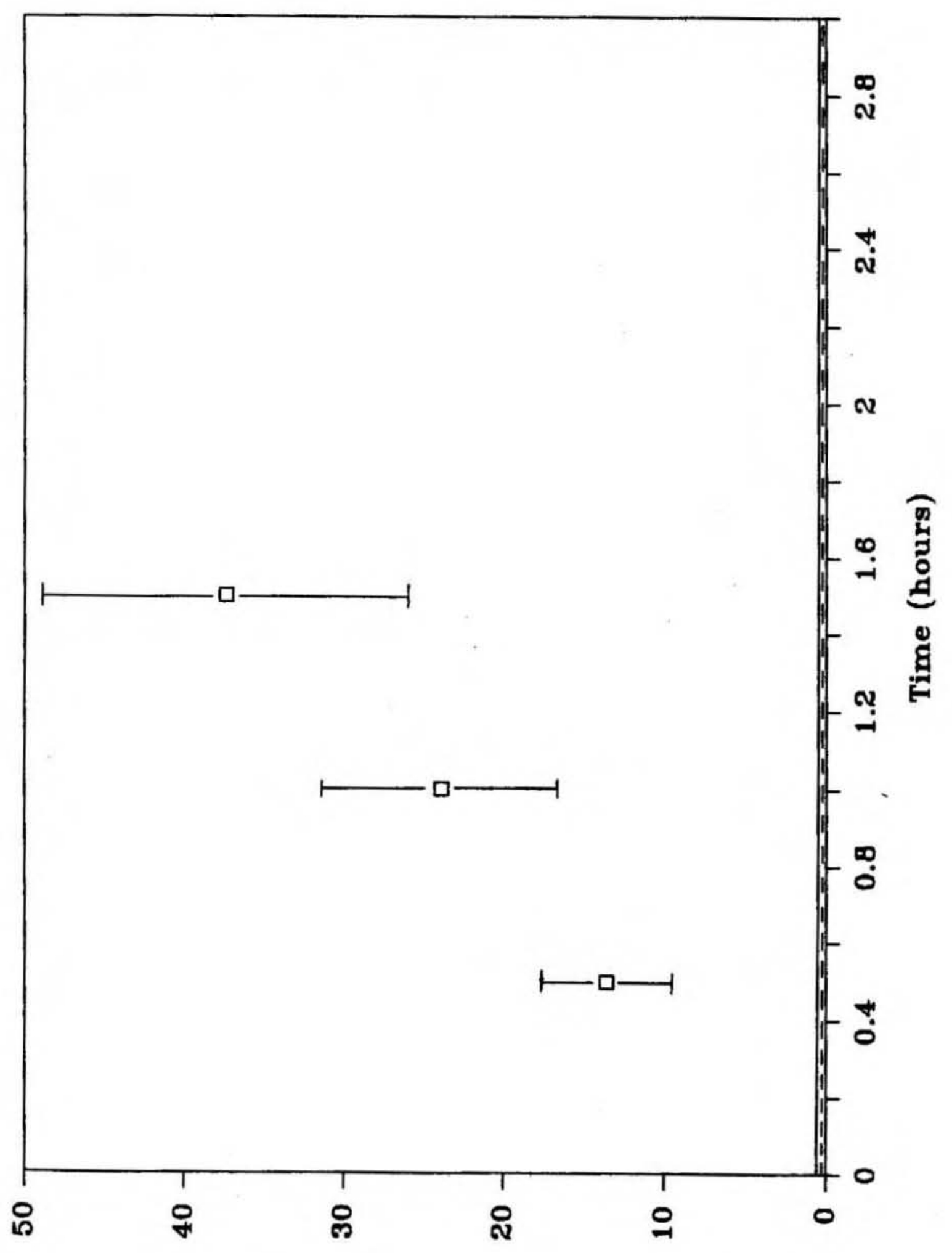

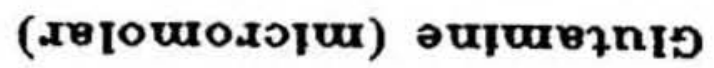


F1gure 3-25. Increase in Intracellular free glutamate concentrations in response to $\mathrm{NH}_{4} \mathrm{Cl}$ enrichment (200 micromolar) of an $\mathrm{NH}_{4}^{+}-11 \mathrm{mited}$ steady state culture of Nannochloris sp. Dotted line represents mean of glutamate concentration in control culture. Solid 11nes indicate 95\% confidence limits. Errors represent propagated estimates of analytical error based on $95 \%$ confidence intervals. 


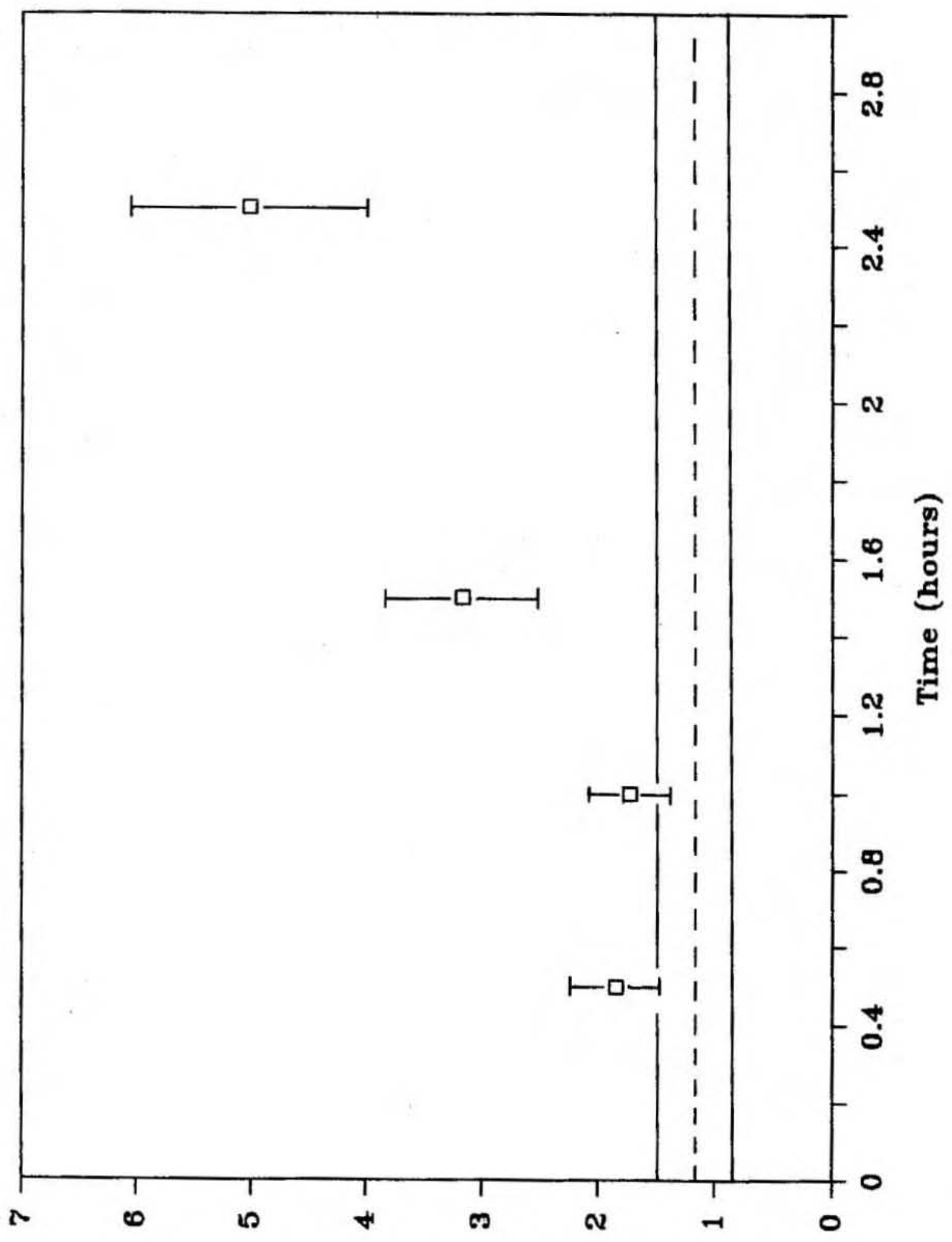

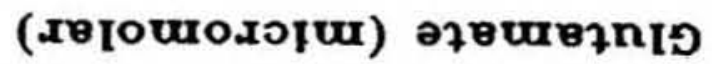


Figure 3-26. Increase in intracellular free proline concentrations in response to $\mathrm{NH}_{4} \mathrm{Cl}$ enrichment (200 micromolar) of an $\mathrm{NH}_{4}^{+}$-11mited steady state culture of Nannochloris sp. Dotted 1ine represents mean of proline concentration in control culture. Solid 1ines indicate $95 \%$ confidence limits. Errors represent propagated estimates of analytical error based on $95 \%$ confidence intervals. 


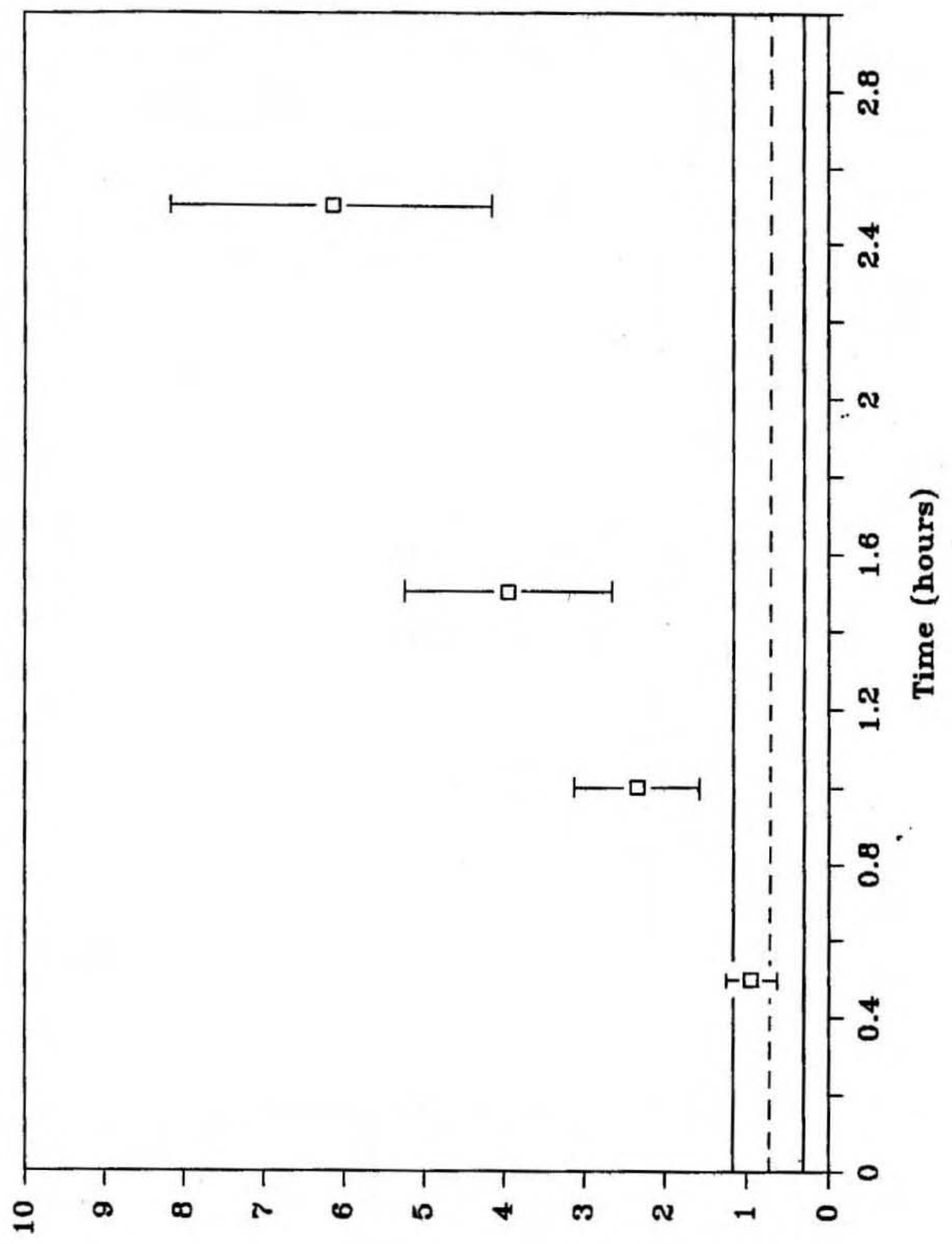

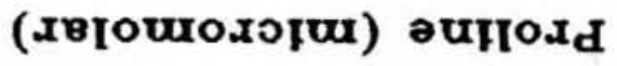


Figure 3-27. Increase in intrace11ular free aspartate concentrations in response to $\mathrm{NH}_{4} \mathrm{Cl}$ enrichment (200 micromolar) of an $\mathrm{NH}_{4}^{+}-1$ mited steady state culture of Nannochloris sp. Dotted line represents mean of aspartate concentration in control culture. Solld 11nes indicate 95\% confidence 11mits. Errors represent propagated estimates of analytical error based on $95 \%$ confidence intervals . 


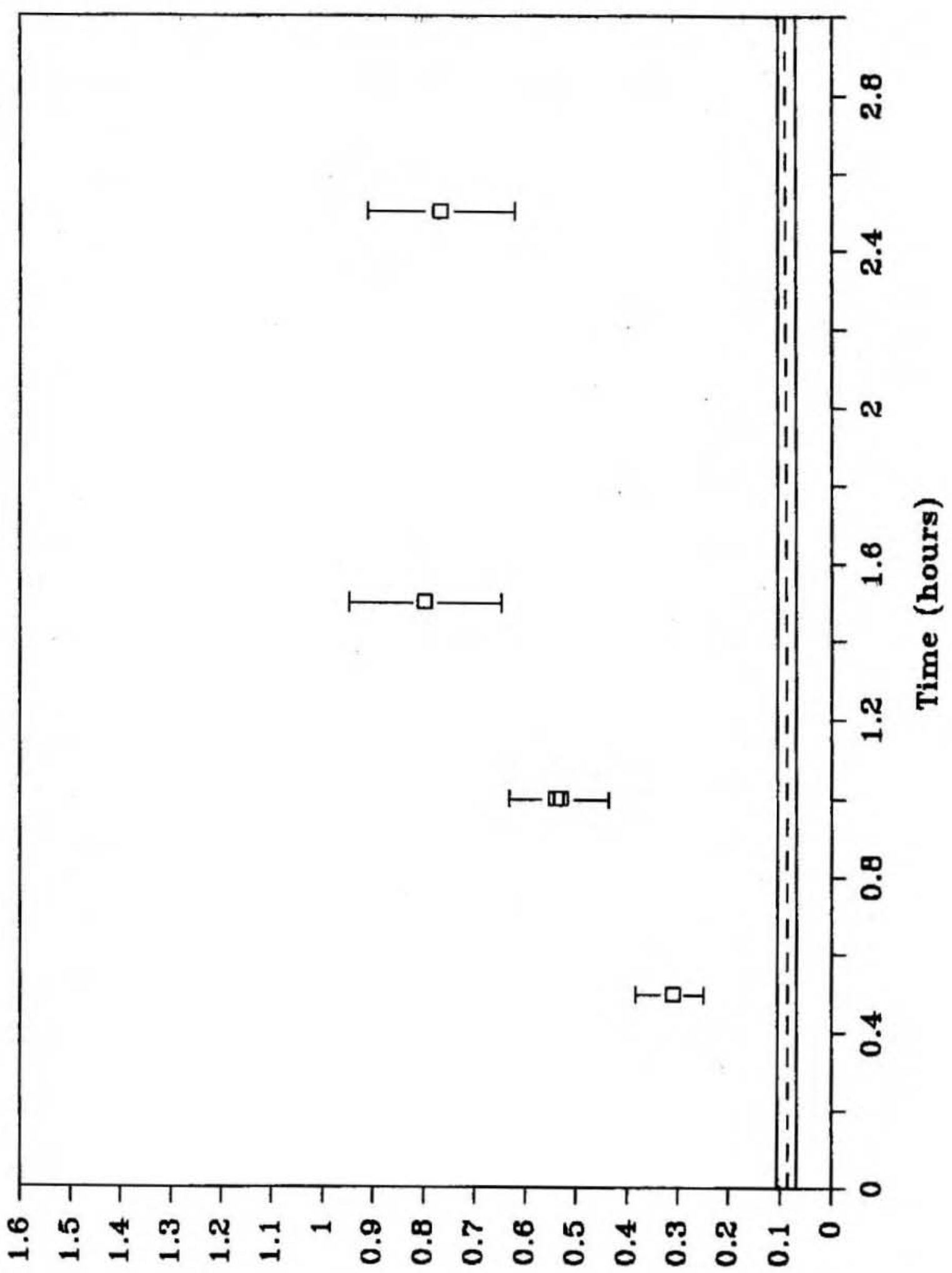

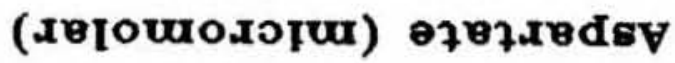


Table 3-10. Proportions of the Intracellular Free Amlno Ac1d Carbon Pool Associated with Individual Amino Acids in Control and NHt Earlched Cultures of Nannochlorts sp.

\begin{tabular}{|c|c|c|c|c|}
\hline \multirow[b]{2}{*}{ Amlno Ac1d } & \multicolumn{3}{|c|}{$\begin{array}{r}\text { Z Intracellular Amino Acld Carbon } \\
\mathrm{NH} 4+\text { Enriched }\end{array}$} & \multirow[b]{2}{*}{$1.5 \mathrm{hr}$} \\
\hline & Control & $0.5 \mathrm{hr}$ & $1.0 \mathrm{ht}$ & \\
\hline ASP & $2.2(0.65)^{a}$ & $1.2(0.36)^{b}$ & $1.4(0.42)$ & $1.3(0.39)$ \\
\hline GLU & $36.1(11.7)$ & $9.3(2.8)$ & $5.5(1.7)$ & $6.4(2.0)$ \\
\hline GLN (+SER) & $7.5(8.1)$ & $68.8(25.9)$ & $76.3(29.6)$ & $74.9(28.9)$ \\
\hline THR & $0.86(0.54)$ & $0.35(0.09)$ & $0.12(0.03)$ & $0.03(0.01)$ \\
\hline GLY & $0.94(0.47)$ & $1.02(0.30)$ & $0.55(0.17)$ & $0.36(0.11)$ \\
\hline ALA & $4.4(1.0)$ & $3.5(1.0)$ & $1.6(0.48)$ & $0.88(0.27)$ \\
\hline BABA & $7.5(2.7)$ & n.d.c & $0.82(0.44)$ & $0.72(0.39)$ \\
\hline PRO & $23.6(14)$ & $4.8(1.9)$ & $7.5(3.1)$ & $7.9(3.2)$ \\
\hline ARG & $10.5(3.5)$ & $6.2(2.8)$ & n.d. & $1.9(0.89)$ \\
\hline VAL & $1.8(0.41)$ & $1.0(0.35)$ & $0.66(0.24)$ & $0.72(0.18)$ \\
\hline ILE & $1.3(0.56)$ & $0.12(0.06)$ & $0.20(0.11)$ & $0.058(0.031)$ \\
\hline LEV & $1.1(0.99)$ & $0.10(0.03)$ & $0.18(0.055)$ & $0.058(0.018)$ \\
\hline PHE & $2.2(1.1)$ & $0.58(0.26)$ & $0.13(0.06)$ & $0.061(0.028)$ \\
\hline LYS & n.d. & $2.92(1.5)$ & $3.9(2.0)$ & $3.6(1.9)$ \\
\hline HIS & $N^{d}$ & n.d. & $0.532(0.18)$ & $0.49(0.17)$ \\
\hline ORN & n.d. & n.d. & $0.65(0.28)$ & $0.60(0.26)$ \\
\hline $\begin{array}{l}\text { Total Free Amlno } \\
\text { Acld Carbon } \\
\text { (mlcrograms/11ter): }\end{array}$ & $193(36)$ & $1190(260)$ & $1880(450)$ & $3000(700)$ \\
\hline
\end{tabular}

${ }^{a}$ Errors for control concentrations (In parentheses) represent $95 \%$ confidence Intervals.

berrors for enriched concentrations (in parentheses) represent propagated estimates of analytlcal error based on 95\% confidence intervals.

c.d. = no data.

$\mathrm{d}_{\mathrm{ND}}=$ not detectable. 
Table 3-11. Comparisons of Intracellular Free Amfno Ac1d Concentrations in Control and NHt Enriched Cultures of Nannochloris sp.

\begin{tabular}{ccc}
\hline & \multicolumn{2}{c}{ Concentration $(\mu \mathrm{M})^{\mathrm{a}}$} \\
\hline Amino Ac1d & $0.076(0.035)^{\mathrm{b}}$ & $0.461(0.100)$ \\
\hline GLY & $0.176(0.023)$ & $0.847(0.322)$ \\
ALA & $0.059(0.007)$ & $0.264(0.117)$ \\
VAL & $0.0344(0.021)$ & $0.071(0.080)$ \\
THR & $0.302(0.091)$ & $0.446(0.301)$ \\
BABA & $0.281(0.077)$ & $0.670(1.10)$ \\
ARG & $0.034(0.014)$ & $0.032(0.044)$ \\
ILE & $0.028(0.026)$ & $0.029(0.037)$ \\
LEU & $0.040(0.018)$ & $0.034(0.065)$ \\
PHE & & \\
\hline
\end{tabular}

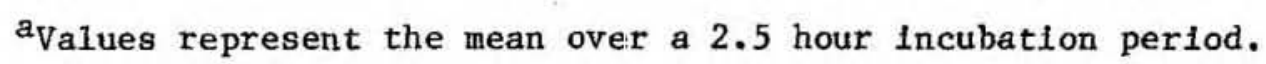

bValues in parentheses represent $95 \%$ confidence intervals. 
valine. Their mean concentrations over a 2.5 hour incubation period are compared in Table 3-11. The change in alanine was unique in that it was highest at 0.5 hours after enrichment, and declined asymptotically to a relatively constant value (Figure $3-28$ ). No significant changes could be demonstrated for threon:lne, Isoleucine, leucine, and phenylalanine (Table 3-11). All the intracellular free amino acids declined as a proportion of total low molecular weight free amino ac1d carbon except for glutamine, aspartate, glycine, 1ysine, and ornithine (Table 3-10).

The distribution of IFAA carbon among individual free amino acids in the control culture (Table 3-10) resembled the steady state values for low relative growth rate (c.f. Table 3-3). The distribution of the IFAA carbon in the enriched culture (Table 3-10) was similar to the high steady state relative growth rate distributions (c.f. Table $3-3$ ) with the exception that glutamine: was the dominant free amino acid in the enriched culture rather than proline as in the steady state case.

The increases in intracellular free amino acid concentrations as a result of nitrogen enrichment are a demonstration of an associated increase in the rate of assimilation of inorganic nitrogen. The accumulation of intracellular free amino acids in response to $\mathrm{NH}_{4}^{+}$ enrichment is a general response of nitrogen depleted algal populations (Reisner et a1., 1960; Turpin and Harrison, 1978; DeManche et a1., 1979; DeManche, 1980; Syrett, 1981; Dortch, 1982; Wheeler, 1983; Wheeler et al., 1983). The 1ncrease in the free amino ac1d pool concentration is 1ikely an indication that subsequent metabolic steps involving their utilization in biosynthesis of macromolecular material are rate 1imiting. However, the increases were not uniform among the different amino acids indicating intermediate rate limiting steps were also involved. 
The dramatic accumulation of glutamine as a result of enrichment (approximately $70 \%$ free amino acid carbon after 1.0 hour) accompanied by an inflial lag in the increase in glutamate concentrations would suggest that biosynthetic nitrogen flux became increasingly less $11 \mathrm{mited}$ by a step subsequent to the glutamine synthetase reaction. In light of the observed differences in glutamine amide and glutamate nitrogen turnover rates for high and low relative steady state growth (Table $3-4$ ), it is likely that as a result of the enrichment, glutamine amide nitrogen turnover probably decreased, while glutamate nitrogen turnover increased. Thus, even though glutamate levels did not increase in association with glutamine, flux of nitrogen increased through the GS/GOGAT system.

Accumulation of glutamate and proline after an inftial lag indicated that ultimately their utilization was also limited by subsequent biosynthetic steps. A decline in concentrations such as that observed for alanine would indicate a relative increase in the utilization/production ratio for that substrate. No significant changes could be demonstrated for threonine, isoleucine, leucine, and phenyalanine (Table 3-11). Th1s is the result of elther a lag in their pool size increases which extended beyond the incubation period, or a tight coupling of production and utilization of these amino acids. These results are clear evidence for changes in mechanisms of processing intracellular nitrogen, which precede an acceleration of growth and protein synthesis. In the next section, I examine the relationship between these changes and patterns of incorporation of inorganic ${ }^{14} \mathrm{C}$. 
Figure 3-28. Increase in intracellular free alanine concentrations in response to $\mathrm{NH}_{4} \mathrm{Cl}$ enrichment (200 micromolar) of an $\mathrm{NH}_{4}^{+}-1$ imited steady state culture of: Nannochloris sp. Dotted line represents mean of alanine concentration fin control culture. Solid lines indicate 95\% confidence 1imits. Errors represent propagated estimates of analytical error based on $95 \%$ confidence intervals. 


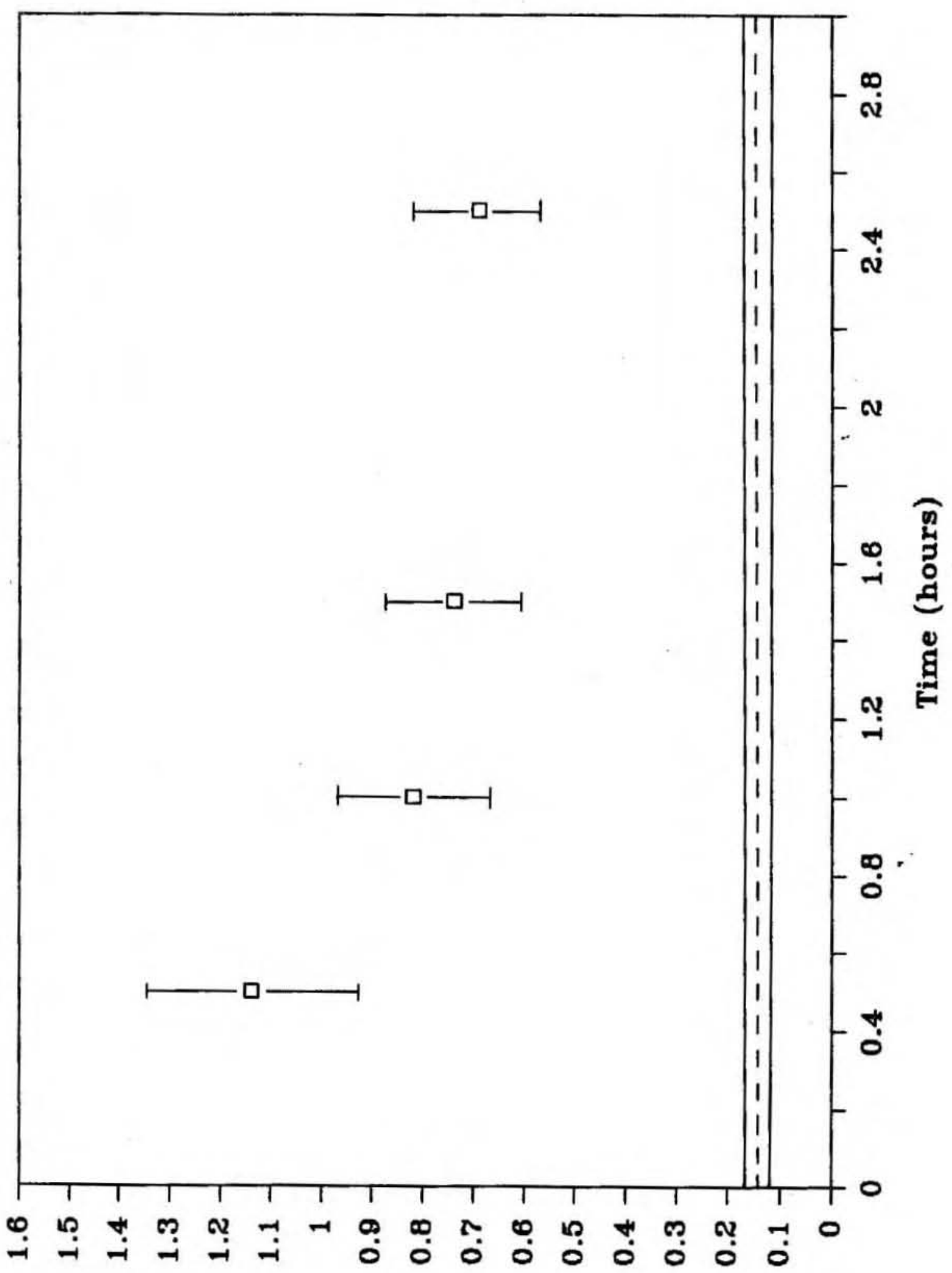

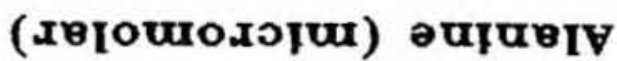


Figure 3-29. Time course of the relative specific activity of total intracellular free amino acid carbon in conticol and enriched $\mathrm{NH}_{4}^{+}-11 \mathrm{mited}$ steady state cultures of Nannochloris sp. Relative specific activity is the specific activity of the amino acid normalized to that of the dissolved inorganic carbon pool; see text for further discussion. Symbols: square, enriched; cross, control. Errors represent propagated estimates of analytical error based on $95 \%$ confidence intervals. 


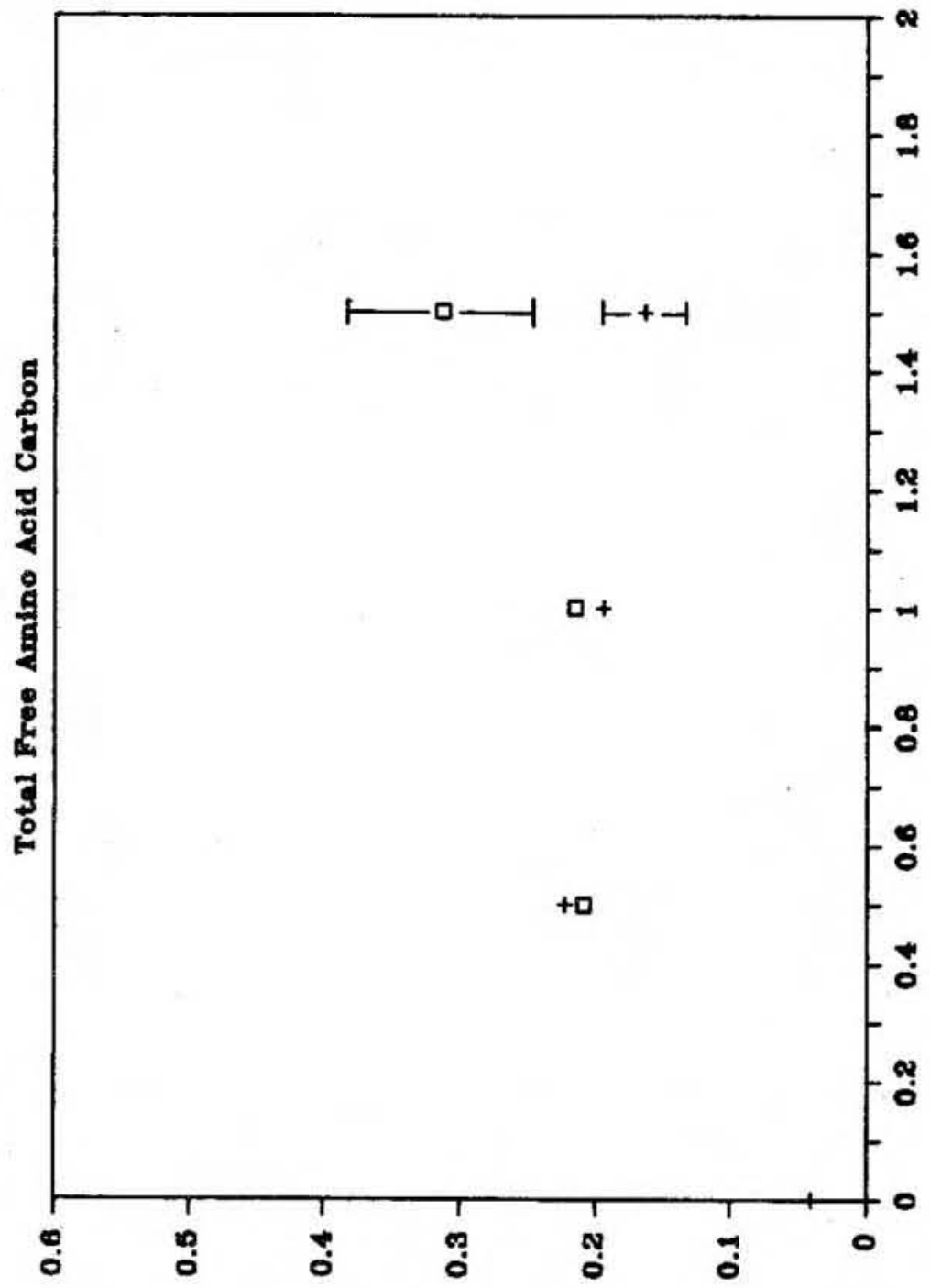

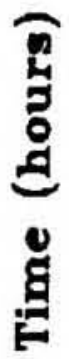

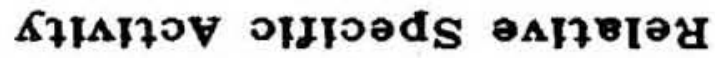


Saturation of Free Anlno Ac1ds w1th 14C in Control and Bnriched Cultures

Saturation rates of total intracellular free amino acid carbon in the control and enriched cultures were similar throughout the first hour of Incubation with 1sotope (F1gure 3-29). The specific activity of the enriched culture 1ncreased slightly above the control by 1.5 hours. This Indicated elther enhanced turnover in the enriched culture, or a suppression of turnover in the control culture as a result of nitrogen depletion.

$\mathrm{NH}_{4}^{+}$enrichment effects on the saturation rates of selected IFAA's are shown in Table 3-12. There were no significant differences between controls and enriched cultures in the saturation rates of glutamate carbon, despite the increased production of glutamine. This increase presumably occurred via the glutamine synthetase reaction which uses glutamate as a substrate. That the source of glutamine was the glutamate pool was supported by the fact that the glutamine specific activity was similar to that of the glutamate pool in the enriched culture. This was also the case at the steady state low relative growth rate. The uniformity in glutamate saturation rates with and without enrichment indicates that the proportion of photosynthetically fixed carbon used in the production of alpha-ketoglutarate, the carbon skeleton of glutamate, was not significantly affected by enrichment (c.f. Fig. 3-10). Nevertherless, the increase in the concentration of glutamine would necessitate enhanced carbon flux through glutamate. This might be a consequence of a very large metabolic pool providing carbon skeletons for glutamate synthesis, such as respiratory intermediates derived from the tricarboxylic acid cycle whose labelilng characteristics might change slowly despite an increased flux through glutamate. 
Table 3-12. Relative Specific Activities of Intracellular Free Amino Ac1da in Control and Enriched Cultures of Nannochlorls sp.

\begin{tabular}{|c|c|c|c|}
\hline $\begin{array}{l}\text { Amlno } \\
\text { Acld }\end{array}$ & $\begin{array}{l}\text { Incubation } \\
\text { Time (hrs) }\end{array}$ & $\frac{\text { Relative Specif }}{\text { Control }}$ & $\frac{\text { fic Activity }}{\text { Enriched }}$ \\
\hline GLU & $\begin{array}{l}0.0 \\
0.5 \\
1.0 \\
1.5 \\
2.5\end{array}$ & $\begin{array}{c}0.110(0.024)^{b} \\
0.238(0.054) \\
0.328(0.071) \\
0.342(0.074) \\
\text { n.d. }\end{array}$ & $\begin{array}{c}\text { n.d.c } \\
0.163(0.036) \\
0.329(0.073) \\
0.270(0.060) \\
0.348(0.077)\end{array}$ \\
\hline GLN & $\begin{array}{l}0.5 \\
1.0 \\
1.5\end{array}$ & $\begin{array}{l}\text { n.d. } \\
0.111(0.037) \\
0.082(0.029)\end{array}$ & $\begin{array}{l}0.246(0.078) \\
0.252(0.082) \\
0.320(0.102)\end{array}$ \\
\hline ASP & $\begin{array}{l}0.5 \\
1.0 \\
1.5 \\
2.5\end{array}$ & $\begin{array}{c}\text { n.d. } \\
0.814(0.189) \\
0.596(0.154) \\
\text { n.d. }\end{array}$ & $\begin{array}{l}0.538(0.121) \\
0.203(0.046) \\
0.249(0.054) \\
0.341(0.073)\end{array}$ \\
\hline PRO & $\begin{array}{l}0.5 \\
1.0 \\
1.5 \\
2.5\end{array}$ & $\begin{array}{c}0.144(0.065) \\
0.079(0.028) \\
\text { n.d. } \\
0.540(0.186)\end{array}$ & $\begin{array}{c}\text { n.d. } \\
\text { n.d. } \\
0.366(0.125) \\
0.548(0.188)\end{array}$ \\
\hline
\end{tabular}

- Relative speciflc activity = dpms/amino acld carbon normallzed to specific activity of the dissolved inorganic carbon pool.

bValues in parentheses represent propagated estimates of analytlcal error based on $95 \%$ confldence $11 \mathrm{mlts}$.

cn.d. - no data. 
Enrichment apparently did not enhance the saturation rate of proline (Table 3-12). The time course of proline specific activity resembled that of glutamate, its precursor. Glutamine saturation was enhanced. In contrast, the time course specific activity change of aspartate decreased as a result of enrichment, a possible indication that its carbon skeleton (oxaloacetate) was increasingly derived from unlabeled cell materlal such as 11p1d. The blosynthesis of ether soluble material was suppressed as a result of enrichment (see following section on effects of enrichment on carbon assimilation into subcellular fractions). It is possible that unlabeled 11pid was used to increase the supply of carbon skeletons for protein synthesis.

As a result of the simllarity in saturation rates, relative differences in amounts of ${ }^{14} \mathrm{C}$ associated with free amino acids in control and enriched cultures will reflect real differences in concentrations. Patterns of isotope incorporation are compared in the next section.

\section{Effects of NH4+ Enrichment on THme Course Distributions of 14C in}

\section{Cellular Material}

Significant effects of $\mathrm{NH}_{4}^{+}$enrichment on total inorganic ${ }^{14} \mathrm{C}$ f1xation rates could not be demonstrated glven the resolution of the time course sampling scheme used (Figure 3-30). In contrast, dramatic differences were observed in patterns of isotope incorporation into different cell material. Comparisons of 1sotope derived carbon incorporation into subcellular fractions for control and enriched cultures are shown in Figure 3-31. Enrichment led to a dramatic increase In the incorporation of 1sotopic carbon into the low molecular weight 
metabolites, primarily at the expense of incorporation into the ether soluble fraction. There was initially no significant increase in protein Incorporation and may have even been a slight depression relative to the control. However, after an inftial lag, an increase in protein incorporation occurred. The lag colncided in approximate timing with the lags seen to precede the increases in glutamate concentrations (F1gure 3-26), stabilization of aspartate (F1gure 3-27) and alanine (F1gure 3-28) concentrations, and increase in the total IFFA carbon specific activity over controls (F1gure 3-29). The increase in incorporation associated with the low molecular weight metabolites was largely associated with an increase in ${ }^{14} \mathrm{C}$ in IFAA, particularly glutamine and glutamate (Table 3-13). Other amino ac1ds whose incorporation contributed significantly Included aspartate, glycine, alanine, proline, and vallne, all of which also significantly increased in concentration over controls. Arginine and beta-aminobutyric acid (or a compound with similar elution characteristics) were also responsible for a small proportion of free amino acid ${ }^{14} \mathrm{C}$ incorporation. However, variability in concentration determinations precluded the demonstration of any consistent relationship to changes in their proportions of total ${ }^{14} \mathrm{C}$ uptake (c.f. Healey, 1979).

The accumulation of intracellular free amino acids under nitrogen replete conditions (DeManche et al., 1979; DeManche, 1980; Dortch, 1982; Wheeler, 1983; Wheeler et al., 1983) has led to the suggestion that protein synthesis ultimately 1imits the assimilation of nitrogen. This contention is supported by my data, in that the rate of labelling of the free amino acids increased within the first 0.5 hour of enrichment, while a subsequent increase in protein labelling rate over the control did not 
Figure 3-30. Time course of total inorganic ${ }^{14} \mathrm{C}$ uptake by control and enriched $\mathrm{NH}_{4}^{+}-11 \mathrm{mited}$ steady state cultures of Nannochloris $\mathrm{sp}$. $\mathrm{NH}_{4} \mathrm{Cl}$ enrichment of 200 micromolar was added at zero time. Culture temperature was $24^{\circ} \mathrm{C}$. 


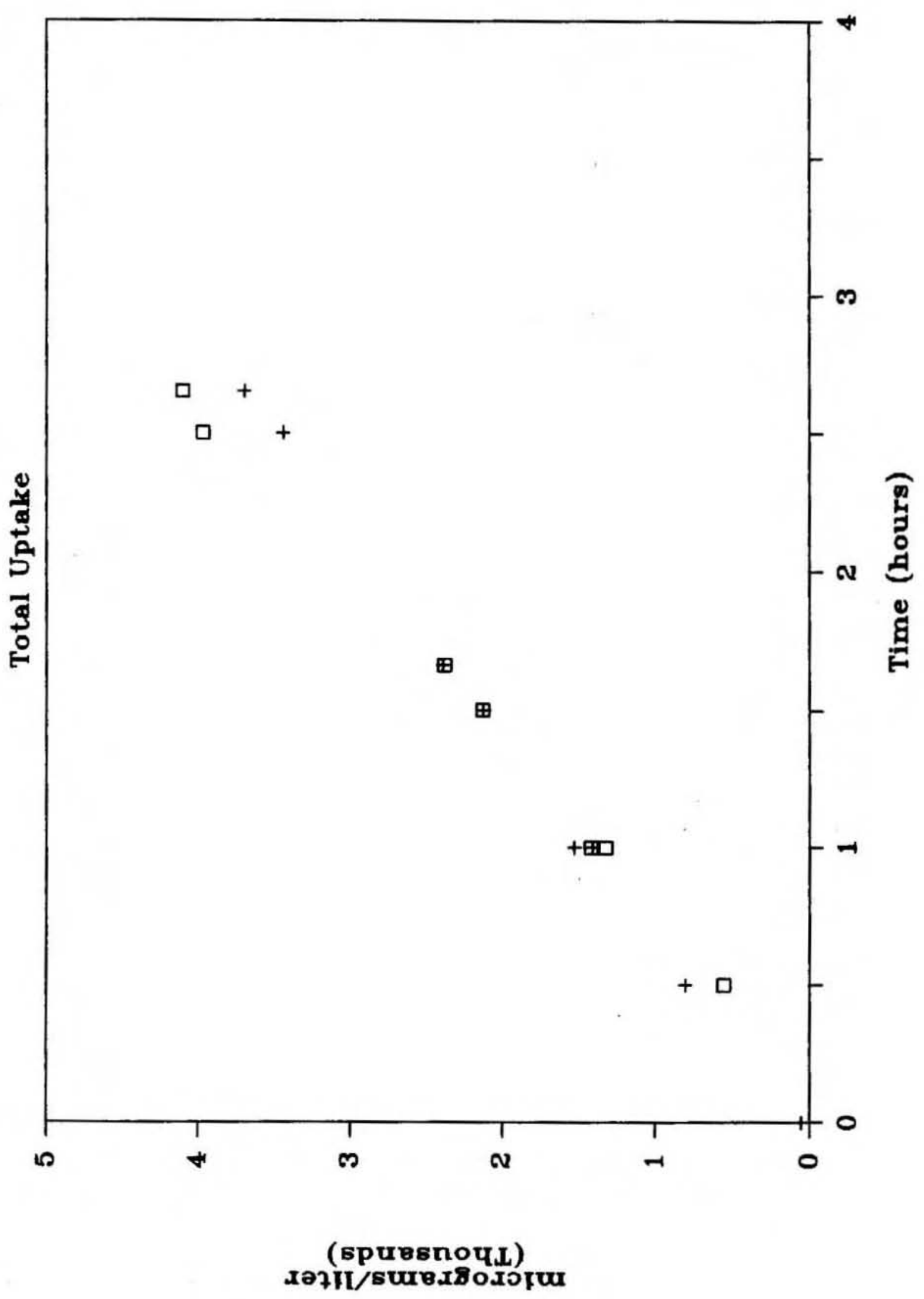


Figure 3-31. Time course of the incorporation of inorganic ${ }^{14} \mathrm{C}$ into subcellular fractions in control and enriched $\mathrm{NH}_{4}^{+}-11 \mathrm{mited}$ steady state cultures of Nannochlor1s sp. growing at $24^{\circ} \mathrm{C}$. Symbols: square, enriched; cross, control. 

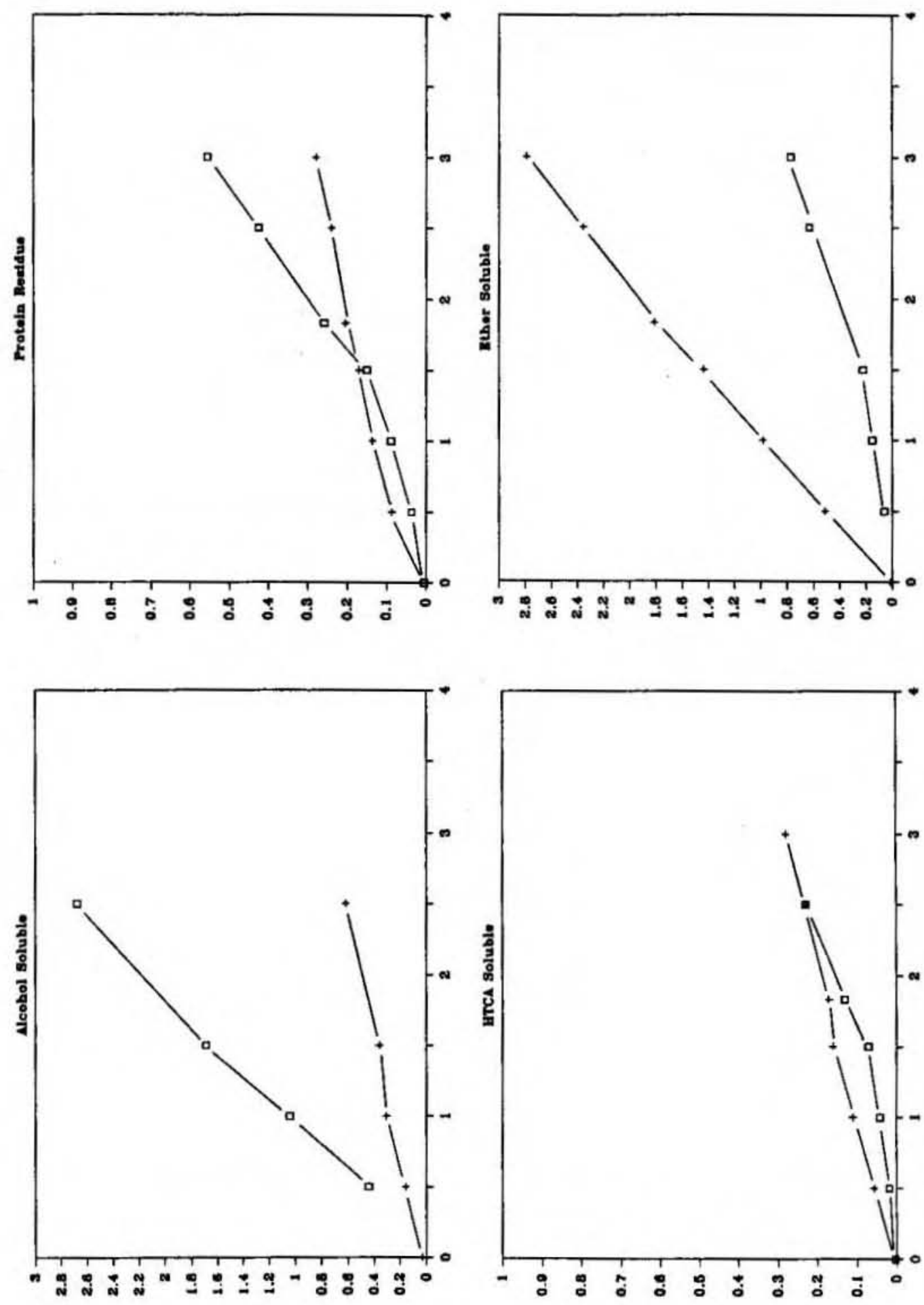

(mpuesnoqu)

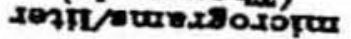


Table 3-13. Distrlbutions of Total ${ }^{14} \mathrm{C}$ Uptake Among Intracellular Free Amino Aclds in Control and Enriched Cultures of Nannochlorls sp.

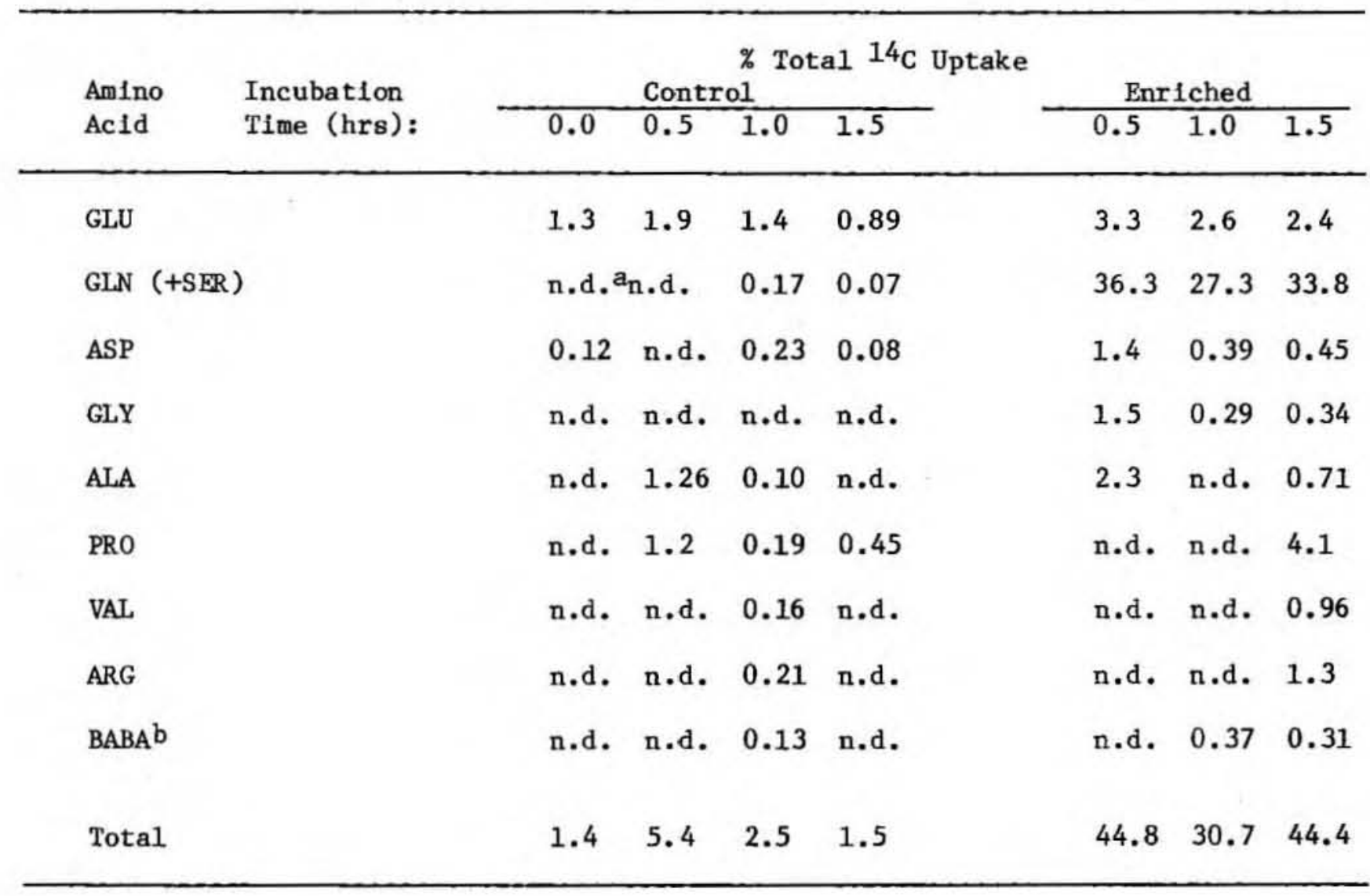

$a_{\text {n.d. }}=$ no data.

beta-aminobutyric acid or a coelutant. 
occur until after 1.5 hours (Figure 3-31). Reasons for such a lag in metabolism may be that the necessary protein synthesizing machinery (e.g. ribosomal RNA) had to be constructed, and amino acid pool sizes had to accumulate in order for nitrogen and carbon flux into protein to increase. It may be that this is only an apparent suppression resulting from dilution of photosynthetically derived carbon skeletons caused by an increased utilization of unlabeled storage material. This might also explain the relatively unaffected specific activity of free glutamate, despite increased carbon flux, and the decrease in aspartate specific activity.

Goldman and Dennett (1984) noted a slight suppression in photosynthesis after enrichment of $\mathrm{NH}_{4}^{+}$ilmited continuous cultures of Nannochlor1s sp. with 16 micromolar $\mathrm{NH}_{4} \mathrm{Cl}$. I did not observe significant differences between total ${ }^{14} \mathrm{C}$ uptake by control and enriched cultures (Figure 3-30). However, the effects referred to by Goldman and Dennett were of a duration and magnitude which would not be detectable at the level of precision of my sampling.

Although there were quantitative differences, the distribution of ${ }^{14} \mathrm{C}-1$ abel among IFAA's (Table 3-14) was a qualitative reflection of the actual carbon distribution (Table 3-10). The changes in patterns of ${ }^{14} \mathrm{C}$ incorporation as a result of enrichment were representative of changes in the actual concentrations and relative abundance of the nitrogen transport mediators. The increase in specific activity of IFAA carbon in the enriched culture over the control, coinclding with enhancement of protein incorporation, increasing glutamate concentration, and stabilization of aspartate and alanine concentrations, were indications of a major shift in metabolism towards accelerated growth. 
Table 3-14. Distributions of ${ }^{14} \mathrm{C}$ Within the Intracellular

Free Amino Acld Pools of Control and Enriched

Cultures of Nannochloris sp.

\begin{tabular}{|c|c|c|c|c|c|c|c|c|}
\hline \multirow{2}{*}{$\begin{array}{l}\text { Anino } \\
\text { Acid }\end{array}$} & \multirow{2}{*}{$\begin{array}{l}\text { Incubat1on } \\
\text { T1me (hrs): }\end{array}$} & \multicolumn{4}{|c|}{$\begin{array}{l}\% \text { Total Intracellular } \\
\text { Control }\end{array}$} & \multicolumn{3}{|c|}{$\begin{array}{r}\text { Amino Acid }{ }^{14} \mathrm{C} \\
\text { Enriched }\end{array}$} \\
\hline & & 0.0 & 0.5 & 1.0 & 1.5 & 0.5 & 1.0 & 1.5 \\
\hline \multicolumn{2}{|l|}{ GLU } & 91.6 & 36.0 & 56.8 & 59.8 & 7.3 & 8.4 & 5.4 \\
\hline \multicolumn{2}{|c|}{ GLN (+SER) } & \multicolumn{2}{|c|}{ n.d. $a_{\mathrm{n}} \cdot \mathrm{d}$. } & 6.9 & 5.0 & 81.0 & 89.0 & 76.1 \\
\hline \multicolumn{2}{|l|}{ ASP } & 8.4 & n.d. & 9.3 & 5.3 & 3.2 & 1.3 & 1.0 \\
\hline \multicolumn{2}{|l|}{ GLY } & n.d. & n.d. & n.d. & n.d. & 3.3 & 0.92 & 0.77 \\
\hline \multicolumn{2}{|l|}{ ALA } & n.d. & 3.4 & 0.63 & n.d. & 5.2 & n.d. & 1.6 \\
\hline \multicolumn{2}{|l|}{ PRO } & n.d. & 22.3 & 7.8 & 30.0 & n.d. & n.d. & 9.2 \\
\hline \multicolumn{2}{|l|}{ VAL } & n.d. & n.d. & 6.3 & n.d. & n.d. & n.d. & 2.2 \\
\hline \multicolumn{2}{|l|}{ ARG } & n.d. & n.d. & 8.7 & n.d. & n.d. & n.d. & 3.0 \\
\hline \multicolumn{2}{|l|}{ BABA } & n.d. & n.d. & 5.2 & n.d. & n.d. & 1.2 & 0.69 \\
\hline
\end{tabular}

$a_{\mathrm{n} \cdot \mathrm{d} .}=$ no data. 
Attempts to probe the metabolism of natural communities which are intimately coupled to their physicochemical environment must recognize the need for more precise time course sampling in order to understand the biochemical events associated with transient physlological states.

\section{PRELIMINARY OBSERVATIONS OF NH4+ ENRICHMENT EFFBCTS ON CARBON METABOLISM IN TWO OTHER SPECIES}

Thus far, I have discussed results with a single specles, Nannochlor1s $\mathrm{sp}$. In the following section, I examine interspectes variations in the characteristics of ${ }^{14} \mathrm{C}$ incorporation in response to $\mathrm{NH}_{4}^{+}$enrichment of $\mathrm{NH}_{4}^{+}$-11mited cultures. The species studied were Dunaliella tertiolecta (clone Dun) and Thalassiosira weissflogil (clone Actin). In addition, the influence of varlations in temperature on responses were assessed. Responses at three different temperatures were compared in D. tertiolecta $\left(24^{\circ} \mathrm{C}\right.$, experiment $1 ; 16^{\circ} \mathrm{C}$, experiment 2 ; $12^{\circ} \mathrm{C}$, experiment 3$)$, and two temperatures in $\underline{T}$. welssflog $11\left(16^{\circ} \mathrm{C}\right.$, experment $2 ; 12^{\circ} \mathrm{C}$ experiment 3 ).

METHODS

Response of Intracellular Free Amino Ac1ds of Dunallella tertiolecta to Nutrient Enrichment

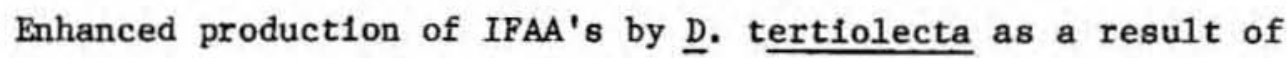
enrichment was assessed using an early stationary phase batch culture of D. tertiolecta which had been grown in " $h / 2$ " media minus nitrate and silicate (Guillard and Ryther, 1962). Cell density was approximately 2.0 $\times 10^{6}$ per $\mathrm{ml}$. Replicate cultures of $10 \mathrm{ml}$ volume in $25 \mathrm{ml} 100 \times 18 \mathrm{~mm}$ borosilicate test tubes were grown at $21^{\circ} \mathrm{C}$ in a $12: 1211$ ght/dark cycle 
to early stationary phase in media described in the general methods for stock cultures. Midway through the photoperiod, $5 \mathrm{ml}$ fresh " $\mathrm{h} / \mathrm{2}^{\text {" media }}$ was added to one of the cultures and they were allowed to incubate for an additional 3 hours. Amino acids were extracted by filtering samples (volumes corrected for the dilution as a result of enrichment) onto a glass fiber filter, rinsing twice with $2 \mathrm{ml}$ artificial seawater, boiling the filters in defonized water for $1 \mathrm{~min}$, and filtering the extract through a sterile 0.2 micron Mill1pore membrane filter. Cindy Lee analyzed the amino acids samples using fluorescence detection of o-phthaldialdehyde derivatives separated by reverse phase ( 5 micron, octyldecasilane) high pressure liquid chromatography (Lindroth and Mopper, 1979).

Effects of NH4+ Enrlchment on TIme Course Distributions of $14 \mathrm{C}$ in Cellular Material

Experiment 1

Dunaliella tertiolecta was cultured under the same conditions as described for Nannochloris sp. In the previous section with the following exceptions. Media composition consisted of $100 \mathrm{micromolar} \mathrm{NH}_{4} \mathrm{Cl}$ and 20 micromolar $\mathrm{NaH}_{2} \mathrm{PO}_{4}$. All other nutrlents were at " $\mathrm{f} / 2$ " levels (without silicate and nitrate) in the artificial seawater base described in the General Methods section. The dilution rate was $0.380(.030)$ day ${ }^{-1}$ and the temperature was $24^{\circ} \mathrm{C}$. Allquots were removed from the steady state culture as described in the previous Nannochloris sp. enrichment experiment and placed in 250ml Erlenmeyer flasks under similar conditions of 1 ight and temperature. Inorganic ${ }^{14} \mathrm{C}$ was added to both flasks, and $\mathrm{NH}_{4} \mathrm{Cl}$ was added to a concentration of 200 micromolar in one 
of the flasks. Samples were filtered on Whatman GF/F glass fiber filters at low vacuum (less than $200 \mathrm{~mm} \mathrm{Hg}$ ). They were subsequently rinsed twice with $2 \mathrm{ml}$ artificial seawater, fumed for 10 minutes with $6 \mathrm{~N} \mathrm{HCl}$, and sealed in Nalgene filmware polypropylene baggles. These were stored in 11quid $\mathrm{N}_{2}$ until analysis. The subcellular fractionation procedure differed from that described in the general methods section in that filters were initially extracted 2 times with $1.5 \mathrm{ml}$ room temperature $10 \%$ trichloroacetic acid instead of the methanol extraction. The procedure was described in the chapter 2 (see Table 2-4), and was analogous to that described by Roberts et al. (1963) as modified by Cuhel et al. (1981b).

\section{Experiment 2}

Joel Goldman kindly provided culture facllities and technical assistance in the incubation and harvesting experiments 2 and 3 . D. $\underline{\text { tertlolecta }}$ and $\underline{T}$. welssflog 11 were grown under $\mathrm{NH}_{4}^{+} 11$ mited steady state conditions using the methods and apparatus described in Goldman (1977) with the exception that concentrations of $\mathrm{NH}_{4} \mathrm{Cl}$ and $\mathrm{NaH}_{2} \mathrm{PO}_{4}$ In the media were 100 micromolar and 20 micromolar respectively. Cultures were grown at $16^{\circ} \mathrm{C}$ at a dilution rate of 0.512 day $^{-1}$ for Dunalie1la tert1olecta and 0.496 day $^{-1}$ for Thalasslosira weissflogil. Before addition of isotope, aliquots were withdrawn from the steady state cultures and placed in incubation vessels under similar conditions of light and temperature. Both aliquots were labeled with inorganic ${ }^{14} \mathrm{C}$ and incubated for 50 minutes. After this period, one of the aliquots was enriched with $\mathrm{NH}_{4} \mathrm{Cl}$ to 16 micromolar.

Samples were filtered onto Whatman GF/F glass fiber filters, rinsed twice with $2 \mathrm{ml}$ artificial seawater, sealed in Nalgene filmware baggles, 
and stored at $-20^{\circ} \mathrm{C}$ until analysis. Samples were fractionated as described in experiment 1.

\section{Exper1ment 3}

Chemostat cultures in this experiment were grown at $12^{\circ} \mathrm{C}$. Dilution

rates were 0.138 day $^{-1}$ for $\underline{D}$. tert1olecta and 0.360 day $^{-1}$ for Thalassiosira we1ssflog11. Enrichment with $\mathrm{NH}_{4} \mathrm{Cl}$ was at zero time rather than 50 minutes. Culture, Incubation, and fractionation procedures were otherwise Identical to those in Experiment 2.

\section{RESULTS AND DISCUSSION}

\section{Dunal1ella tertiolecta}

The pattern of increase in IFAA levels in an early stationary phase culture of D. tertiolecta (Table 3-15) to some extent resembled those seen for Nannochloris sp. after $\mathrm{NH}_{4} \mathrm{Cl}$ enrichment of a $\mathrm{NH}_{4}^{+}-1$ imited continuous culture (Table 3-11). The increases were primar11y assoclated with a few free amino acids. Most of the increase could be attributed to glutamate, beta-glutamate, glutamine, glycine + threonine, and alanine + gamma-aminobutyric acid. A number of other amino ac1ds increased relative to control levels, particularly the basic amino aclds, ornithine and lysine. Proline was not assayable by the o-phthaldialdehyde method, and my separation did not distingulsh beta-glutamate from glutamate. Hence, comparisons of these amino acids are not possible. It is important to recognize that the stationary phase cultures had been grown in a rlch media where there was no clear 11miting factor. The increase In IFAA's upon replentshment of the media reflects a general response of a culture which is shifting out of stationary phase. 
Table 3-15. Intracellular Free Amlno Ac1d Concentrations In Control and Enriched Cultures of D. tertlolecta

\begin{tabular}{lll}
\hline \multirow{2}{*}{$\begin{array}{l}\text { Amino } \\
\text { Ac1d }\end{array}$} & \multicolumn{1}{c}{ Concentration (micrograms per 11ter) } \\
\cline { 2 - 3 } & Control & Enriched \\
\hline ASP & 4.82 & 7.78 \\
GLU & 7.28 & 18.8 \\
BGLU & 4.91 & 62.4 \\
SER & 2.02 & 11.8 \\
GLN & 0.0 & 24.4 \\
GLY+THR & 7.05 & 45.1 \\
ALA+GABA & 2.49 & 24.4 \\
BABA & 2.83 & 3.62 \\
AABA & 6.13 & 13.1 \\
MET & 5.44 & 6.92 \\
VAL & 6.26 & 10.9 \\
PHE & 5.64 & 11.5 \\
ILE & 6.94 & 12.8 \\
LEU & 7.59 & 12.1 \\
ORN & 0.0 & 12.5 \\
LYS & 0.0 & 4.16 \\
TOTAL & & 282.5 \\
\hline
\end{tabular}


In experiment 1, effects of $\mathrm{NE}_{4}^{+}$enrichment on patterns of carbon incorporation in an $\mathrm{NH}_{4}^{+}$limited steady state culture of Dunaliella tertiolecta resembled those reported for Nannochloris sp. In that there was little effect on total inorganic ${ }^{14} \mathrm{C}$ fixation, while 1sotope Incorporation into the low molecular welght metabolites was enhanced relative to controls (Figure 3-32). However, the increased incorporation was at the expense of incorporation into the hot trichloroacetic acid soluble material, rather than the ether soluble nonpolar material as in the case of Nannochloris sp. In addition, enhancement of protein incorporation occurred Immediately, without the lag which was observed for Nannochloris sp. (c.f. F1gure 3-31).

In experiment 2, addition of $\mathrm{NH}_{4}^{+}$after one hour resulted in an immediate change in incorporation patterns of $\underline{D} \cdot$ tertiolecta (Figure 3-33) which were consistent with the responses discussed in Experiment 1. Again, there were relatively minor effects on total rate (Figure 3-34). Sharp increases in labelling of cold acid soluble low molecular weight metabolites occurred at the expense of the hot trichloroacetic acid material as reflected in the relative distribution of label. Similarly, proteln incorporation was immediately enhanced by enrichment (F1gure 3-33).

The responses seen in experiment 3 were generally consistent with those of the other experiments, indicating the observed responses were largely temperature independent within the described range. D. tertiolecta again displayed large rapid increases in cold trichloroacetic acid soluble incorporation at the expense of incorporation into hot trichloroacetic acid (Figure 3-35), and proteln residue incorporation was 1mmediately enhanced. There was a slight reduction as a result of 
$\mathrm{NH}_{4} \mathrm{Cl}$ addition in total uptake (F1gure 3-36) which was not apparent at the higher temperatures.

\section{Thalassiosira we1ssflogil}

Observations of the response of $\underline{T}$. welssflogi1 to $\mathrm{NH}_{4}^{+}$enrichment revealed intrinsic metabolic differences from the other species. There was a substantial reduction in total ${ }^{14} \mathrm{C}$ uptake at $16^{\circ} \mathrm{C}$ (Experiment 2, F1g. 3-37) which was not apparent at $12^{\circ} \mathrm{C}$ (Experiment 3, F1gure 3-38). As mentioned by Goldman and Dennett (1984), $\mathrm{NH}_{3}$ at high levels can uncouple oxidative phosphorylation and be toxic. However, the levels of enrichment should not have been high enough to ellcit such a response. Despite this result, enrichment appeared to have much less dramatic effects on the distribution of incorporated ${ }^{14} \mathrm{C}(\mathrm{F} 1 \mathrm{~g} \cdot 3-39$, exp. 2; Fig. 3-40, exp. 3) than observed for Nannochlor1s sp. and D. tertiolecta. There was apparently 11 ttle effect of $\mathrm{NH}_{4}^{+}$enrichment on the proportion of incorporated ${ }^{14} \mathrm{C}$ associated with the cold trichloroacetic ac1d soluble material and, if anything, it resulted in a decreased proportion of label associated with the low molecular we1ght pools at $12^{\circ} \mathrm{C}$ ( F1g. 3-40, exp. 3). Even before enrichment, a much larger proportion of total ${ }^{14} \mathrm{C}$-label was associated with low molecular weight metabolites in $\underline{T}$. we1ssflogi1 than in the other species. There did appear to be some enhancement of protein incorporation, to some extent at the expense of the cold trichloroacetic acid and ether soluble fractions (Figure 3-39, experiment 2; Figure 3-40, experiment 3). This Increase was small compared to the responses seen in $\underline{D}$. tertiolecta and Nannochloris sp. Wheeler et al. (1983) found that $\underline{\text { T. welssflog11 }}$ required a longer period to deplete an $\mathrm{NH}_{4}^{+}$pulse from the medium, 
Figure 3-32. Time course of the incorporation of inorganic ${ }^{14} \mathrm{C}$ into subcellular fractions in control and enriched $\mathrm{NH}_{4}^{+}-11 \mathrm{mited}$ steady state cultures of Dunallella tertiolecta growing at $24^{\circ} \mathrm{C} . \mathrm{NH}_{4} \mathrm{Cl}$ enrichment of 200 micromolar was added at zero time. Symbols: open circles, enriched; closed circles, control. 

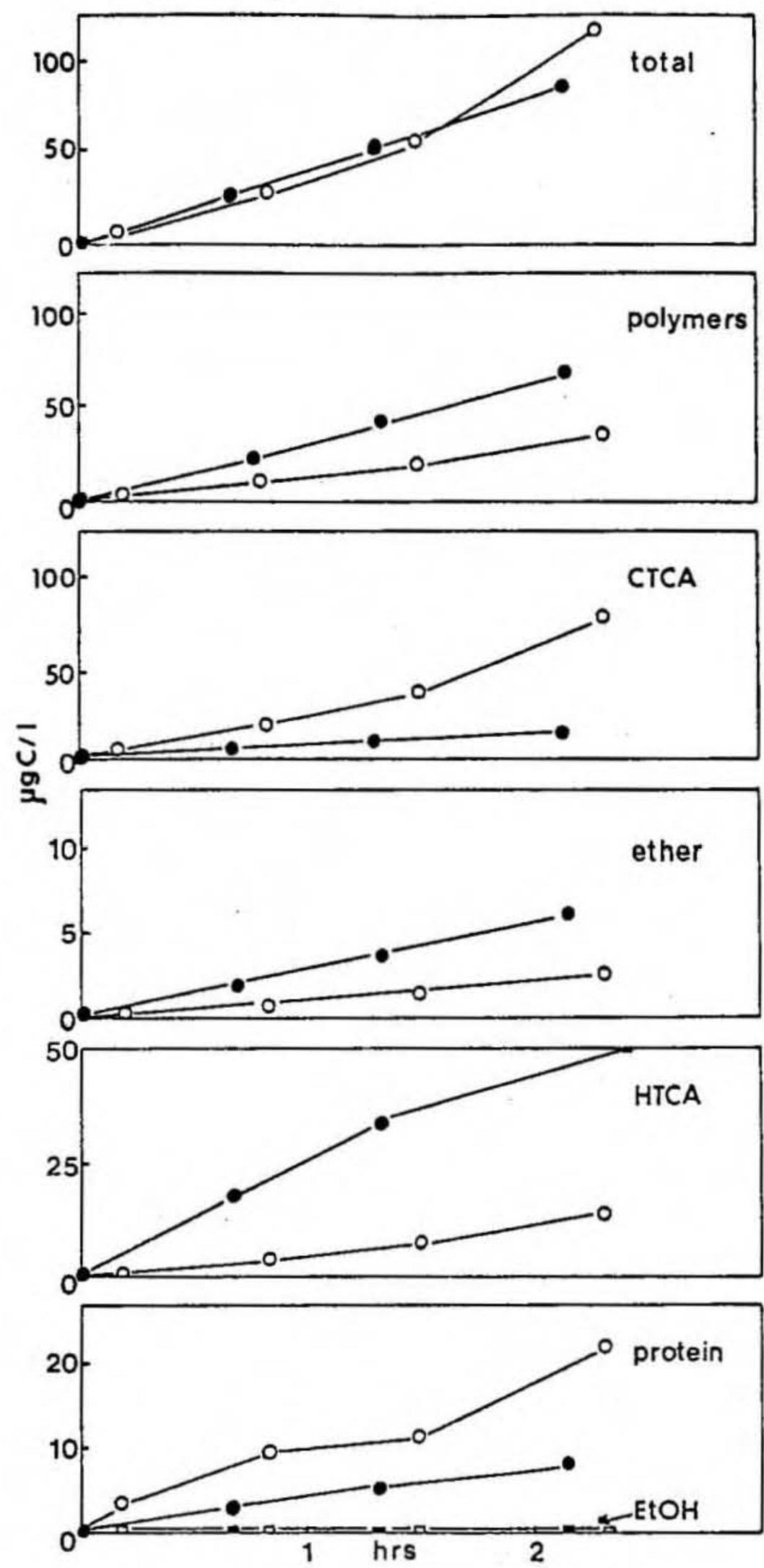
Figure 3-33. Time course of the incorporation of inorganic ${ }^{14} \mathrm{C}$ into subcellular fractions in control and enriched $\mathrm{NH}_{4}^{+}-1$ imited steady state cultures of Dunaliella tertiolecta growing at $16^{\circ} \mathrm{C}$. Dotted Ines Indicate point during incubation when $\mathrm{NH}_{4} \mathrm{Cl}$ (16 micromolar) was added. Symbols: square, enriched; cross, control. 

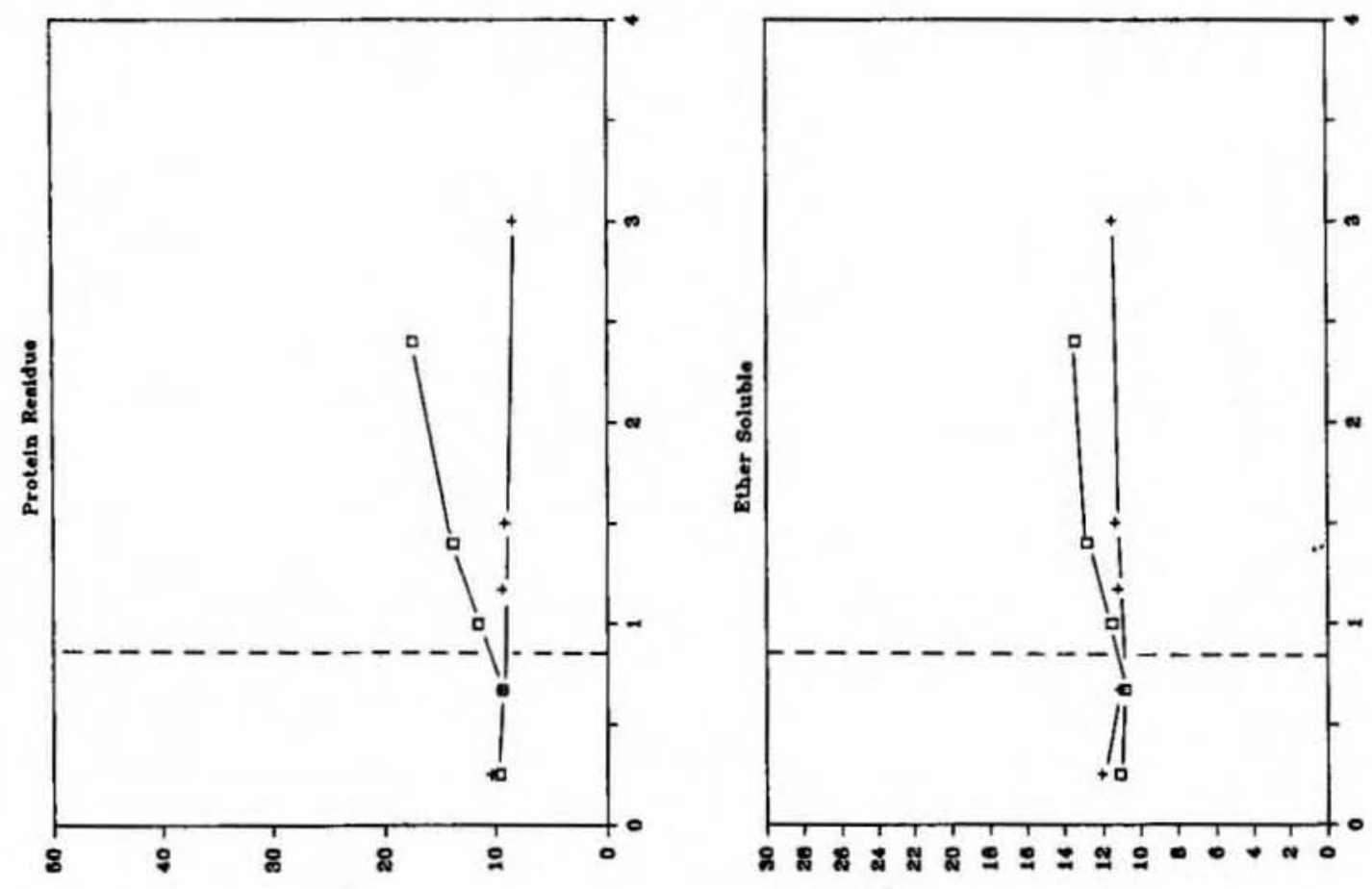

焉
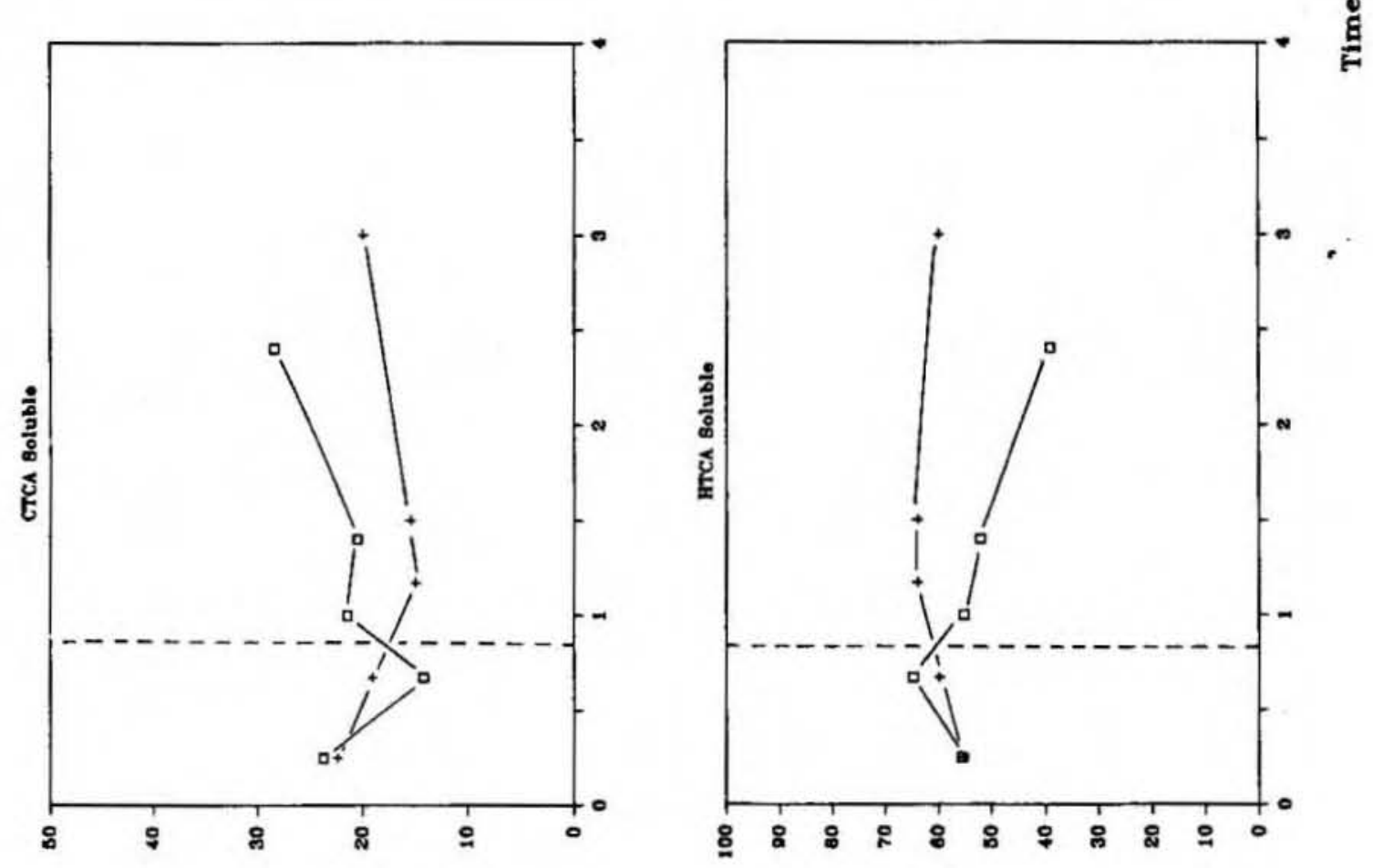

๙0 
Figure 3-34. Time course of total inorganic ${ }^{14} \mathrm{C}$ uptake by control and enriched $\mathrm{NH}_{4}^{+}$-1imited stieady state cultures of Dunaliella tertiolecta growing at $16^{\circ} \mathrm{C}$. Dotted 11ne indicates point during incubation when $\mathrm{NH}_{4} \mathrm{Cl}$ enr1chment ( 16 micromolar) was added. Symbols: square, enriched; cross, control. 


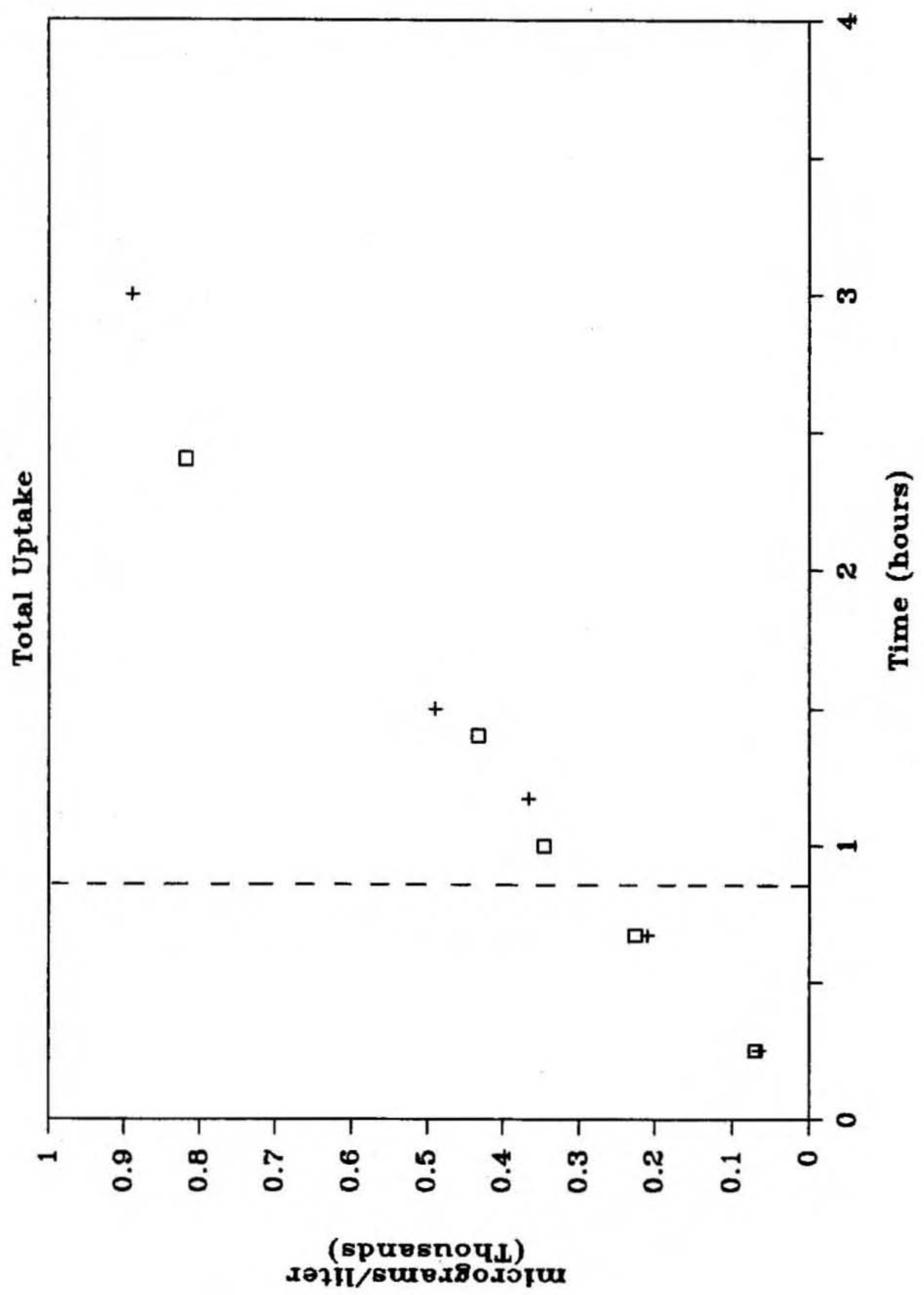


Figure 3-35. Time course of the distribution of incorporated inorganic ${ }^{14} \mathrm{C}$ among subcellular fractions in control and enriched $\mathrm{NH}_{4}^{+}$-1imited steady state cultures of Dunaliella tertiolecta growing at $12^{\circ} \mathrm{C}$. Symbols: square, enriched; cross, control. 

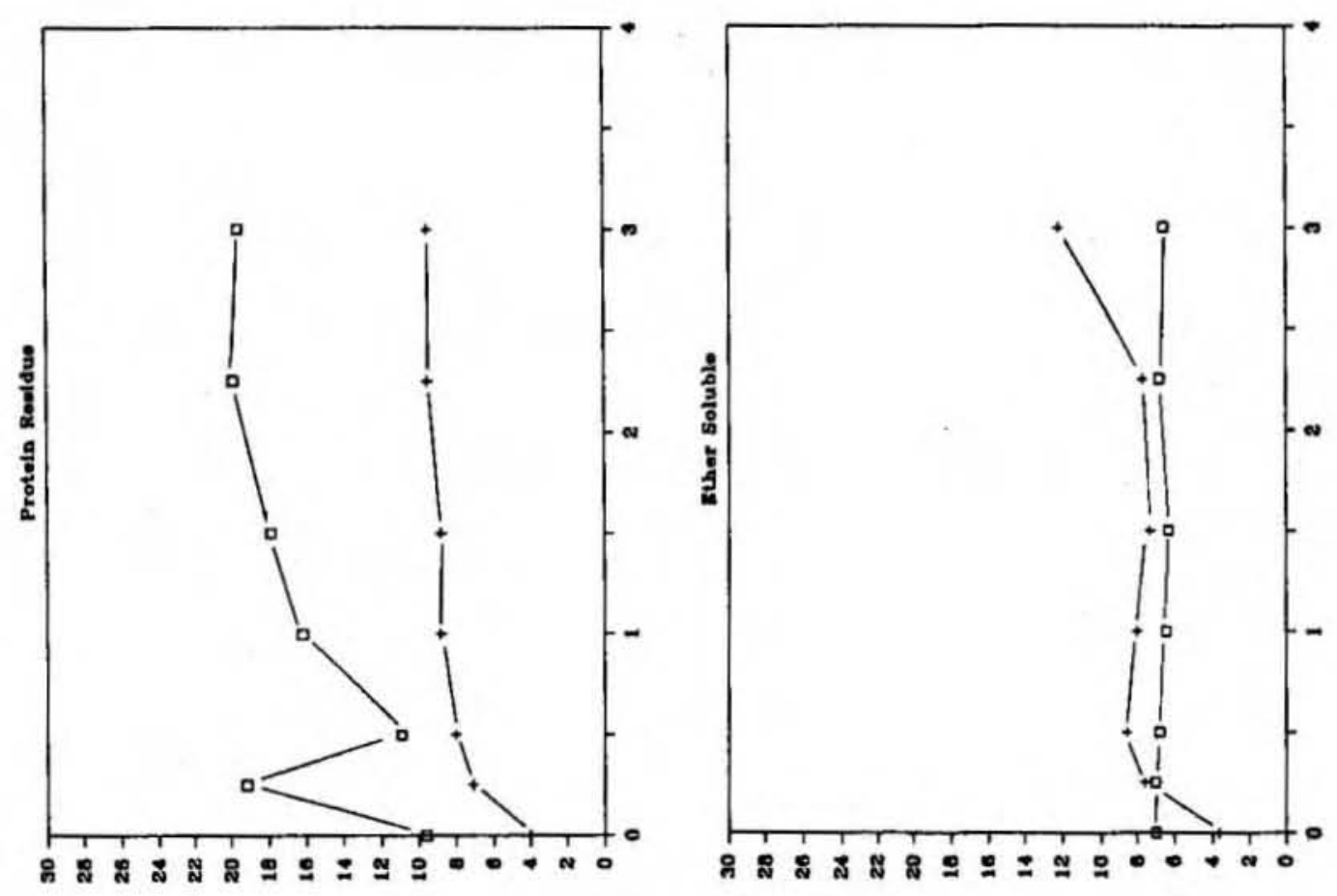

蛋
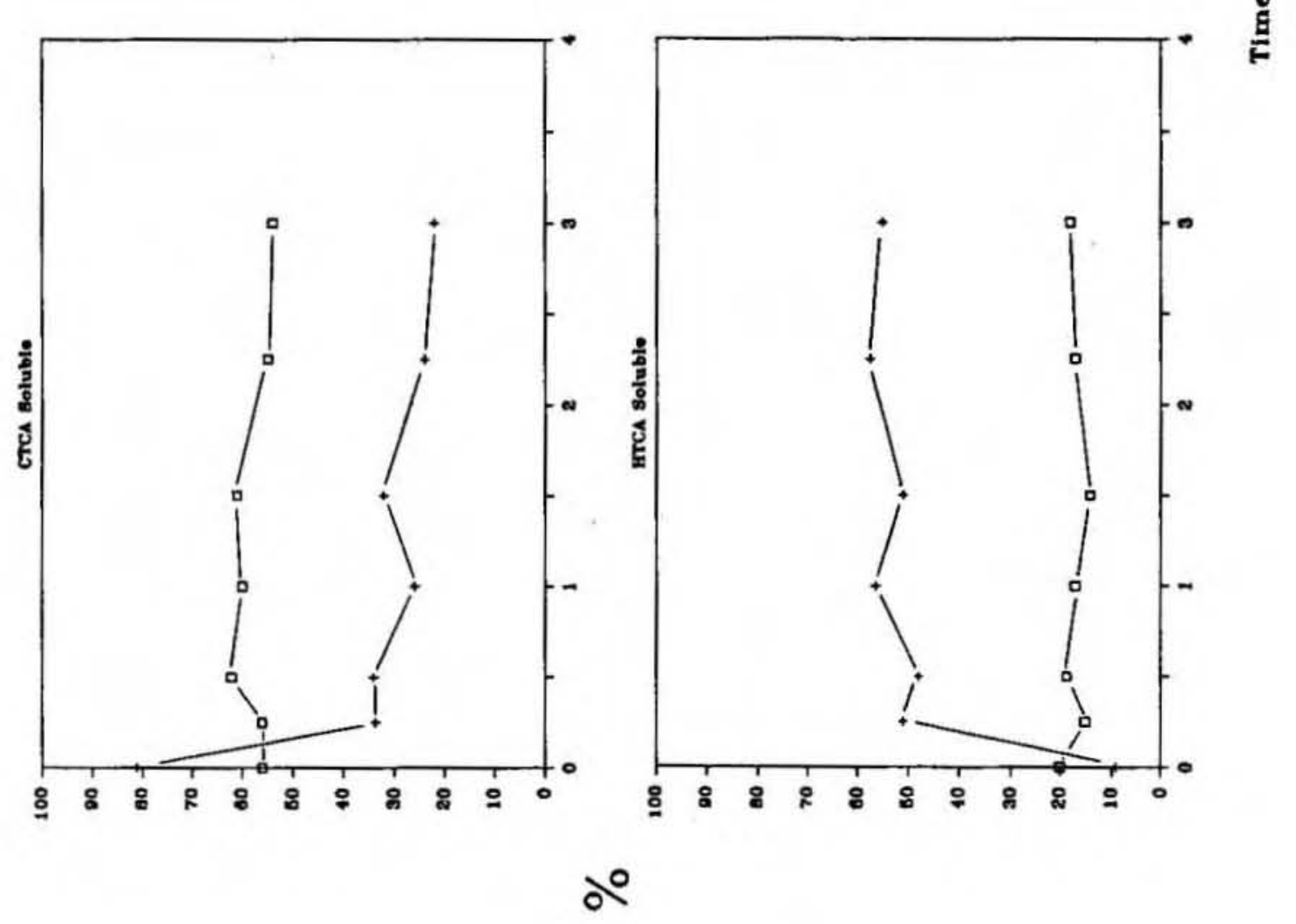
Figure 3-36. Time course of total inorganic ${ }^{14} \mathrm{C}$ uptake by control and enriched $\mathrm{NH}_{4}^{+}-1$ mited steady state cultures of Dunallella tertiolecta growing at $12^{\circ} \mathrm{C}$. $\mathrm{NH}_{4} \mathrm{Cl}$ enrichment of 16 micromolar was added at zero time. Symbols: square, enriched; cross, control. 


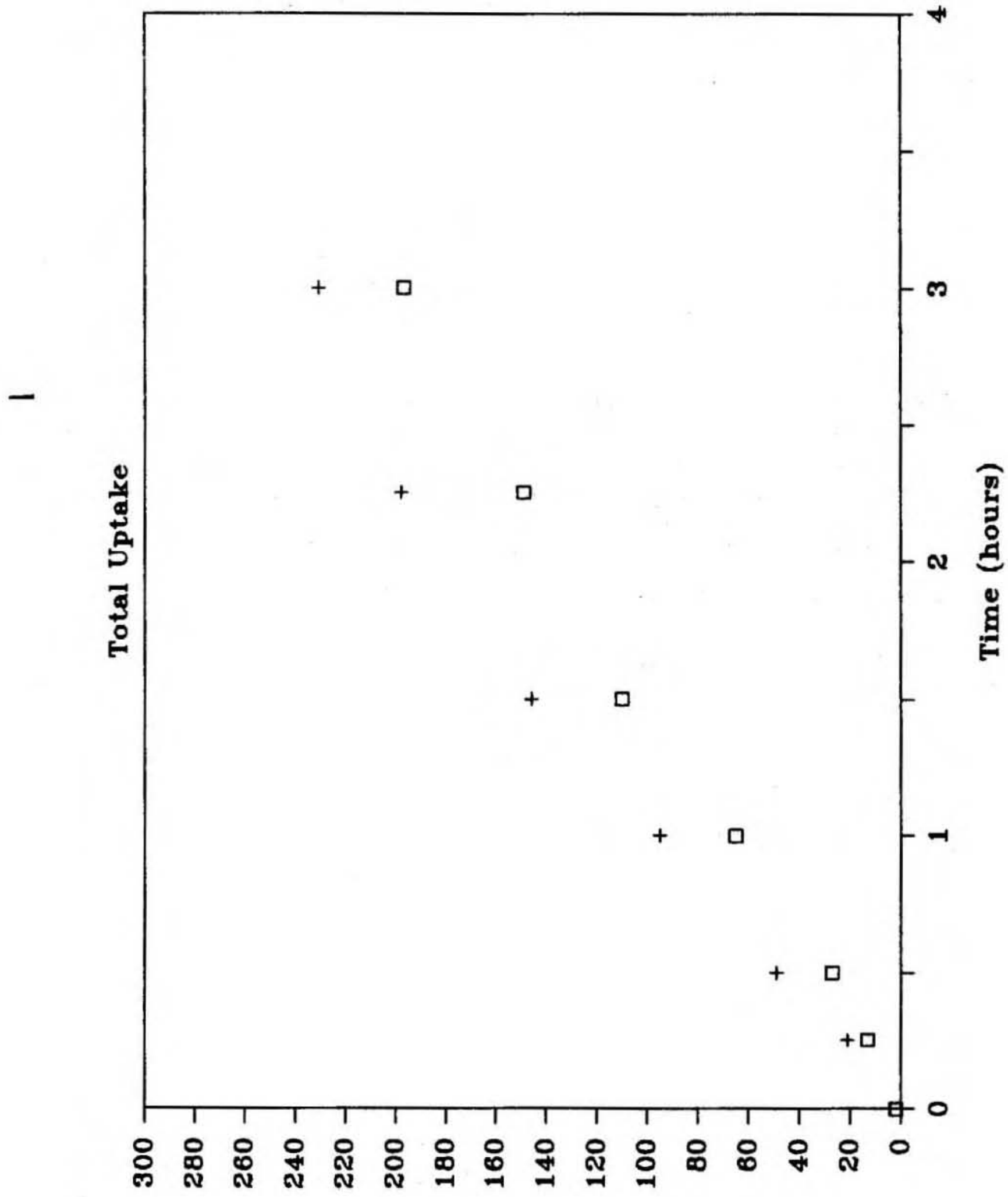


Figure 3-37. Time course of total inorganic ${ }^{14} \mathrm{C}$ uptake by control and enriched $\mathrm{NH}_{4}^{+}-11 \mathrm{mited}$ steady state cultures of Thalass1osira weissflogi1 growing at $16^{\circ} \mathrm{C}$. Dotted 1ine indicates point during enrichment when $\mathrm{NH}_{4} \mathrm{Cl}$ enrichment (16 micromolar) was added. Symbols: square, enriched; cross, control. 


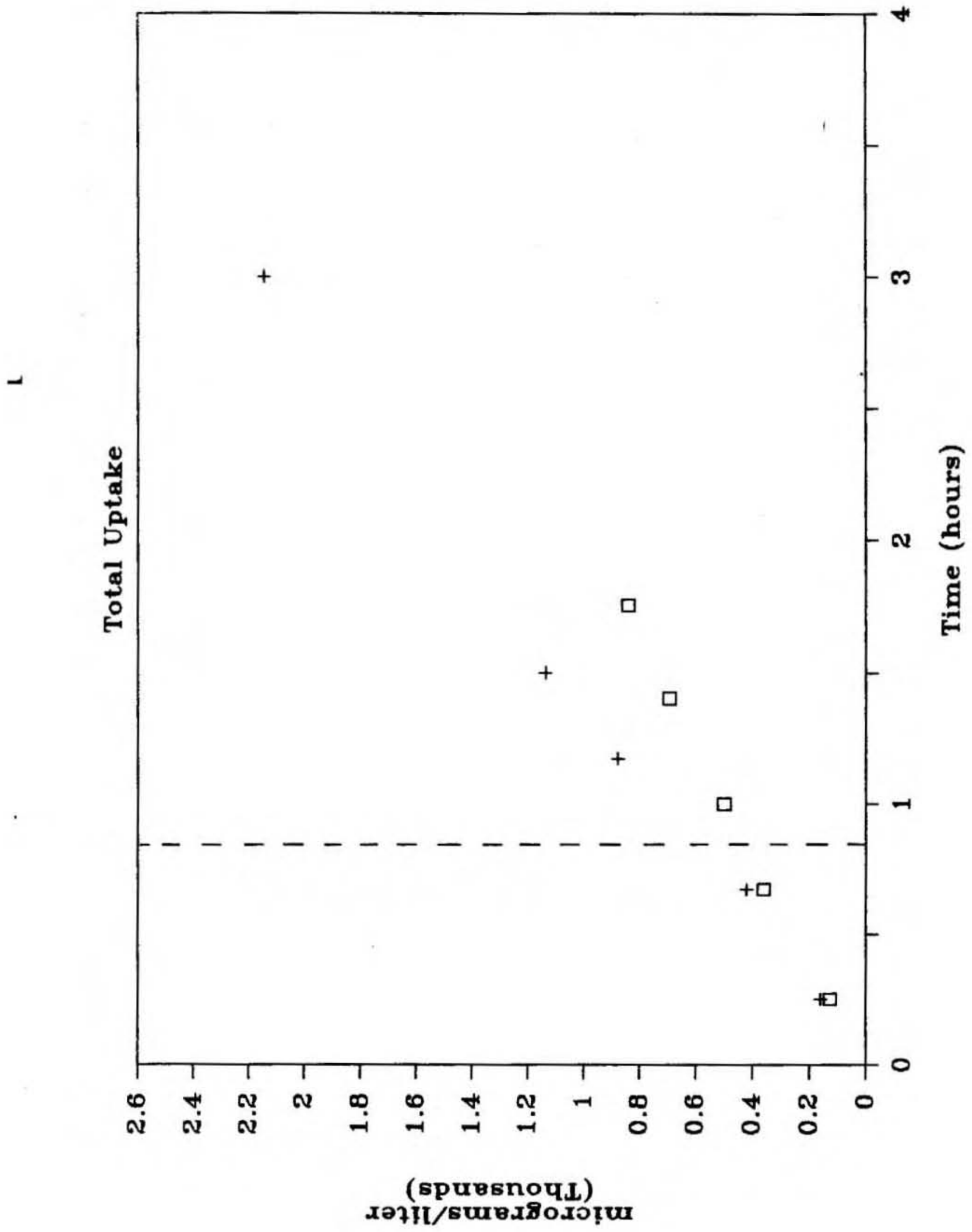


Figure 3-38. Time course of total inorganic ${ }^{14} \mathrm{C}$ uptake by control and enriched $\mathrm{NH}_{4}^{+}-11 \mathrm{~m} 1$ ted steady state cultures of Thalassiosira weissflog 11 growing at $12^{\circ} \mathrm{C}$. $\mathrm{NH}_{4} \mathrm{Cl}$ enrichment of 16 micromolar was added at zero time. Symbols: square, enriched; cross, control. 


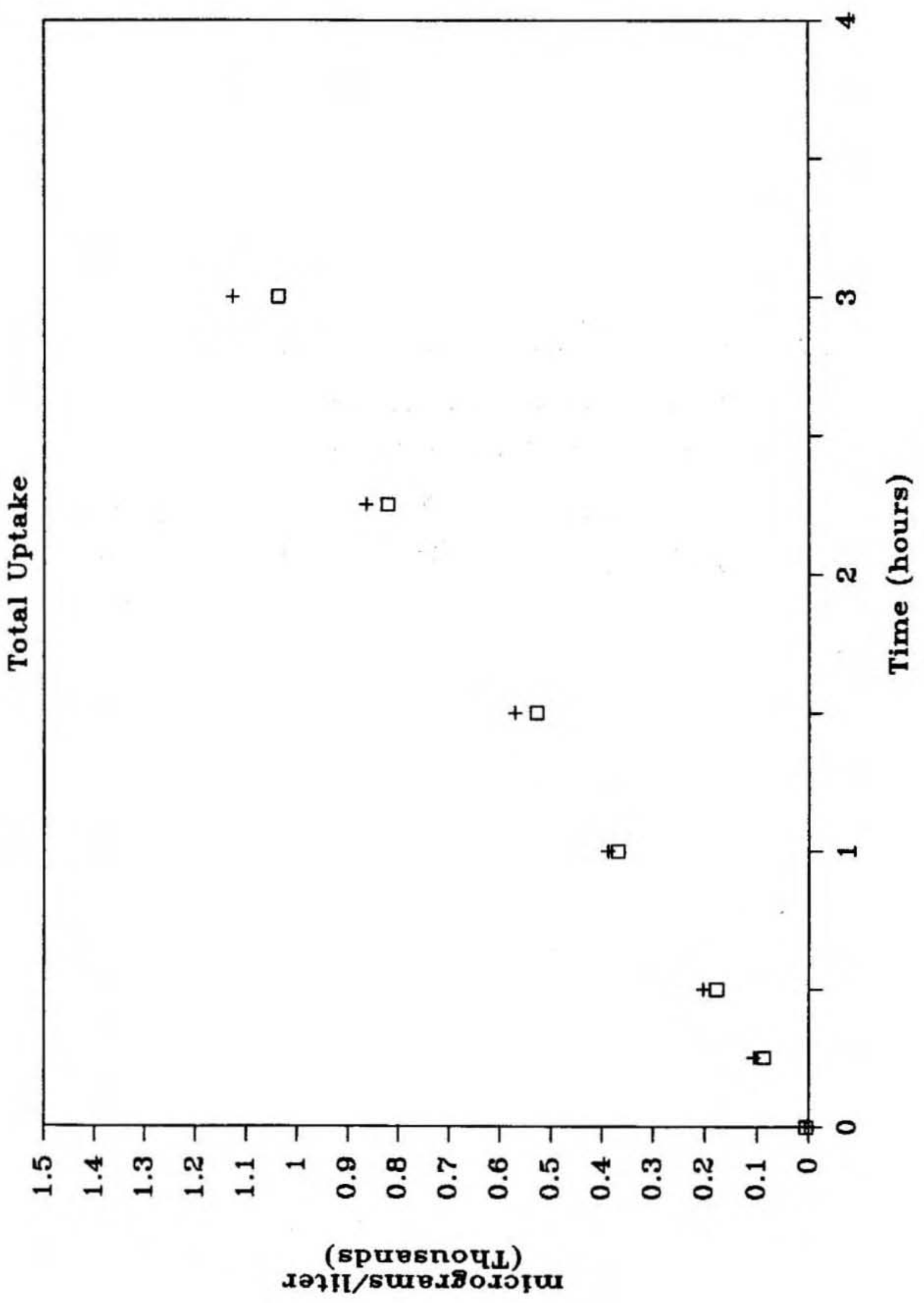


Figure 3-39. Time course of the distribution of incorporated inorganic ${ }^{14} \mathrm{C}$ among subcellular fractions in control and enriched $\mathrm{NH}_{4}^{+}$-1imited steady state cultures of Thalass1osira welssflog 11 growing at $16^{\circ} \mathrm{C}$. Dotted lines indicate point during incubation when $\mathrm{NH}_{4} \mathrm{Cl}$ (16 micromolar) was added. Symbols: square, enriched; cross, control. 

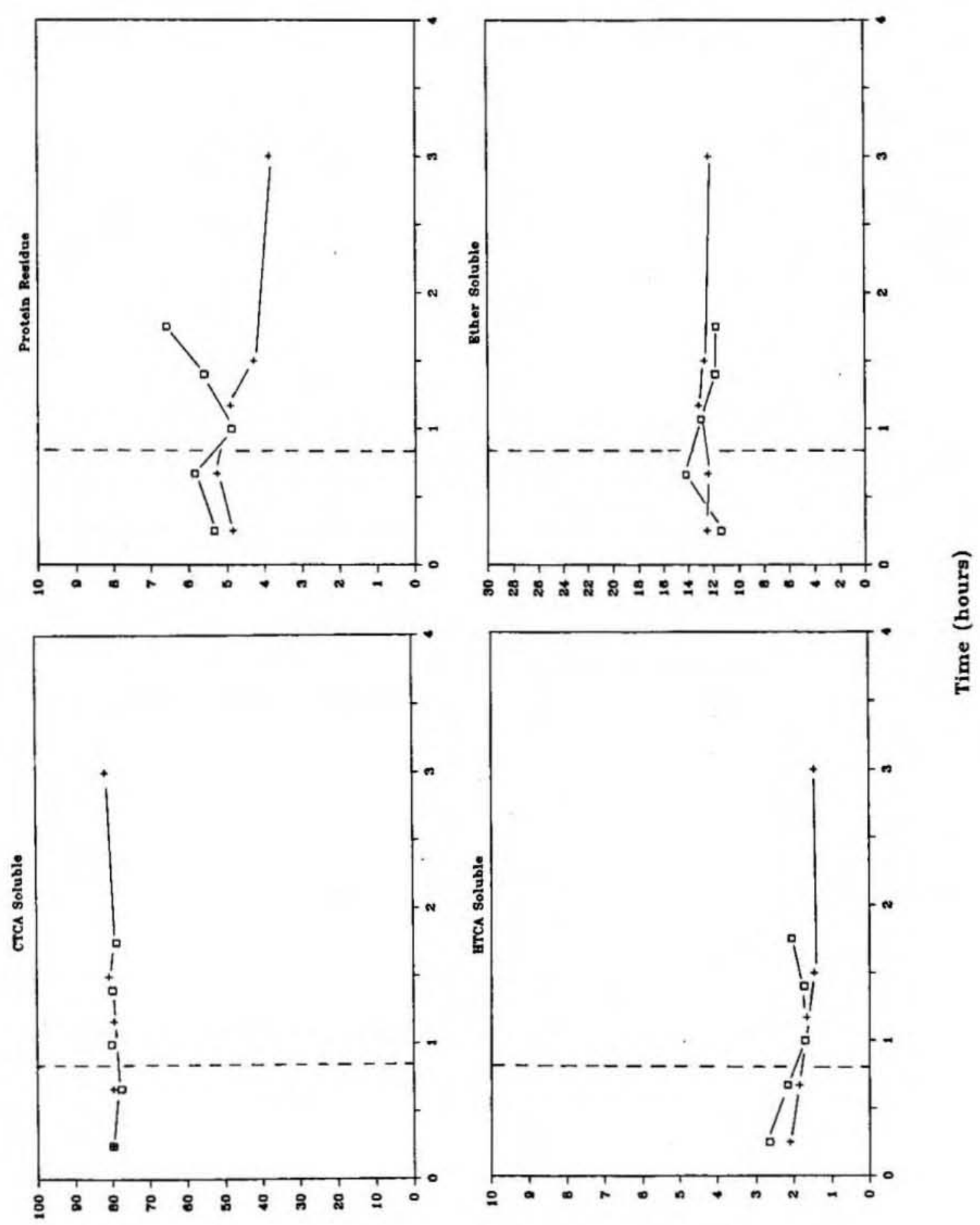

$$
\text { ㅇํ }
$$


Figure 3-40. Time course of the distribution of incorporated inorganic ${ }^{14} \mathrm{C}$ among subcellular fractions in control and enriched $\mathrm{NH}_{4}^{+}-1$ imited steady state cultures of Thalassiosira weissflogi1 growing at $12^{\circ} \mathrm{C}$. Symbols: square, enriched; cross, control. 

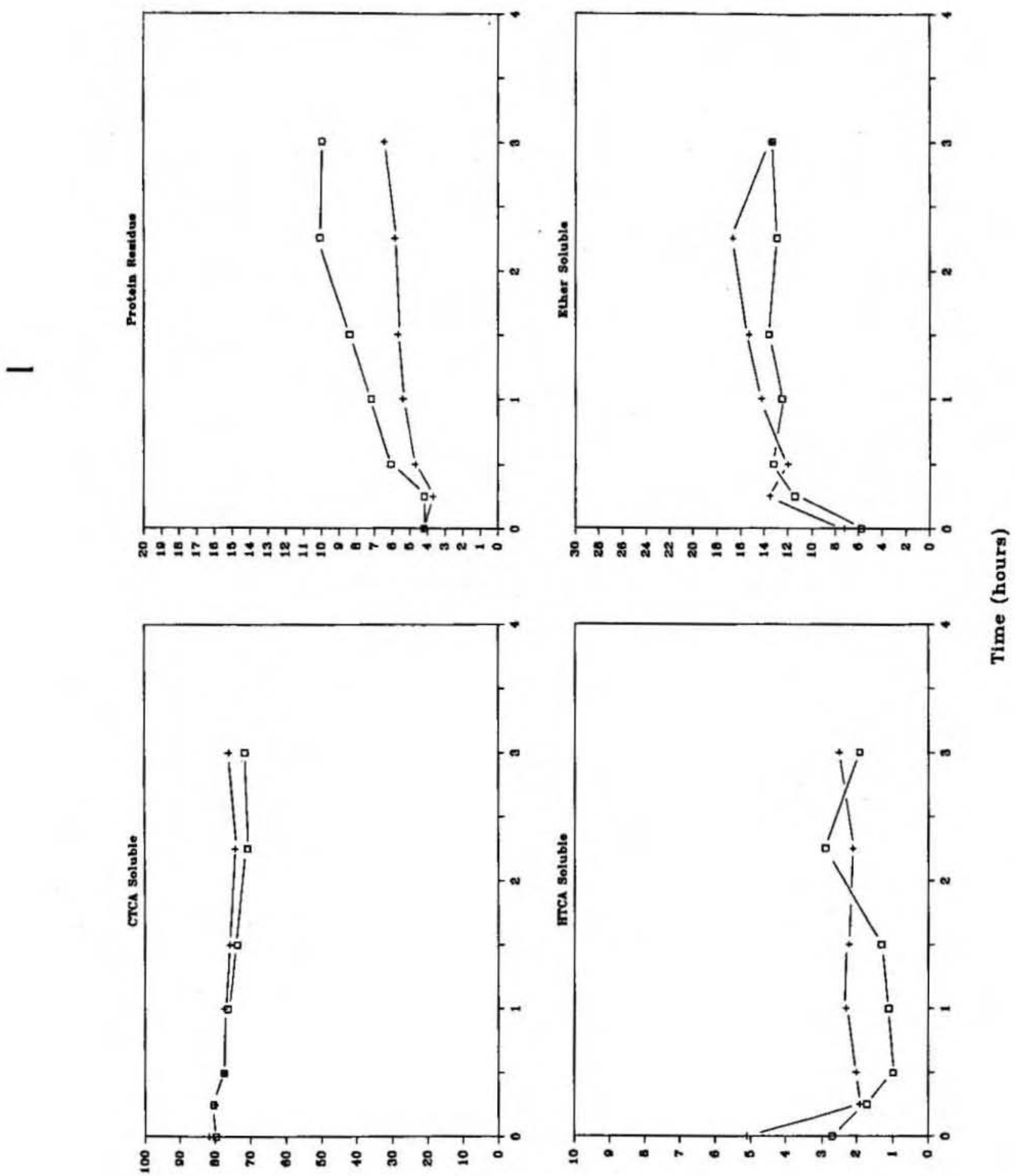

ㅇํ 
and Intracellular nitrogen accumulated in the orcier $\mathrm{NH}_{4}^{+}$, IFAA's, and f1nally protein. It should be noted that the cultures used by Wheeler et al. were synchronous and growing in a 11ght/dark cycle while my cultures were asynchronous growing in continuous light. As a result, some of the kinetics of the response may have been masked in my experiments. However, the results of Wheeler et al. (1983) demonstrated that Initial uptake rates and overall. depletion kinetics were very similar regardless of when the pulse was gttven in the 11ght/dark cycle. Their demonstration of a slower rate of depletion of internal nitrogen pools is consistent with my observations of a lack of dramatic change in carbon metabolism as a result of enrichment. The expected increase in IFAA's based on their observations was not refilected in an increase in cold trichloroacetic acid soluble incorporation in my experiment. It is possible that $\mathrm{NH}_{4}^{+}$was assimilated into existing carbon skeletons. Another possibility is that the acid extraction included reserve polysaccharide, beta-1,3-glucan, which 1.8 present in diatoms and is acld soluble (Myklestad, 1977). The fractionation procedure used in this experiment would not distinguish this as carbohydrate, but rather include it as cold trichloroacet1c acid sol.uble material.

In contrast to the relatively slow nitrogen metabolism, Goldman and Glibert (1982) found that speciflc $\mathrm{NH}_{4}^{+}$uptake was higher for $\underline{\mathrm{T}}$. welssflogi1 than $\underline{D}$. tert:1olecta over a wide range of nitrogen limited growth rates. The preliminary results from this study further emphasize the fact that metabolic responses to nitrogen 1imitation are highly species specific, as are patterns of carbon metabolism in general. Such differences may play a role in defining population structure in environments where nitrogen is a potential growth limiting substrate and 
transient nitrogen uptake capabils.ties are important. More detalled comparisons of the behaviour of specific free amino acids (e.g. glutamate and glutamine) in different species may lead to the identification of metabolic responses which are not species specific, can be probed with inorganic ${ }^{14} \mathrm{C}$, and would therefore serve as useful indicators of metabolic status of natural autotrophic populations.

\section{CONCLUSIONS}

This study characterized effects of variations in the $\mathrm{NH}_{4}^{+}$-1imited steady state growth rate on compositional dynamics and ${ }^{14} \mathrm{C}$ incorporation of free and protein amino acids in the marine chlorophyte, Nannochloris sp. It was found that by characterizing the differential behaviour of intracellular free amino acids, considerable information about metabolism could be obtained. Low glutamine/glutamate ratios were associated with low relative growth rate, consistent with the increased importance of the GS reaction in limiting inorganic nitrogen assimilation.

The presence of proline as a large proportion of intracellular free amino ac1d pool of a microalga has not been previously reported to my knowledge. Decreases in cellular pools of free proline with increasing $\mathrm{NH}_{4}^{+}$limitation indicated that proline served as a nitrogen storage reservolr. Proline is structurally related to glutamate, and might also serve as a source of carbon skeletons during rapid assimilation of $\mathrm{NH}_{4}^{+}$. It may also play a role as an osmoregulator. Its slow saturation characteristics supported the view that it was not a central metabolic intermedlate. 
For glycine + alanine, aspartcte, and valine at the high relative growth rate, saturation rates were rapid enough that specific activities could be assumed to be equivalent to that of the dissolved inorganic carbon pool. In general, specific activities of other free amino acids were less than the that of the dissolved inorganic carbon pool even after 3 hours. Saturation rates of individual free amino acids were generally lower at the low relative growth rate. However, the saturation rate of total IFAA carbon was s:Lmilar for the high and low relative growth rates. This was largely the result of a decline in the proportion of IFAA carbon in proline at the low relative growth rate. Consequently, the abundance of IFAA carbon relative to cellular carbon provides a growth related index of carbon flux through the IFAA pool (1.e. higher relative abundance $=$ higher relative growth rate). Nitrogen turnover rates were generally higher for the free amino acids than the saturation rates with inorganic ${ }^{14} \mathrm{C}$, a consequence of the 1ndependence of carbon and nitrogen flux through the free amino ac1d pool. Trends related to growth rate in the turnover rates of carbon and nitrogen were similar. The relationship between saturation characteristics of intracellular free amino acids and nascent proteln amino acids was influenced by growth rate. At the low relat:Lve growth rate, the saturation rates of nascent protein glutamate, glycine + alanine, and valine were higher than corresponding free amino acld specific activities. This indicated metabolic segregation of protein amino acld precursor pools, which was not apparent at the high relative growth rate. Nascent protein glycine and alanine appeared to have rapidly saturating precursors at both high and low relative growth rates, providing a foundation for further study of their utility in accurately estimating protein synthesis. This approach is examined in Chapter 4. 
Distributions of incorporated ${ }^{14} \mathrm{C}$ incorporation among individual free amino acids and protein provided qualitative descriptions of relative abundances of cellular carbon. Such an approach may be useful for assessing the physlological state of the metabolically active algal populations, without detrital or non-autotrophic interference. Distributions of incorporated ${ }^{14} \mathrm{C}$ also qualitatively reflected increases in free amino acid concentrations caused by $\mathrm{NH}_{4}^{+}$ enrichment. The responses of the free amino acids were highly sensitive to the increase in $\mathrm{NH}_{4}^{+}$concentration, in contrast to total ${ }^{14} \mathrm{C}$ uptake. Individual species differed in their responses to $\mathrm{NH}_{4}^{+}$ enrichment with respect to the distribution of ${ }^{14} \mathrm{C}$ among different cell materials. It may be that responses at the level of the free amino acids are less subject to interspecies variations. If so, evaluating patterns of isotope incorporation into the free amino acids in response to $\mathrm{NH}_{4}^{+}$enrichment would be a useful means of diagnosing the nitrogen status of phytoplankton populations.

A more complete characterization of the manner in which other environmental conditions (such as 11ght, temperature), diel variations, and species composition influence metabolism may eventually permit direct and rapid assessment of the physlological state of natural autotrophic populations, and rates and composition of the primary organic matter being produced. Such information will lead to a better understanding of the role of marine phytoplankton in influencing the dynamics of particulate organic matter, and a general understanding of this primary level in trophodynamic processes. 
CHAPTER 4. RELATIONSHIPS BETWEEN NET SYNTHESIS RATES OF PROTEIN AMINO ACIDS AND INCORPORATION OF INORGANIC ${ }^{14} \mathrm{C}$ IN MARINE PHYTOPLANKTON 


\section{INTRODUCTION}

The production of protein is closely associated with the growth of all living organisms, and 1 is nutritionally essential to all heterotroph1c organisms. Marine phytoplankton are the primary source of protein for the marine food chain. Accurate estimates of this primary Input are required in order to understand marine ecosystem trophodynamics, and the role of phytoplankton in influencing the flux and compositional dynamics of particulate organic matter. Moreover, since the proportion of algal metabolism associated with protein synthesis varies in relationship with the growth rate of the population (e.g. Chapter 3), the ability to accurately trace autotrophic production of protein in relationship to total carbon fixation will be a useful tool for assessing population physiological state.

The ${ }^{14} \mathrm{C}$ technique for measuring rates of photosynthet1c carbon fixation (Steeman-Nielsen, 1952) provided a sensitive and specific assay of phytoplankton activity in units which could be directly compared to blomass. Desplte the controversy surrounding the methodology and interpretation of the results it provides, it remalns one of the most powerful and widely applied methods for estimating photosynthetic activity. The ubiquitous nature of carbon in living biomass allows the use of ${ }^{14} \mathrm{C}$ to trace various levels of metabolism. This is the basis underlying fractionation procedures which involve the 1solation and radioassay of operationally defined cellular materlal having general characteristics which can be related to different types of metabolism.

In chapter 3 , I discussed methods for improving the ut1lity of results obtained from fractionation procedures. These include: a) precise chemical definitions of cell material in order to clarify 
relationsh1ps between observed 1sotope distributions and actual metabolic characteristics, and b) adequate descriptions of the kinetics of 1sotope distribution, and its relationship to chemical composition and biosynthetic rates. The application of these methods towards the 1sotopic tracing of protein synthesis are considered in this chapter. In addition, I have examined the potential impact of the interruption of steady state growth, such as might arise from sample confinement, on 1sotope incorporation into protein.

\section{BACKGROUND:}

\section{Tracing Production of Particulate Protein Amino Acids}

The essential role which amino acids play in the growth of all living organisms makes them an ideal class of blogenic compounds for 1nvestigating the relationship between the composition of primary organic matter produced by phytoplankton and the composition of total particulate organic material found in the environment. By tracing the production of this specific class of compounds with ${ }^{14} \mathrm{C}$, I eliminate the ambiguities associated with undefined subcellular fractions. The second problem associated with fractionations, that is the dependence of 1sotoplc distribution with time, will be evaluated in the laboratory in several representative phytoplankton specles. The intracellular free amino acid pool specific activity may not necessarily reflect the specific activity of the protein amino acid precursor pool (e.g. Oaks and Bidwell, 1970; Bassham et a1., 1964; Trewavas, 1972; Huffaker and Peterson, 1974; Wheeler and Stephens, 1977; chapter 3, this thesis). Th1s results in an ambiguous relationship between isotope incorporation into protein and net 
protein synthesis. In chapter 3, I noted that protein had the slowest 1sotope kinetics of the polymer fractions. Isotope kinetics were different for the individual protein amino acids, and varied with the nitrogen limited growth rate. Glycine and alanine contained in nascent protein consistently displayed rapid saturation kinetics. My approach in this chapter was to compare predicted net production of individual protein amino acids as defined by continuous culture dilution (growth) rate with observed production as determined by ${ }^{14} \mathrm{C}$ incorporation. The results provide information about the isotope kinetics of various protein amino acid precursor pools, and identify those protein amino acids whose precursors rapidly attain the specific activity of the exogenous dissolved Inorganic carbon pool.

Li and Goldman (1981) compared carbon spec1fic growth rates of several species with their continuous culture growth rates. In a number of instances, this rate did not agree with the growth rate defined by the culture dilution rate. Overestimates were probab1y due to turnover in excess of net production. Underestimates might have occurred as a result of nutrient depletion accompanying the interruption of steady state growth. Goldman et al. (1981a) found that unenriched samples which had been removed from steady state cultures of some species exhibited time dependent decreases in carbon incorporation with1n a few hours. Th1s demonstrates the importance of time course sampling for distinguishing patterns of isotope kinetics from perturbations in culture metabolism as a result of the interruption of steady state.

Ii and Harrison (1982) suggested that isotope incorporation into protein may be less likely to overestimate net synthesis than total isotopic carbon incorporation. During the eastern Canadian arctic summer 
(24 hour photoperiod), L1 and Harrison (1982) compared isotope Incorporation patterns for samples from consecutive 2 hour Incubations w1th those of a 32 hour incubation. From the1r results, they suggested that the short incubations tended to reflect gross 1sotope incorporation and as a result yielded higher estimates of incorporation than from samples taken in the latter portion of the extended incubation. The protein fraction seemed to show the least discrepancy between the 1ong and consecutive short incubations. This might mean that protein is less subject to turnover in excess of net production. However, such turnover does occur in higher plants and algae, and is a function of physiological state (e.g. Trevawas, 1972; Huffaker and Peterson, 1974; Bates, 1981; Cuhel et al., 1984). I will present results wh1ch demonstrate that under certain conditions, protein turnover signiflcantly affects 1sotope incorporation characteristics.

\section{Radiolsotopic Tracing of Microbial Activities}

Radiolsotopic tracers other that ${ }^{14} \mathrm{C}$ which can be associated with distinct types of cell material have been used to monitor microblal activities in natural systems. These include ${ }^{3} \mathrm{H}$-adenine ( $\operatorname{Karl}, 1981$, Kar1 et al., 1981a,b; Kar1, 1979; Winn and $\operatorname{Kar} 1,1984)$ and ${ }^{32}{ }^{\mathrm{PO}} 4$ (Cuhel et al., 1983; Cuhel and Waterbury, 1984) to assess nucleic acid blosynthesis, and ${ }^{35} \mathrm{SO}_{4}$ to trace the production of protein (Bates, 1981; Cuhel et al., 1981a,b,c,1982a,b,1983). Unl1ke 1norganic ${ }^{14} \mathrm{C}$, these procedures do not provide an assay of metabolic activity specific to phytoplankton as bacterial activity will also be measured. Furthermore, sensitivity is limited in the case of ${ }^{35} \mathrm{SO}_{4}$ as a result of dilution by the large ambient $\mathrm{SO}_{4}$ levels, and in the case of 


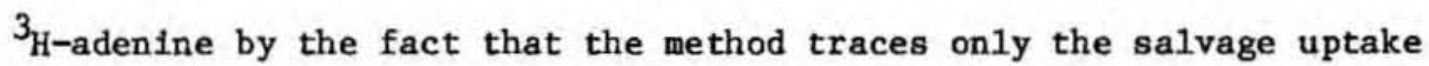
of adenine, a minor contribution to total nucleic acid biosynthesis. Addition of ${ }^{3} \mathrm{H}$-adenine and ${ }^{32} \mathrm{PO}_{4}$ may perturb existing uptake kinetics. In contrast, inorganic ${ }^{14} \mathrm{C}$ can be added in truly tracer amounts to very high specific activities. This investigation provides basic information required to optimize methods for ${ }^{14} \mathrm{C}$ tracing of protein amino acid production by natural phytoplankton populations. * * * *

A major emphasis of this study will be to assess the impact of changes in various environmental conditions on the kinetics of 1sotope incorporation into protein. In order that these results can be useful to other investigators, descriptions of biomass parameters as a function of growth rate are provided. In particular, I described the compositional relationship of protein to other cellular materials. This information provides an Index of the cultures' physiological states (e.g. Rhee, 1978; Goldman, 1980; Dortch, 1982; Maske, 1982). I initally described the compositional variations assoclated with steady state growth of Nannochloris sp. under two different light intensities and varying degrees of $\mathrm{NH}_{4}^{+}$IImltation. Subsequent1y, intercomparisons were made of the chemical composition of three other species grown under $\mathrm{NH}_{4}^{+}$-limited steady state conditions at a single light intensity. The results provide a description of compositional differences, both within a single species as a result of environmentally induced changes in metabolism, and between species as a result of intrinsic metabolic differences. Such variations in metabolism influence observed kinetics of isotope incorporation. It is the main objective of this chapter to evaluate such variations in ${ }^{14} \mathrm{C}$ kinetics, and determine the optimal 
conditions for accurate and precise estimation of protein synthesis on the basis of isotopic carbon incorporation. In chapter 5, I demonstrate the use of this information to assess the metabolic characteristics of a natural phytoplankton population, and the role of primary inputs of protein in influencing the compositional dynamics and flux of particulate organic matter.

\section{METHODS}

Compar1son of Protein Assay Methodologies

Knowledge about the relationship of protein to other cellular materials is useful in providing an index of the growth and physiological state of the algal culture. Such information facilitates

intercomparisons between results of other studies and the characteristics of protein synthesis and associated patterns of carbon incorporation which are presented here. In order to determine the extent to which results obtained by my method for protein analysis can be generalized to results of other studies, I compared different methodologies for assaying protein. Results are shown in Table 4-1 for $10 \mathrm{~g}$ phase batch cultures of Nannochloris sp. adapted to a high 11 ght intensity $\left(176 \pm 70 \mu \mathrm{E} \cdot \mathrm{m}^{-2}\right.$. $s^{-1}$ ). The two methods, the Bradford assay (Bradford, 1976) using the Coomassie brilliant blue dye reagent provided commercially by Blo-Rad, and the analysis of individual protein amino acid residues, yleld similar results. The estimate of protein nitrogen was slightly lower for the residue method. Differences between methods were within the limits of analytical error. A slight underestimate would be expected since the amlde groups of glutamine and asparagine are lost and tryptophan is destroyed during acid hydrolysis (DeJong et al., 1981). Fowden (1954) 
Table 4-1. Bulk Chemical Composition Parameters For High Light ${ }^{a}$ Batch Cultures of of Nannochloris sp.

\begin{tabular}{|c|c|c|c|c|}
\hline $\begin{array}{l}\% \text { Total POC } \\
\text { in Protein }\end{array}$ & $\begin{array}{l}\% \text { Total PON } \\
\text { in Protein }\end{array}$ & $\begin{array}{l}\frac{\mathrm{Chl}}{\mathrm{a}}_{\text {Protein Carbon }} \\
(\mu \mathrm{g} / \mu \mathrm{g}) \times 100\end{array}$ & $\mathrm{C}: \mathrm{N}$ & $\frac{\text { Carbon }}{\text { Ch1 a }}$ \\
\hline \multicolumn{5}{|c|}{ Bradford protein assay: ${ }^{b}$} \\
\hline $23.1(6.2)$ & $55(15)$ & $4.6(1.0)$ & $6.1-8.9$ & $95.7(6.2)$ \\
\hline \multicolumn{5}{|c|}{$\frac{\text { Residue analysis of }}{\text { hydrolyzed protein: }}$} \\
\hline $21.9(3.9)$ & $42.8(9.5)$ & $5.7(0.8)$ & 6.6 & $81(12)$ \\
\hline
\end{tabular}

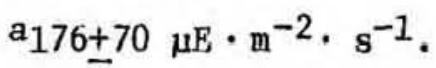

b Errors (in parentheses) represent $95 \%$ confldence intervals.

cErrors (in parentheses) represent propagated estimates of analytical error based on $95 \%$ confidence intervals. 
also pointed out that the basic amino acids arginine, lysine and histidine may be partially destroyed during hydrolysis in the presence of carbohydrate. Finally, I did not assay tyrosine, cysteine, and methionine so they were not included in the results.

All other methods were described in chapter 2.

\section{RESULTS AND DISCUSSION}

Effects of Growth Conditions on Chemical Composition of Nannochloris sp.

The relationship of protein to other biomass parameters in high light

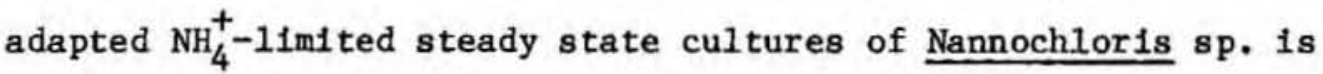
shown in Table 4-2. The compositional parameters are representative of the steady state culture conditions. As noted in chapter 3 (Table 3-2), the percentage of particulate organic carbon associated with protein decreases with decreasing growth rate. In conjunction, the chlorophyll a/protein carbon and $C: N$ ratios increase. No significant change in the POC/chlorophy11 a ratio could be demonstrated. In $\mathrm{NH}_{4}^{+}-1$ imited cultures adapted to low light conditions $\left(28 \pm 9 \mu \mathrm{E} \cdot \mathrm{m}^{-2} \cdot \mathrm{s}^{-1}\right)$, no significant decrease in the percentage of POC in protein was seen with decreasing growth rate (Table 4-3), nor was there a substantlal change in the $C: N$ ratio. The chlorophyll a/protein carbon ratio decreased with increasing nitrogen limitation, in contrast to the increase seen under high light conditions. Thus, during growth under high light conditions, proteln synthesis is more sensitive to nitrogen supply than chlorophyll a production, while under low light conditions, this relationship is reversed. The chlorophyll a/protein carbon ratio was generally higher and the $\mathrm{POC} / \mathrm{chlorophy} 11$ a ratio lower under low light relative to high light conditions. Chan (1978) found a similar pattern of chlorophyll 
Table 4-2. Bulk Chemical Composittion Parameters For High Light ${ }^{a}$ NHt-limited Steady State Cultures of Nannochloris sp.

\begin{tabular}{|c|c|c|c|c|c|}
\hline $\begin{array}{c}\text { Relative Growth } \\
\text { Rate }^{\mathrm{b}}\end{array}$ & $\begin{array}{l}\% \text { Total POC } \\
\text { In Proteinc }\end{array}$ & $\begin{array}{l}\% \text { Total PON } \\
\text { in Prote1n }\end{array}$ & $\begin{array}{l}\text { Chl a } \\
\text { Protein Carbon } \\
\text { (ug/ug) x100 }\end{array}$ & $\mathrm{C}: \mathrm{N}$ & $\begin{array}{l}\frac{\text { Carbon }}{\text { ChI a }} \\
(\mu \mathrm{g} / \mu \mathrm{g})\end{array}$ \\
\hline $0.933(0.031)$ & $18.9(4.9)$ & $31.2(21.0)$ & $4.3(1.1)$ & 6.2 & $124(42)$ \\
\hline $0.458(0.014)$ & $16.8(3.0)$ & $36.8(8.4)$ & $5.1(0.5)$ & 7.4 & $117(28)$ \\
\hline $0.229(0.016)$ & $8.8(2.0)$ & $42.0(7.3)$ & $6.8(1.0)$ & 17.1 & $166(38)$ \\
\hline
\end{tabular}

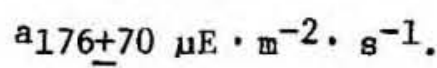

$b_{G r o w t h}$ rate normalized to maximum growth rate $\left(1.44(0.04)\right.$ day $\left.^{-1}\right)$ under similar conditions of 1 ight and temperature. Growth ratte errors (in parentheses) represent $95 \%$ confidence intervals.

c Errors for all compositional parameters (in parentheses) represent propagated estimates of analytical error based on $95 \%$ confidence intervals. 
Table 4-3. Bulk Chemical Composition Parameters For Low Lighta Batch and NHt-limited Steady State Cultures of Nannochloris sp.

\begin{tabular}{|c|c|c|c|c|c|}
\hline $\begin{array}{l}\text { Relative Growth } \\
\text { Rate }^{\mathrm{b}}\end{array}$ & $\begin{array}{l}\% \text { Total POC } \\
\text { in Proteinc }\end{array}$ & $\begin{array}{l}\% \text { Total PON } \\
\text { in Protein }\end{array}$ & $\begin{array}{l}\stackrel{\mathrm{Chl} \text { a }}{\text { Protein Carbon }} \\
\text { (ug/ug) } \times 100\end{array}$ & $\mathrm{C}: \mathrm{N}$ & $\frac{\text { Carbon }}{\text { Chl } \stackrel{a}{(u g / u g)}}$ \\
\hline Batch: & & & & & \\
\hline $\begin{array}{l}1.00(0.09) \\
\text { Steady State: }\end{array}$ & n.d. & n.d. & n.d. & 7.5 & $52.3(9.4)$ \\
\hline $0.864(0.092)$ & $9.8(1.9)$ & 51 (35) & $16.5(1.8)$ & n.d. & n.d. \\
\hline $0.723(0.063)$ & $14.5(2.8)$ & $36.5(7.9)$ & $15.0(1.6)$ & n.d. & n.d. \\
\hline $0.283(0.060)$ & $14.0(2.6)$ & $38.7(8.6)$ & $10.1(1.6)$ & 9.2 & $70.4(14.7)$ \\
\hline
\end{tabular}

a $28 \pm 9$ uE $\mathrm{m}^{-2} \mathrm{~s}^{-1}$.

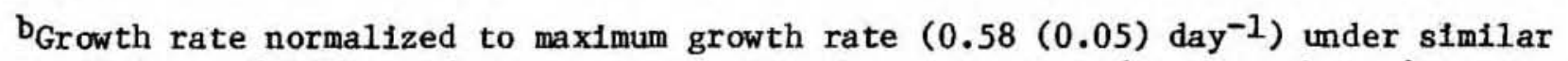
conditions of light and temperature. Growth rate errors (1n parentheses) represent $95 \%$ confidence intervals.

cErrors of all compositional parameters (in parentheses) represent propagated estimates of analytical error based on $95 \%$ confidence intervals. 
a/protein ratios in response to 1 ight intensity in a survey of selected diatoms and dinoflagellates. This indicates that chlorophyll production was enhanced relative to total blomass in low 11 ght adapted cultures, a common1y observed response of algae (e.g. Beale and Appleman, 1971; Bearda11 and Morris, 1976; Prezelin, 1976; Falkowski and Owens, 1980; Perry et al., 1981; Richardson et a1., 1983). The fact that the chlorophyll a/proteln carbon ratio declined with decreasing growth rate under low light conditions indicates that nitrogen limitation suppressed the low light enhanced chlorophyll production. Reduction in steady state chlorophyl1 a content with Increasing nitrogen 11mitation has been reported by other investigators (Caperon and Meyer, 1972; Thomas and Dodson, 1972). These results demonstrate that the regulation of chlorophyll synthesis in Nannochloris sp. is more sensitive to nitrogen supply under low 11 ght conditions. In contrast, the \%POC in protein was lower at high relative growth rate under low light conditions, and did not decrease wth increasing nitrogen limitation. This suggests that the proportion of carbon metabolism associated with protein synthesis was less sensitive to Increasing nitrogen limitation at the low 11ght intensity (c.f. Cook, 1963).

A possiblity which must be recognized is that an unknown substrate other than $\mathrm{NH}_{4}^{+}$was 1imiting. For example, increased demand for some trace substrate might accompany growth under low light intensities. Further proof that inorganic nitrogen was limiting is required.

\section{Interspecies Comparisons of Chemical Composition}

Comparisons of compositional parameters among different species growing under high light $\mathrm{NH}_{4}^{+}$-1imited steady state conditions reveal 
differences (Table 4-4 and 4-5), but for the most part, these differences were within the range of environmentally induced varlations seen for Nannochloris sp. The blomass parameters reported here strengthen earlier arguements by Parsons et al. (1961) that the chemical composition of different species is remarkably similar. Morris (1981) pointed out that environmentally induced varlations can be more important than species changes in determining particulate organic matter composition. In Chattone1la (011sthodiscus) 1uteus, the percentage of PON in protein Increased and the $C: N$ ratio decreased with increasing growth rate as has been reported for other algae (Rhee, 1978; Dortch, 1982). The growth rate range may have been inadequate to detect changes in the other parameters.

Biomass parameters expressed on a per average cell basis are shown for high 11ght (Table 4-6) and low I1ght (Table 4-7) adapted continuous cultures of Nannochloris $\mathrm{sp}$. at $\mathrm{NH}_{4}^{+}-11 \mathrm{mited}$ isteady state. Cellular levels of both nitrogen and protein decreased with decreasing growth rate under high light conditions. In low light adapted cultures (Table 4-7), no decrease in nitrogen per cell was associated with decreasing growth rate. Carbon per cell remained relatively constant for both the light saturated and light limited cultures, an indilcation that carbon was a relatively conservative cellular material. Chlorophyll a per cell was generally higher at low 1ight, consistent with the higher chlorophyll a/protein carbon and $\mathrm{POC} /$ chlorophyll a ratios (c.f. Table 4-3).

In contrast to the similarities among species in their bulk chemical composition, cellular abundances of different: substances varied widely apparently in association with variations in cell size (e.g. Chan, 1978). C. 1uteus, which was the species of largest cell size, had the 
Table 4-4. Bulk Chemical Composition Parameters For High Light ${ }^{a}$ $\mathrm{NH}_{4}-11 \mathrm{~mL}$ ted Steady State Cultures of Selected Marine Algae

\begin{tabular}{|c|c|c|c|c|c|c|}
\hline Specles & $\begin{array}{l}\text { Relative Growth } \\
\text { Rate }^{\text {b }}\end{array}$ & $\begin{array}{l}\text { \% Total POC } \\
\text { In Prote inc }\end{array}$ & $\begin{array}{l}\text { X Total PoN } \\
\text { In Protein }\end{array}$ & $\begin{array}{l}\text { Ch1 a } \\
\text { Proteln Carbon } \\
\text { (ug/ug) } \times 100\end{array}$ & $\mathrm{C}: \mathrm{N}$ & $\frac{\text { Carbon }}{\operatorname{Ch1} \underline{a}}$ \\
\hline Chaetoceros slmplex & $0.574(0.064)$ & $15.8(3.0)$ & $41.4(9.3)$ & $10.5(1.3)$ & 10.3 & $60.3(9.5)$ \\
\hline Chroomonas sallna & $0.804(0.082)$ & $20.0(3.6)$ & 34 (11) & $9.5(1.8)$ & 6.5 & $53(12)$ \\
\hline
\end{tabular}

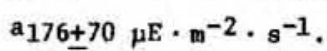

bSteady state growth rate normallzed to maximum under simllar conditions of 11 ght and temperature. Maximum growth rate for ‥ slmplex was $2.3(0.23)$ day $^{-1}$. Maximun growth rate for c. salina was $0.52(0.05)$ day $^{-i}$. All growth rate errors (In parentheses) represent $95 \%$ confidence intervals.

CErrors of all compositional parameters ( 1 n parentheses) represent propagated estimates of analytlcal error based on $95 \%$ confidence Intervals. 
Table 4-5. Bulk Chemical Composition Parameters For High Lighta Batch and $\mathrm{NH}_{4}$-11mited Steady State Cultures of Chattonella luteus

\begin{tabular}{|c|c|c|c|c|c|}
\hline $\begin{array}{l}\text { Relative Growth } \\
\text { Rate }^{\text {b }}\end{array}$ & $\begin{array}{l}\% \text { Total POC } \\
\text { in Proteinc }\end{array}$ & $\begin{array}{l}\% \text { Total PON } \\
\text { in Protein }\end{array}$ & $\begin{array}{l}\text { Chl a } \\
\text { Protein Carbon } \\
(\mu \mathrm{g} / \mu \mathrm{g}) \times 100\end{array}$ & $C: N$ & $\begin{array}{l}\frac{\text { Carbon }}{\text { ChI a }} \\
(\mu g / \mu g)\end{array}$ \\
\hline \multicolumn{6}{|l|}{ Batch: } \\
\hline $1.00(0.11)$ & $16.8(4.0)$ & 54 (15) & $8.3(1.8)$ & 10.8 & $72(13)$ \\
\hline \multicolumn{6}{|l|}{ Steady State: } \\
\hline $0.920(0.110)$ & $9.8(2.3)$ & $55.1(5.6)$ & $11.2(1.4)$ & 21.3 & $92(22)$ \\
\hline $0.540(0.075)$ & $15.9(3.0)$ & $85.0(12.1)$ & $6.7(0.94)$ & 17.7 & $94(13)$ \\
\hline
\end{tabular}

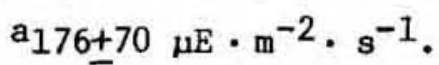

$b_{G r o w t h}$ rate normalized to maximum growth rate $\left(0.54(0.06)\right.$ day $\left.^{-1}\right)$ under similar conditions of light and temperature. Growth rate errors (in parentheses) represent $95 \%$ confidence intervals.

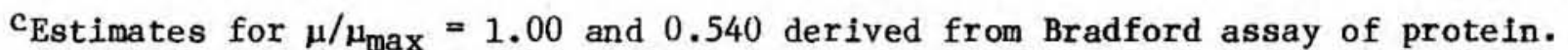
Estimates for $\mu / \mu_{\max }=0.920$ derived from residue analysis of protein. Errors of all compositional parameters (in parentheses) represent propagated estimates of analytical error based on $95 \%$ confidence intervals. 
Table 4-6. Cellular Chemical Composition Parameters of High Llghta Batch and $\mathrm{NH}_{4}$-1imited Steady State Cultures of Nannochloris sp.

\begin{tabular}{|c|c|c|c|c|}
\hline $\begin{array}{c}\text { Relative Growth } \\
\text { Rate }^{\text {b }}\end{array}$ & $\begin{array}{l}\text { Carbon } \\
\text { per cel1c } \\
(\mathrm{pg})\end{array}$ & $\begin{array}{l}\text { Nitrogen } \\
\text { per cell } \\
\quad(f g)\end{array}$ & $\begin{array}{l}\mathrm{Ch} 1 \text { a } \\
\text { per cel1 } \\
(\mathrm{fg})\end{array}$ & $\begin{array}{c}\text { Protein Carbon } \\
\text { per ce11 } \\
\text { (pg) }\end{array}$ \\
\hline \multicolumn{5}{|l|}{ Batch: } \\
\hline $1.0(0.03)$ & $4.2(2.0)$ & $550(130)$ & $50(17)$ & $0.74(0.08)$ \\
\hline $0.933(0.030)$ & $3.0(0.7)$ & $500(330)$ & $24.0(6.0)$ & $0.57(0.06)$ \\
\hline $0.458(0.014)$ & $2.9(0.8)$ & $400(130)$ & $25.0(3.0)$ & $0.49(0.08)$ \\
\hline $0.229(0.016)$ & $3.6(0.7)$ & $210(28)$ & $22.0(2.0)$ & $0.32(0.04)$ \\
\hline
\end{tabular}

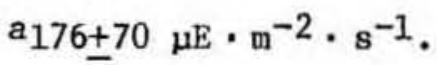

b Growth rate normalized to maximum growth rate $\left(1.44(0.04)\right.$ day $\left.^{-1}\right)$ under similar conditions of 1 ight and temperature. Growth rate errors (in parentheses) represent $95 \%$ confidence intervals.

cErrors for all compositional parameters (in parentheses) represent propagated estimates of analytical error based on $95 \%$ confidence intervals. 
Table 4-7. Cellular Chemical Composition Parameters of Low Iight ${ }^{a}$ Batch and NHt-1Im1ted Steady State

Cultures of: Nannochloris sp.

\begin{tabular}{|c|c|c|c|c|}
\hline $\begin{array}{l}\text { Relative Growth } \\
\text { Rate }^{\text {b }}\end{array}$ & $\begin{array}{l}\text { Carbon } \\
\text { per cel1c } \\
\text { (pg) }\end{array}$ & $\begin{array}{l}\text { Nitrogen } \\
\text { per cell } \\
\text { (fg) }\end{array}$ & $\begin{array}{l}\text { per cel1 } \\
\text { (fg) }\end{array}$ & $\begin{array}{c}\text { Protein Carbon } \\
\text { per cell } \\
\text { (pg) }\end{array}$ \\
\hline \multicolumn{5}{|l|}{ Batch: } \\
\hline $1.0(0.08)$ & $3.8(0.9)^{\mathrm{b}}$ & $490(120)$ & 74 (15) & n.d. \\
\hline \multicolumn{5}{|l|}{ Steady State: } \\
\hline $0.864(0.092)$ & n.d. & $320(180)$ & $100(16)$ & $0.64(0.12)$ \\
\hline $0.723(0.063)$ & n.d. & $5] .0(150)$ & 100 (23) & $0.69(0.17)$ \\
\hline $0.283(0.060)$ & $5.0(1.1)$ & $540(130)$ & 71 (12) & $0.70(0.12)$ \\
\hline
\end{tabular}

$a_{29+9} \mathrm{uE} \mathrm{m}^{-2} \mathrm{~s}^{-1}$

${ }^{b_{G r o w t h}}$ rate normalized to maximum growth rate $\left(0.58(0.05)\right.$ day $\left.^{-1}\right)$ under similar conditions of 11 ght and temperature. Growth rate errors (in parentheses) represent $95 \%$ confidence intervals.

CErrors of all compositional parameters (in parentheses) represent propagated estimates of analytical error based on $95 \%$ confidence intervals. 
Table 4-8. Cellular Chemlcal Composition Parameters of

HIgh Llght ${ }^{a} \mathrm{NH}_{4}-11 \mathrm{mlted}$ Steady State Cultures of Selected Marine Algae

\begin{tabular}{|c|c|c|c|c|c|}
\hline Species & $\begin{array}{c}\text { Relative Growth } \\
\text { Rate }^{\mathrm{b}}\end{array}$ & $\begin{array}{l}\text { Carbon } \\
\text { per ce } 11^{c} \\
\text { (p8) }\end{array}$ & $\begin{array}{l}\text { Nitrogen } \\
\text { per cell } \\
\left(\mathrm{fg}_{\mathrm{g}}\right)\end{array}$ & $\begin{array}{l}\text { Chl a } \\
\left.\text { per } f_{g}\right)\end{array}$ & $\begin{array}{c}\text { Protein Carbon } \\
\text { per cell } \\
(\mathrm{pg})\end{array}$ \\
\hline \multicolumn{6}{|c|}{ Chattonella Iuteus } \\
\hline \multicolumn{6}{|c|}{ Batch: } \\
\hline & $1.0(0.11)$ & $610(150)^{b}$ & $57000(16000)$ & $8500(1900)$ & $100(30)$ \\
\hline \multicolumn{6}{|c|}{ Steady State: } \\
\hline & $\begin{array}{l}0.921(0.110) \\
0.540(0.075)\end{array}$ & $\begin{array}{l}311(100) \\
340(100)\end{array}$ & $\begin{array}{l}14600(4200) \\
19000(5200)\end{array}$ & $\begin{array}{l}3400(860) \\
3800(990)\end{array}$ & $\begin{array}{ll}31 & (8) \\
55 & (16)\end{array}$ \\
\hline \multicolumn{6}{|c|}{ Chaetoceros simplex } \\
\hline & $0.574(0.064)$ & $10.9(3.0)$ & $1060(720)$ & $181(42)$ & $1.7(.4)$ \\
\hline \multicolumn{6}{|l|}{ Chroomonas } \\
\hline & $0.804(0.082)$ & $84(25)$ & $13000(5200)$ & $1600(470)$ & $17(4)$ \\
\hline
\end{tabular}

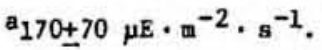

bSteady state growth rate normalized to maxlmure under simllar condltions of light and temperature. Maximum growth rate for C. Iuteus was $0.54(0.06)$ day $^{-1}, 2.3(0.23)$ day $^{-1}$ for $\underline{C}$. slaplex, and $0.52(0.05)$ day $^{-1}$ for $\underline{C}$. sallna. All growth rate errors represent $95 \%$ coofidence intervals.

CErrore of all compositional parameters (In parentheses) represent propagated estimates of analytlcal error based on $95 \%$ confidence intervals. 
largest values for carbon, nitrogen, chlorophyll a, and protein on a per average cell basis (Tab.le 4-8). Values for Chroomonas salina and

Chaetoceros simplex werie intermediate between $\underline{\text { C. Iuteus and Nannochloris }}$ sp. (c.f. Tables 4-6 and 4-8).

\section{Kinetics of Isotope Incorporation: Agreement Between Predicted and} Observed Carbon Incorpoiration Rates

From the results priesented in chapter 3 and in the preceding section, it is apparent that environmental conditions influence cellular composition, a reflection of their impact on metabolic processes. A prerequisite to estimating the rate of a specific biosynthetic process, in this case protein synthesis, using inorganic ${ }^{14} \mathrm{C}$ as a tracer, is to evaluate the potential impact of environmentally induced changes in metabolism on the isotope kinetics. I have compared predicted and observed carbon incorpoication rates into total particulate organic carbon (POC), total particulate protein amino acids (PPAA), and individual protein amino acids in steady state cultures where the inorganic ${ }^{14} \mathrm{C}$ was added directly to the chemostat vessel. Assuming complete and Instaneous equilibration of precursors with the dissolved inorganic ${ }^{14} \mathrm{C}$ and negligible cell decay (c.f. Goldman, 1977), the rate of isotope Incorporation into protein $(d p * / d t)$ in a steady state culture where influent flow is not interrupted will be the difference between the rate of protein synthesis and the dilution of labeled protein by inflowing media:

$$
d P^{*} / d t=D P_{0}-D P^{*}(t)
$$


where $D$ is the dilution rate of the chemostat, $P_{0}$ is the steady state protein carbon concentration, $t$ is the incubation time, and $P^{*}(t)$ is the predicted quantity of 1sotope in protein. Equation (4-1) is a first order linear differential equation, with inftial conditions $P *(0)=0$. Solving for $p *(t)$ :

$$
P *(t)=P_{0}\left(1-e^{-D t}\right)
$$

For most of the experiments, it was not possible to maintain influent flow throughout the incubation period. Under conditions where flow is interrupted, the predicted quantity of isotope in protein ( $\left.P^{*}(t)\right)$ was:

$$
P^{*}(t)=P_{0}\left(e^{D t}-1\right)
$$

The derivation of this equation is similar to that described by Roberts et a1. (1963). It assumes no deviations from the steady state blosynthetic rates despite the interruption of flow, so that the chemostat is effectively viewed as a batch culture with growth rate $D$. As I will demonstrate, this assumption is not always appropriate. Under conditions where Dt is sma11 (1.e. less than 0.05), $P^{*}(t)$ approximates $\mathrm{P}^{*}(\mathrm{t})$. The initlal rate of slope of observed incorporation was estimated by linear regression and compared to the predicted rate which was defined as:

$$
R_{p}=p^{*}(\Delta t) / \Delta t
$$


or:

$$
R_{p}^{\prime}=p^{*}(\Delta t) / \Delta t
$$

where $\Delta t$ was the period over wh1ch observed incorporation was regressed.

As previously pointed out, these equations are based on the assumption that precursors to proteln synthesis are completely and instaneously equilibrated with inorganic ${ }^{14} \mathrm{C}$. If equilibration is not complete, than the rates predicted by equations 4-4 and 4-5 will

overestimate observed incorporation. In contrast, if protein turnover in excess of net synthesis is significant, then the observed incorporation rate may be greater than the predicted rate. Examples of these cases are discussed in subsequent sections.

Predicted rates of POC production were obtained by substituting the steady state POC concentration for $P_{0}$ in equations 4-1 through 4-5.

\section{High Light Adapted Steady State Cultures of Nannochloris sp.: Isotope} Kinetics at High and Low Relative Growth Rates

$\underline{P O C \text { and PPAA }}$

Comparisons of regressions of total inorganic ${ }^{14} \mathrm{C}$ uptake with predicted POC production rates under high light conditions indicated excellent agreement at all growth rates (Figure 4-1). In contrast, incorporation of isotope into isolated PPAA was less than the predicted rate of carbon incorporation (Figure 4-2). H1gher predicted carbon incorporation into protein than observed isotope incorporation rates can 
be caused by both incomplete saturation of precursors with inorganic ${ }^{14} \mathrm{C}$

as well as deviations from steady state in response to the interruption of steady state. In some cases, it is possible to distinguish these two sources of discrepancy by examining the time course patterns in incorporation.

The time course of isotopic carbon incorporation into total PPAA during the first 1.5 hours for the high and low relative growth rates are shown in Figure 4-3 in relationship to the predicted incorporation. The point at which the influent flow was stopped during the incubation is designated by an arrow. The predicted rate exceeded the observed rate before flow was stopped in both the high and low relative growth rate cases. This tendency was not an artifact due to perturbations of steady state, since it was also observed during the Initial stages of a separate chemostat experiment where flow was not stopped and steady state was maintained throughout a 66 hour incubation period (Figure 4-4). Further evidence for the slow saturation characteristics of protein precursors was revealed in short term 1sotopic carbon distributions of batch cultures where nutrient depletion would not be a problem. Isotope incorporation Initially underestimated the actual proportions of carbon associated with the protein fraction (F1gure 3-18).

Nitrogen depletion effects did manifest themselves later in the $\mathrm{NH}_{4}^{+}$-1imited cultures where flow was stopped. Examining the time course for the entire 3 hour incubation periods for total PPAA incorporation at high and low relative growth rate, it is evident that the observed incorporation rate decreases with time particularly at the low relative growth rate $(\mathrm{F} 1 \mathrm{~g}, \mathrm{4-5})$. However, for the initial period where flow was not stopped, observed incorporation was less than the 
predicted rates. A similar discrepancy was seen for the exper1ment where f1ow was not stopped (F1gure 4-6). However, observed Incorporation approached the predicted values as the incubation progressed. By 20 hours (F1g. 4-7), differences between predicted and observed values were negligible.

These results 1llustrate that the interruption of steady state can lead to the rapid onset of time dependent decreases in protein carbon incorporation rates. Therefore, inspection of time course incorporation patterns is necessary in order to distingulsh non-steady state artifacts from kinetic phenomena as causes for discrepancles between observed and predicted carbon incorporation. As will be demonstrated, this is particularly important in understanding the characteristics of carbon incorporation into Individual protein amino acids.

\section{Carbon Incorporation into Individual Protein Amino Ac1ds}

In Figure 4-8, incorporation rates of selected protein amino acids are shown in relationship to the predicted rates for the high and low relative growth rates respectively. The biosynthetic pathways demonstrated in higher plants for these amino acids are diagrammed in Figure 4-9. Glycine and serine biosynthesis can be derived from 3-phosphoglycerate produced by the RuDP carboxylase reaction of the Calvin cycle (Miflin and Lea, 1977). Under these conditions, their production would be closely coupled to the supply of photosynthetically fixed carbon. This is consistent with the good agreement between predicted and observed incorporation rates of glycine (Figures 4-8 and 4-10), and the observations in chapter 3 that nascent protein glycine was Immediately saturated with the inorganic carbon pool. Alanine also shows 
close agreement between predicted and observed incorporation rates (Figures 4-8 and 4-10), in agreement with the rapid saturation of nascent protein alanine (chapter 3, Table 3-5). Alanine is a product of the reductive amination of pyruvate. A proposed route for the incorporation of photosynthetically derived ${ }^{14} \mathrm{C}$ into pyruvate is via the transport of triose phosphates from the chloroplast into the cytosol (Heber, 1974; Ieech and Murphy, 1976). Once there, the action of the glycolytic enzymes could convert these molecules to pyruvate, which can subsequentiy diffuse (Schulze-Siebert et al., 1984) back into the chloroplast where it may undergo transamination with glutamate (e.g. Leech and Murphy, 1976). However, the close agreement between the observed and predicted incorporation into alanine indicates that its pyruvate carbon skeleton rapidly equilibrates with the dissolved inorganic carbon pool. If the above transport scheme is correct, this would require that either the entire cytosolic pyruvate pool was saturated or the source of pyruvate used for protein alanine biosynthesis was compartmentalized. The pool size of pyruvate was not measured in this study. The possibility that it was small and in a rapid state of turnover cannot be ruled out. Recently, the presence of pathways for conversion of 3-phosphoglycerate (3PGA) to pyruvate have been demonstrated to exist within splnach chloroplasts (Fig. 4-11, taken from Schultze-Selber et al., 1984). Such a mechanism would provide for a more direct means of production of alanine from photosynthetically fixed carbon. Furthermore, as I pointed out in chapter 3 , at the low relative growth rate there were differences between the bulk intracellular free glycine + alanine pool specific activity and that of the nascent protein glycine and alanine. Such a phenomenon could be explained by the presence of an isolated 
Figure 4-1. Comparisons of observed total ${ }^{14} \mathrm{C}$ uptake rates with theoretical particulate organic carbon production rates in high light $\left(176 \mu \mathrm{E} \cdot \mathrm{m}^{-2} \cdot \mathrm{s}^{-1}\right) \mathrm{NH}_{4}^{+}-1$ imited steady state cultures of Nannochloris sp. Observed total ${ }^{14} \mathrm{C}$ uptake rates were determined by linear regression of the initial 1.5 hour time course of isotope incorporation. Errors represent propagated estimates of analytical error based on $95 \%$ confidence intervals. 


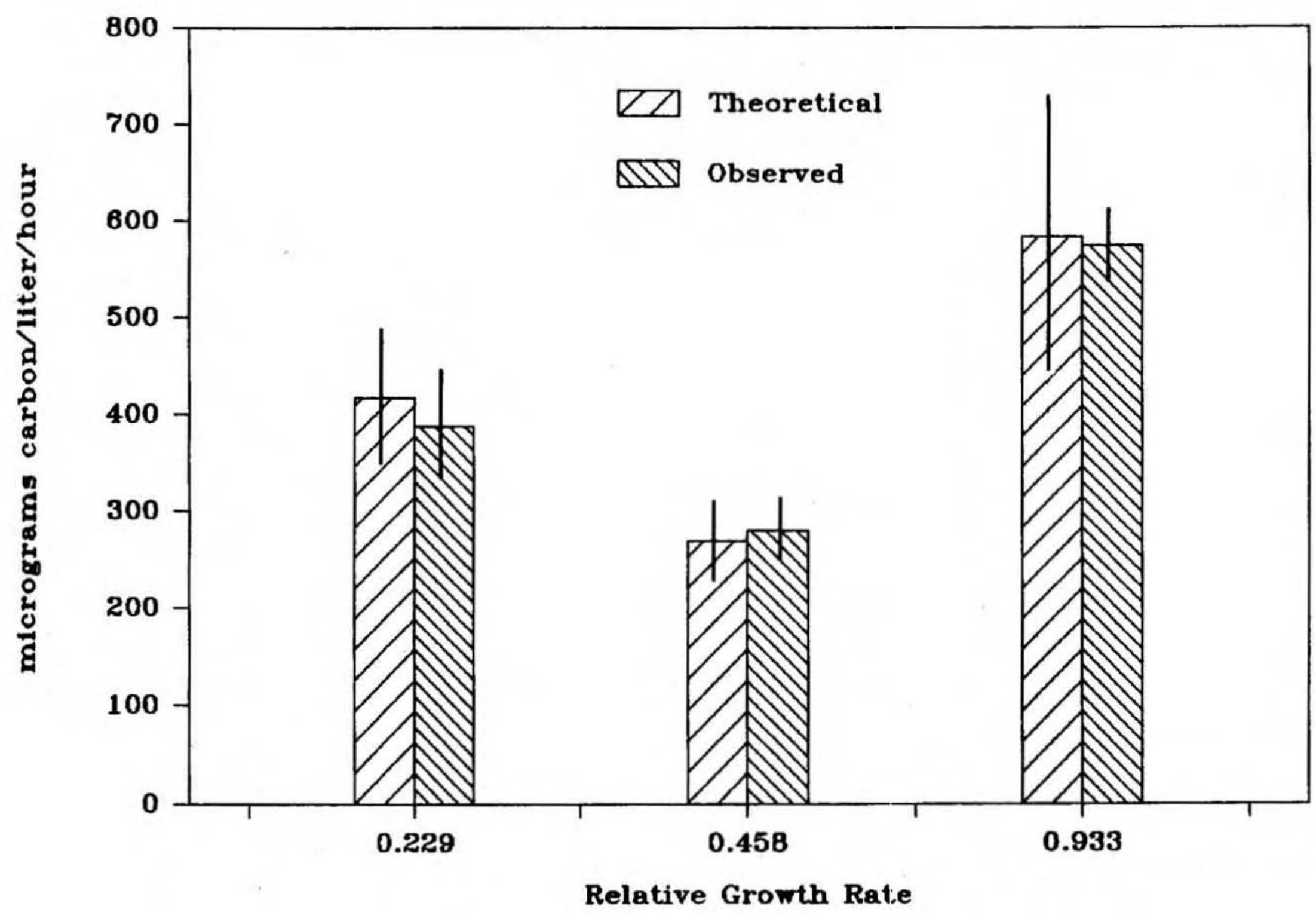


Figure 4-2. Comparisons of observed particulate protein amino acid 1sotope incorporation rates with theoretical rates in high 11ght (176 $\mu \mathrm{E}$. $\left.\mathrm{m}^{-2} \cdot \mathrm{s}^{-1}\right) \mathrm{NH}_{4}^{+}-1$ imited steady state cultures of Nannochloris $\mathrm{sp}$. Observed isotope incorporation rates were determined by linear regression of a 3 hour time course. Errors represent propagated estimates of analytical error based on $95 \%$ confidence intervals. 


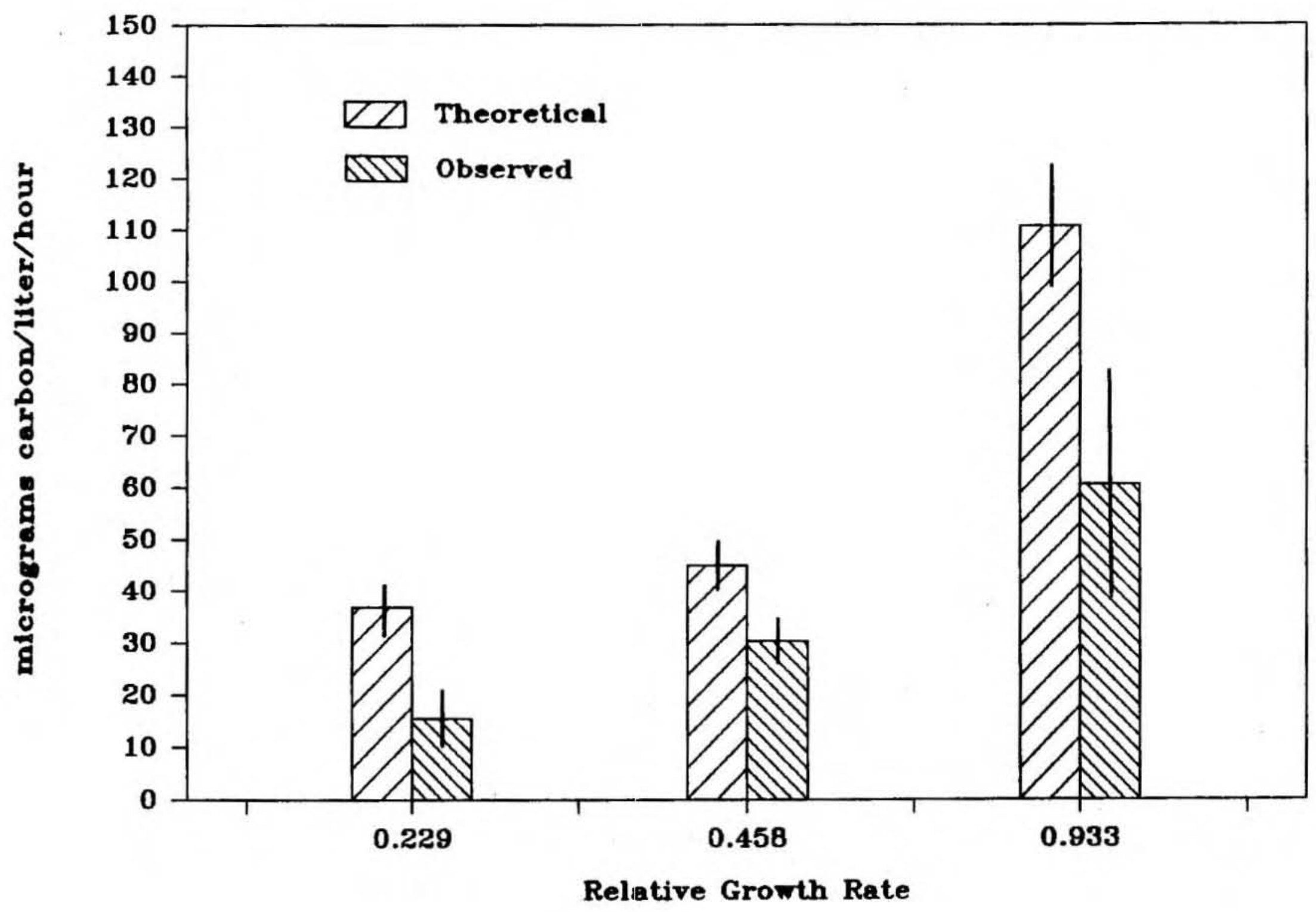


Figure 4-3. Observed and predicted 1.5 hour: time courses of isotopic carbon incorporation into particulate protejin amino acids where flow was interrupted during the incubation of high 1 light $\left(176 \mu \mathrm{E} \cdot \mathrm{m}^{-2} \cdot \mathrm{s}^{-1}\right)$ $\mathrm{NH}_{4}^{+}-1$ imited steady state cultures of Nannochloris sp. Upper solld line represents the predicted rate for the high relative growth rate culture $\left(\mu / \mu_{\max }=0.933\right)$ and the dotted line: the predicted rate for the low relative growth rate culture $\left(\mu / \mu_{\max }=0.229\right)$. Lines connecting symbols drawn by eye. Arrows indicate point:s during the incubations when influent flow was stopped. Symbols: squares, sum of carbon Incorporation into individual protein amino acid residues at the high relative growth rate; triangles, incorporation into hot trichloroacetic acid insoluble at the high relative growth rate; + , sum of carbon Incorporation into individual protein amino acid residues at the low relative growth rate; $X$, incorporation into hot trichloroacetic acid insoluble at the low relative growth rate. 


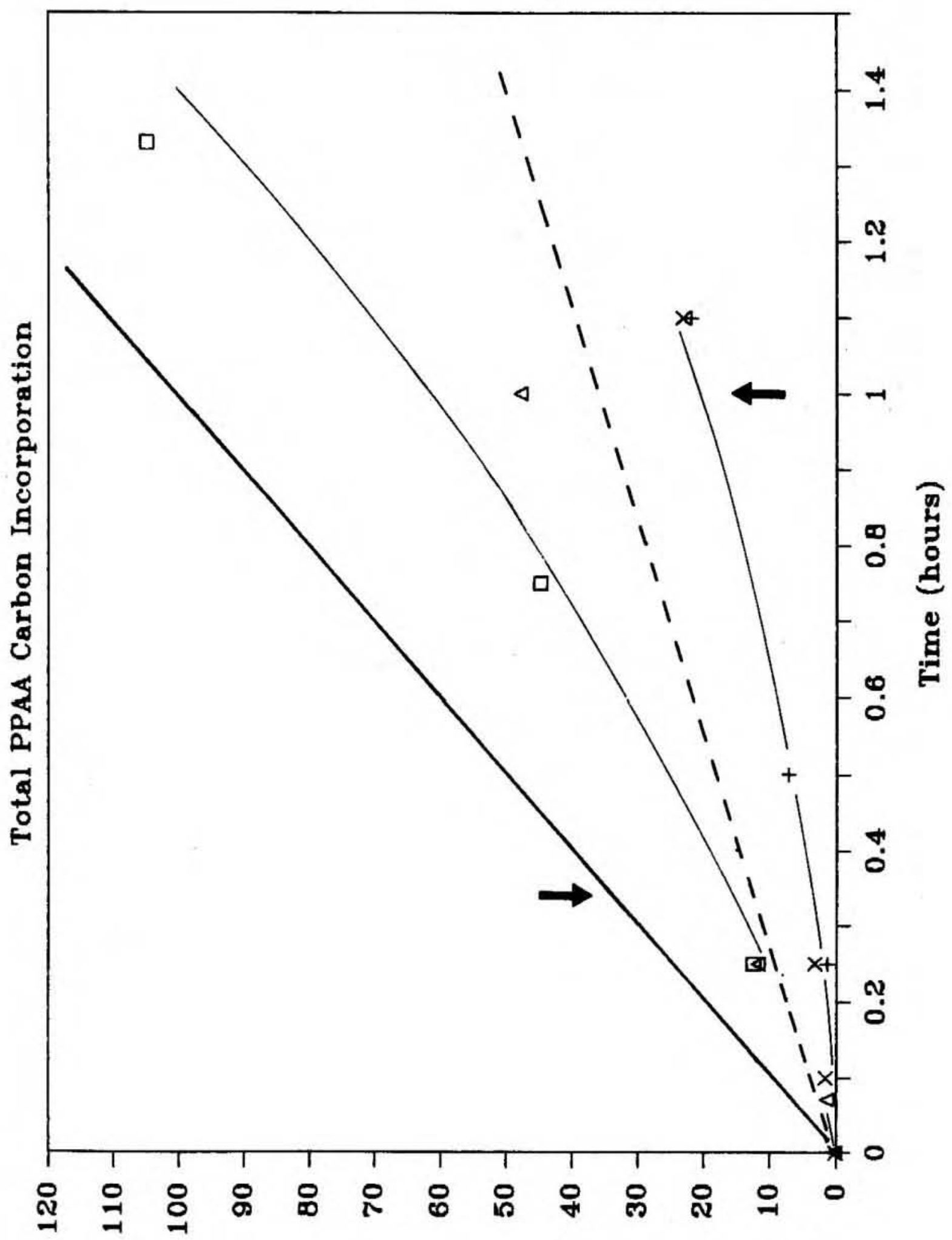


Figure 4-4. Observed and predicted 1.0 hour time courses of 1sotope incorporation into particulate protein amino acids of a high light (176 $\left.\mu \mathrm{E} \cdot \mathrm{m}^{-2} \cdot \mathrm{s}^{-1}\right) \mathrm{NH}_{4}^{+}-1$ imited steady state culture of Nannochloris sp. $\left(\mu / \mu_{\max }=0.458\right)$. Flow was not interrupted during the incubation. Solid line represents the predicted rate. 


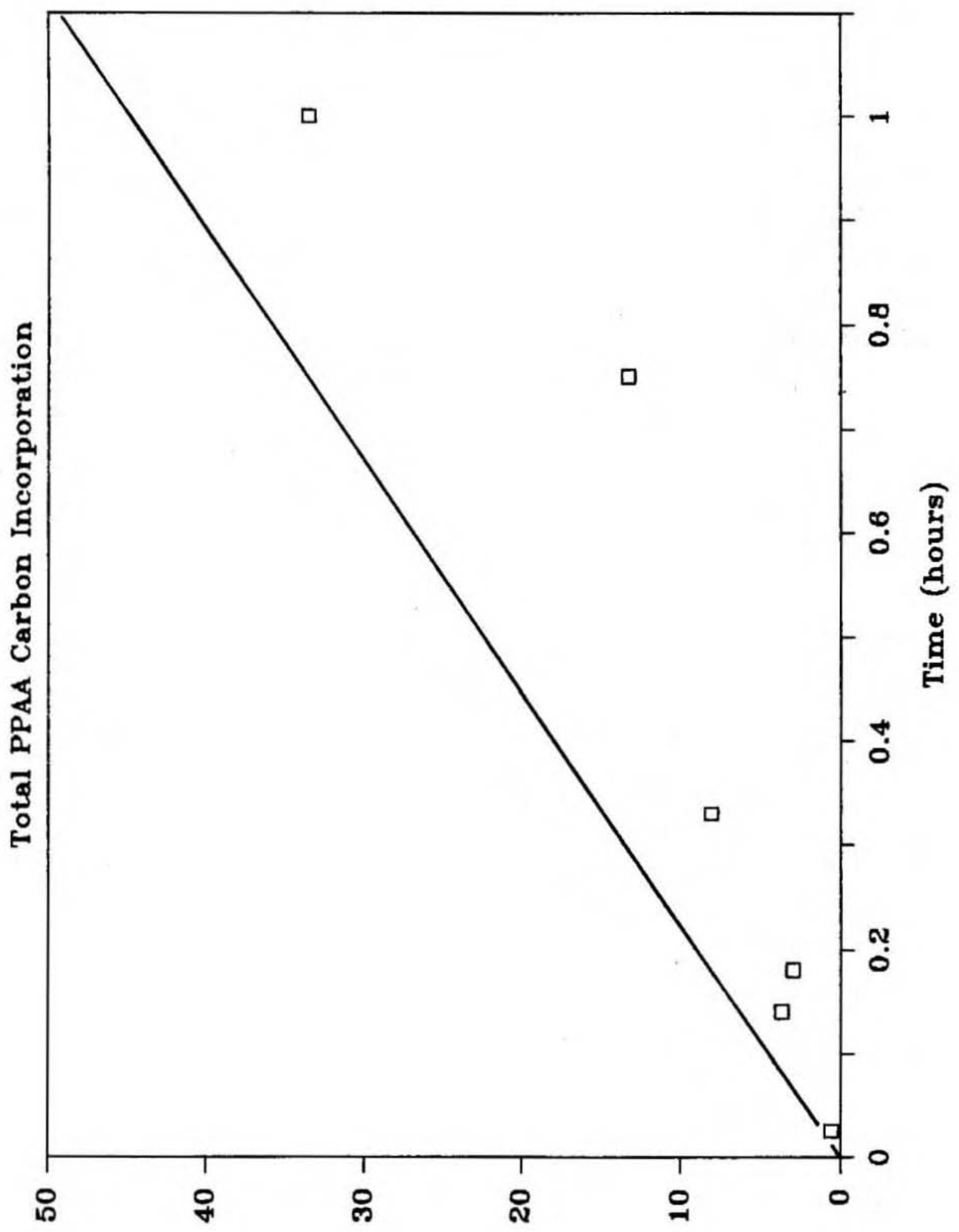


Figure 4-5. Observed and predicted 3 hour time courses of 1sotope Incorporation into particulate proteln amino acids where flow was interrupted during the incubation of high 1 ight $\left(176 \mu \mathrm{E} \cdot \mathrm{m}^{-2} \cdot \mathrm{s}^{-1}\right)$ $\mathrm{NH}_{4}^{+}$-1imited steady state cultures of Nannochloris $\mathrm{sp}$. Upper solid line represents the predicted rate for the high relative growth rate culture $\left(\mu / \mu_{\max }=0.933\right)$ and the dotted 1ine the predicted rate for the low relative growth rate culture $\left(\mu / \mu_{\max }=0.229\right)$. Ifnes connecting symbols drawn by eye. Arrows indicate points during the incubations when Influent flow was stopped. Symbols: squares, sum of carbon incorporation into individual protein amino acid residues at the high relative growth rate; triangles, incorporation into hot trichloroacetic acid insoluble at the high relative growth rate; + , sum of carbon incorporation into individual protein amino ac1d residues at the low relative growth rate; $\mathrm{X}$, incorporation into hot trichloroacetic acid insoluble at the low relative growth rate. 


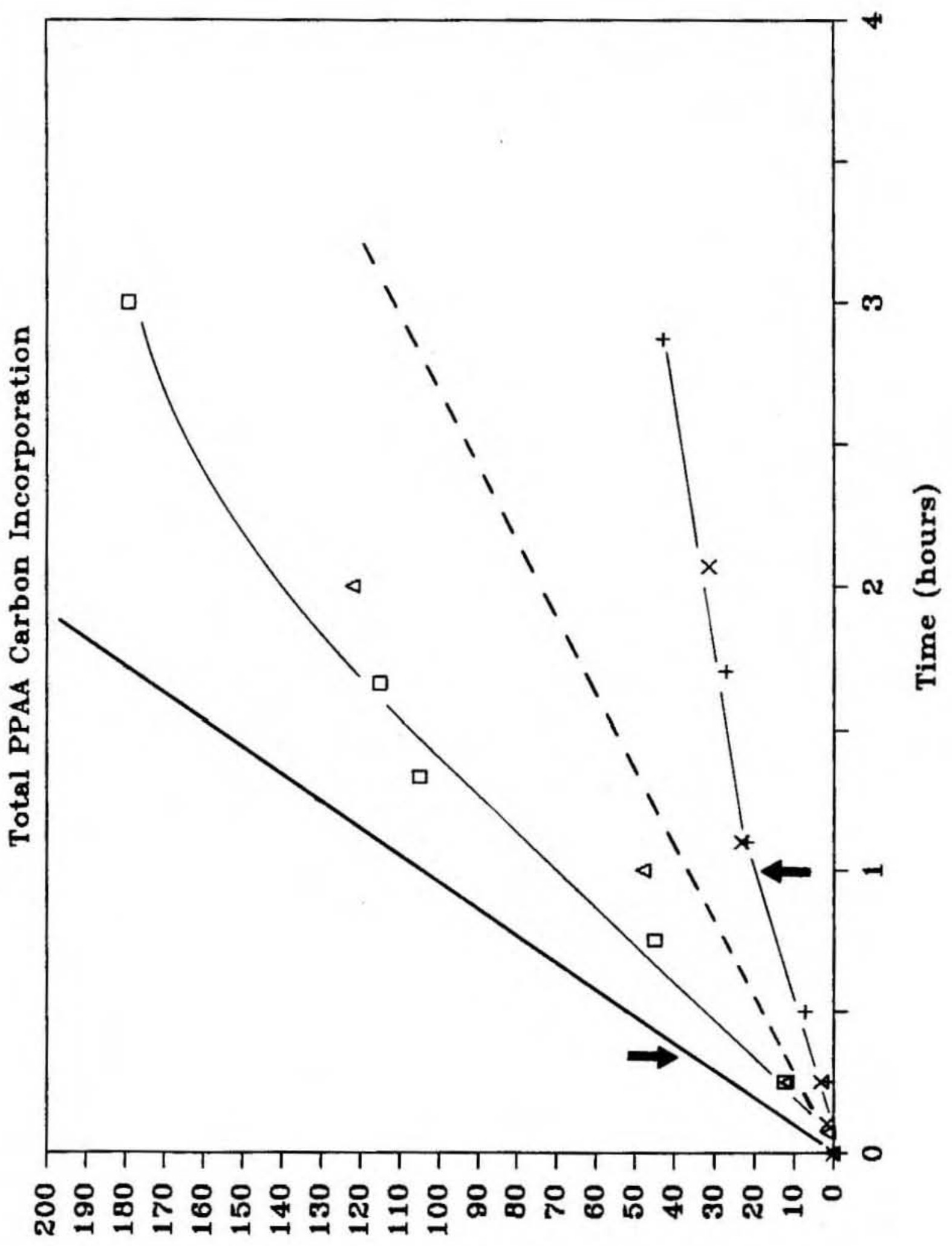


F1gure 4-6. Observed and predicted 6 hour time courses of 1sotope incorporation into particulate protein amino acids of a high light (176 $\left.\mu \mathrm{E} \cdot \mathrm{m}^{-2} \cdot \mathrm{s}^{-1}\right) \mathrm{NH}_{4}^{+}-1$ im1ted steady state culture of Nannochloris sp. $\left(\mu / \mu_{\max }=0.458\right)$. Flow was not interrupted during the incubation. Solid line represents the predicted rate. 
Total PPAA Carbon Incorporation

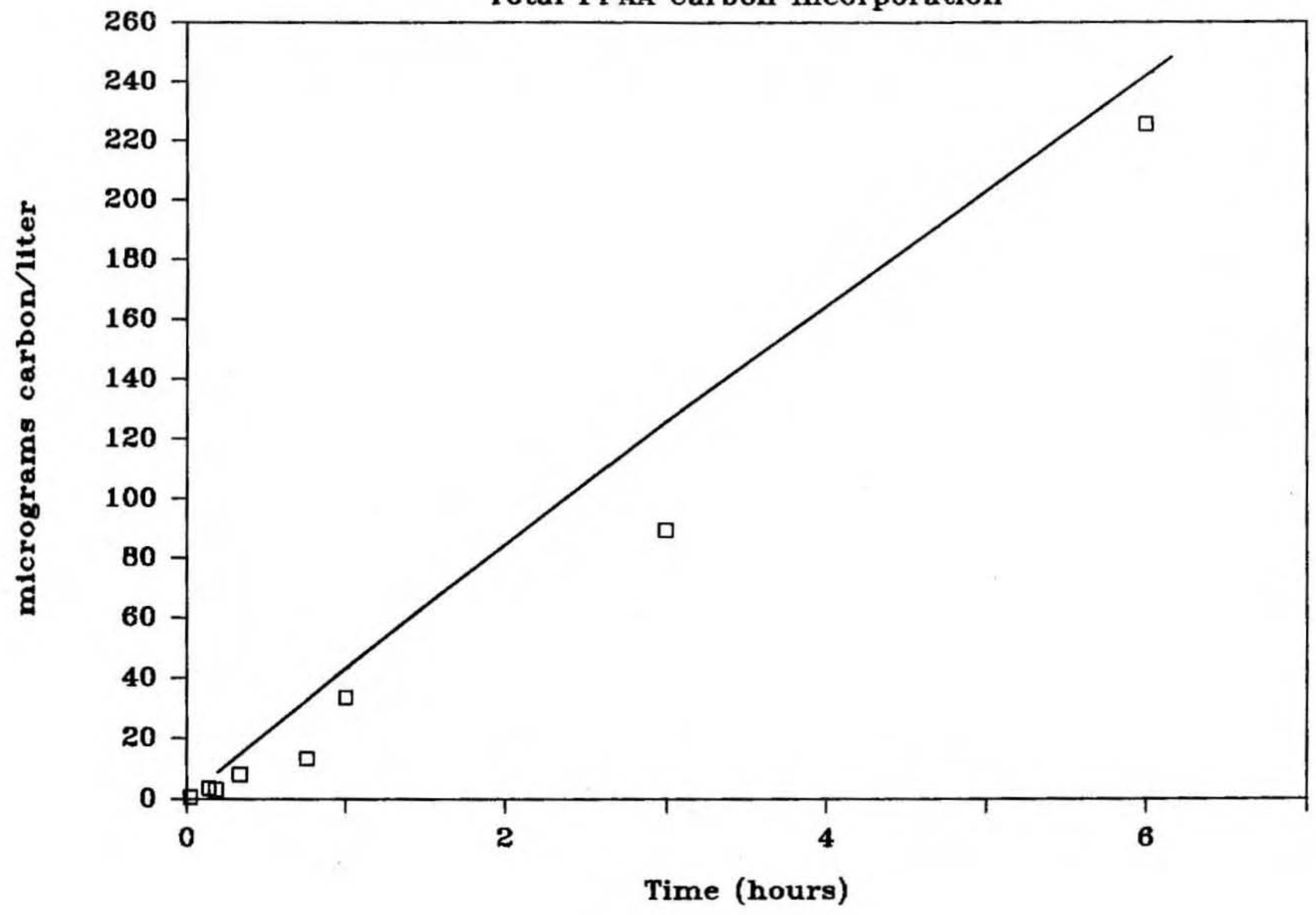


Figure 4-7. Observed and predicted 66 hour time courses of isotope 1ncorporation into particulate protein amino acids of a high light (176 $\left.\mu \mathrm{E} \cdot \mathrm{m}^{-2} \cdot \mathrm{s}^{-1}\right) \mathrm{NH}_{4}^{+}-11 \mathrm{mited}$ steady state culture of Nannochloris sp. $\left(\mu / \mu_{\max }=0.458\right)$. Flow was not interrupted during the incubation. Solld line represents the predicted rate. Area of overlap with Fig. 4-6 Indicated by dotted 1ines. 


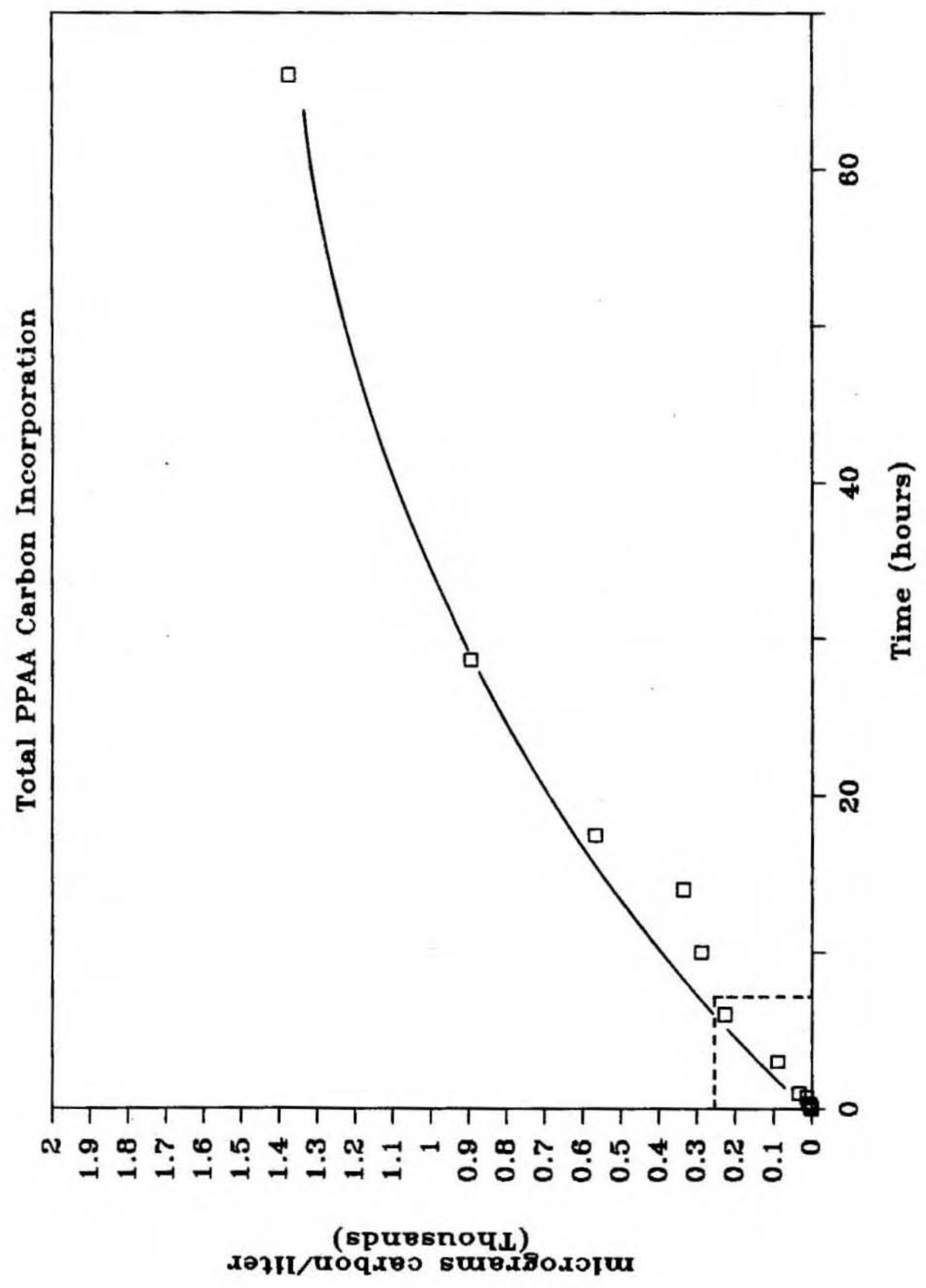


Figure 4-8. Theoretical and observed rates of 1sotoplc carbon incorporation into alanine (ALA), glycine (GJY), glutamate (GLU), and aspartate (ASP) in protein of high light $\left(176 \mu \mathrm{E} \cdot \mathrm{m}^{-2} \cdot \mathrm{s}^{-1}\right)$ $\mathrm{NH}_{4}^{+}$-11mited steady state cultures of Nannochloris sp. Results from high $\left(\mu / \mu_{\max }=0.933\right)$ and low $\left(\mu / \mu_{\max }=0.229\right)$ relative growth rate cultures are shown. Errors represent propagated estimates of analytical error based on $95 \%$ confidence intervals. 


\section{$-$}


Figure 4-9. Simplified diagram showing the major pathways assoclated with the biosynthesis of glycine (GLY), serine (SER), glutamine (GLN), glutamate (GLU), alanine (ALA), and aspartate (ASP). After Miflin and Lea (1977) and Miflin et al. (1980). PGA = phosphoglycerate, PEP = phosphoenolpyruvate, $\mathrm{PYR}=$ pyruvate, $\mathrm{OAA}=$ oxaloacetate, $\mathrm{TCA}=$ tricarboxylic acid cycle, $\mathrm{KGA}=$ alpha-ketoglutatarate, RUDP $=$ r1bulose-1,5-d1phosphate, FDP = fructose-1,6-diphosphate; G6P = glucose-6-phosphate. Formation of glycine and serine from glycolate may 1nvolve participation of peroxisomes and mitochondria (not indicated, see Keys et al., 1978, in Miflin et al., 1980). The proposed direct formation of phosphoenolpyruvate and pyruvate within the chloroplast (Schulze-Slebert et al., 1984) is also not shown. 


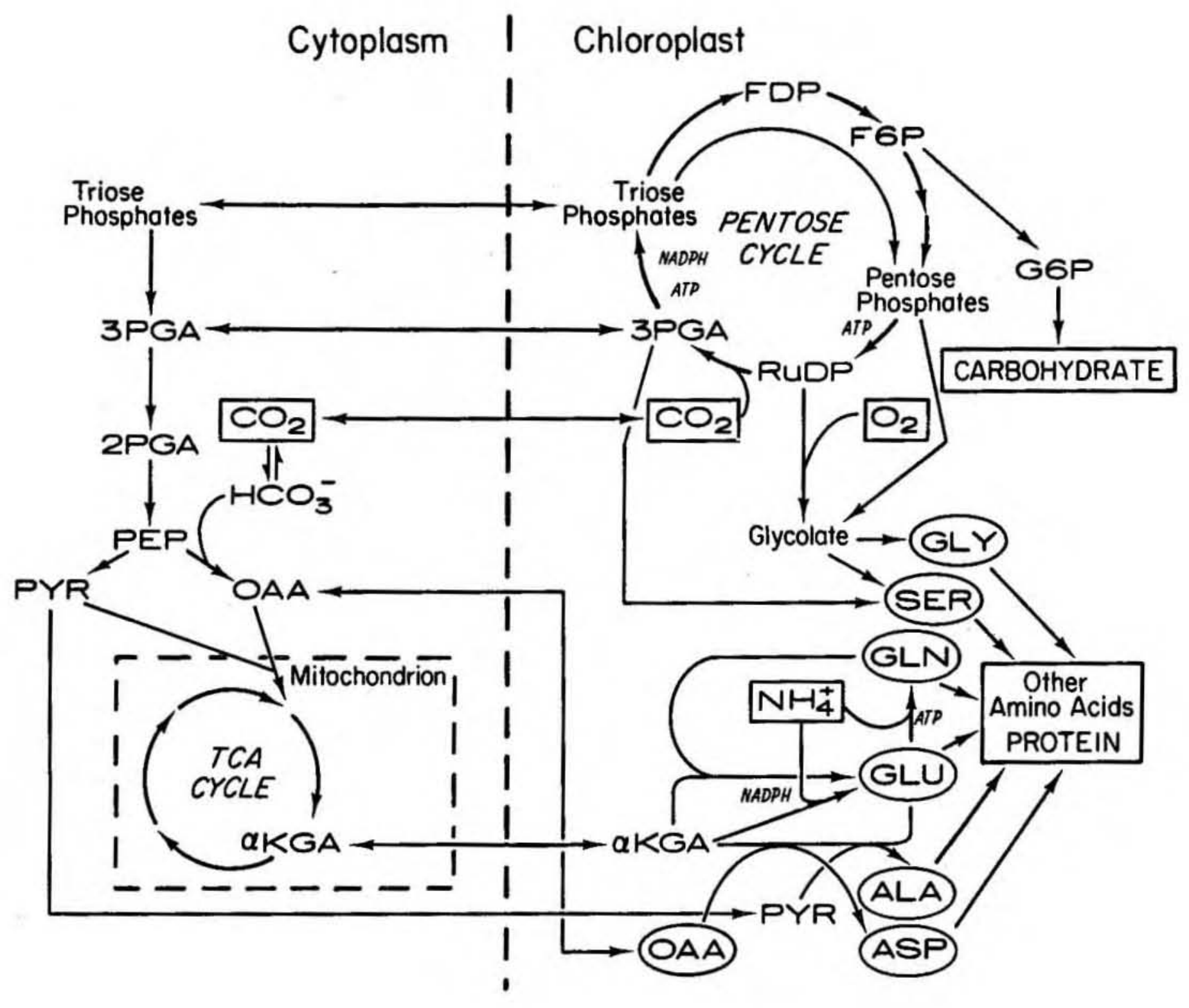


Figure 4-10. Observed and predicted time courses of isotope incorporation into glycine, alanine, glutamate, and aspartate in protein of high light $\left(176 \mu \mathrm{E} \cdot \mathrm{m}^{-2} \cdot \mathrm{s}^{-1}\right) \mathrm{NH}_{4}^{+}-11 \mathrm{mited}$ steady state cultures of Nannochloris sp. Solid lines represent predicted rates for the high relative growth rate culture $(0.933)$ and dotted lines the predicted rates for the low relative growth rate culture $(0.229)$. Flow was stopped at 1 hour for $\mu / \mu_{\max }=0.229$ and 0.33 hours for $\mu / \mu_{\max }=$ 0.933 (indicated by arrows). Symbo1s: squares, carbon incorporation into the individual protein amino acid at the high relative growth rate; + , carbon incorporation into the Individual proteln amino acid at the low relative growth rate. 

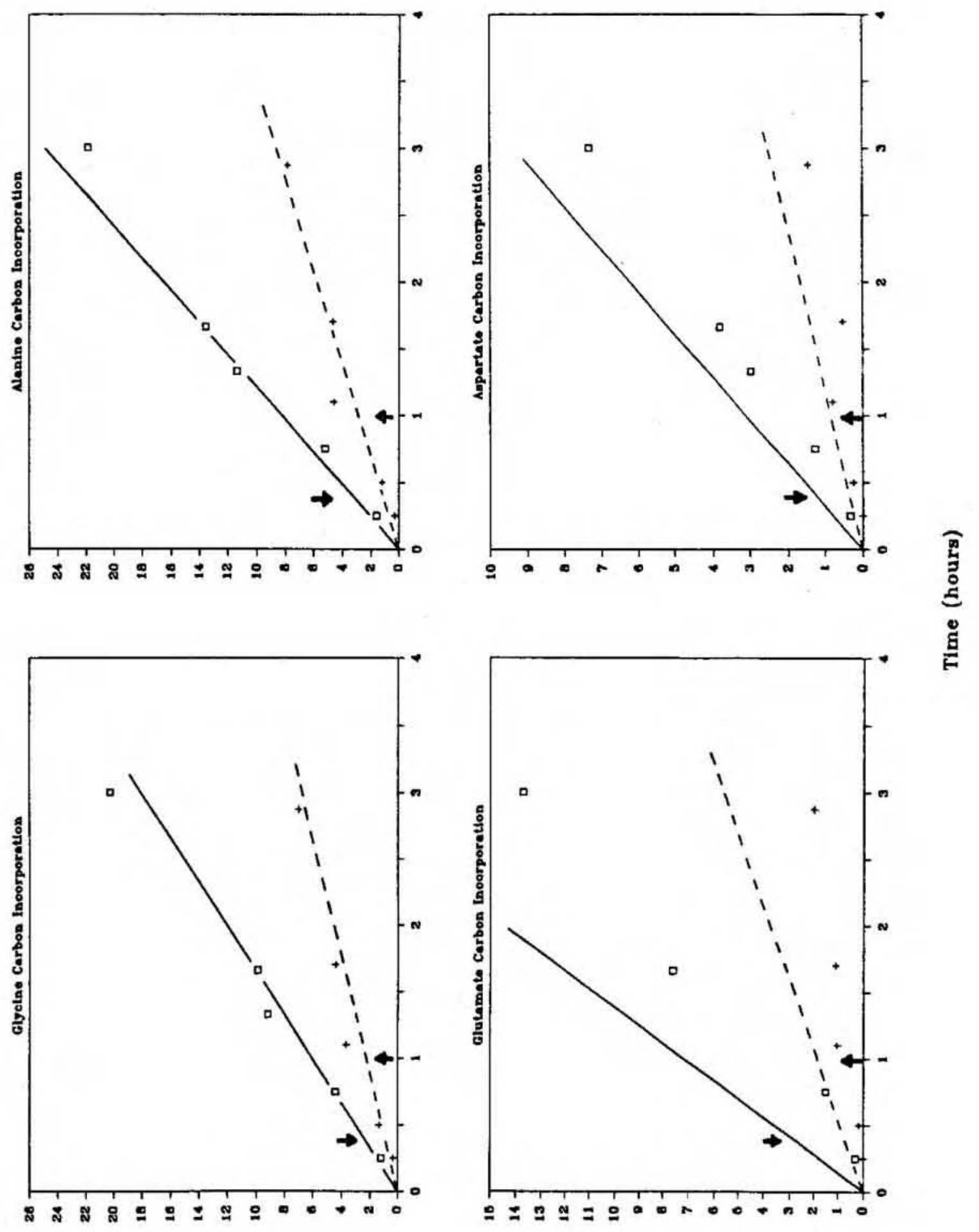
F1gure 4-11. Dlagram showing proposed routes for intrachloroplast production and utilization of PEP and pyruvate. From Schulze-Siebert et al. (1984). 


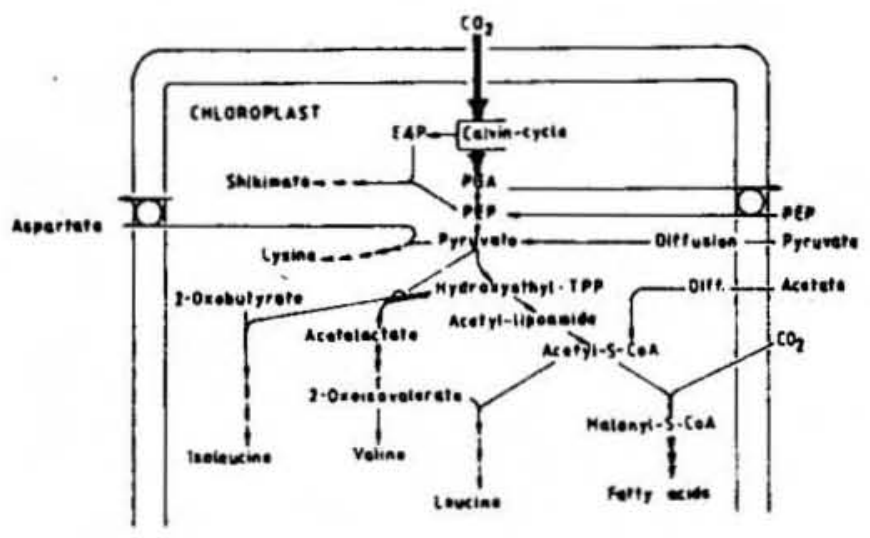


rapidly turning over precursor pool (e.g. the chloroplast pool) which serves as the preferred source for protein synthesis. However, the observed rates of intrachloroplast carbon flow into pyruvate observed by Schulze-Slebert et al. were low, and addition of exogenous pyruvate to chloroplasts suspensions led to enhanced synthesis of alanine, lysine, and the branched chain amino acids (valine, isoleucine, and leucine). Thus further investigation is required in order to determine the relative importance of production of pyruvate directly from 3PGA within the chloroplast.

Predicted and observed incorporation rates of glutamate and aspartate agreed within analytical error at the high growth rate (Fig. 4-8). In the case of glutamate, this was at least partially due to the large regression error resulting from the low number of data points (4). At the lower growth rate, observed protein glutamate incorporation underestimated the predicted rate (Fig. 4-8). Examining the time course of incorporation for these protein amino acids (Fig. 4-10), it is clear that they both initially underestimate their predicted incorporation rates. However, the rate of incorporation approaches the predicted slope during the incubation reflecting the gradual equilibration of their precursor pools. Referring to $\mathrm{FIg}$. 4-9, the carbon skeleton for aspartate is oxaloacetate (OAA) and that of glutamate is alpha-ketoglutarate. Both are involved in the tricarboxylic acid cycle (e.g. Miflin and Lea, 1977; Miflin et al., 1980; Schulze-Siebert et al., 1984). The presence of chloroplast enzymes for their synthesis has not been demonstrated. The cytosol carbon skeletons are able to exchange with the chloroplast pools. Consequently, the nonlinear patterns of incorporation into glutamate and aspartate probably reflect the 
saturation characteristics of the "respiratory" intermediates from which they are derived. There was some Indication of nutrient depletion effects at the 1 ow growth rate.

Phenyalanine is synthesized from erythrose-4-phosphate, an intermediate of the photosynthetic carbon reduction cycle, and phosphoenolpyruvate (PEP) (Fig. 4-12). Agreement of 1ts observed labelling rate with the predicted rate (Fig. 4-13) suggests its carbon skeleton precursors saturated rapidly with inorganic ${ }^{14} \mathrm{C}$. Erythrose-4-phosphate is derived from the photosynthetic carbon reduction cycle, and would be expected to rapidly saturate with inorganic ${ }^{14} \mathrm{C}$. PEP is the precursor to pyruvate and oxaloacetate (OAA). As previously mentioned, the intrachloroplastic conversion of 3PGA to PEP and on to pyruvate has been demonstrated in spinach chloroplasts (Schulze-Siebert et a1., 1984). This could explain the rapid equilibration of protein phenylalanine (see also chapter 3, nascent protein specific activity of phenylalanine, Table $3-5$ ). The fact that protein aspartate did not show as rapid equilibration as phenylalanine could be explained if the OAA pool was large relative to the PEP pool, or if the OAA used to produce aspartate was derived from a separate more slowly saturating pool of PEP.

Blosynthetic pathways demonstrated in higher plants for the amino acids threonine, valine, isoleucine, leucine and lysine utilize aspartate and pyruvate as precursors (F1g. 4-14, taken from Miflin and Lea, 1977). The characteristics of carbon incorporation into these amino acids (Fig. 4-15 and 4-16) were generally consistent with the blosynthetic pathways which have been described for higher plants. Protein threonine observed carbon incorporation agrees quite closely with the predicted rate at high 
Figure 4-12. Pathways associated with the biosynthesis of tryptophan, tyrosine, and phenylalanine. From Miflin and Lea (1977). 
D-erythrose - \$-phosphato phosphoenol pyruvate

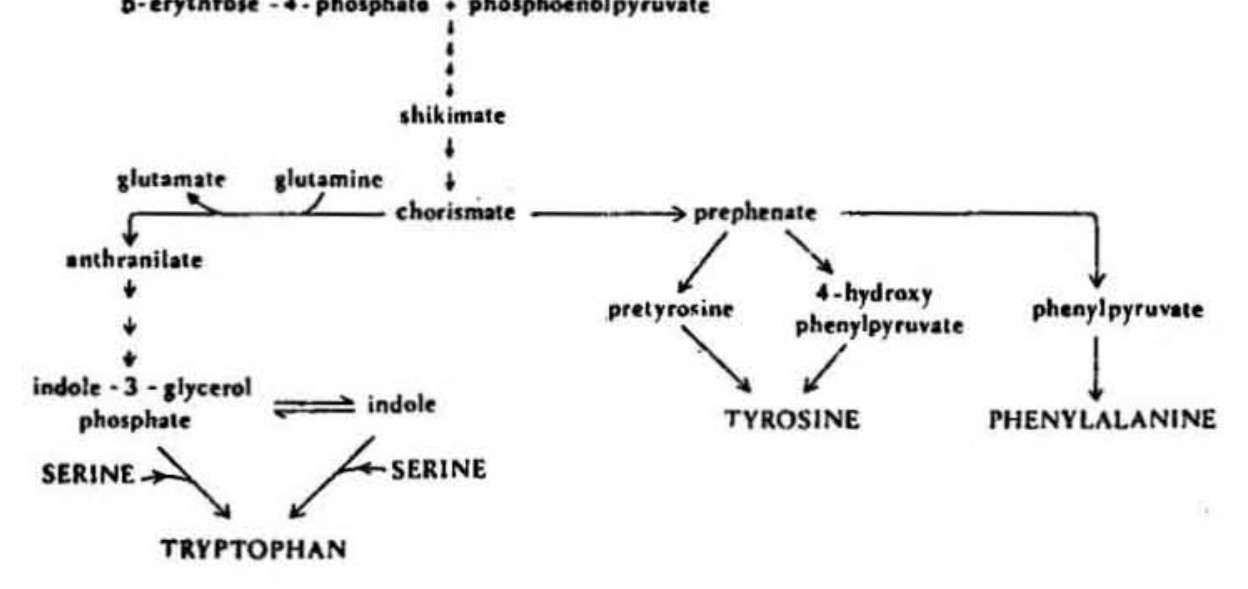


Figure 4-13. Observed and predicted time courses of 1sotope incorporation into phenyalanine in protein of high 1 ight $\left(176 \mu \mathrm{E} \cdot \mathrm{m}^{-2}\right.$. $\left.\mathrm{s}^{-1}\right) \mathrm{NH}_{4}^{+}$-11mited steady state cultures of Nannochloris $\mathrm{sp}$. Soldd line represents predicted rate for the high relative growth rate culture $\left(\mu / \mu_{\max }=0.933\right)$ and dotted line the predicted rate for the low relative growth rate culture $\left(\mu / \mu_{\max }=0.229\right)$. Flow was stopped at 1 hour for $\mu / \mu_{\max }=0.229$ and 0.33 hours for $\mu / \mu_{\max }=0.933$ (indicated by arrows). Symbols: squares, carbon incorporation into the protein phenyalanine at the high relative growth rate; + , carbon incorporation into protein phenyalanine at the low relative growth rate. 
Phenylalanine Carbon Incorporation

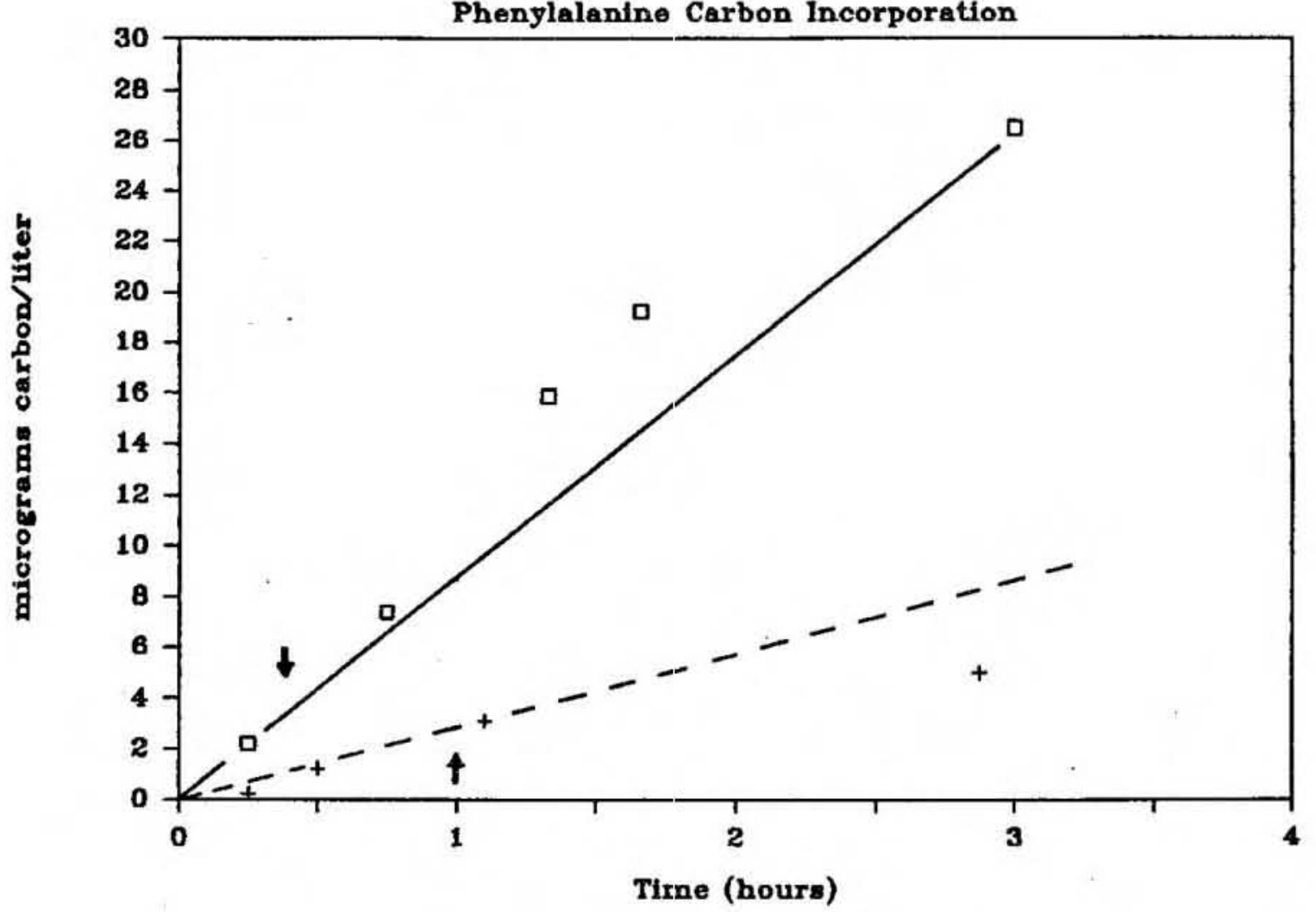


F1gure 4-14. Pathways associated with the biosynthesis of methionine, threonine, 1soleucine, lysine, valine, and leucine. From Miflin and Lea (1977). 


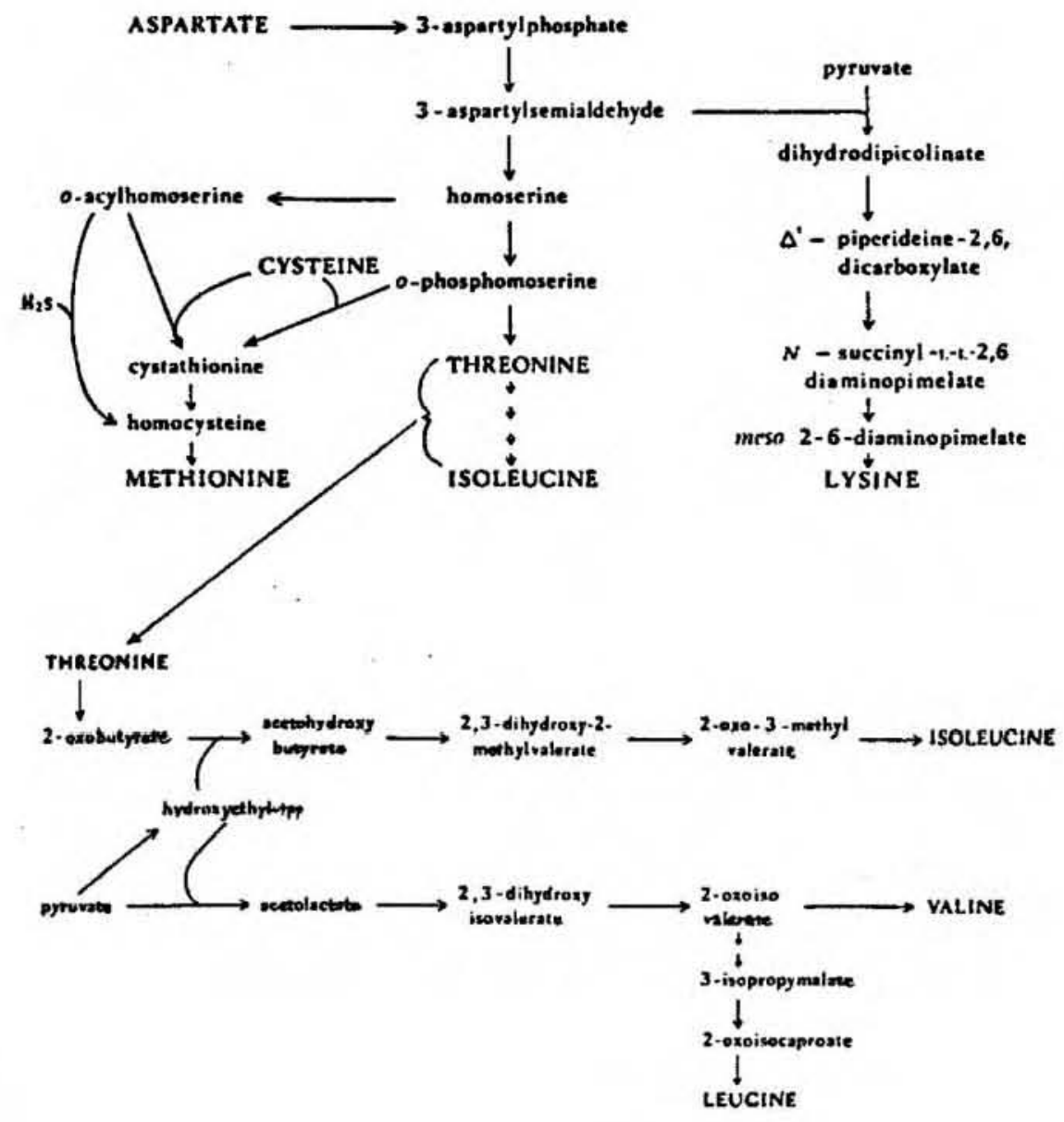


Figure 4-15. Theoretical and observed rates of 1sotopic carbon Incorporation into 1soleucine (ILE) + leucine (LEU), proline (PRO) + arginine (ARG), valine (VAL), phenyalanine (PHE), lysine (LYS), and threonine $(T H R)$ in protein of high 1 ight $\left(176 \mu \mathrm{E} \cdot \mathrm{m}^{-2} \cdot \mathrm{s}^{-1}\right)$ $\mathrm{NH}_{4}^{+}-11$ imited steady state cultures of Nannochloris sp. at high $\left(\mu / \mu_{\max }=0.933\right)$ and $10 \mathrm{w}\left(\mu / \mu_{\max }=0.229\right)$ relative growth rates. Errors represent propagated estimates of analytical error based on $95 \%$ confidence intervals. 


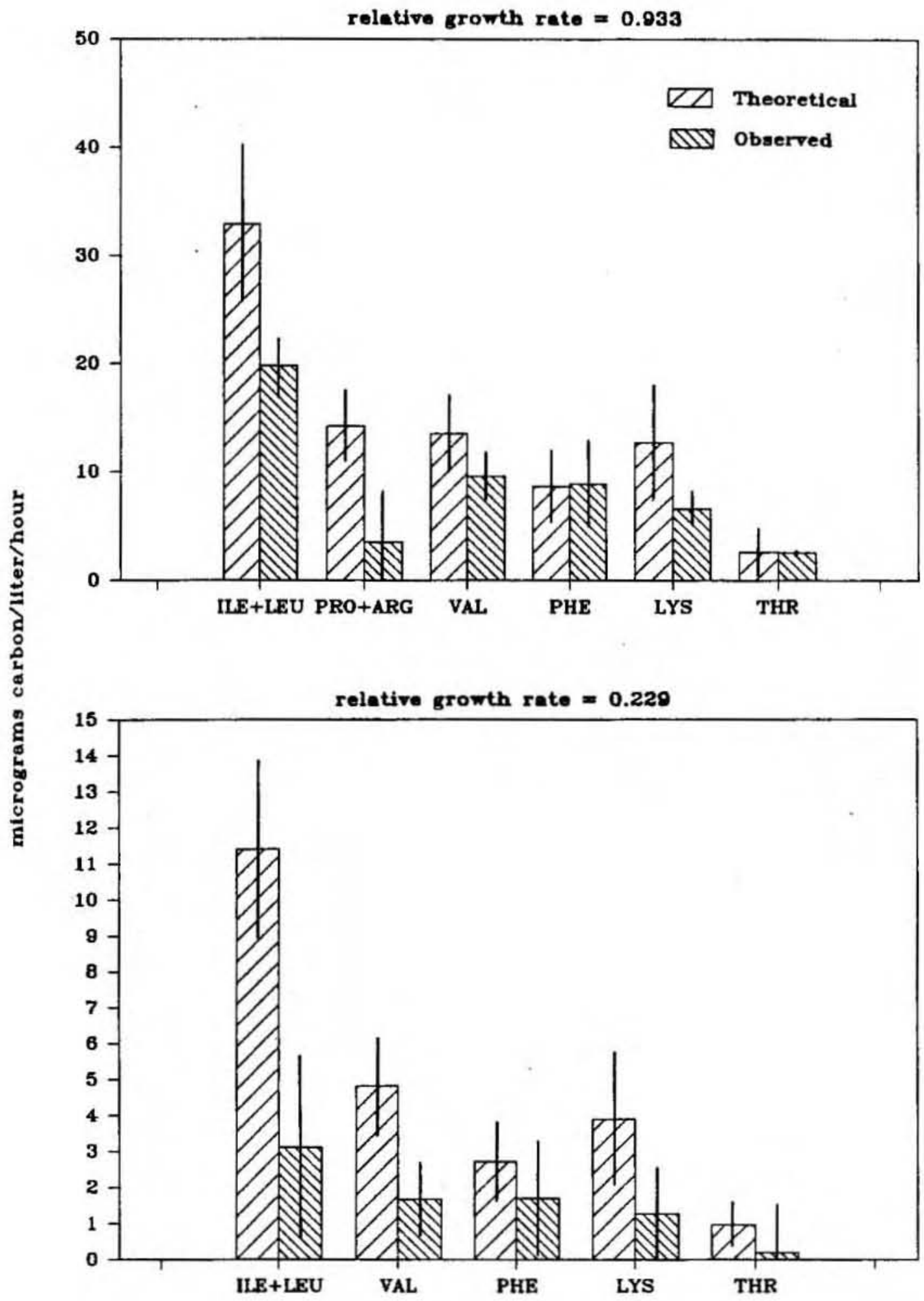


Figure 4-16. Observed and predicted time courses of isotope incorporation into threonine, valine, 1soleucine + leucine, and lysine in protein of high 1 ight $\left(176 \mu \mathrm{E} \cdot \mathrm{m}^{-2} \cdot \mathrm{s}^{-1}\right) \mathrm{NH}_{4}^{+}$-1imited steady state cultures of Nannochloris sp. Solid lines represent predicted rates for the high relative growth rate culture $\left(\mu / \mu_{\max }=0.933\right)$ and dotted lines the predicted rates for the low relative growth rate culture $\left(\mu / \mu_{\max }=0.229\right)$. Flow was stopped at 1 hour for $\mu / \mu_{\max }=0.229$ and 0.33 hours for $\mu / \mu_{\max }=0.933$ (indicated by arrows). Symbols: squares, carbon incorporation into the individual protein amino acid at the high relative growth rate; + , carbon incorporation into the Individual protein amino acid at the low relative growth rate. 

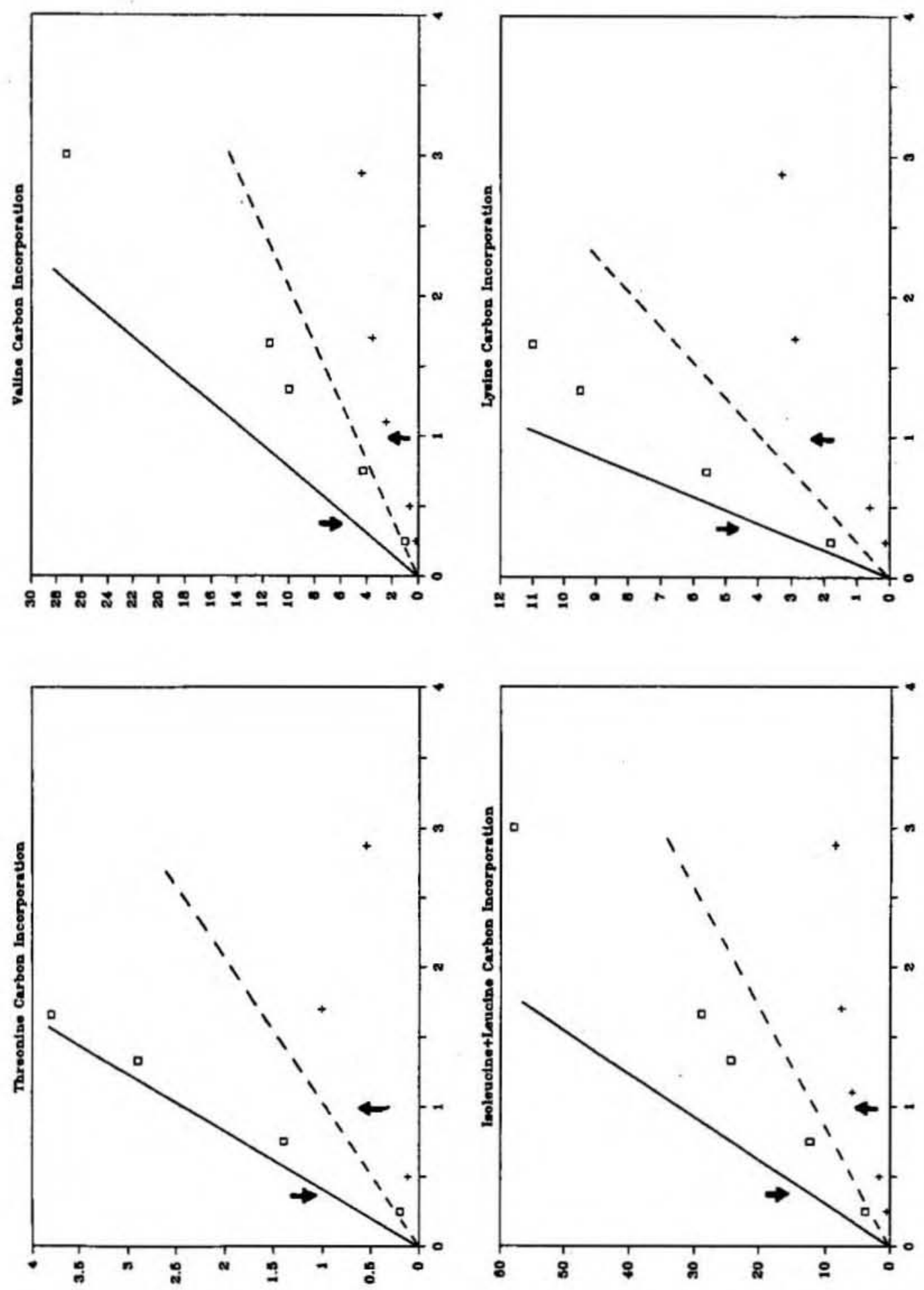

ฮี 
relative growth rate, but less so at low relative growth rate which is consistent with the saturation characteristics of its precursor, aspartate (Figure 4-10). Although there was no clear evidence for depletion effects at the high relative growth rate, this did appear to be a factor at the low relative growth rate.

The observed incorpciration into lysine at the high relative growth rate was difficult to explain. Initially, the observed incorporation rate approached the predicted rate, but then continuously decreased (F1g. 4-16). Th1s seems inconsistent with 1ts presumed precursors aspartate and pyruvate, but may reflect a non-steady state response. Observed incorporation was consisitently low at the low relative growth rate. Observed carbon incorporation into valine and isoleucinetleucine consistently underestimated the predicted incorporation. At the high relative growth rate, the observed rate increasingly approached the predicted slope. At the low relative growth rate, decreasing incorporation in the lat:er part of the incubation period indicated that there was a depletion effect after the interruption of influent flow. As will be discussed in the next section, the biosynthetic characteristics of valine, and the analytical accessibility of both free and protein valine make it an Ideal model amino acid for a more detalled kinetic analysis which clearly distinguishes isotope equilibration effects from those due to nitrogen depletion.

Elucidation of N1trogen Depletion Effects Using Valine as a Model Protein Amino Actd

Unlike some of the other free amino acids such as aspartate and glycine, free valine hası only one clearly defined sink, protein. The 
ability to quantify both free and protein valine concentrations provide a unique opportunity to examine the kinetics of isotope incorporation into protein valine in more detail. This exercise provides a means for distinguishing isotope equilibration effects from non-steady state nitrogen depletion responses. The following assumptions were made in calculating predicted incorporation into protein valine:

1) assume that the intracellular free valine pool is not compartmentalized, and

2) the flux of carbon through the intracellular valine pool is equal to the net protein valine synthesis rate. Furthermore,

3) all carbon entering the free valine pool is in complete equilibrium with inorganic ${ }^{14} \mathrm{C}$. Finally,

4) assume a steady state (i.e. no net increase in biomass, this is a reasonable assumption given the short incubation period). Given these assumptions, let $\mathrm{C}$ be the dissolved inorganic carbon pool, $\mathrm{F}$ be the Intracellular free valine carbon concentration, and $P$ the protein valine carbon formed from F:

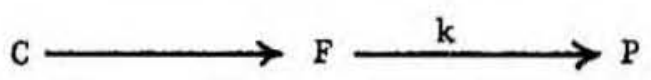

where $k$ is a production rate constant (c.f. Roberts et al., 1963). At time 0 , the radioactive form of $C\left(C^{*}\right)$ is added to the medium. The quantity of isotope in the intracellular free valine pool can be described as:

$$
F^{*}(t)=F_{0}\left(1-e^{-k t}\right)
$$


where $F^{*}(t)=$ the amount of label in the pool at time $t$, and $F_{0}=$ the initial free valine carbon concentration which is measured directly. The rate of isotope incorporation into protein valine (dP*/dt) w111 be:

$$
\mathrm{dP} * / \mathrm{dt}=\mathrm{kF}^{*}(\mathrm{t})
$$

Integration yields the predicted quantity of 1sotope in protein valine at time $t$ :

$$
P *(t)=k F_{0}\left(t+\left(e^{-k t} / k\right)-(1 / k)\right)
$$

The term $\mathrm{kF}_{\mathrm{o}}$ is equal to the steady state rate of carbon flux into protein valine. This can be approximated for short incubation times as the product of the proteln valine carbon concentration, $P_{0}$, and the dilution rate of the chemostat, D, both of which can be determined directly. Substituting:

$$
P *(t)=D P_{0}\left(t+\left(e^{-k t} / k\right)-(1 / k)\right)
$$

where $k=\left(D P_{0} / F_{0}\right)$ in units of hours ${ }^{-1}$. Fig. 4-17 shows the relationship between the predicted incorporation and the observed value for protein valine carbon Incorporation at high and low relative growth rates. There is excellent agreement initially, an indication that the assumptions were reasonable. Subsequently the observed values begin to fall below the predicted isotope incorporation, a likely nutrient depletion response. This is particularly evident at the low relative growth rate. 
The fact that the kinetics of protein valine labelling can be described solely on the basis of the intracellular free valine pool concentration and the predicted rate of carbon flux into protein valine suggests that the specific activity of carbon entering the intracellular free valine pool, pyruvate, is simllar to that of the dissolved inorganic carbon pool. This is also consistent with the rapid labelling of alanine, for which pyruvate is the carbon skeleton (Fig. 4-10).

The results of the patterns of carbon incorporation under high light conditions have demonstrated that the majority of the discrepancy between observed and predicted carbon Incorporation into protein is due to the Incorporation characteristics of the branched chain amino acids valine, Isoleucine, and leucine, as well as glutamate, and to some extent lysine. Initially, the kinetics of isotope distribution are the predominant cause of discrepancles. However, non-steady state effects are potentially important later in the incubation. Non-steady state effects were immediately evident at the low relative growth rate once the flow of media was stopped.

In the next section, the kinetics of protein incorporation of photosynthetically fixed inorganic ${ }^{14} \mathrm{C}$ in low light adapted $(28 \pm 9 \mu \mathrm{E}$. $\left.\mathrm{m}^{-2} \cdot \mathrm{s}^{-1}\right) \mathrm{NH}_{4}^{+}-11 \mathrm{mited}$ cultures are described. As shall be demonstrated, incorporation patterns were substantially different in the situation where growth was limited by the energy supply as well as by the nutrient supp1y. 
Figure 4-17. Comparisons of observed 1sotope incorporation into protein valine with that predicted on the assumption that all carbon flux through the free intracellular valine pool was associated with synthesis of protein valine. Curve represents results of mode1. 
$-301-$

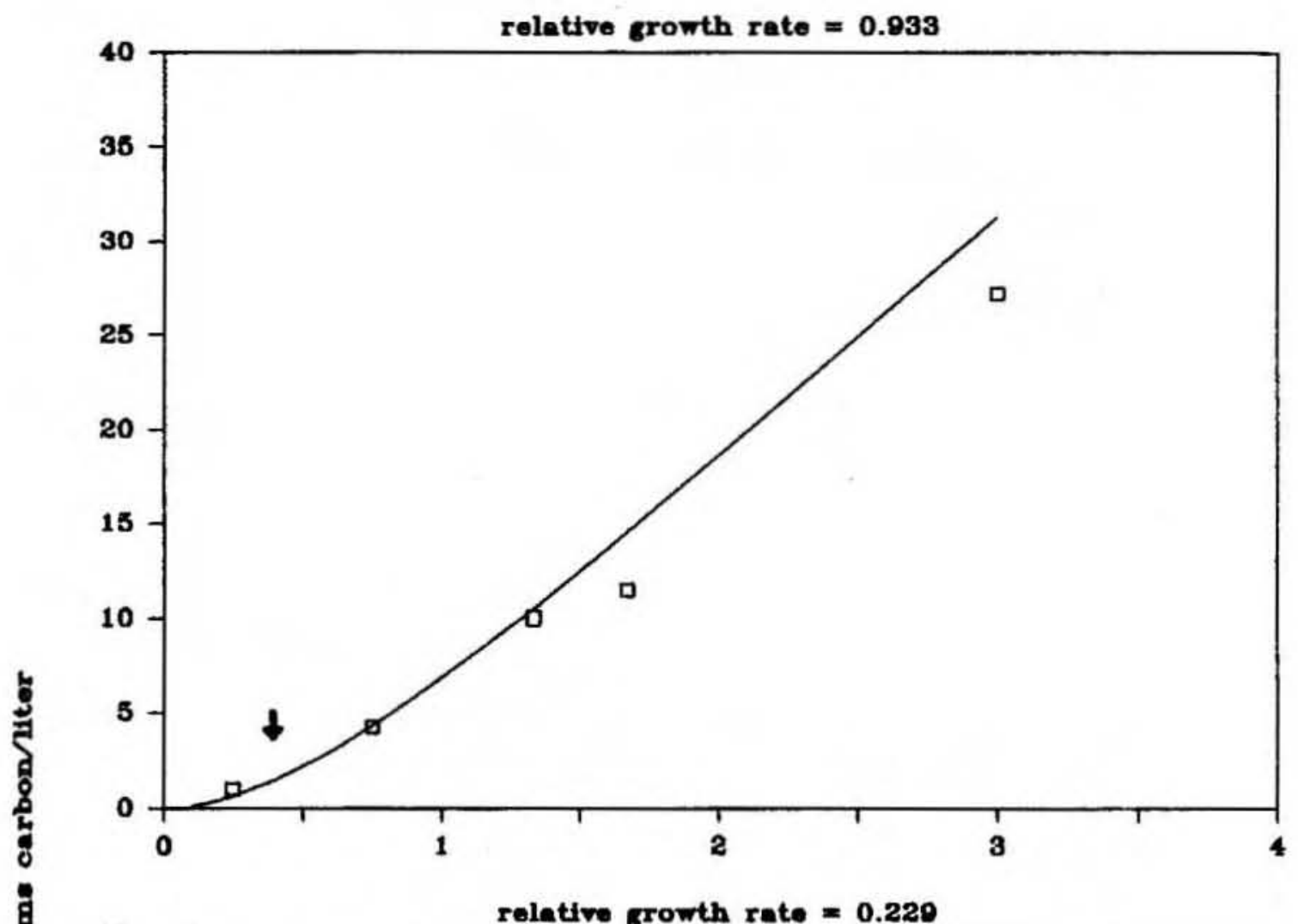

1. 12 relative growth rate $=0.220$

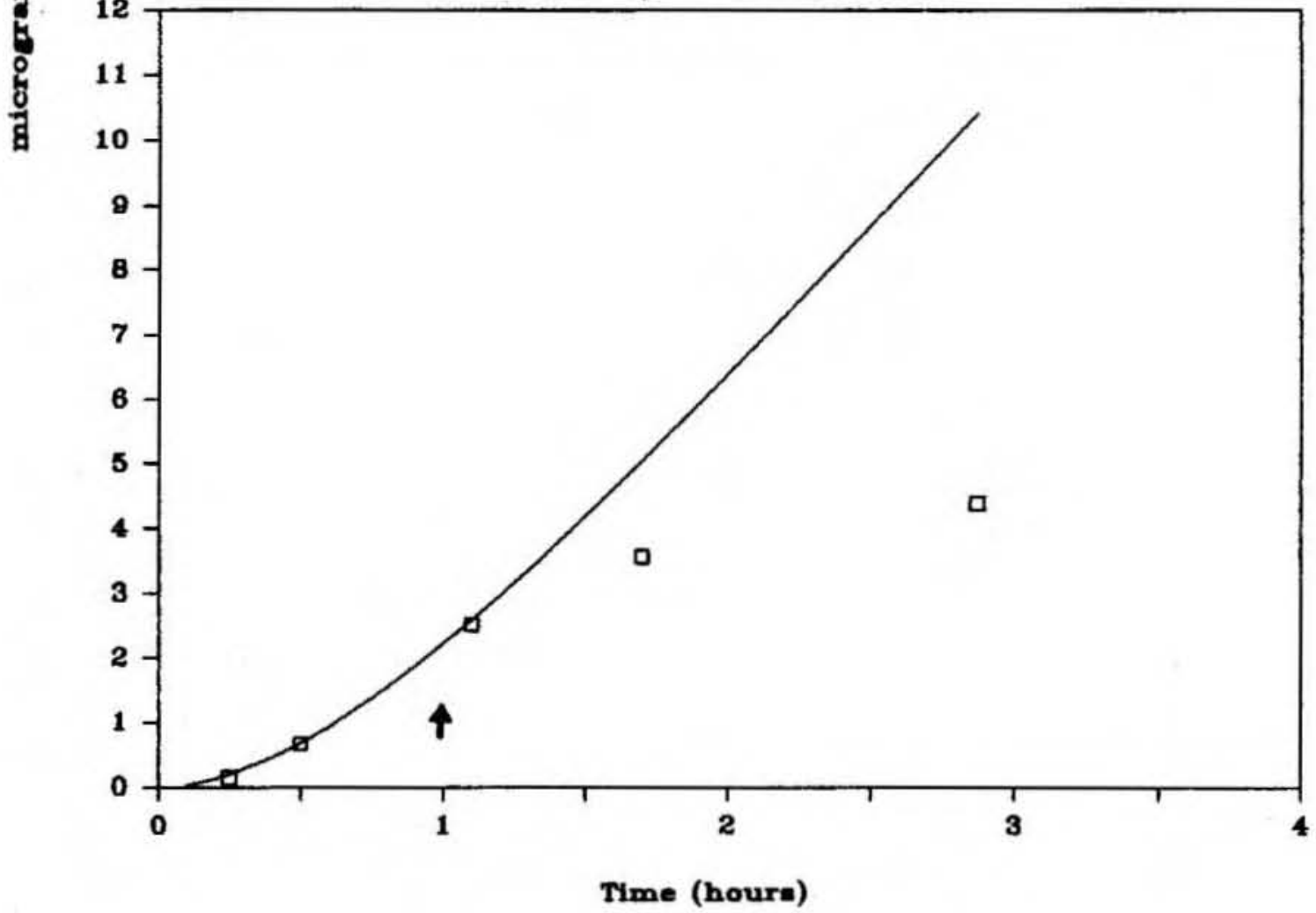


Comparisons of Carbon Incorporation and Net Protein Synthesis Rates in Nannochloris sp. under Combined Conditions of NH4+-11mitation and Low

Light

POC Predicted versus Observed Production

As for the case of high light adapted cultures, predicted and observed $P O C$ production agreed within analytical error at the high relative growth rates (FIg. 4-18). There did appear to be a tendency for observed Incorporation to exceed the predicted rate at the low relative growth rate, but the discrepancy was marginally significant.

\section{Total PPAA Carbon Predicted versus Observed Production}

Observed total PPAA carbon production was generally within analytical error of the predicted rates ( $F 1 g .4-19$ ), in contrast to the 11ght saturated case (Fig. 4-2). Because of small sample sizes ( $n=4$ ), errors were large for the middle and low relative growth rates. Examination of the time course of carbon incorporation did reveal a tendency for the observed PPAA carbon incorporation to exceed the predicted value at the low relative growth rate (Fig. 4-20). Further evidence of observed carbon incorporation exceeding the predicted values was found by examining the individual protein amino acids.

Individual Protein Amino Acid Observed versus Predicted Carbon Incorporation

As for the light saturated case, different amino acids behaved differently in their characteristics of 1sotope incorporation and their relationship to predicted rates. At all growth rates, both alanine and 
glycine observed rates exceeded the predicted (Fig. 4-21). The differences were significant for both alanine and glycine at the middle growth rate $\left(\mu / \mu_{\max }=0.723\right)$. However, at the highest and lowest growth rate, only in the case of glycine was the difference significantly beyond the limits of analytical error. Examining the time course patterns of carbon incorporation into glycine and alanine, it can be seen that observed carbon incorporation consistently exceeds the predicted rate (Fig. 4-22). This is also the case for aspartate at the low relative growth rate. The regressions for alanine and aspartate at the low relative growth rate were not significantly different from zero due to the small number of points $(n=4)$. Nevertheless, the observed data was consistently greater than the predicted incorporation. Glutamate observed carbon incorporation was low initially for all relative growth rates (Fig. 4-22), consistent with patterns seen in the light saturated cultures (FIg. 4-10). However, during the latter portion of the Incubation at the low relative growth rate, observed production exceeded the predicted rate.

The agreement between observed and predicted carbon Incorporation rates was generally well within the limits of analytical error for the other amino acids (Fig. 4-23), with the exception of proline for which observed incorporation was consi.stently below the predicted rates as in the high light cultures. Data obtained during the latter perfods of incubation for isoleucine, leucine, threonine, phenylalanine also tended to be above the predicted incorporation at the low relative growth rate, and even for the middle relative growth rate in the case of phenyalanine and threonine (Fig. 4-24). Lysine observed incorporation was variable at the high relative growth rate, and was generally in agreement with 
Figure 4-18. Observed total ${ }^{14} \mathrm{C}$ uptake rates and theoretical organic carbon production rates of low 1ight $\left(28 \mu \mathrm{E} \cdot \mathrm{m}^{-2} \cdot \mathrm{s}^{-1}\right)$ $\mathrm{NH}_{4}^{+}-11$ mited steady state cultures of Nannochloris sp. Observed total ${ }^{14} \mathrm{C}$ uptake rates were determined by linear regression of a 3 hour t1me course. Errors represent propagated estimates of analytical error based on $95 \%$ confidence intervals. 


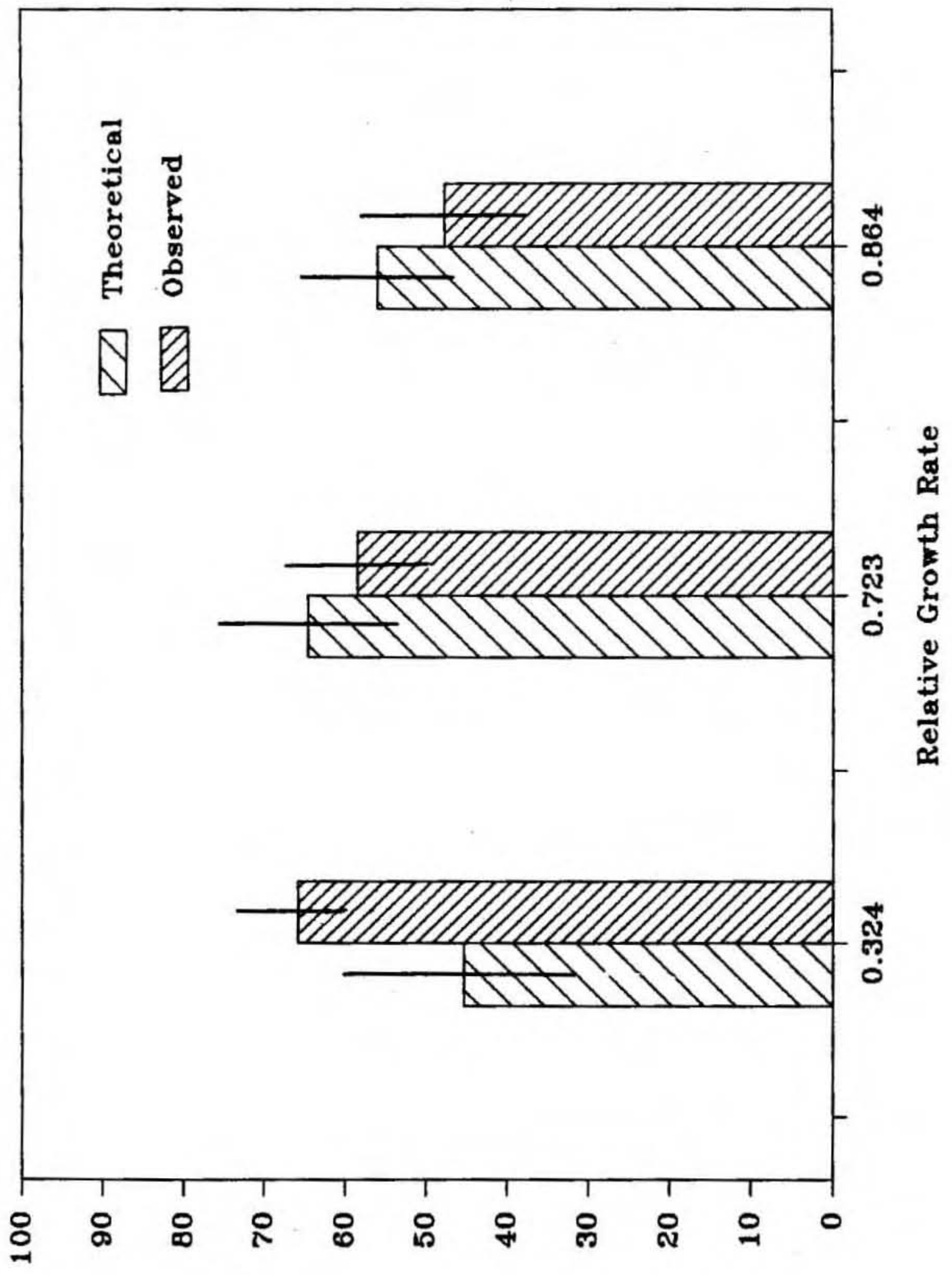


Figure 4-19. Theoretical and observed rates of 1sotopic carbon incorporation into particulate protein amino acids (PPAA) of low light $\left(28 \mu \mathrm{E} \cdot \mathrm{m}^{-2} \cdot \mathrm{s}^{-1}\right) \mathrm{NH}_{4}^{+}-1$ imited steady state cultures of Nannochloris sp. Observed 1sotope incorporation rates were determined by 11near regression of a 3 hour time course. Errors represent propagated estimates of analytical error based on $95 \%$ confidence intervals. 


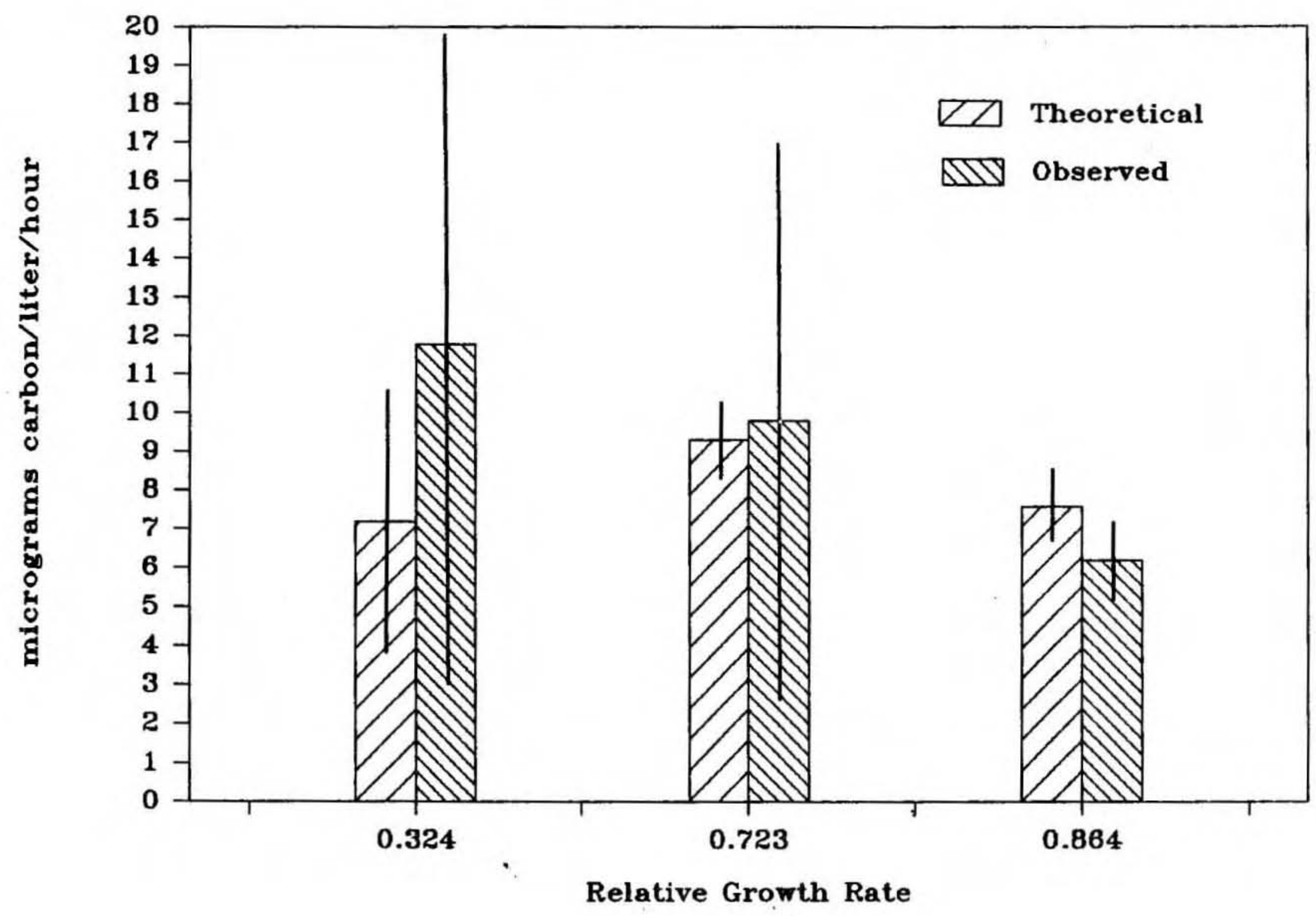


Figure 4-20. Observed and predicted time courses of 1sotope incorporation into partilculate protein amino acids of low light $(28 \mu \mathrm{E}$. $\left.\mathrm{m}^{-2} \cdot \mathrm{s}^{-1}\right) \mathrm{NH}_{4}^{+}$-1imited steady state cultures of Nannochloris sp. Solid line represents the predicted rate for the high relative growth rate culture $\left(\mu / \mu_{\max }=0.864\right)$. The long dashed line is the predicted rate for the middle relative growth rate culture $\left(\mu / \mu_{\max }=0.723\right)$, and the short dashed 11ne, the predicted rate for the low relative growth rate culture $\left(\mu / \mu_{\max }=0.324\right)$. Flow was 1nterrupted at zero time. Symbols: squares, sum of carbon incorporation into individual protein amino acid residues at the high relative growth rate; circles, sum of carbon incorporation into individual protein amino acid residues at the middle relative growth rate; + , sum of carbon incorporation into Individual protein amino actd residues at the low relative growth rate. 


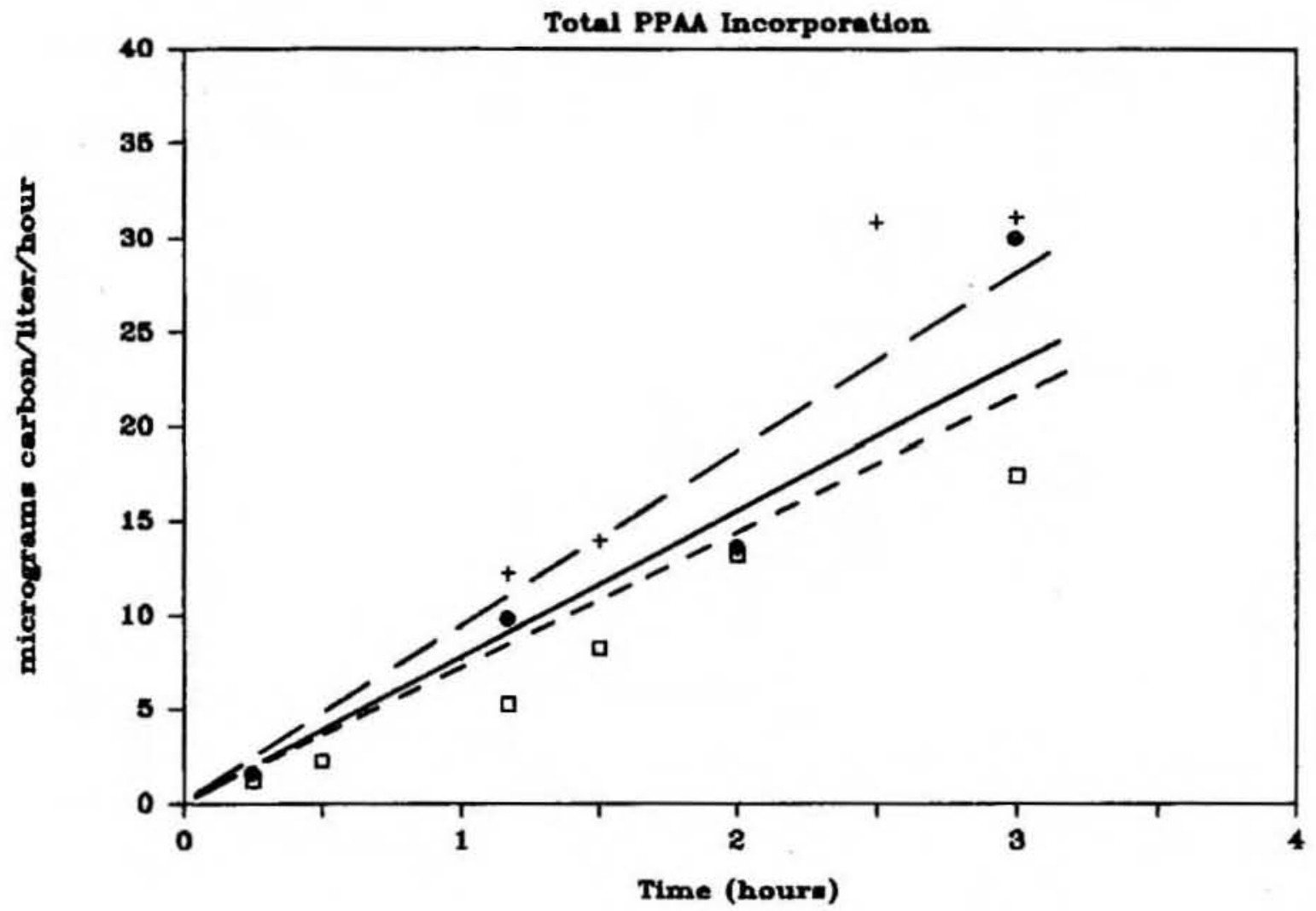


F1gure 4-21. Theoretical and observed rates of 1sotopic carbon incorporation into alanine (AIA), glycine (GLY), glutamate (GLU), and aspartate (ASP) in protein of low light $\left(28 \mu \mathrm{E} \cdot \mathrm{m}^{-2} \cdot \mathrm{s}^{-1}\right)$ $\mathrm{NH}_{4}^{+}$-limited steady state cultures of Nannochloris sp. Observed 1sotope incorporation rates were determined by linear regression of a 3 hour time course. Errors represent propagated estimates of analytical error based on $95 \%$ confidence intervals. 

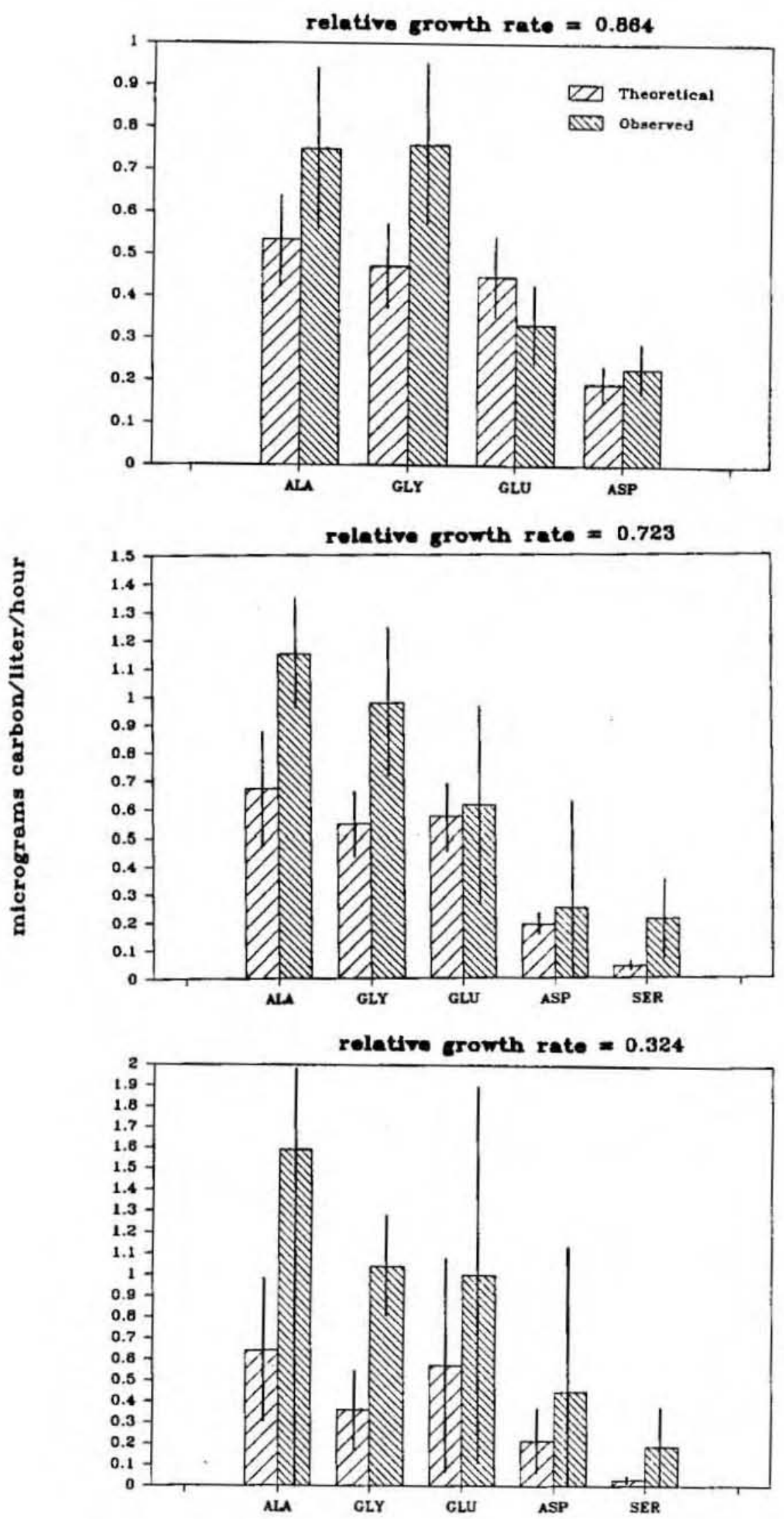
F1gure 4-22. Observed and predicted time courses of 1sotope incorporation into alanine, glycine, glutamate, and aspartate in protein of low light $\left(28 \mu \mathrm{E} \cdot \mathrm{m}^{-2} \cdot \mathrm{s}^{-1}\right) \mathrm{NH}_{4}^{+}-11 \mathrm{mited}$ steady state cultures of Nannochloris sp. Solld line represents the predicted rate for the high relative growth rate culture $\left(\mu / \mu_{\max }=0.864\right)$. The long dashed line is the predicted rate for the middle relative growth rate culture $\left(\mu / \mu_{\max }=0.723\right)$, and the short dashed line, the predicted rate for the low relative growth rate culture $\left(\mu / \mu_{\max }=0.324\right)$. Flow was interrupted at zero time. Symbols: squares, sum of carbon incorporation Into Individual protein amino acid residues at the high relative growth rate; c1rcles, sum of carbon incorporation into individual protein amino ac1d residues at the middle relative growth rate; + , sum of carbon Incorporation into individual protein amino acid residues at the 1ow relative growth rate. 

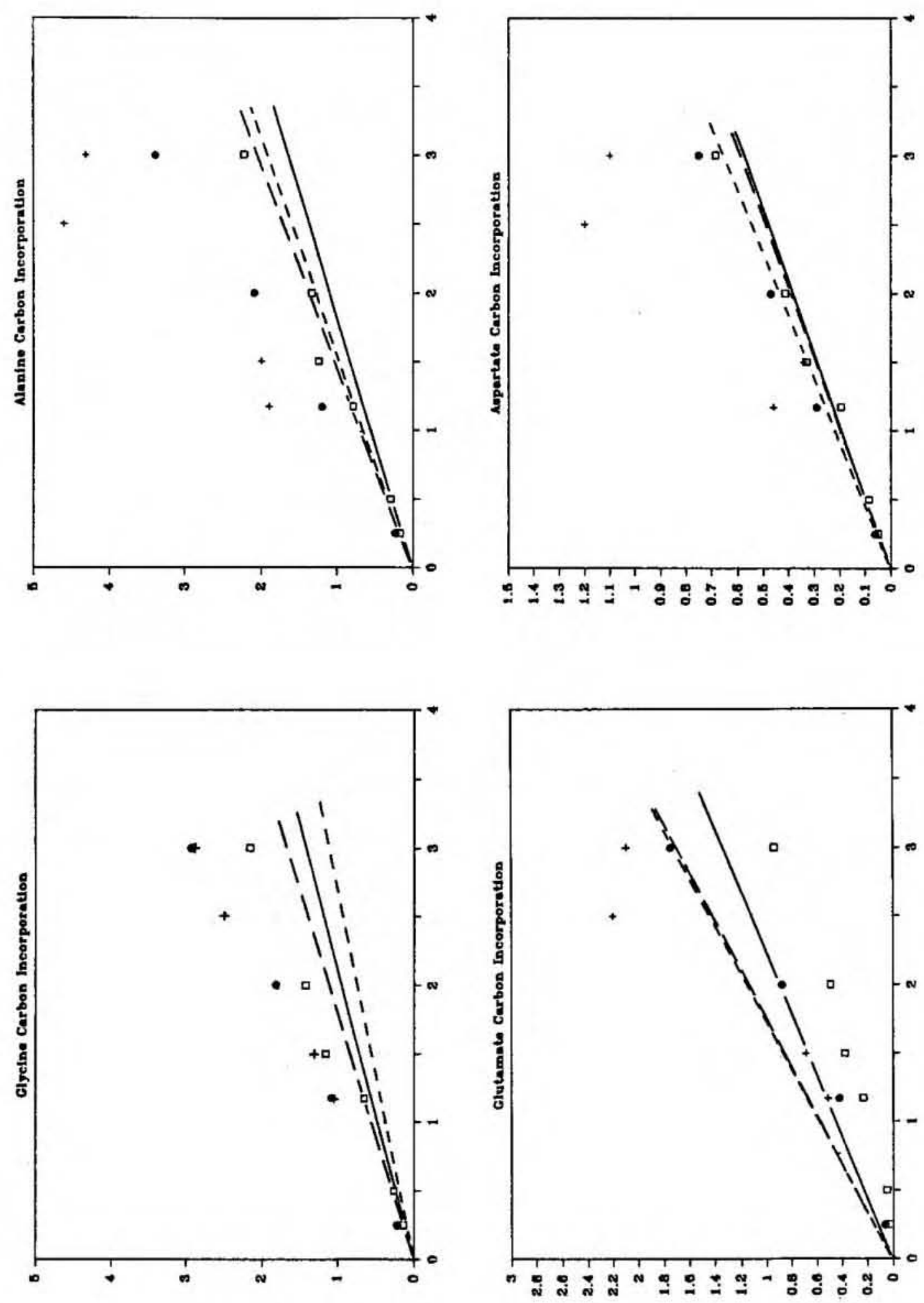
Figure 4-23. Theoretical and observed rates of 1sotopic carbon incorporation into isoleucine (IIE) + leucine (LEU), proline (PRO), phenyalanine (PHE), lysine (LYS), and threonine (THR) in protein of low light $\left(28 \mu \mathrm{E} \cdot \mathrm{m}^{-2} \cdot \mathrm{s}^{-1}\right) \mathrm{NH}_{4}^{+}-11 \mathrm{mited}$ steady state cultures of Nannochloris sp. Observed isotope incorporation rates were determined by linear regression of a 3 hour time course. Errors represent propagated estimates of analytical error based on $95 \%$ confidence intervals. 


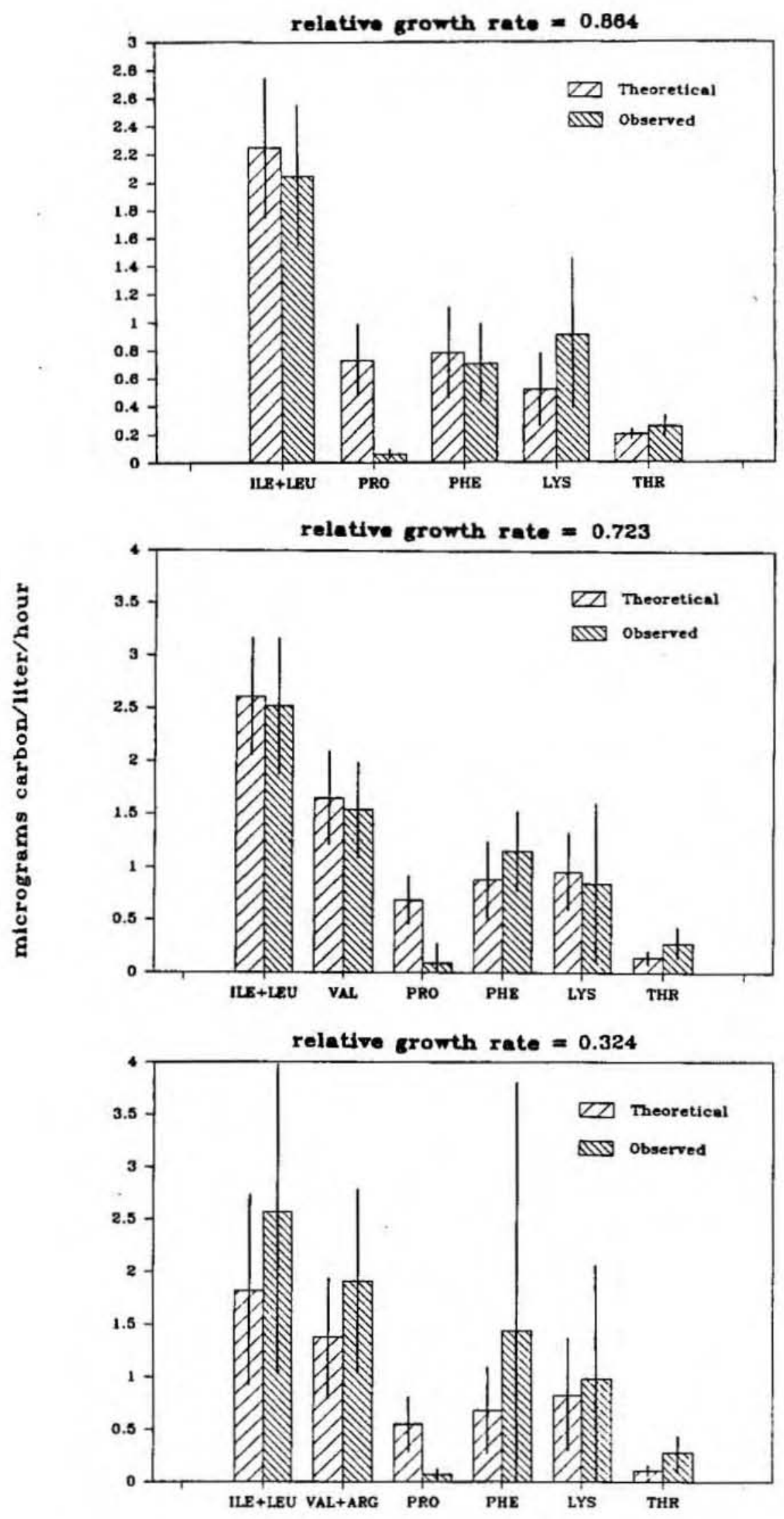


Figure 4-24. Observed and predicted time courses of isotope incorporation into threonine, 1soleucine + leucine, phenyalanine, and lysine in protein of low light $\left(28 \mu \mathrm{E} \cdot \mathrm{m}^{-2} \cdot \mathrm{s}^{-1}\right) \mathrm{NH}_{4}^{+}-1$ imited steady state cultures of Nannochloris sp. Solid line represents the predicted rate for the high relative growth rate culture $\left(\mu / \mu_{\max }=\right.$ 0.864). The long dashed line, the predicted rate for the middle relative growth rate culture $\left(\mu / \mu_{\max }=0.723\right)$, and the short dashed line, the predicted rate for the low relative growth rate culture $\left(\mu / \mu_{\max }=\right.$ 0.324). Flow was interrupted at zero time. Symbols: squares, sum of carbon incorporation into individual protein amino acld residues at the high relative growth rate; circles, sum of carbon incorporation into individual protein amino acid residues at the middle relative growth rate; + , sum of carbon incorporation into individual protein amino acid residues at the 1 ow relative growth rate. 

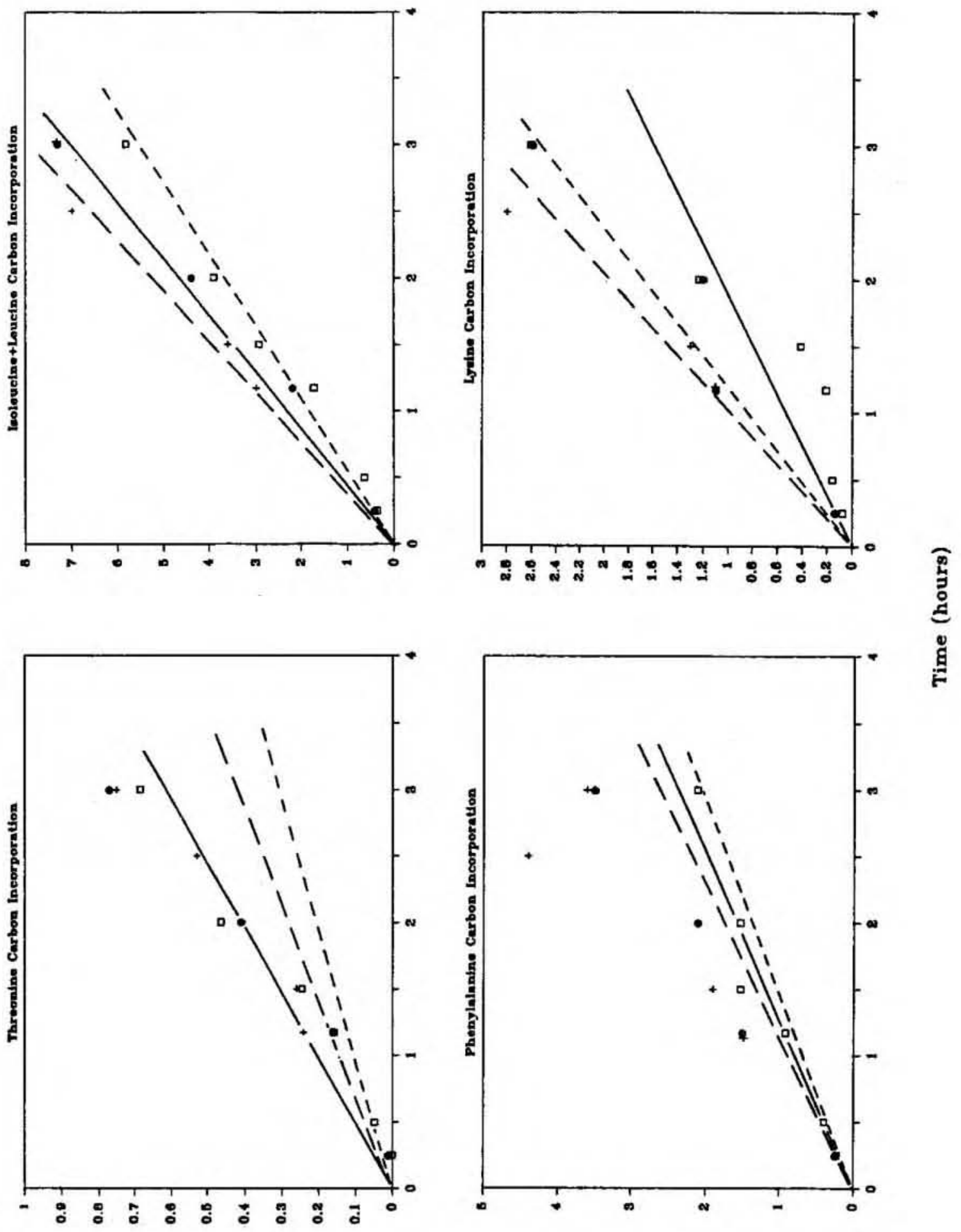
predicted incorporation at the low and middle growth rates.

\section{Protein Turnover}

The substantial discrepancles between predicted carbon incorporation and the observed isotope incorporation rate is in marked contrast to the results observed for the high light adapted cultures. The tendency for Isotope incorporation to exceed the predicted rate was particularly evident in the case of the amino acids which exhibited rapid saturation kinetics under high light conditions (alanine, glycine, threonine, and phenylalanine). The discrepancy was most pronounced at the low relative growth rate.

The simplest explanation for these results would be that the gross rate of protein synthesis significantly exceeds the net protein synthesis rate. That is, the total flux of amino acids into protein exceeds the net increase in protein amino acids. Turnover of protein in excess of net synthesis has been recognized as a common phenomenon in higher plants (Huffaker and Peterson, 1974). However, due to limitations in methodology, 11ttle is known about the factors which regulate the breakdown of protein. One of the factors which makes the determination of protein degradation rates difficult is the potential compartmentalization of the precursor amino acid pools from the total intracellular free amino acid pool. The intracellular isolation of the precursor pools means that their specific activities may be quite different from the total intracellular free amino acid pool. Results from chapter 3 demonstrated that compartmentalization was a factor in the 1sotope kinetics in Nannochloris sp., and its relative importance varied In response to relative growth rate. 
Trewavas (1972) solved the precursor pool problem by 1solating and determining the specific activity of methionine bound to transfer RNA, which is unambiguously the immediate precursor source for incorporation of methionine into protein. He found that degradation was enhanced when cultures were grown at low levels of $\mathrm{MgSO}_{4}$.

Although it is not possible to estimate the true degradation rate of protein from the results I've presented, it is possible to derive a minfmum value for protein degradation necessary to explain the overestimates of predicted incorporation rates by the observed carbon incorporation. This is a minimum estimate because protein precursor specific activities may be less than that of the dissolved inorganic carbon. However, from results obtained with the high light cultures, we know that precursor pools of glycine and alanine tend to equilibrate rapidly. Consequently, in basing my estimates of carbon incorporation on the characteristics of these two amino acids, 1t should be reasonable to assume that the precursor pool specific activity was equal to that of the Inorganic carbon. Another reason this approach yields is only a minimum estimate is that degraded unlabeled protein may be reut1lized in protein synthesis, thereby further diluting the precursor pool. Similarly, degradation of labeled protein would lead to a reduction in the incorporation rate and an underestimate of the total amino acid flux into protein. However, this latter constraint should not be substantial for the short incubation periods used here.

The calculation of protein turnover is based on the following equation adapted from Trewavas (1972):

$$
d P / d t=P_{0}\left(k_{s}-k_{d}\right)
$$


where $d P / d t=$ the net protein synthesis rate, $P_{0}=$ the steady state carbon concentration of the protein amino acid, and $k_{s}$ and $k_{d}$ are the synthesis and degradation rate constants respectively. dP/dt can be approximated for short incubation times as the product of $P_{0}$ and the dilution rate of the chemostat, D. The term $k_{s} P_{0}$, the total carbon flux through the protein amino acid, can be estimated from the rate of isotope incorporation (this assumes complete saturation of precursors with inorganic ${ }^{14} \mathrm{C}$ ). Substituting into equation $4-10$ and solving for $k_{d}:$

$$
k_{d}=\left(k_{s} P_{0}-D P_{0}\right) / P_{0}
$$

This can be further simplified as follows:

$$
k_{d}=\left(k_{s} P_{0}\right) / P_{0}-D
$$

Estimates for $k_{s}$ and $k_{d}$ are shown in Table 4-9 for the three experiments conducted under low light conditions. The results demonstrate the importance of protein degradation relative to total protein synthesis. The degradation constants are relatively unaffected by changes in the relative growth rate. It appears then that the Increased discrepancy between observed and predicted carbon incorporation rates with decreasing relative growth rate is a consequence of the decline in the synthesis rate, as opposed to an increase in the degradation rate. The impact of protein turnover on incorporation patterns is substantial. At the low relative growth rate, the degradation rate constant was more than half the synthesis rate 
constant. These results, in conjunction with observations of the characteristics of high light cultures, indicate that turnover becomes important under 11ght 11mited isituations.

Results with high 11 ght cultures did not indicate 1mportant turnover of protein in excess of net synthesis, as can be concluded from the close agreement between observed and predicted 1ncorporation rates of glycine and alanine. The magnitude of protein turnover seen here was sufficlently large so as to have been apparent in the high light cultures if it was occuring. It may be concluded that e1ther increased light intensity inhibited protein turnover, or that evidence for turnover was obscured at the higher 11ght intensity for one or more of the reasons given previously. $\mathrm{LI}$ and Goldman (1981) noted that for some specles, the observed incorporation of inorganic ${ }^{14} \mathrm{C}$ overestimated the predicted POC production rate. However, my results with Nannochloris sp. do not appear to represent an overall increase in the turnover of carbon biomass. Although there did appear to be an increasing trend in the degradation rate constant for total carbon, it was not significantly different from zero for any of the experiments (Table 4-9). Th1s suggests that the turnover rate of protein exceeded that of the remaining carbon biomass. The turnover of protein provides a way of altering the general proteln constituents and enzymatic complement of the cell (Huffaker and Peterson, 1974). It is an important source of amino acids for protein synthesis when nutrients are limiting. Turnover of existing protein may be less energetically demanding than de novo synthesis which could explain why this process was enhanced under low light conditions in Nannochloris sp. 
Table 4-9. Turnover Rate Constants for Lighta and NHt-Limited Steady State Cultures of Nannochloris sp.

\begin{tabular}{cccccccc}
\hline $\begin{array}{c}\text { Relative } \\
\text { Growth Rate }\end{array}$ & \multicolumn{2}{c}{$\begin{array}{c}\text { Glycine } \\
\mathrm{k}_{\mathrm{s}}\end{array}$} & $\mathrm{k}_{\mathrm{d}}$ & $\mathrm{k}_{\mathrm{s}} \begin{array}{c}\text { Alanine } \\
\left(\mathrm{day}^{-1}\right)\end{array}$ & $\mathrm{k}_{\mathrm{d}}$ & $\mathrm{k}_{\mathrm{s}}$ & POC \\
\hline 0.864 & $0.82(0.26)$ & $0.31(0.26)$ & $0.70(0.23)$ & $0.19(.23)$ & $0.43(0.11)$ & $-0.07(0.11)$ \\
0.723 & $0.74(0.24)$ & $0.34(0.24)$ & $0.72(0.19)$ & $0.29(0.19)$ & $0.38(0.10)$ & $-0.05(0.10)$ \\
0.324 & $0.50(0.15)$ & $0.34(0.16)$ & $0.43(0.48)$ & $0.26(0.48)$ & $0.22(0.05)$ & $0.05(0.06)$ \\
\hline
\end{tabular}

$a_{28+9} \mu \mathrm{E} \cdot \mathrm{m}^{-2} \cdot \mathrm{s}^{-1}$.

b Gowth rate normalized to maximum growth rate $\left(0.58(0.05)\right.$ day $\left.^{-1}\right)$ under sfmilar conditions of $11 \mathrm{ght}$ and temperature.

cErrors of all rate constants (in parentheses) represent propagated estimates of analytical error based on $95 \%$ confidence intervals. 
Morris et al. (1974) Investigated the incorporation patterns of Phaeodactylum tricornutum under light limited conditions. They found that the ratio of carbon incorporation into the hot trichloroacetic acid insoluble fraction relative to total incorporation was higher under low light conditions. Konopka and Schnur (1980) also observed a relative Increase in 1sotope incorporation into protein at lower 11ght intensities. My results illustrate that protein turnover may have been a factor in their experiments, perhaps indicating that the patterns they observed were not entirely due to a relative increase in net protein synthesis, but rather, an increase in the importance of protein turnover in relationship to net protein synthesis.

Another consideration is the extent to which turnover of protein rather than net synthesis is responsible for observed night incorporation of isotope into hot trichloroacetic acid insoluble material of phytoplankton populations (e.g. Smith and Morr1s, 1980a,b; Morris and Skea, 1978; Morris et a1., 1981; Cuhel et a1., 1984). Cuhel et al. (1984) observed significant increases in equilibrium ${ }^{14} \mathrm{C}$ and ${ }^{35} \mathrm{~S}$ labeled protein during the dark perfod in laboratory cultures of Dunalle1la tert1olecta grown on a 1ight/dark cycle. They concluded that night synthesis of protein was significant. On the basis of laboratory observations that exchange of ${ }^{35} \mathrm{SO}_{4}$ with protein sulfur in stationary phase cultures was substantlally less than that of inorganic ${ }^{14} \mathrm{C}$, they argued that short term incorporation of ${ }^{35} \mathrm{SO}_{4}$ more closely reflected net synthesis under conditions where protein turnover was significant. However, their results did not exclude the possibility of exchange of ${ }^{35} \mathrm{SO}_{4}$ in the absence of net protein synthesis. 
Comparisons of Observed and Predicted Carbon Incorporation in Other Spectes of Marine Algee

Observed and Predicted Carbon Incorporation Into Particulate Organic Carbon

Observed and predicted POC production rates agreed well for all species examined under high light conditions, and moderate to high relative growth rates (F1g. 4-25). One exception to this was Chroomonas salina, in which observed incorporation exceeded the predicted rate. This Indicates that the total flux of carbon exceeded the net synthesis rate of carbon blomass in this specles under the specified growth conditions. The values of the degradation rate constants $\left(k_{s}=0.674\right.$ $(0.111)$ day $^{-1}, k_{d}=0.264(0.111)$ day $\left.^{-1}\right)$ show that degradation or respiratory breakdown accounts for a substantial proportion of total carbon fixation in this species.

\section{PPAA Observed versus Predicted Carbon Incorporat1on}

Observed PPAA carbon incorporation rates were, in all cases, below the predicted carbon Incorporation rates (Fig. 4-26). In some cases the discrepancy was more than a factor of 6 . There are two possible causes for such discrepancles. As pointed out for Nannochloris sp., the kinetics of saturation of protein precursors may result in the incorporation of amino acids of specific activity lower than that of the exogenous inorganic carbon pool. A second explanation for low observed rates of 1sotope incorporation relative to predicted rates was that interrupting the steady state growth conditions may have led to nonlinear decreases in the protein carbon incorporation rate. In the experiments 
conducted with Chattone1la 1uteus, Chroomonas salina, and Chaetoceros simplex, influent flow was interrupted at time zero (i.e. the time of isotope addition). For Nannochloris sp., flow was interrupted after .33 hours beyond isotope addition, so that these experiments are comparable. Time courses of PPAA observed carbon incorporation revealed a pronounced time dependent decrease in the incorporation rate for cultures of $\underline{\mathrm{C}}$. simplex (F1g. 4-27). Such a decrease is strong evidence for the manifestation of non-steady state responses. Although the observed slopes of Incorporation for the other species were below that predicted, non-linearity was less apparent. As will be demonstrated, different amino acids respond differently to the interruption of steady state.

Observed versus Predicted Carbon Incorporation Into Ind1vidual Prote1n Amino Acids

Chattonella 1uteus

Observed carbon incorporation rates into individual protein amino ac1ds in $\underline{\mathrm{C}}$. Iuteus are compared to the predicted rates in Fig. 4-28. They resembled those for Nannochloris sp. In that the observed and predicted carbon incorporation rates into protein glycine and alanine agreed well. Agreement was also good for protein serine. The time course incorporation patterns for these protein amino acids indicates rapld saturation of their precursor pools (Figure 4-29). For glutamate and aspartate, the observed rates were below the predicted rates (Fig. 4-28). However, the time course of carbon 1ncorporation revealed that the observed slope of incorporation approached the predicted rate by 3 hours (F1g. 4-29). 
F1gure 4-25. Observed total ${ }^{14} \mathrm{C}$ uptake rates and theoretical particulate organic carbon production rates of high 1 ight $\left(176 \mu \mathrm{E} \cdot \mathrm{m}^{-2}\right.$. $\left.\mathrm{s}^{-1}\right) \mathrm{NH}_{4}^{+}$-11mited steady state cultures of four species of marine phytoplankton. Nanno $=$ Nannochloris sp. $\left(\mu / \mu_{\max }, 0.933\right) ; 01$ isth $=$ Chattone1la 1uteus $(0.921)$, Chaet $=$ Chaetoceros simplex $(0.574)$; Chroom $=$ Chroomonas salina $(0.804)$. Observed total ${ }^{14} \mathrm{C}$ uptake rates were determined by linear regression of a 3 hour time course. Errors represent propagated estimates of analytical error based on $95 \%$ confidence intervals. 


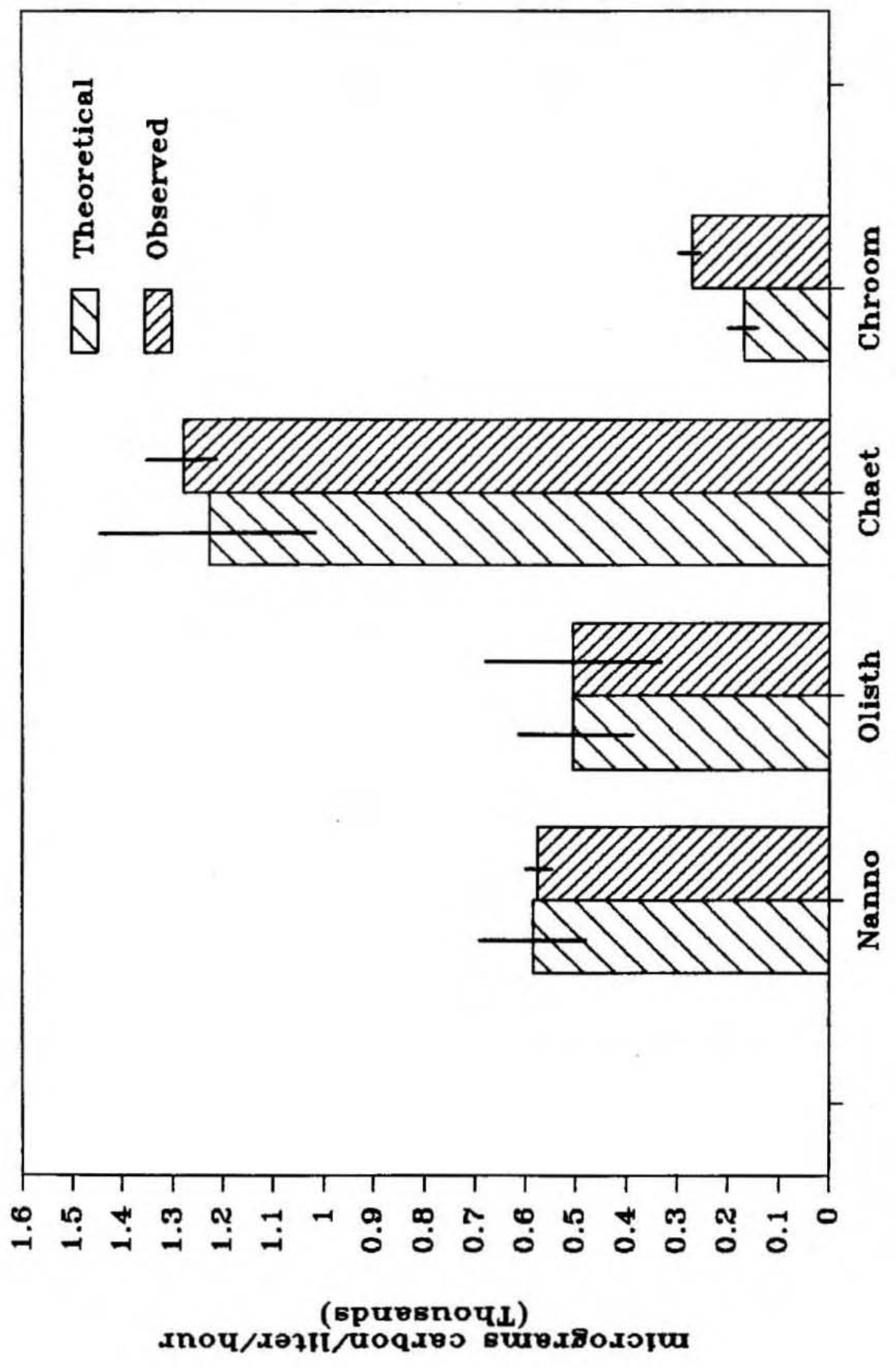


Figure 4-26. Theoretical and observed rates of isotopic carbon incorporation into particulate protein amino acids of high light (176 $\mu \mathrm{E}$. $\left.\mathrm{m}^{-2} \cdot \mathrm{s}^{-1}\right) \mathrm{NH}_{4}^{+}-11 \mathrm{~m}$ ted steady state cultures of four species of marine phytoplankton. Nanno $=$ Nannochloris $8 p \cdot\left(\mu / \mu_{\max }, 0.933\right)$; 011sth $=\underline{\text { Chattone1la luteus }}(0.921)$, Chaet $=$ Chaetoceros simplex $(0.574)$; Chroom $=$ Chroomonas salina $(0.804)$. Observed isotope incorporation rates were determined by linear regression of a 3 hour time course. Errors represent propagated estimates of analytical error based on $95 \%$ confidence intervals. 


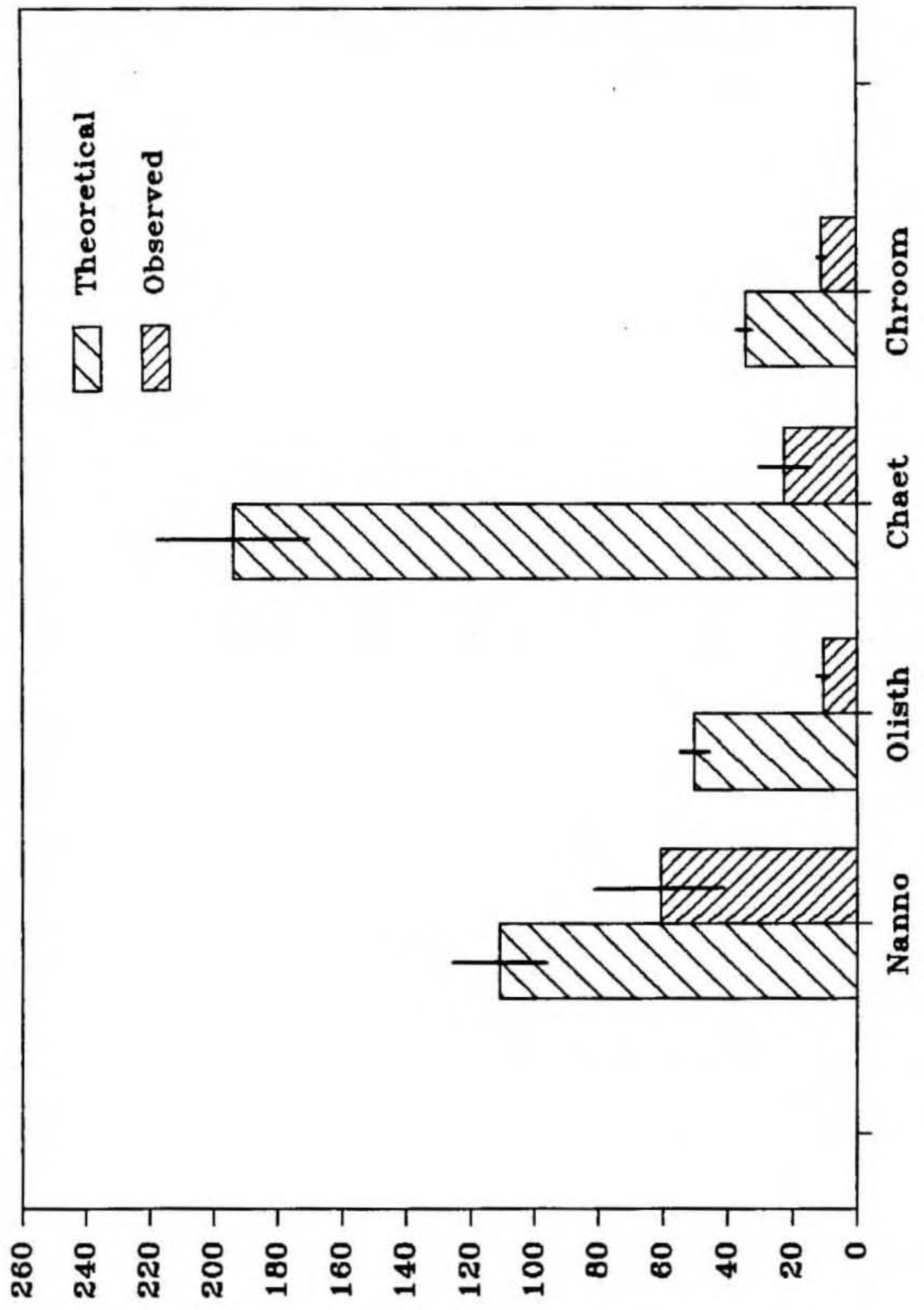


Figure 4-27. Observed and predicted time courses of isotopic carbon incorporation into particulate protein amino acids of high light (176 $\mu \mathrm{E}$. $\left.\mathrm{m}^{-2} \cdot \mathrm{s}^{-1}\right) \mathrm{NH}_{4}^{+}$-limited steady state cultures of Chattonella

luteus $\left(\mu / \mu_{\max }, 0.921\right)$, Chroomonas salina $(0.804)$, and Chaetoceros simplex $(0.574)$. Flow was stopped at zero time. Solid line represents the predicted rate. 
-331-
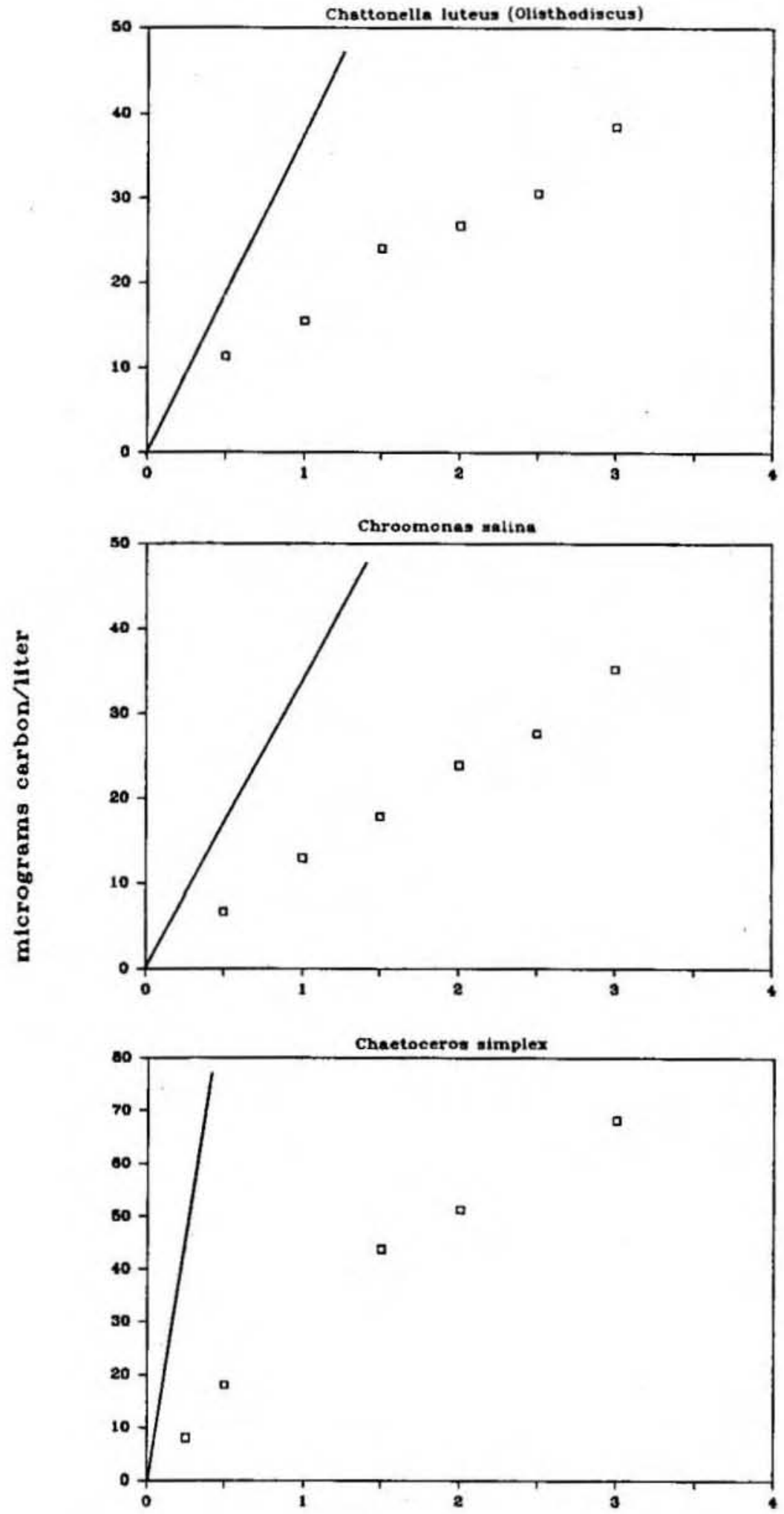

Time (hours) 
Figure 4-28. Theoretical and observed rates of 1sotopic carbon incorporation into alanine (ALA), glycine (GLY), glutamate (GLU), aspartate (ASP), and serine (SER) in protein of high light (176 $\mu \mathrm{E}$. $\left.\mathrm{m}^{-2} \cdot \mathrm{s}^{-1}\right) \mathrm{NH}_{4}^{+}$-11mited steady state cultures of Chattone11a Iuteus $\left(\mu / \mu_{\max }, 0.921\right)$, Chroomonas salina $(0.804)$, and Chaetoceros simplex $(0.574)$. Observed isotope incorporation rates were determined by linear regression of a 3 hour time course. Errors represent propagated estimates of analytical error based on $95 \%$ confidence intervals. 


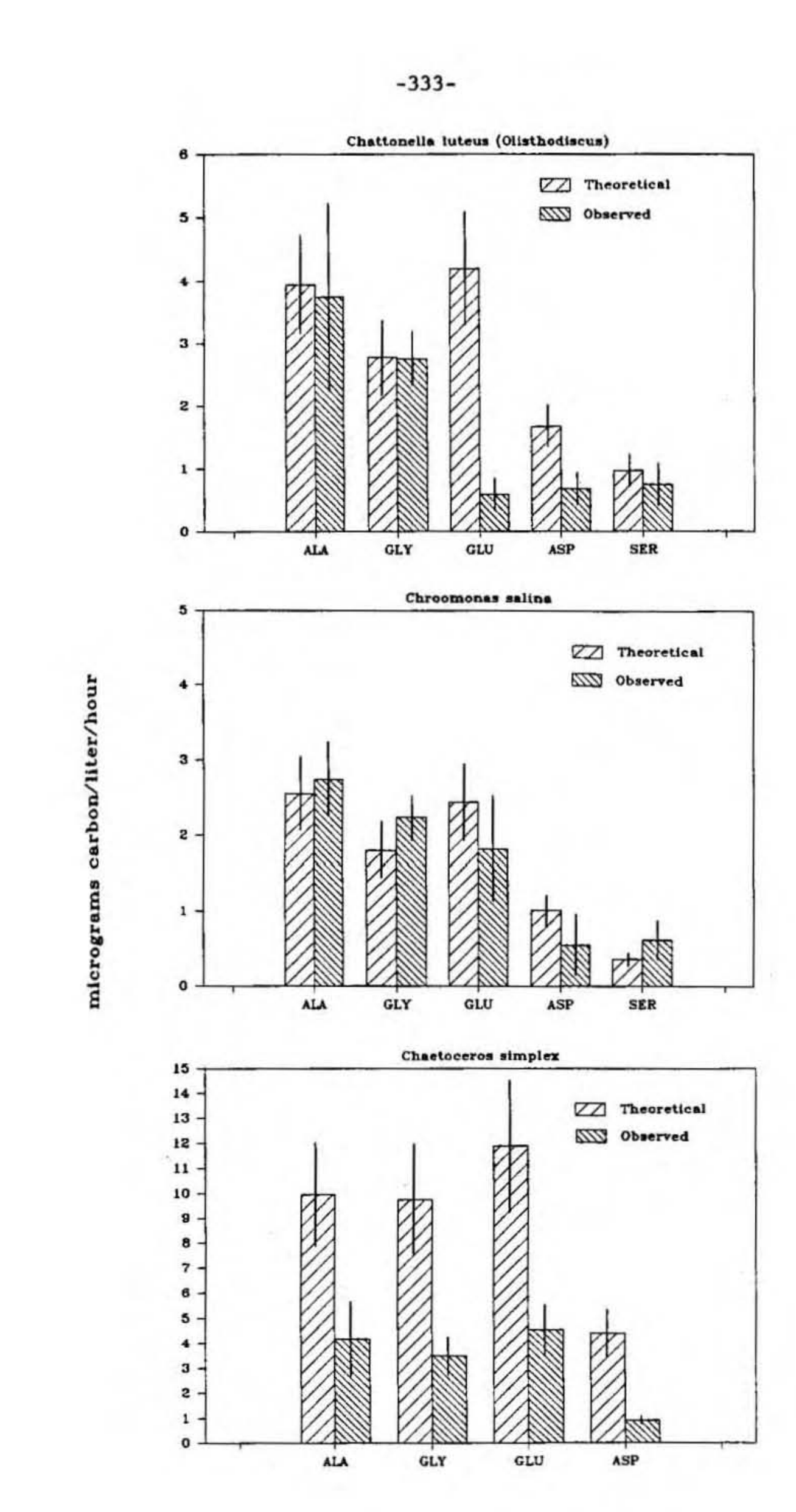


Figure 4-29. Observed and predicted time courses of observed isotope incorporation into glycine, alanine, glutamate and aspartate in protein of a high 11ght $\left(176 \mu \mathrm{E} \cdot \mathrm{m}^{-2} \cdot \mathrm{s}^{-1}\right) \mathrm{NH}_{4}^{+}-1$ imited steady state cultures of Chattonella 1uteus $\left(\mu / \mu_{\max }=0.921\right)$. Flow was stopped at zero time. Solid line represents the predicted rate. 

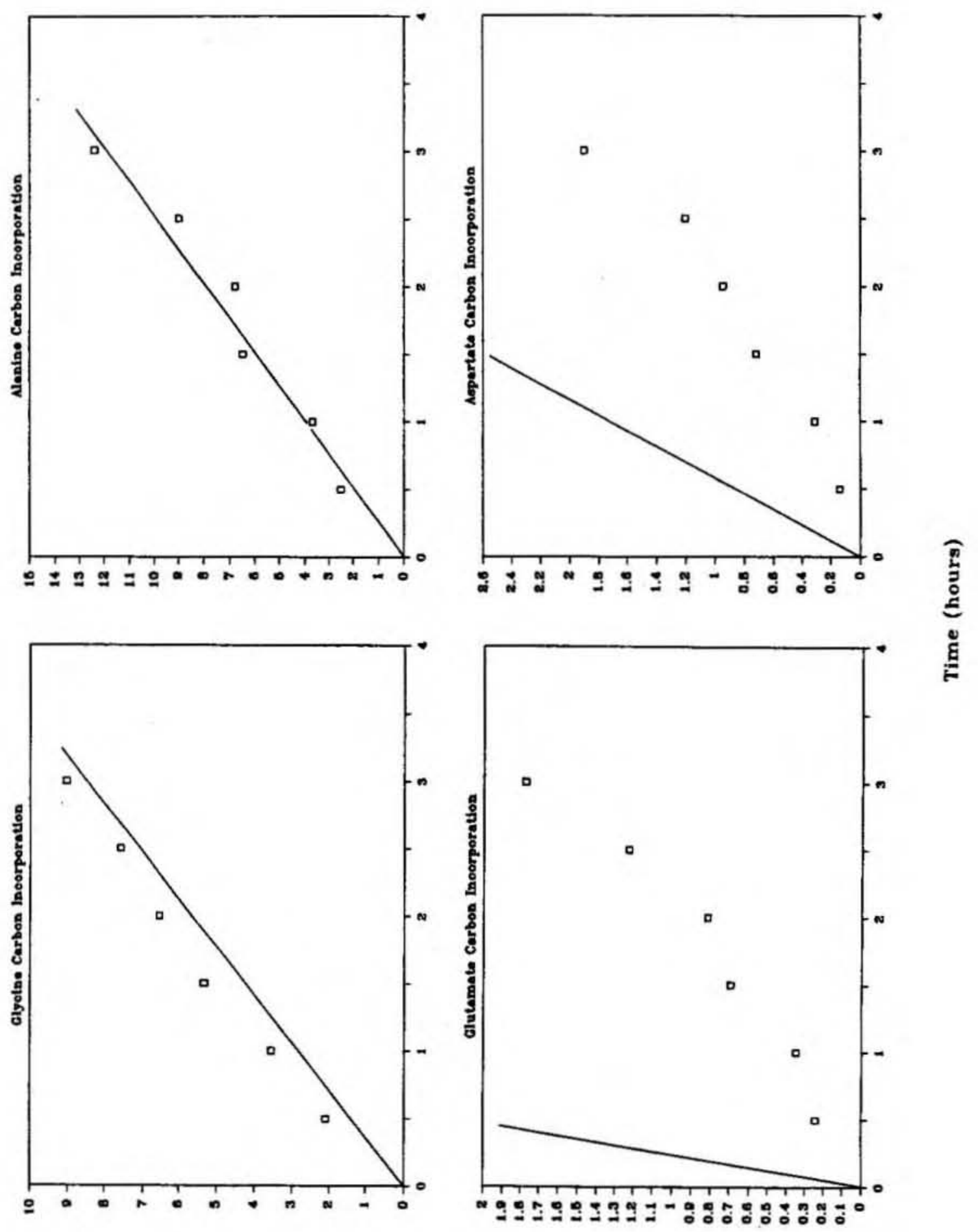

хәวI/ 
For the remaining protein amino acids, the observed incorporation substantially underestimated the predicted rate (Fig, 4-30). This was also the case for Nannochloris sp. at the low relative growth rate. Threonine was low, a consequence of the saturation characteristics of its likely precursor, aspartate. However, both in the case of threonine and the other protein amino acids, there was evidence for non-steady state responses. The observed incorporation into phenylalanine, isoleucinetleucine, valinetarginine, lysine, and proline exhibited time dependent decreases in rates (Fig. 4-31). This indicates that the supply of newly fixed inorganic carbon to the production of the precursors to these protein amino acids was suppressed, presumably as a result of the interruption of influent flow into the chemostat. The fact that observed Incorporation into alanine and glycine continues to reflect their predicted net synthesis rates, and that observed slopes of incorporation into glutamate and aspartate continuously approach their predicted carbon Incorporation rates (FIg. 4-29) is an indication that protein synthesis continued despite the reduction in flux of photosynthetically fixed inorganic carbon. This suggests a selective regulation of the metabolic flux of photosynthetically fixed carbon into specific amino acids in response to the reduced $\mathrm{NH}_{4}^{+}$supply.

C. 1uteus is a large celled algae. It is possible that continued synthesis of the other amino acids became more important at an intracellular location other than the photosynthet1c site. A reduced supply of $\mathrm{NH}_{4}^{+}$could lead to a reduction in the supply of photosynthetically derived carbon skeletons for amino acid blosynthesis as has been demonstrated in higher plants (e.g. Platt et al., 1977; Paul et al., 1978; Mohamed and Gnaman, 1979). Such a regulatory effect might 
result in an increased utilization of unlabeled PEP and pyruvate from the cytosol. PEP is a substrate in the biosynthesis of threonine, isoleucine, and lysine, and pyruvate in the blosynthesis of leucine and valine. So an unlabeled supply of pyruvate to the chloroplast could generate the decline in the observed label incorporation rates. However, pyruvate is also the carbon skeleton of alanine. Thus this argument is inconsistent with the rapid labelling characteristics of alanine. PEP is a substrate in the blosynthesis of phenyalanine. However, one would expect the inputs of unlabeled PEP to be reflected as decreased labelling rate of aspartate wh1ch was not observed. These results suggest that synthesis of threonine, valine + arginine, isoleucine + leucine, lysine, phenylalanine, and proline was metabolically segregated from glycine, alanine, glutamate, and aspartate.

The high Initial rates of incorporation suggest that early in the incubation period, a greater proportion of photosynthetically derived carbon supplies the production of these protein amino ac1ds. If indeed protein synthesis continues at a relatively constant rate as suggested by the incorporation characteristics of glycine and alanine, then the simplest explanation for the rapid initial rate of label incorporation followed by a time dependent decrease in the rate of isotope Incorporation into the other amino acids is that their precursors must be supplied with carbon from a source other than the chloroplast.

\section{Chroomonas salina}

The labelling characteristics of individual protein amino acids of $\underline{c}$. salina were similar in many respects to the observations of the other species, supporting the view that basic blosynthetic pathways associated 
Figure 4-30. Theoretical and observed rates of 1sotopic carbon incorporation into isoleucine (ILE) + leucine (LEU), valine (VAL) + arginine (ARG), proline (PRO), phenyalanine (PHE), 1ysine (LYS), and threonine (THR) in protein of high 11ght $\left(176 \mu \mathrm{E} \cdot \mathrm{m}^{-2} \cdot \mathrm{s}^{-1}\right)$ $\mathrm{NH}_{4}^{+}-11$ mited steady state cultures of Chattonella 1 uteus $\left(\mu / \mu_{\text {max }}\right.$, $0.921)$, Chroomonas salina $(0.804)$, and Chaetoceros simplex $(0.574)$. Observed 1sotope incorporation rates were determined by linear regression of a 3 hour time course. Errors represent propagated estimates of analytical error based on $95 \%$ confidence intervals. 
$-339-$

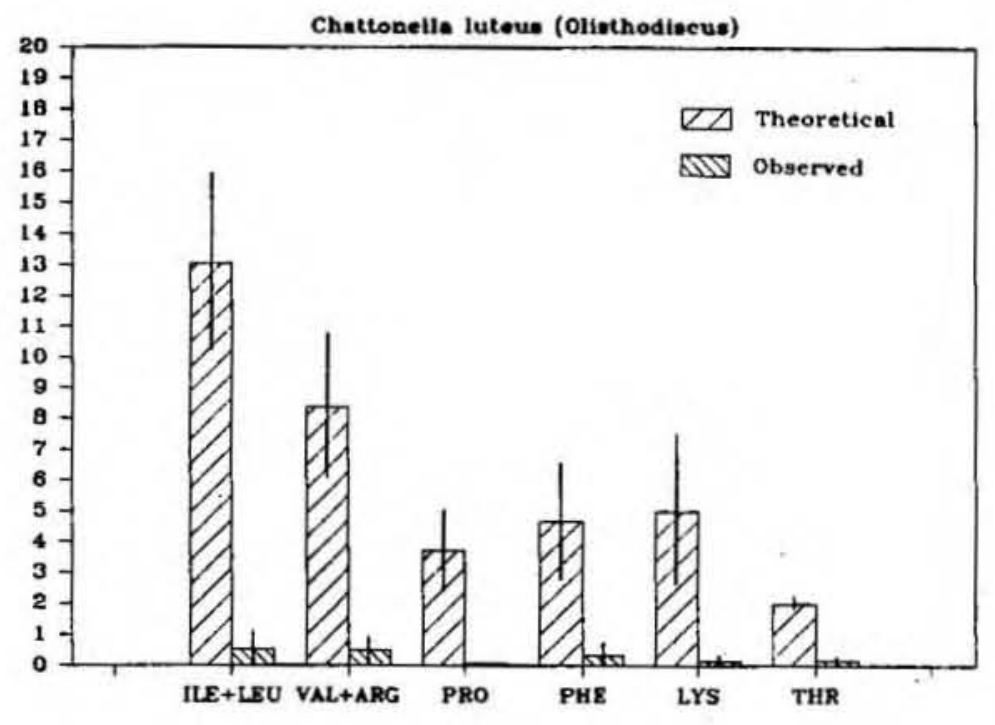

Chroomonas salina

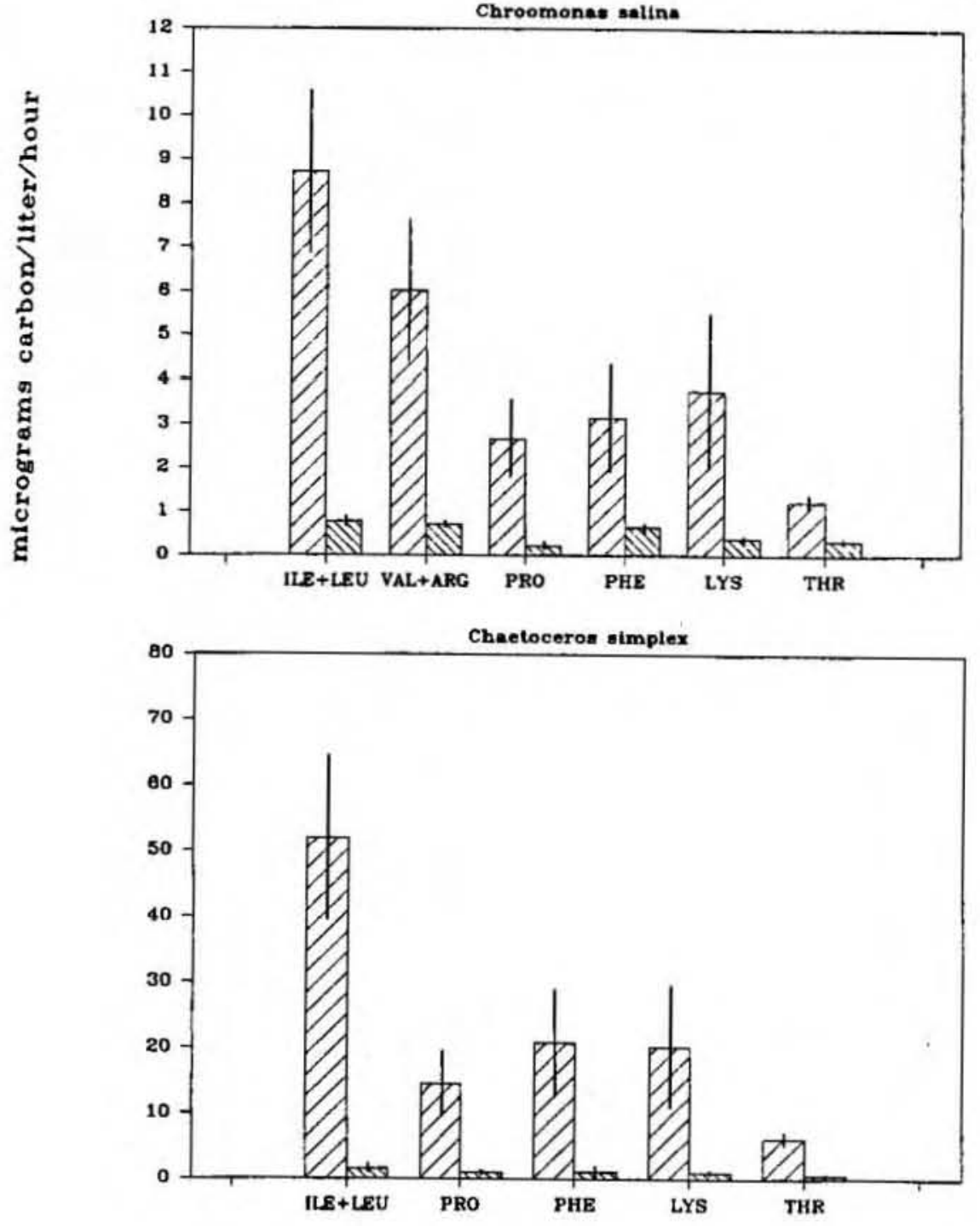


Figure 4-31. Observed and predicted time courses of 1sotope incorporation into threonine, valine + arginine, 1soleucine + leucine, 1ysine, phenyalanine, and proline in protein of high light (176 $\mu \mathrm{E}$. $\left.\mathrm{m}^{-2} \cdot \mathrm{s}^{-1}\right) \mathrm{NH}_{4}^{+}$-1imited steady state cultures of Chattonella luteus $\left(\mu / \mu_{\max }=0.921\right)$. Flow was stopped at zero time. Solid line represents the predicted rate. 

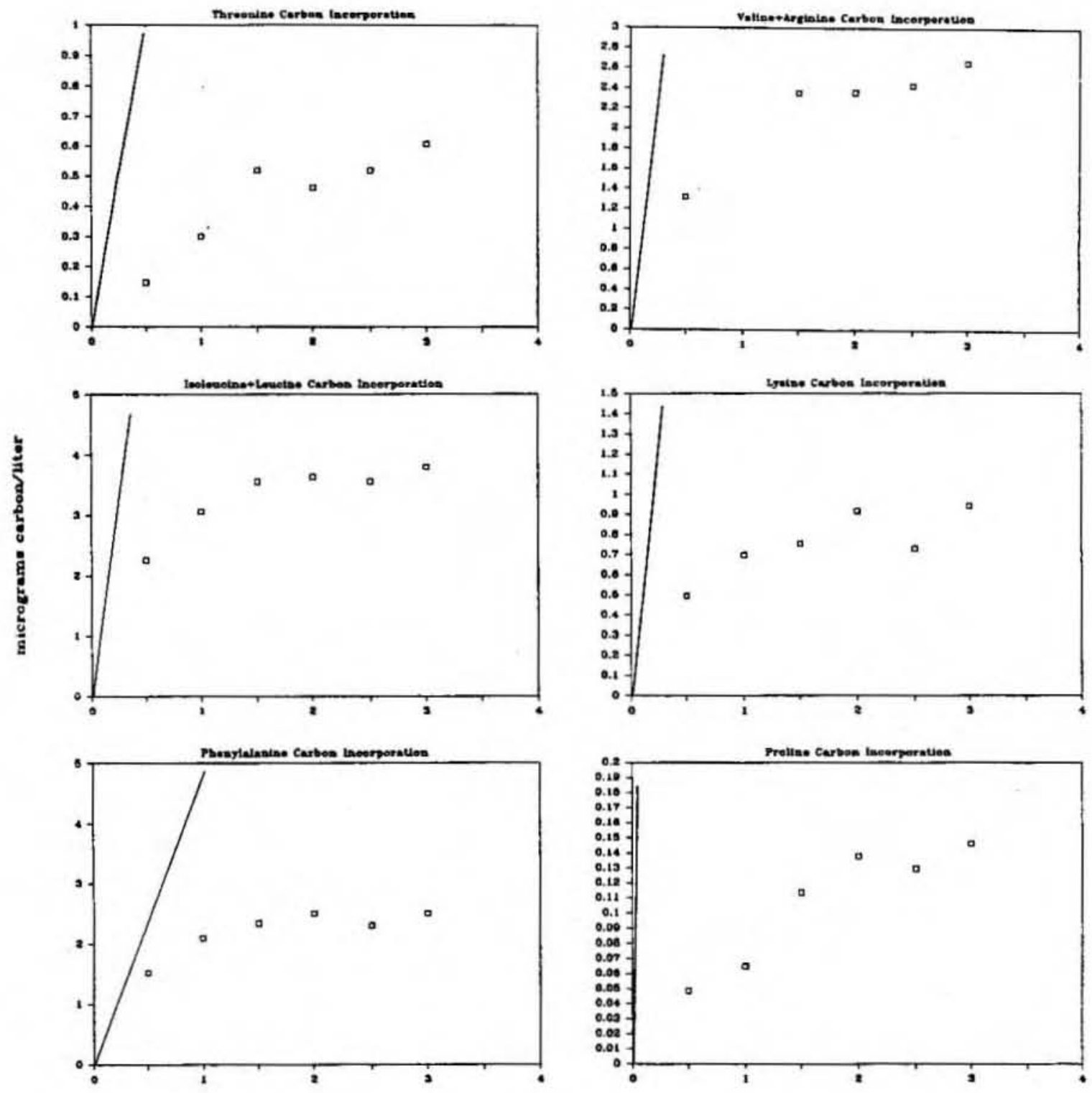

Time (bours) 
with algal protein metabolism are similar among different taxonomic groups. Alanine and g1ycine again show good agreement between observed and predicted carbon incorporation rates (Fig. 4-28 and Fig. 4-32). The observed isotope incorporation into glycine did slightly exceed the predicted rate, similar to the situation observed for low light cultures of Nannochloris sp. Th1s was also the case for serine, whose synthesis is closely linked to that of glycine by way of the photorespiratory cycle. However, regression analysis did not reveal differences outside the limits of analytical error (F1g. 4-28).

The observed incorporation rate into protein glutamate continuously Increased during the incubation (Fig. 4-32). This pattern resembled that seen for Nannochloris sp. and $\underline{C}$. Iuteus, and could be explained by the presence of a relatively large slowly saturating precursor pool. Aspartate incorporation was variable, but tended to be less than the predicted rate (FIg. 4-32).

Incorporation into other amino acids also substantially underestimated the predicted rate, as was seen for $\underline{\mathrm{C}}$. $\underline{\text { luteus }}$ (F1g. 4-30). Threonine observed incorporation was substantially below the predicted value but tended to increase (Fig. 4-33). Time courses of incorporation into valine + arginine, isoleucine + leucine, lysine, and phenylalanine resembled the patterns observed for $\underline{\mathrm{C}}$. 1uteus in that they displayed an initial rapid rate of incorporation of labelling followed by a lower relatively steady rate. However, unlike C. 1uteus, incorporation rates of phenylalanine and isoleucine + leucine did not approach zero (c.f. Figs, 4-31 and 4-33). Both appear to display an initial rapid rate of incorporation of label followed by a lower relatively steady rate. It Is unlikely that these represent linear rates of incorporation, since the 
resulting intercept would be far in excess of the blank. This nonlinear decrease in carbon incorporation again suggests a decreased flux of photosynthetically derived carbon into the carbon skeletons of these amino acids. The observed incorporation into proline reflected the labelling characteristics of glutamate, the precursor to proline.

\section{Chaetoceros simplex}

C. simplex was particularly sensitive to the interruption of steady state. All observed rates underestimated the predicted incorporation rates (Figs. 4-28 and 4-34), even in the case of glycine and alanine where predicted rates were underestimated by more than a factor of 2 . Underestimates were even more dramatic for threonine, isoleucine + leucine, phenylalanine, lysine, and proline (Figs, 4-32 and 4-35). For glycine, alanine, phenyalanine, threonine, and isoleucine + leucine the observed incorporation continuously decreased from an intitially higher rate. In the case of glycine and alanine, this initial rate was close to the predicted rate. Non-linear decreases were less evident for glutamate, proline, and aspartate, despite the fact that observed incorporation rates were less than predicted rates. This was 1ikely due to a compensating effect of the saturation of precursor pools, which would counter the depletion induced decrease.

Protein metabolism of $\underline{\mathrm{C}}$. simplex appears to be extremely sensitive to the 1nterruption of steady state. This was not a generalized metabolic response since non-steady state decreases were not observed in total ${ }^{14} \mathrm{C}$ uptake rate (c.f. Goldman et al., 1981b). This illustrates how considerably more information about population metabolism can be obtained through the tracing of specific biosynthetic processes. It appears that 
Figure 4-32. Observed and predicted time courses of 1sotope incorporation into g1ycine, alanine, glutamate and aspartate in protein of high 11ght $\left(176 \mu \mathrm{E} \cdot \mathrm{m}^{-2} \cdot \mathrm{s}^{-1}\right) \mathrm{NH}_{4}^{+}-1$ imited steady state cultures of Chroomonas salina $\left(\mu / \mu_{\max }=0.804\right)$. Flow was stopped at zero time. Solld line represents the predicted rate. 

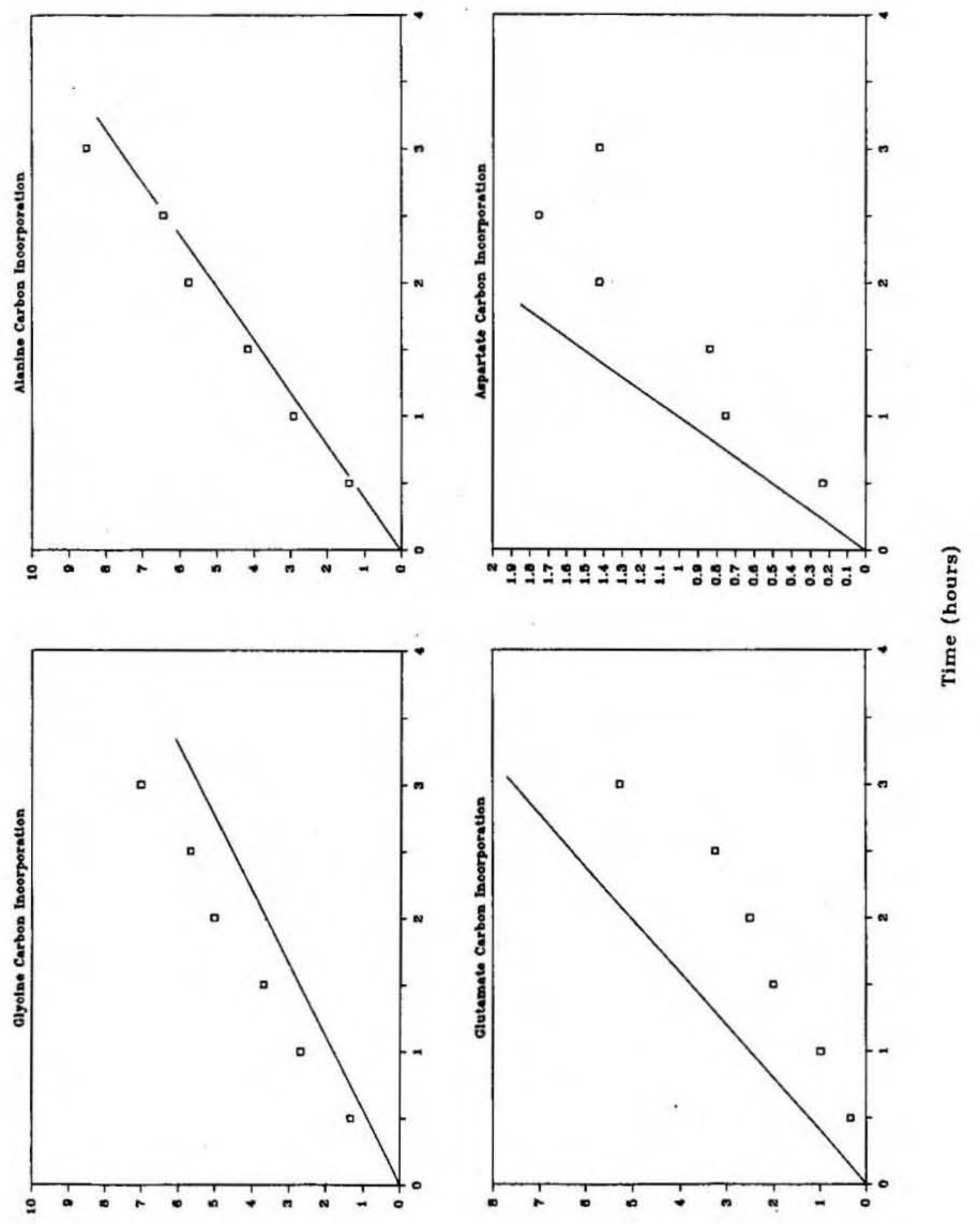

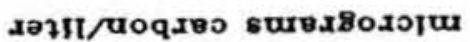


Figure 4-33. Observed and predicted time courses of isotope incorporation into threonine, valine + arginine, isoleucine + leucine, lysine, phenyalanine, and proline in protein of high light (176 $\mu \mathrm{E} \cdot$ $\left.\mathrm{m}^{-2} \cdot \mathrm{s}^{-1}\right) \mathrm{NH}_{4}^{+}-11 \mathrm{mited}$ steady state cultures of Chroomonas salina $\left(\mu / \mu_{\max }=0.804\right)$. Flow was stopped at zero time. Solld IIne represents the predicted rate. 

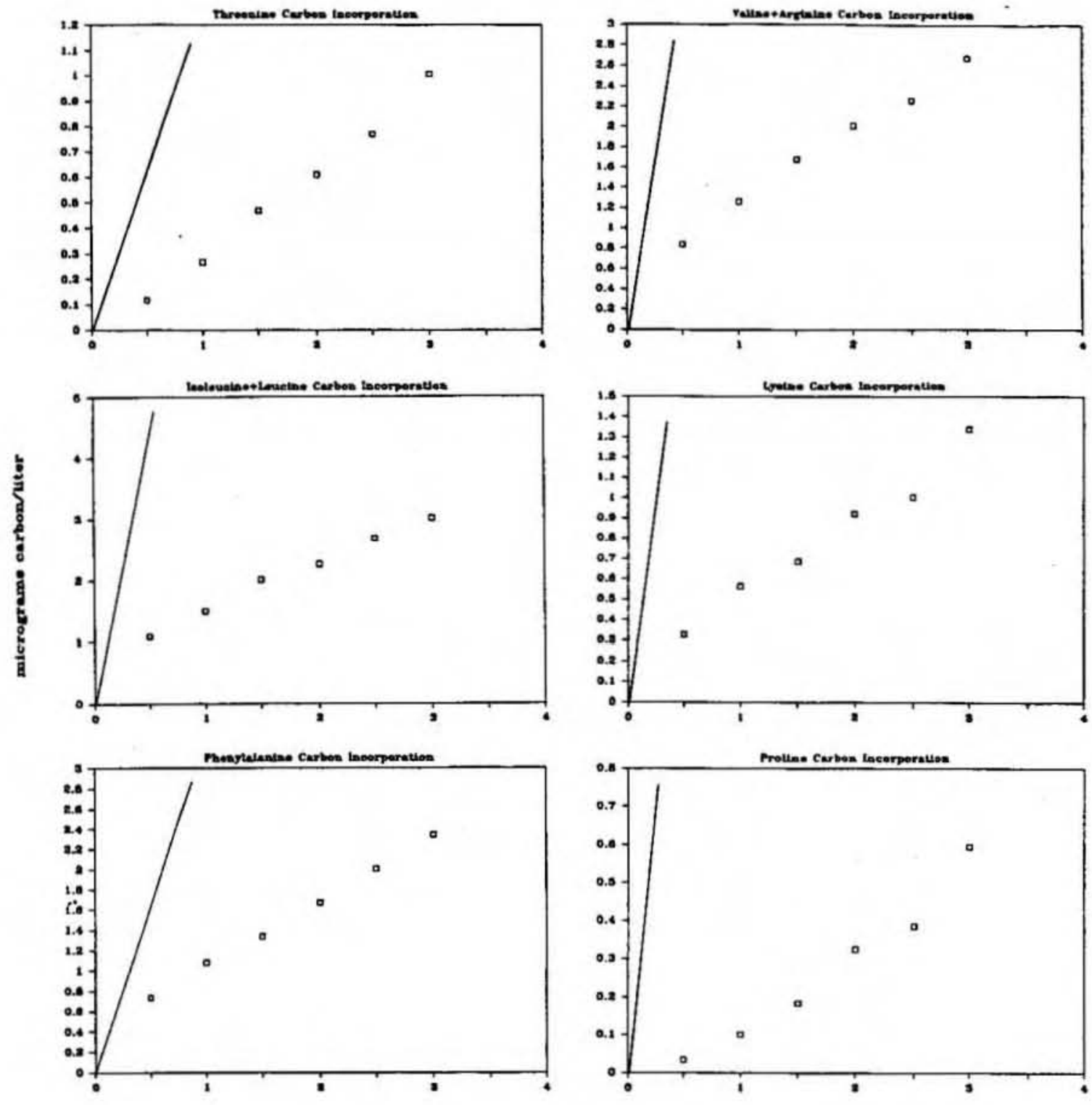

Time (hours) 
Figure 4-34. Observed and predicted time courses of 1sotope incorporation into glycine, alanine, glutamate and aspartate in protein of high 11ght $\left(176 \mu \mathrm{E} \cdot \mathrm{m}^{-2} \cdot \mathrm{s}^{-1}\right) \mathrm{NH}_{4}^{+}-1$ imited steady state cultures of Chaetoceros simplex $\left(\mu / \mu_{\max }=0.574\right)$. Flow was stopped at zero time. Solld line represents the predicted rate. 

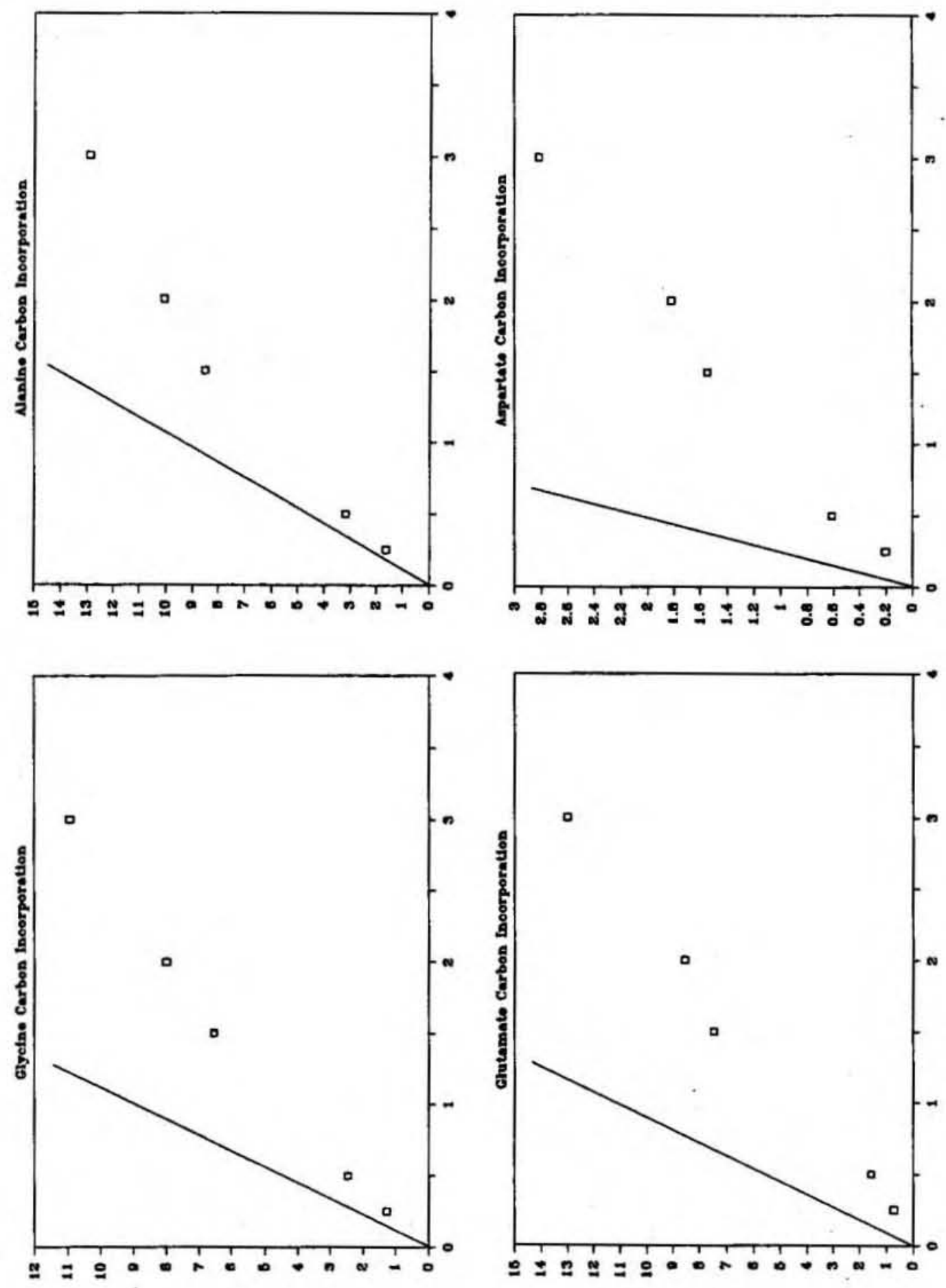

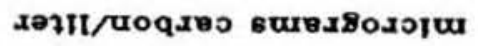


F1gure 4-35. Observed and predicted time courses of isotope Incorporation into threonine, valine + arginine, isoleucine + leucine, lysine, phenyalanine, and proline in protein of high 11ght (176 $\mu \mathrm{E}$. $\left.\mathrm{m}^{-2} \cdot \mathrm{s}^{-1}\right) \mathrm{NH}_{4}^{+}-11 \mathrm{mited}$ steady state cultures of Chaetoceros simplex $\left(\mu / \mu_{\max }=0.574\right)$. Flow was stopped at zero time. Solid line represents the predicted rate. 

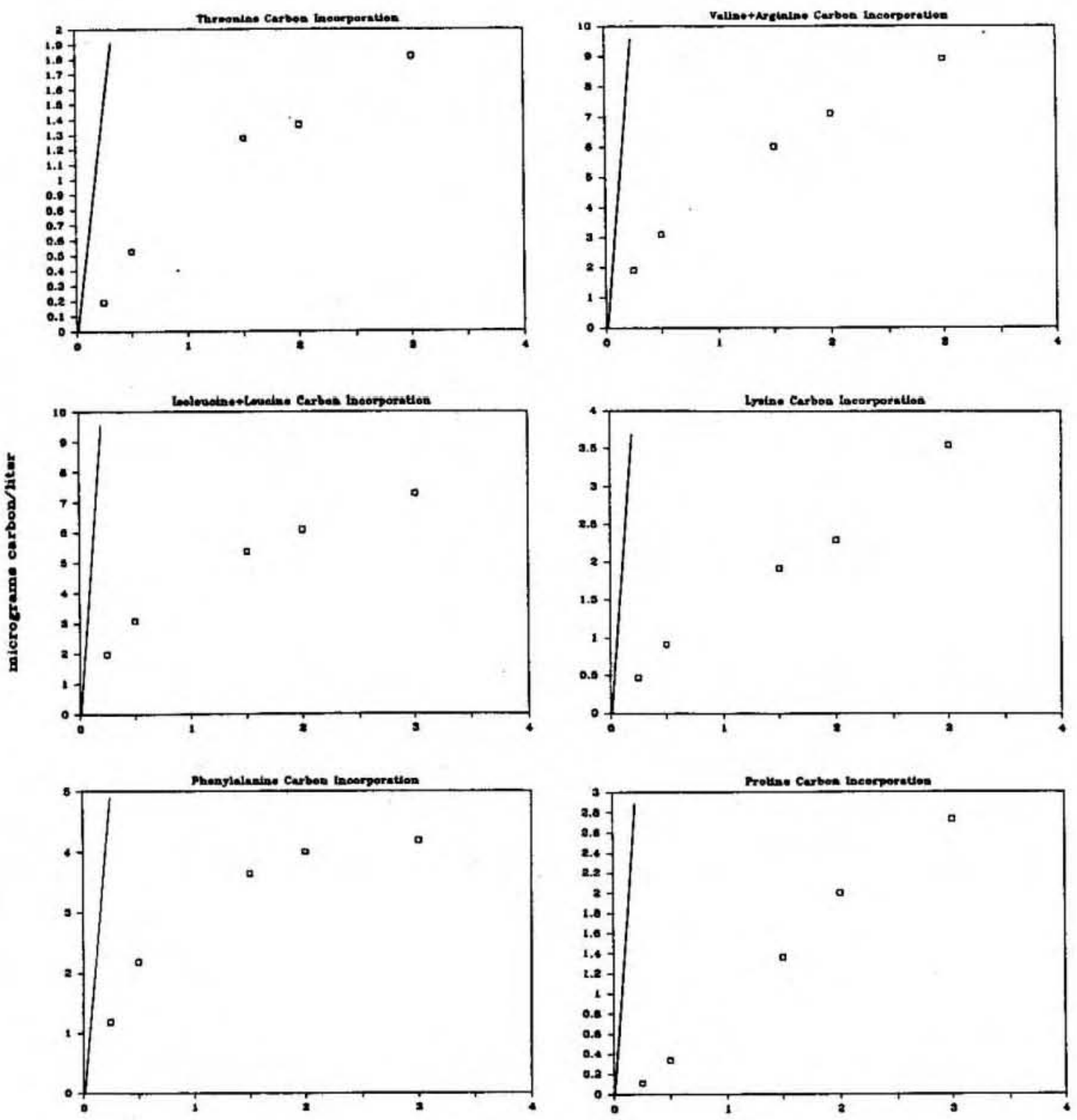

Time (hourn) 


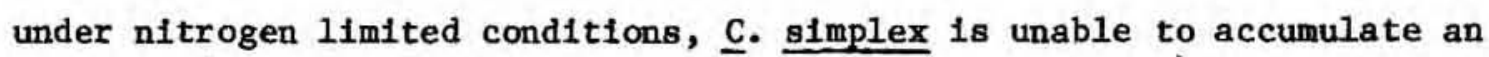
Internal supply of nitrogen sufficient to maintain growth for an extended period. C. simplex had the highest growth rate of all the species examined in this study. It may be that this higher rate of metabolism led to a more rapid manifestation of non-steady state responses.

\section{CONCLUSIONS}

This investigation has contributed to existing information about two potentially important sources of variation in the protein content of primary organic matter being introduced into the marine environment. These include 1) environmental cond1tions affecting metabolism within a single organism, and 2) intrinsic metabolic differences among species. The results demonstrate that environmentally induced variations within a single species may encompass the range of differences between species growing under similar conditions. For the species examined in this study grown under similar conditions, proteln is a relatively constant proportion of total carbon. This is consistent with the original conclusions of Parsons et a1. (1961), who surveyed the chemical composition of a variety of marine algae and found them to be quite similar. As Morris (1981) noted, it appears that environmental factors are more important than variations in species composition in influencing the relative abundance of protein in the primary organic matter. This conclusion is supported by the varlety of studies which have 1llustrated the substantial varlations in algal protein relative to other cell material in response to changing growth conditions (e.g. Cook, 1963; Handa, 1969; Myklestad and Haug, 1972; Darley et al., 1976; Rhee, 1978; Hitchcock, 1980; Dortch, 1982). 
The main objective of this investigation was to evaluate the characteristics of isotopic incorporation into protein in order to optimize methods for quantifying the production of particulate protein amino acids by autotrophs. The variations in composition referred to above reflect variations in the metabolism. Such metabolic changes also influence the isotope kinetics, and must be recognized as potentlally important factors affecting relationship of isotope incorporation into protein and net protein synthesis. The environmental condition which had the most dramatic effect on the 1sotope kinetics in Nannochloris sp. was light intensity. Precursors saturated much more rapldly under low light conditions, and as demonstrated in Table 4-9, the low synthesis rates associated with low 1 ight intensity and low relative growth rate make the impact of protein degradation on total isotope incorporation significant. Consequently, attempts to estimate protein synthesis using isotope Incorporation under dark or low 11ght and low nutrient conditions, must recognize that some of the observed isotope incorporation may be the result of turnover, rather than net protein synthesis.

In addition to the characteristics of precursor saturation, the effects of nutrient depletion must be recognized, and incorporation must be evaluated in a time course in order to know the appropriate time scales over which to determine protein synthesis rates (Goldman et al., 1981). Results with high 11ght $\mathrm{NH}_{4}^{+}-1$ imited cultures of Nannochloris sp. Indicated that nutrient depletion effects were a function of the nutrient prehistory, being more substantial in more nutrient limited cultures. This may reflect the presence of variable internal pools of nitrogen which can be ut1lized after the exogenous nitrogen supply is 
interrupted. Such pools may be present in higher levels in the less nutrient 11mited cultures. This is certainly true for the intracellular free amino ac1ds (chapter 3, Table 3-1). However, t1me dependent reductions in the IFAA pools were not found to be assoclated with the observed decrease of carbon incorporation into protein (Table 4-10). I did not measure the intracellular $\mathrm{NH}_{4}^{+}$pool. It may be that this pool was more important in regulating the flux of photosynthetic carbon into protein amino acids. Th1s would be consistent with the observations of regulatory effects of $\mathrm{NH}_{4}^{+}$on photosynthetic enzymes in a higher plant (Mohamed and Gnaman, 1979). The potential impact of nutrient depletion may be substantial, and yet not necessarily reflected in an obviously nonlinear pattern of incorporation into total PPAA carbon due to the mixed kinetics of the different individual amino acids. Efforts have been made to measure protein synthesis based on ${ }^{14} \mathrm{C}$ incorporation in nitrogen 1imited populations (DiTullio and Laws, 1983; Laws et al., 1985). Of course, the environment of a chemostat is very different from a natural system which contains more than just phytoplankton. However, it is important to recognize that long incubation periods without detalled time course descriptions of carbon incorporation may yield rates which underestimate the actual proteln synthesis rate.

The other species also showed evidence for nutrient depletion effects. In the case of $\underline{\text {. }}$ simplex, there was marked nonlinearity in Incorporation patterns even in the amino acids which were least sensitive to this effect (1.e. glycine and alanine). The comparisons between the different species did illustrate, however, fundamental similarities in the basic pathways associated with the supply of photosynthetically fixed carbon to protein production. Precursors to glycine and alanine 
Table 4-10. Intracellular Free Amino Acid

Carbon Concentrations in $\mathrm{High} \mathrm{Light}^{\mathrm{a}}$

NHt-IImited Steady State Cultures of Nannochloris sp.

\begin{tabular}{lcc}
\hline $\begin{array}{c}\text { Incubation Time } \\
\text { (hrs) }\end{array}$ & $\begin{array}{c}\text { Relative Growth } \\
\text { Rate }\end{array}$ & $\begin{array}{c}\text { IFAA Micrograms } \\
\text { Carbon per Liter }\end{array}$ \\
\hline 0.005 & 0.229 & 116 \\
0.07 & & 120 \\
0.25 & & 138 \\
1.1 & & 150 \\
2.1 & & 100 \\
2.9 & 0.933 & 127 \\
0.1 & & 450 \\
0.25 & & 455 \\
1.0 & & 450 \\
1.0 & & 611 \\
3.0 & & 355 \\
\hline
\end{tabular}

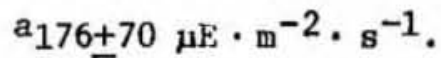

$\mathrm{b}_{\text {Growth }}$ rate normalized to maximum growth rate $\left(1.44(0.04)\right.$ day $^{-1}$ ) under similar conditions of $11 \mathrm{ght}$ and temperature. 
consistently saturated rapidly, so that agreement between predicted and observed carbon incorporation was good. Although the observed Incorporation into protein glycine and alanine tended to be less than the predicted rate in $\underline{\text {. }}$ simplex, the Initial incorporation rates did approximate the predicted rates before the onset of depletion effects.

The characteristics of protein glycine and alanine carbon 1ncorporation make them ideal model proteln amino acids for tracing protein synthesis in mixed autotrophic populations. Their relative abundance in protein was found to be highly consistent, irrespective of growth conditions or specles (Table 4-11). The proportions I found were similar to those found by other investigators (Table 4-12). My estimates did tend to exceed the relative abundances determined by sequencing protein. This is likely a consequence of the preferential recovery of glycine and alanine from hydrolysis leading to an apparent increase in their relative abundance (see Methods, Table 2-4; see also Roberts et al., 1963). Desplte the discrepancy, the studies do suggest that g1ycine and alanine are a highly consistent proportion of protein from a wide range of organisms. An optimal approach towards estimating protein synthesis will be to characterize the synthesis rates of glycine and alanine, and use their known average abundance in protein to determine the total protein synthesis rate. In Table 4-13, I extrapolated glycine and alanine incorporation rates to total protein carbon incorporation based on their relative abundance in average protein. These estimates are compared to observed and predicted carbon incorporation rates. Observed rates were consistently the lowest, a consequence of slow kinetics of labelling of other amino acids, and non-steady state decreases in protein synthesis. Predicted rates were below the 
Table 4-11. Relative Abundance of Glycine and Alanine in Protein of Different Algal Sources

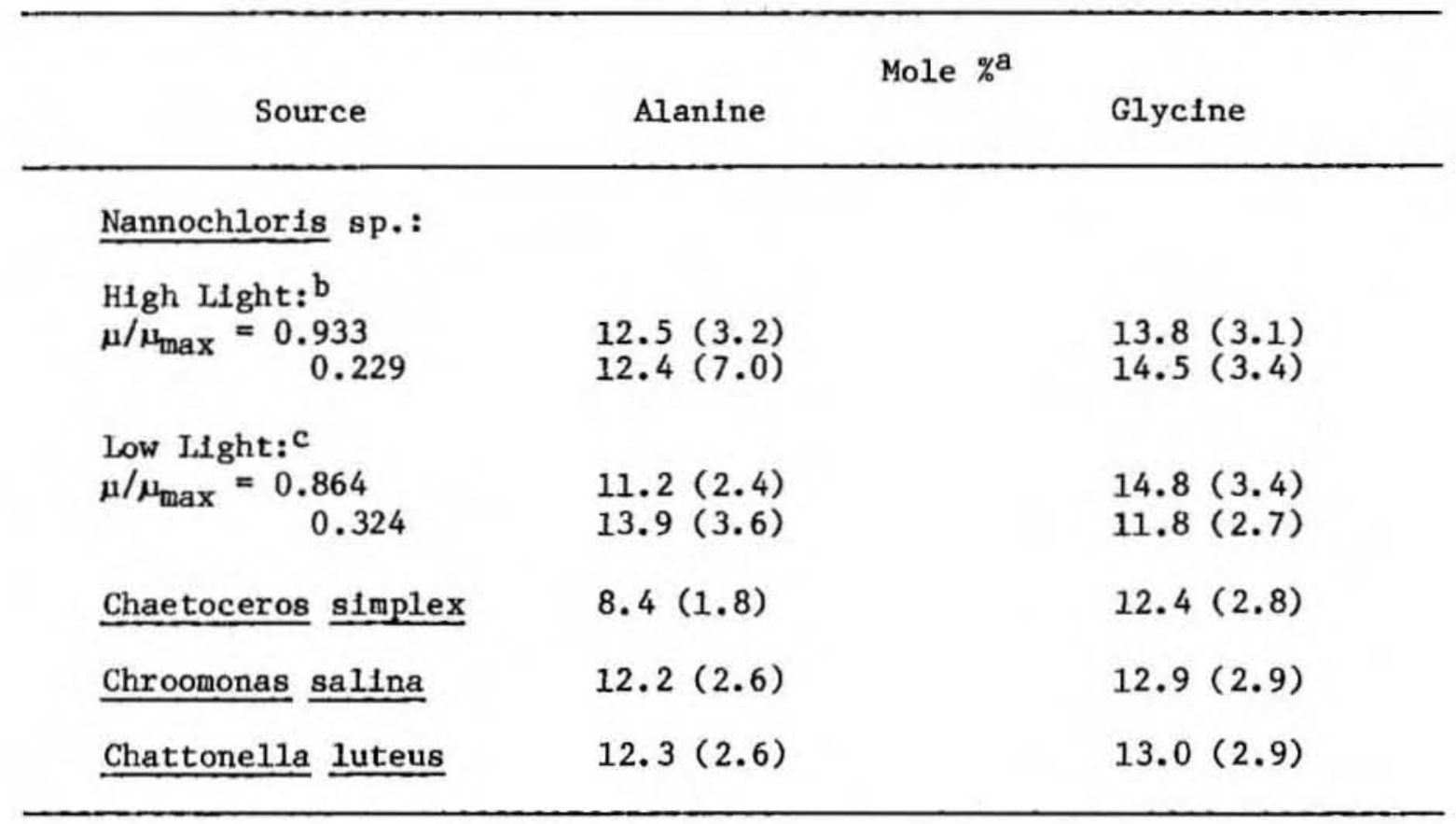

arrors (In parentheses) represent propagated estimates of analytical error based on $95 \%$ confidence intervals.

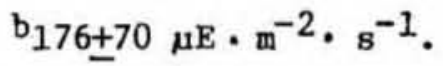

$\mathrm{c}_{28+9} \mu \mathrm{E} \cdot \mathrm{m}^{-2} \cdot-1$. 
Table 4-12. Relative Abundance of Glycine and Alanine in Protein

\begin{tabular}{|c|c|c|}
\hline Source & Alanine & Glycine \\
\hline \multicolumn{3}{|l|}{ SEQUENCED PROTEIN: } \\
\hline Jukes et al. (1975) & 8.7 & 7.9 \\
\hline $\begin{array}{c}\text { Doolittle (1981): } \\
\text { Newat } \\
\text { Atlas }\end{array}$ & $\begin{array}{l}7.6 \\
8.2\end{array}$ & $\begin{array}{l}7.9 \\
8.8\end{array}$ \\
\hline \multicolumn{3}{|l|}{ ACID HYDROLYSIS: } \\
\hline $\begin{array}{l}\text { Fowden (1954) } \\
\text { Chlorella vulgar1a } \\
\frac{\text { Anabaena }}{\text { Ayllndrica }} \\
\text { Navicula } \\
\text { Tribonema aequale }\end{array}$ & $\begin{array}{l}9.5 \\
7.0 \\
7.6 \\
10.4\end{array}$ & $\begin{array}{l}7.6 \\
6.5 \\
7.1 \\
7.6\end{array}$ \\
\hline $\begin{array}{l}\text { Cowey and Corner (1963) } \\
\text { Skeletonema } \\
\text { suspended particulate }\end{array}$ & $\begin{array}{l}9.2 \\
8.4(6.7-11.4)\end{array}$ & $\begin{array}{l}11.6 \\
16.6(12.5-21.7)\end{array}$ \\
\hline $\begin{array}{l}\text { Degens (1970) } \\
\text { Sargasso Sea (surface) } \\
\text { Buzzards Bay }\end{array}$ & $\begin{array}{l}5.8-6.5 \\
8.8\end{array}$ & $\begin{array}{l}7.8-10.0 \\
12.1\end{array}$ \\
\hline $\begin{array}{l}\text { S1ezen and Mague (1978) } \\
\text { (suspended partlculate) }\end{array}$ & 10.0 & 13.4 \\
\hline $\begin{array}{l}\text { Malta and Yanada (1978) } \\
\text { (suspended partlculate) }\end{array}$ & 9.0 & 15.4 \\
\hline
\end{tabular}


Table 4-13. Comparison of Observed, Predicted and Extrapolated Protein Carbon Incorporation Rates

\begin{tabular}{|c|c|c|c|c|c|}
\hline \multirow{3}{*}{$\begin{array}{l}\text { Relative } \\
\text { Growth Rate }\end{array}$} & \multicolumn{5}{|c|}{$\frac{\text { Proteln Carbon Incorporation Rates }}{\text { (mIcrograms }}$} \\
\hline & & & Extrapola & ted & \\
\hline & Observed & Predicted & Gly & Ala & $\begin{array}{l}\text { Combined } \\
\text { Mean }\end{array}$ \\
\hline 0.933 & $85(34)$ & 111 (12) & $203(44)$ & $148(30)$ & 165 (24) \\
\hline 0.229 & $18(11)$ & $37(5)$ & $72(18)$ & $56(15)$ & $62(11)$ \\
\hline
\end{tabular}

aErrors (in parentheses) represent propagated estimates of analytical error based on $95 \%$ confidence intervals.

b Growth rate normalized to maximum growth tate $\left(1.44(0.04)\right.$ day $\left.^{-1}\right)$ under similar conditions of 1 ight and temperature. 
extrapolated rates. This: is expected since the predicted rate is based on the protein carbon which is recovered from hydrolysis. Some of the amino acids are destroyed, while alanine and glycine are preferentially recovered.

Because glycine and alanine are preferentially recovered, and generally show good agreement between predicted and observed Incorporation rates, they are ideal model protein amino acids for tracing the primary production of particulate protein. In the next chapter, I describe a study where this approach was used to estimate the proportion of primary production associated with protein production in a natural phytoplankton community and compare this to the protein content of particulate organic matter. 
CHAPTER 5. PRIMARY PRODUCTION OF PARTICULATE ORGANIC CARBON AND PARTICULATE PROTEIN AMINO ACIDS IN SALT POND, MA:

THE RELATIONSHIP TO THE COMPOSITION OF

PARTICULATE ORGANIC MATTER 
$-362-$ 


\section{INTRODUCTION}

Particulate organic matter (POM) in euphotic systems is a complex matrix of chemical substances which originate largely as a result of biological activity. Photoautotrophs account for the bulk of POM production in euphotic systems of the world's oceans. The production and metabolism of blogenic compounds by photoautotrophs w111 depend on environmentally induced and intrinsic metabolic characteristics of the species making up the phytoplankton population (e.g Morr1s, 1981). However, the relationship of the chemical composition of POM to the biochemical composition of living algal biomass may be obscured by the presence and activities of other organisms and detritus (e.g. Ze1tzchel, 1970; Banse, 1974, 1977; Beers et al., 1975; Eppley et al., 1977; Barlow, 1982a). Hence, the abundance and composition of POM cannot be exclusively attributed to the activities of primary producers.

The composition of POM is a function of the rates of production of Individual organic components, and their rates of removal from POM (F1gure 5-1). The inputs of POM to euphot1c systems consist of gross primary production by photoautotrophs, chemosynthetic production, secondary production at the expense of dissolved organic matter, and allocthonous sources such as aeollan transport, resuspension, groundwater intrusion, runoff and advection and diffusion from other water masses. Processes wh1ch remove POM Include autotrophic and heterotrophic respiration, autolysis, excretion and exudation, macroheterotrophic grazing and assimilation, sedimentation, and advection and diffusion. The unique chemical characteristics of individual biogenic molecules make them differentially susceptible to heterotrophic degradation and transformation (e.g. Wakeham et al., 1980; Lee et al., 1983; Gagosian et 
F1gure 5-1. Processes involved in production and removal of organic matter in aquatic environments. 


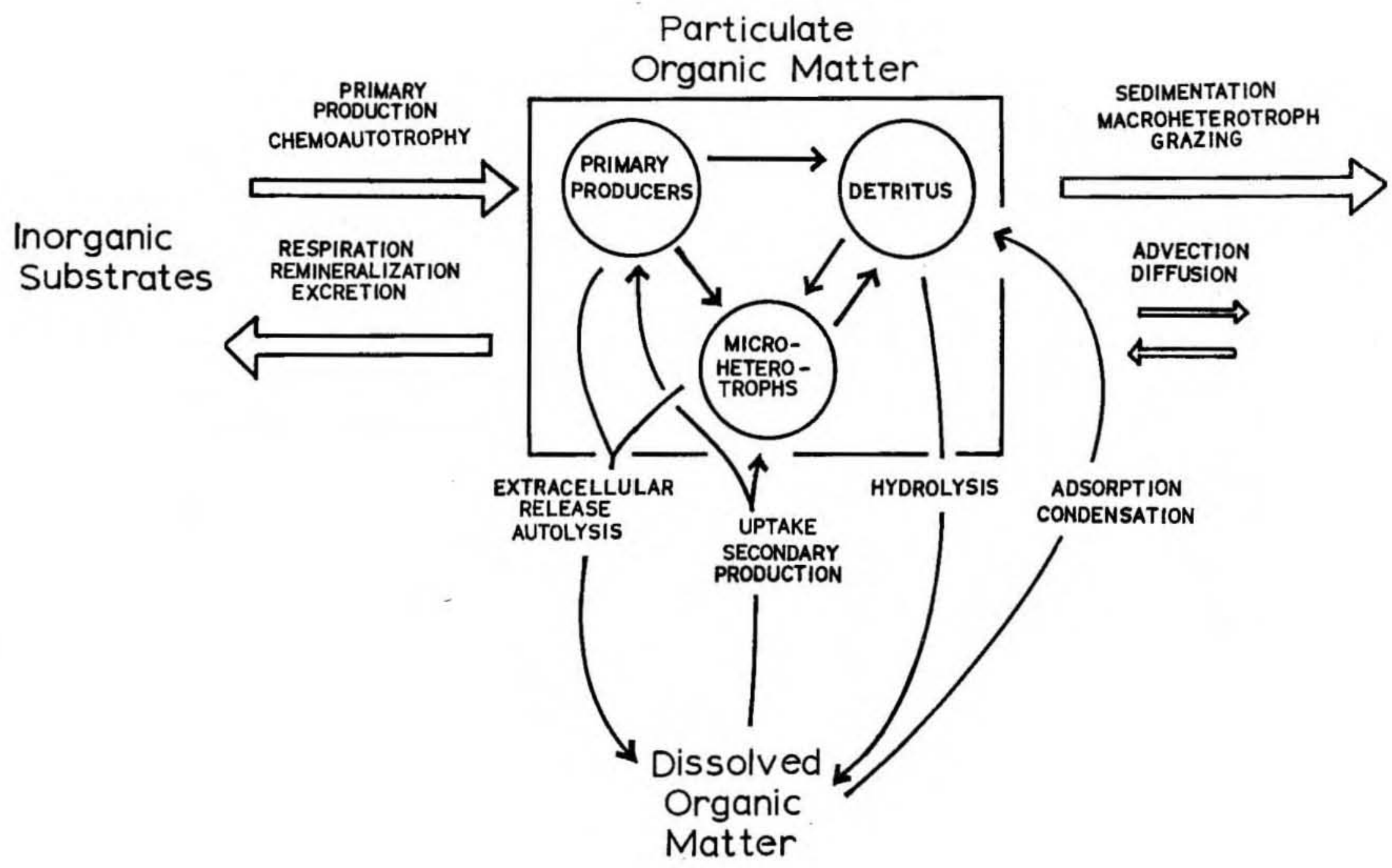


al., 1982; Karl, 1982). As a result, chemically distinct types of particulate organlc matter will, under some circumstances, have different turnover rates in euphotic systems. Precise descriptions of the dynamic relationship between distinct components making up POM will provide insight as to the kinds of processes which control POM composition and concentration, as well as the characteristics of organisms which mediate these processes (e.g. Lee and Cronin, 1984). Information about time dependent concentration changes is not by 1tself adequate to describe the dynamics of individual materials, since it reveals nothing about the actual rate of flux in a system where there are inputs as well as outputs throughout the water column. Through assessment of differential changes In the production and concentrations of individual biogenic materials, it is possible to distinguish the impact of primary production from the effects of secondary transformations on organic matter composition and concentration.

Previous investigations have compared the relationship of carbon and nitrogen assimilation by natural phytoplankton populations to the relative abundance of particulate organic carbon and particulate organic nitrogen (e.g. Eppley et al., 1977; Slawyk et al., 1978; Eppley et al., 1979; Sharp et al., 1980; Harrison et al., 1983). Although positively correlated, C:N assimilation ratios were generally quantitatively different from the particulate ratios. Both larger and smaller assimilation ratios were observed, and the range was much larger than for particulate ratios. Some of the discrepancies may be attributable to the fact that carbon and nitrogen uptake may be uncoupled, and consequently not reflect the algal elemental composition (Collos and Slawyk, 1979; Goldman et al., 1981a). 
Because of the nutritional 1mportance of particulate protein, factors which control its relative abundance in particulate organic matter ultimately influence the flux of organic matter to higher trophic levels. In Chapter 4, I described the optimal approach to estimating the production of particulate amino acids on the basis of radiolsotopic carbon incorporation. The ability to measure both concentrations and primary production of particulate protein amino acids (PPAA) in conjunction with particulate organic carbon (POC) make it possible to determine whether the relative abundance of POC and PPAA reflects the metabolism of the active autotrophic population.

To date, there has not been an invest1gation which has independently estimated primary production of POC and PPAA, and compared these measurements to the relative abundance of POC and PPAA in the particulate organic matter. A major objective of th1s study was to estimate rates of POC and PPAA primary production in natural populations growing under various environmental conditions. This provided an indication of the proportion of photosynthetic metabolism associated with protein synthesis. The relative magnitude of these primary 1nputs was compared to the relative abundance of POC and PPAA in order to determine the extent to which POM composition reflects population metabolism (Figure 5-2).

The study was conducted in a small marine pond, Salt Pond ( $\mathrm{K} 1 \mathrm{~m}$ and Emery, 1971). The semi-enclosed nature of the pond increased the probability that processes occurring within the pond ecosystem were primarily responsible for POM composition and abundance. Under conditions where POM compostion did not reflect the blosynthetic activities of the photoautotrophic population, I sought to determine 
Figure 5-2 . Simplifled diagram 1llustrating the influence of primary inputs and net removal of organic matter on particulate organic matter composition. 


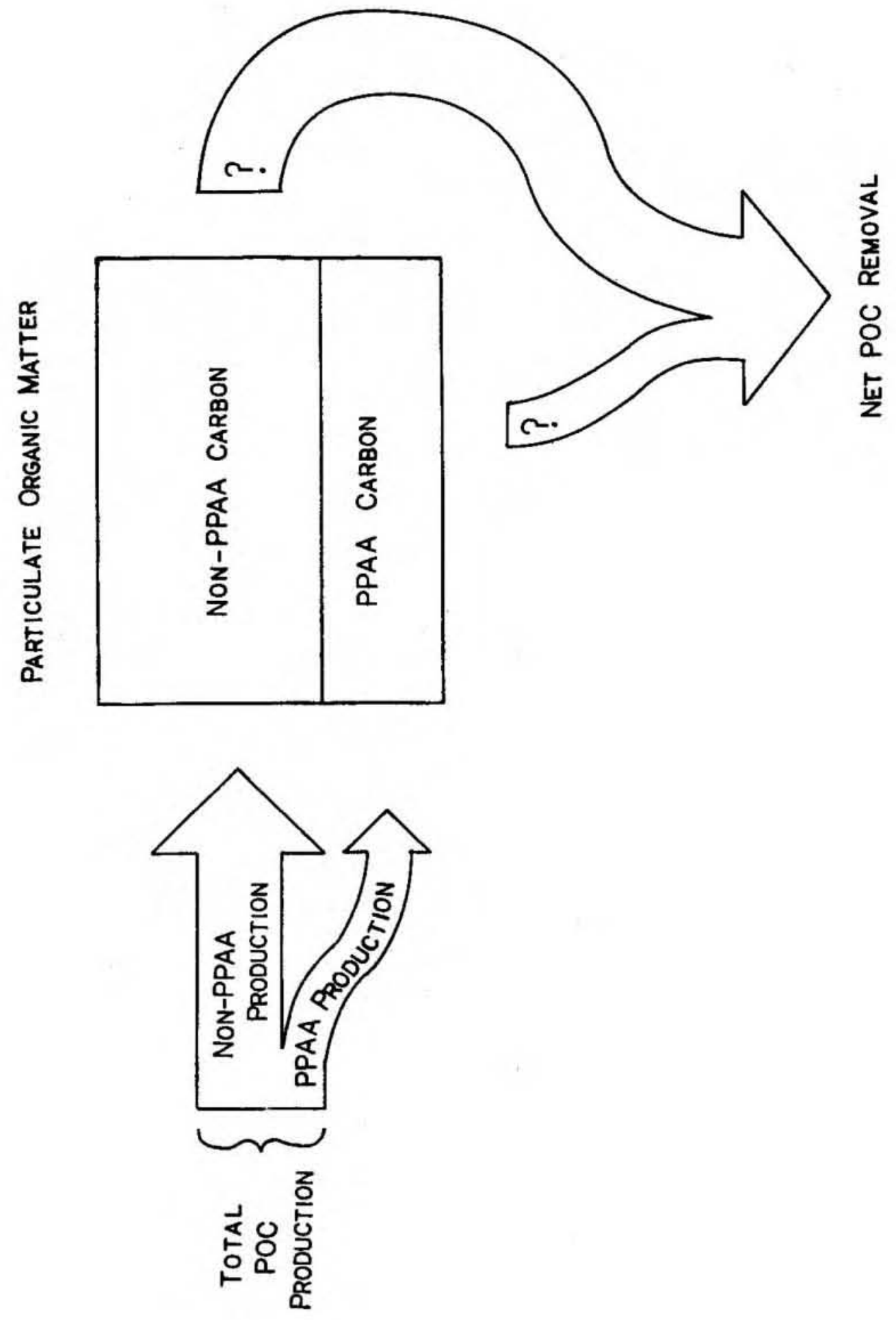


whether such discrepancies were the result of differential changes in rates at which POC and PPAA are introduced by primary production, or a consequence of differential removal of POC and PPAA by secondary transformational processes. Net rates of removal of POC and PPAA from the mixed layer were estimated by quantifying differences between estimated production and observed changes in concentration.

RESULTS AND DISCUSSION

Compositional Dynamics of Particulate Organic Matter in a Well Mired Euphotic System

The following assumptions regarding Salt Pond are 1mplicit in subsequent discussion of fleld observations:

1) Salt Pond has a shallow well mixed euphotic layer, so that POM is generally homogeneously distributed throughout a mixed euphotic layer. This assumption states that POM composition at one meter, where sampling took place, reflects compiosition throughout the mixed layer. This assumption is supported by several observations. On the days where Incubations were conducte:d, chlorophyll a concentrations were uniform throughout the upper $1.0-1.5$ meters (Figure 5-3). The mixed layer depth extended to between 1.0 and 3.0 meters, as indicated by a distinct pyncnocline in this depth range (F1gure 5-4). Langmuir circulation is commonly observed in Salt Pond as evidenced by distinct slicks (convergence zones) Interspersed between turbulent areas (divergence zones). Dispersion of dye added at the surface was rapid during such a perlod. 
2) Non-in situ inputs of particulate organic carbon (POC) (e.g. mixing from other water masses (Vineyard Sound), run-off and ground water intrusion, bottom resuspension, and atmospheric sources) are negligible for the upper mlxed layer of Salt Pond. This assumption states that the bulk of organic matter in the euphotic layer is produced by organisms residing there, and is supported by the semi-enclosed nature of Salt Pond. However, the potential for allochthonous inputs of organic matter must be recognized, particularly in view of the presence of a large bird population and the observed accumulation of eelgrass (Zostera mar1na) along the leeward shore.

Surface salinities in Salt Pond were of the order of 10 o/oo lower than Vineyard Sound, the adjoining water mass. This indicated substantial freshwater inputs, and the potentlal for exogenous inputs of DOC, which through utilization by microheterotrophs might ultimately influence POM composition. In order to assess the 1mportance of non-in situ inputs of DOC, concentrations of DOC were determined in ground water 1 meter below ground at a site adjacent to the pond where inputs were most 1ikely to be significant. These concentrations were compared to rain water and surface Salt Pond water in Table 5-1 along with corresponding dates of sampling. Although ground water and rain water concentrations were of the same order of magnitude, Salt Pond surface water had the highest concentration. If the transformation of exogenous DOC into POC was significant relative to total primary production, then a decrease in the surface water $D O C$ concentrations relative to exogenous sources would be expected. This was apparently not the case. 
F1gure 5-3. Depth profiles of chlorophyll a on days during which incubations were conducted in Salt Pond. Symbols: square, chlorophyll a; cross, total pigments (phaeop1gments + chlorophy11 a). A, 20 July 83; B, 5 Aug 83; C, 10 Aug 83; D 26 Aug 83; E, 1 Sept 83; F, 3 Oct 83. 


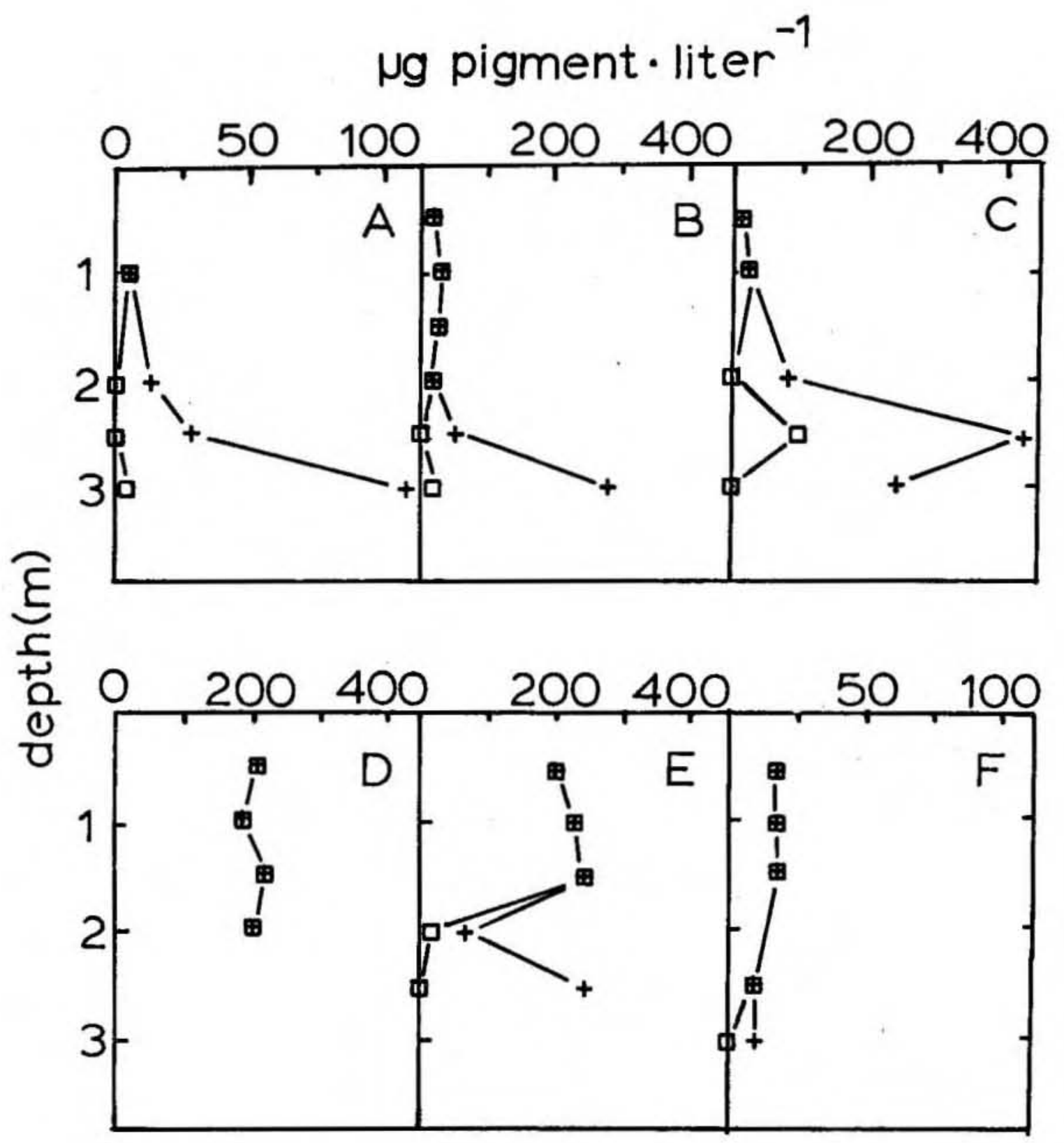


F1gure 5-4. Depth profiles of specific gravity during study period in Salt Pond. Sigma $=\left[\right.$ (density of seawater at $t^{\circ} \mathrm{C} /$ density of pure water at $\left.\left.4^{\circ} \mathrm{C}\right)-1\right] 1000$, after Cox et al. (1970). $19 \mathrm{July} 83$ and $26 \mathrm{July}$ 83 data were provided courtesy of Brian Howes and Stuart Wakeham. 


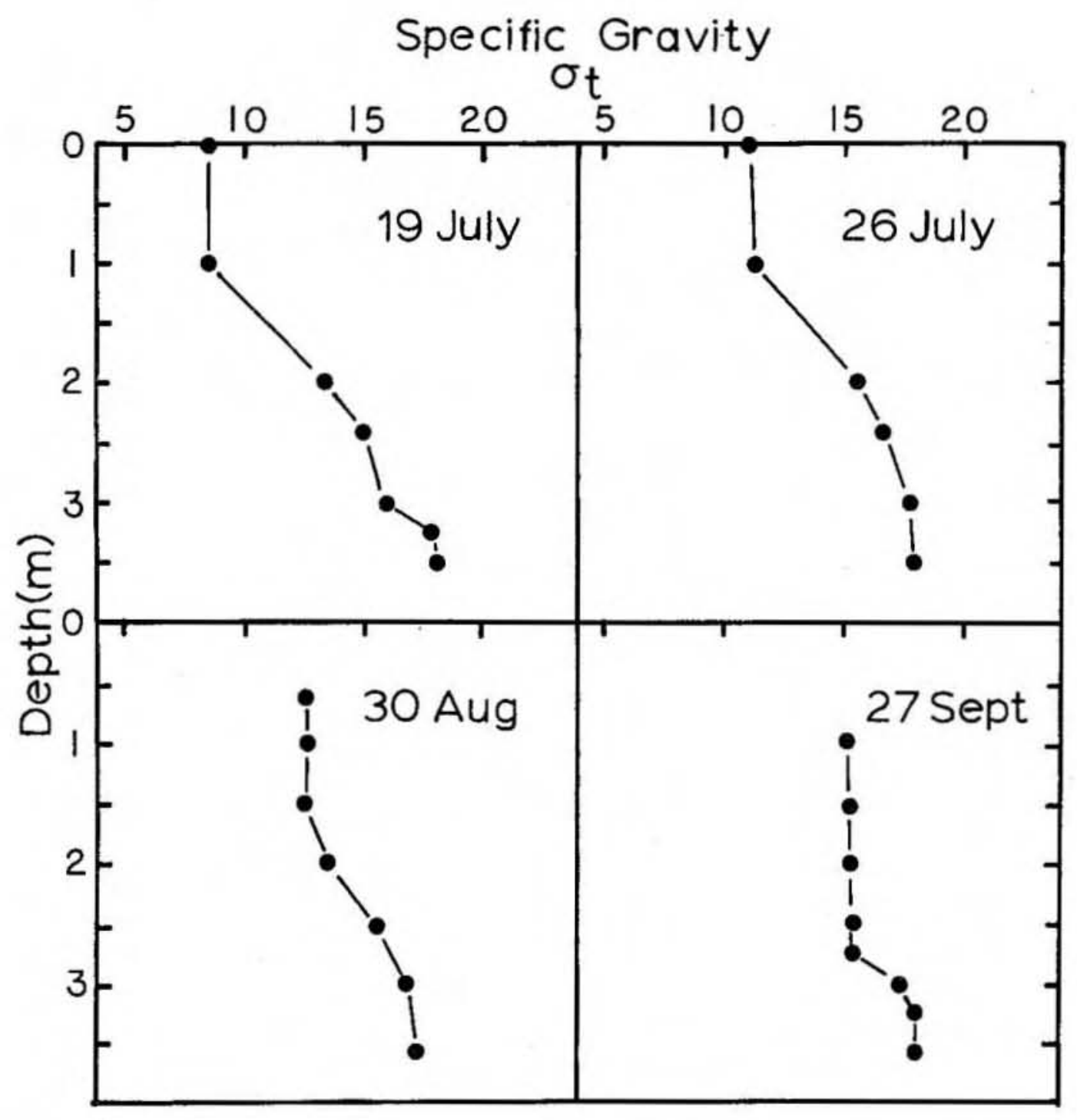


Table 5-1. Dissolved Organic Carbon Concentrations (DOC) From Ground Water, Rain Water, and Salt Pond Surface Water

\begin{tabular}{|c|c|c|c|c|}
\hline Date & $\begin{array}{l}\text { Source/ } \\
\text { Location }\end{array}$ & mean & $\begin{array}{c}\text { DOC } \\
\text { carbon/1fter) } \\
\text { standard } \\
\text { error }\end{array}$ & $\mathrm{n}$ \\
\hline 25 Sept 84 & Ground Water: $(1 \mathrm{~m})^{\mathrm{a}}$ & 3.52 & 0.05 & 2 \\
\hline 25 Sept 84 & Surface Runoff ${ }^{b}$ & 2.00 & - & - \\
\hline $\begin{array}{l}4 \text { Sept } 84 \\
12 \text { Sept } 84\end{array}$ & $\underset{\text { Rainwater }}{\text { Rat }}$ & $\begin{array}{l}1.70 \\
1.70\end{array}$ & $\overline{-}$ & $\overline{-}$ \\
\hline $\begin{array}{l}24 \text { Aug } 84 \\
27 \text { Aug } 84 \\
13 \text { Sept } 84 \\
20 \text { Sept } 84\end{array}$ & $\begin{array}{l}\text { Salt Pond } \\
\text { Surface (lm) } \\
" \\
" \\
"\end{array}$ & $\begin{array}{l}6.38 \\
5.30 \\
6.59 \\
5.17\end{array}$ & $\begin{array}{l}0.08 \\
0.05 \\
0.29 \\
0.08\end{array}$ & $\begin{array}{l}2 \\
2 \\
2 \\
2\end{array}$ \\
\hline
\end{tabular}

a Taken from site one meter below the ground adjacent to pond where ground water intrusion was $11 \mathrm{kely}$ to be significant.

b Taken from drainage ditch flowing into pond. 
3) Heterotrophic transformational processes differentially affect the chemically distinct constituents of POM over time, resulting in selective changes in composition. This assumption is amply supported by observations of depth dependent transformations in the composition of POM (Wakeham et al., 1980; Lee et al., 1983; Gagosian et al., 1982), selective assimilation of biochemical components in the food source (Scott, 1980), and release of fecal material depleted in nitrogen (Small et al., 1983). Processes such as advection and diffusion, sedimentation, and grazing by macroheterotrophs may or may not be selective with respect to chemical composition. The above ideas provide a basis for determining which processes are controlling POM flux in the mixed layer.

Given the above assumptions, it is possible to define a POM mass balance at the sampling site. The changes in the concentration $\mathrm{C}_{1}$ of a given component of POM at this point can be expressed as a difference between in situ rates of production and removal:

$$
\mathrm{dC}_{1} / \mathrm{dt}=\left(\mathrm{P}_{1}+\mathrm{P}_{2}+\mathrm{P}_{\mathrm{a} / \mathrm{d}}+\mathrm{P}_{\mathrm{c}}\right)-
$$

The term $\mathrm{dC}_{1} / \mathrm{dt}$ is the rate of change in concentration of a given component. The terms on the right hand side of the equation are grouped into production (P) terms and removal (R) terms. Production terms Include autotrophic or primary production $\left(\mathrm{P}_{1}\right)$, secondary production through microheterotrophy $\left(P_{2}\right)$, chemosynthetic production $\left(P_{c}\right)$, and allochthonous inputs through advection or diffusion ( $\mathrm{Pa} / \mathrm{d})$. Removal terms include losses due to respiratory degradation $\left(R_{r}\right)$, losses due to 
conversion to DOC ( $\left.\mathrm{R}_{\mathrm{DOC}}\right)$, losses by physical processes such as sedimentation $\left(R_{s}\right)$ or advective or diffusive losses $\left(R_{a / d}\right)$, and finally, macroheterotrophic grazing $\left(R_{g}\right)$. Microheterotrophs would be included in filtered samples, and were considered part of the POM.

In this study, measurements were made of POC and PPAA production and concentration. Thus $\mathrm{dC}_{1} / \mathrm{dt}$ and $\mathrm{P}_{1}$ are known for POC and PPAA. The other production and removal terms can be combined into a composite rate term, $\mathrm{R}_{\mathrm{N}}$, which represents the rate of net outward flux of POM from the sampling point. Thus:

$$
\mathrm{dC} / \mathrm{dt}=\mathrm{P}_{1}-\mathrm{R}_{\mathrm{N}}
$$

where:

$$
\begin{aligned}
R_{N}= & P_{1}-d C / d t \\
& =\left(R_{r}+R_{D O C}+R_{s}+R_{a / d}+R_{g}\right)-\left(P_{2}+P_{a / d}+P_{c}\right)
\end{aligned}
$$

This relationship will be used as a guideline for the discussion of results comparing concentrations and production characteristics of POC and PPAA.

\section{Incubation Procedures}

Production rates were determined using in situ incubation techniques (sampler incubation device, SID; Taylor et al., 1983) at the 1 meter depth. All estimates were derlved from relatively short term (2-4 hours) t1me course sampling methods. In situ incubations were conducted on six separate days throughout the two and one-half month sampling period (20 
July - 3 October 83). The use of In situ incubation methods was an essential aspect of this investigation since the main focus was to examine the relationship of fluxes of chemically distinct organic substances which may be differentially susceptible to sampling artifacts (e.g. Chapter 4). The fact that incubations were initiated and sampled 1n s1tu minimizes the potential problem that production characteristics might be a result of artifacts due to sampling methodology. An additional and fundamental consideration of any study examining the distribution of radiolsotoplc carbon among different organic substances 18 the degree to which this distribution is a function of the t1me of incubation, whether it be the result of isotopic kinetics within the photoautotrophs, or containment effects which would cause deviations from the actual in situ rates as a result of physlological changes. I have attempted to minimize the latter artifact by keeping incubations relatively short (2-3 hours) and conducting time course sampling so that the onset of containment effects would be signaled by characteristic deviations from linearity (Taylor et al., 1983; Goldman et al., 1981a; see also Chapter 4). Furthermore, assessments of PPAA production will 1nclude estimates based on 1sotope incorporation characteristics of proteln glycine and alanine, which have been shown to have rapid precursor saturation and relatively close agreement between theoretical and isotopically derived production rates for several algal species (Chapter 4).

A further consideration is the effect of transformation of labeled primary organic matter by microzooplankton grazers included in the Incubation vesse1 (e.g. Smith et a1., 1984). For the short incubation periods used in this study, this should not have a significant impact on 
Incorporation characteristics unless the grazing rate was considerably in excess of the algal growth rate. Under these conditions, a significant decrease in algal standing biomass would have lead to a non-linear decrease in carbon incorporation rates. For the majority of incubations conducted, short term uptake of $\mathrm{C}^{14}$-inorganic carbon was effectively linear (e.g. Flgure 5-5), and consequently should have been a reflection of the steady state in 소 1 incorporation rates.

In Table 5-2, results show 1ittle or no discrepancles between total fixed carbon (ac1d non-volatile) and particulate carbon (retained on GF/F f11ter) for incubations throughout the summer. Th1s rules out the possibility that significant accumulation of labeled DOC was occurring elther as a result of algal excretion or exudation, or as a result of "sloppy feeding". Significant DOC production could st111 have occurred If it was derived from an unlabeled source (c.f. Mague et al., 1980), or was taken up as rapidly as 1t was produced (e.g. Ammerman et al., 1984; Hagstrom et al., 1984). However, it is 1ikely that linear incorporation of label into individual materials for relatively short incubation times was primarily a reflection of algal metabolism.

\section{Primary Production of Particulate Organic Carbon}

Rates of POC primary production are shown for the study period along w1th concentrations of chlorophyll a and POC (F1gure 5-6). In the first three experiments ( 20 July $83-10$ August 83 ), 2 or more replicate incubations were made in order to assess the analytical variation in POC production rate determinations. In Table 5-3, the coefficient of variation in production rates for the replicates is compared to that for the overall mean for that period (mean $=47 \mathrm{mlcrograms}$ carbon $/ 11$ ter/hour, 
$95 \%$ conf. int. $=11, n=7)$. The proportion of variability associated w1th replicate measurements was $33.5 \%$, while that associated with between day variation was $66.5 \%$. Differences between replicate incubations were not significant, while between day differences were (ANOVA, P less than $0.05)$.

During the latter portion of the summer, consecutive morning and midday Incubations were conducted. Coefficients of variation were slightly higher than for the replicate incubations, although there was no consistent trend in the differiences between the morning and midday incubations (Table 5-4).

Between day differences dur:ing the period from 20 July to 3 October 83 could not be explained by correlations of efther assimilation numbers (1.e. m1crograms carbon f1xed per mlcrogram chlorophyll a per hour) or total POC production (micrograms carbon f1xed per 11ter per hour) with efther temperature or phosphate concentration (Table 5-5). However, there was a significant positive correlation between POC production and total inorgan1c nitrogen concentrations. As will be discussed, nitrogen may be an 1mportant factor influencing the population metabolism and POM compositional dynamics.

\section{Integrated POC Production Estimates}

In comparing POC production $\left(\mathrm{P}_{1}\right)$ to observed changes in POC concentration $(d c / d t)$, mean production rates were used. Daily production of POC was estimated by extrapolating the mean production rate for the whole summer over an 11 hour photoperiod. This corresponded to the period when sunlight was at or greater than $40 \%$ or more of maximum (F1gure 5-7). This represents $90 \%$ or more of the integrated 1ight energy 
F1gure 5-5. Representative Incubation (5 Aug 83) showing POC production in conjunction with surface light regime. 


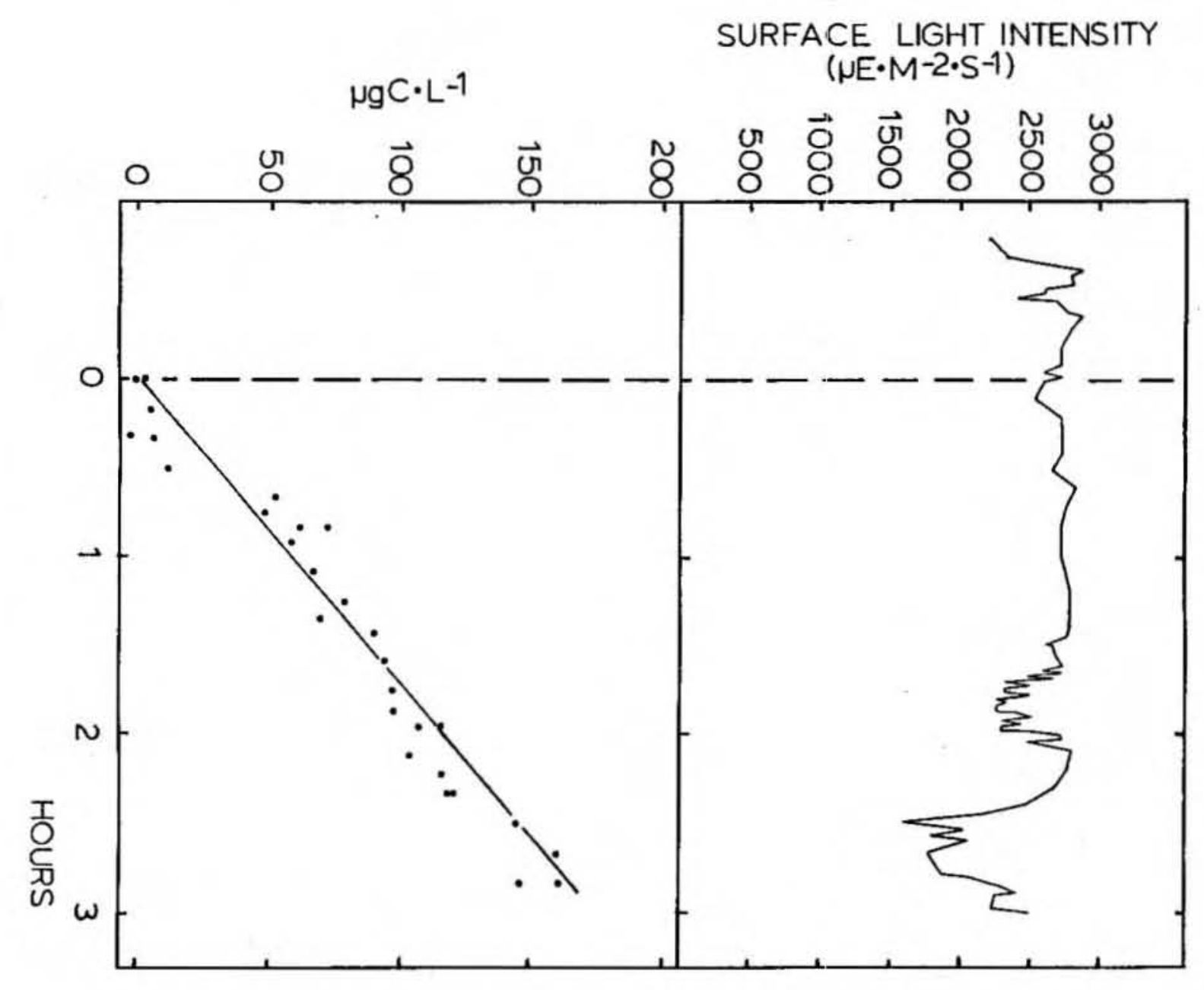


Figure 5-6. POC production during sampling period shown in relationship to dynamics of chlorophyll a and particulate POC. Solid line represents the overall mean for the summer (dotted lines indicate $95 \%$ confidence limits). Units for chlorophyll a are multiplied by ten to bring them up to scale. 


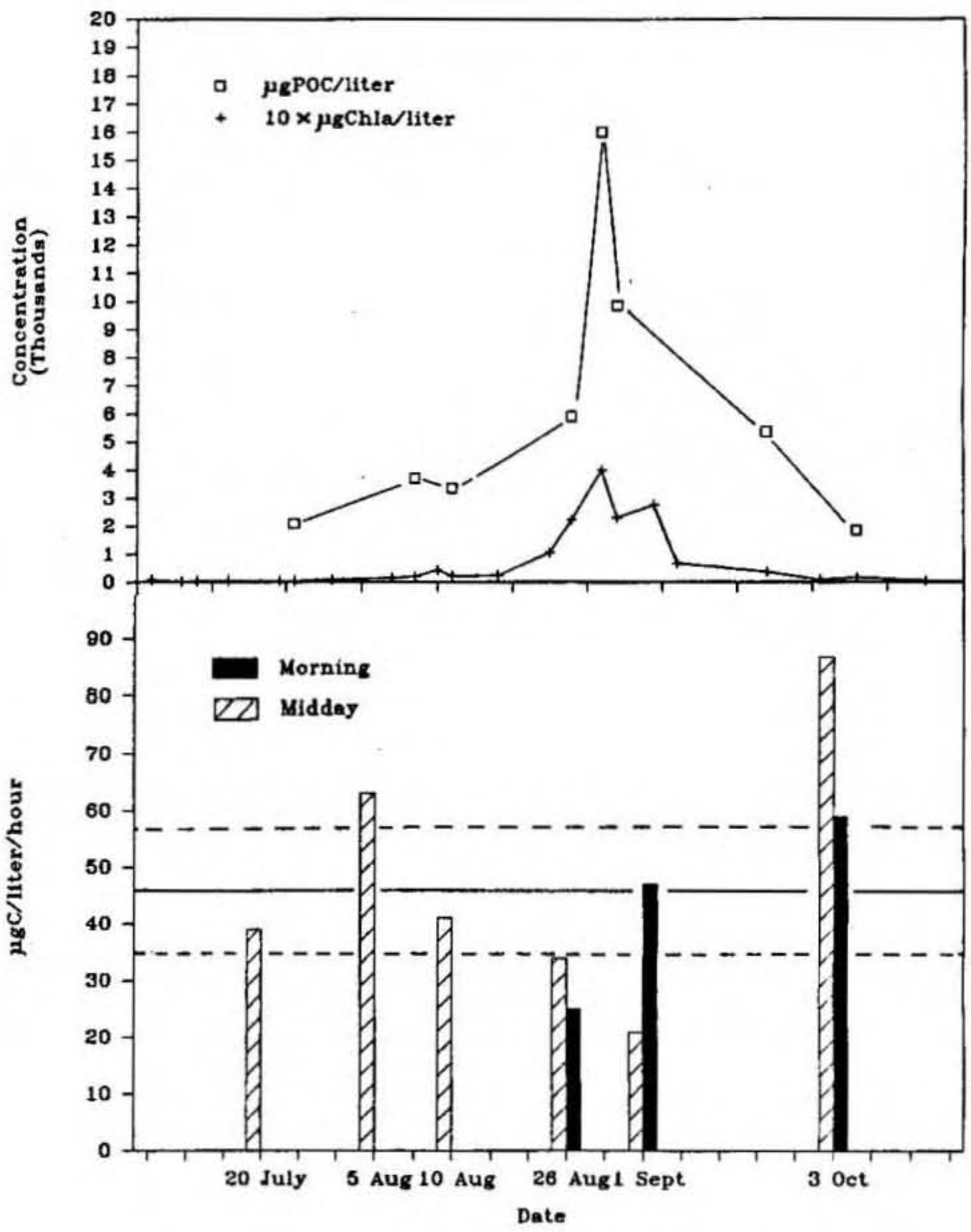


Figure 5-7. Diel light regime from 1982 during the same time of year as the period of study in Salt Pond. The interval of daylight over which midday production rates were extrapolated is Indicated by the dotted 1ines. Data provided courtesy of Dr. Pat Glibert. 


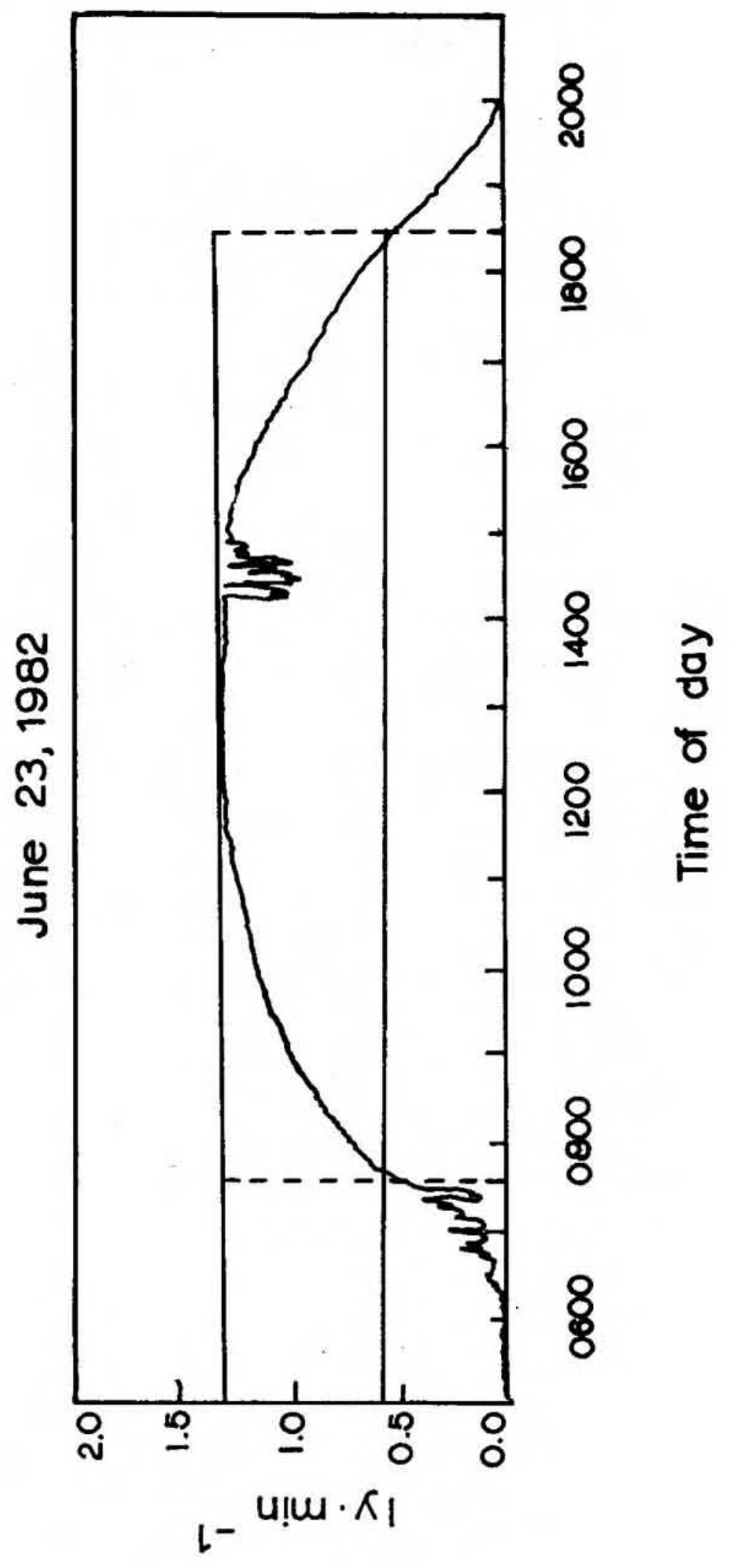


Table 5-2. Comparison of Inorganic ${ }^{14} \mathrm{C}$ Fixation as Determined by Acidification/Sparglng and Filtration

\begin{tabular}{|c|c|c|c|c|}
\hline Date & $\begin{array}{l}\text { Incubation } \\
\text { Period } \\
\text { (hours) }\end{array}$ & $\begin{array}{c}\text { Production } \\
\text { Rate } \\
\left(\mu \mathrm{gC} \cdot \mathrm{1}^{-1} \cdot \mathrm{hr}^{-1}\right)\end{array}$ & $\mathrm{n}$ & $\begin{array}{c}\text { Method } \\
\mid\end{array}$ \\
\hline 20 July 83 & $\begin{array}{l}1.8 \\
1.7\end{array}$ & $\begin{array}{l}38(10)^{a} \\
36(6)\end{array}$ & $\begin{array}{l}14 \\
10\end{array}$ & $\begin{array}{l}\text { filtration } \\
\text { acid }\end{array}$ \\
\hline 5 Aug 83 & $\begin{array}{l}2.8 \\
2.8\end{array}$ & $\begin{array}{l}55(13) \\
55(6)\end{array}$ & $\begin{array}{l}6 \\
23\end{array}$ & $\begin{array}{l}\text { filtration } \\
\text { acid }\end{array}$ \\
\hline 10 Aug 83 & $\begin{array}{l}2.6 \\
2.5\end{array}$ & $\begin{array}{l}45(6) \\
43(8)\end{array}$ & $\begin{array}{l}4 \\
14\end{array}$ & $\begin{array}{l}\text { filtration } \\
\text { acld }\end{array}$ \\
\hline 1 Sept 83 & $\begin{array}{l}3.2 \\
1.98\end{array}$ & $\begin{array}{l}21(2) \\
24(2)\end{array}$ & $\begin{array}{l}12 \\
16\end{array}$ & $\begin{array}{l}\text { filtration } \\
\text { acid }\end{array}$ \\
\hline 3 oct 83 & $\begin{array}{l}2.6 \\
2.7\end{array}$ & $\begin{array}{l}87(12) \\
89(9)\end{array}$ & $\begin{array}{l}12 \\
16\end{array}$ & $\begin{array}{l}\text { filtration } \\
\text { acid }\end{array}$ \\
\hline
\end{tabular}

a Errors in parentheses represent $95 \%$ confidence intervals. 
Table 5-3. Coefficients of Variation for Replicate Production Estimates

\begin{tabular}{llll}
\hline Date & $\begin{array}{c}\text { Mean } \\
\text { Production Rate } \\
\left(\mu \mathrm{gC} \cdot \mathrm{I}^{-1} \cdot \mathrm{hr}^{-1}\right)\end{array}$ & $\mathrm{n}$ & $\begin{array}{c}\text { Coefficient } \\
\text { of Varlation } \\
(\%)\end{array}$ \\
\hline 20 July 83 & 39 & 2 & 19 \\
5 Aug 83 & 63 & 2 & 9 \\
10 Aug 83 & 41 & 3 & 10 \\
Overal1 Mean & 47 & 7 & 23 \\
\hline
\end{tabular}


Table 5-4. Particulate Organic Carbon Production Rates for Consecutive Incubations in Salt Pond, Summer 1983

\begin{tabular}{|c|c|c|c|c|}
\hline Date & Time of Day & Production ${ }^{a}$ & Mean & $\begin{array}{l}\text { Coefficient } \\
\text { of Variation }\end{array}$ \\
\hline 26 Aug 83 & $\begin{array}{l}0930-1250 \\
1130-1415\end{array}$ & $\begin{array}{l}25(12) \\
34(12)\end{array}$ & 29 & 23 \\
\hline 1 Sept 83 & $\begin{array}{l}0900-1200 \\
1050-1400\end{array}$ & $\begin{array}{l}47(6) \\
21(2)\end{array}$ & 34 & 54 \\
\hline 3 oct 83 & $\begin{array}{l}0815-1050 \\
1010-1230\end{array}$ & $\begin{array}{l}59(6) \\
87 \text { (11) }\end{array}$ & 73 & 27 \\
\hline
\end{tabular}

a 
Table 5-5. Product-Moment Correlation Coefficlents for the Relationships Between Selected Environmental Parameters and Assimilation Number and Production Rate

\begin{tabular}{|c|c|c|c|c|}
\hline Parameter & Assimilation & $\underset{\mathrm{n}}{\text { number }} \mathrm{a}^{\mathrm{a}}$ & $\underset{r}{\text { Product }}$ & $\mathrm{n}^{\mathrm{b}}$ \\
\hline $\mathrm{PO}_{4}$ & -0.644 & 9 & -0.283 & 9 \\
\hline Temperature & 0.228 & 9 & -0.366 & 9 \\
\hline $\begin{array}{l}\text { Dissolved } \\
\text { Inorganic } \mathrm{N}\end{array}$ & 0.269 & 9 & $0.728^{c}$ & 9 \\
\hline
\end{tabular}

$a_{\mu g}$ carbon fixed/ug chla/hour

$b_{\mu g}$ carbon fixed/liter/hour

cSignificant at the $\mathrm{P}=0.05$ level. 
during the photoperiod. I assumed that diel fluctuations in production around the midday rate w1:Ll not be significantly greater than between-day varlation in rates, and hence adequately described by the error assoclated with the overail production mean for the summer. However, in view of observations of substantial diel varlations in photosynthetic ability of natural phytopilankton populations (Lorenzen, 1963; Harding et al., $1982 \mathrm{a}, \mathrm{b})$ the potentlal for such varlations must be recognized. In general, these studies Indicated that maximal photosynthetic ability occurred before or near the middle of the light period. Extrapolation of midday rates in this study may have resulted in a slight overestimate of production. However, my observations showed that midday rates were nelther consistently higher or lower than morning rates (Table 5-4, Figure 5-6).

In F1gure 5-6, the overall mean for the summer (46 micrograms carbon/11ter/hour, $95 \%$ confidence interval $=11, \mathrm{n}=13$ ) 1s compared to the individual determinations of midday production at one meter. Although it provided an upper estimate of production during the bloom, this mean rate was st111 not adequate to explain POC increases associated with the bloom peak, indicating a transient increase in primary production in excess of measured rates during that period. This will be discussed further in a later section.

An additional consideration in estimating production is the validity of extrapolating rates measured at one meter throughout the mixed layer. I assumed that the mean production rate represents a light saturated photosynthetic rate, and that this rate is uniform throughout the mixed layer. Simulated in situ photosynthesis-irradiance experiments during summer of 1982 revealed that the production was generally saturated at or 
above $30 \%$ surface inc1dent 11ght (F1gure 5-8, Table 5-6). Surface 1ncldent 11ght regimes were comparable for the 1982 and 1983 incubations (not shown). For the period from 20 July to 10 August 83 , extinction coefficlents determined for the water column indicated that one meter in s1tu 11ght 1ntensities were between $20-40 \% I_{0}$ (F1gure 5-9, Table 5-7). Based on the 1982 fleld observations and published values of photosynthesis-1rradiance relations for pure cultures (Falkowsk1 and Owens, 1980), I argue that at the light intensities observed, the potential reduction in production rates at one meter due to 11ght limitation was within the limits of analytical variation. Light limitation was certainly a factor lower in the mixed layer. Light 1imitation may have also been 1mportant later in the summer. The correlation between the natural logarithm of the assimilation number for all incubations conducted in summer 1983 and quantum flux (microeinsteins per $\mathrm{m}^{2}$ per hour, integrated over the incubation period and corrected for extinction by the water column) was significant at the $99 \%$ level (correlation coefficient $=0.828, \mathrm{n}=9$ ). This is probably Indicative of light limitation of production rates during the bloom period when extinction was high (Table 5-7) and incident solar radiation was relatively low (Table 5-8).

\section{Particulate Prote1n Amino Ac1d Production}

PPAA production rates based on observed incorporation into total PPAA, as well as incorporation in hot trichloroacetic ac1d insoluble materlal, and protein glycine and alanine for the period from $20 \mathrm{July}$ to 3 October 83 are shown in Table 5-9. I also included rates of total PPAA 
Figure 5-8. Time course of carbon fixation by surface samples from Salt Pond Incubated during midday under natural sunlight attenuated to different Intensities. Upper panel is an experiment conducted on 9 September 1982, and lower panel is an experiment conducted on 17 August 1982. Symbols: squares, $80 \%$ incldent 1ight; circles, $30 \%$; triangles, $10 \% ; x, 1 \%$. 


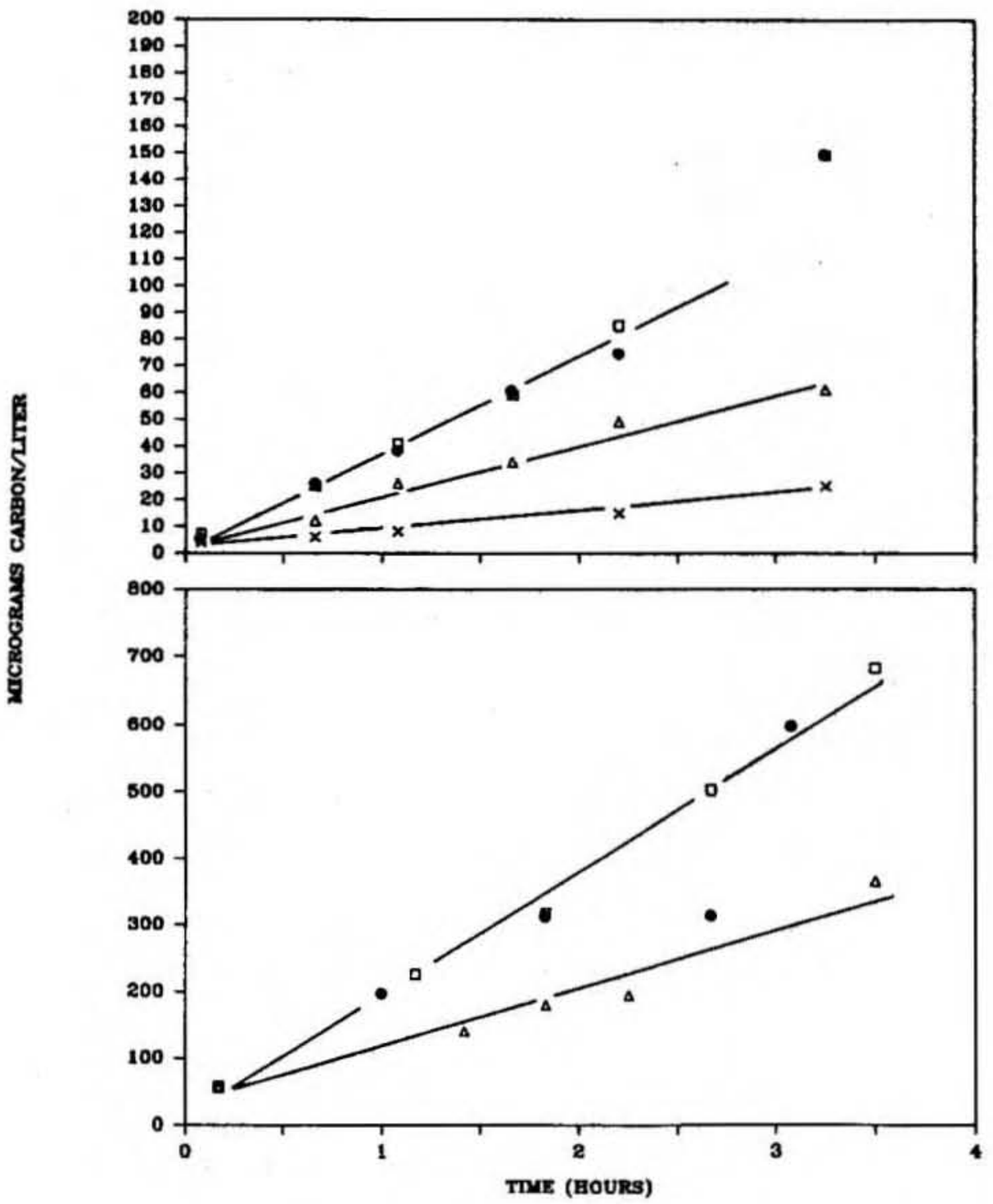


Figure 5-9. Proportion of surface light reaching 1 meter during study perlod in Salt Pond. 


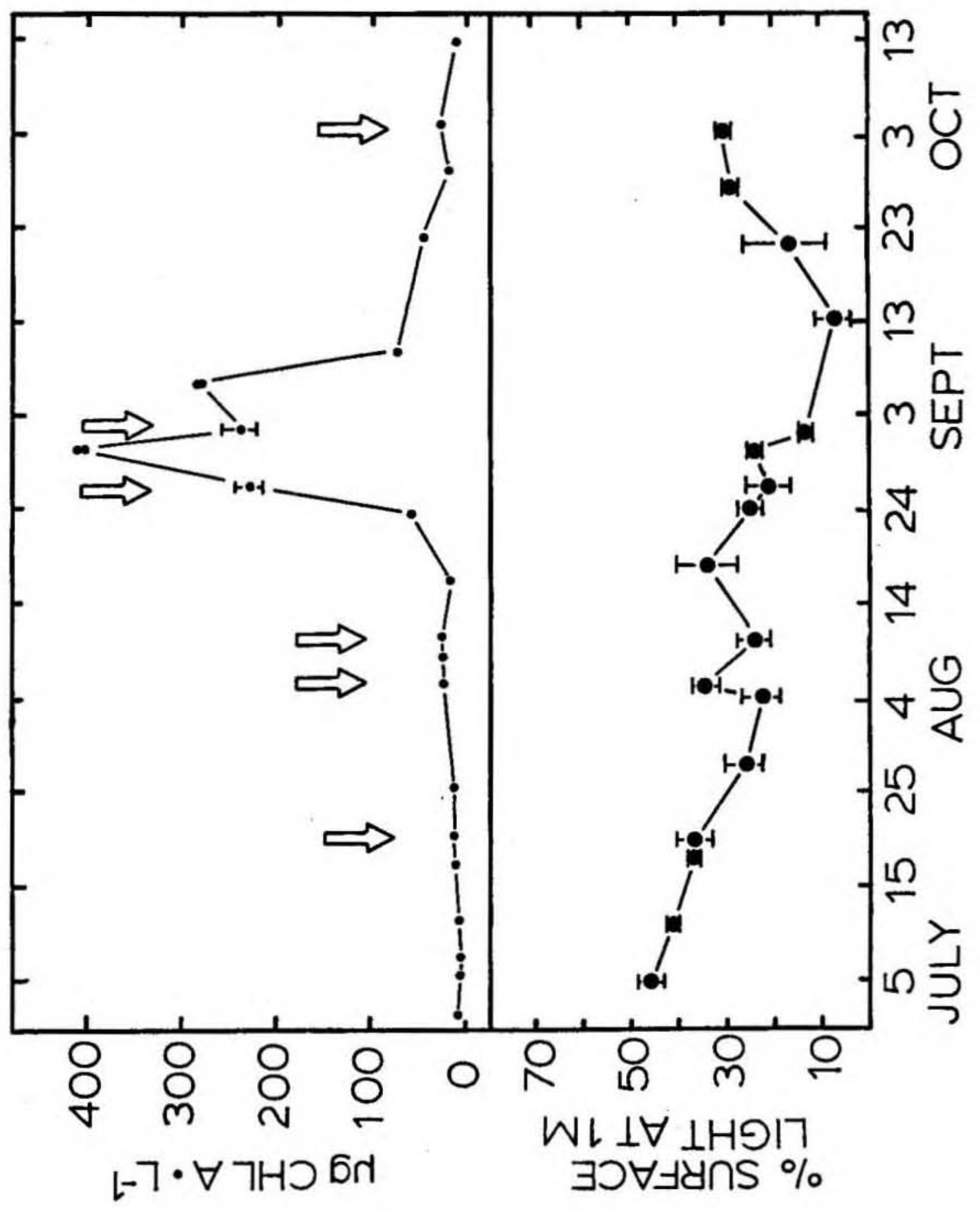


Table 5-6. Simulated In Situ Production Rates for Salt Pond, 1982

\begin{tabular}{ccc}
\hline$I_{0}$ & 17 Aug $82 \frac{\text { Production Rate }_{9}^{a}}{9}$ Sept 82 \\
80 & $204(19)$ & $44(4)$ \\
30 & $157(300)$ & $43(13)$ \\
10 & $90(30)$ & $19(4)$ \\
1 & n.d. & $7(2)$ \\
\hline
\end{tabular}

$a_{\mu g}$ carbon/11ter/hour. Errors represent $95 \%$ confidence intervals. 
Table 5-7. Light Extinction in the Mixed Layer of Salt Pond, Summer 1983

\begin{tabular}{lcc}
\hline Date & Extinction Coefficlent ${ }^{\mathrm{a}}$ & $\begin{array}{l}\% \mathrm{I}_{\text {ot }} \text { at } \\
\text { meter }\end{array}$ \\
\hline 20 July 83 & $-1.18(0.19)^{\mathrm{b}}$ & $23-37$ \\
5 Aug 83 & $-1.24(0.28)$ & $23-37$ \\
10 Aug 83 & $-1.36(.18)$ & $21-31$ \\
26 Aug 83 & $-1.89(.38)$ & $10-22$ \\
1 Sept 83 & $-2.66(.34)$ & $5-10$ \\
3 oct 83 & $-1.22(0.06)$ & $28-31$ \\
\hline
\end{tabular}

$a_{\text {Extinction coefficient }}=\ln \left(I_{z} / I_{0}\right) \times(1 / z)$ where $I_{z} / I_{0}$ is the proportion of incident light reaching depth $z$ in meters.

${ }^{\mathrm{b}}$ Errors represent $95 \%$ confidence intervals. 
Table 5-8. Surface Incldent and Atmosphere Corrected

Solar Radlation: 10 Aug - 1 Sept 83, Salt Pond ${ }^{a}$

\begin{tabular}{|c|c|c|c|c|}
\hline Date & $\begin{array}{l}\text { Surface Incident } \\
\text { (A) }\left(10^{3} \text { w }\right.\end{array}$ & $\begin{array}{c}\text { Atmosphere } \\
\text { (B) } \\
\left.\text { t-hours } / \mathrm{m}^{2}\right)\end{array}$ & Corrected & $\mathrm{A} / \mathrm{B}$ \\
\hline 10 Aug 83 & 7.1 & 10.3 & & 0.7 \\
\hline 11 & 2.1 & 10.2 & & 0.2 \\
\hline 12 & 1.2 & 10.2 & & 0.1 \\
\hline 13 & 2.8 & 10.1 & & 0.3 \\
\hline 14 & 5.0 & 10.1 & & 0.5 \\
\hline 15 & 4.3 & 10.0 & & 0.4 \\
\hline 16 & 6.9 & 10.0 & & 0.7 \\
\hline 17 & 6.8 & 9.9 & & 0.7 \\
\hline 18 & 0.8 & 9.9 & & 0.1 \\
\hline 19 & 5.2 & 9.8 & & $.5^{2}$ \\
\hline 20 & 6.0 & 9.8 & & .6 \\
\hline 21 & 7.1 & 9.7 & & 0.7 \\
\hline 22 & 5.4 & 9.6 & & 0.6 \\
\hline 23 & 6.6 & 9.6 & & 0.7 \\
\hline 24 & 6.7 & 9.5 & & 0.7 \\
\hline 25 & 6.5 & 9.5 & & .7 \\
\hline 26 & 5.9 & 9.4 & & 0.6 \\
\hline 27 & 5.3 & 9.4 & & 0.6 \\
\hline 28 & 3.7 & 9.3 & & 0.4 \\
\hline 29 & 1.6 & 9.2 & & 0.2 \\
\hline 30 & 1.8 & 9.2 & & 0.2 \\
\hline 31 & 1.6 & 9.1 & & 0.2 \\
\hline 1 Sept 83 & 5.5 & 9.1 & & 0.6 \\
\hline
\end{tabular}

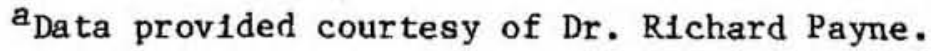


Table 5-9. Particulate Proteln Am1no Acid Production Rates

\begin{tabular}{|c|c|c|c|c|c|c|}
\hline \multirow[b]{2}{*}{ Date } & \multirow[b]{2}{*}{$\begin{array}{l}\text { Total } \\
\text { PPAA }\end{array}$} & \multicolumn{3}{|c|}{ Production Rate ${ }^{a}$} & \multirow{2}{*}{\multicolumn{2}{|c|}{ Extrapolated }} \\
\hline & & $\begin{array}{c}\text { TCA } \\
\text { Insoluble }\end{array}$ & glycine & alanine & & $\begin{array}{l}\text { ted } \\
\text { sequenced }\end{array}$ \\
\hline 20 July 83 & $3.3(2.3)$ & $2.9(0.6)$ & $0.26(0.18)$ & $0.26(0.19)$ & $3.9(2.0)$ & $5.8(3.1)$ \\
\hline 5 Aug 83 & $3.1(2.2)$ & $5.5(3.1)$ & $0.25(0.15)$ & $0.52(0.48)$ & $4.8(2.5)$ & $7.7(4.1)$ \\
\hline 10 Aug 83 & $3.3(1.6)$ & $3.6(1.6)$ & $0.31(0.14)$ & $0.28(0.18)$ & $4.6(1.8)$ & $6.8(2.8)$ \\
\hline 26 Aug 83 & $2.8(2.4)$ & $4.4(2.1)$ & $0.16(0.27)$ & $0.18(0.34)$ & $2.6(3.3)$ & $3.9(5.1)$ \\
\hline $\begin{aligned} 1 \text { Sept } & 83 \\
& \text { Morning } \\
& \text { Midday }\end{aligned}$ & $\begin{array}{l}6.0(0.9) \\
3.1(1.2)\end{array}$ & $\begin{array}{l}6.4(2.7) \\
3.9(1.2)\end{array}$ & $\begin{array}{l}0.68(0.10) \\
0.24(0.09)\end{array}$ & $\begin{array}{l}0.78(0.13) \\
0.20(0.31)\end{array}$ & $\begin{array}{l}11.3(1.5) \\
4.2(1.6)\end{array}$ & $\begin{array}{l}16.8(2.9) \\
6.5(2.7)\end{array}$ \\
\hline 3 oct 83 & $7.4(2.7)$ & $7.6(2.8)$ & $0.38(0.09)$ & $0.52(0.13)$ & $6.9(1.3)$ & $10.6(2.3)$ \\
\hline $\begin{array}{l}\text { M1dday Means: } \\
20 \text { July - } 10 \text { Aug }\end{array}$ & $3.2(1.1)$ & & $0.27(0.07)$ & $0.35(0.13)$ & & \\
\hline $20 \mathrm{July}-1$ Sept & $3.1(0.8)$ & & $0.23(0.05)$ & $0.27(0.09)$ & & \\
\hline
\end{tabular}

a 
production extrapolated from the incorporation characteristics of protein g1ycine and alanine. Extrapolated rates were determined by two methods:

a) from the average proportions of glycine and alanine in protein recovered by my method, and b) from average proportions of glycine and alanine reported for sequenced proteins (Jukes et al., 1975; Dolittle, 1981). These proportions are compared to those observed for Salt Pond protein in Table 5-10. The proportions from hydrolyzed protein were quite similar for laboratory and field experiments, while those from sequenced protelns were lower, consistent with observations discussed in Chapter 4 regarding the preferential recovery of glycine and alanine residues from hydrolysis. Comparisons of extrapolated rates to observed incorporation into total PPAA (Table 5-9) 1ndicated the extrapolated rates were generally higher, consistent with observations of rapld saturation of glycine and alanine precursor pools (Chapters 3 and 4). However, for a given Incubation, rates generally agreed within analytical error. An exception to this occurred for the morning incubation on 1 September 83 , where extrapolated rates were consistently higher than both the observed incorporation Into total PPAA, and the incorporation into hot acid insoluble material. Rates of incorporation into the hot trichloroacetic acid insoluble fraction consistently agreed with the incorporation rates into total PPAA, suggesting that protein is the predominant substance responsible for incorporation into the hot acid Insoluble fraction. However, this relationship cannot be generalized to all systems, particularly in populations containing significant proportions of dinoflagellates (Hitchcock, 1981). Dinoflagellates were not a major species in the populations in this study. 
Table 5-10. Proportion of Glycine and Alanine Carbon in Protein Recovered from Hydrolysis

\begin{tabular}{|c|c|c|}
\hline \multirow[b]{2}{*}{ Source } & \multicolumn{2}{|c|}{ \% Protein Carbon } \\
\hline & Glycine & Alanine \\
\hline \multicolumn{3}{|l|}{ Salt Pond: } \\
\hline 20 July 83 & 6.4 & 7.2 \\
\hline 5 Aug 83 & 6.8 & 9.4 \\
\hline 10 Aug 83 & 6.3 & 6.8 \\
\hline 1 Sept 83 & 6.0 & 7.6 \\
\hline 3 oct 83 & 5.7 & 8.4 \\
\hline $\begin{array}{l}\text { Mean from laboratory } \\
\text { experiments: }\end{array}$ & $5.6(0.4)$ & $7.4(1.0)$ \\
\hline $\begin{array}{l}\text { Mean based on sequenced } \\
\text { protein: }{ }^{a}\end{array}$ & $3.4(0.7)$ & $5.1(0.8)$ \\
\hline
\end{tabular}

a Jukes et al., 1975; Dollttle, 1981 
In general, all rates were remarkably uniform from day to day, which suggested a relative stable rate of population growth over a wide range of environmental conditions. Consistency in production rates was assumed and mean protein production rates were used to estimate flux of PPAA through the mixed layer. The observed total PPAA incorporation rates (Table 5-9) were used as an estimate of total PPAA production, and regarded as a conservative minimum estimate of the actual net protein synthesis rate. Calculations were also made individually for glycine and alanine for comparative purposes. For flux calculations, midday production rates were pooled and the mean rate used (Table 5-9). The rates were assumed to represent an integrated rate of production over the mixed layer as for POC production. Dafly production estimates were made by assuming an 11 hour photoperiod. The $95 \%$ confidence intervals were propagated throughout all calculations.

\section{Relationship Between Production and Concentration}

Total PPAA concentration is illustrated in F1gure 5-10 along with chlorophy11 a and POC concentrations. During the latter portion of August, increases in concentrations occurred which were assoclated with a bloom of 0listhodiscus majmus. Projected concentration changes of POC and PPAA based on mean production rates were compared to observed concentrations (Figure 5-1.1). It is obvious that production generally exceeded observed changes in concentrations, which was evidence for substantial net removal of: organlc matter from the mixed layer. One exception to this occurred for POC during the interval between $26-30$ Aug 83 Immediately before the bloom. During this interval, projected POC concentrations were substantially lower than observed concentrations. 
The estimated minimum POC production rate necessary to account for the Increase in POC during this interval given an 11 hour photoperiod was 229 micrograms carbon per 11 ter per hour. This rate exceeded the mean rate by a factor of 4 .

The otherwise relatively high projected concentrations suggest substantial losses of particulate organic matter were occurring. The observed rates of change in concentration ( $\mathrm{dc} / \mathrm{dt}$ ) and the estimated daily production rates $\left(P_{1}\right)$ appear in Table 5-11. Differences are expressed as a dally net removal rate $\left(\mathrm{R}_{\mathrm{N}}\right)$. In order to facilltate comparisons between PPAA and POC, the net dally removal rates were expressed as percentages of the mean concentrations of POC and PPAA for the corresponding period. If net 1088 occurred preferentially from PPAA carbon, this would result in a discrepancy between the ratio of PPAA production/POC production and the PPAA carbon concentration/POC concentration rat1o. In the remainder of the discussion, the characteristics of POC compositional dynamics for the periods before and during the bloom are compared.

\section{Prebloom Comparisons of POC and PPAA Dynamics}

In Figure 5-12, the PPAA carbon production/POC production ratios are compared to the PPAA/POC concentration ratios. Before 1 September 83, the PPAA/POC production ratios were similar to the concentration ratios. This was also the case for glycine. Net dally removal rates of PPAA, glycine, and alanine were virtually the same as those of POC, in the range of approximately $10-15 \%$ per day. These observations suggest that during the period before the bloom, the composition of bulk POM reflected that being produced by the primary photoautotrophs, and that substantial 
Figure 5-10. Particulate organic carbon (POC), chlorophyll a , and particluate protein amino acld (PPAA) concentrations in the Salt Pond mixed layer during the study perlod. Arrows indicate days during which production Incubations were conducted. 


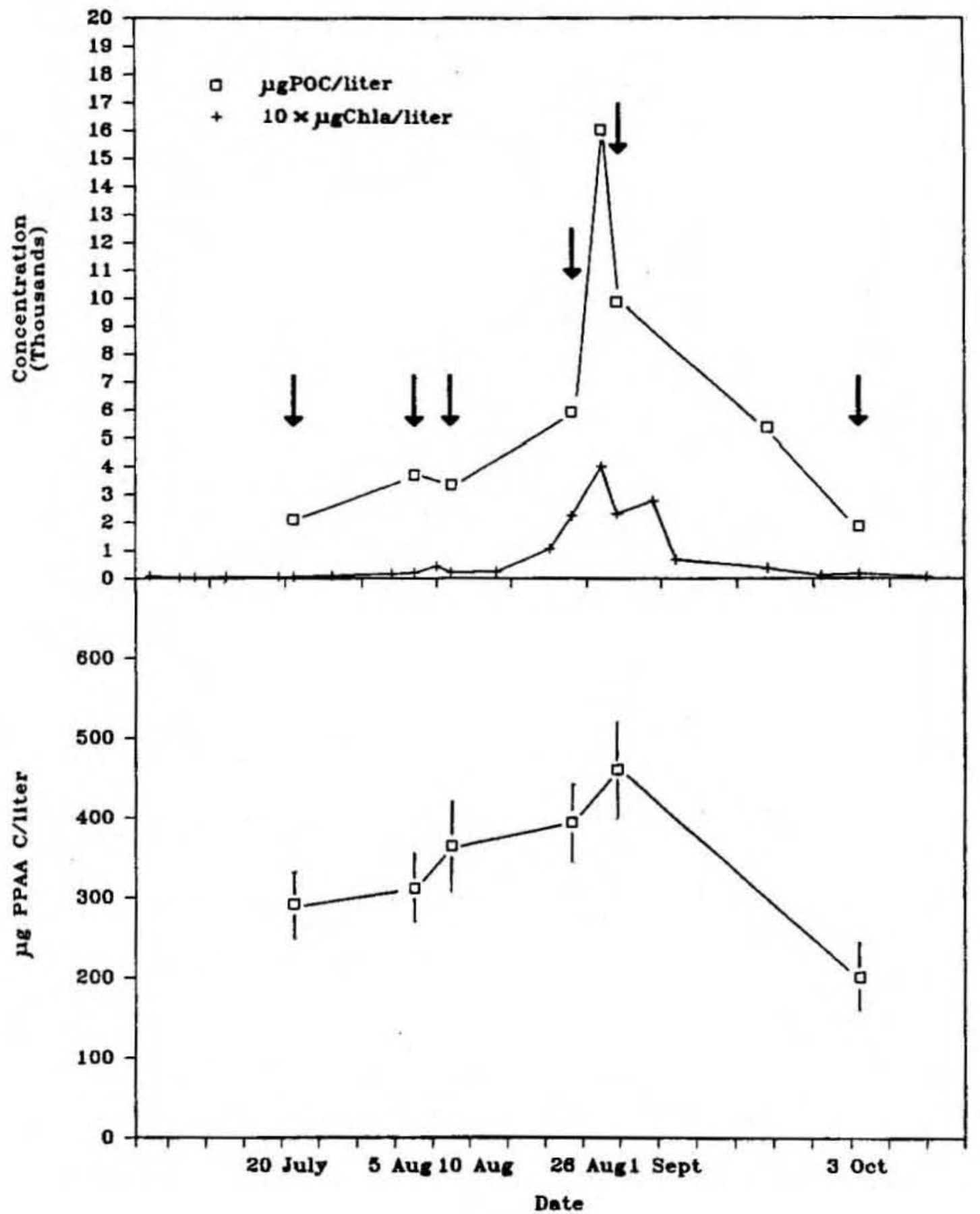


Figure 5-11. Comparison of observed concentrations of particulate organic carbon (POC) and particulate prote1n amino acids (PPAA) to the projected concentrations biased on mean production rates. 

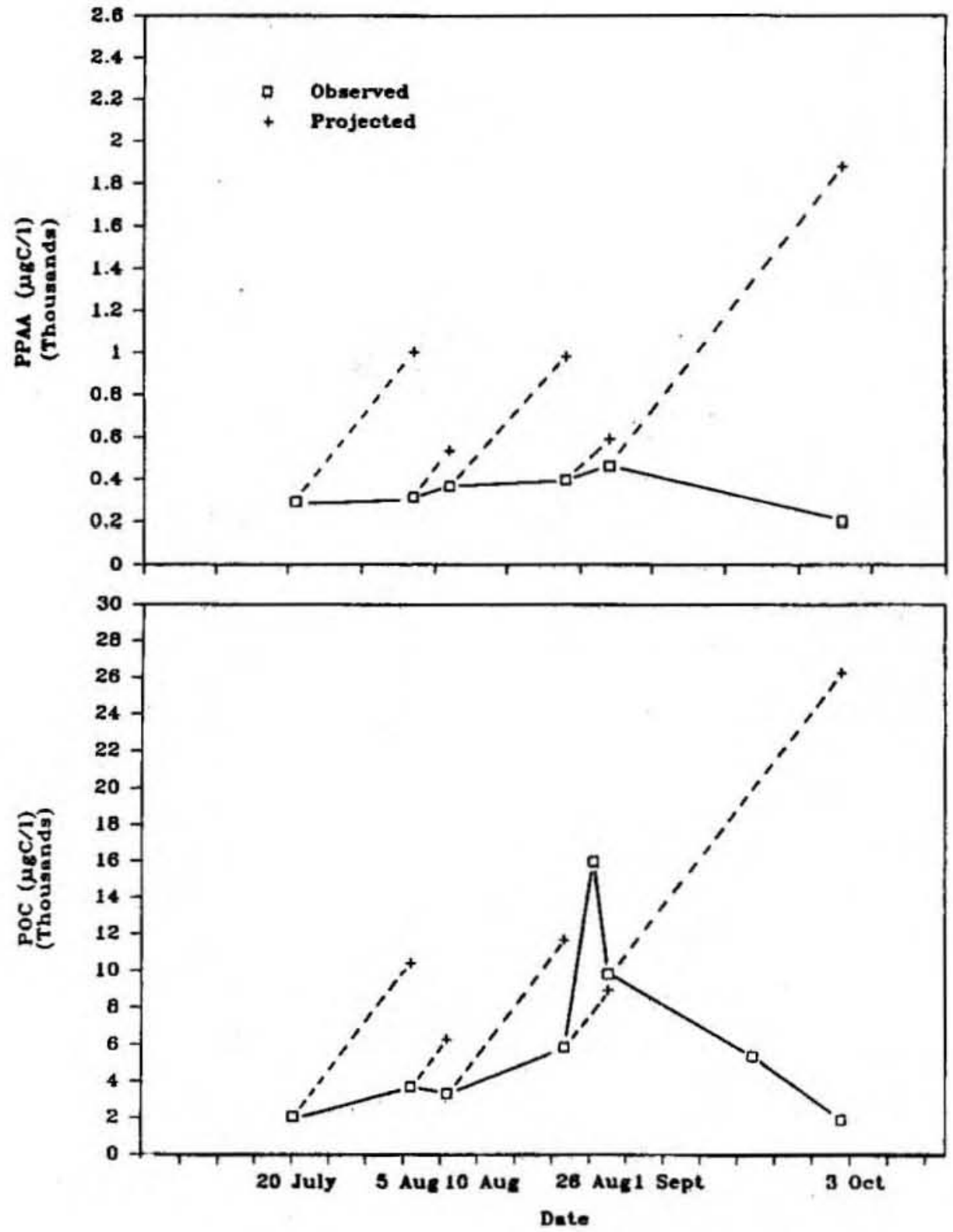
F1gure 5-12. Comparison of production and concentration ratios of particulate protein amino acids (PPAA) and protein glycine relative to particulate organic carbon (POC). Percentages represent either the proportion of total POC in PPAA carbon, or the proportion of total observed ${ }^{14} \mathrm{C}$ uptake (POC production) associated w1th incorporation into PPAA. Errors represent propagated estimates of analytical error based on 95\% confidence intervals. 


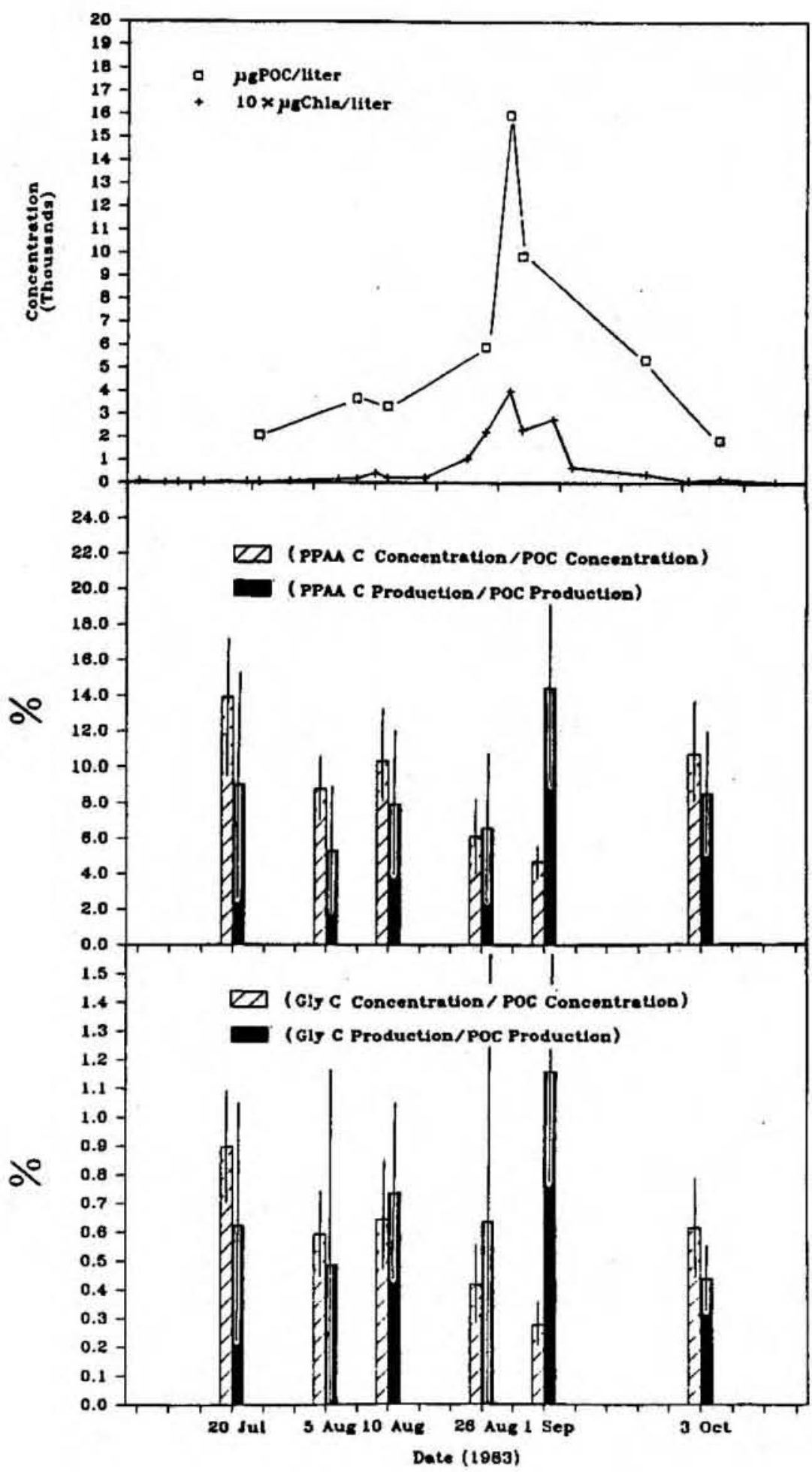


Table 5-12. Productlon and Net Removsl of POC and PPAA

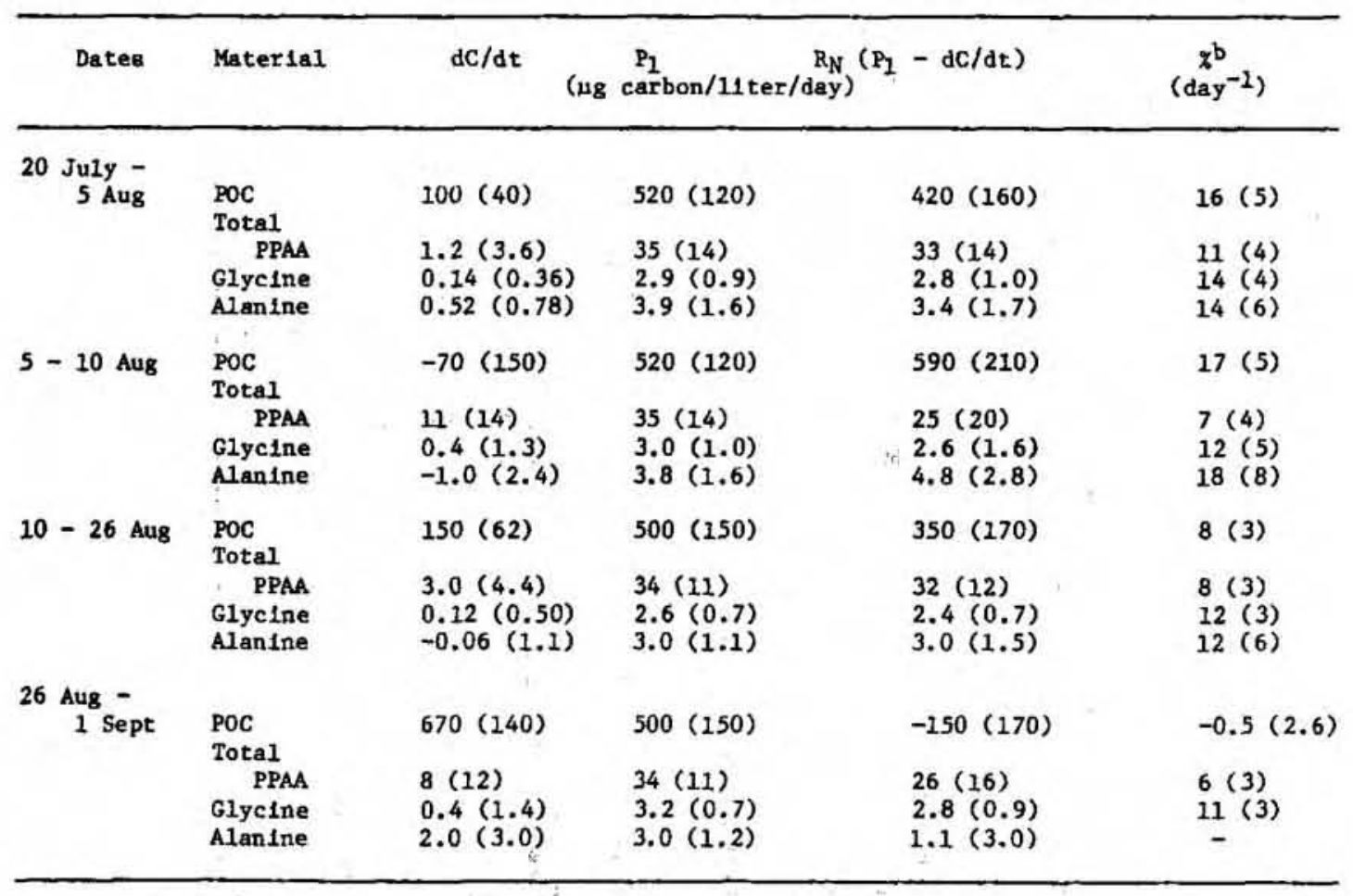

$a_{\mathrm{dc}} / \mathrm{dt}$ is the change in concentration divided by the number of days in the period indicated. $P_{1}$ is the dally production rate based on midday production estimates multiplled by an 11 hour photoperlod. See text for furcher discussion. Errors represent propagated estimates of analytical error based on $95 \%$ confldence intervals.

bepresents $R_{N}$ expressed as a percentage of the mean concentration for the corresponding time perlod. 
amounts of POM were belng removed from the euphotic system of Salt Pond by processes which did not differentiate between PPAA and POC.

Referring to equation (2), non-selective removal processes could include sedimentation $\left(R_{8}\right)$, non-selective grazing $\left(R_{g}\right)$, and advection and diffusion $\left(R_{a / d}\right)$. The possibility that POM was being removed by sedimentation out of the euphotic mixed layer was considered by determining the relationship between the remineralization of organic matter below the mixed layer and POM lost from the layer. These calculations, based on integrated changes in dissolved inorganic carbon and POC concentrations are given in Table 5-12. Clearly, this a complicated system, and the assumption that changes in the concentrations of $\mathrm{CO}_{2}$ are due solely to remineralization is subject to dispute. Many other factors influence this concentration including advective or diffusive exhange, reassimilation by chemosynthesis or sulfur photosynthesis, and remineralization of allochthonous inputs of organic matter such as eelgrass or groundwater intrusion. Nevertheless, the results indicated that $\mathrm{CO}_{2}$ production, which could not be accounted for by In situ changes in POC, exceeded the 108 sate of organic matter from the mixed layer. This indicates that degradation rates below 3 meters are adequate to account for the losses estimated from the euphotic layer If such losses are entirely due to sedimentation. Therefore, sedimentation may have been a significant source of removal. Non-selective grazing $\left(R_{g}\right)$ is another route of removal which would not differentlate between POC and PPAA. For example, macrozooplankton, which would be excluded from POM by our sampling methods (202 u mesh), might graze and subsequently assimflate, respire, and excrete or release resulting waste products. Such waste products may be efther dissolved

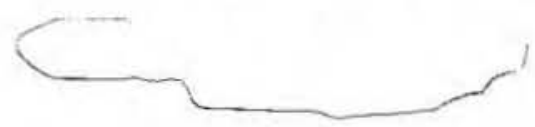


Table 5-12. Changes in Dissolved Inorganic and Particulate Organic Carbon in Relationship to the Net Removal of Particulate Organic Carbon From the Mixed Layer in Salt Pond, Summer 1983

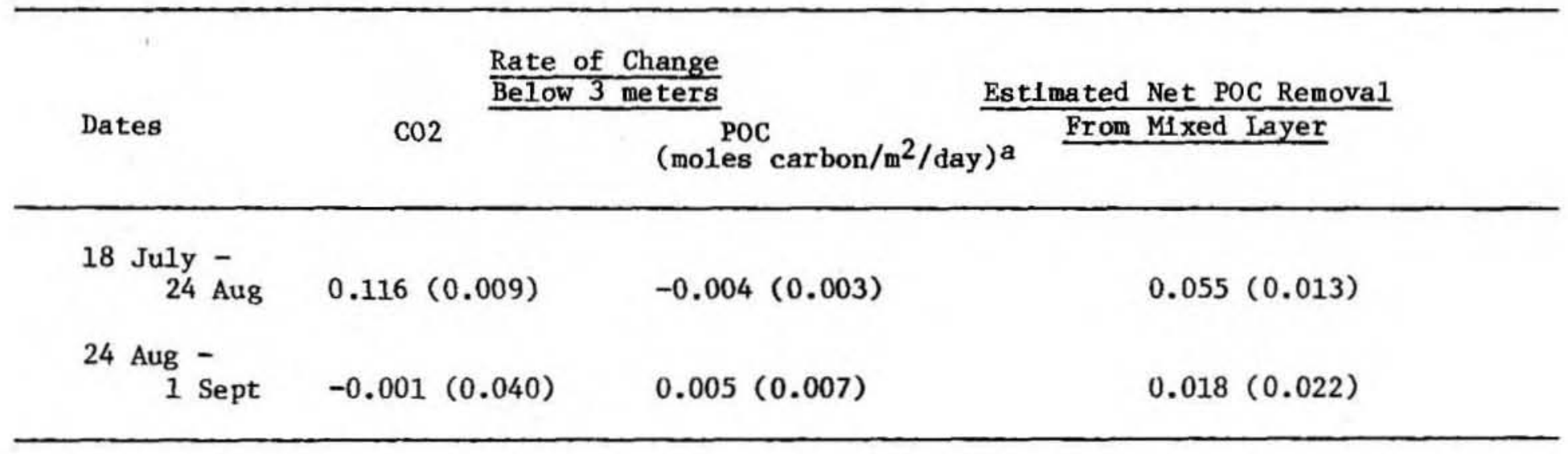

${ }^{a}$ Errors in parentheses indicate propagated estimates of analytical error based on $95 \%$ confidence ifmits. 
organic or inorganic material, or particulate fecal matter. However, if the release of fecal material is significant, this could introduce particulate material into the POM of significantly altered composition (Small et a1., 1983), which is not necessarily consistent with my observations. Alternatively, if the characteristics of fecal matter is such that 1t rapidly sinks, production of fecal matter might be a means of accelerating sedimentation of POM out of the mixed layer. This material would 11kely not be included in the incubation vessel.

Microzooplankton would be included in both the incubation vessel and filtered subsamples. Furthermore, grazing by microzooplankton may result in particle production (Stoecker, 1984). The presence and activities of the microzooplankton population did not lead to a measurable discrepancy between POM composition and primary organic matter produced by the algal population during the prebloom perfod (F1g. 5-12). Additional information is required about the composition, abundance, and activities of the microheterotrophs, and the fate of the organic matter on which they feed, in order to assess their importance in the compositional dynamics of POM in the mixed layer.

Advective losses $\left(R_{a / d}\right)$ may have occurred via the outlet channel connecting to Vineyard Sound. Est1mates of exchange through the channel Indicated it may have been as much as $5 \%$ day $^{-1}$ of the total volume of Salt Pond, and $11 \%$ day $^{-1}$ of the mixed layer volume. Further information about the hydrodynamics of the pond and actual organic matter transport through the channel is required in order to quantitate such 1osses. 
Contributions of POM not due to In situ autotrophic activity could occur from advection and diffusion $\left(P_{a / d}\right)$, chemotrophic production $\left(P_{c}\right)$, In situ secondary production $\left(P_{2}\right)$, and adsorption of DOM to POM. If processes which result in input of POM other than primary production are not negligible relative to primaxy production during the prebloom perfod, then efther they were introducing material of similar composition with respect to PPAA and POC, or were coupled to efficient removal so that accumulation of non-primary POM 1s negligible. Dark uptake of inorganic ${ }^{14} \mathrm{C}$ was generally low relative to total primary production (Table 5-13), which would indicate that chemosynthetic production $\left(P_{c}\right)$ was small relative to autotrophic production. Secondary production $\left(\mathrm{P}_{2}\right)$ could contribute non-primary organic matter. The potential importance of such production is currently the subject of considerable dispute (e.g. Sorokin, 1981; Willlams, 1981). Cuhel (1981) reported ranges in prote1n/POC composition of two bacterial species depending on nutritional state, which span the ranges for POM reported here. Hence it is possible bacteria could be introducing POM of similar composition to that produced by photoautotrophs. On the other hand, some loss of organic matter would occur due to bacterial respiration $\left(R_{r}\right)$. Other components of $R_{r}$ Include microzooplankton respiration and autotrophic respiration. Such activities would be expected to selectively enrich the PPAA content of POM according to reports of several investigators that protein is relatively less susceptible to respiratory degradation than other cell materlal (e.g. Van Liere et al., 1979; Handa, 1969; Lorenzen and Kaushik, 1976; Darley et a1., 1976; Hitchcock, 1980; Scott, 1980; Fukami et al., 1985). My observations for the prebloom period are not consistent with the hypothesis that these 
Table 5-13. Dark Uptake Rates of Inorgan1c ${ }^{14} \mathrm{C}$ : Salt Pond, Summer 1983

\begin{tabular}{ll}
\hline Date & Uptake Rate \\
\hline 20 July 83 & $10(11)$ \\
5 Aug & $1.4(0.4)$ \\
10 Aug & $-0.6(1.4)$ \\
26 Aug & $-0.3(2.8)$ \\
1 Sept & $0.7(1.2)$ \\
3 oct & $-13(7)$ \\
\hline
\end{tabular}

$a_{\mu g}$ carbon/11ter/hour. Errors represent $95 \%$ confidence intervals. 
selective processes are the predominant routes of removal of POM from the euphotic zone.

Advective inputs $\left(P_{a / d}\right)$ would include those from Vineyard Sound through the channel, and other sources within the pond. Chlorophy1l concentrations were generally higher in Salt Pond than in Vineyard Sound (data not shown). It seems likely that in s1tu production would have been more important in influencing the composition of POM in the pond mixed layer. In view of the dynamic mixing regime of Salt Pond, it seems likely that advective and diffusive inputs and outputs of POM within the pond were occurring. If this is the case, then the composition of incoming material must have been similar to that of the POM produced in situ at the sampling site during the pre-bloom period. This would suggest that primary organic matter of relatively similar composition is being produced throughout the mixed layer (1.e. no significant vertical or horizontal gradients in POC production relative to PPAA production).

The results indicate that within the limits of analytical precision, the protein composition of primary produced organic matter was similar to the existing POM composition. Furthermore, estimated rates of primary production were more than adequate to account for observed POM concentration increases. This is consistent with the view that algal blosynthetic activity was the predominant factor influencing the protein content of POM, and ultimately, controlled its flux to higher trophic levels during the period preceding the bloom. 
POC and PPAA Dynamics During Bloom

During the decline of the bloom, the PPAA/POC production ratio was significantly higher than the PPAA/POC concentration rat1o (Figure 5-12). Glycine showed a similar trend. This pattern was observed for both the morning and midday incubations (Table 5-14), although for the morning incubation the difference between production ratios and concentration ratios were significantly outside the limit of analytical error only in the case of glycine and alanine for the morning incubation. Th1s was primarily because PPAA/POC concentration ratios were significantly higher than for the midday incubation. In view of the short interval between the initiation of the incubations ( 2 hours), it is difficult to envision that a real change in POM composition of the magnitude indicated actually occurred. PPAA concentration ratios were based on estimates from samples taken directly from the incubation chamber. In contrast, $P O C$ concentrations were est1mated from samples taken Independently. This leads to speculation that observed compositional differences between incubations may have been due to spatial and/or temporal heterogeneity in the distribution of organic matter. However, as previously ment1oned, the depth profiles of chlorophy11 a concentrations did indicate a relatively uniform distribution around the one meter depth where sampling and incubations were conducted ( $F 1 \mathrm{~g}, 5-3)$. Therefore, it is also possible that the difference was related to population metabolism. Despite the differences, both incubations did show a tendency for the production ratios to exceed the concentration ratios. In the next section, I w111 discuss how changes in environmental conditions may have generated metabolic responses leading to the observed discrepancles. 
Table 5-14. Comparisons of MornIng and Midday Production and Composition Ratios, Salt Pond, 1 Sept 83

\begin{tabular}{|c|c|c|c|}
\hline Time of Day & Materla1 & $\begin{array}{c}\% \\
\text { Tota1 POC Production }\end{array}$ & $\begin{array}{c}\% \\
\text { Total POC }\end{array}$ \\
\hline $0900-1200$ & $\begin{array}{l}\text { total PPAA } \\
\text { Glycine } \\
\text { Alanine }\end{array}$ & $\begin{array}{l}12.6(2.5)^{a} \\
1.4(0.3) \\
1.6(0.3)\end{array}$ & $\begin{array}{r}9.1(1.8) \\
0.54(0.13) \\
0.71(0.16)\end{array}$ \\
\hline $1050-1400$ & $\begin{array}{l}\text { total PPAA } \\
\text { Glycine } \\
\text { Alanine }\end{array}$ & $\begin{array}{l}14.6(5.8) \\
1.2(0.4) \\
0.9(1.5)\end{array}$ & $\begin{array}{l}4.7(0.9) \\
0.28(0.07) \\
0.36(0.07)\end{array}$ \\
\hline
\end{tabular}

aErrors In parentheses represent $95 \%$ confidence intervals. 


\section{Production Characteristics and Population Metabolism}

During the bloom, significant changes in physical parameters occurred which may have resulted in changes in population metabolism. Inorganic nitrogen concentrations (particularly $\mathrm{NH}_{4}^{+}$) were high immediately before the bloom, and subsequently decreased rapldly (F1gure 5-13). Light intensities at the one meter depth also decreased during the bloom (Figure 5-9, Table 5-7). As previously discussed, significant correlations were observed for the relationships between total POC production rate versus inorganic nitrogen concentrations (Table 5-5), and assimilation number versus quantum flux at one meter (correlation coefficient $=0.828, P$ less than 0.05 ). These observations indicate that light limitation, nitrogen limitation, or both led to the bloom decline. Additional evidence in support of light limitation of the bloom population was the pronounced decrease in the POC/chlorophyll a ratios (Figure 5-14).

In Chapter 4, 1t was noted that under conditions of 1 ight and nitrogen limitation, protein turnover could account for a significant portion of total protein label incorporation in Nannochloris sp., leading to an overestimate of net protein synthesis. Such a phenomenon could explain the observed discrepancles between the high proportions of primary production associated with PPAA, as compared to the PPAA/POC concentration ratios. This would mean the discrepancy was due to a kinetic artifact of isotope incorporation, rather than a real difference between the blosynthetic patterns of the population and the composition of POM. Th1s view 1s supported by the fact that discrepancles were larger in the case of glycine and alanine (Table 5-14) than for total protein, an observation similar to that seen for light and nitrogen 
Figure 5-13. 0rthophosphate, ammonium, nitrate, and nitrite concentrations at the one meter sampling depth in relationship to particulate organic carbon (POC) and chlorophyll a concentrations during the period of study in Salt Pond. 


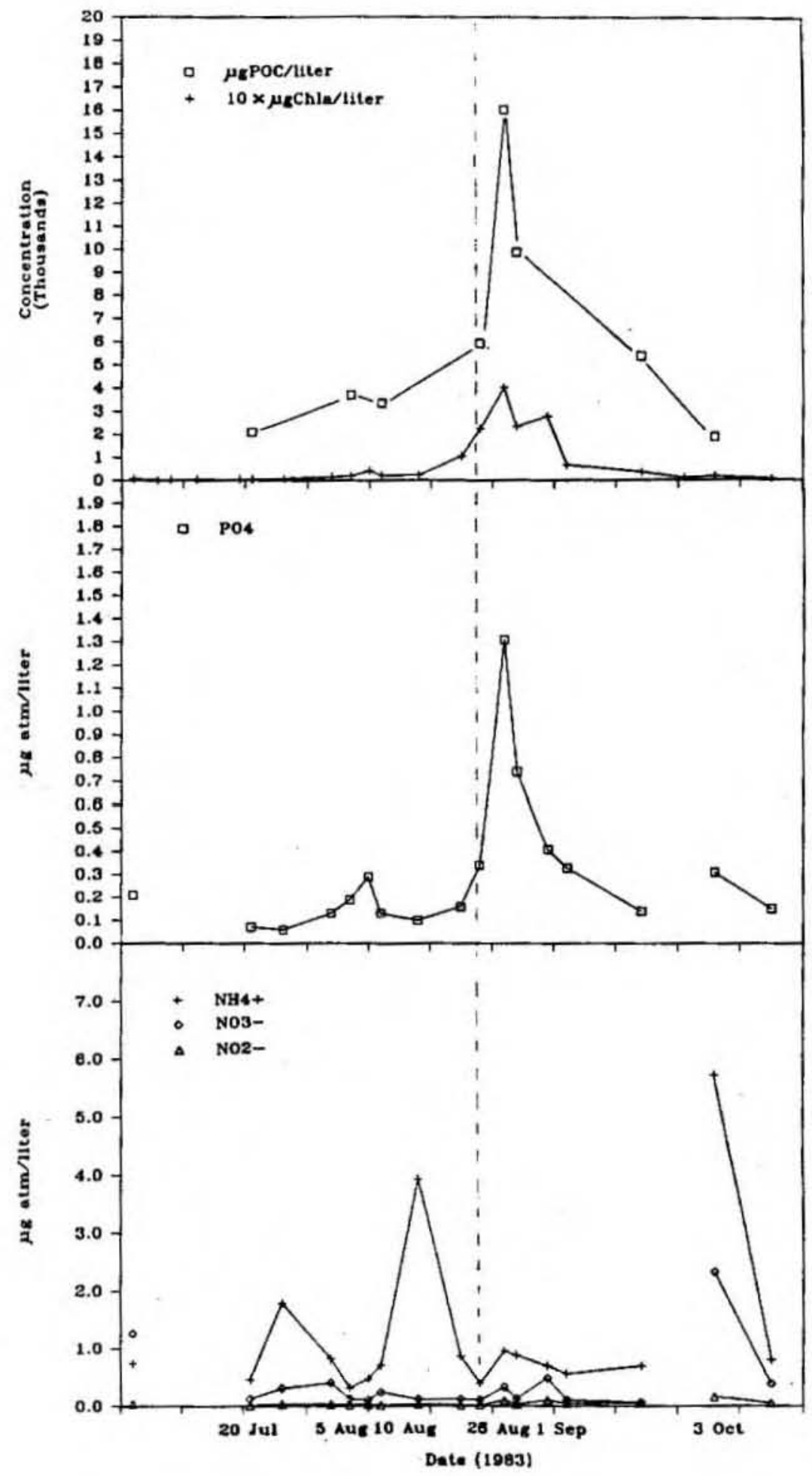


F1gure 5-14. Particulate organlc carbon to chlorophyl1 a ratios during the study period in Salt Pond. 


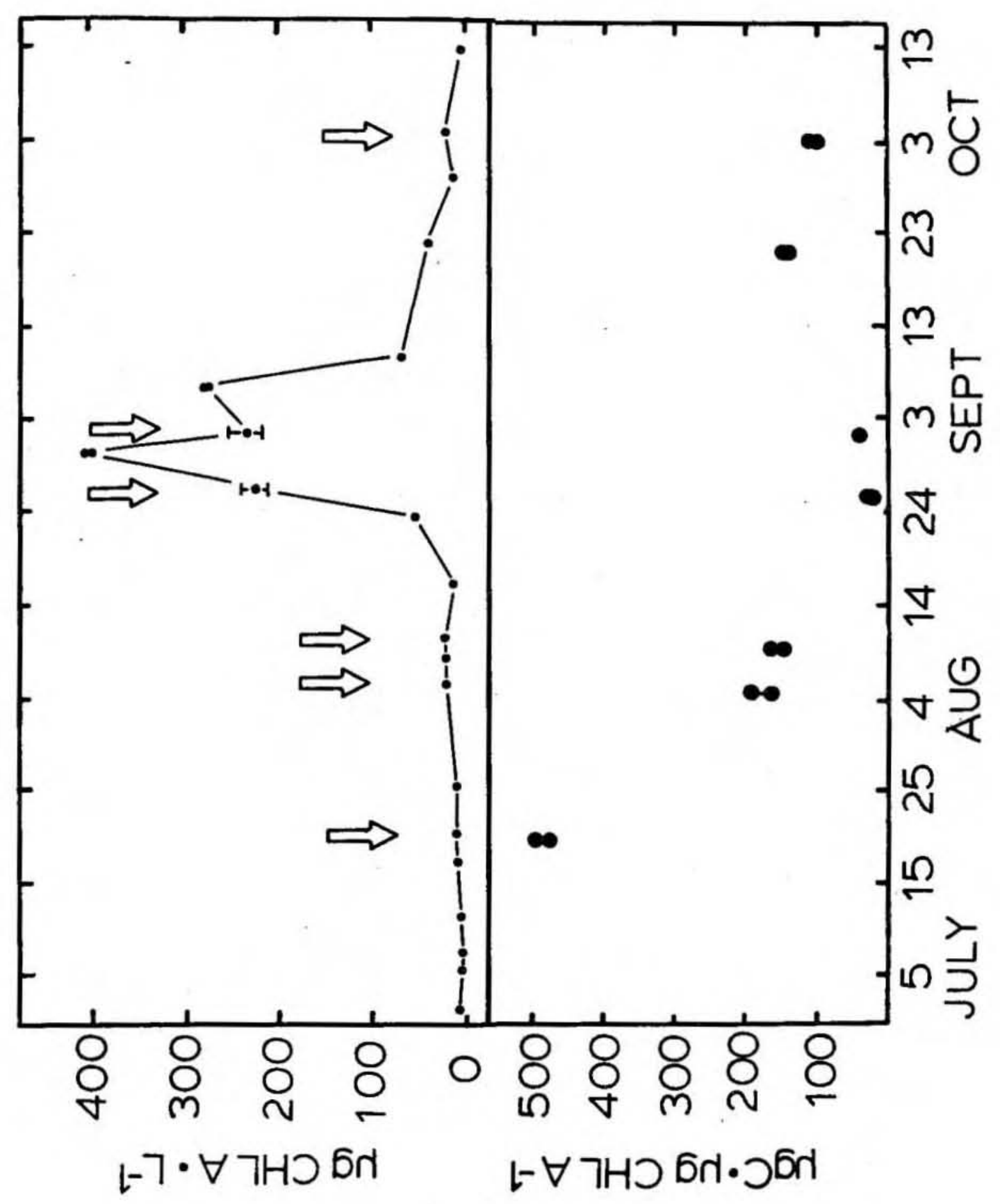


limited cultures of Nannochloris sp. Obviously, the metabolic characteristics of 0listhodiscus magnus may be different from Nannochloris sp. In addition, metabolic and compositional characteristics of populations growing under diel light cycles are 11kely to be different from laboratory continuous cultures.

Variations between day and night metabolism were considered as a possible explanation for the fact that the midday PPAA/POC production ratio was higher than the midday PPAA/POC concentration ratio (Figure 5-12, Table 5-14). This would require either night production of total particulate carbon at a higher relative rate than particulate amino acids, or preferential catabolism or respiratory degradation of protein relative to other cell material. Neither of these possibilities is consistent with previous observations of preferential conservation of proteln at the expense of storage material during the dark period in synchronous laboratory cultures grown in 1ight/dark cycles (Handa, 1969; Darley et al., 1976; Lorenzen and Kaush1k, 1976; VanLiere et a1., 1979; Hitchcock, 1980). However, day/night varlations in protein metabolism of Olisthodiscus species has not been investigated, so generalizations should be considered tenative.

In view of the low capacity of 0listhodiscus luteus for nitrogen uptake ( $K_{8}$ approximately 2 micromolar, Tomas, 1979), it is reasonable to assume that the bloom population was nitrogen limited. Although nutrient concentrations during the bloom were below the saturation uptake determined for $\underline{0}$. luteus (Figure 5-13), it is likely that they could have been utilized by other algae. The pattern of biosynthesis during the decline of the bloom may have reflected the metabolic activity of other species in the mixed algal population. Changes in patterns of 
Incorporation of labelled carbon into subcellular materlal provided additional evidence that changes in population physlological state occurred during the bloom (Figure 5-15). One interpretation of these observations is that as a result of the accumulation of senescent biomass, the bulk composition of POM did not reflect the metabolism of an active algal population which was distinct from the declining bloom population. This would result in a real input of PPAA in excess of 1 ts proportion in POC. In the following section, I propose several mechantsms which could lead to enhanced removal of protein and the resulting discrepancy between production and composition.

Net Removal of PPAA Relative to POC During the Bloom

The calculations of net removal shown in Table 5-11 indicate more rapid removal of PPAA relative to POC during the bloom. Referring to equation (2), selective grazing $\left(R_{g}\right)$ of protein enriched organic matter would be a potential mechanism for enhanced PPAA removal. Investigations with another 0listhodicus species, 01isthodiscus luteus, have found it to be relatively unpalatable to zooplankton (Verity and Stoecker, 1982; Tomas and Deason, 1981). Thus it is 11kely that algae able to utilize existing nitrogen concentrations would be selectively grazed $\left(R_{g}\right)$. Furthermore, grazers may preferentlally assimilate proteln (Scott, 1980), and release fecal material depleted in n1trogen (Small et al., 1983). Such activities would suppress the influence of the active autotrophs on POM composition, despite their potentlal importance as a source of protein for higher trophic levels.

Differential susceptibilities of POC and PPAA to decomposition and transformation into $D O C\left(R_{D O C}\right)$ could also lead to selective removal of 
F1gure 5-15. Proportion of total ${ }^{14} \mathrm{C}$ incorporation associated with subcellular fractions of natural phytoplankton populations during the study period in Salt Pond. Open bars, hot trichloroscetic ac1d Insoluble (1ncluding prote1n); thinly hatched, hot trichloroacetic acid soluble (polysacharride and nucleic acid); densely hatched, lipophylic; solid bars, alcohol soluble. 


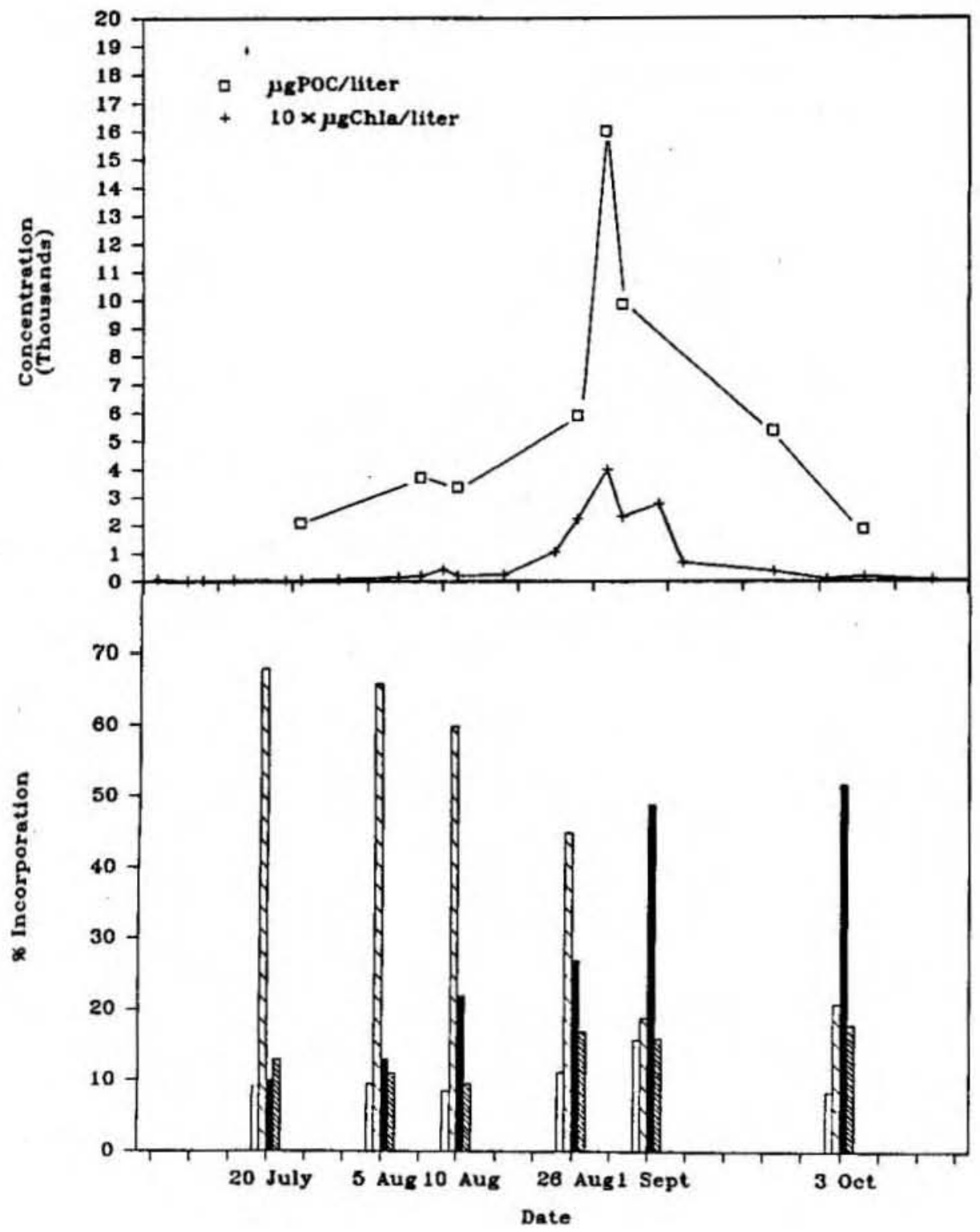


protein. As the bloom neared its peak, the bloom species population likely became increasingly senescent. Hence, both autolytic activities and decomposition of organic matter would have become relatively nore Important in affecting POM composition (c.f. Jassby and Goldman, 1974). Lee and Cronin (1984) reported that depth dependent losses of particulate amino acids from suspended particulate matter were enhanced in more productive areas. Significant extracellular proteolytic action on soluble proteins has been demonstrated (Ho1libaugh and Azam, 1983; Somville and B1llen, 1983) and could also serve as a mechanism for the accelerated breakdown of protein in 1nactive algal biomass. Release of DOC accompanying blooms has been observed previously, including the release of amino acids (Ittekot, 1982). From results of decomposition studies (e.g. Harrison, 1980), phosphorus is known to be one of the most rapldly remineralized elements. $\mathrm{PO}_{4}^{3-}$ concentrations varled directly with POC and chlorophyl1 a (Figure 5-13), and the observed increase may have reflected accelerated decomposition of organic matter. Further evidence in support of enhanced decomposition was provided by the work of Lee and Hicke (mans. sub.). They determined that production of putrescine, a polyamine indicative of protein degradation, was accelerated during the bloom period.

Although it is 1ikely that significant chemotrophic production ( $P_{c}$ ) can be ruled out on the basis that dark uptake was not important relative to total productivity (Table 5-12), secondary production $\left(P_{2}\right)$ could introduce POM relatively low in PPAA/POC. Th1s will be a function of the physiological state of the bacterial population as well as the composition of their growth substrate. Fukami et al. (1985) found that decomposing algal material was inftially enriched in protein due to 
colonization by bacteria. However, the extent to which this type of laboratory study can be generalized to natural systems is questionable. As previously mentioned, because of the potential for spatial and temporal heterogeneity in sampling, advection or diffusion could have selectively influenced the PPAA/POC ratio. Therefore, for future investigations, I recommend that direct comparisons of materials within the incubation chamber be made.

Physical removal $\left(R_{p}\right)$ such as sedimentation could also be selective with respect to PPAA/POC content if more rapidly sedimenting particles were enriched in protein. Lee and Hicke (mans. sub.) observed an increase in the concentration of putrescine and ornithine with depth, which would be consistent with decomposition of sinking phytoplankton proteln. However, diffusive flux from the sediment or decomposition of allocthonous organic matter such as eel grass could also contribute to the levels of these compounds.

The fact that the bloom consisted of a large-celled flagellated organism (01isthodiscus magnus) may have lead to a proportionate decrease in sedimentation rates. $\mathrm{CO}_{2}$ production below three meters, (as determined by changes in concentration) apparently decreased during the bloom (Table 5-13), but such c1rcumstantial evidence cannot be used to infer changes in actual flux from the mixed layer. It is possible that the characteristics of 01isthodiscus magnus led to an increased residence time of senescent biomass in the mixed layer, thereby masking the impact of the biosynthetic activities of other algae on POM composition. 


\section{CONCLUSIONS}

This study is a first attempt to determine the importance of primary Inputs of POC and PPAA in ciontrolling their relative abundances in the POM, and to assess the degree to which the relative abundances of these b1ochemicals were Indicative of the metabolic state of the phytoplankton population. In addition, production of PPAA and POC was compared to observed changes in their cioncentrations, in order to estimate and compare net removal rates and evaluate the potential impact of autotrophic inputs on POM composition.

During the period before the bloom, the composition of bulk POM suggested production by the photoautotrophs. Primary Inputs were significant relative to observed concentrations, consistent with the view that algal blosynthetic activity was an 1mportant factor controling the composition of particulate organic matter. Production exceeded observed changes in concentration of POC and PPAA, Indicating that substantial amounts of POM were being removed from the euphotic system of Salt Pond by processes which did not ifferentiate between PRAA and POC. Non-selective removal processes which could have been responsible for these observations included sedimentation, non-selective grazing, and advection and diffusion.

During the bloom perlod, the proportion of total POC production associated with particulate protein amino acid production was significantly higher than the PPAA/POC ratio in the particulate organic matter. In view of low Inorganic nitrogen concentrations and low light intensities, it was suggested that the decline of the 011sthodiscus magnus bloom may have resulted from both 11ght and nitrogen 11mitation. The fact that the PPAA/POC production ratio was higher than the PPAA/POC 
concentration ratio could be explained by turnover of protein in excess of net synthesis. Other mechanisms were proposed as possible explanations of the discrepancy including selective grazing and enhanced decomposition of accumulated senescent blomass, which would have suppressed the Influence of the active photoautotrophs on POM composition.

Discrepancles between primary production and POM composition were observed only in a situation of unusually high particulate organic matter concentrations and only during a single sampling period. In general, within the limits of analytical precision, the composition of particulate organic matter reflected the biosynthetic activities of the algal population. These results are consistent with the view that, during the period of study, algal blosynthetic activity was the predominant factor controlling the relative abundance of protein in the particulate organic matter, and the corresponding flux of protein to higher trophic levels in the mixed layer of Salt Pond.

A major 11mitation in interpreting these results was the need for greater precision and higher frequency in sampling. Nevertheless, this study 11lustrates an approach which can lead to an Increased understanding of the compositional dynamics of individual biogenic compounds, and the characteristics of organisms which control them. It is my oplnion that through careful assessments of the behaviour of compounds which are markers of blochemical activitles, it will be possible to advance our understanding of the role of microblal metabolism in trophodynamic and blogeochemical activity in aquatic ecosystems. 


\section{REFERENCES}

Alldredge, A. L., 1979. The chemlcal composition of macroscopic aggregates in two neretic seas. L1mnol. Oceanogr. 24, 855-866.

Ammerman, J. W., J. A. Fuhrman, A. Hagstrom, and F. Azam, 1984. Bacterioplankton growth in seawater: I. Growth kinetics and cellular characteristics in seawater cultures. Mar. Ecol. Prog. Ser. 18, 31-39.

Andersson, A., C. Lee, F. Azam, and A. Hagstrom, 1985. The release of free amino acids by heterotrophic marine microflagellates. Mar. Ecol. Prog. Ser. In press.

Andrews, P., and P. J. leB. Williams, 1971. Heterotrophic utilization of dissolved organtc compounds in the sea. III. Measurement of the oxidation rates and concentrations of glucose and amino acids in sea water. J. Mar. Btol. Assoc., U.K. 51, 111-125.

Anikouchine, W. A., and R. W. Sternberg, 1973. The World Ocean: An Introduction to Oceanography. Prent1ce Hall, Inc. New Jersey. 338 pp.

Anitla, N. J., B. R. Berland, and D. J. Bonin, 1980. Proposal for an abridged nitrogen turnover cycle in certain marine plank tonic systems involving hypoxanthine-guanine excretion by cillates and their re-utilization by phytoplankton. Mar. Ecol. Prog.Ser. 2, 97-103.

Azam, F., and J. W. Ammerman, 1984. Cycling of organic matter by bacterloplankton in pelagic marine ecosystems: microenvironmental considerations. In: Flows of Energy and Materials in Marine Ecosystems (M. J. R. Fasham, ed.) Plenum Publishing Corp., New York.

Azam, F., T. Fenchel, J. G. Fleld, J. S. Gray, L. A. Meyer-Reid, and F. Thingstad, 1983. The ecological role of water-cloumn microbes in the sea. Mar. Ecol. Prog. Ser. 10, 257-263.

Azam, F., and 0. Holm-Hansen, 1973. Use of tritiated substrates in the study of heterotrophy in seawater. Mar. B1ol. 23, 191-196.

Banse, K., 1974. On the role of bacterloplankton in the Tropical Ocean. Mar. Biol. 24, 1-5.

Banse, K., 1977. Determining the carbon-to-chlorophyll rat1o of natural phytoplankton. Mar. Biol. 41, 199-212.

Banse, K., 1982. Cell volumes, maximal growth rates of unicellular algae and ciliates, and the role of ciliates in the marine pelagial. Limnol. Oceanogr. 27, 1059-1071.

Barlow, R. G., 1980. The blochemical composition of phytoplankton in an upwelling region off South Africa. J. exp. mar. Biool. Ecol. 45 , 83-93.

Barlow, R. G., 1982a. Phytoplankton ecology in the southern Benguela current. I. Blochemical composition. J. exp. Mar. Biol. Ecol. 63, 209-227.

Barlow, R. G., 1982b. Phytoplankton ecology in the Southern Benguela current. II. Carbon assimilation patterns. J. Exp. Mar. Biol. Ecol. $63,229-237$.

Barlow, R. G., and J. L. Henry, 1982. Patterns of carbon assimilation in phytoplankton from the Southern Ocean. Fish. Bull. S. Afr. 16, 25-29.

Bassham, J. A. and M. K1rk, 1964. Photosynthesis of amino acids. Blochim. Blophys. Acta $90,553-562$. 
Bassham, J. A., A. A. Benson, L. D. Kay, A. Z. Harris, A. T. Wilson, and M. Calvin, 1954. The path of carbon in photosynthes1s. XXI. The cyclic regeneration of carbon dioxide acceptor. J. Amer. Chem. Soc. $76,1760-1770$.

Bassham, J. A., B. Morawlecka, and M. K1rk, 1964. Prote1n synthes1s during photosynthesis. Blochim Blophys. Acta 90, 542-552.

Bates, S. S., 1981. Determination of the physiological state of marine phytoplankton by use of radiosulfate incorporation. J. exp. mar. Biol. Ecol. 51, 219-239.

Bayer, E., E. Gram, B. Kaltenegger, and R. Uhmann, 1976. Separation of amino acis by high performance liquid chromatography. Anal. Chem. 48, 1106-1109.

Baylor, E. R., and W. H. Sutcliffe, Jr., 1963. Dissolved organic matter in seawater as a source of particulate food. Limnol. Oceanogr. 4 , 369-371.

Beale, S. I., and D. Appleman, 1971. Chlorophy11 synthes1s in Chlorella. Regulation by degree of 11ght 11mitation of growth. Plant. Phys. 47, 230-235.

Beardall, J., and I. Morr1s, 1976. The concept of 11ght intensity adaptation in marine phytoplankton: some experimetns with Phaeodactylum tricornutum. Mar. B101. 37, 377-387.

Beers, J. R., F. M. H. Re1d, and G. L. Stewart, 1975. Microplankton of the North Pacific Central Gyre. Population structure and abundances, June 1973. Int. Revue. ges. Hydrob1ol. 60, 607-638.

Bell, W. H., 1980. Bacterfal utilization of algal extracellular products. 1. The kinetic approach. Lfmnol. Oceanogr. 25, 1007-1020.

Bell, W. H., 1983. Bacterial utilization of algal extracellular products. 3. The specificity of the algal-bacterial interaction. Limnol. Oceanogr. 28, 1131-1143.

Bell, W. H., and E. Sakshaug, 1980. Bacterlal ut1lization of algal extracellular products. 2. A kinetic study of natural populations. L1mno1. Oceanogr. 25, 1021-1033.

Bell, W. H., and R. Mitchell, 1972. Chemotact1c and growth responses of marine bacteria by algal extracellular products. B1ol. Bull. 143, 265-277.

Beudeker, R. F., 1984. Glycolate metabolism is under nitrogen control in Chorella. Plant Phys. 75, 516-520.

Bidwell, R. G. S., R. A. Barr, and F. C. Steward, 1964. Protein synthesis and turn-over in cultured plant tissue: sources of carbon synthesis and the fate of the protein beakdown products.

Bishop, J. K. B., D. R. Ketten, M. P. Bacon, and W. B. S1lker, 1977. The chemistry, biology, and vertical flux of particulate matter from the upper $400 \mathrm{~m}$ of the equatorial Atlantic Ocean. Deep-Sea Res. 24, 511-548.

B1shop, J. K. B., D. R. Ketten, and J. M. Edmond, 1978. The chemistry, biology, and vertical flux of particulate matter from the upper $400 \mathrm{~m}$ of the Cape BAsin in the southeast Atlantic Ocean. Deep-Sea Res. $\underline{25}$, 1121-1161.

Bradford, M., 1976. A rap1d and sensitive method for the quantitation of microgram quantities of protein utilizing the principle of proteln-dye binding. Anal. Blochem. 72, 248-?.

Calvin, M. and P. Massin1, 1952. The path of carbon in photosynthesis. XX. The steady state. Experent1a 8, 445-484. 
Caperon, J., and J. Meyer, 1972. N1trogen limited growth of marine phytoplankton. I. changes in population characterlstics with steady state growth rate. Deep Sea Res. 19, 601-618.

Caperon, J., D. Sche11, J. Hirota, and E. Laws, 1979. Ammonlum excretion rates in Kaneohe Bay, Hawall measured by an ${ }^{15} \mathrm{~N}$ isotope dilution technique. Mar. B1ol. 54, 33-?.

Carpenter, E. J., and J. J. McCarthy, 1975. Nitrogen fixation and uptake of combined nitrogenous nutrlents by Oscillatoria ( $\operatorname{Tr} 1$ chodesmium) thiebaut11 in the western Sargasso Sea. L1mnol. Oceanogr. 20, 389-401.

Carpenter, E. J., and J. S. Lively, 1980. Revlew of estimates of algal growth using ${ }^{14} \mathrm{C}$ tracer techniques. In: Primary Productivity in the Sea (P. G. Falkowsk1, e.d.) Plenum Press, New York. pp. 161-178.

Catt $\overline{1011 \mathrm{co},}$ R. A., J. C. Boothroyd, and S. P. G1bbs, 1976. Synchronous growth and plastid replication in the naturally wall-1ess alga1 Olisthodiscus luteus. Plant Phys1ol. 57, 497-503.

Cauwet, G., 1978. Organic chemistry of sea water particulates: concepts and developments. Oceanol. Acta 1, 99-105.

Cauwet, G., 1981. Non-living particulate matter. In: Marine Organic Chemistry. Evolution, Composition, Interactions and Chemistry of Organlc Matter In Seawater (E. K. Duursma and R. Dawson, eds.) Elsevier Sclentific Publishing Co., New York. pp. 71-89.

Chan, A. T., 1978. Comparative physlological study of marine diatoms and dinoflagellates in relation to Irradiance and cell size. I. Growth under continuous 11ght. J. Phycol. 14, 396-402.

Chan, A. T., 1980. Comparative physiological study of marine diatoms and dinoflagellates in relation to irradlance and cell size. II. Relationship between photosynthesis, growth, and carbon/chlorophy11 a ratio. J. Phycol. 16, 428-432.

Chau, Y. K., L. Chuecas, and J. P. R 1 ley, 1967. The component combined amino acids of some marine phytoplankton species. J. mar. biol. Ass. U.K. 47, 543-554.

Chisholm, S. W., 1981. Temporal patterns of cell division in unicellular algae. In: Physlological Bases of Phytoplankton Ecology. (T. Platt, ed.) Can. Bul1. Fish. Aquat. Sc1. 210, 150-181.

Christie, W. W., 1973. Ilpid Analysis. Isolation, Separation, Identification, and Structural Analysis of Lipids. Pergamon Press, New York.

Cole, J. J., G. E. L1kens, and D. L. Strayer, 1982. Photosynthetically produced dissolved organic carbon: an important carbon source for planktonic bacterla. Limnol. Oceanogr, 27, 1080-1090.

Collos, Y. and G. Slawyk, $1979 .{ }^{13} \mathrm{C}$ and ${ }^{15} \mathrm{~N}$ uptake by marine phytoplankton. I. Influence of nitrogen source and concentration in laboratory cultures of diatoms. J. Phycol. 15, 186-190.

Conover, R. J., 1980. General rules of grazing in pelagic ecosystems. In: Primary Production in the Sea (P. G. Falkowsk1, ed.) Plenum Press, New York. pp. 461-485.

Conover, S. A. M., 1975. Partitioning of nitrogen and carbon in cultures of the marine diatom Thalasslosira fluviatilis supplied with nitrate, ammonfum, or urea.

Cook, J. R., 1963. Adaptations in growth and division in Euglena effected by energy supply. J. Protozool. 10, 436-444. 
Cowey, C. B., and E. D. S. Corner, 1963. On the nutrition and metabolism of zooplankton. II. Relationship between the marlne copepod Calanus helgolanidis and particulate material in P1ymouth sea water, in terms of amino acid composition. J. mar. blol. Ass. U. K. 43, 495-511.

Cox, R. A., M. J. McCartney, and F. Culkin, 1970. The specific gravity/salinity/temperature relationshlp in natural sea water. Deep-Sea Res. 17, 679-689.

Crawford, C. C., J. E. Hobble, and K. L. Webb, 1974. The utilization of dissolved free amino acids by estuarine microorganisms. Ecology 55, 551-563.

Cuhe1, R. L., 1981. Assimilatory sulfur metabollsm in marine microorganisms. Ph.D. thesis, Woods Hole Oceanogr. Inst. Also Woods Hole Oceanogr. Inst. Pub1. 81-29. 418pp.

Cuhe1, R. L., C. D. Taylor, and H. W. Jannasch, 1981a. Assimilatory sulfur metabolism in marine microorganisms: characteristics and regulation of sulfate transport in Pseudomonas halodurans. J. Bacteriol. 147, 340-349.

Cuhel, R. L., C. D. Taylor, and H. W. Jannasch, 1981b. Assimilatory sulfur metabolism in marine mlcroorganisms: sulfur metabolism, growth, and protein synthesis of Pseudomonas halodurans and Alteromonas luteo-violaceus during sulfacte 11mitation. Arch. Microblol. $130,1-7$.

Cuhel, R. L., C. D. Taylor, and H. W. Jannasch, 1981c. Assimflatory sulfur metabolism in marine microorganisms: sulfur metabolism, proteln synthesis, and growth of Pseudomonas halodurans and Alteromonas luteo-violaceus during unperturbed batch growth. Arch. Microbiol. $130,8-13$.

Cuhe1, R. L., C. D. Taylor, and H. W. Jannasch, 1982a. Assimilatory sulfur metabolism in marine microorganisms: sulfur metabolism, protein synthesls, and growth of Pseudomonas halodurans and Alteromonas luteo-violaceus durfig unperturbed batch growth. Appl. Environ. M1 crobiol. 43, 151-159.

Cuhe1, R. L., C. D. Taylor, and H. W. Jannasch, 1982b. Assimilatory sulfur metabolism in marine microorganisms: considerations for the application of sulfate incorporation into proteln as a measure of natural marine microbial protein synthesis. Appl. Environ. Microbio1. 43, 160-168.

Cuhe1, R. L., H. W. Jannasch, C. D. Taylor, and D. R. S. Lean, 1983. Microblal growth and macromolecular synthesis in the northwestern Atlantic Ocean. Limnol. Oceanogr. 28, 1-18.

Cuhel, R. L., P. B. Ortner, and D. R. S. Lean, 1984. Night synthesis of proteln by algae. Limnol. Oceanogr. 29, 731-744.

Cuhel, R. L., and J. B. Waterbury, 1984. Blochemical composition and short term nutrient incorporation patterns in a uniceilular marine cyanobacterfum, Synechococcus (WH7803). L1mnol. Oceanogr. 29, 370-374.

Darley, W. M., C. W. Sullivan, and B. E. Volcanl, 1976. Studles on the blochemistry and fine structure of sllica shell formation in diatoms. Division cycle and chemical composition of Navicula pelliculosa during 11ght-dark synchronized growth. Planta (Berl.) $130,159-167$. 
Davenport, J. B., and B. Maguire, Jr., 1984. Quantitative graln density autoradiography and the intraspecific distribution of primary productivity in phytoplankton. Limnol. Oceanogr. 29, 410-416.

Dawson, R., and K. Gocke, 1978. Heterotrophic activity in comparison to the free amino acid concentration in Baltic sea water samples. Oceanol. Acta $1,45-54$.

Dawson, R., and E. K. Duursma, 1981. State of the art. In: Marine Organlc Chemlstry (E. K. Duursma and R. Dawson, eds.) Elsevler Sclentific Publishing Co., New York. pp. 497-512.

DeJong, C., G. J. Hughes, E. VanWleringen, and K. J. Wilson, 1982. Amino acid analyses by high-performance liquid chromatography. An evaluation of the usefulness of pre-column Dns derivatization. J. Chromatog. 241, 345-359.

DeManche, J. M., 1980. Varlations in phytoplankton physiological parameters during transient nitrogen environments. Ph.D. thesis, Oregon State University, Corvallis.

DeManche, J. M., H. C. Cur1, Jr., D. W. Lundy, and P. L. Donaghay, 1979. The rapld response of the marine diatom Skeletonema costatum to changes in external and internal nutrient concentration. Mar. B1ol. $53,323-333$.

Degens, E. T., 1970. Molecular nature of n1trogenous compounds in sea water and recent marine sediments. Occ. Publ. Inst. Mar. Sci., Univ. Alaska 1, 77-106.

Derenbach, J. B., and P. J. 1eB. Will1ams, 1974. Autotroph1c and bacterial producion: fractionation of plankton populations by differential filtration of samples from the English Channel. Mar. Biol. 25, 263-269.

DiTullio, G. R., E. A. Laws, 1983. Estimates of phytoplankton N uptake based on ${ }^{14} \mathrm{CO}_{2}$ incorporation into protein. Limnol. Oceaongr. 28, 177-185.

Dolittle, R. F., 1981. Slmilar amino acld sequences: chance or common ancestry? Sclence 214, 149-159.

Donaghay, P. L., J. M. DeManche, and L. F. Sma11, 1978. On predicting phytoplankton growth rates from carbon:nitrogen ratios. Limnol. Oceaongr. 23, 359-362.

Dortch, Q., 19 $\overline{82}$. Effect of growth conditions on accumulation of internal nitrate, ammonium, amino aclds, and protein in three marine dlatoms. J. Exp. Mar. Ecol. Biol. 61, 243-264,

Dring, M. J., and D. H. Jewson, 1982. What does ${ }^{14} \mathrm{C}$ uptake by phytoplankton really measure? A theroretical modelling approach. Proc. R. Soc. Lond. B 214, 351-368.

Dugdale, R. C., and J. J. Goerlng, 1967. Uptake of new and regenerated forms of nitrogen in primary productivity. Limnol. Oceanogr. 12, 196-206.

Edge, P. A., and T. R. Ricketts, 1977. The effect of nitrogen refeeding on the carbohydrate content of nitrogen starved cells of Platymonas striata Butcher. Planta 136, 159-162.

Eppley, R. W., W. G. Harrison, S. W. Chlsholm, and E. Stewart, 1977. Particulate organic matter in surface waters off southern California and its relationship to phytoplankton. J. Mar. Res. 35, 671-696.

Eppley, R. W., and B. J. Peterson, 1979. Pariculate organic matter flux and planktonic new production in the deep ocean. Nature 282, 677-680. 
Falkowsk1, P. G., and T. G. Owens, 1978. Effects of 11ght intensity on photosynthesis and dark respiration in six species of marine phytoplankton. Mar. B1ol. 45, 289-295.

Falkowsk1, P. G., and T. G. Owens, 1980. Light-shade adaptation: two stratagies in marine phytoplankton. Plant Phys. 66, 592-595.

Fallon, R. D., and T. D. Brock, 1979. Decomposition of blue-green algal (cyanobacterial) blooms in Lake Mendota, Wisconsin. App1. Environ. Microblol. $37,820-830$.

Ferguson, R. L., E. N. Buckley, and A. V. Palumbo, 1984. Response of marine bacterloplankton to differential filtration and confinement. Appl. Environ. Microbiol. 47, 49-55.

Ferguson, R. L., and W. G. Sunda, 1984. Utilization of amino acids by planktonic marlne bacteria: importance of clean technique and 10 w substrate additions. Limnol. Oceanogr. 29, 258-274.

Flsher, T. R., P. R. Carlson, and R. T. Barber, 1981. Some problems in the interpretation of ammonium uptake kinetics. Mar. Biol. Letters $2,33-44$.

Fitzwater, S. E., G. A. Knauer, and J. H. Mart1n, 1982. Metal contamination and 1 ts effect on primary production measurements. Limnol. Oceanogr. 27, 544-551.

Fogg, G. E., 1956. Photosynthesis and formation of fats in a diatom. Annls. Bot., N. S. 20, 265-285.

Fogg, G. E., 1959. Nitrogen nutrition and metabolic patterns in algae. Symp. Soc. Exp. B1ol. 13, 106-125.

Fogg, G. E., 1962. Extracellular products. In: Physlology and Blochemistry of Algae (R. A. Lewin, ed.). Academlc Press, New York. pp. 475-489.

Fogg, G. E., 1977. Excret1on of organ1c matter by phytoplankton. L1rono1. Oceanogr. 22, 576-577.

Fowden, L., 1954. A comparison of the composition of some algal proteins. Annls. Bot. $18,258-266$.

Fukami, K., U. S1midu, and $\bar{N}$. Taga, 1985. Microblal decomposition of phyto- and zooplankton in seawater. I. Changes in organic matter. Mar. Ecol. Prog. Ser. 21, 1-5.

Gagosian, R. B., S. 0. Smlth, and G. E. Nigrell1, 1982. Vertical transport of sterold alcohols and ketones measured in a sediment trap experiment in the equatorial Atlantic Ocean. Geochim. Cosmochim. Acta 46, 1163-1172.

Gagosian, R. B., and C. Lee, 1981. Processes controlling the distribution of blogenlc organic compounds in seawater. In: Marine Organic Chemistry. Evolution, Composition, Interactions and Chemistry of Organlc Matter in Seawater (E. K. Duursma and $R$. Dawson, eds.) Elsevier Sclentific Publishing Co., New York. pp. 91-123.

Garfield, P. C., T. T. Packard, and L. A. Codispot1, 1979. Particulate proteln in the Peru upwelling system. Deep Sea Res. 26 (6A), 623-639.

Garside, C., 1984. Apparent $15_{\mathrm{N}}$ uptake kinetics resulting from remineralization. Limnol. Oceanogr. 29, 204-210.

Garside, C., and P. M. Glibert, 1984. Computer modeling of $15_{\mathrm{N}}$ uptake and remineralization experiments. Limnol. Oceanogr. 29, 199-204.

Gast, V., and U. Horstmann, 1983. N-remineralization of phyto- and bacterloplankton by the marine clllate, Euplotes vannus. Mar. Ecol. Prog. Ser. 13, 55-60. 
Gleskes, W. W. C., G. W. Krosy, and M. A. Baars, 1979. Current ${ }^{14} \mathrm{C}$ methods for measuring primary production: gross underestimates in oceanic waters. Netherlands $J$. Sea Res, 13, 58-78.

Glibert, P. M. and J. C. Goldman, 1981. Rapld ammonlum uptake by marine phytoplankton. Mar. B1ol. Letters 2, 25-31.

Glibert, P. M., F. If pschultz, J. J. McCarthy, and M. A. Altabet, 1982. Isotope dilution models of uptake and remineralization of ammonium by marine plankton. Limnol. Oceanogr. 27, 639-650.

Goldman, J. C., 1977. Steady state growth of phytoplankton in continuous culture: comparison of internal and exterinal nutrient equations. J. Phycol. 13, 251-258.

Goldman, J. C., 1980. Physiological processes, nutrlent avallability, and the concept of relative growth rate in marine phytoplankton ecology. In: Primary Productiv1ty in the Sea (P. G. Falkowsk1, ed.) Plenum Press, New York. pp. 179-194.

Goldman, J. C. , and J. J. McCarthy, 1978. Steady-state growth and ammonlum uptake of a fast-growing marine diatom. Limnol. Oceanogr. $23,695-703$.

Goldman, J. C., and D. G. Peavey, 1979. Steady-state growth and chemlcal composition of the marine chlorophyte Dunaliella tertiolecta in nitrogen-11mited cultures. Appl. Environ. Microbiol. 38, 894-901.

Goldman, J. C., J. J. McCarthy, and D. W. Peavey, 1979. Growth rate influence on the chemical composition of phytoplankton in oceanic waters. Nature 279, 210-215.

Goldman, J. C., C. D. Taylor, and P. M. Glibert, 1981a. Nonlinear time-course uptake of carbon and ammonium by marine phytoplankton. Mar. Ecol. Prog. Ser. 6, 137-148.

Goldman, J. C., M. R. Dennett, and C. B. Riley, 1981b. Marine phytoplankton photosynthes 1 s and transient ammonlum avallability. Mar. B1ol. Letters 2, 323-331.

Goldman, J. C., and P. $\bar{M}$. Glibert, 1982 . Comparative rapld ammonlum uptake by four specles of marine phytoplankton. L1mnol. Oceanogr. 27, 814-827.

Goldman, J. C., and P. M. Glibert, 1983. Kinetlcs of Inorganle nitrogen uptake by phytoplankton. In: N1trogen in the Marine Environment (E. J. Carpenter and D. G. Capone, eds.) Academic Press, New York. pp. 233-274.

Goldman, J. C., and M. R. Dennett, 1984. Photosynthet1c responses of 1.5 phytoplankton species to ammonium pulsing. Marine Ecology Progress Sertes.

Goltermann, H. L., 1964. Minerallzation of algae under sterlle conditions or by bacterlal breakdown. Verh. Internat. Verein. $11 \mathrm{mno1}$. 15, 544-548.

Gulllard, R. R. L., 1975. Culture of phytoplankton for feeding marine invertebrates. In: Culture of Marine Invertebrate Animals (W. L. Smith and M. H. Chanley, eds.) Plenum Publishing Corp., New York. pp. 29-60.

Guillard, R. R. L., and J. H. Ryther, 1962. Studies on marine planktonic diatoms. I. Cyclotella nana Hustedt and Detonula confervacea (Cleve) Gran. Can. J. Microbiol. 8 , 229-239.

Gutel'makher, B. L., 1973. Autoradlography as a method of determining the relative contributin of individual algal species to the primary production of plankton. Hydroblo1. J. 9, 161-64. 
Hagström, A., J. W. Ammerman, S. Henrlchs, and F. Azam, 1984.

Bacterloplankton growth in seawater: II. Organlc matter utilization during steady state growth in seawater cultures. Mar. Ecol. Prog. Ser. $18,41-48$.

Hammer, K. D., and U. H. Brockman, 1983. Rhythmic release of dissolved free amino acids from partly synchronized Thalasslosira rotula under nearly natural conditions. Mar. Biol. 74, 305-312.

Handa, N., 1969. Carbohydrate metabolism in the marine diatom, Skeletonema costatum. Mar. B1ol. 4, 208-214.

Handa, H., 1970. Dissolved and particulate carbohydrates. Occ. Publ. Inst. Mar. Sc1., Un1v. Alaska, 1, 129-152.

Harding, L. W., Jr., B. B. Prezelin, B. M. Sweeney, and J. L. Cox, 1982a. Diel oscillations of the photosynthesis-irradiance (P-I) relationship in natural assemblages of phytoplankton. Mar. B1ol. 67, 167-178.

Harding, L. W., Jr., B. B. Prezelin, B. M. Sweeney, and J. L. Cox, 1982b. Primary production as Influenced by dlel perfodicity of phytoplankton photosynthesis. Mar. Biol. 67, 179-186.

Harris, G. P., S. I. Heaney, and J. F. Talling, 1979. Physlological and environmental constraints in the ecology of the planktonic dinoflagellate Ceratium hirundinella. Freshwater B1ol. 9, 413-428.

Harris, G. P., and B. B. Piccinin, 1977. Photosynthesis by natural phytoplankton populations. Arch. Hydroblol. 80, 405-457.

Harrison, W., 1978. Experimental measurements of nitrogen remineralization in coastal waters. Limnol. Oceanogr. 23, 684-694.

Harrison, P. J., H. L. Conway, and R. C. Dugdale, 1976. Marine diatoms grown in chemostat under silicate or ammonium limitation. 1. Cellular chemical composition and steady state growth kinetics of Skeletonema costatum. Mar. B1ol. 35, 177-186.

Harrison, W. G. 1980 . Nutrient regeration and primary production in the sea. In: Primary production in the sea (P. G. Falkowski, ed.) Plenum Press, New York, pp. 433-460.

Harrison, W. G., D. Douglas, P. Falkowsk1, G. Rowe, and J. Vidal, 1983. Summer nutrient dynamics of the Middle Atlantic Bight: nitrogen uptake and regeneration. J. Plankton Res. $\underline{5}, 539-556$.

Harvey, G. R., 1983. Dissolved carbohydrates in the New York bight and the varlability of marine organic matter. Mar. Chem. 12, 333-339.

Haug, A., S. Myklestad, and E. Sakshaug, 1973. Studies on the phytoplankton ecology of the Trondhelmsfjord. I. The chemical composition of phytoplankton populations. J. exp. mar. Biol. Ecol. $11,15-26$.

Healey, F. P., 1979. Short-term responses of nutrient deficient algae to nutrient addition. J. Phycol. 15, 289-299.

Heber, U., 1974. Metabolite exchange between chloroplasts and cytoplasm. Ann. Rev. Plant Phys1o1. 25, 393-421.

Hellebust, J. A., 1965. Excretion of some organic compounds by marine phytoplankton. Limnol. Oceanogr. 10, 192-206.

Hellebust, J. A., and R. G. S. Bidwe11, 1964. Protein turnover in attached wheat and tobacco leaves. Can. J. Bot. 42, 1-12.

Hendrickson, P., K. G. Sellner, B. Rojas de Mendiola, N. Ochoa, and R. Zimmermann, 1982. The composition of particulate organic matter and biomass in the Peruvlan upwelling region during ICANE 1977 (Nov. 14-Dec. 2). J. Plank. Res. 4, 163-186. 
H1pkin, C. R., and P. J. Syrett, 1977. Some effects of nltrogen-starvation and carbohydrate metabolism in Ank1strodesmus braunil. Planta 133, 209-214.

H1tchcock, G. L., 1978. Labelling patterns of carbon-14 in net plankton during a winter-spring bloom. J. exp. mar. B1ol. Ecol. 31, 141-153.

H1tchcock, G. L., 1980. Diel varlation in chlorophyll a, carbohydrate and protein content of the marine diatom Skeletonema costatum. Mar. B1ol. 57, 271-278.

Hitchcock, G. L., 1981. Photosynthate partitioning in cultured marine phytoplankton. I. Dinoflagellates. J. exp. mar. B1o1. Ecol. 69, 21-36.

Hobble, J. E., C. C. Crawford, and K. L. Webb, 1968. AmIno ac1d flux In an estuary. Sclence 159, 1463-1464.

Hobson, L. A., 1971. Relationships between particulate organic carbon and micro-organisms in upwelling areas off Southwest Africa. ??

Hobson, L. A., D. W. Menzel, and R. T. Barber, 1973. Primary productivity and sizes of pools of organic carbon in the mixed layer of the oceans. Mar. B1ol. 19, 298-306.

Hollibaugh, J. T., A. B. Carruthers, J. A. Fuhrman, and F. Azam, 1980. Cycling of organfic nitrogen in marine plantkon communitles studied in enclosed water columns. Mar. Blol. 59, 15-21.

Hollibaugh, J. T., and F. Azam, 1983. M1crobial degradation of dissolved protelns in seawater. Limnol. Oceanogr. $28,1104-1116$.

Holligan, P. M., R. P. Harris, R. C. Newe11, D. S. Harbour, R. N. Head, E. A. S. Linley, M. I. Lucas, P. R. G. Tranter, and C. M. Weekley, 1984. Vertical distribution and partitioning of organic carbon in mixed, frontal, and stratifled water of the English Channel. Mar. Ecol. Prog. Ser. 14, 111-127.

Holm-Hansen, 0., K. Nish1da, V. Moses, and M. Calvin, 1959. Effects of mineral salts on short term Incorporation of carbon dioxide in Chlorella. J. Exptl. Bot. 10, 109-124.

Huffaker, R. C., and L. W. Peterson, 1974. Proteln turnover in plants and possible means of its regulation. Ann. Rev. Plant Physiol. 25, 363-392.

Ittekkot, V., 1982. Varlations of dissolved organic matter during a plankton bloom: qualitative aspects based on sugar and amino acid analyses. Mar. Chem. 11, 143-158.

Ittekkot, V., U. Brockman, W. Michaelis, and E. T. Degens, 1981. Dissolved free and combined carbohydrates during a phytoplankton bloom in the northern North Sea. Mar. Ecol. Prog. Ser. 4, 299-305.

Ittekot, V., E. T. Degens, and U. Brockmann, 1982. Monosaccharide composition of acid-hydrolyzable carbohydrates in particulate matter during a plankton bloom. Limnol. Oceanogr. 27, 770-776.

Jannasch, H. W., 1974. Steady state and the chemostat in ecology. LImnol. Oceanogr. $19,716-720$.

Jassby, A. D., and C. $\bar{R}$. Goldman, 1974. Loss rates from a lake phytoplankton community. L1mnol. Oceaongr. 19, 618-627.

Jeffries, H. P., 1969. Seasonal composition of temperate plankton communties: free amino aclds. Limnol. Oceanogr. 14, 41-52.

Jeffrles, H. P., 1970. Seasonal composition of temperate plankton communities: fatty acids. Limnol. Oceanogr. 15, 419-426. 
Jensen, L. M., 1984. Antimicrobial action of antibiotics on bacterial and algal carbon metabolism: on the use of antiblotics to estimate bacterlal uptake of algal extracellular products. Arch. Hydrobiol. 99, 423-432.

Johannes, R. E., 1964. Phosphorus excretion and body size in marine animals: microzooplankton and nutrient regeneration. Science 146, 923-924.

Johannes, R. E., 1965. Influence of mrine protozoa on nutrient regeneration. Limnol. Oceanogr. 10, 434-442.

Johnson, B. D., 1976. Non-living particle formation from bubble dissolution. L1mnol. Oceanogr. 21, 444-446.

Joiris, C., 1977. On the role of heterotrophic bacteria in marine ecosystems: some problems. Helgoländer wiss. Meeresunters. 30 , 611-621.

Jukes, T. H., R. Holmquist, and H. Moise, 1975. Amino acld composition of proteins: selection against the genetic code. Science 189, 50-51.

Kanazawa, T., K. Kanazawa, M. R. Kłrk, and J. A. Bassham, 1972. Regulatory effects of ammonia on carbon metabolism in Chlorella pyrenoldosa during photosynthesis and respiration. B1och1m. B1ophys. Acta 256, 656-669.

Kanazawa, T., M. R. K1rk, and J. A. Bassham, 1970. Regulatory effects of ammonia on carbon metabolism in photosynthesising Chlorella pyrenotdosa. Blochim. B1osphys. Acta 205, 401-408.

Karl, D. M., 1980. Cellular nucleotide measurements and applications in microbial ecology. Microbial. Rev. 44, 739-796.

Karl, D. M., 1981. Simultaneous rates of ribonuclelc ac1d and deoxyribnucleic acid synthesis for estimating growth and cell division of aquatic microbial communities. Appl. Environ. Microbiol. 42, 802-810.

Kar1, D. M., 1982. Microblal transformations of organic matter at oceantc interfaces: a revlew and prospectus. EOS $\underline{63}, 138-140$.

Kar1, D. M., C. D. W1nn, and D. C. L. Wong, 1981a. RNA synthesis as a measure of microbial growth in aquatic environments. I. Evaluation, verification and optimization of method. Mar. B1o1. 64, 1-12.

Karl, D. M., C. D. Winn, and D. C. L. Wong, 1981b. RNA synthesis as a measure of microblal growth in aquatic environments. II. Field Applications. Mar. B1ol. 64, 13-21.

Kattner, G., G. Gercken, and K. D. Hamner, 1983. Development of 11pids during a spring plankton bloom in the northern North Sea. II. Dissolved 11pids and fatty acids. Mar. Chem. 14, 163-173.

KIm, C. M., and K. O. Emery, 1971. Salt Pond: topography, sediments, and water. Salt Pond Bird Sancturar1es, Inc.--Annual Report 1971.

Kirchman, D., 1983. The production of bacteria attached to particles suspended in a freshwater pond. Limnol. Oceanogr. 28, 858-872.

Kirk, P. R., and R. M. Leech, 1972. Amino actd blosynthesis by 1solated chloroplasts during photosynthesis.

Konopka, A., 1982. Physlological ecology of a metalimnetic 0scillatoria rubsescens population. Limno1. Oceanogr. 27, 1154-1161.

Konopka, A., and M. Schnur, 1981. Blochemical composition and photosynthetic carbon metabolism of nutrient limited cultures of Mer1smopedis tenuissima (Cyanophyceae). J. Phycol. 17, 118-122.

Konopka, A., and M. Schnur, 1980. Effect of light 1ntensity on macromolecular synthesis in cyanobacteria. Microb. Ecol. 6, 291-301.

Koybayash1, Y., and D. V. Maudsley, 1974. B1olog1cal applications of liquid scintillation counting. Academic Press, New York. 196 pp. 
Landry, M. R., 1977. A revlew of important coincepts in the trophic organization of pelagic ecosystems. Helgoländer wiss. Meeresunters. $30,8-17$.

Larsen, P. 0., K. L. Cornwell, S. L. Gee, and J. A. Bassham, 1981. Amino acid synthesis in photosynthesizing spinach and rates of labeling from ${ }^{14} \mathrm{CO}_{2}$. Plant Phys1o1. 68, 292-299.

Larsson, U., and A. Hagstrom, 1979. Phytoplankton exudate release as an energy source for the growth of pelagic bacteria. Mar. Biol. $\underline{52}$, 199-206.

Laws, E. A., and D. C. L. Wong, 1978. Studles of carbon and nitrogne metabolism by three marine phytoplankton species in nitrate-1imited continuous culture. J. Phycol. 14, 406-416.

Laws, E. A., and T. T. Bannister, 1980. Nutrient- and 11ght-11mited growth of Thalassiosira fluviatilis in continuous culture with Implications for phytoplankton growth in the oceans. Limnol. Oceanogr. 25, 457-473.

Laws, E. A., W. G. Harrison, and G. R. D1Tu1110, 1985. A comparison of nitrogen assimilation rates based on $15_{\mathrm{N}}$ uptake and autotrophic protein synthes1s. Deep-Sea Res. 32, 85-9.5.

Lean, D. R. S., and B. K. Burnison, 1979. An evaluation of errors in the ${ }^{14} \mathrm{C}$ method of primary production measurement. Limnol. Oceanogr. 24, 917-928.

Lee, C., and C. Cronin, 1982. The vertical flux of particulate organic nitrogen in the sea: decomposition of amino alcds in the Peru upweling area and the equatorial Atlantic. J. Mar. Res. 40, 227-251.

Lee, C., S. G. Wakeham, and J. W. Farrington, 1983. Varlations in the composition of particulate organic matter in a time serles sediment trap. Mar. Chem. 13, 181-194.

Lee, C., and C. Cronin, 1984. Particulate amino acids in the sea: effects of primary production and decomposition. J. Mar. Res. 42, 1075-1097.

Leech, R. M., and D. J. Murphy, 1976. The cooperative function of chloroplasts in the biosynthesis of small molecules. In: The Intact Chloroplast (J. Barber, ed.) pp. 365-401.

LA, W. K. W., and J. C. Goldman, 1981. Problems in estimating growth rates of marine phytoplankton from short-tierm ${ }^{14} \mathrm{C}$ assays. Microbial Eco1. 7, 113-121.

LA, W. K. W., H. E. Glover, and I. Morris, 1980. Physlology of carbon photoassimilation by Oscillatorla thlebautil in the Carribbean Sea. Limnol. Oceaongr. 25, 447-456.

L1, W. K. W., and T. Platt, 1982. Distributioin of carbon among photosynthetic end-products of phytoplanktion of the eastern Canadian arctic. J. Phycol. 18 ,

L1, W. K. W., and W. G. Harrison, 1982. Carboin flow into the end-products of photosynthesis in short and long incubations of a natural phytoplankton population. Mar. Biol. 72, 175-182.

Little, J. E., R. E. Sjogren, and G. E. Carson, 1979. Measurement of proteolytic activity in natural waters. Applied Environ. Microbiol. 37, 900-908.

Lorenzen, C. J., 1963. Diurnal varlation in photosynthetic activity of phytoplankton populations. Limnol. Oceanogr. $8,56-62$.

Lorenzen, H., and B. D. Kaushtk, 1976. Experinents with synchronous Anacystis nidulans Ber. Deutsch. Bot. Ges. Bd. 89, 491-498. 
MacN1col, P. K., 1978. Determination of specific radioactivity of plant amino acids using dansylation. Anal. Blochem. 85, 71-78.

Mague, T. H., E. Friberg, D. J. Hughes, and I. Morris, 1980. Extracellular release of carbon by marine phytoplankton; a physlologlcal approach. L1mnol. Oceanogr. 25, 262-279.

Maguire, B. Jr., and W. E. Ne111, 1971. Species and Individual productivity in phytoplankton communities. Ecology 52, 903-907.

Malta, Y., and M. Yanada, 1978. Particulate protein in coastal waters, with special reference to seasonal variation. Mar. B101. 44, 329-336.

Marra, J., and K. Heinemann, 1984. A comparison between noncontaminating and conventional incubation procedures in primary production measurements. Limnol. Oceanogr. 29, 389-392.

Maske, H., 1982. Ammonlum-11mited continuous cultures of Skeletonema costatum in steady and transitional state: experimental results and mode1 s1mulations. J. mar. b1o1. Ass. U. K. 62, 919-943.

McCarthy, J. J. and J. C. Goldman, 1979. Nitrogenous nutrition of marine phytoplankton in nutrient depleted waters. Sclence 203, 670-672.

McCarthy, J. J., 1972. The uptake of urea by natural populations of marine phytoplankton. Llmnol. Oceanogr. 17, 738-748.

Menzel, D. W., and J. H. Ryther, 1970. Distribution and cycling of organic matter in the oceans. Occ. Publ. Inst. Mar. Sci., Univ. Alaska, 1, 31-54.

Menze1, D. W., and R. F. Vaccaro, 1964. The measurement of dissolved organic and particulate carbon in seawater. Limnol. Oceanogr. 9 , 138-142.

Miflin, B. J., P. J. Lea, and R. M. Wallsgrove, 1980. The role of glutamine in ammonia assimilation and reassimilation in plants. In: Glutamine: Metabolism, Enzymology, and Regulation ( ed.) Academ1c Press, New York. pp. 213-234.

Miflin, B. J., and P. J. Lea, 1977. AmIno acld metabolism. Ann. Rev. Plant Physiol. 28, 299-329.

Mills, W. R., P. J. Lea, and B. J. Miflin, 1980. Photosynthetic formation of the aspartate family of amino acids in isolated chloroplasts. Plant Phys1o1. 65, 1166-1172.

Mohamed, A. H., and A. Gnanam, 1979. A possible mechanlsm of ammonium Ion regulation of photosynthetic carbon flow in higher plants. Plant Phys1o1. 64, 263-268.

Mopper, K., and P. Lindroth, 1982. Diel and depth varlations in dissolved free amino acids and ammonium in the Baltic SEa determined by shipboard HPLC analysis. L1mnol. Oceanogr. 27, 336-347.

Morris, I., 1981. Photosynthetic products, physiological state, and phytoplankton growth. In: Physlological Bases of Phytoplankton Ecology. (T. Platt, ed.) Can. Bu11. Fish. Aquat. Sc1. 210, 83-102.

Morris, I., A. E. Sintth, and H. E. Glover, 1981. Products of photosynthesis in phytoplankton off the Orinoco river and in the Carribean Sea. Limnol. Oceanogr. ?

Morris, I., H. E. Glover, and C. S. Yentsch, 1974. Products of photosynthesis by marine phytoplankton: the effect of environmental factors on the relative rates of protein synthesis. Mar. B1ol. 27, 1-9.

Morris, I., and W. Skea, 1978. Products of photosynthesis in natura1 populations of marlne phytoplankton from the Gulf of Maine. Mar. B101. 47, 303-312. 
Myklestad, S. and A. Haug, 1972. Production of carbonhydrates by the marine diatom Chaetoceros Affinis var. Willei (Gran) Hustedt. I. Effect of the concentration of nutrients in the culture medium. J. exp. mar. Blol. Ecol. 9, 125-136.

Myklestad, S., 1977. Production of carbohydrates by marine planktonic diatoms. II. Influence of the N:P ratio in the growth medium on the assimllation ratio, growth rate, and carbohydrates by Chaetoceros affinis var. willei (Gran) Hustedt and Skeletonema costatum (Grev.) Cleve. J. exp. mar. Blol. Ecol. 29, 161-179.

Neess, J. C., R. C. Dugdale, V. A. Dugdale, and J. J. Goering, 1962. Nitrogen metabolism in lakes. Il Measurement of nitrogen fixation with $15 \mathrm{~N}$. Limnol. Oceanogr. 7, 163-169.

Nienhaus, P. H., 1981. Distribution of organlc matter in 1iving organisms. In: Marine Organlc Chemistry. Evolution, Composition, Interactions and Chemistry of Organic Matter in Seawater (E. K. Duursma and R. Dawson, eds.) Elsevier Sclentific Publishing Co., New York. pp. 31-69.

Oaks, A., and R. G. S. Bidwe11, 1970. Compartmentation of intermediary metabolites. Ann. Rev. Plant Phys1o1. 21, 43-66.

Olive, J. H., and J. H. Morrison, 1967. Varlations in distribution of ${ }^{14} \mathrm{C}$ in cell extracts of phytoplankton living under natural conditions. Limnol. Oceanogr. 12, 383-391.

0live, J. H., and D. M. Benton, and J. Kishler, 1969. Distribution of C-14 in products of photosynthesis and its relationship to phytoplankton composition and rate of photosynthesis. Ecology 50, 380-386.

Packard, T. T., and Q. Dortch, 1975. Particulate protein-nitrogen in North Atlantic Surface waters. Mar. B101. 33, 347-354.

Paerl, H. W., 1974. Bacterial uptake of dissolved organlc matter in relation to detrital aggregation in marine and freshwater systems. LImnol. Oceanogr. 19, 966-972.

Paer1, H. W., 1984. An evaluation of freeze fixation as a phytoplankton preservation method for microautoradiography. Limnol. Oceaongr. 29, 417-426.

Parris, N., and D. Gallel1, 1984. Dansylation of amino acids and byproduct formation. J. Liquid Chrom. 7, 917-924.

Parsons, T. R., K. Stephens, and J. D. H. Strickland, 1961. On the chemical composition of eleven species of marine phytoplankters. J. F1sh. Res. Bd. Can. 18, 1001-1016.

Parsons, T. R., M. Takahashi, and B. Hargrave, 1977. B1ological Oceaographic Processes. Pergamon Press, New York. 332 pp.

Paul, J. S., K. L. Cornwe11, and J. A. Bassham, 1978. Effects of ammonta on carbon metabolism in photosynthesizing isolated mesophyll cell from Papaver somniferum L. Planta 142, 49-54.

Perry, M. J., M. C. Talbot, and R. S. Alberte, 1981. Photoadaptation in marine phytoplankton: response of the photosynthetic unit. Mar. B101. 62, 91-101.

Peterson, B. J., 1980. Aquatic primary productivity and the ${ }^{14} \mathrm{C}-\mathrm{CO}_{2}$ method: a history of the productivity problem. Ann. Rev. Ecol. Syst. 11, 359-385.

Pine, M. J., 1972. Turnover of intracellular protelns. Ann. Rev. Microbiol. 26, 103-126. 
Platt, S. G., Z. Plaut, and J. A. Bassham, 1977. Ammonla regulation of carbon metabolism in photosynthesizing leaf discs. Plant Physiol. $60,739-742$.

Pomeroy, L. R., 1974. The ocean's food web, a changing paradigm. B1osclence 24, 499-504.

Porter, K., M. L. Pace, and J. F. Battery, 1979. Cillate protozoans as 11nks in freshwater planktonic food cha1ns. Nature 277, 563-565.

Poulet, S. A., and V. Martin-Jezequel, 1983. Relationsh Ips between dissolved free amino acids, chemical composition and growth of the marlne diatom Chaetoceros debile. Mar. B1ol. 77, 93-100.

Prezelin, B. B., 1976. The role of peridinin-chlorophyll a-prtoeins in the photosynthetic 1ight adaption of marine dinoflageliater, Glenodinium sp. Planta (Berl.) 130, 225-233.

Priscu, J. C., and C. R. Goldman, 19 $\overline{83 .}$. Carboxylating enzyme activity and photosynthetic endproducts of phytoplankton in the shallow and deep chlorophy11 layers of Castle Lake. L1mnol. Oceanogr. 28, 1168-1181.

Rausch, T., 1981. The estimation of microalgal protein content and its meaning to the evaluation of algal blomass. I. Comparison of methods for extracting protein. Hydroblologia 78, 237-251.

Redalje, D. G., 1983. Phytoplankton carbon blomass and specific growth rates determined with the labeled chlorophy11 a technique. Mar. Ecol. Prog. Ser. 11, 217-225.

Redalje, D. G., and E. A. Laws, 1983. The effects of environmental factors on growth and the chemlcal and biochemical composition of marine diatoms. I. Light and temperature effects. J. Exp. Mar. B1ol. Eco1. 68, 59-79.

Redalje, D. G., and E. A. Laws, 1981. A new method for estimating phytoplankton growth rates and carbon b1omass. Mar. B1ol. 62, 73-79.

Relsner, G. S., R. K. Gering, and J. F. Thompson, 1960. The metabolism of nitrate and ammonla by Chlorella. Plant Phys1ol. 35, 48-52.

Remsen, C. C., 1971. The distribution of urea in coastal and oceanic waters. Limnol. Oceanogr. 16, 732-740.

Reynolds, C. S., H. R. Morlson, and C. Butterwick, 1982. The sedimentary flux of phytoplankton in the south basin of Windermere. Limnol. Oceanogr. 27, 1162-1175.

Rhee, G-Yu11, 1973. A continuous culture study of phosphate uptake, growth rate, and polyphosphate in Scenedesmus sp. J. Phycol. $\underline{9}$, 495-506.

Rhee, G. Y., 1978. Effects of N:P atomic ratio and nitrate Iimlation on algal growth, cell composition, and nitrate uptake. Limnol. Oceanogr. $23,10-25$.

Rhee, G., 1980.' Continuous culture in phytoplankton ecology. Adv. Aquat. Microblo1. 2, 151-203.

Richardson, K., J. Beardall, and J. A. Raven, 1983. Adaptation of unfcellular algae to irradiance: an analysis of strategles. New Phyto1. 93, 157-191.

Roberts, R. B., P. H. Abelson, D. B. Cowle, E. T. Botton, and R. J. Britten, 1963. Studies of biosynthesis in Eschericla coll. Carnegle Inst. Wash. Pub1. 607. 521pp.

Sche11, D. M., 1974. Uptake and regeneration of free amino aclds in marine waters of Southeast Alaska. Limnol. Oceanogr. 19, 260-270. 
Schifrin, N. S., and S. W. Chisholm, 1981. Phytoplankton 11pids: interspecific differences and effects of nitrate, silicate, and 11ght-dark cycles. J. Phycol. 17, 374-384.

Schindler, D. W., and S. K. Holmgren, 1971. Pr1mary production and phytoplankton in the experimental lakes area, Northwestern Ontaria, and other low carbonate waters, and a liquid scintillation method for determing ${ }^{14} \mathrm{C}$ activity in photosynthesis. J. Fish. Res. Board Can. 28, 189-201.

Schulze-Siebert, D., D. Helneke, H. Scharf, and G. Schultz, 1984. Pyruvate derived amino acids in spinach chloroplasts. Synthesis and regulation during photosynthetic carbon metabolism. Plant Physiol. 76, 465-471.

Scott, J. M., 1980. Effect of growth rate of the food alga on the growth/ingestion efficlency of a marine herbivore. J. mar. biol. Ass. U.K. 60, 681-702.

Sharp, J. H., 1977. Excretion of organlc matter by phytoplankton: Do healthy cells do it? Limnol. Oceanogr. 22, 381-399.

Sharp, J. H., M. J. Perry, E. H. Renger, and R. W. Eppley, 1980. Phytoplankton rate processes in the ollgotrophic waters of the central North Paclfic Ocean. J. Plank. Res. 2, 335-353.

Sleburth, J. McN., K. M. Johson, C. M. Burney, and D. M. Lavole, 1977. Estimation of in situ heterotrophy using diurnal changes in dissolved organic matter and growth rates of plcoplankton in diffusion culture. Helgoländer wiss. Meeresunters. 30, 565-574.

Sieburth, J. McN., V. Smetacek, and J. Lenz, 1978. Pelagic ecosystem structure: Heterotrophic compartments of the plankton and their relationship to plankton size fractions. Limnol. Oceanogr. 23 , 1256-1263.

Slezen, R. J., and T. H. Mague, 1978. Amino acids in suspended particulate matter from oceanic and coastal waters of the Pacific. Mar. Chem. 6, 215-231.

Slawyk, G., Y. Collos, and J. Auclair, 1977. The use of ${ }^{13} \mathrm{C}$ and ${ }^{15} \mathrm{~N}$ isotopes for the simultaneous measurement of carbon and nitrogen turnover rates in marine phytoplankton. L.Imnol. Oceanogr. 22, 925-932.

Smal1, L. F., S. W. Fowler, S. A. Moore, and J. LaRosa, 1983. Dissolved and fecal pellet carbon and nitrogen release by zooplankton in troplcal waters. Deep-Sea Res. 30, 1199-1.220.

Smayda, T. J., 1970. The suspension and sinking of phytoplankton in the sea. Oceanogr. Mar. Biol. Ann. Rev. 8, 353-414.

Smlth, A. E., and I. Morris, 1980a. Synthesis of 11pid during photosynthesis by phytoplankton of the Southern Ocean. Sclence 207, 197-199.

Smith, A. E., and I. Morr1s, 1980b. Pathways of carbon assimilation in phytoplankton from the Antarctic Ocean. Limnol. Oceanogr. 25, 865-872.

Smlth, D. C., J. A. Bassham, and M. K1rk, 1961. Dynamics of the photosynthesisof carbon compounds. II. Amino acid synthesis. Bioch1m. Blophys. Acta 48, 299-313. *

Smith, D. F., and S. M. J. Horner, 1981. Tracer kinetic analysis applied to problems in marlne blology. In: Physiologlcal Bases of Phytoplankton Ecology (T. Platt, ed.) Can. Bull. Fish. Aquat. Sci. 210, 113-125. 
Smlth, R. C., K. S. Baker, and P. Dustan, 1981. Fluorometer technlques for the measurement of ocean chloropyl1 in the support of remote sensing. Ref. Rep. Scripps Instn. Oceanogr., 81-17, 1-14. (Scrlpps Institution of Oceanography, La Jolla, California, U.S.A. 92093).

Smith, R. E. H., and J. Kalff, 1983. Sample preparation for quantitative autoradlography of phytoplankton. Limnol. Oceanogr. 28, 383-389.

Somville, M., and G. Blilen, 1983. A method for determining exoproteolytic activity in natural waters. Limnol. Oceanogr. $\underline{28}$, 190-193.

Sorokin, Y. I., 1981. M1croheterotrophlc organisms in marine ecosystems. In: Analysis of marine ecosystems (A. R. Longhurst, ed.) Academic Press, London. pp. 293-342.

Steele, J. H., 1974. The structure of marine ecosystems. Harvard University Press, Cambridge, MA. 128 pp.

Steele, J. H., and I. E. Baird, 1962. Carbon-chlorophyll relations in cultures. Limnol. Oceanogr. 7, 101-102.

Steeman-Nielsen, E., 1952. The use of radoactive carbon $\left({ }^{14} \mathrm{C}\right)$ for measuring organic production in the sea. J. Cons., Cons. Int. Explor. Mer. 18, 117-140.

Stewart, C. R., S. F. Boggess, D. Aspina1l, and L. G. Paleg, 1977. Inhibition of proline oxidation by water stress. Plant Physiol. 59, 930-932.

Stoecker, D. K., 1984. Particle production by planktonic clliates. Limnol. Oceangr. 29, 930-940.

Stout, J. D., 1980. The role of protozoa in nutrlent cycling and energy flow. Adv. Microb. Ecol. 4, 1-50.

Strathmann, R. R., 1967. Estimating organic carbon content of phytoplankton from cell volume or plasma volume. Llmnol. Oceanogr. 12, 411-418.

Syrett, P. J., 1953. The assimilation of ammonia by nitrogen-starved cells of Chlorella vulgaris. II. The assimilation of ammonium to other compounds. Annls. Bot. (London) 17, 20-36.

Syrett, P. J., 1981. N1trogen metabollsm of m1croalgae. In: Physiologcial bases of phytoplankton ecology (T. Platt, ed.) Can. Bull. F1sh. Aquat. Sc1. 210, 182-210.

Tapuh1, Y., D. E. Schmidt, W. Lindner, and B. L. Karger, 1981. Dansilation of amino acids for high performance liquid chromatography analysis. Anal. Blochem. 115, 123-129.

Taylor, C. D., J. J. Molongosk1, S. E. Lohrenz, 1983. Instrumentation for the measurement of phytoplankton production. L1mnol. Oceanogr. $\underline{28}$, 781-787.

Thomas, W. H., and A. N. Dodson, 1972. On nftrogen deficlency in tropical pacific oceanic phytoplankton. II. Photosynthetic and cellular characteristics of a chemostat-grown diatom. Limnol. Oceanogr. 17, 515-523.

Thomas, W. H., and R. W. Krauss, 1955. N1trogen metabo11sm in Scenedesmus as affected by environmental changes. Plant Physiol. 30 , 113-122.

Tomas, C. R., 1978. 011sthodiscus luteus (Chrysophyceae). I. Effects of salinity and temperature on growth, motility, and survival. J. Phycol. 14, 309-313.

Tomas, C. R., 1978. 011sthodiscus 1uteus (Chrysophyceae). II. Formation and survival of a benthic stage. J. Phycol. 14, 314-319. 
Tomas, C. R., 1979. Olisthodiscus 1uteus (Chrysophyceae). III. Uptake and utilization of nitrogen and phosphorus. J. Phycol. 15, 5-12.

Tomas, C. R., 1980. Olisthodlscus Iuteus (Chrysophyceae). IV. Effects of light intensity and temperature on photosynthesis and cellular composition. J. Phyco1. 16, 149-156.

Tomas, C. R., 1980. 011sthod.scus luteus (Chrysophyceae). V. Its occurrence, abundance, and dynamics in Narragansett Bay, Rhode Island. J. Phycol. 16, 157-166.

Tomas, C. R., and E. E. Deason, 1981. The Influence of grazing by two Acartia species on 01isthodiscus luteus Carter. P. S. Z. N. I: Marine Ecology 2, 215-223.

Trewavas, A., 1972. Determination of the rates of protein synthes1s and degradation in Lema minor. Plant Physiol. 49, 40-46.

Turpin, D. H., and P. J. Harrison, 1978. Fluctuations in free amino acid pools of Gymnodinium simplex (Dinophyceae) in response to ammonia perturbation: evidence for glutamine synthetase pathway. J. Phycol. $14,461-464$.

Van Llere, L., L. R. Mur, and C. E. Glbson, and M. Herdman, 1979. Growth and physiology of Osc1llatorla agardhil Gomont cultivated in continuous culture with a 11ght-dark cycle. Arch Microblol. 123, 315-318.

Venrick, E. L., J. R. Beers, and J. F. Helnboke1, 1977. Possible consequences of contalning mlcroplankton for physlological rate measurements. J. exp. mar. Blol. Eco1. 26, 55-76.

Verity, P. G., and D. Stoecker, 1982. Effects of 01lsthodiscus 1uteus on the growth and abundance of tintinnids. Mar. B101. 72, 79-87.

Vollenwelder, R. A., and A. Nauwerck, 1961. Some observations on the ${ }^{14} \mathrm{C}$ method for measuring primary production. Verh. Internat. Verein. Limnol. 14, 134-139.

Wakeham, S. G., J. W. Farrington, R. B. Gagosian, C. Lee, H. DeBarr, G. E. Nigrell1, B. W. Tripp, S. 0. Smith, and N. M. Frew, 1980. Organic matter fluxes from sediment traps in the equatorlal Atlantic Ocean. Nature 286, 798-800.

Wangersky, P. J., 1977. The role of particulate matter in the productivity of surface water. Helgoländer wiss. Meerersunters $\underline{30}$, 546-564.

Watt, W. D., 1971. Measuring the primary production rates of Individual phytoplankton specles in natural mixed populations., Deep Sea Res. $18,329-339$.

Webb, K. L., and R. E. Johannes, 1967. Studles of the release of dissolved free amino aclds by marine zooplankton. Llmnol. Oceanogr. $12,376-382$.

Wheeler, P. A., 1983. Phytoplankton nitrogen metabolism. In: Nitrogen In the Marine Environment (E. J. Carpenter and D. G. Capone, eds.) Academic Press, New York. pp. 309-346.

Wheeler, P. A., B. B. North, and G. C. Stephens, 1974. Amino ac1d uptake by marine phytoplankters. Llmnol. Oceanogr. 19, 249-259.

Wheeler, P. A., and G. C. Stephens, 1977. Metabolic segregation of intracellular free amino acids in Platymonas (Chlorophyta). J. Phycol. 13, 193-197. 
Wheeler, P. A., R. J. 01son, and S. W. Ch1sholm, 1983. Effects of photocycles and periodic ammonium supply on three marine phytoplankton species. II. Ammonium uptake and assimilation. J. Phyco1. 19, 528-533.

Whittle, K. J., 1977. Marine organlsms and their contribution to organlc matter in the ocean. Mar. Chem. 5, 381-411.

Wiebe, W. J., and D. F. Smith, 1977. Direct measurement of dissolved organic carbon release by phytoplankton and incorporation by microheterotrophs. Mar. B1o1. 42, 213-223.

Wiedmeler, V. T., S. P. Porterfleld, and C. E. Hendrich, 1982. Quantitation of Dns-amlno acids from body tissues and fluids using high-performance 11quid chromatography. J. Chromatog. 231, 410-417.

W11llams, P. J. leB., 1981. Incorporation of microheteroph 1c processes into the classical paradigm of the planktonic food web. Kleler Meeres forsch., Sonderh. $5,1-28$.

Williams, P. J. leB., T. Berman, and 0. Holm-Hansen, 1976. Amino acld uptake and respiration by marine heterotrophs. Mare. Biol. 35, 41-47.

Winn, C. D., and D. M. Kar1, 1984. Laboratory callbrations of the [ ${ }^{3}$ ] adenine technique for measuring rates of RNA and DNA synthesis in marlne microorganisms. Appl. Environ. Microbiol. 47, 835-842.

Woodwe1l, G. M., R. H. Whittaker, W. A. ReIners, G. E. Likens, C. C. Delwiche, and D. B. Batkin, 1978. The blota and the world carbon budget. Sclence 199, 141-146.

Yentsch, C. S., 1974. Some aspects of the environmental physlology of marine phytoplankton: a second look. Oceanogr. Mar. B1ol. 12, 41-75.

Yentsch, C. S., and D. W. Menzel, 1963. A method for the determination of phytoplankton chlorophy11 and pheophyt1n by fluorescence. Deep Sea Res. 10, 221-231.

Zeltzschel, B., 1970. The quantlty, composition and distribution of particulate matter in the Gulf of California. Mar. B1ol. 7, 305-318. 


\section{BIOGRAPHY}

I was born in Newton, Kansas on the 20th of December, 1955. Newton is a town in the heart of the Midwest, about as far from any large body of water as you can get while still being in the United States. I began my gradual migration towards aquatic environments in 1959 when my family moved to Marshfield, W1sconsin, where my father, an M.D. In Internal Medicine, joined the Marshfleld Clinic. Although Marshfield is not exactly coastal, it was much closer to the Great Lakes and other bodies of water than Kansas. The beauty of northern Wisconsin and Michigan lakes is unique and wonderful. My first glimpse of an ocean was in 1965 when my family visted Atlantic City (then a pretty resort city) on our way to the New York world's falr. I do not remember specifically how I felt about a career cholce at that point, but I do know it was the beginning of a lasting love for the ocean.

Around the seventh and elght grades, after some vascillation between the choices of being an M.D. or an oceanographer, I decided to make oceanography my career. My father supported my choice, and helped me research educational opportunities in the fleld. It was at this point that I began to reallze being an oceanographer entalled more than just learning how to scuba dive. Fortunately, I had an excellent chemistry teacher in high school, T. K., who made the subject an enjoyable challenge rather than an unpleasant requirement.

I majored in chemistry during my freshman and sophomore years at the University of Wisconsin In Madison. After a semester doing undergraduate research on the synthesis of cis, trans-dicyclopropenes, I realized a need for more blological flavor in my studies. Oceanography, it seemed, was the ideal vehicle for combining both biological and chemical research. I made the decision to transfer to the Unfversity of Oregon in Eugene in hopes that its relative proximity to the ocean might provide more opportunity for marine related studies.

The summer of 1976 marked a major transition in my life. My father's death led to second thoughts about leaving my family and friends for the West Coast. Yet their support of my decision, and my father's earlier encouragement helped me through this difficult period. Once at the University of Oregon, I knew I had made the right decision. A summer at the Oregon Institute of Marine Blology strengthened my desire to study oceanography. A course in invertebrate zoology qualified me for a job with Beak Consultants of Portland, OR, conducting a brief survey of intertidal community gradients for Mobil 011 in Puget Sound. During the following term at the $U$. of 0 ., I continued research along these 1 ines working under Greg Daly, a graduate student studying tidal gradient effects on competition among rocky intertidal invertebrates.

Although I enjoyed these experlences, I felt they lacked the balance between biology and chemistry I was seeking. I took advantage of $U$. of $0 . ' s$ extensive biochemistry curriculum, and became involved in a project with Dr. Robert Terwilliger using spectropolarimetric techniques to compare structures of polychaete hemoglobins. The summer of 1978, I returned to Marshfield to work for Dr. Mary Treuhaft at the Marshfield Medical Foundation on a project involving the 1mmunochemical characterization of thermophilic actinomycetes. I gained experience in microblological techniques which later pald off during my thesis research. 


\section{BIOGRAPHY (continued)}

Returning to the $U$. of 0 ., I continued my undergraduate research using spectropolarimetry to study temperature dependent premelting phenomena in calf thymus DNA. My varied interests resulted in my graduating with a B.A. In biology and chemistry in december of 1978. For the next few months, I waited for word on my applications to graduate programs in oceanography and pald the bills by working for my friend and advisor, Dr. William Bradshaw, studying the developmental physlology of larval mosquitos.

I was lucky enough to be accepted by the MIT/WHOI Joint Program, and traversed the country to the East Coast. The unique nature of the program fosters independence and allowed me to choose thesis research which drew on my past experiences, and Introduced me to new and challenging ones. 